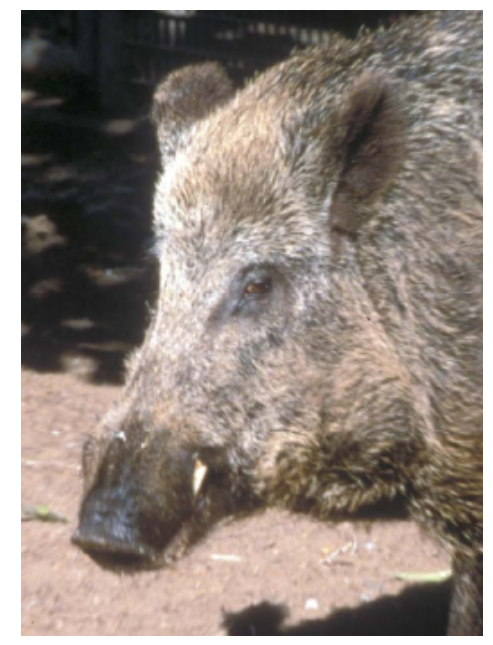

SRNL-RP-2009-00869

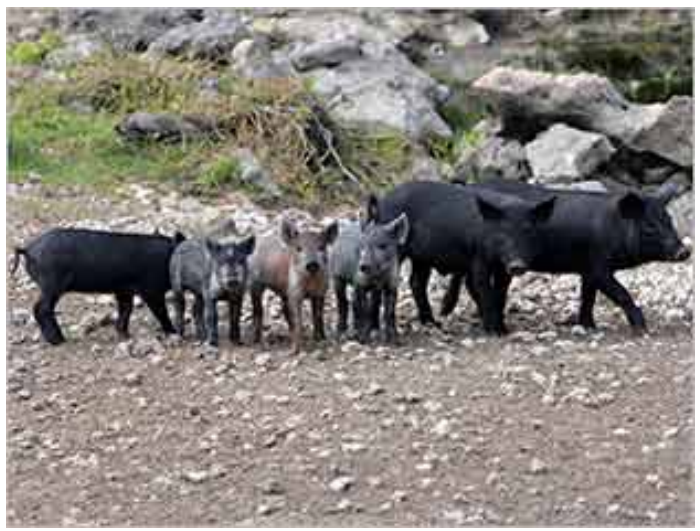

\title{
Wild Pigs
}

\section{BIOLOGY, DAMAGE, CONTROL TECHNIQUES AND MANAGEMENT}

\section{Savannah River National Laboratory \\ Aiken, South Carolina}
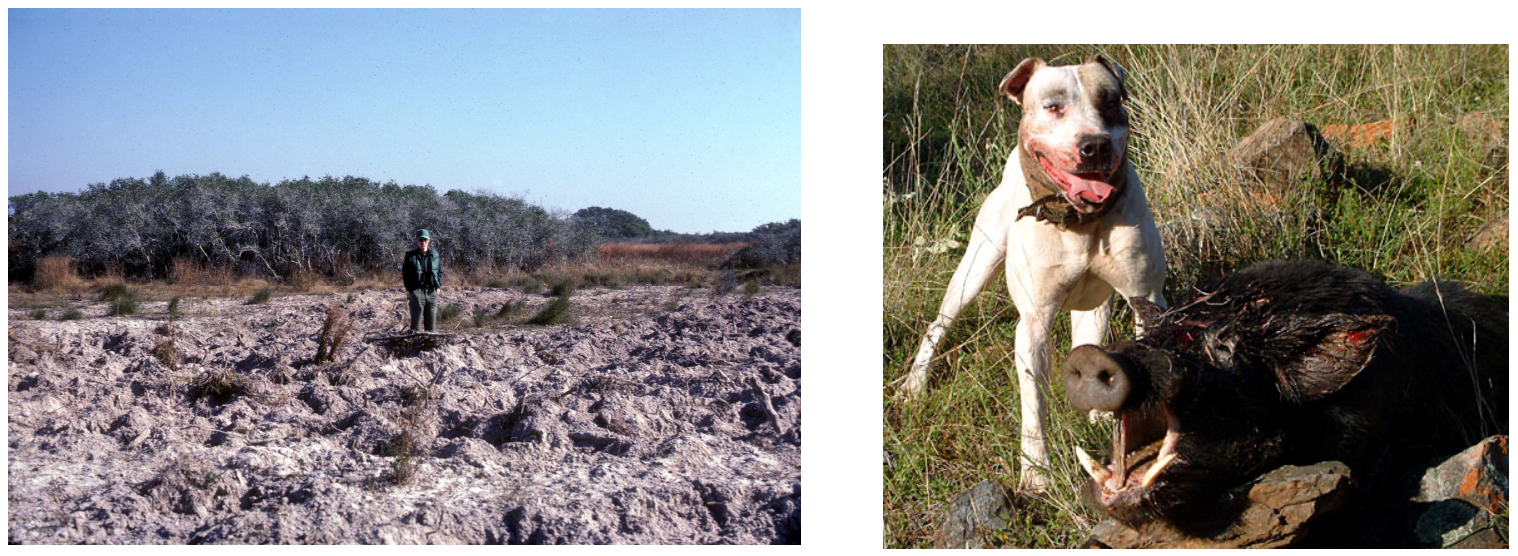
Paper and electronic copies of

Wild Pigs:

Biology, Damage, Control Techniques and Management SRNL-RP-2009-00869

can be obtained by contacting:

Savannah River National Laboratory Savannah River Nuclear Solutions LLC

Savannah River Site

Aiken, SC 29808 


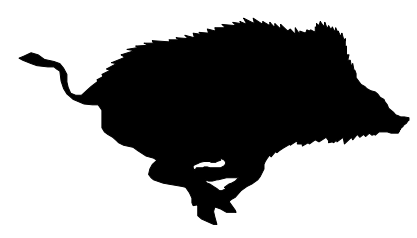

Wild Pigs

\section{BIOLOGY, DAMAGE, CONTROL TECHNIQUES \\ AND MANAGEMENT}

John J. Mayer and I. Lehr Brisbin, Jr.

Editors

Savannah River National Laboratory

Aiken, South Carolina 
This document was prepared by Savannah River Nuclear Solutions, LLC, under contract number DE-AC09-08SR22470 with the United States of America, represented by the Department of Energy. Neither the U.S. Government nor Savannah River Nuclear Solutions, LLC nor any of their employees makes any warranty, expressed or implied, or assumes any legal liability or responsibility for any apparatus, product, or process disclosed, or represents that its use would not infringe on privately owned rights. References herein to any specific commercial products, process, or service by trade name, trademark, manufacturer, or otherwise does not necessarily constitute or imply its endorsement, recommendation, or favoring by the U. S. Government or Savannah River Nuclear Solutions, LLC.

\title{
Including Contributed Papers from the
}

\section{Wild Pig Symposium Augusta, Georgia}

\section{Sponsored by}

\author{
U. S. Forest Service - Savannah River
}

\author{
U. S. Department of Energy
}

Westinghouse Savannah River Company, L.L.C.

South Carolina Chapter of the Soil and Water Conservation Society

University of Georgia - Savannah River Ecology Laboratory 
Wild Pigs

\section{Wild Pigs:}

\section{Table of Contents}

\begin{tabular}{|c|c|}
\hline & Page \\
\hline $\begin{array}{l}\text { Introduction } \\
\text { John J. Mayer and I. Lehr Brisbin, Jr. }\end{array}$ & 1 \\
\hline Part I. Biology of Wild Pigs & 3 \\
\hline $\begin{array}{l}\text { Taxonomy and History of Wild Pigs in the United States }{ }^{\text {a }} \\
\text { John J. Mayer }\end{array}$ & 5 \\
\hline $\begin{array}{l}\text { Wild Pig Physical Characteristics } \\
\text { John J. Mayer }\end{array}$ & 25 \\
\hline $\begin{array}{l}\text { Wild Pig Reproductive Biology }{ }^{\text {a }} \\
\text { Christopher E. Comer and John J. Mayer }\end{array}$ & 51 \\
\hline $\begin{array}{l}\text { Wild Pig Behavior } \\
\text { John J. Mayer }\end{array}$ & 77 \\
\hline $\begin{array}{l}\text { Wild Pig Food Habits } \\
\text { Stephen S. Ditchkoff and John J. Mayer }\end{array}$ & 105 \\
\hline $\begin{array}{l}\text { Wild Pig Physiological Ecology } \\
\text { Stam M. Zervanos }\end{array}$ & 145 \\
\hline $\begin{array}{l}\text { Wild Pig Population Biology } \\
\text { John J. Mayer }\end{array}$ & 157 \\
\hline $\begin{array}{l}\text { Natural Predators of Wild Pigs in the United States } \\
\text { John J. Mayer }\end{array}$ & 193 \\
\hline $\begin{array}{l}\text { Wild Pig Field Sign } \\
\text { John J. Mayer }\end{array}$ & 205 \\
\hline Part II. Wild Pig Damage & 219 \\
\hline $\begin{array}{l}\text { Overview of Wild Pig Damage a } \\
\text { John J. Mayer }\end{array}$ & 221 \\
\hline $\begin{array}{l}\text { Diseases and Parasites of Wild/Feral Swine }{ }^{\text {a }} \\
\text { David E. Stallknecht and Susan E. Little }\end{array}$ & 247 \\
\hline Part III. Control Techniques for Wild Pigs & 259 \\
\hline $\begin{array}{l}\text { Wild Pig Trapping Techniques }{ }^{\text {a }} \\
\text { John J. Mayer and Paul E. Johns }\end{array}$ & 261 \\
\hline $\begin{array}{l}\text { Use of Trained Hunting Dogs to Harvest or Control Wild Pigs }{ }^{\text {a }} \\
\text { John J. Mayer, Rollie E. Hamilton, and I. Lehr Brisbin, Jr. }\end{array}$ & 275 \\
\hline $\begin{array}{l}\text { Efficacy of Shooting as a Control Method for Feral Hogs }{ }^{\text {a }} \\
\text { Doug M. Hoffman }\end{array}$ & 289 \\
\hline $\begin{array}{l}\text { Contraception of Feral Pigs: A Potential Method for Population and Disease Control }{ }^{\text {a }} \\
\text { Lowell Miller, Gary Killian, Jack Rhyan and Tommy Dees }\end{array}$ & 293 \\
\hline $\begin{array}{l}\text { Other Control Techniques for Wild Pigs } \\
\text { John J. Mayer }\end{array}$ & 297 \\
\hline $\begin{array}{l}\text { Comparison of Five Harvest Techniques for Wild Pigs }{ }^{a} \\
\text { John J. Mayer }\end{array}$ & 315 \\
\hline
\end{tabular}




\section{Table of Contents (Continued)}

Part IV. Wild Pig Management Case Studies

Savannah River Site ${ }^{\mathrm{a}}$

John J. Mayer and Laurel A. Moore-Barnhill

Great Smoky Mountains National Park Wild Hog Control Program ${ }^{\text {a }}$

William H. Stiver and E. Kim Delozier

Cumberland Island Feral Hog Management ${ }^{\text {a }}$

W. Edward O'Connell and John F. Fry

Fort Benning Military Reservation ${ }^{\mathrm{a}}$

Stephen S. Ditchkoff and Michael S. Mitchell

The Pigs of Ossabaw Island: a Case Study of the Application of Long-term Data in

Management Plan Development ${ }^{\mathrm{a}}$

I. Lehr Brisbin, Jr., and Michael S. Sturek

Prevalence of Antibodies to Selected Disease Agents in an Insular Population of Feral

Swine

D. Bart Carter, Kyle K. Henderson, I. Lehr Brisbin, Jr., Clarence Bagshaw and Michael Sturek

Influence of Habitat Attributes on Removal of Feral Hogs from Merritt Island National Wildlife Refuge

Arik Rosenfeld, C. Ross Hinkle and Marc Epstein

a Papers presented at the 2004 Wild Pig Symposium in Augusta, Georgia 
Wild Pigs

\section{Wild Pigs:}

Introduction

John J. Mayer and I. Lehr Brisbin, Jr.

Savannah River National Laboratory, Savannah River Nuclear Solutions, LLC, Savannah River Site, Aiken, South Carolina 29808 (JJM)

Savannah River Ecology Laboratory, P. O. Drawer E, Aiken, South Carolina 29803 (ILB)

The existence of problems with wild pigs (Sus scrofa) is nothing new to the Western Hemisphere. Damage by these introduced animals was reported as far back as 1505 by the early Spanish colonies in the Caribbean, where wild pigs were killing the colonists' cattle. Droves of these animals also ravaged cultivated crops of maize and sugarcane on islands in the West Indies during this same time period. These wild pigs reportedly were very aggressive and often attacked Spanish soldiers hunting rebellious Indians or escaped slaves on these islands, especially when these animals were cornered. The documentation of such impacts by introduced populations of this species in the United States has subsequently increased in recent years, and continued up through the present (Towne and Wentworth. 1950, Wood and Barrett 1979, Mayer and Brisbin 1991, Dickson et al. 2001).

In spite of a fairly constant history in this country since the early 1900 s, wild pigs have had a dramatic recent increase in both distribution and numbers in the United States. Between 1989 and 2009, the number of states reporting the presence of introduced wild pigs went from 19 up to as many as 44 . This increase, in part natural, but largely manmade, has caused an increased workload and cost for land and resource managers in areas where these new populations are found. This is the direct result of the damage that these introduced animals do. The cost of both these impacts and control efforts has been estimated to exceed a billion dollars annually (Pimentel 2007). The complexity of this problem has been further complicated by the widespread appeal and economic potential of these animals as a big game species (Tisdell 1982, Degner 1989). Wild pigs are a controversial problem that is not going away and will likely only get worse with time.

Not only do they cause damage, but wild pigs are also survivors. They reproduce at a rate faster than any other mammal of comparable size, native or introduced; they can eat just about anything; and, they can live just about anywhere. On top of that, wild pigs are both very difficult to control and, with the possible exception of island ecosystems, almost impossible to eradicate (Dickson et al. 2001, Sweeney et al. 2003).

The solution to the wild pig problem has not been readily apparent. The ultimate answer as to how to control these animals has not been found to date. In many ways, wild pigs are America's most successful large invasive species. All of which means that wild pigs are a veritable nightmare for land and resource managers trying to keep the numbers of these animals and the damage that they do under control. Since the more that one knows about an invasive species, the easier it is to deal with and hopefully control. For wild pigs then, it is better to "know thy enemy" than to not, especially if one expects to be able to successfully control them.

In an effort to better "know thy enemy," a two-day symposium was held in Augusta, Georgia, on April 21-22, 2004. This symposium was organized and sponsored by U.S.D.A. Forest Service-Savannah River (USFS-SR), U. S. Department of Energy-Savannah River Operations Office (DOE-SR), the Westinghouse Savannah River Company (WSRC), the South Carolina Chapter of the Soil \& Water Conservation Society, and the Savannah River Ecology Laboratory (SREL). The goal of this symposium was to assemble researchers and land managers to first address various aspects of the biology and damage of wild pigs, and then review the control techniques and management of this invasive species. The result would then be a collected synopsis of what is known about wild pigs in the United States. Although the focus of the 
symposium was primarily directed toward federal agencies, presenters also included professionals from academic institutions, and private-sector control contractors and land managers.

Most of the organizations associated with implementing this symposium were affiliated with the Savannah River Site (SRS), a $803 \mathrm{~km}^{2}$ federal nuclear facility, located in western South Carolina along the Savannah River. The SRS was a very appropriate facility to host this symposium. The SRS has been dealing with its wild pig problem since the early 1950s. A lot has been learned about these animals at the site over the ensuing decades. Between the USFS-SR, DOE-SR, SREL, and the site's management and operations contractor, which is currently Savannah River Nuclear Solutions, SRS organizations have conducted a wealth of research on this wild pig population, spanning a broad spectrum of topics and disciplines. In fact, the SRS wild pig population is among the most studied, and possibly is the best studied population of this invasive species found in the United States today. Unfortunately, with all of that work, the ultimate answer to controlling wild pigs and their impacts still has not been found. Over the years, control efforts at SRS have been successful in keeping the site's wild pig numbers in check; but it's an ongoing task that one cannot let up on.

This volume represents the collected synopsis that was the goal of the aforementioned symposium. This edited report contains papers representing some of the symposium's presentations, papers from researchers who were not able to attend the symposium, as well as several papers that were added to round out the volume to achieve the original symposium's intended scope. Collectively, this report presents a detailed source of information on the biology, damage, control techniques and management case studies on wild pigs in the United States.

\section{Literature Cited}

Dickson, J. G., J. J. Mayer, and J. D. Dickson. 2001. Wild hogs. Pp. 191-192, 201-208. In J. G. Dickson (ed.), Wildlife of Southern forests: Habitat \& management. Hancock House Publishers, Blaine, Washington.

Degner, R. L. 1989. Economic importance of feral swine in Florida. Pp. 39-41. In N. Black (ed.), Proceedings: Feral pig symposium. April 27-29, Orlando, Florida, Livestock Conservation Institute, Madison, Wisconsin.

Mayer, J. J., and I. L. Brisbin, Jr. 1991. Wild pigs in the United States: Their history, comparative morphology, and current status. The University of Georgia Press, Athens, Georgia.

Pimentel, D. 2007. Environmental and economic costs of vertebrate species invasions into the United States. Pp. 2-8. In G. W. Witmer, W. C. Pitt, and K. A. Fagerstone (eds). Managing vertebrate invasive species: Proceedings of an international symposium. USDA/APHIS Wildlife Services, National Wildlife Research Center, Fort Collins, Colorado.

Sweeney, J. R., J. M. Sweeney, and S. W. Sweeney. 2003. Feral hog, Sus scrofa. Pp. 1164-1179. In G. A. Feldhammer, B. C. Thompson, and J. A. Chapman (eds.), Wild mammals of North America: Biology, management, and conservation. The Johns Hopkins Univ. Press, Baltimore, Maryland.

Tisdell, C. A. 1982. Wild pigs: Environmental pest or economic resource? Pergamon Press, New York.

Towne, C. W., and E. N. Wentworth. 1950. Pigs from cave to cornbelt. University of Oklahoma Press, Norman, Oklahoma.

Wood, G. W., and R. H. Barrett. 1979. Status of wild pigs in the United States. Wildlife Society Bulletin, 7(4):237-246. 
Wild Pigs

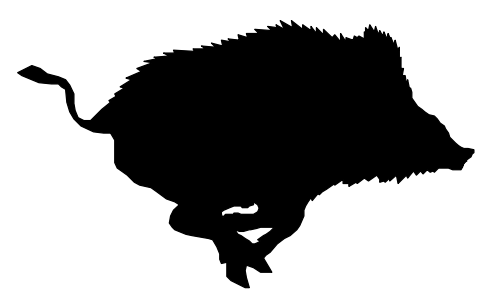

Part I

Biology of Wild Pigs 
SRNL-RP-2009-00869

This page left blank intentionally 
Wild Pigs

\section{Biology of Wild Pigs:}

\section{Taxonomy and History of Wild Pigs in the United States}

John J. Mayer

Savannah River National Laboratory, Savannah River Nuclear Solutions, LLC, Savannah River Site, Aiken, South Carolina 29808

\section{Introduction}

Wild pigs belonging to the species Sus scrofa are not native to the Western Hemisphere. In fact, the same is true for all species within the swine family, Suidae (Mayer et al. 1982). The only pig-like mammals native to the Nearctic and Neotropical zoogeographic realms are the peccaries (Family Tayassuidae) (Mayer and Brandt 1982, Sowls 1984, Mayer and Wetzel 1986, 1987). The presence of wild S. scrofa in the New World is solely attributable to introductions by man. Such introductions have been both intentional (e.g., Eurasian wild boar released as a new big game species) and accidental (e.g., escaped domestic swine that have gone wild). Excluding the polar regions, similar introductions of this species have also been made throughout other non-native areas (e.g., Australia, Oceania, sub-Saharan Africa) (Tisdell 1982, Mayer and Brisbin 1991). Such introductions date back at least as far as 3,000 years ago with the human colonization of Oceania (Allen et al. 2001, Lum et al. 2006).

The Recent native distribution of the Eurasian wild boar extends from Western Europe to the Maritime Territory of eastern Siberia, extending southwards as far the Atlas Mountain region of North Africa, the northern Mediterranean Basin and the Middle East north of the Arabian Peninsula, through India, IndoChina, Japan (including the Ryukyu Islands), Taiwan and the Greater Sunda Islands of Southeast Asia (Fig. 1). In addition, fossil and subfossil specimens of this species are known only from the Paleartic, Oriental, and Ethiopian realms (Mayer and Brisbin 1991). In the last four centuries, wild boar have become scarce or rare in parts of their range as a result of both habitat loss (i.e., caused mostly by deforestation) and overhunting (Clutton-Brock 1981, Fernández et al. 2006). During that period, this species was even completely extirpated in the British Isles, Denmark, Scandinavia, the Japanese island of Hokkaido, and parts of North Africa and the Russian Federation (Tisdell 1982, Oliver et al. 1993). Restocking efforts have been undertaken to restore depleted wild boar populations in a number of locations (e.g., Tisdell 1982, Genov et al. 1991, Apollonio et al. 1992, Massei and Tonini 1992, Martinoli et al. 1997). Well-established populations of reintroduced wild boar now exist in the southern portions of both Sweden and England (Hansson and Fredga 1996, Goulding 2003, Lemel et al. 2003). In addition, there have also been recent increases of wild boar within the species' native range (e.g., Genov 1981, Boschi 1984, Sáez-Royuela and Telleria 1986, Casanova 1988, Herrero 1996, Urayama and Takahashi 1995). Supplementary feeding, increased protection/regulated hunting, reduced predation and changes in land use practices have all contributed to these increases (DEFRA 2004).

The Eurasian wild boar is the single wild ancestor to most ancient and modern domestic swine breeds (Clutton-Brock 1981, Oliver et al. 1993, Giuffra et al. 2000). The Sulawesi warty pig (S. celebensis) has also been domesticated; but as such was never widely dispersed beyond Sulawesi and the Moluccan, Lesser Sunda, and west Sumatran islands (Groves, 1981, Oliver et al. 1993, Larson et al. 2007). Based on sequencing the mitochondrial DNA (mtDNA) genome, there is clear evidence for multiple independent centers of domestication of the wild boar across Eurasia. In addition, these analyses suggest a much earlier divergence from the wild ancestral forms than had been previously estimated. Further, a subsequent introgression of European and Asian domestic stocks occurred $\sim 200$ years ago. The various lineages and breeds of domestic swine were subsequently dispersed worldwide in nonpolar areas from their Eurasian 
centers of origin (Giuffra et al. 2000, Alves et al. 2003, Larson et al. 2005, Wu et al. 2007). The global dispersal of this species has been a combination of both the spread of domestic stock as well as the translocation of wild boar. These wild boar, along with domestic swine that have either escaped or been released from captivity and become wild-living (i.e., feral hogs), form the basis for the introduced wild pigs now found in the non-native areas of every continent except Antarctica.

\section{Taxonomy}

The taxonomic hierarchy of the Eurasian wild boar is as follows: Domain: Eukaryota, Kingdom Animalia, Phylum Chordata, Subphylum Vertebrata, Class Mammalia, Subclass Theriformes, Infraclass Holotheria, Cohort Placentalia, Order Artiodactyla, Suborder Suina, Superfamily Suoidea, Family Suidae, and Subfamily Suinae. The genus Sus contains eight species: S. barbatus, bearded pig; S. bucculentus, Viet Nam warty pig; S. cebifrons, Visayan warty pig; S. celebensis, Sulawesi warty pig; S. philippensis, Philippine warty pig; S. salvanius, pygmy hog; S. scrofa, Eurasian wild boar; and S. verrucosus, Javan warty pig. S. scrofa contains 18 currently recognized subspecies (modified from Groves 1981 and Mayer and Brisbin 1991) as follows:

S. s. algira Loche 1867:59 - North African wild boar; type locality country of Beni Sliman, Algeria.

S. s. attila Thomas 1912:105 - Eastern European wild boar; type locality Kolozsvar, Transylvania, Romania.

S. s. chirodontus Heude 1899:130 - Southern Chinese wild boar; type locality Poyang Lake, Kiangsi, China.

S. s. coreanus Heude 1897:191 - Korean wild boar; type locality Fusan, Korea.

S. s. cristatus Wagner 1839:435 - Indian wild boar; type locality probably the Malabar Coast of India.

S. s. davidii Groves 1981:37 - Southwest Asian wild boar; type locality Sind, Pakistan.

S. s. jubatus Miller 1906:745 - Southeast Asian wild boar; type locality Trong, Lower Siam, Thailand.

S. s. leucomystax Temminck 1842:6 - Japanese wild boar; type locality Japan.

S. s. lybicus Gray 1868:31 - Middle Eastern wild boar; type locality Xanthus, near Gunek, Turkey.

S. s. moupinensis Milne-Edwards 1872:93 - Northern Chinese wild boar; type locality Moupin, Sze-Chwan, China.

S. s. nigripes Blanford 1875:112 - Central Asian wild boar; type locality Tien Shan Mountains, Kashgar District, Sinkiang, China.

S. s. riukiuanus Kuroda 1924:11 - Ryukyu wild boar; type locality Kabira, Ishigakijima, Ryukyu Islands.

S. s. scrofa Linnaeus 1758:49 - Western European wild boar; type locality Germany.

S. s. sibiricus Staffe 1922:51 - Mongolian wild boar; type locality Tunkinsk Mountains, southern Siberia.

S. s. taivanus Swinhoe 1864:383 - Taiwanese wild boar; type locality Taiwan.

S. s. ussuricus Heude 1888:54 - Siberian wild boar; type locality Ussuri Valley, eastern Siberia.

S. s. vittatus Müller and Schlegel 1842:172 - Indonesian wild boar; type locality Padang, Sumatra.

S. s. zeylonensis Blyth 1851:173 - Sri Lankan wild boar; type locality Sri Lanka.

Based on both geographic and morphological criteria, Groves and Grubb (1993) have distinguished four "subspecies groupings" of Eurasian wild boar. These include the following: (1) "Western races" of Europe, and the Middle East, extending at least as far as Central Asia; (2) "Indian races" of the Sub-Himalayan region from Iran in the west to northern India in adjacent countries as far east as Burma and west Thailand, and southern India and Sri Lanka; (3) "Eastern races" of Mongolia and the Far East, Japan, Taiwan, to southeastern China and Viet Nam; and (4) "Indonesian races" from the Malay Peninsula, Sumatra, Java, Bali and certain offshore islands.

The recently recognized geographic races of Eurasian wild boar have varied in number from 14 to 23 described subspecies (Martys 1991). These subspecies are largely based on morphological characteristics with a notable variation in size (Groves 1981, Mayer and Brisbin 1991, Kusatman 1992). Aside from 


\section{Wild Pigs}

names synonymized due to the rules of nomenclatural priority, both morphological and genetic analyses (e.g., Epstein 1971, Groves 1981, Randi et al. 1989, Mayer and Brisbin 1991, Alves et al. 2003, Larson et al. 2005) have also been used to question the validity of several previously-accepted wild boar subspecies (e.g., S. s. baeticus - Andalusian wild boar, S. s. castilianus - Castilian wild boar, S. s. majori - Italian wild boar, S. s. meridionalis - Sardinian wild boar, and S. s. sennaariensis - Nile River wild boar).

The origin of S. scrofa appears to have occurred in Southeast Asia (Larson et al. 2005), where the greatest diversity of the entire genus Sus exists (Groves 1981, Lucchini et al. 2005). This was followed by an initial dispersal into India, and then subsequent radiations into East Asia, with a final, progressive spread across Eurasia into Western Europe (Larson et al. 2005). This progression is consistent with the clinal morphological data, with wild boar increasing in size somewhat to the north, and more significantly decreasing to the west (Groves 1981, Mayer and Brisbin 1991, Kusatman 1992, Mayer et al. 1998). Sus scrofa is currently the most widespread species in the Suidae (Groves 1981, MacDonal and Frädrich 1991, Oliver et al. 1993).

As the single wild ancestor of domestic swine, the Eurasian wild boar and its domesticated counterpart are considered to be conspecifics. Aside from the debate over the use of scientific nomenclature for domestic animals (e.g., Groves 1971, Melville 1977, Van Gelder 1979), the application of S. scrofa for Eurasian wild boar, domestic swine, feral hogs, as well as hybrids between these forms is commonly accepted by most systematic zoologists (MacDonal and Frädrich 1991, Mayer and Brisbin 1991).

\section{History}

All wild pigs found in the United States belong to the species Sus scrofa. Basically, two types of Sus scrofa, Eurasian wild boar and domestic swine, were introduced into this country. Because these two types are conspecifics, wherever both of them were found together in the wild, interbreeding occurred. As a result, there are now three general types of wild pigs present (Fig. 2). However, because this situation represents a very diverse hybrid complex, the distinguishing lines among these three general types are not always clear morphologically (Mayer and Brisbin 1993). Genetic analyses may be necessary to sort out the ancestry of a specific population of unknown origin (e.g., Spencer and Hampton 2005).

An additional taxonomic question concerning this species in the United States exists regarding the initial ancestry of the wild pig in Hawaii. These animals are generally assumed to have been domesticated $S$. scrofa (Tomich 1969, Kramer 1971). However, it has also been suggested that the original stock brought to this Pacific island archipelago could have been a mixture of two Sus species, S. scrofa and S. celebensis, from Southeast Asia (Groves 1981, 1983, 2001). Larsen et al. (2005, 2007) ruled out a significant contribution of $S$. celebensis based on mtDNA comparisons among Pacific pigs, including wild individuals from Hawaii. Whatever the initial taxonomic source, it is also likely that the more recent introductions, beginning with the one made by Capt. Cook in 1778, have altered or even completely swamped-out the early Polynesian stock that might have represented a hybrid ancestry (Baker 1975, Mayer and Brisbin 1991, Allen et al. 2001).

The origins of wild pigs in the United States were widespread and varied. Additional new introductions have continued through the present. Because such new introductions are ongoing on relatively a constant basis, and the vast majority are not reported, and in some cases, are clandestine in nature, it is would extremely difficult, if not virtually impossible, to attempt to develop a comprehensive history of what types of wild pigs were introduced where, when and by whom. Detailed accounts of the history of many of these introductions can be found in Mayer and Brisbin (1991).

Additionally, the apparent presence of remains of swine in pre-Columbian Indian sites has led to at least one theory that $S$. scrofa was initially brought into the Western Hemisphere across the Bering land bridge, Beringia, by the early human emigrants into North America (Quinn 1970a, 1970b). In contrast to these theories, most paleozoologists attribute these specimens to the incorporation of recent material into older assemblages (Mayer and Brisbin 1991). 
Historically, the first manmade introduction of pigs into the United States was on the Hawaiian Islands. These animals were carried there by the early Polynesian immigrants who first colonized these islands. Pigs were abundant on all of the islands within this archipelago at the time of the first European contact in the $18^{\text {th }}$ Century. The first pigs to be brought to continental North America were of European origin. These animals were initially introduced by the early Spanish explorers (e.g., De Soto and Cortes). Such introductions were followed by similar actions by the French and English explorers and then colonists in the New World (Mayer and Brisbin 1991).

Origin of Feral Hogs - Of the two types of Sus scrofa that were originally brought into the United States from the Old World, the initial introductions of domestic swine predated that of the first Eurasian wild boar by almost fifteen centuries. The first of these occurred with the colonization of the Hawaiian Islands. Early settlers, from Tahiti and the Marquesas as well as other island groups, arrived in large double-hulled sailing canoes at this large Pacific archipelago as early as 400 AD. Over time, these were followed by other groups of Pacific islanders. The pig, one of the favorite domesticated animals found in prehistoric Oceanic societies, was carried along on these early voyages during the settlement of east Polynesia. In addition to being an important food source, pigs also played a crucial cultural role in rituals, politics, and rites of passage throughout the region (Allen et al. 2001). As had been done elsewhere, the early Polynesian colonists in Hawaii released their domestic pigs to wander the forests surrounding the newly established settlements. These free-ranging stocks formed the initial basis of the feral hog populations found in this island group (Mayer and Brisbin 1991).

The next important importation of domestic swine into the Western Hemisphere came with the second voyage of Christopher Columbus in 1493. In contrast to his first voyage, the fleet assembled for this second effort consisted of seventeen ships and 1,500 men and boys, including sailors, soldiers, colonists, priests, officials, gentlemen of the court, as well as a number of horses (Daegan and Cruxent 1993). To outfit such a large expedition, the "Grand Fleet" stopped at the Canary Islands to obtain provisions. Among the livestock acquired were eight "selected" domestic pigs that were taken onboard at the island of Gomera (Lewinsohn 1964, Donkin 1985). These animals and their offspring became the stock that populated the newly formed settlements and outposts on the islands of Cuba, Hispaniola and Jamaica (Towne and Wentworth 1950). In the absence of competing species, these pigs rapidly multiplied with enormous success in Hispaniola, and quickly became a pest (Crosby 1972, Sauer 1966). Because of that, pigs were not among the relief supplies requested at La Isabela, Columbus's colony on Hispaniola, in 1494 (Parry and Kieth 1984, Daegan and Cruxent 1993). An official proclamation was even issued by the Spanish Crown in 1505 to reduce the numbers of wild pigs found in the West Indies at that time (Zadik 2005). In 1506, thirteen years after Columbus first introduced domestic swine to the West Indies, the Spanish colonists had to begin hunting the feral descendents of the eight original animals because the then present droves of wild pigs were killing cattle and ravaging cultivated crops of maize and sugarcane (Ensminger 1961, Donkin 1985).

The presence of a pig tooth at the archaeological site of what is believed to be Columbus's colony of La Navidad further complicates the aforementioned accepted history. La Navidad was the doomed settlement of 39 Spanish sailors established by Columbus in 1492 after his flagship, the Santa Maria, was wrecked off the north coast of Haiti. Upon his return in November of 1493, Columbus found all of his men dead, the fort burned, and the supplies dispersed among the Indians over a distance of several kilometers. Columbus abandoned the area, and left to establish La Isabela 113 kilometers to the east. Stable isotopic analysis of that individual pig tooth indicates that the animal was most likely raised in the area around Seville in Spain (Daegan 1992, Daegan and Cruxent 1993). If accurate, and assuming that this animal was not a recent transplant from Spain to the Canary Islands, this would appear to be counter to the largely accepted source of the first domestic pigs being brought by Columbus from Gomera to the West Indies on his second voyage. A recent analysis of the mitochondrial DNA of the Canarian Black pig, the ancient native domestic breed of swine found on the Canary Islands, showed that these animals have a mixed ancestry of European and Asian domestic swine haplotypes (Clop et al. 2004).

When the Spanish explorers provisioned expeditions headed to the North American mainland, they captured some of these free-ranging pigs on the Caribbean islands to take with them (Mayer and Brisbin 1991). In other instances, pen-raised domestic pigs were acquired from the Spanish colonists on some of 


\section{Wild Pigs}

these islands. For example, long-legged Spanish herding pigs were bartered from Cuban plantation owners for some of these expeditions (Clayton et al. 1993). From these animals sprang the immense herds that sustained such Spanish explorers as Cortés and De Soto on their journeys to the mainland during the early $1500 \mathrm{~s}$. It was from these ambulatory stocks of swine used by these initial expeditions that the first welldocumented feral populations of wild pigs originated in the continental United States (Mayer and Brisbin 1991).

The credit for having been first to bring domestic pigs to the continental United States goes to Juan Ponce de León. On his second expedition to Florida, De León brought several species of livestock, including pigs, with the plan of establishing a settlement in Florida as a base to further explore the region. The expedition was attacked by local Indians shortly after making landfall. Many of the group's members were wounded, including De León, who later died of his wounds after returning to Cuba. The paucity of information about this failed expedition does not include any information as to whether or not the Spaniards had time to unload the livestock after landing in the Port Charlotte area of the west coast of Florida (Davis 1935, Mayer and Brisbin 1991).

The expedition of Hernando de Soto is attributed as the first documented source that introduced pigs into the continental United States. Based on his travels on the mainland (1528-1536), Cabeza de Vaca had reported a northern sea to De Soto. The latter thought it was the Pacific Ocean, the sea which Balboa had discovered earlier in Panama while accompanied by a younger De Soto. De Soto thought he could travel to China by crossing America using De Vaca's alleged northern sea. Following the examples of Cortéz and Pizarro, De Soto planned to take a herd of pigs along on his expedition to "La Florida" in order to supply his party and any settlements that might be established along the group's route with meat. De Soto's expedition was large, consisting of nine ships, over 600 men and women, 253 horses, and a great store of provisions. Among those important provisions were pigs (Clayton et al. 1993). The actual number of pigs carried to mainland by De Soto's fleet is a matter of some uncertainty. The number typically cited is thirteen sows, which was stated by "A Gentleman of Elvas," the anonymous chronicler of the expedition. However, this would be counter to Elvas' earlier reference in his journal of "many" swine being provided to De Soto by Vasco Porcallo de Figueroa, after De Figueroa was named as the captain-general of the expedition. The number "thirteen sows" was noted later in Elvas' expedition account in association with the fact that the herd of swine being driven by the Spaniards had increased significantly. It could be that Elvas did not include the boars and young pigs in this total, since the sows were the ones responsible for farrowing the offspring that increased the size of the herd (Mayer and Brisbin 1991). It could also be that Elvas was referring to all of the animals, both sexes and all ages, since it was common in the early Spanish expedition chronicles to use the feminine plural (i.e., "puercas") for either or both of the sexes when referring to swine (Zadik 2005). In contrast to Elvas' estimate, Garcilaso de la Vega ("the Inca") noted that De Soto had originally brought more than 300 head of swine, both male and female, from Cuba to supply the expedition. However, De la Vega was not actually on the expedition, and his chronicles were a compilation of the notes of several of De Soto's men and interviews with others that had survived the journey and later returned to Spain. Whichever is correct, these swine increased to a reported total of 700 . Over three years, De Soto and his army traveled through what are now 14 states. Along the 4,988-km journey, the pigs variously escaped into the wild and were either given to or stolen by the Indians encountered by the Spaniards. Many of these animals were maintained as marked free-ranging stock and apparently multiplied. On the return trip, the expedition found a sow that had been lost on the outward journey, and which now had 13 piglets, each with markings on their ears (i.e., notches) (Clayton et al. 1993).

De Soto was followed by many other Spanish, English and French explorers and colonists that brought pigs to the continental U. S. (e.g., Pedro Menéndez de Avilés, Juan de Oñate, Pierre de Iberville, Fernando del Bosque, Rene-Robert Cavelier Sieur de La Salle, and Sir Walter Raleigh). The escaped pigs from these various expeditions and settlements went wild and rapidly became established in a variety of areas. These pigs proved to be a favorite game animal for the Native American hunters (Crosby 1972). In his exploration of the American Southwest, Francisco Vásquez de Coronado encountered Indians who had been hunting and exploiting wild pigs as a food resource since well before his arrival (Zadik 2005). In the mid-1560s, two short-lived French colonies in eastern Florida attributed the fact that they did not starve to 
SRNL-RP-2009-00869

the pork that was provided to them by the local Indians who were hunting the already established wild pigs in that area (Mayer and Brisbin 1991).

Among the domestic livestock being raised in the early settlements in the European colonies in the New World, pigs were among the most common (Towne and Wentworth 1950, Zadik 2005). This was especially true in the central East Coast and northeastern portions of the United States (Towne and Wentworth 1950). Confronted with a shortage of labor relative to the supply of land and to the amount of work that was needed to be done in establishing these new settlements, the colonists could not supervise their livestock as thoroughly as European farmers did. Every available hand was required to clear fields, grow food, and build houses, roads, fences, and other necessities (Anderson 2004). Because of this, the free-ranging of domestic livestock, including swine, was a commonly practiced husbandry method employed in these colonies. In fact, open range legally existed in most states in this country until the mid1900s. Free-ranging was also a very economic method for raising pigs. These animals were simply turned loose into an unfenced area to fend for themselves, foraging and reproducing on their own. Being opportunistic omnivores, pigs can readily find forage resources in the wild to sustain themselves. In addition, abundant oak and chestnut mast in the Appalachians offered a good return in meat for almost no investment in feed or care. In late autumn, the semi-feral "woods hogs" were rounded up and slaughtered, and their fatty flesh was made into salt pork, which along with Indian corn was a staple of the early American diet. Individual animals could also be caught using trained dogs, penned and corn fed for a brief period, and then slaughtered for meat. Often, these free-ranging domestic swine went wild. Combined with the escaped stock from the earlier expeditions, these animals established the early populations of wild pigs throughout the eastern and southwestern United States (Mayer and Brisbin 1991).

In many places in the United States, these feral or "woods" hog populations continued to survive in rural areas. This was especially true in the southern states. Many areas even developed systems of "hog rights," whereby ear notching or other methods were used to establish the ownership of semi-wild or free-ranging domestic swine. In locations with established populations of truly "wild" pigs that had no defined ownership, these animals represented a prolific source of meat for human consumption in rural areas. Although considered to be huntable game in some locations, a legal game status was not granted to these animals in most areas. The passage of the so-called "fence" or closed-range livestock laws in the early to mid 1900s led to the decline or elimination of some of these populations. In spite of such laws, some freeranging of domestic swine did persist well into the mid and late 1900s (Mayer and Brisbin 1991).

Eurasian Wild Boar Introductions - Beginning in the late 1800s, Eurasian wild boar were introduced into several areas of the United States to provide a new huntable big game species for wealthy sportsmen. Most of these introductions were into fenced shooting preserves. Many were followed by secondary introductions into other locations. A number of these later releases were made into unfenced areas. In other instances, the wild boar were able to break out of and escape the fenced enclosures where they were being maintained. In such areas where feral hogs were already established, interbreeding between the two forms readily occurred, further masking the taxonomic composition of the wild pigs found in those areas (Mayer and Brisbin 1991, 1993).

The first introduction of pure wild boar into the United States took place in New Hampshire in the late 1800s. Austin Corbin, the millionaire founder of the Long Island Railroad and Coney Island, purchased approximately 12,141 ha in the mountains of Sullivan County. A 9,500-ha portion was enclosed with game fencing and known as Corbin's Park. In September of 1890, Corbin released 13 wild boar that had been purchased from Karl Hagenbeck in Germany. The animals became established within the park, and various numbers of them escaped from the enclosure over the ensuring years. These "outside" wild boar, as they came to be known, have never persisted long in the wild, typically being aggressively hunted down by locals upon learning of their presence in the area. As many as two subsequent introductions of wild boar have been made into the park since the original stocking. The impact of these has had an undetermined effect on the Corbin's Park population. A population of wild boar still exists within the park, now incorporated as the Blue Mountain Forest Association (Mayer and Brisbin 1991). Recently, a number of the park's wild boar have escaped through breaches in the enclosure's fence caused by either severe weather or vandals. These animals have ranged widely throughout the surrounding area, and have even been observed crossing over into Vermont (Conaboy 2006, Washburn 2008, C. Swan, pers. comm.). In 


\section{Wild Pigs}

November 2005, one of the parks' wild boar was hit and killed in a collision with a vehicle in Petersborough, New Hampshire (Conaboy 2006). Another wild boar, likely an escapee from the park, was hit on a highway near Lancaster, Massachusetts in October of 2008. Only injured in the collision, that animal had to be euthanized (Smiley 2008).

In the spring of 1902, millionaire Edward H. Litchfield released 15-20 wild boar from Germany onto his 3,200-ha estate, Litchfield Park, in Hamilton County, New York. About six years after being released, some of these animals escaped from Litchfield's enclosed preserve. These animals dispersed into the area's forest, mostly in the north side of the upper portion of Little Tupper Lake on and around the Whitney Preserve (now called the William C. Whitney Wilderness Area). One was reported killed by local hunters in that area in 1918. Descendants of Litchfield's wild boar reportedly survived in the wild for up to 20 years after the introduction (Anon. 1902, Whipple 1919, Mayer and Brisbin 1991).

The mountains of western North Carolina were the location of the next significant Eurasian wild boar introduction. This specific introduction had the greatest single impact on the composition of wild pigs in the United States. In 1912, a financial advisor named George Gordon Moore was allowed to establish a game preserve on Hooper Bald in Graham County, North Carolina, as partial payment for his efforts in a business venture. Among the game species that Moore released into two fenced enclosures on the preserve were 13 wild boar, surprisingly the same number as had been released into Corbin's Park. These animals were purchased from a European animal dealer; however, the specific origin of these animals has remained unknown. From the very beginning, the wild boar were able to root out of their enclosure, which was made of split-rail fencing. However, most chose to remain within the fenced preserve. After a period of about 10 years, a large organized hunt caused most of the remaining animals to break through the rail fencing and escape into the surrounding hills. These animals extended their range for a considerable distance, and even spread into Tennessee. Both feral hogs and free-ranging domestic swine were present in the area at that time, and crossbreeding occurred freely. All degrees of intergrades between wild boar and feral hogs have been found in that population since then (Mayer and Brisbin 1991).

In 1924, Moore obtained a dozen wild pigs from the area around Hooper Bald, and shipped the animals to California. In late 1925 or early 1926, these wild pigs were released on Moore's property between the Carmel Valley and the Los Padres National Forest in Monterey County. As their numbers began to increase, descendants of Moore's wild pigs were obtained to stock on private and public lands elsewhere in the state. As had happened in North Carolina, interbreeding with already established feral populations further increased the physical diversity seen in the California hybrid wild pigs. Through both natural dispersal and continued introductions by man, the Eurasian wild boar phenotype has now been bred into or genetically affected most of the wild pig populations found in California (Mayer and Brisbin 1991).

In addition to California, descendants of the Hooper Bald wild pigs have been the subject of numerous secondary introductions throughout the southeastern United States (Fig. 3). A number of these translocations were made into other areas of both North Carolina and Tennessee. Both private individuals and state wildlife agencies used progeny of the Hooper Bald animals to either enhance existing or establish new wild pig populations in at least Florida, Georgia, South Carolina, West Virginia, and Mississippi. Hybrid wild pigs in northern Tennessee have also expanded their range into southern Kentucky (Mayer and Brisbin 1991).

The next two introductions were made into the central coastal region of Texas. The first of these was made onto a piece of property called the St. Charles Ranch, Aransas County, which had been acquired by the San Antonio Loan and Trust Company in 1919. Leroy G. Denman, Sr., chairman of the board of the bank, assumed management of the ranch. A "great many" feral hogs were present on the property at that time. As part of the management program for the ranch, it was decided to upgrade the quality of this population. Initially, well-bred Hampshire domestic swine were released, but these individuals failed to survive in the wild. Since the property was also being managed as a game refuge, it was then decided to introduce wild boar onto the ranch. Several introductions of wild boar stock occurred. The first two consisted of a female and male from the Brackenridge Park Zoo in San Antonio. This pair prospered in a small enclosure on the ranch, but do not reproduce. A second pair, obtained from the Houston zoo, was released into the enclosure and some reproduction occurred. Several additional wild boar were then obtained from the zoos 
in St. Louis and Milwaukee. None of these animals survived. A wild-caught sow from the ranch was then penned with the zoo males. A number of cross-bred pigs were produced through these and subsequent pairings of the various captive animals. A male wild boar was purchased from the Blue Mountain Forest Association, but it died enroute to the ranch. Some of the cross-bred animals were released onto the ranch lands. When the property was purchased by the federal government as a new national wildlife refuge, the owners were allowed to remove as many wild pigs as possible. Between 1 October 1936 and 30 July 1939, 3,391 hogs were trapped and either shipped out for sale or butchered at the site. The wild pig population increased since the federal acquisition, and still exists on what is now the Aransas National Wildlife Refuge (Denman 1938, Mayer and Brisbin 1991).

In 1939, Denman acquired some property of his own in Calhoun County, further to the northeast along the Texas coast. Similar to the St. Charles, Denman decided to use this new parcel of land, called the Powder Horn Ranch, as a wildlife preserve. As had been done on the St. Charles, Denman purchased several wild boar of both sexes from the San Antonio, St. Louis and San Diego zoos, along with two wild males from Leon Springs, Texas, and released them into an enclosure on the property. Denman also attempted to relocate animals from the St. Charles, but all of those efforts failed. These animals on the Powder Horn eventually escaped the enclosure, and increased their numbers, dispersing into the surrounding ranchlands and coastal area (Denman 1942, 1949). Some of the wild boar even crossed Espiritu Santo Bay during low tides and are now present on Matagorda Island. Descendants of one of the Denman introductions were also stocked onto San Jose Island in Aransas County. In 1973, 17 wild boar from the Powder Horn Ranch were released into the coastal area around Chalmette, Louisiana. These animals have since dispersed into the surrounding marshlands (Mayer and Brisbin 1991).

In the early 1940s, Harry Brown, a rancher in the Edward's Plateau region of northern Bexar County, Texas, purchased several wild boar and released them into an enclosure on his property. The origin of these animals is unknown. Several years later, a storm washed out some of the enclosure's fencing, and these animals escaped into the nearby hill country. The wild boar hybridized with the already resident feral hogs in the area. This population increased in size, and spread into portions of neighboring Medina and Bandera counties. Descendants of the Edward's plateau wild boar population have subsequently been stocked into other areas in Texas, variously including Comal County in the Edward's Plateau, Webb County in south Texas, and Throckmorton and Haskell counties in northern Texas (Mayer and Brisbin 1991).

In June of 1972, wild boar began showing up in the area around Sabael, near Indian Lake, in Hamilton County, New York. Although it was originally thought to have been remnant animals from the Litchfield Park introduction, the actual origin of these animals was never determined. Six of the wild boar were either shot or hit and killed in vehicle collisions. Seven were captured and sent to the Bronx Zoo. There have been no subsequent reports of any of these animals surviving in that area. A male and female from the Bronx Zoo were later purchased by and brought to the Blue Mountain Forest Association in New Hampshire. This pair was kept in the sanctuary area of the preserve and later died of natural causes. It is unclear as to whether or not any genetic input from these animals made it into the Corbin's Park wild boar population (Mayer and Brisbin 1991).

Other introductions of wild boar or animals reported to be "wild boar" have taken place in several locations around the United States. A number of these releases were reported to have occurred on the barrier islands of Georgia and North Carolina. On the Georgia coast, this included the islands of Cumberland, Little Cumberland, Jekyll, St. Simons, Little St. Simons, Ossabaw and Wassaw. Specifically, wild boar obtained from King Humbert of Italy were released onto Jekyll Island, Georgia (Mayer and Brisbin 1991). The morphology of the wild pigs on Ossabaw and Cumberland islands would also corroborate an earlier introduction of wild pigs with at least some wild boar ancestry (J. J. Mayer, unpubl. data). Other wild boar introductions have also reportedly occurred on Santa Cruz Island, California, and in Alachua County, Florida, Cherokee County, Alabama, and Laurens, Telfair, Ben Hill and Jeff Davis counties, Georgia (Mayer and Brisbin 1991).

Beginning in the mid 1980s, there have been introductions of new Eurasian wild boar stock into the country. The first was the introduction of animals from the Berlin Tierpark to the San Diego Zoo (Mayer 


\section{Wild Pigs}

and Brisbin 1991). A couple of founder "lines" of imported Eurasian wild boar from farms in Canada have also been imported into the United States in the past decade. These have included both the Kalden and Andres lines of wild boar. In addition, the Bzikot line of Eurasian wild boar was reportedly imported from the Bialowieza Forest in Poland in the early 1990s (Palmer 2003).

\section{RECENT STATUS}

During the past decade, wild pigs have been collectively reported from 44 states (e.g., Hutton et al. 2006, Fogarty 2007) (Table 1). Of these, 21 are states with established or long-term persistent populations. A total of 12 states have wild pig populations that are transitional or emerging in nature. In general, the animals in those states are found in a number of counties and appear to be numerous enough to become well established in the near future. At the same time, the numbers in those states are still low enough that an intense control/eradication program might be successful in eliminating these populations. The remaining 11 states have very localized numbers of wild pigs in one to three counties. These animals are either recently released wild pigs or escaped individuals from private or commercial fenced enclosures. Some of these occurrences represent upwards of 100 or more animals, while others merely note the reported presence of wild pigs in those states. The fate of these latter wild pigs may be temporary in nature at best. The taxonomic composition of these populations varies from pure feral hog to pure Eurasian wild boar. However, most of the wild pig populations found in the United States at this time are composed of hybrids between the two founding stocks (Mayer and Brisbin 1991, Dickson et al. 2001). At least a few small localized populations of pure Eurasian wild boar exist in this country at present, having originated from farmed animals brought down from Canada (J. J. Mayer, unpubl. data).

Between 1989 and the present, the number of states reporting the presence of wild pig has doubled in less than two decades. Similar to the initial introductions of this species into this continent, this new range increase has also been manmade. Concurrent with this range expansion has been an increase in the estimate national population size of this species (i.e., 1-2 million up to 2-6 million animals). Gipson et al. (1998) noted that this range expansion in the central part of the country was largely due to clandestine releases by wild pig hunting enthusiasts. Other expansions have been the result of these animals escaping from fenced shooting preserves (e.g., in Michigan, New York State and Pennsylvania). Such newly established populations can expand rapidly, often before the state and local agencies realize what was happening. For example, in Pennsylvania, the state agencies had received reports of wild pigs in scattered occurrences around the state. However, the conclusion of a state task force that eventually looked into the situation came to a much more serious conclusion. Wild pigs were found in up to 15 Pennsylvania counties, and numbered as many as 3,000 animals at that point in time (Crable 2007). Often, the way that state agencies first learn about a new wild pig population is when reports of animal sightings or damage start coming in. If immediate actions are not taken to remove those animals, the population can become established very quickly.

The identified sporthunting sources (i.e., clandestine releases and escapes from fenced preserves) of this species increase are consistent with the fact that wild pigs have become the second most popular big game animal in North America, second only to white-tailed deer (Odocoileus virginianus) in the numbers harvested every year (Kaufman et al. 2004). Because of continuing illegal releases of wild pigs into new areas, the number of states with these animals will probably increase. In fact, the potential exists to ultimately have introduced populations of wild pigs in all 50 states at some time in the future. 
Table 1. Listing of states with wild pig populations or reported sightings, status (i.e., E - established or long-term persistent; $\mathrm{T}$ - transitional or emerging; and $\mathrm{R}$ - recent releases/escapees), and the locations and estimated number of animals in each state. The bases for the state estimates are as follows: a - recent annual hunter harvest percentage, assuming that approx. 10-30\% of total population is taken per year; $\mathrm{b}$ - rough bounding estimate; and $\mathrm{c}$ - published estimate.

\begin{tabular}{|c|c|c|c|c|c|}
\hline \multirow[t]{2}{*}{ State } & \multirow[t]{2}{*}{ Status } & \multirow[t]{2}{*}{ Location(s) Present within State } & \multicolumn{2}{|c|}{$\begin{array}{c}\text { Approximate Number of } \\
\text { Animals }\end{array}$} & \multirow{2}{*}{$\begin{array}{l}\text { Basis } \\
\text { For } \\
\text { Estimate }\end{array}$} \\
\hline & & & $\begin{array}{c}\text { Low } \\
\text { Estimate }\end{array}$ & $\begin{array}{c}\text { High } \\
\text { Estimate }\end{array}$ & \\
\hline Alabama & E & All 67 counties in the state & 90,000 & 300,000 & $\mathrm{a}$ \\
\hline Alaska & $\mathrm{R}$ & Wrangell-Petersburg County & 0 & 100 & $\mathrm{~b}$ \\
\hline Arizona & $\mathrm{E}$ & $\begin{array}{l}\text { Coconino, La Paz, Mohave, } \\
\text { Navajo, Pima and Yavapai } \\
\text { counties }\end{array}$ & 500 & 1,000 & $\mathrm{~b}$ \\
\hline Arkansas & E & All 75 counties in the state & 60,000 & 200,000 & $\mathrm{a}$ \\
\hline California & $\mathrm{E}$ & 56 out of 58 counties in the state & 200,000 & 400,000 & a \\
\hline Colorado & $\mathrm{T}$ & 16 of 64 counties in the state & 200 & 700 & $\mathrm{a}$ \\
\hline Florida & $\mathrm{E}$ & All 67 counties in the state & 300,000 & $1,000,000$ & $\mathrm{c}$ \\
\hline Georgia & E & 137 of 159 counties in the state & 200,000 & 600,000 & a \\
\hline Hawaii & $\mathrm{E}$ & $\begin{array}{l}\text { Islands of Hawaii, Maui, Lanai, } \\
\text { Molokai, Oahu and Kauai }\end{array}$ & 10,000 & 40,000 & a \\
\hline Idaho & $\mathrm{R}$ & Near Kamiah, Idaho & 0 & 100 & $\mathrm{~b}$ \\
\hline Illinois & $\mathrm{T}$ & 11 of 102 counties in the state & 500 & 1,000 & $\mathrm{~b}$ \\
\hline Indiana & $\mathrm{T}$ & 14 of 92 counties in the state & 500 & 1,000 & $\mathrm{c}$ \\
\hline Iowa & $\mathrm{T}$ & $\begin{array}{l}\text { De Moines, Henry, Louisa, and } \\
\text { Muscatine counties }\end{array}$ & 100 & 200 & $\mathrm{a}$ \\
\hline Kansas & $\mathrm{T}$ & 27 of 105 counties in the state & 500 & 1,000 & $\mathrm{c}$ \\
\hline Kentucky & E & 13 of 120 counties in the state & 1,000 & 2,000 & $\mathrm{c}$ \\
\hline Louisiana & E & 39 of 64 counties in the state & 3,000 & 5,000 & $\mathrm{~b}$ \\
\hline Maine & $\mathrm{R}$ & Penobscot County & 0 & 100 & $\mathrm{~b}$ \\
\hline Maryland & $\mathrm{R}$ & $\begin{array}{l}\text { Charles, Carroll and Allegany } \\
\text { counties }\end{array}$ & 0 & 100 & $\mathrm{~b}$ \\
\hline Massachusetts & $\mathrm{R}$ & Worcester County & 0 & 100 & $\mathrm{~b}$ \\
\hline Michigan & $\mathrm{T}$ & 67 of 83 counties in the state & 500 & 1,000 & $\mathrm{~b}$ \\
\hline Minnesota & $\mathrm{R}$ & Big Stone County & 25 & 50 & $\mathrm{c}$ \\
\hline Mississippi & E & 78 of 82 counties in the state & 5,000 & 10,000 & $\mathrm{c}$ \\
\hline Missouri & E & 26 of 115 counties in the state & 1,000 & 5,000 & $\mathrm{c}$ \\
\hline Nebraska & $\mathrm{T}$ & $\begin{array}{l}\text { Brown, Harlan, Nance, Seward, } \\
\text { Thurston and Valley counties }\end{array}$ & 0 & 100 & $\mathrm{~b}$ \\
\hline Nevada & $\mathrm{T}$ & Humboldt and Clark counties & 200 & 300 & $\mathrm{c}$ \\
\hline $\begin{array}{l}\text { New } \\
\text { Hampshire }\end{array}$ & $\mathrm{R}$ & $\begin{array}{l}\text { Sullivan County; various sightings } \\
\text { over the years in the southern } \\
\text { two-thirds of the state }\end{array}$ & 0 & 100 & $\mathrm{~b}$ \\
\hline New Jersey & $\mathrm{R}$ & Gloucester County & 0 & 100 & $\mathrm{~b}$ \\
\hline New Mexico & E & Grant, Hidalgo and Union counties & 250 & 500 & $\mathrm{c}$ \\
\hline New York & $\mathrm{T}$ & $\begin{array}{c}\text { Broome, Cayuga, Cortland, } \\
\text { Onondaga, Tioga and Tompkins } \\
\text { counties }\end{array}$ & 0 & 100 & $\mathrm{~b}$ \\
\hline
\end{tabular}




\section{Wild Pigs}

Table 1. Listing of states with wild pig populations or reported sightings, status (i.e., E - established or long-term persistent; $\mathrm{T}$ - transitional or emerging; and $\mathrm{R}$ - recent releases/escapees), and the locations and estimated number of animals in each state. The bases for the state estimates are as follows: a - recent annual hunter harvest percentage, assuming that approx. 10-30\% of total population is taken per year; $\mathrm{b}$ - rough bounding estimate; and $\mathrm{c}$ - published estimate. (Continued)

\begin{tabular}{|c|c|c|c|c|c|}
\hline \multirow[t]{2}{*}{ State } & \multirow[t]{2}{*}{ Status } & \multirow[t]{2}{*}{ Location(s) Present within State } & \multicolumn{2}{|c|}{$\begin{array}{c}\text { Approximate Number of } \\
\text { Animals }\end{array}$} & \multirow{2}{*}{$\begin{array}{c}\text { Basis } \\
\text { For } \\
\text { Estimate }\end{array}$} \\
\hline & & & $\begin{array}{c}\text { Low } \\
\text { Estimate }\end{array}$ & $\begin{array}{l}\text { High } \\
\text { Estimate }\end{array}$ & \\
\hline North Carolina & $\mathrm{E}$ & 16 of 100 counties in the state & 1,000 & 2,000 & $\mathrm{c}$ \\
\hline North Dakota & $\mathrm{R}$ & McKenzie and Rolette counties & 0 & 100 & $\mathrm{~b}$ \\
\hline Ohio & $\mathrm{T}$ & 26 of 88 counties in the state & 500 & 1,000 & $\mathrm{c}$ \\
\hline Oklahoma & $\mathrm{E}$ & All 77 counties in the state & 3,000 & 5,000 & $\mathrm{c}$ \\
\hline Oregon & $\mathrm{E}$ & 18 of 36 counties in the state & 1,000 & 2,000 & $\mathrm{c}$ \\
\hline Pennsylvania & $\mathrm{T}$ & 18 of 67 counties in the state & 2,000 & 3,000 & $\mathrm{c}$ \\
\hline South Carolina & $\mathrm{E}$ & 42 of 46 counties in the state & 131,000 & 392,000 & $\mathrm{a}$ \\
\hline South Dakota & $\mathrm{R}$ & Lake County & 0 & 100 & $\mathrm{~b}$ \\
\hline Tennessee & $\mathrm{E}$ & 32 of 95 counties in the state & 1,000 & 2,000 & $\mathrm{c}$ \\
\hline Texas & $\mathrm{E}$ & 233 of 254 counties in the state & $1,000,000$ & $3,000,000$ & $\mathrm{c}$ \\
\hline Vermont & $\mathrm{R}$ & Windsor County & 0 & 100 & $\mathrm{~b}$ \\
\hline Virginia & $\mathrm{E}$ & 6 of 95 counties in the state & 500 & 1,000 & $\mathrm{c}$ \\
\hline Washington & $\mathrm{E}$ & $\begin{array}{c}\text { Grays Harbor, Mason, Skagit and } \\
\text { Whatcom counties }\end{array}$ & 100 & 500 & $\mathrm{c}$ \\
\hline West Virginia & $\mathrm{E}$ & 7 of 55 counties in the state & 100 & 500 & $\mathrm{c}$ \\
\hline \multirow[t]{2}{*}{ Wisconsin } & $\mathrm{T}$ & 29 of 72 counties in the state & 300 & 1,000 & $\mathrm{c}$ \\
\hline & & Total Estimates & $2,013,775$ & $5,979,950$ & \\
\hline
\end{tabular}




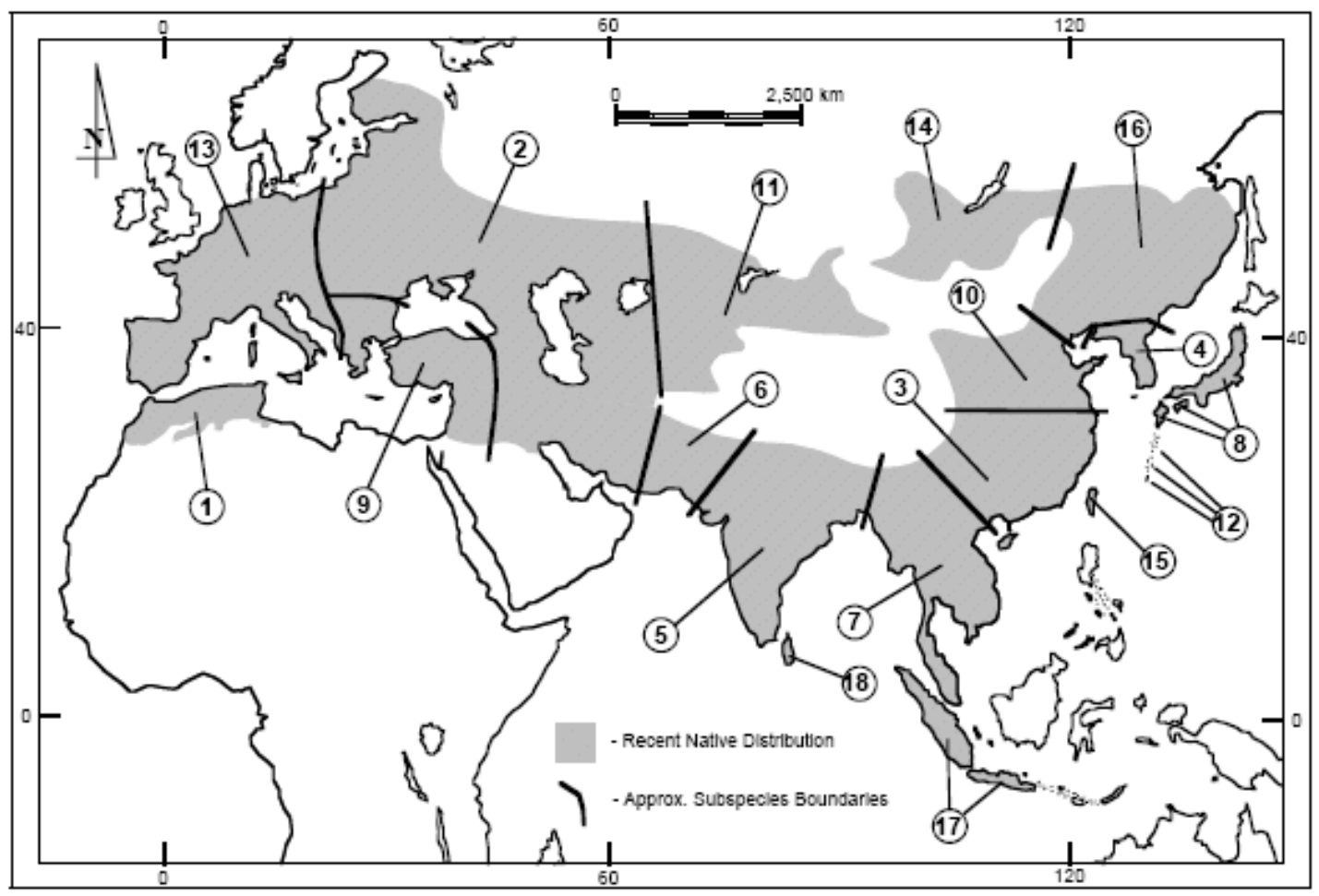

Fig. 1. The recent distribution (shaded area) of Eurasian wild boar (Sus scrofa spp.) with approximate subspecies boundaries. The subspecies are as follows: (1) S. s. algira; (2) S. s. attila; (3) S. s. chirodontus; (4) S. s. coreanus; (5) S. s. cristatus; (6) S. s. davidii; (7) S. s. jubatus; (8) S. s. leucomystax; (9) S. s. lybicus; (10) S. s. moupinensis; (11) S. s. nigripes; (12) S. s. riukiuanus; (13) S. s. scrofa; (14) S. s. sibiricus; (15) S. s. taivanus; (16) S. s. ussuricus; (17) S. s. vittatus; and (18) S. s. zeylonensis. Map modified from Mayer et al. 1998. 
Wild Pigs

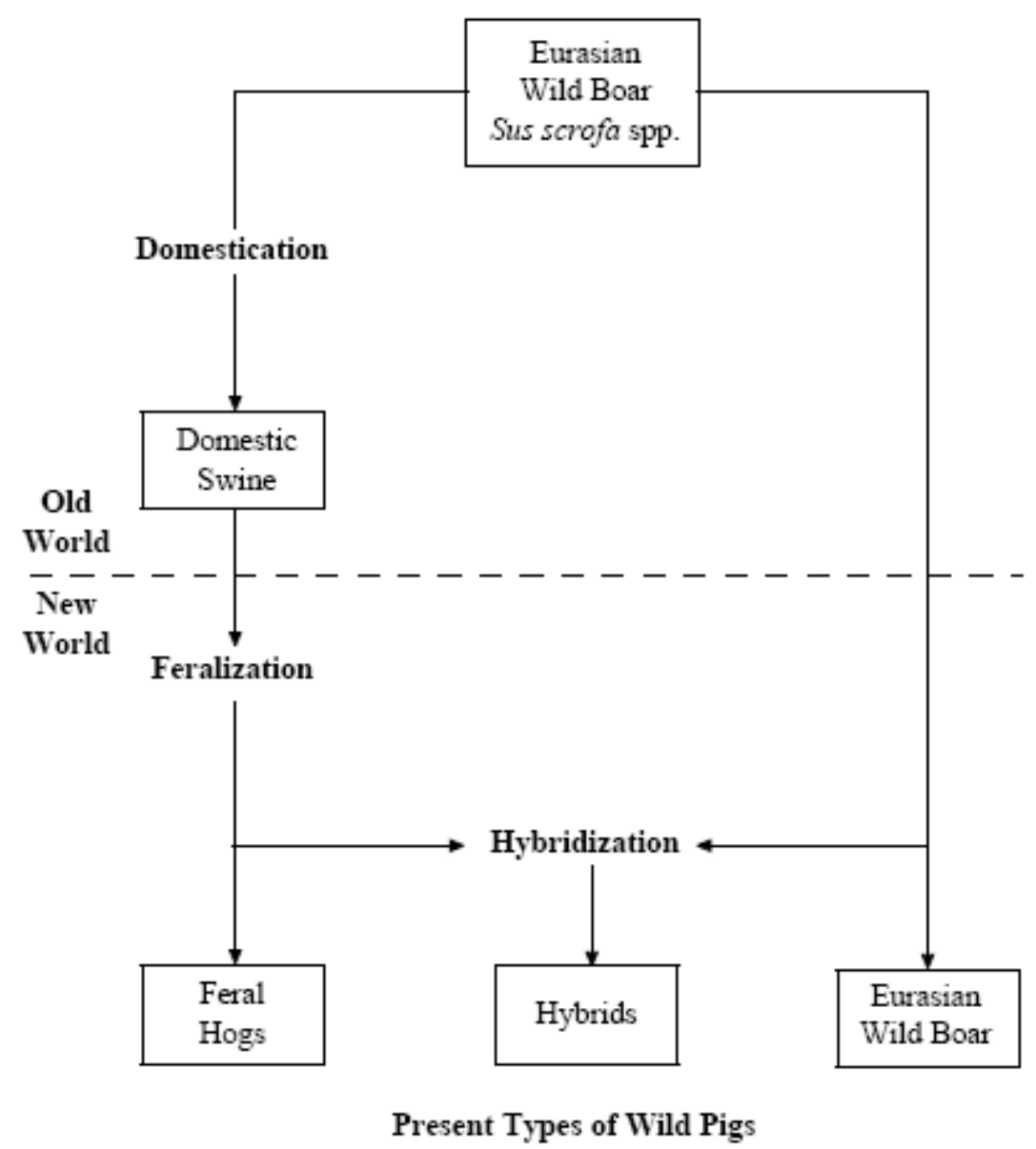

Fig. 2. Taxonomic composition of the introduced wild pigs (Sus scrofa) found at present in the United States. 


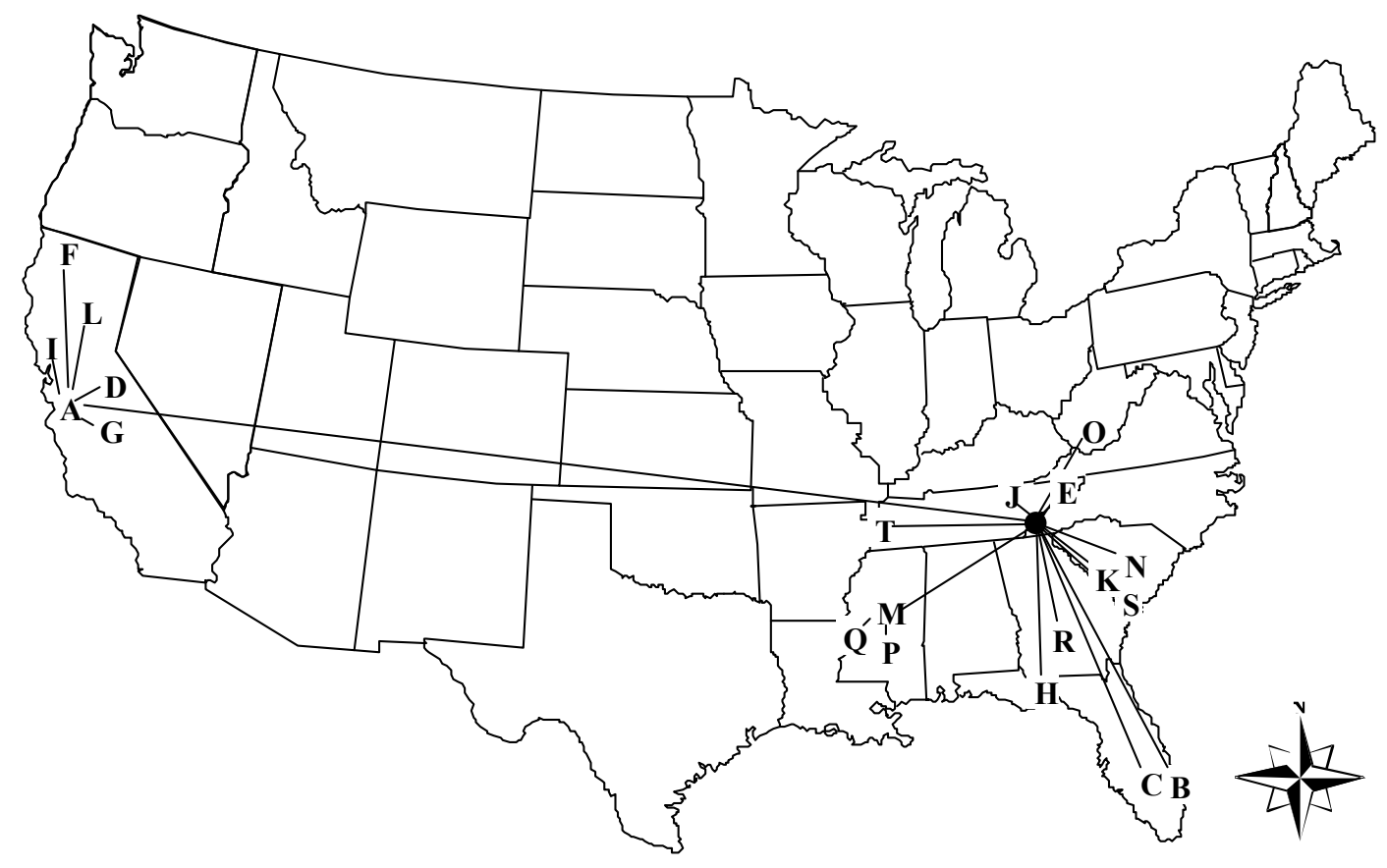

Fig. 3. Illustration of the subsequent introductions of wild pigs from the Hooper Bald introduction (black circle) to other locations in the United States. The dates and locations of these releases are as follows: A - 1925-26, Monterey County, CA; B - mid 1950s, late 1970s, Palm Beach County, FL; C - mid 1950s, Polk and Highlands counties, FL; D - 1957, 1970, Fresno County, CA; E - early 1960s, Washington, Greene and Unicoi counties, TN; F - 1960s, Shasta County, CA; G - 1961, 1965, San Benito County, CA; H - 1961, Eglin Air Force Base, FL; I - 1961, Mendocino County, CA; J - 1962, 1965 and 1966, Cumberland County, TN; K - 1968, Aiken County, SC; L - 1968, Tehama County, CA ; M - late 1960s, Copiah County, MS; N - early 1970s, Richland and Calhoun counties, SC; O 1971, Boone County, WV; P - 1971, Madison County, MS; Q - 1973, near Port Gipson, MS; R 1975, Houston County, GA; S - 1978, Allendale County, SC; and T - 1979, Lauderdale County, TN. Other subsequent translocations have also taken place from a number of these sites (Data from Mayer and Brisbin 1991). 


\section{Wild Pigs}

\section{Literature Cited}

Allen, M. S., E. A. Matisoo-Smith, and A. Horsburgh. 2001. Pacific "Babes": Issues in the origins and dispersal of Pacific pigs and the potentials of mitochondrial DNA analysis. International Journal of Osteoarchaeology, 11:4-13.

Alves, E., C. Óvilo, M. C. Rodríguez, and L. Silió. 2003. Mitochondrial DNA sequence variation and phylogenetic relationships among Iberian pigs and other domestic and wild pig populations. Animal Genetics, 34(5):319-324.

Anderson, V. D. 2004. Virginia DeJohn Anderson on Somer Islands' "Hogge Money." Environmental History, 9(1):128-129.

Anonymous. 1902. Litchfield Park receives a carload of wild boars - Andrew Carnegie building a camp. The New York Times, June 8:16.

Apollonio, M., E. Randi, and S. Toso. 1992. A morphological and biochemical approach to some European wild boars systematic problems. Pp. 23-30. In B. Bobek, K. Perzanowski, and W. L. Regelin (eds.), Global trends in wildlife management. Transactions of the $18^{\text {th }}$ International Congress of Game Biologists, Vol. II, Swiat Press, Krakow-Warsaw, Poland.

Baker, J. K. 1975. The feral pig in Hawaii Volcanoes National Park. Transactions of the California-Nevada Section of the Wildlife Society, 22:74-80.

Boschi, I. 1984. Amélioration d'une population de sanglier dans le parc natural de la Maremme. Pp. 169-172. In F. Spitz and D. Pépin (eds.), Symposium International sur le Sanglier. Les Colloques de l'INRA 22, INRA, Toulouse, France.

Casanova, P. 1988. Effetti del sovraccarico di daino e di cinghiale in alcuni ambienti Mediterranei: La tenuta di San Rossore, Pisa. Accademia Italiana di Scienze Forestali. Annali, 37:167-185.

Clayton, L. A., V. J. Knight, and E. C. Moore. 1993. The De Soto Chronicles: The Expedition of Hernando De Soto to North America 1539-1543. The University of Alabama Press, Tuscaloosa, Alabama.

Clop, A., M. Amills, J. L. Noguera, A. Fernández, J. Capote, M. M. Ramón, L. Kelly, J. M. H. Kijas, L. Andersson, and A. Sàchez. 2004. Estimating the frequency of Asian cytochrome B haplotypes in standard European and local Spanish pig breeds. Genetics Selection Evolution, 36(2004):97-104.

Clutton-Brock, J. 1981. Domesticated animals from early times. University of Texas Press, Austin, Texas.

Conaboy, C. 2006. Is New Hampshire a state full of boars? Concord Monitor Online. January 7. http://www.concordmonitor.com/apps/pbcs.dll/article?AID=/20060108/REPOSITORY/601080357

Crable, A. 2007. Feral pigs are going hog wild in Pennsylvania. Lancaster New Era, April 10.

Crosby, A. 1972. The Columbian Exchange. Westport, Connecticut.

Davis, T. F. 1935. Juan Ponce de Leon's voyages to Florida. Quarterly Proceedings of the Florida Historical Society, 14:1-70.

Deagan, K. A. 1992. La Isabela, foothold in the New World. National Geographic, 181(1):40-53.

Deagan, K., and J. M. Cruxent. 1993. From Contact to Criollos: The Archaeology of Spanish Colonization in Hispaniola. Proceedings of the British Academy, 81:67-104. 
Denman, L. G., Sr. 1938. Letter to LeRoy C. Stegeman, New York State College of Forestry at Syracuse. Dated June 16.

1942. Letter to Robert J. Kleberg, Jr., King Ranch. Dated February 2.

Denman, L. G., Jr. 1949. Letter to W. C. Glazener, Division of Wildlife Restoration, Texas Game, Fish and Oyster Commission. Dated August 16.

DEFRA (Department for Environment, Food and Rural Affairs). 2004. The ecology and management of wild boar in southern England. Central Science Laboratory, Hutton, York, United Kingdom.

Dickson, J. G., J. J. Mayer, and J. D. Dickson. 2001. Wild hogs. Pp. 191-192, 201-208. In J. G. Dickson (ed.), Wildlife of Southern forests: Habitat \& management. Hancock House Publishers, Blaine, Washington.

Donkin, R. A. 1985. The peccary - With observations on the introduction of pigs to the New World. Transactions of the American Philosophical Society, 75(5):1-152.

Ensminger, M. E. 1961. Swine science. The Interstate Printers \& Publishers, Danville, Illinois.

Epstein, H. 1971. The origin of domestic animals of Africa. Africana Publishing Corp., New York. Vol. II,

Fernández, N., S. Kramer-Schadt, and H. Thulke. 2006. Viability and risk assessment in species restoration: planning reintroductions for the wild boar, a potential disease reservoir. Ecology and Society, 11(1):1-6.

Fogarty, E. P. 2007. National distribution of feral hogs and related stakeholder attitudes. M.S. Thesis. Mississippi State University, Mississippi State, Mississippi.

Genov, P. 1981. Die Verbreigtung des Schwarzwildes (Sus scrofa L.) in Eurasiens und seine Ampassung au die Nahrungsverhaltnisse. Zeitschrift für Jagdwissenschaft, 27(4):221-231.

Genov, P., H. Nikolov, G. Massei, and S. Gerasimov. 1991. Craniometrical analysis of Bulgarian wild boar (Sus scrofa) populations. Journal of Zoology (London), 225:309-325.

Gipson P. S., B. Hlavachick, and T. Berger. 1998. Range expansion by wild hogs across the central United States. Wildlife Society Bulletin, 26:279-286.

Giuffra, E., J. M. H. Kijas, V. Amarger, O. Carlborg, J. T. Jeon, and L. Andersson. 2000. The origin of the domestic pig: Independent domestication and subsequent introgression. Genetics, 154(4):1785-1791.

Goulding, M. J. 2003. Wild boar in Britain. Whittet Books, Ltd., Suffolk, United Kingdom.

Groves, C. 1981. Ancestors for the pigs: Taxonomy and phylogeny of the genus Sus. Technical Bulletin No. 3. Department of Prehistory, Research School of Pacific Studies, Australian National University, Canberra, Australia.

Groves, C. P. 1971. Request for a declaration modifying Article 1 so as to exclude names proposed for domestic animals from zoological nomenclature. Bulletin of Zoological Nomenclature, 34:137-139.

1983. Pigs east of the Wallace Line. Journal de la Société des Océanistes, 77(39):105-119.

2001. Taxonomy of wild pigs of Southeast Asia. Asian Wild Pig News, 1(1):3-4.

Groves, C. P., and P. Grubb. 1993. The Eurasian suids: Sus and Babyrousa - Taxonomy and description. Pp. 107-111. In W. L. R. Oliver (ed.), Pigs, peccaries and hippos: Status survey and conservation 


\section{Wild Pigs}

action plan. International Union for the Conservation of Nature and Natural Resources, Gland, Switzerland.

Hansson, L., and K. Fredga. 1996. The mammal fauna of Sweden. Hystrix, 8(1-2):31-33.

Herrero, J. 1996. Iniciación al resultado de las repercusiónes del incremento de las poblaciónes de jabalí en áreas de montaña. Departmento de Agricultura y Medio Ambiente gobierno de Aragon, Zaragoza, Spain.

Hutton, T., T. DeLiberto, S. Owen, and B. Morrison. 2006. Disease risks associated with increasing feral swine numbers and distribution in the United States. Wildlife and Fish Health Committee, Midwest Association of Fish and Wildlife Agencies, Rhinelander, Wisconsin.

Kramer, R. J. 1971. Hawaiian Land Mammals. Charles E. Tuttle Company, Rutland, Vermont.

Kaufman, K., R. Bowers, and N. Bowers. 2004. Kaufman focus guide to mammals of North America. Houghton Mifflin, New York.

Kusatman, B. 1992. The origins of pig domestication with particular reference to the Near East. Ph.D. Dissertation, Institute of Archaeology, University College, London, United Kingdom.

Larson, G., K. Dobney, U. Albarella, M. Fang, E. Matisoo-Smith, J. Robins, S. Lowden, H. Finlayson, T. Brand, E. Willerslev, P. Rowley-Conwy, L. Andersson, and A. Cooper. 2005. Worldwide phylogeography of wild boar reveals multiple centers of pig domestication. Science, 307(5715):1618-1620.

Larson, G., T. Cucchi, M. Fujita, E. Matisoo-Smith, J. Robins, A. Anderson, B. Rolett, M. Spriggs, G. Dolman, T.Kim, N. T. D. Thuy, E. Randi, M. Doherty, R. A. Due, R. Bollt, T. Djubiantono, B. Griffin, M. Intoh, E. Keane, P. Kirch, K. Li, M. Morwood, L. M. Pedriña, P. J. Piper, R. J. Rabett, P. Shooter, G. Van den Bergh, E. West, S. Wickler, J. Yuan, A. Cooper, and K. Dobney. 2007. Phylogeny and ancient DNA of Sus provides insights into neolithic expansion in Island Southeast Asia and Oceania. Proceedings of the National Academy of Sciences of the United States of America, 104(12):4834-4839.

Lemel, J., J. Truvé, and B. Söderberg. 2003. Variation in ranging and activity behaviour of European wild boar Sus scrofa in Sweden. Wildlife Biology, 9 (Suppl. 1):29-36.

Lewinsohn, R. 1964. Animals, men and myths: A history of the influence of animals on civilization and culture. Fawcett Publications, Greenwich, Connecticut.

Lucchini V., E. Meijaard, C. H. Diong, C. P. Groves, and E. Randi. 2005. New phylogenetic perspectives among species of South-east Asian wild pig (Sus sp.) based on mtDNA sequences and morphometric data. Journal of Zoology, 266:25-35.

Lum, J. K., J. K. McIntyre, D. L. Greger, K. W. Huffman, and M. G. Vilar. 2006. Recent Southeast Asian domestication and Lapita dispersal of sacred male pseudohermaphroditic "tuskers" and hairless pigs of Vanuatu. Proceedings of the National Academy of Sciences of the United States, 103(46):17190-17195.

Macdonal, A. A., and H. Frädrich. 1991. Pigs and peccaries: What are they? Pp. 7-19. In R. H. Barrett and F. Spitz (eds.), Biology of Suidae. Imprimerie des Escartons, Briancon, France.

Martinoli, A., A. Zilio, M. Cantini, G. Ferrario, and M. Schillaci. 1997. Distribution and biometry of the wild boar (Sus scrofa) in the Como and Varese provinces. Hystrix, 9(1-2):79-83.

Martys, M. F. 1991. Monographie des eurasiatischen Wildschweines (Sus scrofa). Bongo, 18(1991):8-20. 
Massei, G., and L. Tonini. 1992. The management of wild boar in the Maremma Natural Park. Pp. 443-445. In F. Spitz, G. Janeau, G. Gonzalez, and S. Aulagnier (eds.), Ongules/Ungulates 91: Proceedings of the international symposium. Toulouse, France, September 2-6, 1991. Société Francaise pour l'Etude et la Protection des Mammifères, and Toulose: Institut de Recherché sur les Grands Mammifères, Paris \& Toulouse, France.

Mayer, J. J., and P. N. Brandt. 1982. Identity, distribution, and natural history of the peccaries, Tayassuidae. Pp. 433-455, In M. A. Mares and H. H. Genoways (eds.), Mammalian Biology in South America. Vol. 6, Special Publication Series, Pymatuning Laboratory of Ecology, Univ. of Pittsburgh, Pennsylvania.

Mayer, J. J., and I. L. Brisbin, Jr. 1991. Wild pigs in the United States: Their history, comparative morphology, and current status. The University of Georgia Press, Athens, Georgia.

1993. Distinguishing feral hogs from introduced wild boar and their hybrids: A review of past and present efforts. Pp. 28-49. In C. W. Hanselka and J. F. Cadenhead (eds.), Feral swine: A compendium for resource managers. Texas Agricultural Extension Service, Kerrville, Texas.

Mayer, J. J., J. M. Novak, and I. L. Brisbin, Jr. 1998. Evaluation of molar size as a basis for distinguishing wild boar from domestic swine: Employing the present to decipher the past. Pp. 39-53, In K. Ryan and J. Quick (eds.), Ancestors for the pigs: Pigs in prehistory. MASCA Research Papers in Science and Archaeology, Vol. 15, University of Pennsylvania Museum, Philadelphia.

Mayer, J. J., O. L. Rossolimo, R. G. Van Gelder, and S. Wang. 1982. Family Suidae. Pp. 315-316, In J. H. Honacki, K. E. Kinman, and J. W. Koepp (eds.), Mammal Species of the World: A Taxonomic and Geographic Reference. Allen Press, Inc. and Assoc. of Systematic Collections, Lawrence, Kansas.

Mayer, J. J., and R. M. Wetzel. 1986. Catagonus wagneri. Mammalian Species, 259:1-5.

1987. Tayassu pecari. Mammalian Species, 292:1-7.

Melville, R. V. 1977. Comments on request for a declaration modifying Article 1 so as to exclude names proposed for domestic animals from Zoological Nomenclature. Z.N. (S.) 1935. Bulletin of Zoological Nomenclature, 34:139-140.

Oliver, W. L. R., and I. L. Brisbin, Jr. 1993. Introduced and feral pigs: Problems, policy, and priorities. Pp. 179-191. In W. L. R. Oliver (ed.), Pigs, peccaries and hippos: Status survey and conservation action plan. International Union for the Conservation of Nature and Natural Resources, Gland, Switzerland.

Oliver, W. L. R., I. L. Brisbin, Jr., and S. Takahashi. 1993. The Eurasian wild pig (Sus scrofa). Pp. 112-121. In W. L. R. Oliver (ed.), Pigs, peccaries and hippos: Status survey and conservation action plan. International Union for the Conservation of Nature and Natural Resources, Gland, Switzerland.

Palmer, T. A. 2003. A brief history of European wild boar in North America. Boar Hunter Magazine, $4(6): 48-49$

Parry, J., and R. Kieth. 1984. The Caribbean. Volume II of The New Iberian World. (5 vols.). Times Books, New York.

Quinn, J. H. 1970a. Occurrence of Sus in North America. Geological Society of America, Abstracts, 2(4):298.

1970b. Special note. Society of Vertebrate Paleontology News Bulletin, 8:33. 


\section{Wild Pigs}

Randi, E., M. Apollonio, and S. Toso. 1989. The systematics of some Italian populations of wild boar (Sus scrofa L.): A craniometric and electrophoretic analysis. Zeitschrift für Saugetierkunde, 54(1989):40-56.

Sáez-Royuela, C., and J. L. Telleria. 1986. The increased population of the wild boar (Sus scrofa L.) in Europe. Mammal Review, 16(2):97-101.

Sauer, C. V. 1966. The Early Spanish Main. University of California Press, Berkeley.

Smiley, C., Jr. 2008. 200-pound wild boar put down after hit on Route 2. Boston Herald.com, October 25. http://news.bostonherald.com/news/regional/view/2008_10_25_200-pound_wild_boar_put_down_ after_hit_on_Route_2/srvc $=$ home $\&$ position $=5$

Sowls, L. K. 1984. The peccaries. University of Arizona Press, Tucson, Arizona.

Spencer, P. B. S., and J. O. Hampton. 2005. Illegal translocation and genetic structure of feral pigs in Western Australia. Journal of Wildlife Management, 69(1):377-384.

Tisdell, C. A. 1982. Wild pigs: Environmental pest or economic resource? Pergamon Press, New York.

Tomich, P. Q. 1969. Mammals in Hawaii. $1^{\text {st }}$ Edition. Special Publication 57. Bishop Museum Press, Honolulu, Hawaii.

Towne, C. W., and E. N. Wentworth. 1950. Pigs from cave to cornbelt. University of Oklahoma Press, Norman, Oklahoma.

Urayama, Y., and S. Takahashi. 1995. Changes in the distribution of and local attitudes toward wild boar in the Kiyomi Village area, Gifu Prefecture. Geographic Review of Japan Series A, 68(10):680-694.

Van Gelder, R. G. 1979. Comments on request for a declaration modifying Article 1 so as to exclude names proposed for domestic animals from Zoological Nomenclature. Z.N. (S.) 1935. Bulletin of Zoological Nomenclature, 36:5-9.

Washburn, B. 2008. Not a bad deer year after all. Concord Monitor Online. November 30. http:/www.concordmonitor.com/apps/pbcs.dll/article?AID=/20081130/SPORTS/811300345

Whipple, J. S. 1919. First wild boar hunt in United States. State Service: The New York State Magazine, 4(January-June):61-64.

Wu, G. S., Y. G. Yao, K. X. Qu, Z. L. Ding, H. Li, M. G. Palanichamy, Z. Y. Duan, N. Li, Y. S. Chen, and Y. P. Zhang. 2007. Population phylogenomic analysis of mitochondrial DNA in wild boars and domestic pigs revealed multiple domestication events in East Asia. Genome Biology, 8(11):R245.

Zadik, B. J. 2005. The Iberian pig in Spain and the Americas in the time of Columbus. M.A. Thesis. University of California, Berkeley. 
SRNL-RP-2009-00869

This page left blank intentionally 
Wild Pigs

\section{Biology of Wild Pigs:}

\section{Wild Pig Physical Characteristics}

John J. Mayer

Savannah River National Laboratory, Savannah River Nuclear Solutions, LLC, Savannah River Site, Aiken, South Carolina 29808

\section{Introduction}

The introduced wild pigs (Sus scrofa) in the United States exhibit a broad spectrum of physical diversity. To a large part, this variability stems from the widely diversified taxonomic/ancestral origins of these animals. In general, both free-ranging domestic swine (i.e., feral hogs) and introduced Eurasian wild boar comprised the initial types of $S$. scrofa established as wild pigs in the Western Hemisphere. However, the ancestral makeup of these animals was far more complex than a simple combination of these two types. For example, the domestic swine introduced into this country over the centuries have morphologically varied from archaic/primitive domestic stock, to derived colonial forms, and most recently, to highly-modified, selectively-bred modern domestic breeds. In addition, the various Eurasian wild boar introduced may have been represented by up to 7 of the 18 typically recognized subspecies found in the Old World. Further, as conspecifics, the hybridization between feral hogs and wild boar has increased the spectrum of physical diversity seen among the wild populations of this species in this country at present (Mayer and Brisbin 1991, 1993).

With these animals being so variable, it is important to know the expected physical variation among the wild pigs that one is trying to manage as a necessary basis to detecting changes that can impact the successful control of these animals (e.g., the illegal introduction of new animals from another population). Otherwise, such unnoticed changes can produce amplified management problems and challenges that will likely result in increased manpower levels of effort and program costs. Further, the removal of wild pigs in a control program provides the opportunity to cost-effectively collect data to either compile or expand such information on the population in question (Brisbin and Mayer 2001). The continued collection of such data will further enable one to monitor the population for changes that might indicate the need to modify the site's wild pig management program.

From a taxonomic perspective, wild pigs in this country are represented by a mosaic of the aforementioned types (i.e., Eurasian wild boar, feral hogs, and hybrids between these two types). Physical differences do exist among these three general types (Mayer and Brisbin 1991, 1993). However, these different types of wild pigs will be treated together in the following sections unless otherwise noted. Within the context of these descriptions, age-defined variation is delineated by specific age classes. The age classes employed here are defined by the pattern of the erupted teeth (Table 1).

\section{Physical Characteristics}

\section{General Description}

Although highly variable in appearance, wild pigs in the United States are all medium-to-large sized animals, with a barrel-like stout body (often with flatten sides), short and slender legs, and a relatively long, pointed head supported by a short neck. The coat is course and bristly, and can vary from sparsely to densely haired with respect to coverage on any one specific animal. Some individuals exhibit a well developed mane along the neck, shoulder and forward portion of the lower back. The snout ends in a seemingly hairless, damp, disk-like plate (i.e., rhinarial pad) on which two external nostrils open anteriorly. The eyes are small. The ears are relatively large, broad structures, which taper to a point at the tip. The 
pinnae can vary from an erect to a drooped or lop-eared form. The front limbs constitute slightly less than one-half of the height at the shoulder. Each foot has four toes, of which the lateral ones are shorter and positioned higher up the limb than the central pair. All of the toes are covered by a keratinized hooves supported by fleshy pads on the rear ventral surface of each digit. The tail is short in length, and covered with hair, especially toward the tip. The conformation of the tail can vary from straight to curled.

Adult boars and sows also differ in their general physical appearance (Fig. 1). In overall proportionate body size, males have a larger head and higher shoulders than females. In their general lateral appearance, boars also have a more angular overall profile of their back compared to sows. Boars further have the presence of a lip curl (i.e., the opening in the lips that allows the protrusion of the adult canines) and external genitalia (i.e., the scrotal sac and the preputial bulb). Adult males have enlarged canines, which visibly protrude from the mouth. In contrast, females have a more rounded profile to their back, equally high shoulders and hips, an insignificant to very slight lip curl, and no readily-apparent external genitalia (i.e., with the exception of the vaginal papilla under the base of the tail). The canines of even adult sows only slightly protrude from the mouth. Mature sows may also have visibly distended mammary glands and teats.

\section{Skeletal Morphology}

In general, the wild pig skeleton is morphologically similar, and in some cases, virtually identical to that of domestic swine. Some taxonomic differences exist (e.g., in long bone length and numbers of certain vertebrae). The major limb bones (e.g., humerus and femur) in wild pigs are also typically smaller in diameter and length compared to those of domestic swine (Hammond 1962). Such differences are likely the product of the growth of wild pigs on a lower plane of nutrition than is seen among domestic populations (Mayer and Brisbin 1991). Overall, the weight of the postcranial skeleton and skull combined comprise between 7 and 12 percent of a wild pig's total body mass (Stribling 1978).

Skull - In overall appearance, the wild pig skull is elongate, especially in the proportional size of the rostral region. The general shape of the skull (i.e., cranium and mandible together) is roughly triangular in the dorsal, ventral or lateral views (Fig. 2). The lateral view of the dorsal profile can vary from being almost straight to a distinctly dished or concave appearance. This condition gets more dished with both age and a better plane of nutrition. The occipital region is enlarged, with the cranium then tapering to the distal end of the rostrum. A less evident anterior tapering is also seen in the mandible. The cranium is elevated terminating posteriorly in a laterally directed occipital ridge or nuchal crest. The rostrum is elongate with the paired nasal bones pointed and the premaxillaries rounded. Beginning on the occipital ridge, the sagittal crest constricts in the parietal region, and then expands to merge with the postorbital processes. The occipital wall of the cranium can be variably angled from a posterior- to an anterior-slanting plane or perspective. The zygomatic arches are substantial in both height and width. The paraoccipital processes are elongate and extend downward from the base of the posterior end of the cranium. The orbits are small and open along the rear margin. Two distinct lacrimal foramina are present on the anterior margin of the orbit. The rostral region adjacent to the canines is enlarged laterally. A sexually-dimorphic ridge (i.e., larger in males; Fig. 3) exists on this maxillary buttress, which physically creates the opening in the lips allowing the exposure of the permanent canines. The external rhinarial pad is poteriorly supported by a nasal sesmoid or rostral bone (i.e., os rostrale), located in the nasal septal cartilage between the pad and the anterior cranium. Wild pig skulls are sexually dimorphic in adults, with the crania and mandibles of males being larger for most measurements (Mayer and Brisbin 1991). Seven skull measurements for 328 adult wild pigs are provided in Table 2. Skulls from the three types of wild pigs are taxonomically discernable through cranial analyses (Mayer and Brisbin 1991, 1993).

Teeth - Wild pigs have a total of 44 permanent teeth for both sexes. Both deciduous and permanent sets exist that erupt sequentially. A variety of dental anomalies and deformities have been described in wild pigs (e.g., Bahadur 1942; Stubbe et al. 1986; Horwitz and Davidovitz 1992; Feldhamer and McCann 2004; Kierdorf et al. 2004, Konjević et al. 2004, 2006, Zinoviev 2009).

The dental formula for the permanent teeth is I 3/3, C 1/1, P 4/4, M 3/3. Within the permanent set, the three upper incisors are spatulate and deeply convex is shape. The crowns of these teeth decrease in 
diameter as the tooth tapers to the root. A diastema exists between the last upper incisor and the canine. The lower incisors are rod-like and only slightly curved. These lower components are lined up in a horizontal plane and set closely together. Both the upper and lower incisors decrease in size from the medial to lateral teeth. The canines all project out of the sockets as sharp-edged, curved tusks (see section on Canine Sexual Dimorphism). The permanent premolars have simple spatulate crowns, with predominant central and smaller lateral cusps on the second through fourth teeth. A diastema occurs between the first and the second premolars in the lower quadrants. The molars are low-crowned bunodont or multi-cuspidate teeth. The first and second molars have two rows of paired cusps, while the third molars have two cusp rows and a single posterior cusp. The lower third molar is the longest tooth of the permanent set.

The deciduous compliment contains 28 teeth. The deciduous dental formula for wild pigs is $\mathrm{i} 3 / 3 \mathrm{c} 1 / 1 \mathrm{p}$ $3 / 3$. The incisors and canines in this set have simple peg-like crowns with pointed distal tip. The deciduous molariform teeth (i.e., premolars) generally resemble the corresponding permanent teeth. The exceptions are that the fourth deciduous upper premolar is more bunodont that the permanent one, and the fourth lower premolar has three cusp rows (i.e., similar to other ungulates). The upper deciduous premolars have two, three, and four cusps, respectively.

The approximate age of eruption of both the deciduous and permanent teeth according to Matschke (1967) is provided in Table 3. The age of eruption of teeth in this species can be effected by nutrition, in that the higher the level of nutrition, the earlier the eruption of these teeth (McCance et al. 1968). Age determination in wild pigs has historically focused around the pattern of tooth eruption, replacement and development (e.g., Matschke 1967; Sweeney et al. 1970; Hayashi et al. 1977; Snethlage 1982; Boitani and Mattei 1991; Clarke et al. 1992; Choquenot and Saunders 1993, Magnell and Carter 2007), which enables aging up to approximately three years. Aging of adult wild pigs (i.e., animals with completely erupted permanent dentition) has required either counting incremental lines of tooth cementum (Henson 1975; Hayashi et al. 1977; Saez-Royuela et al. 1989; Genov et al. 1992; Clarke et al. 1992; Choquenot and Saunders 1993), measuring pulp cavity width (Saez-Royuela et al. 1989), evaluating the juxtaposition of the spina ristae facilais relative to the upper third molar on a cleaned cranium (Dub 1952), scoring exposure of the molar dentine (Mayer 2002), or visual estimation of tooth wear (Kozlo 1973; Hayashi et al. 1977; Barrett 1971; Clarke et al. 1992; Choquenot and Saunders 1993). Jaerisch (1933) described a method for aging subadult and adult boars using the size and amount of wear on the tusks or canine teeth.

Canine Sexual Dimorphism - The permanent canines or tusks of male wild pigs are significantly larger than those in females. In addition, the shapes of these teeth differ markedly between the two sexes (Fig. 3; Mayer and Brisbin 1988). Behavioral sex differentiation is the apparent cause for the sexual dimorphism observed in this species (Herring 1972). These differences as so characteristic that these teeth can be used to accurately determine the sex of wild pigs that are over 14 months of age (Mayer and Brisbin 1988). The permanent canines erupt at approximately seven to twelve months of age. The lower canines of both sexes extend in an anterolateral direction out of the socket, curving dorsally, and in some older males, posterolaterally. In males, the upper canines extend in an anterolateal direction out of the socket, then curve dorsally and occasionally medially. The upper canines of females extend in a ventrolateal direction out of the socket, continuing in a lateral but never in a dorsal direction as in the males (Fig. 3; Mayer and Brisbin 1988).

The lower canines in males are partially or wholly semicircular in shape and triangular in cross section. The cross-sectional shape is consistent from the base of the wear surface to the root apex. The root apex stays open and the tooth remains evergrowing except in old individuals. The overall length of the tooth (i.e., around the outside of the curve) averages approximately $185 \mathrm{~mm}$ and typically varies in adults from 125 up to $440 \mathrm{~mm}$ (Mayer and Brisbin 1988, J. J. Mayer, unpubl. data). Anecdotal accounts exist of some tusks exceeding $500 \mathrm{~mm}$. These teeth grow at a rate of about $6 \mathrm{~mm}$ per month; however, most of this growth is lost by abrasion with the upper tusk (Barrett 1971). The lack of sufficient abrasion between the upper and lower tusks can result in the lower teeth growing back into the boar's mouth, and even into the mandible (Fig. 4). This condition, however, is more common in domestic boars and wild barrows (i.e., castrated boars) than in uncastrated wild males. Approximately 62 percent (range - 35-73 percent) of the total length of the lower canines are contained within the tooth's mandibular socket. The teeth are on 
SRNL-RP-2009-00869

average $23 \mathrm{~mm}$ by $13 \mathrm{~mm}$ in cross section at the gumline in adults. Enamel covers the anterior-medial and anterior-lateral faces of the tooth. The female lowers canines are also semicircular in shape and are roughly triangular in cross section, with the edges being more rounded than in the males. Unlike the situation in males, enamel only covers the crown of the lower canines in sows, forming a distinct enamocementum junction line (i.e., similar to most mammalian teeth). The female lower canine tapers from the enamocementum junction line to the apices of the crown and root. The root canal closes in females at about 3-4 years of age; whereupon the tooth ceases any further linear growth. The mean length of the female lower canine is $73 \mathrm{~mm}$, and varies from 55 to $104 \mathrm{~mm}$. The roots comprise 31-80 percent (mean 64 percent) of the tooth's length. The cross section of a sow's lower tusk averages $14 \mathrm{~mm}$ by $9 \mathrm{~mm}$ (Mayer and Brisbin 1988, Mayer 1991).

In both sexes, the upper canines are normally shorter than the lower counterparts. The male upper canines approach a semicircular shape along the outer curve, and are roughly trapezoidal in cross section. As in the lower teeth, the root apex remains open and the tooth evergrowing, except in very old animals. The crosssectional shape tapers from the gumline to the apices of the crown and the root. Enamel only occurs on the ventral surface and in two narrow ridges along the anterior and posterior margins of the tooth. Where it occurs, the enamel extends along the entire length of the tooth. The overall length of the upper canine in males averages $93 \mathrm{~mm}$ (range - 57 to $198 \mathrm{~mm}$ ), and the cross-sectional dimensions at the gumline are about $22 \mathrm{~mm}$ by $15 \mathrm{~mm}$. Similar to the lower component, misalignment can cause longer lengths in the upper canines (Fig. 5). In the females, the upper canines are barely semicircular in the lateral view, and are somewhat triangular in cross section with rounded edges. The tooth tapers from the enamocementum line to both the crown and root apices. As in the lower counterpart, the enamel only covers the crown. The root canals in these upper teeth also close, ceasing any further growth, at about 3-4 years of age. The female upper canines average $48 \mathrm{~mm}$ long (range - 35 to $69 \mathrm{~mm}$ ) and are about $15 \mathrm{~mm}$ by $9 \mathrm{~mm}$ in cross section at the gumline (Mayer and Brisbin 1988).

Postcranial Skeleton - Wild pigs have a total of approximately 50-55 vertebrae. This variation in swine is common to both sexes in this species with no dimorphic differences (Shaw 1929, Freeman 1939). The number of vertebrae varies by region as follows: cervical -7 , thoracic $-13-16$; lumbar $-5-7$, sacral -4 , and caudal - 20-26 (Shaw 1929, Getty 1975). The variability in vertebrae stems from a combination of natural variability and variability due to artificial selection under domestication. As would be expected, the variation in the number of vertebrae also produces differences in body length (e.g., the more vertebrae, the longer the body). In accordance with the variation in vertebrae, the number of ribs can vary from 13 to 17 (Freeman 1939). As in all suid species, the metapodials are not fused (i.e., no canon bone is formed). The digits number four per limb, with the lateral toes being shorter than the central ones. The lateral digits on the forefeet are positioned lower on the limb than the hindfoot counterparts. Each digit contains three phalangeal bones below the metapodials. Various skeletal deformities have been documented in the limbs of wild pigs (Olivier 1904, Nowak 1962, Ptak 1962, Valentinčič 1974, Stukelj 2002). Aging estimates using the postcranial skeleton have included techniques using epiphyseal closure (Bridault et al. 2000) and shaft length and breadth (Vigne et al. 2000).

\section{Total Body Mass}

The observed range in total body mass (i.e., intact weight with no internal organs removed) among wild pigs is one of the most variable parameters from population to population. As a species, Sus scrofa has the potential to reach very large body masses. The record was a domestic boar that was reported to weigh $1,157 \mathrm{~kg}$ (Anon. 2002). However, individuals of this species that are born and grow to physical maturity in the wild seldom achieve such large weights. Recent reports of harvested wild pigs exceeding $450 \mathrm{~kg}$ have turned out to be capture-reared males that either were released or escaped into the wild before being killed. Wild pigs are born at approximately 900 grams (range of 494 to 1,620), or 0.9 percent of their adult body mass. Growing wild pigs gain between 0.001 to $0.26 \mathrm{~kg}$ per day, the mean rate of which increases with age (Pine and Gerdes 1973, Pavlov 1980, Schortemeyer et al. 1985, McIlroy 1989, Baubet et al. 1995). As these animals increase in age, females grow at a consistent and slightly faster rate toward achieving their adult body mass than do males. In contrast, males exhibit a greater absolute weight gain than females of the same age. This sexually dimorphic difference with the males being larger is consistent for all age classes, with males averaging and ranging larger than females of each comparable age class. Overall, 


\section{Wild Pigs}

males are about 1.2 to 1.4 times larger than females. This difference typically becomes significant during the second year of life. In addition, Barrett (1971) reported that barrows (i.e., castrated males) were significantly larger than both intact boars and sows. Taxonomic differences in this dimorphism also exist, with Eurasian wild boar exhibiting a greater percent difference in male-female body mass than either feral hogs or wild boar $x$ feral hog hybrids. The average adult body mass of wild pigs is approximately $85 \mathrm{~kg}$. Comparable body masses for adults of each sex average $70-75 \mathrm{~kg}$ for females and $95-100 \mathrm{~kg}$ for males. Some insular populations of wild pigs are substantially smaller than this, with adult animals averaging around $40 \mathrm{~kg}$. The growth in body mass among wild pigs continues until about the fifth year of life, where after this variable decreases with advancing age. Tooth wear and loss have been speculated to affect the ability of these senescent animals to feed and maintain their body mass. Total body masses as low as $18 \mathrm{~kg}$ have been reported for very old adult wild pigs (Wood and Brenneman 1977). Typically maximum body masses observed in wild pig populations do not exceed 200-250 kg. Exceptional specimens have been reported to exceed $300 \mathrm{~kg}$. Heck (1950) reported on a 350-kg wild boar taken in the Caucasus Mountains. Rutledge (1965) anecdotally reported the weight of a large feral boar taken from the Santee River delta in South Carolina as $405 \mathrm{~kg}$. In all instances of these exceptional weights, the animals were males. Total body mass in wild pigs can be estimated by using regression equations from gutted weights (e.g., Henry 1969; Barrett 1971; Belden et al. 1985; Mattioli and Pedone 1995; Mayer 2003), heart girth (Mayer 2003), and external body dimensions (Mayer 2003).

\section{External Body Dimensions}

Similar to total body mass, the external dimensions of wild pigs are also highly variable. A lot of the variation observed in the external dimensions stems from the diverse taxonomic origin of these animals. Wild pigs are born on average at approximately 22 to 28 percent of the adult size for the various dimensions (J. J. Mayer, unpubl. data). Based on a sample of 358 specimens, a summary for adult wild pigs of each sex is provided (Table 4) for the following external dimensions: total length, head-body length, tail length, hind foot length, ear length, shoulder height, and snout length (defined in Mayer and Brisbin 1993). Comparisons of these data resulted in hind foot length being the least variable, and the tail length being the most variable. In all of the variables compared within this sample, males were significantly larger than females with a $p \leq 0.05$. The males were on average between 4.5 and 9.2 percent larger than the females in these various dimensions. Henry (1970), Sweeney (1970), Barrett (1971), and Belden and Frankenberger (1979) found similar percent differences between the sexes in the body dimensions of adult wild pigs from different location in the United States. However, some studies (e.g., Brisbin et al. 1977, Henry 1970) found these differences not to be significant between the sexes in adult animals. In the comparison of the sexes in both the sample of 358 adult wild pigs and Barrett's sample, the most significant differences were seen in shoulder height followed by head/snout length. As with the body mass, the mean differences in the various external dimensions between the sexes increased with age. Dzieciolowski et al. (1990) reported that males increased in body length slightly faster than females. Body length growth in wild pigs ceases at between 3 to 5 years of age (Hell and Paule 1983, Dzieciolowski et al. 1990, Saunders 1993). The best dimensions to use for distinguishing between the three general types of wild pigs were snout and hind foot lengths (Mayer and Brisbin 1993).

\section{Coat Coloration Patterns}

The coat coloration patterns observed among populations of wild pigs are extremely diverse (Fig. 6). These vary from solid to mixed coloration patterns. The simplest of these is the solid coloration. This can be expressed as any of the basic colors (i.e., black, red-brown or white), and is observed in feral hogs and hybrids. The next pattern is spotted or mottled. This is a mixed pattern of two or more of the basic colors and is highly variable. Again, this pattern is observed only in feral hogs and hybrids. The most unique or unusual is the belted or shoulder band pattern. This is often referred to as a Hampshire band after the domestic breed most recognized for this specific coloration pattern. The belted pattern has a base coloration of either black or some shade of red-brown, with a white band completely around the shoulder region and on the front legs. The black base is much more common. In spite of being genetically dominant, shoulder bands are not common among wild pigs. It has been observed in both feral hogs and hybrids. Uncommon in occurrence, a form of counter shading can also be seen in wild pigs. This consists of a darker upper color with a lighter color toward and on the underside. This is typically seen with either 
black or red-brown as the upper color and white as the underside counter-shading. This can also been observed in combination with spotting. The presence of light points can be observed with any of the aforementioned patterns. Light points consist of white coloration on the distal portions of the snout, ears, legs, and tail. The coverage of this pattern can be extensive or just a small amount (Mayer and Brisbin 1991).

The most complex pattern observed in wild pigs is the adult wild/grizzled pattern exhibited by Eurasian wild boar and some hybrids with feral hogs (Fig. 6). Contrary to earlier anecdotal descriptions (e.g., Holman 1941, McNally 1955, Mooney 1966), pure wild boar are not solid black. The wild/grizzled pattern includes a coat of light brown to black with white or tan distal tips on the bristles, especially over the lateral portions of the head and distal portions of the snout. The face, cheeks, and throat are grizzled in appearance with white-tipped bristles. The undersides are lighter, and the points (similar to the light points defined above) are dark brown to black. A distinct dark stripe can also be evident in the thoracic region of the middorsum of the adult coloration pattern (Mayer and Brisbin 1991).

Some wild pigs exhibit a striped juvenile pattern. This coloration has been described as a "chipmunk-like" or "watermelon-striped" pattern. It consists of a light grayish-tan to brown base coat, with a dark brown to black spinal stripe and three to four brown irregular longitudinal stripes with dark margins along the length of the body. This is found in all of the subspecies of Eurasian wild boar, wild boar $\mathrm{x}$ feral hog hybrid populations, and in some feral hog populations. This coloration pattern, assumed to function as camouflage for the young piglets, changes to the adult pattern of the individual in question at between four to six months of age. After losing the striped juvenile pattern, wild boar or some hybrids enter a reddish phase of the adult coat coloration pattern. This will usually persist until these animals are about a year old (Mayer and Brisbin 1991, Mayer 1992).

The frequency of coat coloration patterns varies among wild pig populations. Solid black is often cited as the most common pattern (Sweeney and Sweeney 1982). However, other populations have spotted coloration as the most common pattern observed (Mayer et al. 1989). The only uniform coat coloration patterns are seen within pure Eurasian wild boar populations; however, even those populations show the age-related variation exhibited by these animals (i.e., striped juveniles, immature reddish phase, and grizzled/wild adult pattern). In addition, spotting patterns have even been reported in pure wild boar populations (Andrzejewski 1974, Briedermann 1986). Based on a sample of 4,014 wild pigs from 13 populations in the United States, the coat coloration percent breakdown was as follows: all black $-32.0 \%$; all white $-6.1 \%$; all red/brown $-4.7 \%$; spotted $-50.6 \%$; belted $-2.8 \%$; wild/grizzled $-3.5 \%$; and miscellaneous $-0.3 \%$ (J. J. Mayer, unpubl. data). "Miscellaneous" includes infrequent or rare coloration patterns such as blue or gray roans.

\section{Hair Morphology}

Wild pigs have three general types of hairs over various areas of their body. These include: (1) bristles, (2) underfur, and (3) vibrissae. The presence, dimensions, density and color of these three types of hair can vary widely with an individual's age, among animals within the same population, between different populations and habitat types, and among the three general types of wild pigs. Additional changes occur between seasons (Mayer and Brisbin 1991).

The hairs of wild pigs can be solid colored or banded. The colors present are either black or red-brown, produced by pigment (i.e., phaemelanin and eumelanin) located in either the medulla or cortex of the hairs. White coloration in this species results from the absence of pigment or pockets of air within the hair shaft. The imbricate cuticular scales covering wild pig hairs are transparent.

Bristles, also technically referred to as modified guard hairs, are relatively straight, comparatively thick, stiff hairs covering almost the entire body of a wild pig. This type of hair is present on the pig year-round. Wild pigs shed their hair from late April through June (Hennig 1981; J. J. Mayer, unpubl. data). The shed or molt occurs sequentially in a pattern of replacement over the entire body (Snethlage 1982). The new bristles replacing the old ones reach a maximum length in late fall or early winter. Bristles are shortest on the distal portions of the limbs and longest along the middorsal area of the back (i.e., dorsal mane). These 


\section{Wild Pigs}

hairs can be solid in color, or in the case of wild pigs with at least some Eurasian wild boar in their ancestry, dark brown or black bristles with a white or light buff tip. In a few instances, wild boar or wild boar/feral hog hybrids have a white or buff band with short black distal tip. Bristles wear through abrasion and often have split or frayed ends. The presence of these split ends in wild pigs bristles was once thought to be taxonomically significant (Henry 1969), but was later disproved (Marchinton et al. 1974). Such distal fracturing of solid black or red-brown bristles can give that portion of the hair shaft a lighter color. This, however, should not be confused with the actual pigment change observed in the lighter tips of the bristles in both wild boar and hybrids.

The size of bristles (i.e., overall length and cross-sectional width) varies between types of wild pigs over the different parts of the body. On average, wild pig bristles average about $50 \mathrm{~mm}$ ( 2 to $149 \mathrm{~mm}$ ) in length middorsally and $32 \mathrm{~mm}$ ( 1 to $76 \mathrm{~mm}$ ) laterally. The middorsal bristles range from 0.1 to $0.5 \mathrm{~mm}$ in midshaft diameter (Mayer and Brisbin 1991, J. J. Mayer, unpubl. data). Eurasian wild boar have the longest and thickest bristles, followed in decreasing dimensions by hybrids, and then feral hogs. Over the body, the middorsal bristles along the spine are the longest. These lengths decrease from the shoulder region back to the region above the hip or pelvis. Average bristle lengths also decrease as one moves down the side of the animal to the belly or underside. In contrast to the dorsal complement, the bristles on the lateral side of the animals increase in mean length from the shoulder to the hip. The middorsal bristles often form a distinct mane, being most evident in the thick winter coat or pelage. The bristles on the tail can be extremely long, reaching up to $400 \mathrm{~mm}$ in length (Mayer and Brisbin 1991, J. J. Mayer, unpubl. data).

The curly or wool-like underfur is the second most common type of hair found on wild pigs. Not all types of wild pigs exhibit this category of hair. It is also not evident year-around in some populations where it is present. In general, underfur has the appearance of wool. It is shorter and thinner than are bristles. It is shed annually when the bristles are shed. Underfur is shortest and most sparse in late spring and summer, and conversely, longest and most dense in the winter and early spring. Unlike the variation seen in bristles, underfur is solid in color. In feral hogs, the underfur is same color as the overlying bristles. In wild boar and hybrids, underfur can vary from smoke gray to dark brown, typically being lighter in color than the overlying bristles.

The newborn or neonate coat of hair varies from the adult coat of hair in that only bristles are present. No underfur is present in very young piglets. This can potentially have a great impact on the ability of these small animals to survive very cold temperatures in some areas. Underfur first begins to appear in piglets at about two months of age (J. J. Mayer, unpubl. data).

The last general type of hair is vibrissae. These are course, stiff, deeply rooted sensory hairs. The presence of vibrissae can be seen concentrated on the mental glands (i.e., a round, raised structure seen on the anterior end of the throat), and scattered in a more widespread pattern over the snout, muzzle, around the eyes, and on the upper and lower lips. Vibrissae are longest on the mental glands, the remainder being relatively short in length. This type of hair is most evident in newborn piglets or in older animals which have shed their winter coat of bristles and underfur.

\section{Soft Tissue Morphology}

Skin - The surface of the skin is relatively smooth, generally resembling that of humans. The skin is thickest on the surface of the lips, on the snout, and between the toes. The skin thickness averages about 1 to $2 \mathrm{~mm}$. On adult boars, this thickness in the area of the shoulder may increase to 3.5 to $4 \mathrm{~mm}$. The skin is underlain by a distinct and often thick layer of fat over the greater part of the body. Stribling (1978) determined that the skin and hair made up approximately 17.5 percent of a wild pig's total body mass.

Teat Count - The number and arrangement of the teats in wild pigs are similar to that seen in domestic swine. The location of the teats in both sexes extends from the thoracic area back to the inguinal region of the animal's ventrum. Typically, the teats are arranged in pairs as follows: 1-2 inguinal pairs, 2-3 abdominal pairs, and 2 thoracic pairs. However, staggered arrangements or supernumerary teats do occur that result in odd numbers of total teats on any one individual. Overall, the numbers of teats in wild pigs 
range from 3 up to 16 (Barrett 1971, Ahmad et al. 1995). The number of teats also varies taxonomically (Table 5). In general, the number of teats increases from Eurasian wild boar to hybrids to feral hogs, and finally to domestic swine. Based on a sample of 475 sows from the wild pig population found on the Savannah River Site, South Carolina, the number of teats averaged 11.3, had a mode of 12, and varied from 9 to 14. Animals with unpaired or odd numbers of teats made up 18 percent of this sample. In addition, some sows with even-numbers sets of teats can also have arrangements of spatially unpaired teats (J. J. Mayer, unpubl. data).

Boar Shoulder Shield - Mature male wild pigs possess a thickened subcutaneous layer of tissue, commonly referred to as the "shield," which overlies the outermost muscles in the boar's lateral shoulder region. This unique anatomical structure, a secondary sexual characteristic found in this species, serves a reported protective function for males fighting for breeding opportunities with estrous females. The shield initially develops as early as 9-12 months of age, and then increases to be found in all adults $(36+$ months of age). Growth of the structure begins in the central lateral shoulder region and then increases to cover an area extending from the posterior neck back to the anterior hips, and from the middorsum down to the proximal margin of the front leg. The mean shield dimensions are as follows: length $-349 \mathrm{~mm}$, height $299 \mathrm{~mm}$, and thickness $-22 \mathrm{~mm}$ ). These dimensions increase with age, physical size, and body mass. The thickness varies seasonally, being greatest during the annual peak of conception, and is positively correlated with the animal's body condition. Injuries indicative of male-male fighting are primarily found on portions of the body covered by the shield. This corroborates the function of this structure as being protective in such aggressive male-male encounters in this species (Mayer 2006, J. J. Mayer, unpubl. data).

Internal Organs - Similar to other aspects of their anatomy, the internal organs in wild pigs closely resemble those of their domestic counterparts; however, those in wild pigs are often either absolutely or proportionately larger. In contrast, some organs are more variable in domestic pigs. Similar to the total body mass difference, organ weights in male wild pigs generally tend to average larger than those in females (Briedermann 1970, Kozlo 1975).

The heart in adult wild pigs averages from approximately 400 to $600 \mathrm{gm}$. Neonatal wild piglets have a heart that weighs about 9 gm (Briedermann 1970, Kozlo 1975). Domestic swine have smaller hearts (e.g., 240 to 500 gm in adults) (Getty 1975). Klein (1997) also found that the intramyocardial connective tissue content was lower in wild pigs compared to domestic swine.

As in domestic swine, the lungs in wild pigs are large paired organs that occupy most of the space in the thoracic cavity. Similar to domestics, Cabral et al. (2001) found in wild pigs that the right lung was divided into four lobes, while the left was divided into two lobes. Lung weights in adult wild pigs average from 900 to 1400 gm, while neonates have lungs that weigh 30 gm (Kozlo 1975, Stribling 1978).

The liver is relatively large and divided into four principal lobes; its average weight in an adult wild pig is about 1600-2000 gm. Neonate livers weigh about 36 gm (Briedermann 1970, Kozlo 1975). Comparable weights for this organ are seen in domestic swine (Getty 1975).

The stomach is large, with an average capacity of 5 to 8 liters. Empty, the stomach in adult wild pigs weighs 265 to $900 \mathrm{gm}$. When full, that weight can increase to 1200 to $2000 \mathrm{gm}$ (Briedermann 1986, Pinna et al. 2007). The ratio of the contents mass to the total stomach mass (i.e., stomach plus contents) was reported to be 0.5 . Mean reported dimensions of the stomachs in adults are as follows: girth - female $=39$ $\mathrm{cm}$, male $=42 \mathrm{~cm}$; greater curvature length - female $=56 \mathrm{~cm}$, male $=60 \mathrm{~cm}$; and lesser curvature length female $=14 \mathrm{~cm}$, male $=14 \mathrm{~cm}$ (Pinna et al. 2007).

The small intestine in adults is 15 to $20 \mathrm{~m}$ long, while the large intestine is 4 to $4.5 \mathrm{~m}$ in length. Empty, these can weigh 2000 to $2600 \mathrm{gm}$, as opposed to 3400 to $4000 \mathrm{gm}$ when full (Bridermann 1986). The small intestine in the wild boar is less developed (i.e., shorter, less surface area and volume, and lighter) than that found in domestic swine (Uhr 1995).

The kidneys are paired; weight of a kidney in an adult wild pig is 250 to $500 \mathrm{gm}$. Size is about $12.5 \mathrm{~cm}$ long and 6-6.5 $\mathrm{cm}$ in width. Neonate kidney weighs about 9 gm (Briedermann 1970, Kozlo 1975, Stribling 


\section{Wild Pigs}

1978). A 2-month-old feral pig from Hawaii was found at necropsy to have four separate, functional kidneys. The two supernumerary kidneys were found caudal to the normal pair and caused partial blockage of the lower colon with resultant fecal impaction (Wilson and McKelvie 1980). Zervanos et al. (1983) found that feral hogs on the barrier islands in Georgia had greater renal concentrating abilities, which may represent an adaptation to an environment of high salt diets and minimum availability of freshwater.

The spleen is long and narrow, and weighs about 200-300 gm in adults, and 2 gm in neonates (Briedermann 1970, Kozlo 1975, Stribling 1978). Fernández-Llario et al. (2004) found that females had larger spleens than males once they reached sexual maturity. In addition, individuals shot in winter had larger spleens than those shot in autumn, the start of the breeding period. In contrast to other reports, no influence of the reproductive status of adult females on their spleen size was found.

The brain in adult wild pigs weighs about 100 to 150 gm (Stribling 1978, Briedermann 1986). Rohrs and Kruska (1969) determined that the brains of domestic pigs averaged 34\% smaller than the brains of European wilds boar. Kruska and Rohrs (1974) contrasted the brain sizes of domestic pigs and wild boars with feral pigs that were introduced to the Galapagos Islands some 70-140 years ago. Interestingly, the brains of the feral pigs were the same size as the domestic pigs (i.e., about one-third smaller than wild boars). Kruska and Rohrs (1974) also discussed the reduced variability in size of almost all brain structures in wild and feral pigs compared to their domestic counterparts.

The individual testes of adult boars vary from about 200 to 600 or more grams in mass (Kozlo 1975, Stribling 1978, Bridermann 1986). A single testis represents approximately 2 to $3 \%$ of the adult animal's total body mass (Stribling 1978, Almeida et al. 2006). The morphology of the seminiferous tubules in wild and domestic pigs is similar; however, Costa and Silva (2006) reported that the efficiency of spermatogenesis in wild boars was smaller than that of domestic males. Almeida et al. (2006) similarly reported a low efficiency in spermatogenesis in wild boar; however, because of the higher number of Sertoli cells per gram of testis in wild boar compared to domestic swine, the overall spermatogenic efficiency between the two types of $S$. scrofa was comparable.

Cutaneous and Scent Glands - Wild pigs have a number of cutaneous glands. Some of these are used in scent marking (e.g., metacarpal glands, preorbital glands, preputial gland, and tusk/lip glands) (Mayer and Brisbin 1986, Groves and Giles 1989). In addition, these animals also possess proctoideal, perineal, mandibular/mental, rhinarial, Harderian, and genal glands. All of these secrete or produce odorous compounds, which may or may not function in scent marking (Getty 1975, Groves and Giles 1989)

\section{Unique Physical Characters}

Two uncommon features of note observed in wild pigs are syndactylous (a.k.a., "mule-footed") hooves and neck wattles (Figs. 7 and 8). The presence of these unusual structures is neither widespread nor frequently observed even where they are known to occur. In a few locations, both characters are found to occur within the same population (Mayer and Brisbin 1991).

The syndactylous condition in swine is structurally only a slight variation from the normal cloven-hoofed condition. Internally, it is caused by a developmental fusion of the last (i.e., distal-most) bones of the two middle toes or digits of the foot. In some cases, the next to the last toe bones can also be fused into a single structure. Externally, the fusion of those two digits gives the appearance of a single, central-toed hoof similar to that found in equines (Fig. 7), hence, the name "mule foot." The lateral digits in the syndactylous condition appear to be normal. Not all syndactylous-footed swine have the condition on all four feet. Although having all four feet either cloven-hoofed or syndactylous-footed is the most frequent condition that one finds, wild pigs have been reported as having anywhere from one up to all four feet with syndactylous hooves (Mayer and Brisbin 1991). Although it has never been abundant, the syndactylous condition in swine has been recognized for a long time. Aristotle, the Greek philosopher and teacher, first recorded the existence of this trait in about $350 \mathrm{BC}$. Darwin (1867) noted that this condition was occasionally observed in swine in various parts of the world. Officially, the "mule foot" as a domestic breed of swine was started in Ohio in 1908. However, even though the breed originated in this country, it was never widely distributed. Initially reported to be immune to hog cholera (i.e., classical swine fever), 
these animals became popular shortly after the breed was initially registered. However, this reported immunity proved to be unfounded, and the breed gradually declined (Towne and Wentworth 1950, Mayer and Brisbin 1991, Bixby et al 1994). As with many types of domestic swine in the United States, syndactylous-footed swine have over the years been released into free-ranging husbandry conditions or escaped from confinement to become wild-living. Wild pig populations exhibiting the syndactylous condition have and, in some cases, still do exist in South Carolina, Georgia, Florida, Texas, and California. Other states that have reportedly produced mule-footed wild pigs include Arkansas, Louisiana, and Mississippi. However, the documentation of these occurrences is sketchy, and thus the authenticity of such animals remains questionable. In general, however, wild pigs exhibiting the syndactylous condition are seemingly becoming rarer (Mayer and Brisbin 1991). Domestic populations of this breed are almost nonexistent (Bixby et al. 1994).

Neck wattles (also called "waddles" or "tassels") do not seem to share the mystery surrounding syndactylous hooves. Similar to the bell on the throat region of a moose's (Alces alces) neck, these structures are gristle protuberances or tubular appendages in the pig's skin (Fig. 8). Neck wattles in pigs are paired structures that grow out of the lower lateral portions of the neck. Wattles are normally approximately 50 to $100 \mathrm{~mm}$ in length and 10 to $20 \mathrm{~mm}$ in diameter. The entire structure is covered with hair.

The "red wattle" breed of domestic swine reportedly originated in the south Pacific, and first appeared in the United States in either the 1700s or 1800s. The breed has never been popular in this country, but did get some interest in the 1980s because of its reputation for having a lean carcass (Mason 1988, Mayer and Brisbin 1991, Porter 1993). The presence of neck wattles has been noted in wild pig populations in Florida, South Carolina, and Texas. Neck wattles are also exhibited by the wild pigs in New Zealand that are of Kunekune breed ancestry (Allen et al. 2001). The populations in southwestern Florida exhibit both neck wattles and syndactylous hooves. In general, neck wattles and syndactylous hooves have only been documented to occur in feral and hybrid wild pigs, but never in any pure Eurasian wild boar (Mayer and Brisbin 1991, 1993). 


\section{Wild Pigs}

Table 1. Age classes of wild pigs based on erupted tooth patterns and used to separate specimens for analysis. Taken from Mayer and Brisbin (1991).

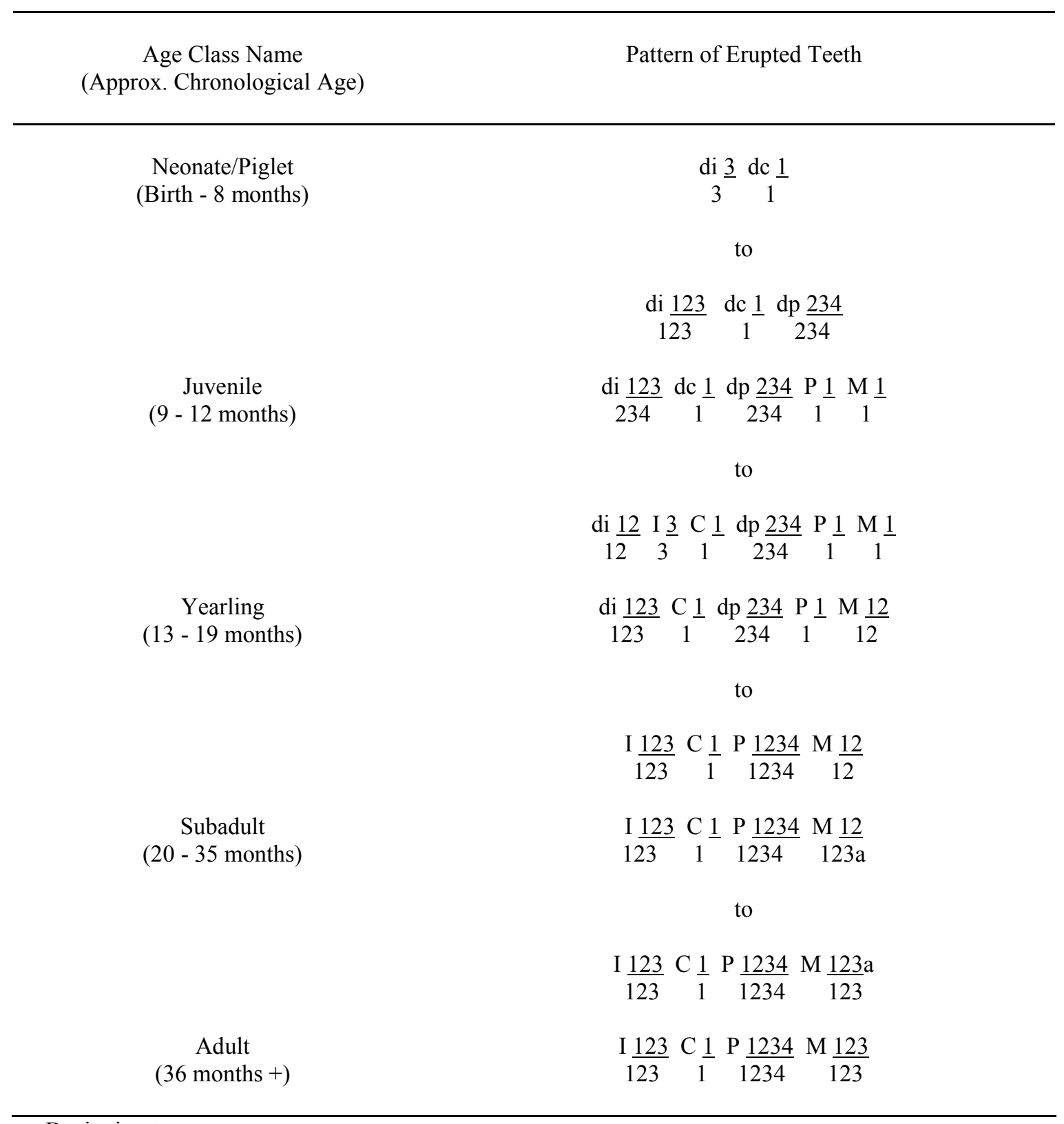

a Beginning to erupt 
Table 2. Summary of seven skull measurements of 328 adult wild pigs. Data were segregated by sex, and included a combined sample of Eurasian wild boar, feral hogs and hybrids. These measurements are defined in Mayer and Brisbin (1991).

\begin{tabular}{ccccccc}
\hline $\begin{array}{c}\text { Measurement } \\
\text { (in mm) }\end{array}$ & Sex & N & Mean & Observed Range & SD & $\begin{array}{c}\text { Percent } \\
\text { Difference }\end{array}$ \\
\hline Condylobasal Length & F & 118 & 296.9 & $226-384$ & 30.9 & \\
& M & 210 & 316.7 & $233-437$ & 34.9 & 6.7 \\
Occipitonasal Length & F & 118 & 310.0 & $234-403$ & 42.1 & \\
& M & 210 & 334.1 & $249-461$ & 47.9 & 7.8 \\
Cranial Height & F & 118 & 130.2 & $90-171$ & 16.3 & \\
& M & 210 & 145.5 & $99-192$ & 16.8 & 11.8 \\
Zygomatic Breadth & F & 118 & 141.1 & $114-174$ & 11.4 & \\
& M & 210 & 150.7 & $114-187$ & 13.5 & 6.8 \\
Mandibular Length & F & 118 & 234.8 & $119-302$ & 28.0 & \\
& M & 210 & 256.1 & $185-359$ & 30.6 & 9.1 \\
Mandibular Height & F & 118 & 110.5 & $82-150$ & 13.7 & \\
& M & 210 & 116.4 & $77-168$ & 13.7 & 5.3 \\
Posterior Mandibular & F & 118 & 122.1 & $97-152$ & 11.5 & \\
Width & M & 210 & 132.2 & $99-166$ & 12.9 & 8.3 \\
\hline
\end{tabular}




\section{Wild Pigs}

Table 3. Approximate chronological age at which the individual teeth erupt in wild pigs. Based on Matschke (1967).

\begin{tabular}{|c|c|c|c|c|}
\hline \multirow[t]{2}{*}{ Tooth } & \multicolumn{2}{|c|}{ Component } & \multicolumn{2}{|c|}{ Age of Eruption (in days) } \\
\hline & Upper/Lower & Deciduous/Permanent & Mean & Range \\
\hline \multirow{4}{*}{ First Incisor } & Upper & Deciduous & 16.4 & $7-22$ \\
\hline & & Permanent & 420.3 & $376-458$ \\
\hline & Lower & Deciduous & 17.1 & $11-20$ \\
\hline & & Permanent & 416.0 & $383-440$ \\
\hline \multirow{4}{*}{ Second Incisor } & Upper & Deciduous & 95.3 & $66-117$ \\
\hline & & Permanent & 739.4 & $654-815$ \\
\hline & Lower & Deciduous & 77.9 & $64-93$ \\
\hline & & Permanent & 610.1 & $561-672$ \\
\hline \multirow{4}{*}{ Third Incisor } & Upper & Deciduous & At birth & - \\
\hline & & Permanent & 273.3 & $225-356$ \\
\hline & Lower & Deciduous & At birth & - \\
\hline & & Permanent & 261.4 & $227-281$ \\
\hline \multirow{4}{*}{ Canine } & Upper & Deciduous & At birth & - \\
\hline & & Permanent & 281.5 & $213-348$ \\
\hline & Lower & Deciduous & At birth & - \\
\hline & & Permanent & 284.1 & $227-348$ \\
\hline \multirow[t]{2}{*}{ First Premolar } & Upper & Permanent & 179.8 & $143-196$ \\
\hline & Lower & Permanent & 203.9 & $159-230$ \\
\hline \multirow[t]{4}{*}{ Second Premolar } & Upper & Deciduous & 61.0 & $51-79$ \\
\hline & & Permanent & 500.0 & $486-523$ \\
\hline & Lower & Deciduous & 82.0 & 63-102 \\
\hline & & Permanent & 491.3 & $457-519$ \\
\hline \multirow[t]{4}{*}{ Third Premolar } & Upper & Deciduous & 13.9 & $11-18$ \\
\hline & & Permanent & 484.3 & $457-496$ \\
\hline & Lower & Deciduous & 27.5 & 23-33 \\
\hline & & Permanent & 475.2 & $427-492$ \\
\hline \multirow[t]{4}{*}{ Fourth Premolar } & Upper & Deciduous & 45.1 & $41-49$ \\
\hline & & Permanent & 505.5 & $427-561$ \\
\hline & Lower & Deciduous & 17.1 & $11-20$ \\
\hline & & Permanent & 490.2 & $427-540$ \\
\hline \multirow[t]{2}{*}{ First Molar } & Upper & Permanent & 180.2 & $161-191$ \\
\hline & Lower & Permanent & 172.3 & $159-179$ \\
\hline \multirow{2}{*}{ Second Molar } & Upper & Permanent & 384.9 & $365-420$ \\
\hline & Lower & Permanent & 384.9 & $361-415$ \\
\hline \multirow[t]{2}{*}{ Third Molar } & Upper & Permanent & 889.4 & $781-990$ \\
\hline & Lower & Permanent & 754.6 & $694-782$ \\
\hline
\end{tabular}


Table 4. Summary of seven external body measurements of 358 adult wild pigs. Data were segregated by sex, and included a combined sample of Eurasian wild boar, feral hogs and hybrids.

\begin{tabular}{ccccccc}
\hline $\begin{array}{c}\text { Measurement } \\
\text { (in mm) }\end{array}$ & Sex & N & Mean & Observed Range & SD & $\begin{array}{c}\text { Percent } \\
\text { Difference }\end{array}$ \\
\hline Total Length & F & 174 & $1,594.4$ & $1,045-1,910$ & 143.0 & \\
& M & 184 & $1,682.4$ & $1,160-2,083$ & 160.2 & 5.5 \\
Head-Body Length & F & 174 & $1,305.3$ & $840-1,580$ & 116.4 & \\
& M & 184 & $1,380.9$ & $950-1,750$ & 129.6 & 5.8 \\
Tail Length & F & 174 & 288.5 & $130-395$ & 46.7 & \\
& M & 184 & 301.6 & $90-410$ & 60.5 & 4.5 \\
Hind Foot Length & F & 174 & 269.8 & $185-333$ & 23.2 & \\
& M & 184 & 285.3 & $200-380$ & 24.4 & 5.6 \\
Ear Length & F & 174 & 149.9 & $86-204$ & 21.5 & \\
& M & 183 & 157.2 & $92-250$ & 24.4 & 4.7 \\
Shoulder Height & F & 174 & 698.4 & $515-1,000$ & 70.3 & \\
& M & 184 & 761.8 & $535-1,060$ & 95.5 & 9.2 \\
Snout Length & F & 174 & 226.6 & $155-305$ & 27.3 & \\
& M & 184 & 244.4 & $160-368$ & 31.7 & 7.5 \\
\hline
\end{tabular}

Table 5. Reported numbers of teats listed by the three primary types of wild pig and domestic swine.

\begin{tabular}{cccc}
\hline $\begin{array}{c}\text { Type of } \\
\text { Wild Pig }\end{array}$ & $\begin{array}{c}\text { Reported } \\
\text { Means }\end{array}$ & Range & References \\
\hline Eurasian Wild Boar & 8,10 & $3-12$ & $\begin{array}{c}\text { Diong 1973, Stubbe and Stubbe 1977, } \\
\text { Dittus 1983, Ahmad et al. 1995, } \\
\text { Vieites et al. 2003 }\end{array}$ \\
Feral Hog & $11,12,13$ & $8-16$ & Barrett 1971, Giles 1980, Diong 1982 \\
Hybrids & 11 & $10-13$ & Duncan 1974 \\
Domestic Swine & $12,13,14$ & $6-32$ & Hulme 1979, Lai et al. 1998 \\
\hline
\end{tabular}




\section{Wild Pigs}
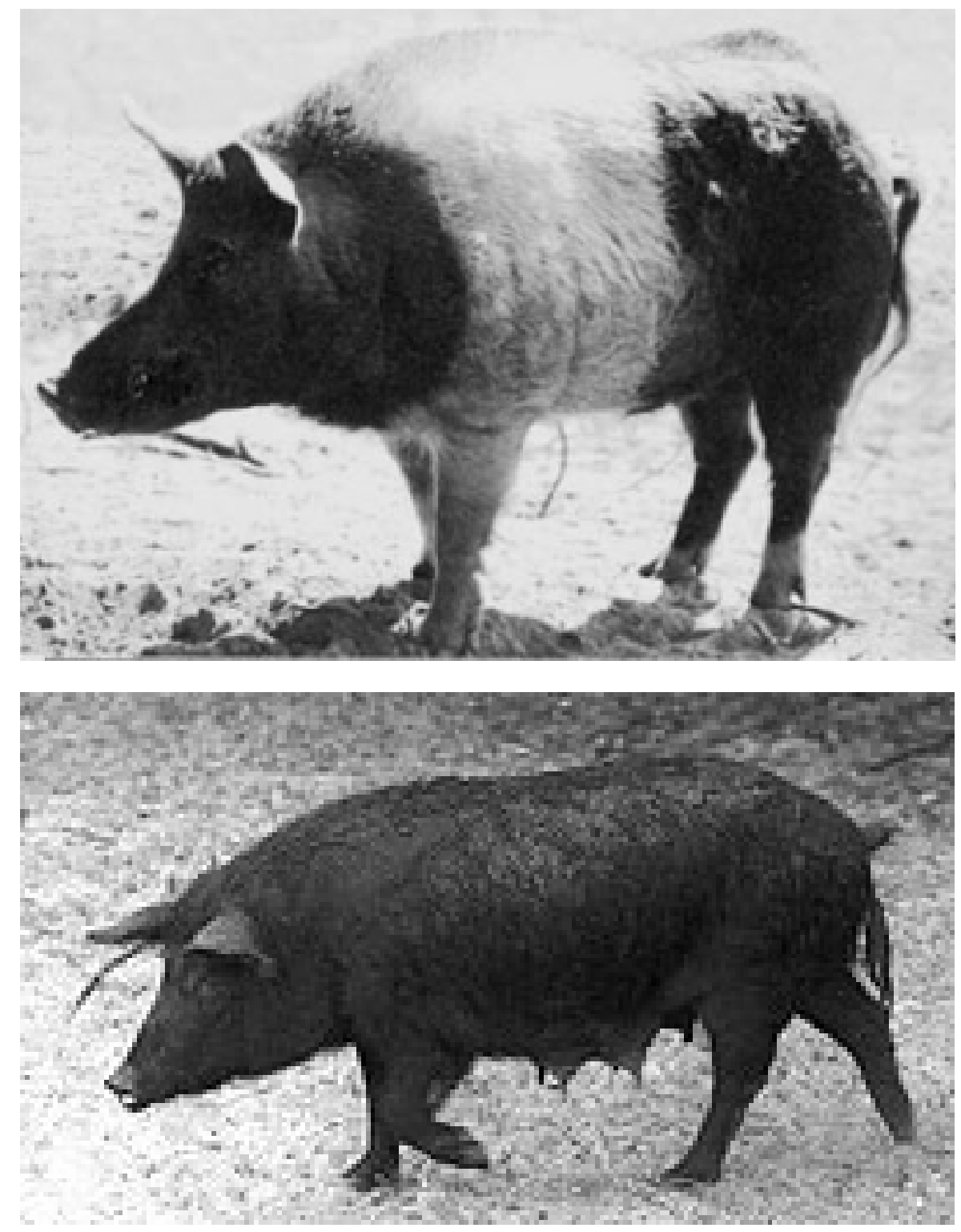

Fig. 1. The general physical appearance of two sexes of adult wild pigs. The upper image is of a male; the lower one is a female. 


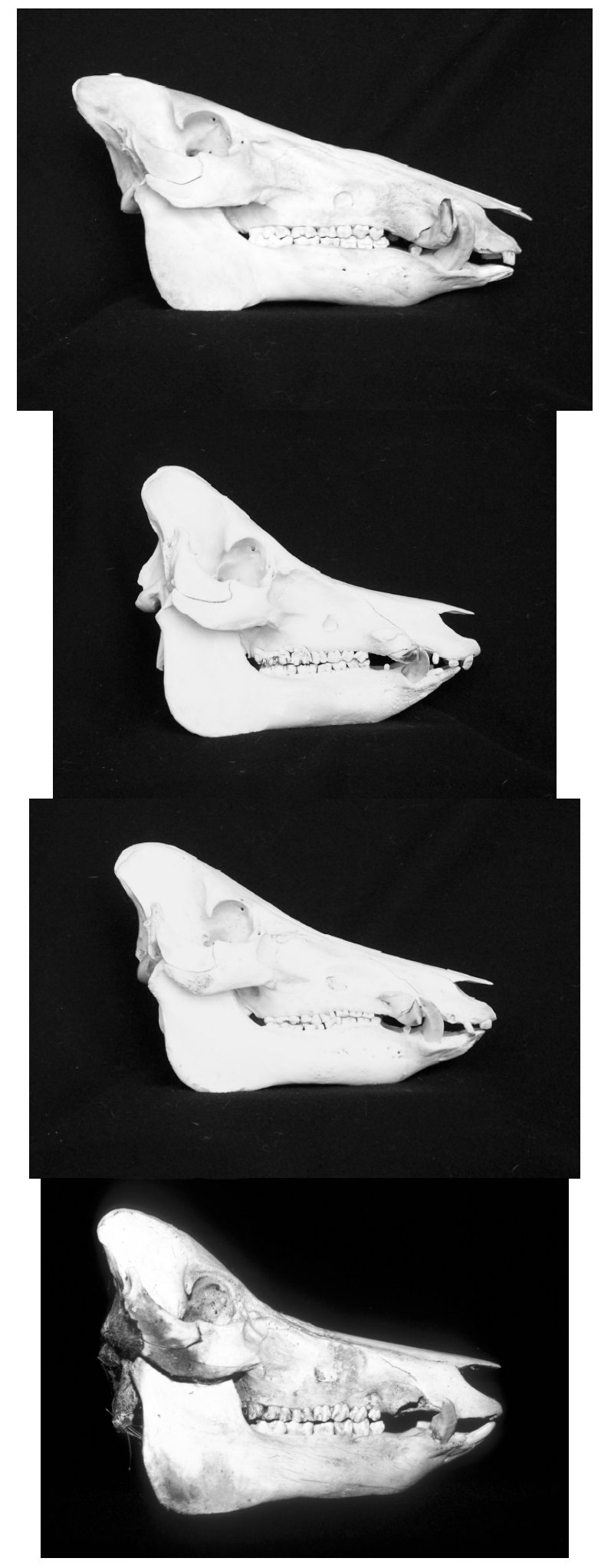

Fig. 2. Lateral appearances of four adult male wild pig skulls. The images are: top - Eurasian wild boar; second - short-term feral pig; third - long-term feral pig; and bottom - wild boar x feral pig hybrid. 


\section{Wild Pigs}

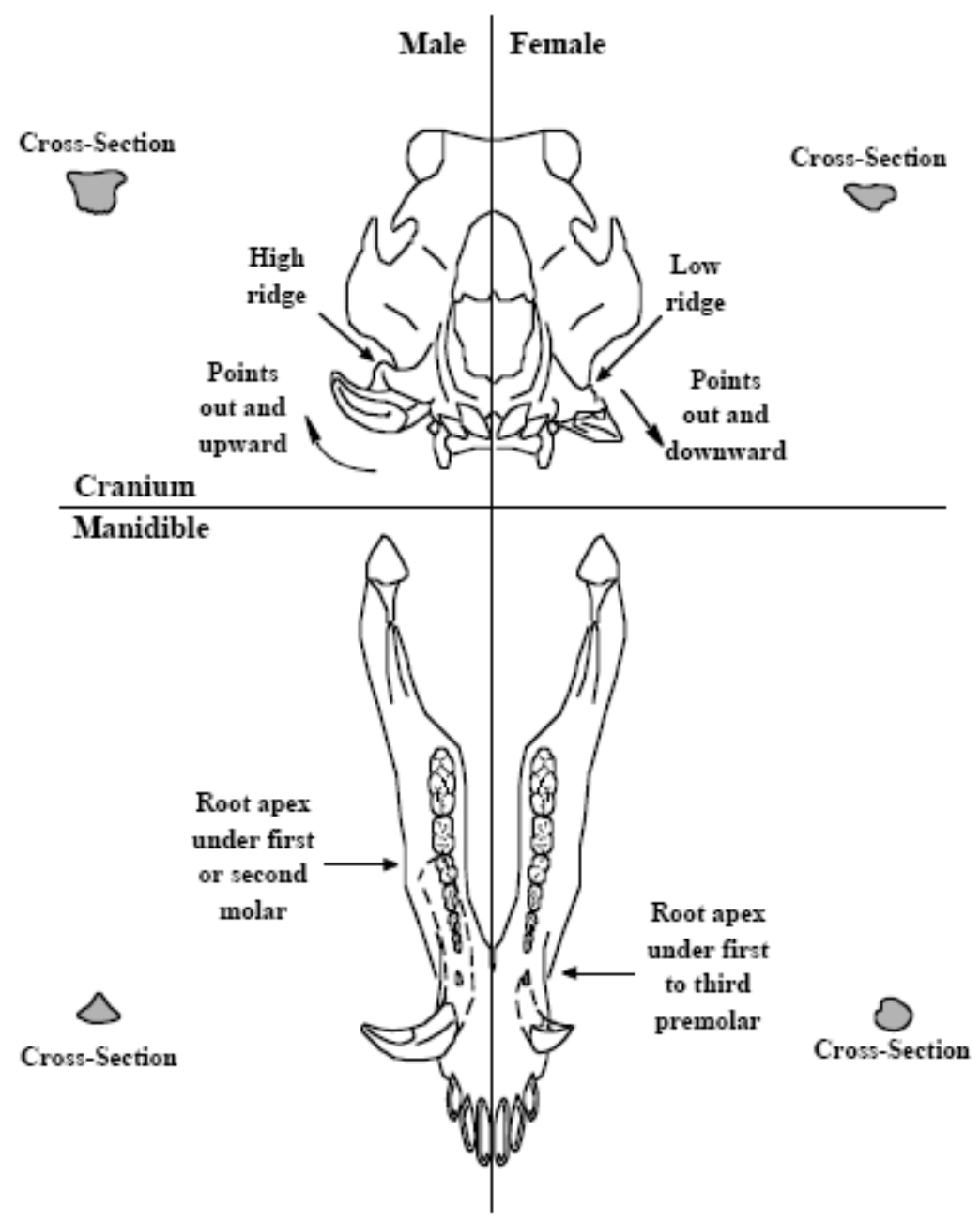

Fig. 3. Difference in appearance of upper and lower canines in adult male and female wild pigs. 


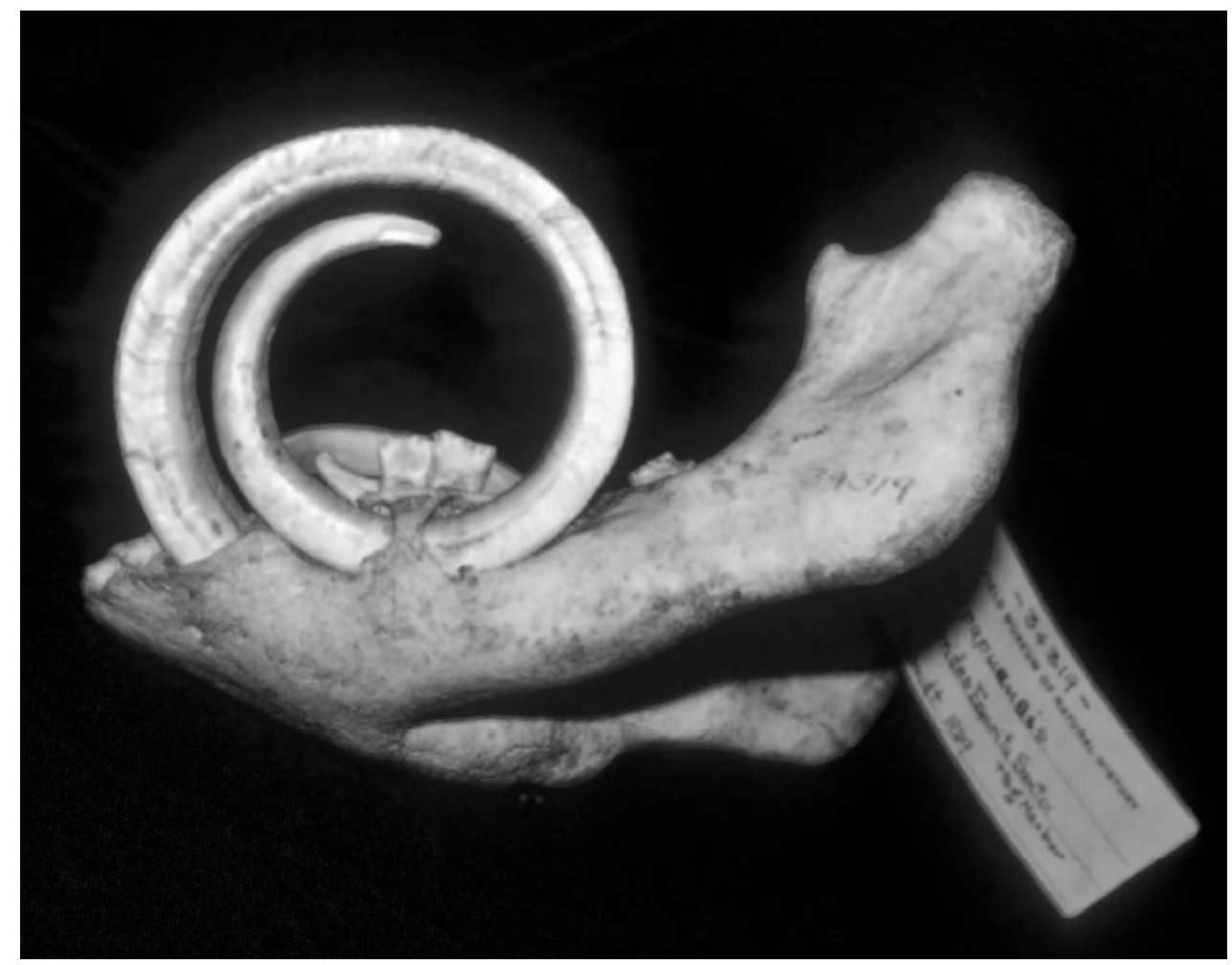

Fig. 4. Lower canine of a captive wild pig from the Vanuatu Islands that has had the upper canine removed to enable unencumbered growth of the lower tooth.

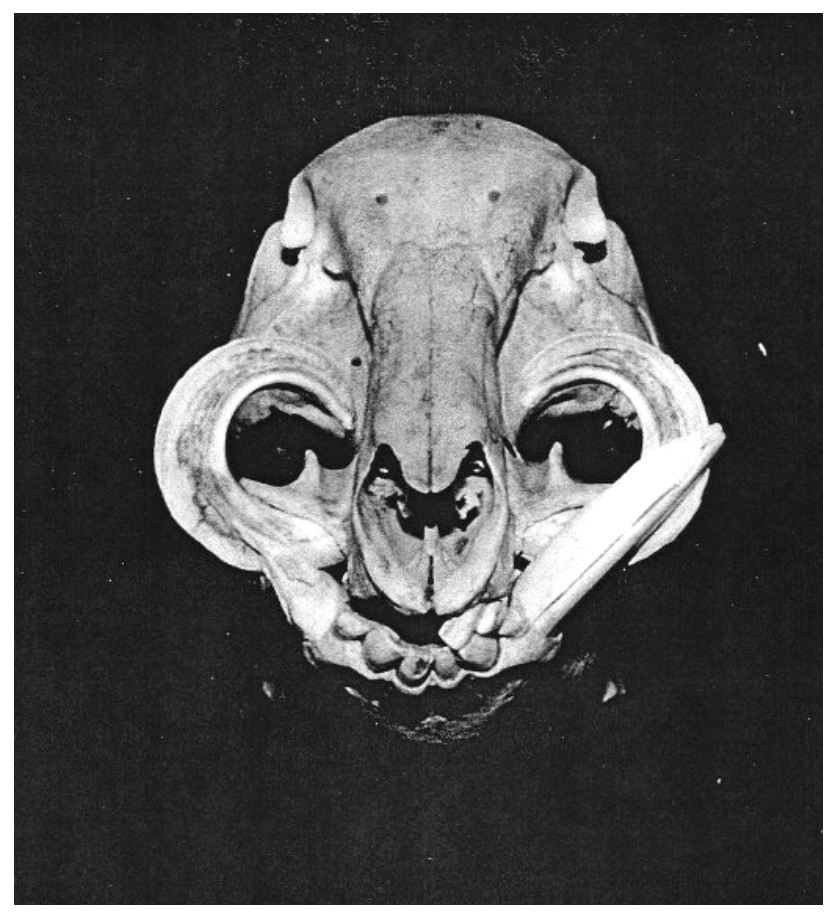

Fig. 5. Upper canine of a wild boar from India that had the angle of the upper canines cause a reduced abrasion with the lower canines, resulting in an increased length of the upper teeth. 


\section{Wild Pigs}
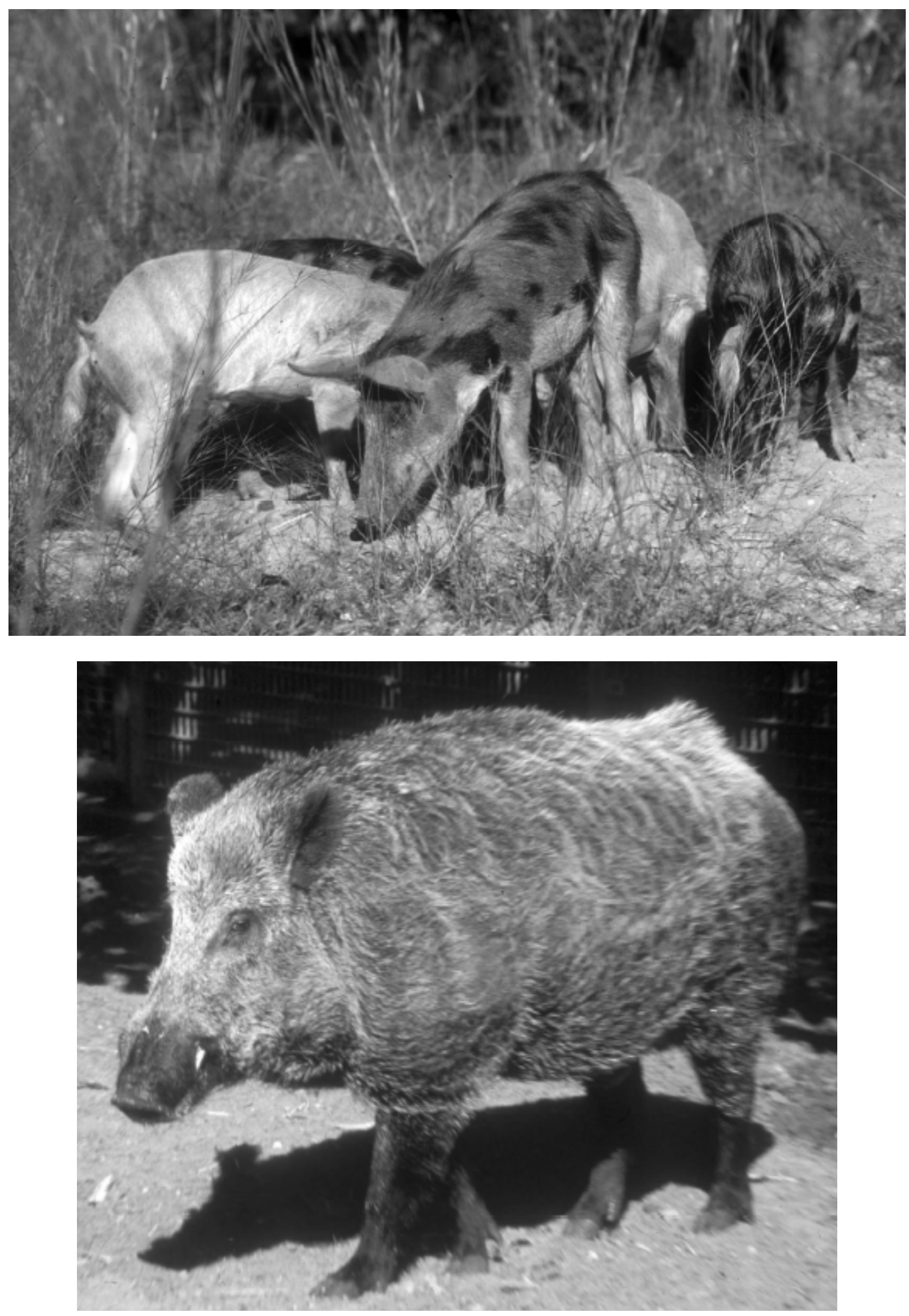

Fig. 6. Wild pig coat coloration patterns can be extremely variable. The top photo is of a group of feral pigs exhibiting a variety of coat coloration patterns. The bottom photo is of a captive Eurasian wild boar exhibiting the wild/grizzled coloration pattern. 


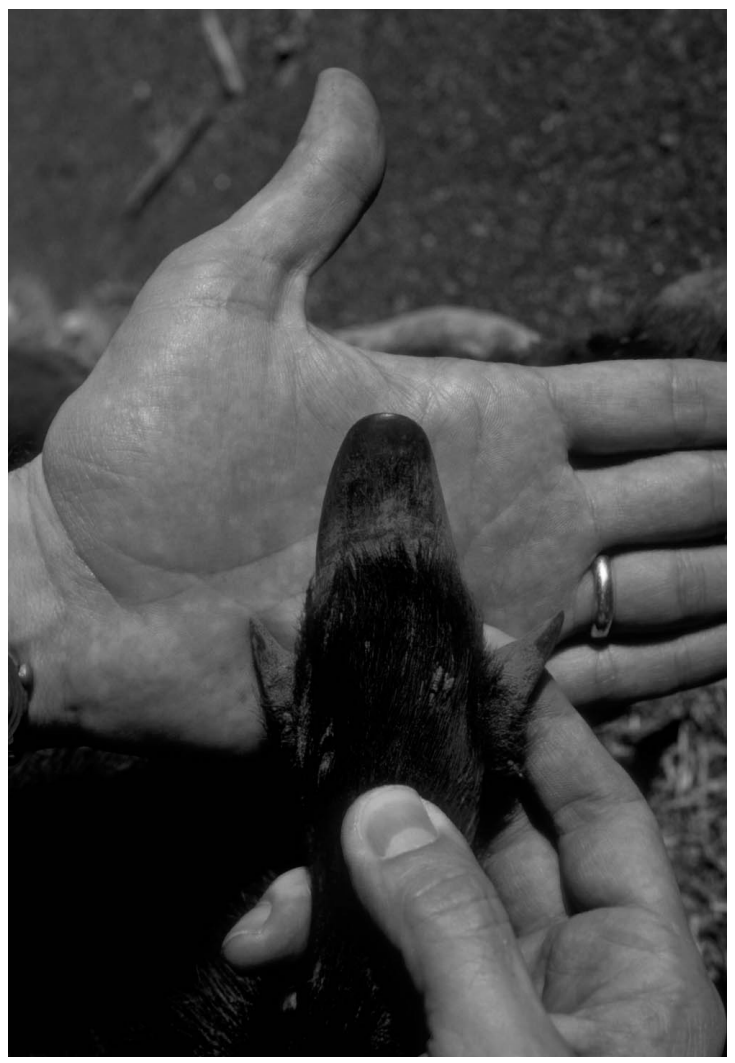

Fig. 7. Posterior foot of a wild pig exhibiting the syndactylous or "mule-footed" condition of the middle toes.

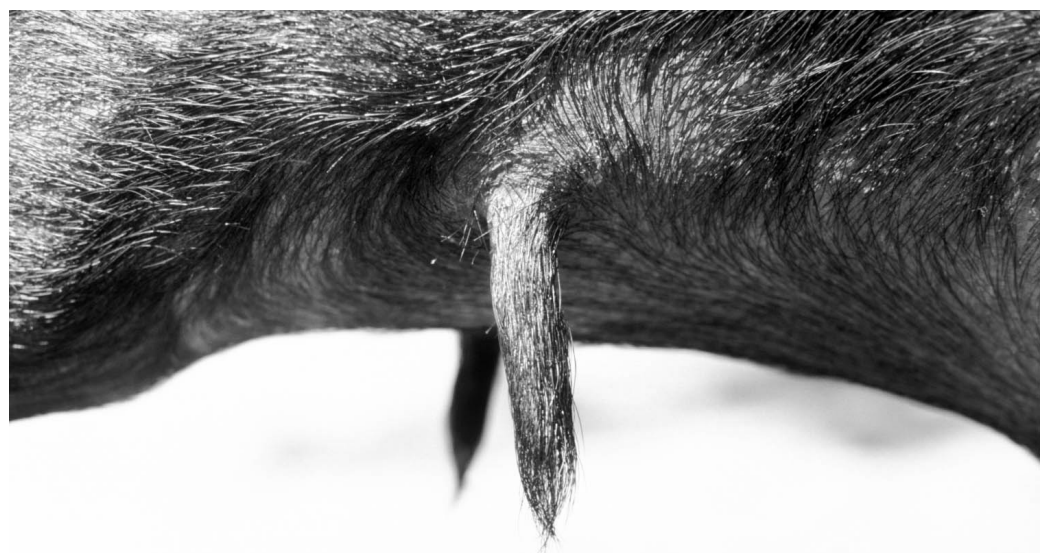

Fig. 8. Waddles or wattles on the neck of an adult female wild pig from Hendry County, Florida. 


\section{Wild Pigs}

\section{Literature Cited}

Ahmad, E., J. E. Brooks, I. Hussain, and M. H. Khan. 1995. Reproduction in Eurasian wild boar in central Punjab, Pakistan. Acta Theriologica, 40(2):163-173.

Almeida, F. F. L., M. C. Leal, and L. R. França. 2006. Testis morphometry, duration of spermatogenesis, and spermatogenic efficiency in the wild boar (Sus scrofa scrofa). Biology of Reproduction, 75(5):792-799.

Andrzejewski, R. 1974. Spotty mutation of the wild boar, Sus scrofa Linnaeus 1758. Acta Theriologica, 19(11):159-163.

Anonymous. 2002. Pork facts 2002/2003. National Pork Board, Des Moines, Iowa.

Bahadur, R. S. 1942. Deformed tush in a boar. Journal of the Bombay Natural History Society, 43(3):522-523.

Barrett, R. H. 1971. Ecology of the feral hog in Tehama County, California. Ph.D. Dissertation, University of California, Berkeley, California.

Baubet, E., G. Van Laere, and J. M. Gaillard. 1995. Growth and survival in piglets. Journal of Mountain Ecology (Ibex), 3:71.

Belden, R. C., and W. B. Frankenberger. 1979. Brunswick hog study. Final performance report, P-R Project W-41-R, Study No. XIII-B-1. Florida Fresh Water Fish and Game Commission Wildlife Research Laboratory, Gainesville, Florida.

Belden, R. C., W. B. Frankenberger, and D. H. Austin. 1985. A simulated harvest study of feral hogs in Florida. Final performance report, P-R Project W-41-R, Study No. XIII-FEC. Florida Fresh Water Fish and Game Commission Wildlife Research Laboratory, Gainesville, Florida.

Bixby, D. E., C. J. Christman, C. J. Ehrman, and D. P. Sponenberg. 1994. Taking stock: the North American livestock census. The MacDonald \& Woodward Publishing Company, Blacksburg, Virginia.

Boitani, L., and L. Mattei. 1991. Determinazione dell' eta' nei cinghiali in base alla formula dentaria. Supplemento alle Ricerche di Biologia della Selvaggina, 19:789-793.

Bridault, A., J. D. Vigne, M. P. Horard-Herbin, E. Pellé, P. Fiquet, and M. Mashkour. 2000. Wild boar Age at death estimates: The relevance of new modern data for archaeological skeletal material. 1. Presentation on the corpus. Dental and epiphyseal fusion ages. Anthropozoologica, 31:11-18.

Briedermann, L. 1970. Zum Korper- und Organwachstum des Wildschweines in der Deutschen Demokratischen Republik. Archiv für Forstwesen, 19(4):401-420.

1986. Schwarzwild. VEB Deutscher Landwirtschaftsverlag, Berlin, Democratic Republic of Germany.

Brisbin, I. L. Jr., R. A. Geiger, H. B. Graves, J. E. Pinder, III, J. M. Sweeney and J. R. Sweeney. 1977. Morphological characteristics of two populations of feral swine. Acta Theriologica, 22(4):75-85.

Brisbin, I. L., Jr., and J. J. Mayer. 2001. Problem pigs in a poke: A good pool of data. Science, 294(November 9):1280-1281.

Cabral, V. P., F. S. Oliveira, M. R. F. Machado, A. A. C. M. Ribeiro, and A. M. Orsi. 2001. Study of lobation and vascularization of the lungs of wild boar (Sus scrofa). Anatomia, Histologia, Embryologia, 30(4):205-210. 
Choquenot, D., and G. Saunders. 1993. A comparison of three aging techniques for feral pigs from subalpine and semi-arid habitats. Wildlife Research, 20(2):163-171.

Clarke, C. M. H., R. M. Dzieciolowski, D. Batcheler, and C. M. Frampton. 1992. A comparison of tooth eruption and wear and dental cementum techniques in age determination of New Zealand feral pigs. Wildlife Research, 19(6):769-778.

Costa, D. S., and J. F. S. Silva. 2006. Wild boars (Sus scrofa scrofa) seminiferous tubules morphometry. Brazilian Archives of Biology and Technology, 49(5):739-745.

Darwin, C. A. 1867. Variation of animals and plants under domestication. D. Appleton \& Company, London, United Kingdom.

Diong, C. H. 1973. Studies of the Malaysian wild pig in Perak and Jahore. Malayan Nature Journal, 26(3/4):120-151.

Diong, C. H. 1982. Population biology and management of the feral pig (Sus scrofa L.) in Kipahula Valley, Maui. Ph.D. Dissertation, University of Hawaii, Honolulu, Hawaii.

Dittus, T. 1983. Untersuchungen beim Wildschwein - Klinische und parasitologische Untersuchungen; Sedation und Narkose; anatomische, pathologische-anatomische und histologische Untersuchungen. Ph.D. Dissertation, University of Munich, Munich, West Germany.

Dub, Dr. 1952. Bestimmung des Schwarzwildalters. Wild und Hund, 55(18):292-293.

Duncan, R. W. 1974. Reproductive biology of the European wild hog (Sus scrofa) in the Great Smoky Mountains National Park. M.S. Thesis, University of Tennessee, Knoxville, Tennessee.

Dzieciolowski, R. M., C. M. H. Clarke, and B. J. Fredric. 1990. Growth of feral pigs in New Zealand. Acta Theriologica, 35(1-2):77-88.

Feldhamer, G. A., and B. E. McCann. 2004. Dental anomalies in wild and domestic Sus scrofa in Illinois. Acta Theriologica, 49(1):139-143.

Fernández-Llario, P., A. Parra, R. Cerrato, and J. Hermoso de Mendoza. 2004. Spleen size variations and reproduction in a Mediterranean population of wild boar (Sus scrofa). European Journal of Wildlife Research, 50(1):13-17.

Freeman, V. A. 1939. Variation in the number of vertebrae in swine. Journal of Heredity, 30:61-64.

Genov, P., G. Massei, Z. Barbalova, and V. Kostova. 1992. Aging wild boar (Sus scrofa L.) by teeth. Pp. 399-402. In F. Spitz, G. Janeau, G. Gonzalez, and S. Aulagnier (eds.), Ongules/Ungulates 91: Proceedings of the international symposium. Toulouse, France, September 2-6, 1991. Societe Francaise pour l'Etude et la Protection des Mammiferes, and Toulose: Institut de Recherche sur les Grands Mammiferes, Paris \& Toulouse, France.

Getty, R. 1975. Sisson and Grossman's the anatomy of the domestic animals. W. B. Saunders Company, Philadelphia, Pennsylvania.

Giles, J. R. 1980. The ecology of feral pigs in western New South Wales. Ph.D. Dissertation, Sydney University, Sydney, Australia.

Groves, C. P., and J. Giles. 1989. Suidae. Pp. 1044-1049. In D. W. Walton and B. J. Richardson (eds.), Fauna of Australia, Mammalia Vol. 1b. Australian Government Publishing Service, Canberra, Australia. 


\section{Wild Pigs}

Hammond, J. 1962. Some changes in the form of sheep and pigs under domestication. Zeitschrift für Tierzuchtung und Zuchtungsbiologie, 77:156-158.

Hayashi, Y., T. Nishida, and K. Mochizuki. 1977. Sex and age determination of the Japanese wild boar (Sus scrofa leucomystax) by the lower teeth. Nippon Juigaku Zasshi, 39(2):165-174.

Heck, L. 1950. Schwarzwild - Lebensbild des Wildschweines. Bayerischer Verlagsgesellschaft, Munich, Federal Republic of Germany.

Hell, P., and L. Paule. 1983. Systematische Stellung des Westkarpatischen Wildschweines Sus scrofa. Acta Scientiarum Naturalium Brno, 17(3):1-54.

Hennig, R. 1981. Schwarzwild: Biologie - Verhalten, Hege und Jagd. BVL Verlagsgesellschaft, Munchen, West Germany.

Henry, V. G. 1969. Estimating whole weights from dressed weights for European wild hogs. Journal of Wildlife Management, 31(1):222-225.

Henry, V. G. 1969. Detecting the presence of European wild hogs. Journal of the Tennessee Academy of Sciences, 44(4):103-104.

Henry, V. G. 1970. Weights and body measurements of European wild hogs in Tennessee. Journal of the Tennessee Academy of Sciences, 45(1):20-23.

Henson, T. M. 1975. Age determination and age structure of European wild hog (Sus scrofa). Project W46-R, TWRA Technical Report No. 75-8. Tennessee Wildlife Resources Agency, Nashville, Tennessee.

Herring, S. W. 1972. The role of canine morphology in the evolutionary divergence of pigs and peccaries. Journal of Mammalogy, 53(3):500-512.

Holman, R. L. 1941. Modern boar-hunting. Fauna, 3(3):90-91.

Horwitz, L. K., and G. Davidovitz. 1992. Dental pathology of wild pigs (Sus scrofa) from Israel. Israel Journal of Zoology, 38(2):111.

Hulme. S. 1979. The book of the pig. Spur Publications, Surry, United Kingdom.

Jaerisch, M. 1933. Das Ansprechen des Alters von Keilern. Wild und Hund, 39(21):360-361.

Kierdorf, U., D. Konjevic, Z. Janicki, A. Slavica, T. Keros, and J. Curlik. 2004. Tusk abnormalities in wild boar (Sus scrofa L.). European Journal of Wildlife Research, 50(1):48-52.

Klein, S. 1997. Quantitative morphologische Untersuchungen an Herzen, Nieren und Nebennieren von Wildschweinen verschiedenen Alters und Geschlechts. Ph.D. Dissertation. Institut für VeterinarAnatomie, Freie Universitat Berlin, Berlin, Germany.

Konjević, D., U. Kierdorf, L. Manojlović, K. Severin, Z. Janicki, A. Slavica, B. Reindl, and I. Pivac. 2006. The spectrum of tusk pathology in wild boar (Sus scrofa L.) from Croatia. Veterinarski Arhiv, 76(Suppl.):S91-S100.

Konjević, D., U. Kierdorf, F. J. M. Verstraete, Z. Janicki, A. Slavica, T. Keros, and K. Severin. 2004. Malformation of the permanent maxillary canine after dental infraction in a wild boar (Sus scrofa L.). Journal of Zoo and Wildlife Medicine, 35(3):403-405. 
Kozlo, P. G. 1973. Opredelenie Vozpacta Cepekuiva Iotlov Dikoro Kabana. Izdatel'stovo Uradzhai, Moscow, U.S.S.R.

1975. Dikiy Kaban. Izdatel'stovo Uradzhai, Minsk, U.S.S.R.

Kruska, D., and M. Röhrs. 1974. Comparative quantitative investigations on brains of feral pigs from the Galapagos islands and of European domestic pigs. Zeitschrift für Anatomie und Entwicklungsgeschichte, 144(1):61-73.

Lai, Y. Y., M. C. Wu, C. T. Liu, and H. L. Chang. 1998. Research note: Analysis of teat characteristics of berkshire pigs imported from USA. Contributions from the Taiwan Livestock Research Institute, 836:323-329.

Magnell, O., and R. Carter. 2007. The chronology of tooth development in wild boar - A guide to age determination of linear enamel hypoplasia in prehistoric and medieval pigs. Veterinarija ir Zootechnika, 40(62):43-48.

Marchinton, R. L., R. B. Aiken, and V. G. Henry. 1974. Split guard hairs in both domestic and European wild swine. Journal of Wildlife Management, 38(2):361-362.

Mason, I. L. 1988. World dictionary of livestock breeds. Third Edition. C.A.B International.

Mattioli, S., and P. Pedone. 1995. Dressed versus undressed weight relaionship in wild boars (Sus scrofa) from Italy. Journal of Mountain Ecology (Ibex), 3:72-73.

Matschke, G. H. 1967. Aging European wild hogs by dentition. Journal of Wildlife Management, 31(1):109-113.

Mayer, J. J. 1991. Tusks: the basic element of trophy wild hogs. The Hoghunter, 1(10):7-8.

1992. Striped piglets: stripes do not always a wild boar make. Hoghunter's Connection, 2(2):10-11.

. 2002. A simple field technique for age determination of adult wild pigs: Environmental information document. WSRC-RP-2002-00635. Westinghouse Savannah River Company, Aiken, South Carolina.

2003. Total body mass estimation methodology for wild pigs at the Savannah River Site: Environmental information document. WSRC-RP-2003-00317. Westinghouse Savannah River Company, Aiken, South Carolina.

. 2006. Characterization and development of the male shoulder shield in an introduced wild pig population. 2006 National Conference on Wild Pigs, Mobile, Alabama. May 21-23. School of Forestry and Wildlife Sciences, Auburn University. Abstracts of Papers. p. 26.

Mayer, J. J., and I. L. Brisbin, Jr. 1986. A note on the scent marking behavior of two captive-reared feral boars. Applied Animal Behaviour Science, 16:85-90.

1988. Sex identification of Sus scrofa based on canine morphology. Journal of Mammalogy, 69(2):408-412.

1991. Wild pigs in the United States: Their history, comparative morphology, and current status. The University of Georgia Press, Athens, Georgia.

. 1993. Distinguishing feral hogs from introduced wild boar and their hybrids: a review of past and present efforts. Pp. 28-49. In C. W. Hanselka and J. F. Cadenhead (eds.), Feral swine: A compendium for resource managers. Texas Agricultural Extension Service, Kerrville, Texas. 


\section{Wild Pigs}

Mayer, J. J., I. L. Brisbin, Jr., and J. M. Sweeney. 1989. Temporal dynamics of color phenotypes in an isolated population of feral swine. Acta Theriologica, 34(17):243-248.

McCance, R. A., P. D. A. Owens, and C. H. Tonge. 1968. Severe undernutrition in growing and adult animals: 18 - the effects on rehabilitation on the teeth and jaws of pigs. British Journal of Nutrition, 22(3):357-368.

McIlroy, J. C. 1989. Aspects of the ecology of feral pigs (Sus scrofa) in the Murchison area, New Zealand. New Zealand Journal of Ecology, 12:11-22.

McNally, T. 1955. Too tough to squeal. Outdoor Life, 115(5):50-51, 111-115.

Mooney, F. 1966. The wild Prussians of Hooper Bald. Wildlife in North Carolina, 30(9):10-13.

Nowak, E. 1962. Lauf eine Wildschweines (Sus scrofa Linnaeus, 1758) mit abgeschossner Klaue. Acta Theriologica, 6(11):311.

Olivier, E. 1904. Deformation pathologique d'un pied de sanglier. Bulletin de 1'Societe Zoologique de France, 29:148-150.

Pavlov, P. M. 1980. The diet and general ecology of the feral pig (Sus scrofa) at Girilambone, N. S. W. M.S. Thesis, Monash University, Melbourne, Australia.

Pine, D. S., and G. L. Gerdes. 1973. Wild pigs in Monterey County, California. California Fish and Game, 59(2):126-137.

Pinna, W., G. Nieddu, G. Moniello, and M.G. Cappai. 2007. Vegetable and animal food sorts found in the gastric content of Sardinian wild boar (Sus scrofa meridionalis). Journal of Animal Physiology \& Animal Nutrition, 91(5-6): 252-255.

Porter, V. 1993. Pigs: a handbook to the breeds of the world. Cornell University Press, Ithaca, New York.

Ptak, W. 1962. Polydactyly in wild boar. Acta Theriologica, 6(11):312-314.

Rohrs, M., and D. Kruska. 1969. Der Einflu der Domestikation auf das Zentralnervensystem und Verhalten von Schweinen. Deutsche Tierärztliche Wochenschrift, 75(19):514-518.

Rutledge, A. 1965. Demons of the delta. Sports Afield 153:69, 167-170.

Sáez-Royuela, C., R. P. Gomariz, and J. L. Telleria. 1989. Age determination of European wild boar. Wildlife Society Bulletin, 17(3):326-329.

Saunders, G. 1993. The demography of feral pigs (Sus scrofa) in Kosciusko National Park. Wildlife Research, 20(5):559-569.

Schortemeyer, J. L., L. L. Hamilton, R. E. Johnson, and D. R. Progulske, Jr. 1985. Wild hog investigations: Everglades hog study XVI - Dispersal and survival of resident and stocked wild hogs in the Everglades, Project W-41, Final Job Performance Report. Florida Game and Fresh Water Fish Commission, Naples, Florida.

Shaw, A. M. 1929. Variations in the skeletal structure of the pig. Scientific Agriculture, 10(1):23-27.

Snethlage, K. 1982. Das Schwarzwild. $7^{\text {th }}$ Edition. Verlag Paul Parey, Hamburg and Berlin, West Germany.

Stribling, H. L. 1978. Radiocesium concentrations in two populations of naturally contaminated feral hogs (Sus scrofa domesticus). M.S. Thesis, Clemson University, Clemson, South Carolina. 
Stubbe, M., I. Stubbe, and W. Stubbe. 1986. Zahnanomalien bei Sus scrofa L., 1758 und kraniometrische daten aus zwei Schwarzwild populationen. Beitrage zur Jagd- und Wildforschung, 14:233-270.

Stubbe, W., and M. Stubbe. 1977. Vergleichende beitrage zur reproduktions und geburtsbiologie von Wildund Hausschewein Sus scrofa L., 1758. Beitrage zur Jagd- und Wildforschung, 10:153-179.

Stukelj, M. A. 2002. A comparison of constitutional features and pathomorphological changes of the foot in wild boar and domestic swine. Veterinarske Novice, 28(10):420-422.

Sweeney, J. M. 1970. Preliminary investigation of a feral hog (Sus scrofa) population on the Savannah River Plant, South Carolina. M.S. Thesis, University of Georgia, Athens, Georgia.

Sweeney, J. M., E. E. Provost, and J. R. Sweeney. 1970. A comparison of eye lens weight and tooth eruption pattern in age determination of feral hogs (Sus scrofa). Proceedings of the Annual Conference of the Southeastern Association of Game and Fish Commissioners, 24:285-291.

Sweeney, J. M., and J. R. Sweeney. 1982. Feral hog. Pp. 1099-1113. In J. A. Chapman and G. A. Feldhammer (eds.), Wild mammals of North America: Biology, management, and economics. The Johns Hopkins Univ. Press, Baltimore, Maryland.

Towne, C. W., and E. N. Wentworth. 1950. Pigs from cave to cornbelt. University of Oklahoma Press, Norman, Oklahoma.

Uhr, G. 1995. The intestinal tract and the Peyer's Patch dimensions of wild boars (Sus scrofa L., 1758) and domestic pigs (Sus scrofa f. domestica). An allometric comparison. Journal of Mountain Ecology (Ibex), 3:72-73.

Valentinčič, S. 1974. Ein Fall der Polidactylie beim Wildschwein. Zentralblatt für Biotechnische Fakultät Universität Ljubljana, 11(1-2):187-189.

Vieites, C. M., C. P. Basso, and N. Bartoloni. 2003. Wild boar (Sus scrofa ferus): Productivity index in an experimental outdoor farm. InVet, 5(1):91-95.

Vigne, J. D., A. Bridault, M. P. Horard-Herbin, E. Pellé, P. Fiquet, and M. Mashkour. 2000. Wild boar Age at death estimates: The relevance of new modern data for archaeological skeletal material. 2. Shaft growth in length and breadth. Archaeological applications. Journal of Mountain Ecology (Ibex), 5:1927.

Wilson, S. E., and D. H. McKelvie. 1980. Supernumerary kidneys occurring in a feral Hawaiian pig. Laboratory Animal Science, 30(4):709-711.

Wood, G. W., and R. E. Brenneman. 1977. Research and management of feral hogs on Hobcaw Barony. Pp. 23-35. In G. W. Wood (ed.), Research and management of wild hog populations. Belle Baruch Forest Science Institute of Clemson University, Georgetown, South Carolina.

Zervanos, S. M., W. D. McCort, and H. B. Graves. 1983. Salt and water balance of feral vs. domestic Hampshire hogs. Physiological Zoology, 56:67-77.

Zinoviev, A. V. 2009. A supernumerary permanent mandibular premolar of wild boar (Sus scrofa L.) from the early medieval Novgorod, Russia. International Journal of Osteoarchaeology, Online Publication. http://dx.doi.org/10.1002/oa.1075 
Wild Pigs

\section{Biology of Wild Pigs: Wild Pig Reproductive Biology}

Christopher E. Comer and John J. Mayer

Arthur Temple College of Forestry and Agriculture, Stephen F. Austin State University, Nacogdoches, Texas 75962-6109 (CEC)

Savannah River National Laboratory, Savannah River Nuclear Solutions, LLC, Savannah River Site, Aiken, South Carolina 29808 (JJM)

\section{Introduction}

As a group, the wild and domestic pigs (Sus scrofa) of North America are characterized by high reproductive potential, with a young age at puberty, large litters, and frequent breeding. The extensive and expanding range of the introduced wild pigs provides evidence of its high reproductive capacity. Between 1988 and 2004, wild pig populations in the United States expanded rapidly, including both increases in states with existing populations and expansion into as many as 20 new states (Mayer and Brisbin 1991, SCWDS 2004). Recently, this species has become the most abundant introduced free-ranging ungulate in the United States (Mayer and Brisbin 1991). Although human translocations contribute to introductions of these animals into new range, the innate reproductive potential of the species is evident in the successful establishment and expansion of these initial introductions. As wildlife managers become more concerned with control and reduction of wild pig populations, more effective and efficient control strategies will be necessary (Sweeney et al. 2003). A thorough understanding of the reproductive biology of this species is key in designing effective management strategies for wild pigs.

For many parameters, the reproductive biology of wild pigs in the United States is intermediate between that of domestic pigs and the Eurasian wild boar. Most wild pigs populations in this country have mixed ancestry between escaped domestic stock (i.e., feral hogs) and Eurasian wild boar introduced for hunting; statistical analysis has shown that a combination of several morphological characteristics is necessary to distinguish among four types (i.e., Eurasian wild boar, domestic swine, feral hogs, and wild boar $\mathrm{x}$ feral hog hybrids) in most locations (Mayer and Brisbin 1991). In addition, wild pig populations tend to revert toward more wild-type appearance and ecology as the time since becoming wild-living increases (Sweeney et al. 2003). In general, domestic swine have been selected for maximum reproductive capacity (e.g., earlier maturity, large litter sizes, etc.) while Eurasian wild boar have less capacity; introduced wild pigs fall somewhere between these extremes depending upon their ancestry. For this reason, and because study of wild pig populations is still somewhat limited, examination of the more extensive literature on domestic swine and Eurasian wild boar is useful in the context of wild pig ecology. Where appropriate we have incorporated this literature into this review; however, we have used data on North American wild pig populations as much as possible.

In this paper we have combined a review of the existing literature on reproduction of wild pigs with the results of decades of wild pig data collection at the Savannah River Site (SRS) in Aiken, Barnwell and Allendale counties, South Carolina. Before 1988, that site was called the Savannah River Plant (SRP). The SRS is an approximately $800-\mathrm{km}^{2}$ federal nuclear facility, which is located in the Upper Coastal Plain of South Carolina, and operated by the U. S. Department of Energy (DOE). The majority of the site is undeveloped, with mixed-age loblolly (Pinus taeda) and longleaf pine (P. palustris) stands on uplands and mature hardwood stands on bottomlands (Imm and McCleod 2005). Wild pigs have been present on the SRS since its acquisition by the federal government in 1951, with subsequent periodic introductions from adjacent properties (Mayer 2005). Hogs are taken by hunters during annual dog-drive hunts for whitetailed deer (Odocoileus virginianus) management. In addition, various active wild pig control programs have been implemented since the early 1950's with good success. Between 1952 and 2004 almost 13,000 
wild pigs have been removed from the SRS (Mayer and Moore-Barnhill this volume). Most of these SRS data have not been published previously, so they are a new addition to the wild pig literature.

\section{Male Reproductive Biology}

Studies of male reproductive physiology in wild pigs are somewhat limited; however, basic parameters have been defined in some populations. Primary spermatocytes first appear in the testis of male domestic swine at about 3 months of age (Day 1962). Domestic boars first produce spermatozoa between 4.6 and 5.2 months of age (Phillips and Zeller 1943). In general, male wild pigs reach physiological puberty slightly later, and significant variation can be seen among populations. Examination of testes in boars from the SRS in South Carolina suggested that they reached puberty between 5 and 7 months (Sweeney et al. 1979). Male feral hogs in Florida apparently matured slightly earlier at 5-5.5 months (Belden and Frankenberger 1989). Boars from the Great Smoky Mountains National Park (GSMNP) reached sexual maturity later at 7.5 to 12 months (Johnson et al. 1982). In addition to the presence of spermatozoa, Johnson et al. (1982) noted significant differences in several testicular measurements between immature and mature boars. At the Dye Creek Ranch in California, Barrett (1978) reported that boars as young as 6 months old attempted to breed; however, these males did not actively participate in breeding until 12 to 18 months. Testicular weights of male wild pigs increased at least up until 3 years of age at GSMNP and in South Carolina (Wood and Brenneman 1977, Johnson et al. 1982). However, significant testicular degeneration was noted in boars aged 5 years of older in South Carolina (Wood and Brenneman 1977).

Male wild pigs are physiologically capable of breeding year-round. No changes in testicular weight or volume were associated with month or season in GSMNP (Duncan 1974, Johnson et al. 1982) or SRS (Sweeney et al. 1979). Motile sperm were also present in mature boars at SRS in every month of the year. A sow in estrous is typically tended by one or more boars during the estrous period. Males compete actively for breeding opportunities, with older and larger boars being dominant over smaller animals. Barrett (1978) cites the presence of older boars as the primary reason that males $<12$ months old were not successful in breeding at Dye Creek Ranch. Based on genetic data, Hampton et al. (2004) found that breeding boars were significantly heavier than non-breeding boars. The most reproductively successful boars in that study were large individuals, weighing more than $90 \mathrm{~kg}$, which also moved further $(>30 \mathrm{~km})$ to secure breeding opportunities. Similar findings suggesting that larger boars disperse further to secure paternity were also reported by Saunders and Kay (1991), Caley (1997), and Lapidge et al. (2004). Competition between males may range from posturing and display to actual combat (Barrett 1978). Kurz and Marchinton (1972) observed two types of antagonistic interactions between feral boars. The first type occurred before establishment of dominance between the two males and consisted of a head-on charge followed by circling, pushing, and attempts to slash each other with their tusks. Interactions between boars that had already established dominance lasted only a few seconds, often consisting of only a few lunges by the dominant boar (Kurz and Marchinton 1972). They also observed a large boar attack and drive off a smaller boar attempting to breed an estrous sow. Male-male fighting among wild pigs has also been described by various other authors (e.g., Barrette 1986, Beuerle 1975, de Poncins 1914, Frädrich 1974). Male wild pigs develop a thick, protective shield of tissue over the shoulders and chest that aids in preventing serious injury during intraspecific combat. This shield becomes increasingly large and thick as the boar ages. Multiple paternity of wild pig litters does occur, but it is very uncommon (Barrett 1978, Delgado et al. 2008). Reproductive activity can also affect the weights in boars during certain times of the year. For example, the body mass of mature male pigs has been reported to drop during the breeding season, with some individuals losing up to 20-25 percent of their body weight. This is due to a combination of testosterone production and the resultant reduced foraging (Frädrich 1984, Goulding 2003, Weiler et al. 1996).

Unlike most wild-living species of large mammals, wild pig populations can often include males, called barrows, which have been castrated. Similar to domestic swine, this neutering is done, typically to younger males (i.e., piglets or shoats), by the owners, resource managers or others from the property in question with the intention of improving the favor/quality of the meat of those boars when they are eventually harvested. In addition, these animals are sometimes also be visually marked (e.g., removal of one or both external ear pinnae) for rapid identification at a distance in the field as one of these neutered males. Barrett (1978) reported that barrows lose the shoulder shield and large shoulders of the intact boars, but retain the 


\section{Wild Pigs}

large tusks. In addition, he also stated that barrows are generally larger in size than either boars or sows. As neutered animals, barrows do not have any functional role in the reproductive biology of these populations; in addition, they typically only comprise a small percentage of the wild pigs found in these areas.

\section{Female Reproductive Biology}

Physiology - The basic reproductive physiology of wild sows is similar in most respects to domestic sows (Hagen et al. 1980). They have a bicornuate uterus and exhibit diffuse placentation. Wild-living sows show a bias toward implantation in the left uterine horn; Sweeney et al. (1979) found that $67 \%$ of corpora lutea were in the left ovary in feral sows from SRP. However, this tendency was not noted in feral sows from Ossabaw Island, Georgia (Sweeney 1979). Duncan (1974) found that 40\% of the corpora lutea occurred in the left ovary, while $50 \%$ of the implanted fetuses were in the left horn among hybrid sows in the GSMNP. The uteri of feral sows showed greater capacity for expansion than those of domestic sows, suggesting that litter size was primarily limited by the number of ova rather than uterine capacity (Hagen et al. 1980). The gestation period of wild sows is similar to that of domestic sows, averaging 112-120 days and ranging from 100 to 140 days. Mean gestation periods for wild sows have been reported as 115 and 119 days (Henry 1968, Mauget 1982). Female Eurasian wild boar may have slightly longer gestation periods (Barrett 1978).

Wild sows are polyestrous, coming into heat every 18-24 days if not successfully bred (Barrett 1978). The average period between estrus cycles is approximately 21 days (Sweeney et al. 2003). A sow's first estrus lasts for approximately 24 hours, but subsequent estrus periods may last from 48 to 72 hours (Barrett 1978). Estrus cycles typically resume within a week after young are weaned, and sows can be ready to breed again at that time (Barrett 1978).

Age at puberty in wild sows is highly variable; it can be as young as 3-4 months of age (Pelton 1976, Giles 1980), but generally occurs between 5 and 12 months of age. Domestic sows generally first breed at 5-8 months, while most female Eurasian wild boar breed first as yearlings ( $>18$ months, Barrett 1978). Mauget et al. (1984) reported that female wild boar must reach a body mass of $35 \mathrm{~kg}$ to achieve maturity, while Giles (1980) gave the comparable threshold for feral sows to begin breeding at 20-30 kg. Wild sows in the GSMNP first bred at between 5 and 8 months of age, with an average of 6 months (Johnson et al. 1982). Sows at Hobcaw Barony in South Carolina also bred as early as 6 months (Wood and Brenneman 1977), but sows from the SRS in South Carolina generally reached puberty at 10 months of age (Sweeney et al. 1979). On Santa Catalina Island in California, the majority (83\%) of sows did not breed until after they were a year old (Baber and Coblentz 1986). A small proportion of sows (4\%) bred at 5-7 months of age. The age of first breeding even within a population may be highly dependent on nutritional status of the females and the age structure of the population (Johnson et al. 1982). For example, Barrett (1978) observed that wild sows using an area of Dye Creek Ranch with abundant food reached puberty at 6-8 months, but that puberty among sows in an area with lower quality nutrition occurred at 8-10 months. The oldest wild sow that was documented to still be breeding was 14 years of age (Dzieciolowski et al. 1992).

Litter Size - Based on fetal counts, mean litter size in wild pigs ranged from 3.0 to 8.4 live fetuses per sow (Table 1). Within these studies, individual litters ranged from 1 to 14 live fetuses. Hanson and Karstad (1959) reported examining a sow carrying 16 fetuses; however, ten of those were either dead in utero or were being reabsorbed. These fetal litter sizes from wild/feral sows are less than those reported for domestic swine (i.e., up to 37 young per litter, ATI 2008). In general, Eurasian wild boar and hybrids have smaller average fetal litters (4-5 piglets) than do feral hogs (5-6 piglets) (Table 1). Differences in litter size between wild/feral and domestic hogs are apparently due to differences in ovulatory rate rather than differences in fetal survival or uterine capacity (Hagen and Kephart 1980, Hagen et al. 1980). Significant prenatal mortality has been noted in both wild/feral and domestic swine. Embryonic losses, as measured by differences between mean number of corpora lutea and mean number of fetuses, in studies of wild pigs ranged from 25\% on Santa Catalina Island (Baber and Coblentz 1986) and in South Texas (Taylor et al. 1998) to $31 \%$ at SRS (Sweeney et al. 1979) and 34\% at Dye Creek Ranch (Barrett 1978). The reasons for these embryonic losses are not clear. In addition, stillborn losses of $6 \%$ are reported in domestic sows (Asdell 1964). These are difficult to separate from postnatal losses in free-ranging wild pig populations, 
but losses from fetal litter size to observed piglets per sow in wild populations ranged from $8 \%$ in Tennessee (Henry 1966) to $38 \%$ on Santa Catalina Island (Baber and Coblentz 1986).

Fetal sex ratios in wild pig litters tend to be male biased, although this bias often is reported as being not significant (Table 3). In contrast, Taylor et al. (1998) reported a significant bias towards males in South Texas litters. In penned studies, fetal sex ratio in feral sows was more biased towards males than in domestic hogs (Hagen and Kephart 1980). Sweeney (1979) noted that stillborn losses in hogs are often higher among male fetuses; thus sex ratios at parturition may be closer to even. A study of Eurasian wild boar suggests that sows may allocate more maternal resources toward offspring of one sex with a presumed long-term fitness advantage (Fernandez-Llario et al. 1999). Servanty et al. (2007) found that fetal sex ratios were male biased for litter sizes up to six and then became female biased in larger litters. These authors also reported that resource availability did not influence the fetal sex ratio. Fernández-Llario and Mateos-Quesada (2005) found that the sex of the heaviest fetus within the litter was significantly more often male during dry years.

Being polyestrous, wild sows are physiologically capable of producing more than one litter in a year, although this is generally uncommon in free-ranging populations. A small proportion of wild sows in California (Baber and Coblentz 1986), GSMNP (Johnson et al. 1982), and Texas (Springer 1977, Taylor et al. 1998) produced multiple litters annually. No incidence of more than one litter per year was reported for hybrid sows in Tennessee (Henry 1966). On Santa Catalina Island, adult sows produced an average of 0.86 litters per year (Baber and Coblentz 1986). However, Barrett (1978) observed that wild sows at Dye Creek Ranch produced an average of 2 litters per year. He suggested that production of second litters was common when sows lost the entire first litters; however, he also observed several sows breeding while still suckling previous litters. Normally sows do not conceive when still nursing a litter of piglets (Conley et al. 1972). Conley et al. (1972) also noted that, although numerous wild sows in Tennessee bred within a month of farrowing, very seldom did these females conceive; when these sows did conceive, only very small litters were produced. Production of multiple litters is more common when food resources are abundant (Barrett 1978). It is also more common among adult wild sows than younger sows. For example, in Texas, adult ( $>21$ months) sows averaged 1.57 litters per year compared to 0.85 per year for yearlings (Taylor et al. 1998). Giles (1980) determined that sows in western New South Wales produced an average of 1.93 litters per year. Four captive feral sows in New Zealand had commenced a third litter after already producing two litters within a year's time; three litters could physiologically be produced by wild sows over a 14-16 month period (Dzieciolowski et al. 1992). However, this has not been documented in the wild to date.

Reproductive rates in wild pigs, including litter size, age at puberty, and number of litters, are sensitive to several factors such as sow age and condition and availability of high-quality forage. Taylor et al. (1998) found that ovulation rates and pregnancy rates were higher for adult wild sows compared to juveniles and yearlings in Texas. Litter sizes did not differ significantly, although the mean litter size for adults was numerically higher than that for yearlings or juveniles. Baber and Coblentz (1986) observed that litter size in wild sows increased from puberty to 2-3 years of age, then declined slightly. Dzieciolowski et al. 1992 noted that large litters among wild pigs in New Zealand only occurred in animals older than 15 months of age. Giles (1980) reported that fetal litter size in feral hogs in New South Wales, Australia, was significantly correlated to the sow's age in some locations, but not in others. Barrett (1978) also observed an increase in litter size with age, but this increase continued to the 4-5-year-old age class. Increases in litter size with sow age and size have also been noted in populations of Eurasian wild boar (Briedermann 1971, Mauget 1982, Saez-Royeula and Telleria 1987, Fernandez-Llario and Mateos-Quesada 1998).

Increases in productivity of domestic swine in response to even short-term increases in nutrition are well established, leading to the practice of "flushing" shortly before ovulation (Matschke 1964). Similar effects have been noted for wild/feral pigs in a variety of habitats. Reproduction in Eurasian wild boar also varies in response to the availability of preferred food items, especially hard and soft mast. Massei et al. (1996) found that both the proportion of females breeding and litter size were dependent on annual production of olives and acorns. In Tennessee, Matschke (1964) attributed reproductive failure in the hybrid population to successive years of oak (Quercus spp.) mast failure. Examination of ovaries suggested that the primary effect was severely reduced ovulation rates. The abundance of acorns is the most commonly cited factor in 
the relationship between nutrition and reproduction in wild pigs. Johnson et al. (1982) and Henry (1966) both observed higher ovulation rates and numbers of young per female during good mast years in portions of Tennessee and North Carolina that were ecologically similar to Matschke's (1964) study. Similar effects on pregnancy rates were noted in two California populations in response to varying acorn production (Pine and Gerdes 1973, Baber and Coblentz 1987). However, this effect is not limited to oak mast and probably reflects general nutritional plane at the time of breeding. In California, Barrett (1978) noted larger litters in well-fed pasture sows compared to poorly-fed backcountry sows. He attributed his observations to differences in conception and implantation rates. On a coastal island in Georgia, Warren and Ford (1997) observed a drastically increased ovulation rate in wild sows coincident with unusually high production and consumption of grape (Vitis sp.) leaves.

Related to availability of forage resources, climatic conditions have also been shown to affect productivity in wild pigs. General drought conditions in Spain resulted in reduced postnatal litter sizes in female Eurasian wild boar (Fernández-Llario and Carranza 2000). Fernández-Llario and Mateos-Quesada (2005) found that the percentage of pregnant sows was higher in rainy years than in dry ones. In addition, females over two years of age significantly increased their litter sizes in those rainy years.

Farrowing - Wild pigs are physiologically capable of breeding throughout the year; however, most populations exhibit either one or two seasonal peaks in breeding and farrowing. Both patterns can even occur within the same population from year to year (Mauget 1982). However, Eurasian wild boar typically only have a single, well-defined breeding season in any one given year. The precise season of farrowing in Eurasian wild boar varies with latitude and other factors, but is generally between March and June (Fernandez-Llario and Carranza 2000). In Spain, farrowing occurred from January to April with a distinct peak in March (Saez-Royeula and Telleria 1987, Fernandez-Llario and Carranza 2000). In Eurasian wild boar, sows apparently were able to synchronize breeding activity when kept together in a forest pen, even in the absence of males (Delcroix et al. 1990). The time of breeding in Eurasian wild boar appears to be largely dependent on food availability, with even short periods of high food availability leading to highly synchronous births among all age classes of sows. However, even in relatively harsh environmental conditions, adult females that exploit low-quality foods appear to be able to give birth at any time of the year (Santos et al. 2006). Extensive supplemental feeding in one Spanish population resulted in a breeding season that was different from nearby populations without food supplementation (Fernandez-Llario and Mateos-Quesada 1998). In most wild/feral pig populations, farrowing occurs in every month of the year (Table 2). However, most show some degree of seasonality in farrowing activity, with one or two peaks in farrowing occurring during the year. The exact months of peak farrowing vary among populations (Table 2) and may vary between years in the same population (Baber and Coblentz 1986, 1987, Mauget 1982). In general, most populations show prominent peaks in farrowing in the winter and spring. Lesser or secondary peaks occur in all four seasons (Table 2). Both photoperiod and nutrition apparently exert some influence on breeding season in wild/feral pigs (Baber and Coblentz 1987, Taylor et al. 1998). Peaks in production of young pigs may be associated with seasonal food abundance, including fall mast production and growth of new succulent vegetation at spring green-up (Belden and Frankenberger 1989). In locations where food availability is less seasonal, farrowing may show less distinct peaks (Barrett 1978, Sweeney et al. 1979). Environmental or climatic factors such as temperature and precipitation also influenced the timing of farrowing (Baber and Coblentz 1986, Taylor et al. 1998).

Wild sows construct a nest in preparation for farrowing, and generally limit their movements during the period when piglets have limited mobility. About one month prior to farrowing, sows at the SRP showed greatly reduced diel movements that were centered on farrowing nest locations (Kurz and Marchinton 1972). Farrowing nests generally consist of shallow depressions in the ground, sometimes with accumulation of bedding material in and around the nest (Kurz and Marchinton 1972, Graves and Graves 1977, Barrett 1978, Mayer et al. 2002). Although some nests are unlined, sows have been observed using a variety of bedding materials, including grass stems and leaves, reeds, fern fronds, tree/shrub leaves, pine straw, Spanish moss, twigs/sticks, eastern hemlock (Tsuga canadensis) boughs, and algaroba (Prosopis chilensis) branches and stems. Woody branches and saplings as large as $2 \mathrm{~m}$ long and approximately 1-2 $\mathrm{cm}$ in diameter have been reported as being bitten off by the sows and used in the nest construction (Mayer et al. 2002). Both domestic and captive-reared wild/feral sows kept in pens rooted in the straw floor covering in attempting to create a depression nest prior to farrowing (Graves and Graves 1977). Wild sows 
SRNL-RP-2009-00869

remained close to the nest for 2 weeks after parturition, and these reduced diel movements in sows persisted for approximately 3 weeks (Kurz and Marchinton 1972). During this time, piglets remained in or around the nest; however, at approximately 3 weeks they began to follow the sow during feeding excursions (Kurz and Marchinton 1972, Barrett 1978). Piglets are weaned at approximately 1-4 months, and separation from the maternal group occurs at 9-12 months (Barrett 1978, Dzieciolowski et al. 1992, Nichols 1962).

After piglets leave the farrowing nest, the sow may join in a loose association with other, possibly related, sows. These multiple family groups typically consist of 2 or 3 adult sows with a variable number of piglets (Kurz and Marchinton 1972, Graves and Graves 1977). Gabor et al. (1999) conducted a detailed analysis of genetic and behavioral group structure in wild pigs from south Texas. Individuals within social groups had extensive home range overlap $(>50 \%)$ and were often observed together. Social groups apparently were territorial and exhibited little range overlap with adjacent groups. Based on visual association and radiotelemetry, they found that social groups corresponded to genetic groupings, and that group membership changed regularly due to dispersal of individuals and fission of social groups (Gabor et al. 1999). Large, mixed-sex groupings of wild pigs may occur occasionally, particularly in the presence of an abundant, favored food source (Barrett 1978, Gabor et al. 1999).

The number of lactating teats on a sow can be used as an estimate of the size of the litter of piglets that she is nursing. Although the numbers of each parameter (i.e., piglets and lactating teats) are not always $100 \%$ consistent with each sow, correlations between these paired parameters were significant (Conley et al. 1972, Diong 1973, Duncan 1974, Giles 1980).

\section{Management}

The high reproductive capacity of wild/feral pigs has produced abundant and expanding populations of this species in a large portion of the United States. This species has been reported to be able to double, and in some locations, even triple their numbers in a population within a year's time frame (Barrett and Birmingham 1994, Waithman 2001). Negative impacts from free-ranging pigs are well documented and include damage to native vegetation, effects on soil characteristics and erosion, disease transmission to domestic swine, and competition with native game and nongame species (Sweeney et al. 2003). Taylor et al. (1998) suggested that the fecundity of feral hogs in South Texas was more than 4 times that of native ungulates, including collared peccaries (Tayassu tajacu) and white-tailed deer (Odocoileus virginianus). Evidence suggests that some populations can withstand high rates of harvest without significant reductions in population density (Barrett and Pine 1980), although sport hunting negatively impacted some populations in Florida (Belden and Frankenberger 1989). Despite these negative impacts, wild/feral pigs are a desirable game species in some areas and translocations of individuals by private hunters is an important factor in range expansion. Therefore, management strategies that can effectively control populations to avoid negative impacts and maintain huntable populations are highly desirable. Detailed knowledge of reproductive parameters for wild/feral pigs is important in formulating these strategies (Hellgren 1993).

Although our knowledge of reproductive biology in wild/feral pigs is currently incomplete, several recommendations can be made to design more efficient control programs. These include the following points.

- Lethal control efforts should focus on the adult female portion of the population. Reproductive parameters, including litter size, frequency of breeding, and pregnancy rates, increase with a sow's age. Removal of males will have little impact on population growth due to the polygynous mating system and the young age at which males reach puberty.

- Control efforts may be targeted toward seasonal peaks in breeding activity to maximize the removal of females that are either pregnant or nursing young, and thereby exploit the temporal vulnerabilities within the population (Henry 1966). The time of peak breeding varies (Table 2), so the period of greatest vulnerability is specific to each population. In addition, knowing the peaks of conception and farrowing within a specific population, it would be possible to increase lethal removal efforts for mature females while these animals are breeding and before their litters are farrowed. 


\section{Wild Pigs}

- The influence of mast crop and, to a lesser extent, other nutritional inputs is very important for reproductive output of wild/feral pigs. This allows the design of control strategies that vary the intensity of effort in response to variables like estimated mast production.

The recommendations show the value that knowledge of reproductive parameters can provide in the design of management strategies. However, more detailed information on wild/feral pig reproduction would allow the construction of population growth models and predictive evaluation of different management regimes. Further research is necessary to better define reproductive parameters for wild/feral pigs, including the influence of environmental factors, the mechanisms underlying the nutritional reproductive response, and density-dependent factors in wild/feral pig reproduction. Proactive and innovative control strategies may be necessary to successfully manage this very productive species.

\section{Savannah River Site Data}

The following is a summary of the reproductive data from a large data set from the SRS wild pig population. These data were collected between 1969 and 2003. Animals were harvested on site through a variety of methods (i.e., shooting, trapping, and dogging), and were categorized by sex and into one of six age classes (i.e., neonate; piglet - 0-0.5 yr; juvenile - 0.5-1 yr; yearling - 1-1.5 yr; subadult - 1.5-3 yr; and adult $-3+\mathrm{yr})$. The latter five age classes were based on the pattern of erupted teeth as defined in Mayer and Brisbin (1991). Neonates were defined as piglets exhibiting the presence of a drying umbilicus and fetal membranes. Total body mass was taken to the nearest 0.5 kilograms. The females were checked for pregnancy and lactation status. Fetal litters were examined for total number of viable embryos. In addition, any embryos/fetuses that were found to have died in utero were noted. Each viable embryo/fetus was checked for the sex, crown-rump length and uterine horn location. Crown-rump length (CRL) measurements were used to determine the fetal age in days (Henry 1968). Knowing the date of collection of the pregnant sow, the fetal age was used to determine the conception and farrowing dates, using a gestation period of 115 days. The number of lactating teats for each sow was recorded. For males, the presence of wounds and scars consistent with intraspecific fighting were noted.

Female Reproductive Data - Out of 2,105 SRS sows examined, a total of 636 (30.2\%) were pregnant. At least some animals in all the age classes (i.e., piglet, juvenile, yearling, subadult and adult) were found to be pregnant (Table 4). The percent occurrence progressively increased with age, with most $(41 \%)$ of the total number of pregnant females being in the adult age class. The overall mean total body mass for the pregnant sows was $142.5 \mathrm{~kg}$, and ranged from 11.5 to $170 \mathrm{~kg}$. The smallest was a piglet that had a fetal litter of 7 embryos, while the largest was an adult that had a fetal litter of 13. As would be expected, the mean total body mass of the pregnant sows also increased with age.

The aforementioned sample of pregnant sows had a mean fetal litter size of 6.1 piglets, which varied from 1 to 14 (Table 4). The mode was 6 . Both the mean and maximum fetal litter sizes increased with the age class and total body mass of the sows. The fetal litter size varied significantly with both the sow's age class $(F=28.9, d f=3, p<0.0001)$, and total body mass $(F=161.1, d f=1, p<0.0001)$. Out of the collective total of 3,289 fetuses/embryos, the age class-specific production increased with age (i.e., piglet $-7 /<1 \%$; juvenile 195/6\%; yearling - 596/18\%; subadult - 880/27\%; and adult - 1,611/49\%). Both even- and odd-numbered litter sizes occurred; however, the tendency toward even-numbered litter sizes was significant $\left(\chi^{2}=6.7\right.$, $d f=1, p<0.009)$. Based on monthly and seasonal comparisons, the fetal litters did not vary significantly in size as to when the litters were either conceived or farrowed. From a sample of 178 pregnant sows, $51 \%$ of the 1,111 fetuses present were found in the left uterine horn. However, this comparison did not differ significantly from parity. Although rare, the left horn in one fetal litter had no implanted fetuses present, while three fetuses were present in the right horn. A case of the reverse situation was not encountered during this study. A comparison of the changes in mean litter size within the SRS wild pig population indicates that approximately $30 \%$ of the piglets are lost between the time that they are in utero and approximately 3-4 months of age (Table 5).

Data on the litter sex ratio were compiled for both fetal and neonatal litters of wild pigs from the SRS. From an aggregate sample of 1,110 fetuses, 556 were males and 554 were females. Only being very 
slightly biased toward males, the fetal sex ratio did not differ significantly from parity. Most (95\%) of these litters contained fetuses of both sexes; however, nine fetal litters had fetuses of only one or the other sex, with six being all male and three being all female. Based on a sample of 446 neonates, 202 were males and 243 were females. This latter litter sex ratio was significantly biased toward females $\left(\chi^{2}=3.8, d f=1\right.$, $p<0.05)$.

Based on a sample of 647 sows examined, 117 (18\%) were found to be lactating. Unlike the incidence of pregnancies among females in this population, lactating sows included only individuals in the juvenile age class and older. No sows in the piglet age class were found to be lactating. The percent of lactation occurrence progressively increased with age, with most $(48 \%)$ of the total being in the adult age class. Overall, the mean number of lactating teats per sow was 5.9, with a range of 2 to 12 . Similar to the pattern seen in the pregnant sows, the mean number of lactating teats was also observed to increase with age (i.e., juvenile -4.0 ; yearling -5.0 ; subadult -6.2 ; and adult -6.3$)$. The numbers of lactating teats varied significantly with the sow's age class $(F=17.2, d f=3, p<0.0001)$.

Based on the discovery of pregnant sows that were also nursing a litter of piglets $(\mathrm{N}=36)$, the ability of sows to produce two litters per year occurs in yearling through adult age classes. Females in the juvenile age class would not be old enough to have produced a second litter following puberty. Within that small sample, most $(58 \%)$ of the sows which produced two litters in a twelve-month period were in the adult age class. Overall, the percent occurrence of sows producing two litters per year within the SRS wild pig population was small $(<6 \%)$. No data were available for the SRS wild pig population to document the occurrence of three litters by one sow during a 12-16 month time period.

Male Reproductive Data - Most of the male reproductive data available for the SRS wild pig population were reported by Sweeney (1970) and Sweeney et al. (1979). However, one wild-caught, captive-reared SRS boar did successfully bred several captive adult sows when that male was estimated to be between only four to five months of age. Based on the relative age determinations of males observed in breeding groups and the presence of scars on aged males from intraspecific fighting, most of the breeding is performed by either subadult or adult males. Over $65 \%$ of the total number of males with fighting scars $(\mathrm{N}=122)$ were in the adult age class. The balance was in the yearling $(7 \%)$ and subadult $(28 \%)$ age classes, with no males in the two youngest age classes having any fighting scars at all. This generally coincides with the age-related development of the shoulder shield (Mayer 2006, J. J. Mayer, unpubl. data).

Breeding Season - Wild pigs on the SRS have been found to be capable of breeding year-round, with pregnant females and litters being encountered during all months of the year (Sweeney 1970, Sweeney et al. 1979, Jenkins and Provost 1964). Based on the monthly data collected from the SRS, the mean incidence of pregnancy is 1.37 litters per year (J. J. Mayer, unpubl. data).

Based on a sample of 304 fetal litters, conception and farrowing dates were calculated based on the mean CRL for each litter. The monthly frequency of conception and farrowing are provided in Fig. 1. Although both reproductive activities occurred year-round, prominent monthly peaks for conception and farrowing occurred in September and January, respectively. Comparative secondary peaks occurred in January and April-May, respectively. The highest period of conception was from August through October, while the comparable peak for farrowing was from December through February. Although conception was a little more spread out, approximately $50 \%$ of the litters out of this sample were born in the December-February timeframe.

The timing of the peak annual farrowing (i.e., mid-winter) within the SRS wild pig population would seem to be maladaptive toward the survival of new-born piglets. Because of both a small body size and the lack of insulating bristles and curly underfur, very young piglets are the least adapted age class to be able to withstand cold weather conditions. In addition, neonatal piglets are unable to effectively regulate their body temperature until approximately two to three days following their birth (Mount 1967), and in some cases up to two weeks postpartum (Hartsock and Graves 1976). Newborn piglets exposed to too low environmental temperatures will die (Varley 1995). As such, this seasonality would seem to be detrimentally-based with respect to viable recruitment within this population. However, having been born in mid-winter, juvenile sows would likely be sexually mature and ready to be bred for the first time when 


\section{Wild Pigs}

the mast crop (i.e., the best protein source available to these animals during the entire year) is available and at its peak. Hence, these females would be in the best possible condition to tolerate the physiological stress associated with pregnancy and the nursing of newborn piglets. This would also be consistent with Barrett's (1978) observation that sows born in the summer would first breed at an older age since they would not be in as good a physical condition as the sows born in mid-winter.

Another factor which would indicate a breeding season would be male-male competition for females. This would be in the form of observations of fighting males and the presence of fresh scars on adult males. Most such fighting has been observed in the fall and early winter. Recently wounded males (i.e., those having open wounds with maggots present) have been most evident from October until early December.

\section{Summary}

Based on the review of the existing literature and the new information from the SRS, the following is a summarized list of the reproductive characteristics of wild pigs:

- In general, wild pigs have a high reproductive potential

- Wild pig reproductive parameters can vary widely between populations

- Differences in these parameters also exist among the three general types of wild pigs (i.e., Eurasian wild boar, feral hogs, and wild boar $\mathrm{x}$ feral hog hybrids)

- $\quad$ Male wild pigs -

- Sexually mature as young as 4-5 months of age; most reach puberty within first year

- Most participate in breeding by 12 to 18 months of age

- Testicular weight increases until 3 years of age; decreases after 5 years of age

- Capable of breeding year-round

- Compete in male-male fighting for breeding opportunities with females

- Most breeding done by larger and older males

- Males develop shoulder shield that protects them during male-male fighting

- Mature males can lose up to $25 \%$ of their body mass during the breeding season

- Female wild pigs -

- Sexually mature as young as 3-4 months of age; most reach puberty within first year

- Polyestrous; come into estrus every 18-24 days if not successfully bred

- Ovulation rate averages 7-8 shed ova; range of 3-15

- Uterine implantation bias toward left horn; however, typically not significant

- Gestation period averages 112 to 120 days; range of 100 to 140 days

- Fetal litter size means of 5-6 piglets; range of 1 to 14

- Intrauterine mortality is approximately $30 \%$

- Male-biased sex composition of fetal litters, however, typically not significant

- Capable of producing more than one litter per year

- Ovulation rates, fetal litter sizes and pregnancy rates all increase with sow's age

- Nutritional input and reproductive output levels in sows are positively correlated

- Farrowing nest built by sow to provide protection for neonates

- Neonatal litter size means of 4-6 piglets; range of 1 to 12

- Mean number of lactating teats per sow of 4-6; range of 1-12

- Number of lactating teats is highly correlated with the number of piglets in the litter

- Litter size in sows reportedly decreases after about the $5^{\text {th }}-7^{\text {th }}$ litter or 4-5 years of age

- Oldest documented breeding wild sow was 14 years old

- Breeding Season

- Breeding can occur year-round

- Typically one to two seasonal peaks in conception and farrowing

- Annual patterns with one or two seasonal peaks can occur within the same population, varying from year to year

- Photoperiod, rainfall and nutrition influence the breeding season 
Table 1. Reproductive parameters reported for wild pig populations, including the type of wild pig (i.e., EWB - Eurasian wild boar, FER - feral hog, HYB - wild boar x feral hog hybrid), study location, mean ovulation rate as corpora lutea per sow, mean fetal litter size as number of live fetuses per sow, and mean postnatal litter size as live piglets per sow (i.e., a - no. of live piglets, $\mathrm{b}$ - no. of lactating teats). NR indicates that the parameter was not reported in a particular study.

\begin{tabular}{|c|c|c|c|c|c|}
\hline $\begin{array}{l}\text { Type of } \\
\text { Wild Pig }\end{array}$ & Location & $\begin{array}{l}\text { Ovulation } \\
\text { Rate }\end{array}$ & $\begin{array}{l}\text { Fetal Litter } \\
\text { Size }\end{array}$ & $\begin{array}{l}\text { Postnatal } \\
\text { Litter Size }\end{array}$ & Reference \\
\hline EWB & Almería, Spain & NR & 4.1 & NR & Abaigar 1992 \\
\hline EWB & Central Punjab, Pakistan & 6.3 & 5.7 & NR & Ahmad et al. 1995 \\
\hline EWB & Germany & $4.9-8$ & $3.7-6.8$ & NR & Ahrens 1984 \\
\hline EWB & France & 5.3 & 4.5 & NR & $\begin{array}{c}\text { Aumaitre et al. } \\
1982\end{array}$ \\
\hline EWB & Canton du Jura, Switzerland & NR & 5.6 & NR & Baettig 1988 \\
\hline EWB & Maurienne Valley, France & NR & 4.1 & NR & Baubet 1998 \\
\hline EWB & Tuscany, Italy & 2.1 & 5.0 & NR & Boitani et al. 1995 \\
\hline EWB & East Germany & NR & $3.6-6.5$ & $4.1-5.7^{\mathrm{a}}$ & Briedermann 1971 \\
\hline EWB & East Germany & 6.5 & 5.3 & NR & Briedermann 1986 \\
\hline EWB & $\begin{array}{l}\text { Mount Meiron, Upper } \\
\text { Galilee, Israel }\end{array}$ & NR & $3.3-5.0$ & NR & Cnaani 1972 \\
\hline EWB & $\begin{array}{l}\text { Sussex and Hereford, } \\
\text { England }\end{array}$ & NR & NR & 4.3 & DEFRA 2004 \\
\hline EWB & $\begin{array}{l}\text { Mahammal, Reza Shah } \\
\text { National Park, Iran }\end{array}$ & NR & $4.5-6.9$ & NR & $\begin{array}{c}\text { de Vos and Sassani } \\
1977\end{array}$ \\
\hline EWB & Perak and Johore, Malaysia & NR & 4.5 & $3.5^{\mathrm{a}}$ & Diong 1973 \\
\hline EWB & Poland & NR & 5.2 & NR & Dzieciolowski 1991 \\
\hline EWB & $\begin{array}{l}\text { Doñana National Park, } \\
\text { Spain }\end{array}$ & NR & 4 & NR & $\begin{array}{c}\text { Fernandez-Llario } \\
1996\end{array}$ \\
\hline EWB & $\begin{array}{l}\text { Doñana National Park, } \\
\text { Spain }\end{array}$ & NR & NR & $3.1^{\mathrm{a}}$ & $\begin{array}{l}\text { Fernandez-Llario } \\
\text { and Carranza } 2000\end{array}$ \\
\hline EWB & $\begin{array}{l}\text { Las Villuercas, Caceres } \\
\text { Province, Spain }\end{array}$ & NR & 3.6 & NR & $\begin{array}{l}\text { Fernandez-Llario } \\
\text { and Mateos- } \\
\text { Quesada } 1998\end{array}$ \\
\hline EWB & $\begin{array}{l}\text { Las Villuercas, Caceres } \\
\text { Province, Spain }\end{array}$ & NR & 3.7 & NR & $\begin{array}{c}\text { Fernandez-Llario et } \\
\text { al. } 1999\end{array}$ \\
\hline EWB & Portugal & NR & 4.2 & NR & Fonseca et al. 2004 \\
\hline EWB & $\begin{array}{c}\text { Natural Park of Monfrague, } \\
\text { Spain }\end{array}$ & NR & 4.2 & NR & Garzon-Heydt 1992 \\
\hline EWB & $\begin{array}{c}\text { Southeastern } \\
\text { Niedersachsen, Germany }\end{array}$ & $5.9-8.3$ & $5.2-7.6$ & NR & Gethöffer 2005 \\
\hline EWB & $\begin{array}{c}\text { Western Eifel, } \\
\text { Rheinland-Pfalz, Germany }\end{array}$ & $5-7$ & $4.6-6.7$ & NR & Gethöffer 2005 \\
\hline EWB & $\begin{array}{l}\text { Pfälzerwald, Rheinland- } \\
\text { Pfalz, Germany }\end{array}$ & $5-7$ & $5.2-6.7$ & NR & Gethöffer 2005 \\
\hline EWB & Ebro River Valley, Spain & 5 & 5 & NR & Herrero et al. 2008 \\
\hline EWB & Pyrenees, Spain & 5 & 4.25 & NR & Herrero et al. 2008 \\
\hline EWB & $\begin{array}{c}\text { Cumberland-Wildparkes, } \\
\text { Austria }\end{array}$ & NR & 5.8 & NR & Martys 1982 \\
\hline
\end{tabular}




\section{Wild Pigs}

Table 1. Reproductive parameters reported for wild pig populations, including the type of wild pig (i.e., EWB - Eurasian wild boar, FER - feral hog, HYB - wild boar x feral hog hybrid), study location, mean ovulation rate as corpora lutea per sow, mean fetal litter size as number of live fetuses per sow, and mean postnatal litter size as live piglets per sow (i.e., a - no. of live piglets, $\mathrm{b}-$ no. of lactating teats). NR indicates that the parameter was not reported in a particular study. (Continued)

\begin{tabular}{|c|c|c|c|c|c|}
\hline $\begin{array}{l}\text { Type of } \\
\text { Wild Pig }\end{array}$ & Location & $\begin{array}{l}\text { Ovulation } \\
\text { Rate }\end{array}$ & $\begin{array}{l}\text { Fetal Litter } \\
\text { Size }\end{array}$ & $\begin{array}{l}\text { Postnatal } \\
\text { Litter Size }\end{array}$ & Reference \\
\hline EWB & $\begin{array}{l}\text { Maremma National Park, } \\
\text { Italy }\end{array}$ & NR & NR & $2.3-4.5^{\mathrm{ab}}$ & Massei et al. 1996 \\
\hline EWB & France & 5.3 & 4.6 & NR & Mauget 1972 \\
\hline EWB & Foret de Chize, France & 5.4 & 4.6 & $4^{\mathrm{a}}$ & Mauget 1980 \\
\hline EWB & Ticino, Switzerland & NR & 4.9 & NR & Moretti 1995 \\
\hline EWB & Hungary & $2-11$ & 6.7 & NR & $\begin{array}{c}\text { Náhlik and Sándor } \\
2003\end{array}$ \\
\hline EWB & $\begin{array}{c}\text { Somiedo Natural Park, } \\
\text { Spain }\end{array}$ & NR & NR & $3.3-3.8^{\mathrm{a}}$ & Nores et al. 2000 \\
\hline EWB & Germany & NR & 4.9 & NR & Oloff 1951 \\
\hline EWB & Tuscany, Italy & NR & 4.9 & NR & Pedone et al. 1991 \\
\hline EWB & Catalonia, Spain & 4.7 & 3.8 & NR & Rosell 1998 \\
\hline EWB & Spain & NR & 4.3 & NR & $\begin{array}{c}\text { Saez-Royuela and } \\
\text { Telleria } 1987\end{array}$ \\
\hline EWB & $\begin{array}{l}\text { Ili River Region, } \\
\text { Kazakstan }\end{array}$ & NR & 5.4 & NR & Pfeffer 1960 \\
\hline EWB & Lower Saxony, Germany & NR & 4.4 & NR & $\begin{array}{l}\text { Pohlmeyer and } \\
\text { Sodeikat } 2003\end{array}$ \\
\hline EWB & East Germany & 6.1 & 6.3 & NR & $\begin{array}{c}\text { Stubbe and Stubbe } \\
1977\end{array}$ \\
\hline FER & $\begin{array}{c}\text { Santa Catalina Island, } \\
\text { CA, USA }\end{array}$ & 6.7 & 5 & $2.1-3.1^{\mathrm{a}}$ & $\begin{array}{c}\text { Baber and Coblentz } \\
1986\end{array}$ \\
\hline FER & $\begin{array}{c}\text { Dye Creek Ranch, CA, } \\
\text { USA }\end{array}$ & 8.5 & 5.6 & NR & Barrett 1971 \\
\hline FER & Levy Co., FL, USA & 6.4 & 5.5 & $3.6^{\mathrm{b}}$ & $\begin{array}{c}\text { Belden and } \\
\text { Frankenberger } \\
1979\end{array}$ \\
\hline FER & $\begin{array}{l}\text { Fisheating Creek Wildlife } \\
\text { Refuge, FL, USA }\end{array}$ & 7.3 & 6.5 & $3.5^{\mathrm{b}}$ & $\begin{array}{c}\text { Belden and } \\
\text { Frankenberger } \\
1990\end{array}$ \\
\hline FER & $\begin{array}{c}\text { Auckland Island, New } \\
\text { Zealand }\end{array}$ & NR & 4 & $2.3^{\mathrm{a}}$ & Challies 1975 \\
\hline FER & $\begin{array}{l}\text { Isla Santiago, Galapagos } \\
\text { Islands, Ecuador }\end{array}$ & NR & 4.7 & $2.3-4.0^{\mathrm{a}}$ & $\begin{array}{c}\text { Coblenz and Baber } \\
1987\end{array}$ \\
\hline FER & $\begin{array}{c}\text { Kipalula Valley, Maui, } \\
\text { HI, USA }\end{array}$ & 7.7 & 5.9 & $3.1^{\mathrm{b}}$ & Diong 1982 \\
\hline FER & $\begin{array}{c}\text { South Island, New } \\
\text { Zealand }\end{array}$ & NR & 6.2 & $5.4^{\mathrm{b}}$ & $\begin{array}{c}\text { Dzieciolowski et al. } \\
1992\end{array}$ \\
\hline FER & Hawaii, HI, USA & NR & 6.4 & $4.3^{\mathrm{b}}$ & Giffin 1972 \\
\hline FER & $\begin{array}{c}\text { Yantabulla, NSW, } \\
\text { Australia }\end{array}$ & 8.5 & 6.3 & $1.9-4.1^{\mathrm{a}}$ & Giles 1980 \\
\hline
\end{tabular}


Table 1. Reproductive parameters reported for wild pig populations, including the type of wild pig (i.e., EWB - Eurasian wild boar, FER - feral hog, HYB - wild boar x feral hog hybrid), study location, mean ovulation rate as corpora lutea per sow, mean fetal litter size as number of live fetuses per sow, and mean postnatal litter size as live piglets per sow (i.e., a - no. of live piglets, $\mathrm{b}-$ no. of lactating teats). NR indicates that the parameter was not reported in a particular study. (Continued)

\begin{tabular}{|c|c|c|c|c|c|}
\hline $\begin{array}{l}\text { Type of } \\
\text { Wild Pig }\end{array}$ & Location & $\begin{array}{l}\text { Ovulation } \\
\text { Rate }\end{array}$ & $\begin{array}{l}\text { Fetal Litter } \\
\text { Size }\end{array}$ & $\begin{array}{l}\text { Postnatal } \\
\text { Litter Size }\end{array}$ & Reference \\
\hline FER & Warren, NSW, Australia & 8.9 & 6.4 & $3.0-5.1^{\mathrm{a}}$ & Giles 1980 \\
\hline FER & $\begin{array}{l}\text { Moree, NSW, Australia } \\
\text { Hakalau Forest National }\end{array}$ & $6.3-7.6$ & $4.6-7.0$ & NR & Giles 1980 \\
\hline FER & $\begin{array}{l}\text { Wildlife Refuge, Island of } \\
\text { Hawai'I, HI, USA }\end{array}$ & 8.5 & 6.7 & $5.0^{\mathrm{b}}$ & Hess et al. 2006 \\
\hline FER & $\begin{array}{c}\text { Namadgi National Park, } \\
\text { ACT, Australia }\end{array}$ & NR & NR & $2.5^{\mathrm{a}}$ & Hone 2002 \\
\hline FER & Illinois, USA & NR & 4,5 & NR & McCann 2003 \\
\hline FER & New Zealand & NR & $5-6$ & $4.1^{\mathrm{a}}$ & McIlroy 1989 \\
\hline FER & Hawaii, HI, USA & NR & 5.4 & $3.5^{\mathrm{a}}$ & Nichols 1962 \\
\hline FER & $\begin{array}{c}\text { Girilambone, NSW, } \\
\text { Australia }\end{array}$ & 7.4 & 6.7 & $4.9^{\mathrm{b}}$ & Pavlov 1980 \\
\hline FER & $\begin{array}{l}\text { Cape York Penninsula, } \\
\text { Queensland, Australia }\end{array}$ & 7.6 & 5.1 & $4.7^{\mathrm{b}}$ & Pavlov 1991 \\
\hline FER & $\begin{array}{c}\text { Prince of Wales Islands, } \\
\text { Australia }\end{array}$ & 5.8 & 5.3 & $4^{\mathrm{b}}$ & Pavlov 1991 \\
\hline FER & $\begin{array}{c}\text { New South Wales, } \\
\text { Australia }\end{array}$ & 8.6 & 7 & $5.2^{\mathrm{b}}$ & Pavlov 1991 \\
\hline FER & $\begin{array}{l}\text { Koscinska National Park, } \\
\text { NSW, Australia }\end{array}$ & NR & 6.6 & NR & Saunders 1993 \\
\hline FER & $\begin{array}{c}\text { Oxley Station, NSW, } \\
\text { Australia }\end{array}$ & NR & $6.4-7.4$ & NR & $\begin{array}{c}\text { Saunders and Giles } \\
1995\end{array}$ \\
\hline FER & Isla de Coco, Costa Rica & NR & 4.4 & NR & Sierra 2001 \\
\hline FER & $\begin{array}{c}\text { Merritt Island NWR, FL, } \\
\text { USA }\end{array}$ & 8.3 & 6.8 & $4.8^{\mathrm{b}}$ & Strand 1980 \\
\hline FER & Ossabaw Island, GA, USA & 7.5 & 4.9 & NR & Sweeney 1979 \\
\hline FER & Hobcaw Barony, SC, USA & 6.1 & 4.7 & NR & Sweeney 1979 \\
\hline FER & SRP, SC, USA & 10.5 & 8.4 & NR & Sweeney 1979 \\
\hline FER & SRP, SC, USA & 10.8 & 7.4 & NR & $\begin{array}{c}\text { Sweeney et al. } \\
1979\end{array}$ \\
\hline FER & $\begin{array}{c}\text { South Texas Plains, TX, } \\
\text { USA }\end{array}$ & $5.4-8.0$ & $4.4-6.3$ & NR & Taylor et al. 1998 \\
\hline FER & $\begin{array}{c}\text { Gulf Coast Prairies, TX, } \\
\text { USA }\end{array}$ & $5.0-7.1$ & $4.7-5.6$ & NR & Taylor et al. 1998 \\
\hline FER & Hobcaw Barony, SC, USA & NR & 5.3 & $4.3^{\mathrm{b}}$ & $\begin{array}{c}\text { Wood and } \\
\text { Brenneman } 1977\end{array}$ \\
\hline HYB & Tellico WMA, TN, USA & 6.8 & 4.7 & $4.2^{\mathrm{a}}$ & Conley et al. 1972 \\
\hline HYB & $\begin{array}{c}\text { GSMNP, NC and TN, } \\
\text { USA }\end{array}$ & 5.6 & 3 & $3.8^{\mathrm{b}}$ & Duncan 1974 \\
\hline HYB & Tellico WMA, TN, USA & NR & 4.9 & $4.5^{\mathrm{a}}$ & Henry 1966 \\
\hline
\end{tabular}




\section{Wild Pigs}

Table 1. Reproductive parameters reported for wild pig populations, including the type of wild pig (i.e., EWB - Eurasian wild boar, FER - feral hog, HYB - wild boar x feral hog hybrid), study location, mean ovulation rate as corpora lutea per sow, mean fetal litter size as number of live fetuses per sow, and mean postnatal litter size as live piglets per sow (i.e., a - no. of live piglets, $\mathrm{b}$ - no. of lactating teats). NR indicates that the parameter was not reported in a particular study. (Continued)

\begin{tabular}{|c|c|c|c|c|c|}
\hline $\begin{array}{l}\text { Type of } \\
\text { Wild Pig }\end{array}$ & Location & $\begin{array}{l}\text { Ovulation } \\
\text { Rate }\end{array}$ & $\begin{array}{l}\text { Fetal Litter } \\
\text { Size }\end{array}$ & $\begin{array}{l}\text { Postnatal } \\
\text { Litter Size }\end{array}$ & Reference \\
\hline HYB & $\begin{array}{c}\text { GSMNP, NC and TN, } \\
\text { USA }\end{array}$ & NR & 3 & $2.8-3.8^{\mathrm{ab}}$ & Johnson et al. 1982 \\
\hline HYB & $\begin{array}{c}\text { Monterey County, CA, } \\
\text { USA }\end{array}$ & NR & 5 & $4.2^{\mathrm{a}}$ & $\begin{array}{c}\text { Pine and Gerdes } \\
1973\end{array}$ \\
\hline HYB & $\begin{array}{c}\text { GSMNP, NC and TN, } \\
\text { USA }\end{array}$ & NR & 4.8 & $2.9^{\mathrm{a}}$ & $\begin{array}{c}\text { Singer and } \\
\text { Ackerman } 1981\end{array}$ \\
\hline HYB & $\begin{array}{c}\text { Cumberland Island, GA, } \\
\text { USA }\end{array}$ & NR & NR & $4^{\mathrm{a}}$ & $\begin{array}{c}\text { Singer and } \\
\text { Stoneburner } 1979\end{array}$ \\
\hline HYB & $\begin{array}{c}\text { GSMNP, NC and TN, } \\
\text { USA }\end{array}$ & NR & 4.8 & $3.0^{\mathrm{a}}$ & Singer et al. 1978 \\
\hline HYB & Aransas NWR, TX, USA & NR & 4.2 & NR & Springer 1977 \\
\hline HYB & $\begin{array}{c}\text { Cumberland Island, GA, } \\
\text { USA }\end{array}$ & 7 & NR & NR & $\begin{array}{l}\text { Warren and Ford } \\
1997\end{array}$ \\
\hline
\end{tabular}


Table 2. Farrowing periods observed in published studies of wild pig populations, including peak months of farrowing and the range of months over which some farrowing was observed.

\begin{tabular}{|c|c|c|c|c|}
\hline \multirow{2}{*}{ Location } & \multicolumn{2}{|c|}{ Farrowing Peak } & \multirow{2}{*}{ Range } & \multirow{2}{*}{ Reference } \\
\hline & Primary & Secondary $^{\mathrm{a}}$ & & \\
\hline $\begin{array}{c}\text { Santa Catalina Island, } \\
\text { CA, USA }\end{array}$ & Summer (Jun) & Fall (Nov) & $\begin{array}{l}\text { Apr-Jul; } \\
\text { Oct-Jan }\end{array}$ & $\begin{array}{c}\text { Baber and } \\
\text { Coblentz } 1986\end{array}$ \\
\hline $\begin{array}{c}\text { Dye Creek Ranch, CA, } \\
\text { USA }\end{array}$ & Fall (Nov) & Summer (Jul) & All year & Barrett 1978 \\
\hline Florida & Winter (Jan) & Spring (Apr) & All year & $\begin{array}{c}\text { Belden and } \\
\text { Frankenberger } \\
1989\end{array}$ \\
\hline Tuscany, Italy & $\begin{array}{l}\text { Spring (Apr- } \\
\text { May) }\end{array}$ & - & All year & Boitani et al. 1995 \\
\hline East Germany & $\begin{array}{l}\text { Spring (Mar- } \\
\text { May) }\end{array}$ & - & Jan-Aug & Briedermann 1971 \\
\hline $\begin{array}{c}\text { Southwestern Piedmont, } \\
\text { Italy }\end{array}$ & $\begin{array}{l}\text { Spring-Summer } \\
\text { (May-Jul) }\end{array}$ & - & All year & Durio et al. 1995 \\
\hline $\begin{array}{c}\text { South Island, New } \\
\text { Zealand }\end{array}$ & $\begin{array}{l}\text { Winter-Spring } \\
\text { (Jul-Nov) }\end{array}$ & Fall (Mar) & All year & $\begin{array}{l}\text { Dzieciolowski et } \\
\text { al. } 1992\end{array}$ \\
\hline $\begin{array}{c}\text { Doñana National Park, } \\
\text { Spain }\end{array}$ & $\begin{array}{l}\text { Winter-Spring } \\
\text { (Feb-Apr) }\end{array}$ & & & $\begin{array}{c}\text { Fernandez-Llario } \\
\text { and Carranza } 2000\end{array}$ \\
\hline $\begin{array}{c}\text { North and Central } \\
\text { Portugal }\end{array}$ & Spring & - & All year & Fonseca et al. 2004 \\
\hline $\begin{array}{l}\text { Natural Park of } \\
\text { Monfrague, Spain }\end{array}$ & Spring (Mar) & - & Feb-Apr & $\begin{array}{c}\text { Garzon-Heydt } \\
1992\end{array}$ \\
\hline $\begin{array}{c}\text { Southeastern } \\
\text { Niedersachsen, Germany }\end{array}$ & $\begin{array}{l}\text { Spring (Mar- } \\
\text { Apr) }\end{array}$ & - & Jan-Aug & Gethöffer 2005 \\
\hline $\begin{array}{c}\text { Western Eifel, } \\
\text { Rheinland-Pfalz, } \\
\text { Germany }\end{array}$ & $\begin{array}{l}\text { Spring (Mar- } \\
\text { Apr) }\end{array}$ & - & Dec-May & Gethöffer 2005 \\
\hline $\begin{array}{l}\text { Pfälzerwald, } \\
\text { Rheinland-Pfalz, } \\
\text { Germany }\end{array}$ & Spring (Mar) & - & Feb-Jul & Gethöffer 2005 \\
\hline Hawaii, HI, USA & Winter (Feb) & Summer (Jul) & All year & Giffin 1972 \\
\hline Tellico WMA, TN, USA & Winter (Jan) & Spring (May) & Dec-Jul & Henry 1966 \\
\hline $\begin{array}{c}\text { GSMNP, NC and TN, } \\
\text { USA }\end{array}$ & Spring (May) & Winter (Jan) & All year & Johnson et al. 1982 \\
\hline $\begin{array}{c}\text { Foret de Chize, France } \\
\text { (Unimodal Type) }\end{array}$ & $\begin{array}{l}\text { Spring (Apr- } \\
\text { May) }\end{array}$ & - & Jan-Sep & Mauget 1982 \\
\hline $\begin{array}{l}\text { Foret de Chize, France } \\
\text { (Bimodal Type) }\end{array}$ & $\begin{array}{l}\text { Summer-Fall } \\
\text { (Aug-Sep) }\end{array}$ & $\begin{array}{l}\text { Winter (Jan- } \\
\text { Feb) }\end{array}$ & Jan-Nov & Mauget 1982 \\
\hline Mt. Harte, New Zealand & Spring (Sep) & - & All year & McIlroy 1989 \\
\hline Ticino, Switzerland & Spring (Mar) & $\begin{array}{l}\text { Summer (Jun- } \\
\text { Jul) }\end{array}$ & All year & Moretti 1995 \\
\hline Hawaii, HI, USA & $\begin{array}{l}\text { Winter-Spring } \\
\text { (Jan-Apr) }\end{array}$ & - & All year & Nichols 1962 \\
\hline
\end{tabular}




\section{Wild Pigs}

Table 2. Farrowing periods observed in published studies of wild pig populations, including peak months of farrowing and the range of months over which some farrowing was observed. (Continued)

\begin{tabular}{|c|c|c|c|c|}
\hline \multirow{2}{*}{ Location } & \multicolumn{2}{|c|}{ Farrowing Peak } & \multirow{2}{*}{ Range } & \multirow{2}{*}{ Reference } \\
\hline & Primary & Secondary ${ }^{\mathrm{a}}$ & & \\
\hline $\begin{array}{l}\text { Cape York Penninsula, } \\
\text { Queensland, Australia }\end{array}$ & $\begin{array}{l}\text { Fall-Winter } \\
\text { (May-Jun) }\end{array}$ & Spring (Sep) & All year & Pavlov 1991 \\
\hline $\begin{array}{c}\text { Prince of Wales Islands, } \\
\text { Australia }\end{array}$ & Winter (Jul) & Spring (Sep) & All year & Pavlov 1991 \\
\hline $\begin{array}{c}\text { New South Wales, } \\
\text { Australia }\end{array}$ & Winter (Jul) & - & All year & Pavlov 1991 \\
\hline $\begin{array}{c}\text { Monterey County, CA, } \\
\text { USA }\end{array}$ & Spring (Mar) & Fall (Oct) & All year & $\begin{array}{c}\text { Pine and Gerdes } \\
1969,1973\end{array}$ \\
\hline $\begin{array}{c}\text { Koscinska National Park, } \\
\text { NSW, Australia }\end{array}$ & Summer (Feb) & - & All year & Saunders 1993 \\
\hline $\begin{array}{c}\text { GSMNP, NC and TN, } \\
\text { USA }\end{array}$ & $\begin{array}{l}\text { Spring-Summer } \\
\text { (Apr-Jun) }\end{array}$ & $\begin{array}{l}\text { Winter (Dec- } \\
\text { Jan) }\end{array}$ & All year & Singer et al. 1978 \\
\hline Aransas NWR, TX, USA & Spring (Mar) & - & Nov-Aug & Springer 1977 \\
\hline SRP, SC, USA & Winter (Feb) & Summer (Jul) & All year & $\begin{array}{c}\text { Sweeney et al. } \\
1979\end{array}$ \\
\hline TX, USA & Summer (Jul) & Winter (Feb) & All year & Taylor et al. 1998 \\
\hline
\end{tabular}


Table 3. Fetal sex ratios within wild pig litters. Data are presented as either total numbers in the sample or the ratio between the two sexes. Dashes indicate a lack of reported information.

\begin{tabular}{|c|c|c|c|c|}
\hline \multirow{2}{*}{ Location } & \multicolumn{2}{|c|}{$\begin{array}{c}\text { Fetal Sex } \\
\text { Number or (Ratio) }\end{array}$} & \multirow{2}{*}{ Significance } & \multirow{2}{*}{ Reference } \\
\hline & Female & Male & & \\
\hline $\begin{array}{c}\text { Santa Catalina Island, CA, } \\
\text { USA }\end{array}$ & - & - & $\mathrm{NS}^{\mathrm{a}}$ & Baber and Coblentz 1986 \\
\hline Tuscany, Italy & $(1.2)$ & $(1.0)$ & - & Boitani et al. 1995 \\
\hline Tellico WMA, TN, USA & 100 & 102 & NS & Conley et al. 1972 \\
\hline Perak and Johore, Malaysia & 18 & 24 & NS & Diong 1973 \\
\hline $\begin{array}{c}\text { Kipalula Valley, Maui, HI, } \\
\text { USA }\end{array}$ & 50 & 56 & $\mathrm{NS}^{\mathrm{a}}$ & Diong 1982 \\
\hline $\begin{array}{c}\text { Las Villuercas, Cáceres } \\
\text { Province, Spain }\end{array}$ & 102 & 112 & $\mathrm{NS}^{\mathrm{a}}$ & $\begin{array}{l}\text { Fernández-Llario et al. } \\
1999\end{array}$ \\
\hline Cáceres Province, Spain & $(1.0)$ & $(1.5)$ & NS & $\begin{array}{l}\text { Fernández-Llario and } \\
\text { Mateos-Quesada } 2005\end{array}$ \\
\hline $\begin{array}{l}\text { Natural Park of Monfrague, } \\
\text { Spain }\end{array}$ & 66 & 58 & NS & Garzon-Heydt 1992 \\
\hline Hawaii, HI, USA & 71 & 77 & NS & Giffin 1972 \\
\hline $\begin{array}{c}\text { Warren, New South Wales, } \\
\text { Australia }\end{array}$ & 131 & 207 & $<0.05^{\mathrm{a}}$ & Giles 1990 \\
\hline Ebro River Valley, Spain & 32 & 48 & NS & Herrero et al. 2008 \\
\hline Pyrenees, Spain & 31 & 22 & NS & Herrero et al. 2008 \\
\hline GSMNP, NC and TN, USA & 6 & 6 & NS & Johnson et al. 1972 \\
\hline Foret de Chize, France & 78 & 71 & $\mathrm{NS}^{\mathrm{a}}$ & Mauget 1982 \\
\hline Hungary & 15 & 12 & NS & Náhlik and Sándor 2003 \\
\hline Hawaii, HI, USA & $(1.0)$ & $(2.2)$ & - & Nichols 1962 \\
\hline SRP, SC, USA & 19 & 31 & NS & Sweeney 1970 \\
\hline SRS, SC, USA & 554 & 556 & $\mathrm{NS}^{\mathrm{a}}$ & This report \\
\hline TX, USA & 131 & 167 & $<0.05^{\mathrm{a}}$ & Taylor et al. 1998 \\
\hline Hobcaw Barony, SC, USA & 81 & 91 & NS & $\begin{array}{l}\text { Wood and Brenneman } \\
1977\end{array}$ \\
\hline
\end{tabular}

${ }^{\mathrm{a}}$ Reported in reference.

Table 4. Comparison of fetal litter size data collected from 636 pregnant sows from the SRS wild pig population. These data, collected between 1968 and 2003, were divided by the sow's age class.

Fetal Litter Size

Age Class of Sow

Number of Litters $\quad$ Mean $\quad$ Observed Range SD

$\begin{array}{ccccc}\text { Piglet } & 1 & 7 & 7 & - \\ \text { Juvenile } & 54 & 4.9 & 2-9 & 1.52 \\ \text { Yearling } & 147 & 5.4 & 1-11 & 1.79 \\ \text { Subadult } & 173 & 6.0 & 1-13 & 1.94 \\ \text { Adult } & 261 & 6.9 & 1-14 & 2.02 \\ & & & & 2.03\end{array}$




\section{Wild Pigs}

Table 5. Temporal comparison of the changes of litter size from the SRS wild pig population. The litter types included fetal litters, neonatal litters, and litters of piglets with one sow.

\begin{tabular}{cccccc}
\hline Type of Litter & $\begin{array}{c}\text { Number } \\
\text { of Litters }\end{array}$ & Mean & Observed Range & SD & $\begin{array}{c}\text { Mean Percent } \\
\text { Decrease from } \\
\text { Previous Type }\end{array}$ \\
\hline Fetal Litters & 636 & 6.1 & $1-14$ & 2.03 & - \\
Neonatal Litters & 64 & 5.4 & $1-11$ & 2.29 & 12 \\
$\begin{array}{c}\text { Litters of Piglets } \\
\text { with One Sow }\end{array}$ & 99 & 4.3 & $1-10$ & 2.27 & 20 \\
\hline
\end{tabular}

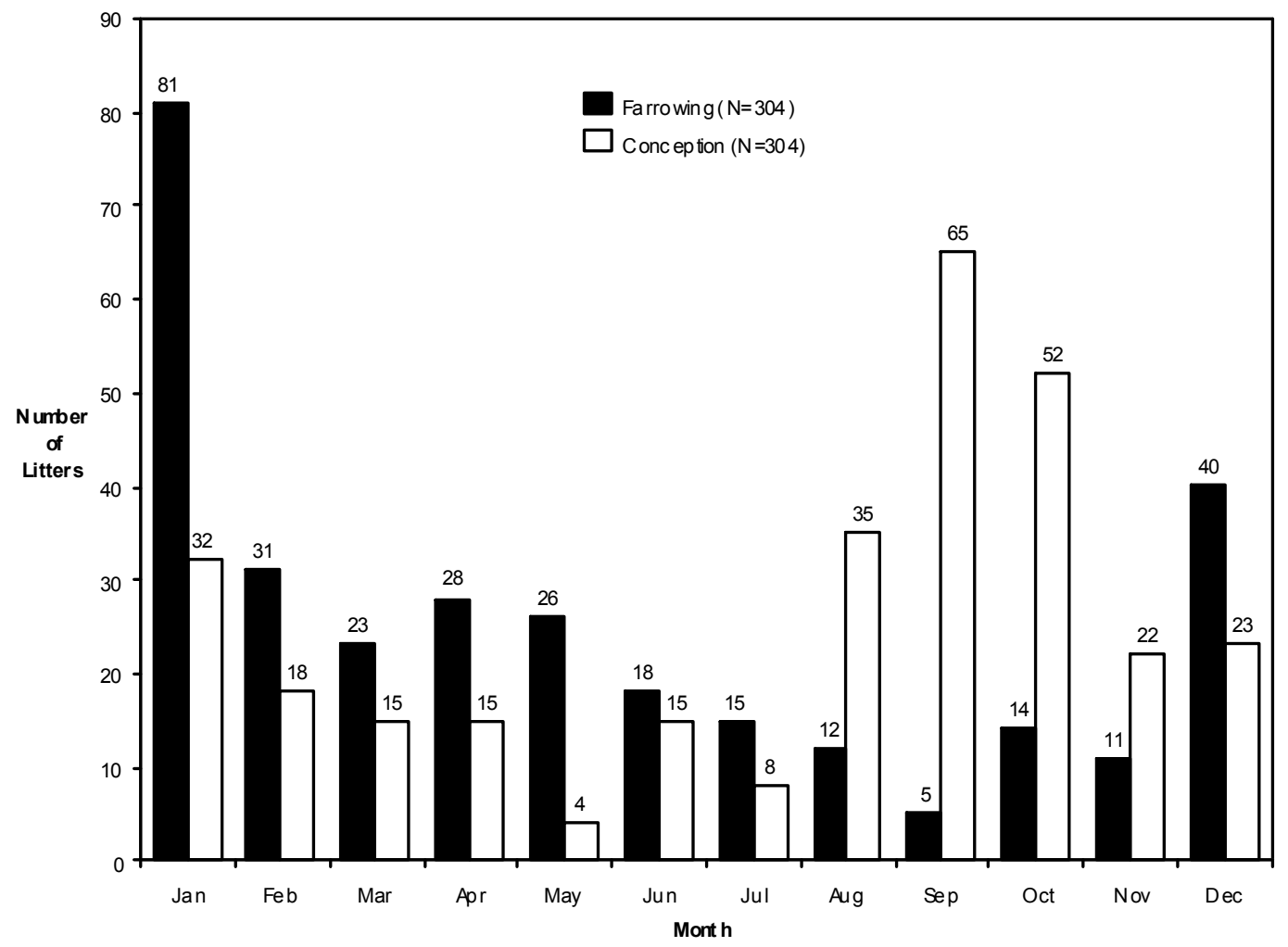

Fig. 1. Monthly histogram of numbers of conceptions and farrowings in the SRS wild pig population. Data calculated from a total of 304 fetal litters. 


\section{Literature Cited}

Abáigar, T. 1992. Parametres de la reproduction chez le sanglier (Sus scrofa) dans le sud-est de la péninsule iberique. Mammalia, 56(2):245-250.

Ahmad, E., J. E. Brooks, I. Hussain, and M. H. Khan. 1995. Reproduction in Eurasian wild boar in central Punjab, Pakistan. Acta Theriologica, 40(2):163-173.

Ahrens, M. 1984. Erganzende Untersuchungen zum Reproduktionsgeschehen beim Schwarzwild. Beitrage zur Jagd- und Wildforschung, 13(8):231-243.

Asdell, S. A. 1964. Patterns of mammalian reproduction. Cornell University Press, Ithaca, NY, USA.

ATI (Agricultural Training Institute). 2008. Annual report - International Training Center on Pig Husbandry. Agricultural Training Institute, Marawoy, Lipa City, Batangas, Philippines.

Aumaitre, A., J. P. Quere, and J. Peiniau. 1984. Influence du milieu sur la reproduction hivernale et la prolificite de la laie. Pp. 69-78. In F. Spitz and D. Pépin (eds.), Symposium International sur le Sanglier. Les Colloques de l'INRA 22, INRA, Toulouse, France.

Baber, D. W., and B. E. Coblentz. 1986. Density, home range, habitat use, and reproduction in feral pigs on Santa Catalina Island. Journal of Mammalogy, 67:512-525.

1987. Diet, nutrition, and conception in feral pigs on Santa Catalina Island. Journal of Wildlife Management, 51:306-317.

Baettig, M. 1988. Recherche et etude du Sanglier dans la Republique et Canton du Jura. Office des eaux et de la protection de la nature, Saint-Ursanne, Jura, Switzerland.

Barrett, R. H. 1971. Ecology of the feral hog in Tehama County, California. Ph.D. Dissertation, University of California, Berkeley, California.

1978. The feral hog at Dye Creek Ranch, California. Hilgardia, 46:283-355.

Barrett, R. H., and D. S. Pine. History and status of wild pigs, Sus scrofa, in San Benito, California. California Fish and Game, 67:105-17.

Barrett, R. H., and G. H. Birmingham. 1994. Wild pigs. Pp. D65-D70. In S. E. Hygnstrom, R. M. Timm, and G. E. Larson (eds.), Prevention and control of wildlife damage. Great Plains Agricultural Council, University of Nebraska, Lincoln, Nebraska.

Barrette, C. 1986. Fighting behavior of wild Sus scrofa. Journal of Mammalogy, 67(1):177-179.

Baubet, E. 1998. Biologie du sanglier en montagne: Biodemographie, occupation de l'espace et regime alimentaire. Ph.D Dissertation, Universite Claude Bernard, Lyon, France.

Belden, R. C., and W. B. Frankenberger. 1979. Brunswick hog study. Final performance report, P-R Project W-41-R, Study No. XIII-B-1. Florida Fresh Water Fish and Game Commission Wildlife Research Laboratory, Gainesville, Florida.

1989. History and biology of feral swine. Pp. 3-10. In N. Black (ed.), Proceedings: Feral pig symposium. April 27-29, Orlando, Florida. Livestock Conservation Institute, Madison, Wisconsin.

1990. Biology of a feral hog population in south central Florida. Proceedings of the Annual Conference of the Southeastern Association of Fish \& Wildlife Agencies, 44:231-249. 


\section{Wild Pigs}

Beuerle, W. 1975. Freilanduntersuchungen zum Kampf- und Sexualverhalten des Europaischen Wildschweines (Sus scrofa L.). Zeitschrift fur Tierpsychologie, 39(1-5):211-258.

Boitani, L., P. Trapanese, and L. Mattei. 1995. Demographic patterns of a wild boar (Sus scrofa L.) population in Tuscany, Italy. Journal of Mountain Ecology (Ibex), 3:197-201.

Briedermann, L. 1971. Zur Reproducktion des Schwarzwildes in der Deutschen Demokratischen Republik. Beitrage zur Jagd- und Wildforschung, 113(7):169-186.

- 1986. Schwarzwild. VEB Deutscher Landwirtschaftsverlag, Berlin, Democratic Republic of Germany.

Caley, P. 1997. Movements, activity patterns, and habitat use of feral pigs (Sus scrofa) in a tropical habitat. Wildlife Research, 24(1):77-87.

Challies, C. N. 1975. Feral pigs (Sus scrofa) on Auckland Island: Status and effects on vegetation and nesting sea birds. New Zealand Journal of Zoology, 2(4):479-490.

Cnaani, G. 1972. Studies on the ecology and the behavior of the wild boar (Sus scrofa lybicus, Gray, 1868) in the Mt. Meiron region. M.S. Thesis, Tel-Aviv University, Tel-Aviv, Israel.

Coblentz, B. E., and D. W. Baber. 1987. Biology and control of feral pigs on Isla Santiago, Galapagos, Ecuador. Journal of Applied Ecology, 24(2):403-418.

Conley, R. H., V. G. Henry, and G. H. Matschke. 1972. Final report for the European hog research project W-34. Tennessee Game and Fish Commission, Nashville, Tennessee.

Day, B. N. 1962. Reproduction of swine. Pp. 279-288. In E. S. E. Hafez (ed.), Reproduction in Farm Animals. $2^{\text {nd }}$ Edition. Lea \& Febiger, Philadelphia, Pennsylvania.

DEFRA (Department for Environment, Food and Rural Affairs). 2004. The ecology and management of wild boar in southern England. Central Science Laboratory, Hutton, York, United Kingdom.

Delcroix, I., R. Mauget, and J. P. Signoret. 1990. Existence of synchronization of reproduction at the level of the social group of the European wild boar (Sus scrofa). Journal of Reproduction and Fertility, 89:613-617.

Delgado, R., P. Fernandez-Llario, M. Azevedo, A. Beja-Pereira, and P. Santos. 2008. Paternity assessment in free-ranging wild boar (Sus scrofa) - Are littermates full-sibs? Mammalian Biology, 73(3):169-176.

de Poncins, V. E. 1914. How wild boars fight. Journal of the Bombay Natural History Society, 22:791-793.

de Vos, A., and A. Sassani. 1977. Eine Studie der Population des Schwarzwildes (Sus scrofa) in dem Mohammad Reza Shah Nationalpark. Zeitschrift für Jagdwissenschaft, 23(3):113-126.

Diong, C. H. 1973. Studies of the Malaysian wild pig in Perak and Jahore. Malayan Nature Journal, 26(3/4):120-151.

1982. Population biology and management of the feral pig (Sus scrofa L.) in Kipahula Valley, Maui. Ph.D. Dissertation, University of Hawaii, Honolulu, Hawaii.

Duncan, R. W. 1974. Reproductive biology of the European wild hog (Sus scrofa) in the Great Smoky Mountains National Park. M.S. Thesis, University of Tennessee, Knoxville, Tennessee. 
Durio, P., U. Gallo-Orsi, E. Macchi, and A. Perrone. 1995. Structure and monthly birth distribution of a wild boar population living in mountainous environment. Journal of Mountain Ecology (Ibex), 3:202-203.

Dzieciolowski, R. 1991. Ecological niches of five big ungulates in a forest tract. Folia Forestalai Polonica, Series A (Lesnictwo), 3:56-70.

Dzieciolowski, R. M., C. M. H. Clarke, and C. M. Frampton. 1992. Reproductive characteristics of feral pigs in New Zealand. Acta Theriologica, 37(3):259-270.

Fernández-Llario, P. 1996. Ecologia del jabali en Doñana: Parametros reproductivos e impacto ambiental. Ph.D. Dissertation, Universidad de Extremadura, Cacerces, Spain.

Fernández-Llario, P., and J. Carranza. 2000. Reproductive performance of the wild boar in a Mediterranean ecosystem under drought conditions. Ethology Ecology and Evolution, 12:335-343.

Fernández-Llario, P., J. Carranza, and P. Mateos-Quesada. 1999. Sex allocation in a polygynous mammal with large litters: the wild boar. Animal Behaviour, 58:1079-1084.

Fernández-Llario, P., and P. Mateos-Quesada. 1998. Body size and reproductive parameters in the wild boar Sus scrofa. Acta Theriologica, 43:439-444.

. 2005. Influence of rainfall on the breeding biology of wild boar (Sus scrofa) in a Mediterranean ecosystem. Folia Zoologica, 54(3):240-248.

Fonseca, C., P. Santos, A. Monzon, P. Bento, A. A. Da Silva, J. Alves, A. Silverio, A. M. V. M. Soares and F. Petrucci-Fonseca. 2004. Reproduction in the wild boar (Sus scrofa Linnaeus, 1758) populations of Portugal. Galemys, 16(Special Issue):53-65.

Frädrich, H. 1974. A comparison of behaviour in the Suidae. Pp. 133-143. In V. Geist and F. R. Walther (eds.), The behavior of ungulates and its relation to management. International Union for the Conservation of Nature and Natural Resources, Morges, Switzerland.

. 1984. Swine and peccaries. Pp. 76-108. In B. Grzimek (ed.), Grzimek's animal life encyclopedia. Volume 13: Mammals IV. Van Nostrand Reinhold Company, New York.

Gabor, T. M., E. C. Hellgren, R. A. Van Den Bussche, and N. A. Silvy. 1999. Demography, sociospatial behaviour and genetics of feral pigs (Sus scrofa) in a semi-arid environment. Journal of Zoology (London), 247:311-322.

Garzon-Heydt, P. 1992. Study of a population of wild boar Sus scrofa castilianus Thomas, 1912 in Spain, based on hunting data. Pp. 489-492. In B. Bobek, K. Perzanowski, and W. L. Regelin (eds.), Global trends in wildlife management. Transactions of the 18th International Congress of Game Biologists, Vol. II. Swiat Press, Krakow-Warsaw, Poland.

Gethöffer, F. 2005. Reproduktionsparameter und Saisonalitat der Fortpflanzung des Wildschweins (Sus scrofa) in drei Untersuchungsgebieten Deutschlands. DVM, Institut fur Wildtierforschung an der Tierarztlichen Hochschule Hannover, Hannover, Germany.

Giffin, J. G. 1972. Compilation of data on the annual breeding cycle of the feral pig in the rain forest on the Island of Hawaii (R), Project No. W-15-1, Job. No. II-A (12); Determination of daily movement patterns home range, growth and development of the feral pigs in the rain forest on the Island of Hawaii (R), Project No. W-15-1, Job. No. II-B (12). Hawaii Division of Fish and Game, Honolulu, Hawaii. 


\section{Wild Pigs}

Giles, J. R. 1980. The ecology of feral pigs in western New South Wales. Ph.D. Dissertation, Sydney University, Sydney, Australia.

Goulding, M. J. 2003. Wild boar in Britain. Whittet Books, Ltd., Suffolk, United Kingdom.

Graves, H. B., and K. L. Graves. 1977. Some observations on biobehavioral adaptations of swine. Pp. 103-110. In G. W. Wood (ed.), Research and management of wild hog populations: Proceedings of a symposium. Belle W. Baruch Forest Science Institute, Clemson University, Georgetown, South Carolina, USA.

Hagen, D. R., and K. B. Kephart. 1980. Reproduction in domestic and feral swine. I. Comparison of ovulatory rate and litter size. Biology of Reproduction, 22:550-552.

Hagen, D. R., K. B. Kephart, and P. J. Wangsness. 1980. Reproduction in domestic and feral swine. II. Interrelationships between fetal size and spacing and litter size. Biology of Reproduction, 23:929-934.

Hampton, J., J. R. Pluske, and P. B. S. Spencer. 2004. A preliminary genetic study of the social biology of feral pigs in south-western Australia and the implications for management. Wildlife Research, 31(4):375-381.

Hanson, R. P., and L. Karstad. 1959. Feral swine in the southeastern United States. Journal of Wildlife Management, 23(1):64-74.

Hartsock, T. G., and H. B. Graves. 1976. Neonatal mortality and nutrition-related mortality in domestic swine. Journal of Animal Science, 42:235-241.

Hellgren, E. C. 1993. Biology of feral hogs (Sus scrofa) in Texas. Pp. 50-58. In C. W. Hanselka and J. F. Cadenhead, (eds.), Feral swine: a compendium for resource managers: Proceedings of a conference. Texas Agricultural Experiment Station, College Station, Texas, USA.

Henry, V. G. 1966. European wild hog hunting season recommendations based on reproductive data. Proceedings of the Annual Conference of the Southeastern Association of Fish and Game Commissioners, 20:139-145.

. 1968. Length of estrous cycle and gestation in European wild hogs. Journal of Wildlife Management, 32(2):406-408.

Herrero, J., A. García-Serrano, and R. García-Gonzalez. 2008. Reproductive and demographic parameters in two Iberian wild boar Sus scrofa populations. Acta Theriologica, 53(4):355-364.

Hess, S. C., J. J. Jeffrey, D. L. Ball, and L. Babich. 2006. Efficacy of feral pig removals at Hakalau Forest National Wildlife Refuge. Transactions of the Western Section of the Wildlife Society, 42:53-67.

Hone, J. 2002. Feral pigs in Namadgi National Park, Australia: Dynamics, impacts and management. Biological Conservation, 105(2):231-242.

Imm, D. W., and K. W. McLeod. 2005. Plant Communities. Pp. 106-161. In J. C. Kilgo and J. I. Blake, editors. Ecology and management of a forested landscape: fifty years on the Savannah River Site. Island Press, Washington, D.C., USA.

Jenkins, J. H., and E. E. Provost. 1964. The population status of the larger vertebrates on the Atomic Energy Commission Savannah River Plant site. Office of Techical Services, Department of Commerce, Washington, D.C. 
Johnson, K. G., R. W. Duncan, and M. R. Pelton. 1982. Reproductive biology of European wild hogs in the Great Smoky Mountains National Park. Proceedings of the Annual Conference of the Southeastern Association of Fish and Wildlife Agencies, 36:552-564.

Kurz, J. C., and R. L. Marchinton. 1972. Radiotelemetry studies of feral hogs in South Carolina. Journal of Wildlife Management, 36:1240-1248.

Lapidge, S. J., B. Cowled and M. Smith. 2004. Ecology, genetics and socio-biology: Practical tools in the design of target-specific feral pig baits and baiting procedures. Proceedings of the Vertebrate Pest Conference, 21:317-322.

Martys, M. 1982. Gehegebeobachtungen zur Geburts- und Reproduktionsbiologie des Europaischen Wildschweines (Sus scrofa L.). Zeitschrift fur Saugetierkunde, 47(2):100-113.

Massei, G., P. V. Genov, and B. W. Staines. 1996. Diet, food availability and reproduction of wild boar in a Mediterranean coastal area. Acta Theriologica, 41:307-320.

Matschke, G. H. 1964. The influence of oak mast on European wild hog reproduction. Proceedings of the Annual Conference of the Southeastern Association of Fish and Game Commissioners, 18:35-39.

Mauget, R. 1972. Observations sur la reproduction du sanglier (Sus scrofa L.) a l'etat sauvage. Annales de Biologie Animal, Biochemique et Biophysique, 12(2):195-202.

1980. Regulations écologiques, comportementales et physiologiques (fonction de reproduction), de l'adaptation du sanglier, Sus scrofa L., au Milieu. Ph.D. Dissertation, L' Universite Francois - Rabelais de Tours, Orleans, France.

1982. Seasonality of reproduction in the wild boar. Pp. 509-526. In D. J. A. Cole and G. R. Foxcroft (eds.), Control of pig reproduction. Butterworth Science, London, United Kingdom.

Mauget, R., R. Campan, F. Spitz, M. Dardaillon, G. Janeau, and D. Pepin. 1984. Synthese des connaisances actuelles sur la biologie du sanglier, perspectives de recherche. Pp. 15-50. In F. Spitz and D. Pepin (eds.), Symposium International sur le Sanglier. Les Colloques de l'INRA 22. INRA, Toulouse, France.

Mayer, J. J. 2005. Wild hog. Pp. 325-330. In J. C. Kilgo and J. I. Blake, (eds.), Ecology and management of a forested landscape: fifty years on the Savannah River Site. Island Press, Washington, D. C., USA.

2006. Characterization and development of the male shoulder shield in an introduced wild pig population. 2006 National Conference on Wild Pigs, Mobile, Alabama. May 21-23. School of Forestry and Wildlife Sciences, Auburn University. Abstracts of Papers. p. 26.

Mayer, J. J., and I. L. Brisbin. 1991. Wild Pigs in the United States: Their history, comparative morphology, and current status. University of Georgia Press, Athens, Georgia, USA.

Mayer, J. J., F. D. Martin, and I. L. Brisbin, Jr. 2002. Characteristics of wild pig farrowing nests and beds in the upper Coastal Plain of South Carolina. Applied Animal Behaviour Science, 78(1):1-17.

McCann, B. 2003. The feral hog in Illinois. M.S. Thesis, Southern Illinois University, Carbondale, Illinois.

Mcllroy, J. C. 1989. Aspects of the ecology of feral pigs (Sus scrofa) in the Murchison area, New Zealand. New Zealand Journal of Ecology, 12:11-22.

Moretti, M. 1995. Birth distribution, structure and dynamics of a hunted mountain population of wild boars (Sus scrofa L.), Ticino, Switzerland. Journal of Mountain Ecology (Ibex), 3:192-196.

Mount, L. E. 1967. The climatic physiology of the pig. Monographs of the Physiological Society, 18:1-271. 


\section{Wild Pigs}

Nádlik, A., and G. Sándor. 2003. Birth rate and offspring survival in a free-ranging wild boar Sus scrofa population. Wildlife Biology, 9(Suppl. 1):249-254.

Nichols, L., Jr. 1962. Ecology of the wild pig. Federal Aid in Wildlife Restoration Final Report Project W5-R-13. Hawaii Department of Land and Natural Resources, Division of Fish and Game, Honolulu, Hawaii.

Nores, C., A. Fernandez Gil, and N. Corral. 2000. Estimación de la población de jabalí (Sus scrofa) por recuento de grupos familiares. Naturalia Cantabricae, 1:53-59.

Oloff, H. B. 1951. Zur Biologie und Okologie des Wildschweines. Beitrag zur Tierkunde und Tierzucht (Frankfurt am Main), 2(1):1-95.

Pavlov, P. M. 1980. The diet and general ecology of the feral pig (Sus scrofa) at Girilambone, N. S. W. M.S. Thesis, Monash University, Melbourne, Australia.

1991. Reproduction of feral pigs from Eastern Australia. Pp. 215-218. In B. Bobek, K. Perzanowski, and W. L. Regelin (eds.), Global trends in wildlife management. Transactions of the $18^{\text {th }}$ International Congress of Game Biologists, Vol. I. Swiat Press, Krakow-Warsaw, Poland.

Pedone, P., L. Mattioli, S. Mattioli, N. Siemoni, C. Lovari, and V. Mazzarone. 1991. Body growth and fertility in wild boars of Tuscany, central Italy. Transactions of the Congress of the International Union of Game Biologists, 20(2):604-609.

Pelton, M. R. 1976. Population studies of the European wild hog in the Great Smoky Mountains National Park (abstract only). Pp. 283. In Abstracts of the first conference on scientific research in national parks. November 9-13. U. S. Department of the Interior, National Park Service, New Orleans, Louisiana.

Pfeffer, P. 1960. L'ecologie du sanglier in Asie Central d'apres les researches d'A. A. Sloudsky. Revue d'Ecologie (La Terre et la Vie), 108:368-372.

Phillips, R. W. and J. H. Zeller. 1943. Sexual development in small and large types of swine. Anatomical Record, 85:387-400.

Pine, D. S., and G. L. Gerdes. 1969. Wild pig study in Monterey County, California. California Department of Fish and Game, Region 3, San Francisco, California.

. 1973. Wild pigs in Monterey County, California. California Fish and Game, 59:126-137.

Pohlmeyer, K., and G. Sodeikat. 2003. Population dynamics and habitat use of wild boar in Lower Saxony. Institute of Wildlife Research, School of Veterinary Medicine, Hannover, Germany.

Rosell, C. 1998. Biologia i ecologia del senglar (Sus scrofa L. 1758) a dues poblacions del nordest ibaric. Aplicacio a la gestio. Ph.D. Dissertation, University of Barcelona, Barcelona, Spain.

Saez-Royuela, C., and J. L. Telleria. 1987. Reproductive trends of the wild boar (Sus scrofa) in Spain. Folia Zoologica, 36:21-25.

Santos, P., P. Fernandez-Llario, C. Fonseca, A. Monzon, P. Bento, A. M. V. M. Soares, P. MateosQuesada, and F. Petrucci-Fonseca. 2006. Habitat and reproductive phenology of wild boar (Sus scrofa) in the western Iberian Peninsula. European Journal of Wildlife Research, 52(3):207-212.

Saunders, G. 1993. The demography of feral pigs (Sus scrofa) in Kosciusko National Park. Wildlife Research, 20(5):559-569. 
Saunders, G., and J. R. Giles. 1995. Ecological comparison of two wild pig populations in semi-arid and sub-alpine Australia. Journal Mountain Ecology (Ibex), 3:152-155.

Saunders, G., and B. Kay. 1991. Movements of feral pigs at Sunny Corner, New South Wales. Wildlife Research, 18:49-61.

SCWDS (Southeastern Cooperative Wildlife Disease Study). 2004. Feral/Wild Swine Populations 2004. Southeastern Cooperative Wildlife Disease Study, College of Veterinary Medicine, University of Georgia, Athens, Georgia.

Servanty, S., J. M. Gaillard, D. Allainé, S. Brandt, and E. Baubet. 2007. Litter size and fetal sex ratio adjustment in a highly polytocous species: The wild boar. Behavioral Ecology, 18:427-432.

Sierra, C. 2001. The feral pig (Sus scrofa, Suidae) in Cocos Island, Costa Rica: Composition of its diet, reproductive state and genetics (in Spanish). Revista de Biología Tropical, 49(3-4):1147-1158.

Singer, F. J., and B. B. Ackerman. 1981. Food availability, reproduction and condition of European wild boar in Great Smoky Mountains National Park. Research/Resource Management Report No. 43. Uplands Field Research Laboratory, Great Smoky Mountains National Park, Gatlinburg, Tennessee.

Singer, F. J., B. B. Ackerman, M. E. Harmon, and A. R. Tipton. 1978. Part I. Census, trapping, and population biology of European wild boar - 1977. Pp. 1-93. In Studies of European wild boar in the Great Smoky Mountains National Park: 1st annual report; a report for the Superintendent. Uplands Field Research Laboratory, Great Smoky Mountains National Park, Gatlinburg, Tennessee.

Singer, F. J., and D. Stoneburner. 1979. Feral pig management. Memorandum N1615. Uplands Field Research Laboratory, Great Smoky Mountains National Park, Gatlinburg, Tennessee.

Springer, M. D. 1977. Ecologic and economic aspects of wild hogs in Texas. Pp. 37-46. In G. W. Wood (ed.), Research and management of wild hog populations: Proceedings of a symposium. Belle W. Baruch Forest Science Institute, Clemson University, Georgetown, South Carolina, USA.

Strand, D. K. 1980. Reproductive ecology and behavior of the Florida feral hog (Sus scrofa). M.S. Thesis, Florida Institute of Technology, Melbourne, Florida.

Stubbe, W., and M. Stubbe. 1977. Vergleichende beitrage zur reproduktions und geburtsbiologie von Wildund Hausschewein Sus scrofa L., 1758. Beitrage zur Jagd- und Wildforschung, 10:153-179.

Sweeney. J. M. 1970. Preliminary investigations of a feral hog (Sus scrofa) population on the Savannah River Plant, South Carolina. Master's Thesis, University of Georgia, Athens, Georgia, USA.

Sweeney, J. M., J. R. Sweeney, and E. E. Provost. 1979. Reproductive biology of a feral hog population. Journal of Wildlife Management, 43:555-559.

Sweeney, J. M., J. R. Sweeney, and S. W. Sweeney. 2003. Feral hog, Sus scrofa. Pp. 1164-1179. In G. A. Feldhammer, B. C. Thompson, and J. A. Chapman (eds.), Wild mammals of North America: Biology, management, and conservation. The Johns Hopkins Univ. Press, Baltimore, Maryland.

Sweeney, J. R. 1979. Ovarian activity in feral swine. Bulletin of the South Carolina Academy of Science $41: 74$.

Sweeney, J. R., J. M. Sweeney, and S. W. Sweeney. 2003. Feral hog (Sus scrofa). Pages 1164-1179 In G. A. Feldhamer, B. C. Thompson, and J. A. Chapman (eds.), Wild Mammals of North America: Biology, Management, and Conservation. Johns Hopkins University Press, Baltimore, Maryland, USA. 


\section{Wild Pigs}

Taylor, R. B., E. C. Hellgren, T. M. Gabor, and L. M. Ilse. 1998. Reproduction of feral pigs in southern Texas. Journal of Mammalogy, 79:1325-1331.

Varley, M. A. 1995. The neonatal pig - development and survival. CAB International, Wallingford, United Kingdom.

Warren, R. J., and C. R. Ford. 1997. Diets, nutrition, and reproduction of feral hogs on Cumberland Island, Georgia. Proceedings of the Annual Conference of the Southeastern Association of Fish and Wildlife Agencies, 51:285-296.

Waithman, J. 2001. Guide to hunting wild pigs in California. California Department of Fish and Game, Wildlife Programs Branch, Sacramento, California.

Weiler, U., R. Claus, M. Dehnhard, and S. Hofacker. 1996. Influence of the photoperiod and a light reverse programme on metabolically active hormones and food intake in domestic pigs compared with a wild boar. Canadian Journal of Animal Science, 76(4):531-539.

Wood, G. W., and R. E. Brenneman. 1977. Research and management of feral hogs on Hobcaw Barony. Pp. 23-35 In G. W. Wood (ed.), Research and management of wild hog populations: Proceedings of a symposium. Belle W. Baruch Forest Science Institute, Clemson University, Georgetown, South Carolina, USA.

. 1980. Feral hog movements and habitat use in coastal South Carolina. Journal of Wildlife Management, 44:420-427.

Zimmerman, D. R., H. G. Spies, H. L. Self, and L. E. Casida. 1960. Ovulation rate in swine as affected by increased energy intake just prior to ovulation. Journal of Animal Science, 19:295-301. 
SRNL-RP-2009-00869

This page left blank intentionally 
Wild Pigs

\section{Biology of Wild Pigs:}

\section{Wild Pig Behavior}

John J. Mayer

Savannah River National Laboratory, Savannah River Nuclear Solutions, LLC, Savannah River Site, Aiken, South Carolina 29808

\section{Introduction}

The behavior of wild pigs (Sus scrofa) is unique among both native and introduced ungulates in North America. In many cases, the employment of successful management strategies developed for these other ungulates (e.g., deer) typically will not work for this invasive species. In the United States, management activities (e.g., control hunts) for white-tailed deer (Odocoileus virginianus) are often also used to concurrently deal with the wild pigs in the same area. For example, the public hunts (i.e., large-scale organized dog drives) at the Savannah River Site (SRS), South Carolina, were initiated to control the population size of the deer herd onsite. At the same time, that management effort was assumed to be adequate for the controlling the numbers within the site's wild pig population. However, between 1981 and 1993, while the deer herd size was kept in check, the site's wild pig population continued to steadily grow. Because of the wild pigs' behavioral response to that method of harvest (specifically the inability of the deer hounds to successfully "drive" wild pigs), it was not possible to remove the number of animals necessary to control the population. With respect to that management strategy, what worked for white-tailed deer, did not work for wild pigs. To be able to better manage wild pigs, it is important to understand their behavior, and therefore their responses to certain control activities and techniques.

Wild pigs are very intelligent and secretive. In addition, these animals are adaptive ecological generalists, capable of exploiting a wide variety of geographic locations, habitats and forage resources (Prater 1965, Rolls 1969, Eisenberg 1981, Land Protection 2001). Frädrich (1974) further observed that wild pigs were more difficult to study than other ungulates because of their "intelligence, shyness and vigilance combined with an acute sense of smell and hearing."

In spite of these challenges, the basis for documenting the understanding of wild pig behavior has evolved dramatically over the past three decades, contributing significantly to our understanding of these animals. Prior to the late 1960s, behavioral studies of wild pigs had been based by and large on work conducted on domestic swine or captive wild pigs. A few early studies (e.g., Stegeman 1938, Oloff 1951, Sludskii 1956, Hanson and Karstad 1959) were exceptions to this. In general, however, the lack of intensive field studies was attributed to the fact that wild pigs were regarded everywhere as a pest and were therefore heavily hunted to keep their numbers in control. This drove these animals to adopt a nocturnal activity pattern and frequently seek shelter in heavy, dense cover, making behavioral studies difficult if not impossible to conduct (Frädrich 1974). In spite of those challenges, a number of behavioral studies of free-ranging wild pigs have been completed since that time (e.g., Barrett 1971, Baber 1977, Van Vuren 1984, Dardaillon 1988, Saunders and Kay 1996, Caley 1997, Fernández-Llario 2004).

The purpose of this paper is to provide a general overview of wild pig behavior. Several topical areas were focused on and addressed in this review, with the intention of providing a basis for understanding wild pig behavior within the context of better managing these animals in control scenarios. In addition to that obtained from the scientific and popular literature, data or information on wild pig behavior from the SRS has also been included. There are three types of wild pigs in United States: Eurasian wild boar, feral hogs (i.e., wild pigs solely of domestic ancestry), and hybrids between these two types. Some behavioral variation does exist among these three types; however these will be treated as one species in the following sections unless otherwise noted for a specific example. 
SRNL-RP-2009-00869

\section{Results/Discussion}

The different aspects of wild pig behavior have been categorized into the following groupings: social unit organization, habitat utilization, daily activity patterns, movement patterns, modes of mobility, home range, male-male competition, maternal behavior, resting/loafing beds, mannerism and attitudes, vigilance behavior, vocalizations, wallowing, rubbing, symbiotic grooming behavior, scent marking, and senses. Each of these groupings is discussed separately in the following sections:

Social Unit Organization - Although not as gregarious as other ungulates (e.g., Bovidae), wild pigs are by their nature social animals. This statement is based on the fact that the species is typically found in groups composed of two or more individuals. Within wild pig populations, the basic social unit is the sow and her litter (i.e., the family group). Males are usually solitary, except when participating in breeding groups; however, groups of two or more mature boars do occur (Kurz 1971, Sweeney et al. 2003, Hughes 1985). Dardaillon (1988) categorized the social units for wild pigs into eleven groupings as follows: single adults, adult groups, single subadults, subadult groups, groups of both adults and subadults, basic family groups (one adult with piglets), "sounders" (several adults with piglets), extended family groups (adults with both piglets and subadults), single piglets, piglet groups, and subadult and piglets groups.

Wild pig group sizes (i.e., two or more animals) vary greatly among populations, but typically average from 3 to 9 and range from 2 up to 30 or more individuals (Eisenberg and Lockhart 1972, Duncan 1974, Barrett 1978). Most of these are composed of single or multiple family groups (Barrett 1978, Eisenberg 1981, Dardaillon 1988). Multiple family groups are organized around two or three reproductively mature highly-related females and their litters, and can contain up to three generations of related animals, including subadults from previous litters (Barrett 1978, Spitz 1986, Lapidge et al. 2004, Spencer et al. 2005). In addition, genetics studies have also shown the existence of surrogacy of young not born within the family group. Multiple paternities were also found to be tolerated within the same group (Lapidge et al. 2004, Spencer et al. 2005). The size of wild pig groups in an area varies depending upon season, habitat and predation (Dardaillon 1988, Eisenberg and McKay 1974). Fernández-Llario et al. (1996) reported that group size reached a maximum during the peak farrowing season. Diong (1982) also noted that wild pig populations with higher reproductive success form larger family groups. Very large groups (i.e., up to $100+$ animals) of wild pigs do occur (Prater 1965, Lekagul and McNeely 1988). Such groups can occasionally be observed in situations of a concentrated attractant (e.g., food resources such as agricultural crops, waterholes in arid areas or during dry seasons). These oversized groups are typically only a temporary localized phenomena and do not persist beyond the immediate site of the attraction (Frädrich 1984).

Although solitary sightings can include either sex or any age class of wild pig, most are composed of mature boars. Most studies have reported that adult males make up from 70 to $90 \%$ of the solitary wild pig sightings (e.g., Challies 1975, Baber 1977, Saunders 1988, Braza and Alvarez 1989). In contrast to these findings, Singer et al. (1978) reported that adult males made up only $13.5 \%$ of those sightings. The reason for that apparent inconsistent observation was not provided. Solitary mature sows are uncommon and thought to usually consist of pregnant sows about to give birth (Baber 1977). Also uncommon, solitary immature pigs are probably either orphaned, temporarily separated from their family group, or in the process of dispersing from their family group.

Depending upon the sex and age of an animal, an individual may temporarily occupy any one of several of Dardaillon's (1988) aforementioned categories. Sows become solitary to prepare for and give birth to their young (Kurz and Marchinton 1972). Following the birth, a sow typically remains alone with her litter until around the time when weaning occurs (i.e., about three to four months of age). After the litter is weaned, two or more sows usually associate and form a larger social unit. These multiple family groups remain more or less stable until breeding activity begins and boars join the sows. At the time of weaning, regular excursions away from the family group are begun by the piglets. Dispersal of young from these groups is a passive process, occurring at about five to ten months of age (Crouch 1983, Hughes 1985). Truvé and Lemel (2003) reported the dispersal time from the family group can occur as late as 16 months of age. The young males are thought to leave the group either voluntarily or by being chased away by older boars 
(Nasimovic 1966, Snethlage 1982). The reason for the dispersal of the young females is still not completely known. Some researchers believe that the young females are also chased out the family group (Gundlach 1968), while others have stated that they stay with the sow for an indefinite period of time (Frädrich 1974). Kaminski et al. (2005) reported that females generally remained with the mother after weaning. After breeding is completed, any remaining shoats continue to follow their mother until just prior to the birth of the sow's new litter. Kaminski et al. (2005) reported that after leaving their natal group, females formed new kin groups with their female siblings. Subsequent to their leaving the family group, boars apparently maintain a solitary existence except for participation in breeding activity. As mature boars get older, their tendency toward maintaining this isolated way of life becomes more pronounced (Frädrich 1974).

Habitat Utilization - Wild pigs occupy and exploit a wide variety of habitats (Eisenberg 1981). The general habitat requirements for this species over most of its range include reliable and adequate seasonally-available forage resources (e.g., mast production during the fall and winter months) and daily access to well-distributed water, shade and escape cover on a year-round basis (Pullar 1950, Wodzicki 1950, Pine and Gerdes 1973, USDA 1981, Baber and Coblentz 1986, Barrett 1982, Choquenot et al. 1996). Given those attributes, wild pigs can thrive as readily in plains as in the mountains, in swamps as well as relatively dry steppes, in remote areas as well as in densely populated areas where they actually thrive close to civilization. Such habitats can range in elevation from sea level up to $4000 \mathrm{~m}$ above msl (Nasimovic 1966, Frädrich 1974, 1984). In fact, as the numbers of these animals in Europe have increased recently, wild pigs have established populations in high alpine/mountainous areas that have not been recently occupied by these animals (Durio et al. 1995, Baubet et al. 2004). Wild pigs are comfortable on flat to very steep terrain. However, these animals do not tend to inhabit deserts, high mountain areas with substantial winter snowfall, or intensive agricultural areas where cover is scarce (Waithman 2001). Throughout its range, the wild pig has shown a preference for riparian and wetland habitats (e.g., forested swamps, bottomland hardwoods, emergent marshes, sloughs, stream/river drainage corridors) as well as mesic upland hardwood forest (e.g., Kurz 1971, Graves 1984, Saunders and Kay 1996, Caley 1997, Laurance and Harrington 1997, Mitchell and Mayer 1997, Dexter 1998, Friebel and Jodice 2009, Sparklin 2009). In fact, the absence of available surface water in an area will effectively preclude the local establishment of this species (Dickson et al. 2001). In spite of that limiting variable, there has been a recent expansion of wild pigs into a number of xeric or semiarid areas of the southwestern United States (Adkins and Harveson 2006, 2007). Other habitats (e.g., pine/conifer forest, arid scrub brush, chaparral, grasslands) are utilized, but typically only on a temporal basis. However, Sparklin (2009) found that wild pigs at Fort Benning, Georgia, used habitats, with one exception, in proportion to the availability at that site. The one exception was upland hardwood forest, which the pigs were found to strongly avoid. That habitat type at Fort Benning had an open understory with little cover, combined with a high level of human activity; the combination of those factors was thought to be the reason for this unexpected avoidance of a mast-producing area that is typically preferred by this species. Throughout the species range, wild pig habitats are strongly associated with cover (DEFRA 2004). With respect to the sexes, Spitz and Janeau (1995) found that females showed a preference for denser habitats than males, which spend more time in the open. Wild pigs regularly modify their habitat use within their home range based on climatic conditions and the availability of food and water (Kurz and Marchinton 1972, Wood and Brenneman 1980, Baber and Coblentz 1986, Choquenot et al. 1996, Dexter 1998). Abrupt or seasonal changes in habitat use by wild pigs in an area are often related to food availability and dietary shifts (Sweeney 1970, Kurz and Marchinton 1972, Graves and Graves 1977, Barrett 1978). In addition, wild pigs will readily adjust to habitat changes caused by fire, logging, and natural catastrophes, except those that result in a loss of mast (USDA 1981). Extreme flooding and heavy snowfalls can also cause these animals to move either up or down in elevation in an area to find suitable habitat (Frädrich 1974).

Daily Activity Patterns - The daily activity patterns of wild pigs vary by location. Frädrich (1974) stated that because man nearly always and everywhere exercises influence on wild pig populations, it is difficult to regard them as either diurnal or nocturnal. Both Kurz and Marchinton (1972) and Wood and Brenneman (1977) reported that wild pigs were largely diurnal. Gundlach (1967) further observed that in relatively undisturbed areas, wild pigs seem to trend toward diurnal activity. However, intense hunting pressure or human activity during the day will drive pigs to become more nocturnal in their activity patterns (Stegeman 1938, Hanson and Karstad 1959, Choquenot et al. 1996, Waithman 2001, Pei 2006). Conley et al. (1972) and Singer et al. (1981) both reported that wild pigs in the southern Appalachians (i.e., an area with 
increased hunting pressure on this species) were more active nocturnally on a year-round basis. Populations of wild boar in Europe have also been reported to be primarily nocturnal, lying up during the day in dense cover (Spitz 1986, Boitani et al. 1994, Lemel et al. 2003, DEFRA 2004). Lemel et al. (2003) even noted that wild boar in Sweden use sunset as an apparent cue for arousal. Mersinger and Silvy (2007) reported that pigs moved greater distances away from both water sources and cover during the night. In general, wild pigs tend toward a seasonally driven activity pattern. Kurz (1971) reported that wild pigs are typically diurnal during the fall, winter and spring months, with activity peaks in early morning and late afternoon and a reduction at midday. During the summer months, the diurnal activity is reduced and nocturnal activity is increased. This shift may be a behavioral means of these animals controlling their body temperature. This pattern is more evident in males than in females (Crouch 1983, Hughes 1985). Wild pigs in California, which tend to be almost exclusively nocturnal during summer, are most active on moonlit nights (Waithman 2001). Similarly, wild pigs elsewhere have been found to be significantly more active on moonlit nights than on dark nights (Pavlov 1980, Mcllroy 1989). The daily activity patterns also vary between the sexes. Sows maintain a relatively constant activity for prolonged periods, while boars exhibit brief bursts of movement followed by a lengthily periods of relative inactivity (Crouch 1983). The activity pattern of sows may vary from the norm during farrowing. Kurz (1971) stated that limited data suggested that sow significantly reduced their daily movements approximately one month before farrowing. In contrast to this finding, Crouch (1983) found no evidence that sows reduced their daily movements during their farrowing period. Typical of a number of ungulate species under captive conditions, groups of wild pigs tend to exhibit spontaneous outbursts of activity, consisting of the animals suddenly rushing around the pen together (Hediger 1964).

Movement Patterns - The movements of wild pigs appear to be characteristic of general wandering or drifting, but are restricted to a defined area (i.e., home range) over periods of time. This wandering or drifting type of movement behavior is probably in response to the following: food availability, population density, reproductive activity, quality and interspersion of habitat, season, climatic conditions, disturbance by humans and social organization (Conley et al. 1972, Kurz and Marchinton 1972, Pavlov 1980, Crouch 1983, Hughes 1985, Choquenot et al. 1996). For example, during poor mast years, wild pigs can become nomadic in their search for alternative forage resources, with mean hourly movement increasing five-fold (Singer et al. 1981). Intersexual differences in daily movements are apparent, with males being consistently more mobile than sows (Kurz and Marchinton 1972, Crouch 1983, Hughes 1985, McIlroy 1989). Immature pigs were also significantly more active than adults (McIlroy 1989). Barrett (1978) noted that barrows (i.e., castrated boars), which did not expend any energy on reproduction and thus spent less time foraging, tended to travel even shorter distances than sows. Wild pigs generally do not move very far in response to minor disturbance, including infrequent hunting, and usually return to their home ranges shortly afterward (Maillard and Fournier 1995, Choquenot et al. 1996, Sodeikat and Pohlmeyer 2003). Mean daily movement was less after disturbance from human pressure $(0.2 \mathrm{~km})$ compared to movement with no disturbance $(0.6 \mathrm{~km})$ (Singer et al. 1981). However, these animals will permanently move to more remote locations, up to five kilometers away, in response to intensive and prolonged disturbances (e.g., large-scale hunting or other control activities) (Choquenot et al. 1996).

Sodeikat and Pohlmeyer (2004) reported that live-trapped wild piglets fled between 0.2 and $4.6 \mathrm{~km}$ from the trap site to available escape cover after being released. In addition, those piglets that were trapped and released for a second time fled shorter distances. Regardless of being a first or second capture, all animals stayed within their home range to find escape cover. After leaving these hiding places, these piglets were found to use well-known paths to join up with their family groups within a short time.

The movement by wild pigs over time typically does not entail long distances. However, in some instances, such long-distance movement can be in response to a stimulus (e.g., a localized high-quality forage resource, intense hunting pressure) (Banoğlu 1952, Choquenot et al. 1996). For example, wild pigs will travel up to 10-18 $\mathrm{km}$ or more in a day to reach fields with crops (Pullar 1950, Conley et al. 1972, Diong 1973, Barrett 1971, Giles 1980, Frädrich 1984, Mayer and Brisbin 1991). In addition, based on genetics data, Lapidge et al. (2004) reported that pigs would move distances in the order of $100+\mathrm{km}$ within days to breed in Queensland, Australia. One animal in Poland was even found to have moved over $250 \mathrm{~km}$ (Andrzejewski and Jezierski 1978). Another animal in Australia moved at least $340 \mathrm{~km}$ in a 3-year period 


\section{Wild Pigs}

(Giles 1977). Cargnelutti et al. (1992) found that, although wild pigs are largely sedentary, long distance dispersion occurred more often in this species than for any other European ungulate.

The different parts of a wild pig's home range are connected by a network of well-defined paths, which are used on a regular basis (Hanson and Karstad 1959, Frädrich 1974). Barrett (1971) noted that wild pigs will continue to confine their travels to such defined trails, even when they cross wide, open areas. He further noted that most wild pig trails follow the shortest possible route from one point of interest to another (e.g., bedding area, water source, feeding area), regardless of the topography or vegetation. For example, wild pigs will even establish and use trails that go straight up a steep hill (e.g., 60-degree slopes) to reach such locations (Nichols 1962, Kramer 1971, Waithman 2001). Wild pigs also utilize the trails made by other large mammals (e.g., white-tailed deer or range cattle) as well as manmade hiking trails, foot paths, and unpaved secondary roads (Graves 1984, J. J. Mayer, unpubl. data). Dardaillon and Beugnon (1987) reported that, in general, wild pigs preferred to move through natural/undeveloped rather than cultivated lands, and would skirt around water in their travels.

Modes of Mobility - Locomotion in wild pigs follows the standard unguligrade cursorial diagonal pattern typical of the Artiodactyls. Further, wild pigs exhibit the three basic symmetric movement gaits (patterns of footfalls) of ungulates including walking, trotting and galloping. In addition, the faster non-walking gaits visually include a "bouncing" trot, a "rocking" lope and a "steady/flat" flex-extension gallop or run. However, by comparison with ruminant artiodactyls, the cursorial ability in suids is at best modest (Vaughn 1986). A wild pig that is walking will typically place its feet in a heel-to-toe pattern such that the hind prints often almost perfectly overlap the front prints. The footfalls also straddle the medial line of the path being traveled. When galloping, a wild pig will often place their footfalls in groups of four with a further distinct pairing of the front and rear pairs. These animals normally travel at a rate of 5 kilometers per hour (Barrett 1978). However, wild pigs are sure-footed, rapid runners and can travel relatively fast over open ground, reaching speeds of up to 40-50 kilometers per hour (Rue 1968, Elman 1974, Robb 1989, Nowak 1999). Barrett (1971) reported that two feral sows, when alarmed, trotted and galloped approximately 5 kilometers in less than 20 minutes (a speed of 15 kilometers per hour). Spitz and Janeu (1990) reported that movement slower than 1 kilometer per hour corresponded to feeding, wallowing, exploring and marking, while travel faster than 2 kilometers per hour included escaping, excursion and dispersal movements. In addition, given their cursorial capabilities and general body shape (i.e., a "running wedge"), wild pigs are able to maneuver at high speeds into and through seemingly almost impenetrable thickets and cover (Banoğlu 1952, Rue 1968).

In addition to being quick-footed on the ground, larger wild pigs can also physically jump over barriers as high as one meter. This ability is not as visually graceful as in other ungulates, but is no less successful in crossing such vertical impediments to travel. This can include wire-mesh and solid fencing as well as other obstacles (Hennig 1981, J. J. Mayer, unpubl. data). These animals can also jump/climb their way over trap walls up to approximately two meters in height (P. E. Johns, pers. comm., J. J. Mayer, unpubl. data).

Wild pigs are also very good, strong swimmers (Matschke and Hardister 1966, Rue 1968, Stephen 1968, Nowak 1999). As such, these animals can easily traverse medium- to large-sized rivers and channels, being able to swim across open waters up to 6-7 kilometers in width (Andrzejewski and Jezierski 1978, Banoğlu 1952, Frädrich 1984). For example, on a number of occasions, wild pigs have been observed to successfully swim across the Savannah River between Georgia and South Carolina in order to evade packs of hunting dogs (Mayer and Brisbin 1991). In addition to rivers and smaller bodies of water, wild pigs are also known to swim across open ocean to reach offshore islands (Frädrich 1984). This is documented by the fact that a number of wild boar have been observed making the crossing to the island of Oléron after swimming at least 1.6 kilometers through open salt water off of the French coast (Bourlière 1970). Thus, contrary to earlier beliefs (Kellogg 1939), water is typically not a hindrance or barrier to movement in this species. However, in spite of this ability, wild pigs will often choose to go around rather than across open water (Kurz 1971, Schortemeyer et al. 1985, Dardaillon and Beugnon 1987).

Home Range - Wild pigs exhibit a home range behavior, in that the movements of these animals are generally restricted to a defined area over an extended period of time. However, a lot of variation in this behavior has been reported by different researchers to date. In general, wild pigs show a general trend 
toward sedentary habits; however, depending upon ecological conditions, these animals may roam about widely in search of better forage conditions (Frädrich 1974, Giles 1980, Pavlov 1980). In addition, periodic irregular shifts in home range occur within this species (Barrett 1978, Wood and Brenneman 1977).

The home range size in wild pigs is variable (Table 1). Typical home ranges in this species cover an area of about $10 \mathrm{~km}^{2}$ (Table 1) and are between 1 to $9 \mathrm{~km}$ in length on a side (Kurz 1971, Saunders 1988). However, home ranges as large as $154 \mathrm{~km}^{2}$ have been reported (Maillard and Fournier 1995). The home range size is determined by a mixture of factors including the absolute and spatial availability of food, water and escape cover, the animal's body weight, and the local density of pigs (Singer et al. 1981, Diong 1982, Saunders 1988, Caley 1993, Massei et al. 1997, Saunders and McLeod 1999). For example, wild pigs inhabiting arid shrub-scrub/woodland areas with poor food supplies have notably larger home ranges than do pigs occupying mesic forested environments with ample forage resources. Home ranges in wild pigs typically increase in size from daily to seasonal, and then to aggregate annual areas utilized. In addition, Gaston et al. (2008) reported that intense hunting pressure causes wild pigs to decrease their home range in an attempt to avoid the hunters.

Boars have larger daily, seasonal and overall home ranges than sows (Choquenot et al. 1996). Sterner (1990) reported that home ranges for boars were 2.5 to 4 times larger than those for sows. There is also greater variation in the male home ranges compared to female home ranges. In contrast to this, Saunders and McLeod (1999) reported that, when the effect of body mass was taken into account, there were no sexual differences in the home ranges of wild pigs. Kurz (1971) noted that boars are given to making excursions beyond their established home range boundaries and then return; sows typically do not exhibit this behavior. Home ranges of boars and sows also overlap extensively between and within the sexes. This is true of the overall range as well as core areas (Baber and Coblentz 1986, DEFRA 2004). However, Adkins and Harveson (2007) reported that range overlap was higher within than between the sexes in wild pigs. Barrett (1971) and Saunders (1988) both found that the home ranges for barrows (i.e., neutered males) were similar to those for females. Kurz (1971) noted that sows appear to reduce their home range approximately one month before farrowing. Singer et al. (1981) reported that sows can also significantly reduce their home ranges when nursing their young. Barrett (1978) further observed that sows with young less than 3 weeks old rarely moved more than $0.5 \mathrm{~km}$ from their farrowing nest location. Sparklin (2009) observed that adult sows used a small portion of their home range from immediately before until approximately 2 weeks after farrowing.

The shapes of a wild pig's home range has been described as ranging from being generally circular to elongate (Singer et al. 1981, McIlroy 1989), and are determined by the local terrain, floral/habitat cover and available resources. Singer et al. (1981) also reported that home ranges were generally more circular in summer than in winter. Kurz (1971) reported that there was a tendency for wild pig home ranges to be bordered by manmade or natural topographic features (e.g., railroad tracks, streams). The use of the area encompassed by the home range is localized or patchy, with the different parts of their home range being connected by a network of paths which are regularly used (Hanson and Karstad 1959, Barrett 1971, Frädrich 1974). One or more core areas, each approximately $<1 \mathrm{~km}^{2}$ in size, exist within a wild pig's home range. Core areas typically contain preferred resting areas. The core areas of males were more scattered within the entire range and less intensively used than those of female (Boitani et al. 1994). Sparklin (2009) found that family groups used well-defined core areas within the social unit's home range. These core areas were located in dense thickets in both pine uplands and hardwood bottoms.

Seasonal variations have also been noted in the home range sizes for wild pigs; although these differences are not consistent and vary depending upon the same suit of factors that generally determine home range size. In general, seasonal home ranges for wild boar in Italy were smallest when food was abundant (Boitani et al. 1994). Singer et al. (1981) reported that summer home ranges for wild pigs in the Great Smoky Mountains National Park (GSMNP) did not differ significantly from the winter ones. However, these authors did note that home ranges in that location did increase significantly during one winter period when the mast crop failed. Sterner (1990) also reported that seasonal differences in home ranges for the wild pigs on Santa Cruz Island, California, were not evident. Kurz (1971) stated that summer and fall home ranges in western South Carolina were smaller than the winter-spring ranges. Both Crouch (1983) 


\section{Wild Pigs}

and Hughes (1985) found that the spring home ranges were smallest for both sexes. However, these studies showed that the fall home range was the largest for males, while the summer data were the largest for the females. The larger fall home ranges for males may be the consequence of increased movements by these boars in search of sows in estrous. Periodic shifts in home range were also noted for wild pigs (Hughes 1985).

Wild pigs are generally not territorial. As noted previously, there is extensive range overlap both between and within the sexes. In general, no defense of an exclusive area by either sex over time is typically reported. In fact, Kurz (1971) reported extensive range overlap among mature males in his study area. The one exception to this behavior might be a few uniquely dominant males. Boitani et al. (1994) reported that large adult boars can be territorial, and will maintain exclusive home ranges during the breeding season in winter. Conley et al. (1972) also noted the existence of anecdotal evidence to support territorial behavior in large males. Sparklin (2009) found that family groups (1 or more adult sows and their young) had nearly exclusive home ranges and had completely exclusive core areas. One of these groups even took over and maintained exclusive control of a high quality food resource (i.e., a sunflower, Helianthus sp., field), which had been used by a different group before the adult females in that second group were removed.

Male-Male Competition - Male wild pigs can be very aggressive toward one another. This intrasexual aggression among boars increases with age. Such interactions are typically, but not always, between two individual boars. The causes of fighting of these aggressive exchanges are primarily one of two things: typically, it is males competing for breeding opportunities with females; less often it can be competition for forage resources. This behavior occurs year-round, but is most frequent during the peak of breeding. Roaring and squealing are typically heard in association with this competition. Most males on the SRS, which appear to have been cut-up during these fights, have been observed in October to December timeframe. Unlike some other suid species (e.g., wart hogs) that exhibit head-on fighting, only lateral fighting is seen within this species (Frädrich 1974). This male-male fighting within S. scrofa has also been described by various authors (e.g., de Poncins 1914, Kurz 1971, Frädrich 1974, Beuerle 1975, Barrette 1986).

A behavioral sequence of male-male lateral fighting has been reported among wild pigs (Gundlach 1968). Initially, the combatants approach each other from a frontal position, sometimes circling one another at this point. Occasionally this involves either one or both facing one another and pawing the ground. At this stage, the two boars can also grind their mouths, snap their jaws at the opponent and produce foamed saliva. The presence of foaming saliva continues throughout most of the balance of the combat. Threatening staccatos of woofs or grunts are uttered during these initial stages of the fight. Two animals then begin strutting shoulder to shoulder, in a stiff-legged parallel walk in the same direction. On each animal, the mid-dorsal bristles are vertically erect, their ears are erect or pricked, and their heads are held upward. During this portion of the sequence, the two males push laterally at each other. They may also engage in a brief wrestling/shoving match. This stage can further include rearing up on their hind legs and pushing, kicking and biting each other from the upright, standing position. One of the boars then moves 180 degrees into a facing position, reestablishing a shoulder to shoulder contact. The two males then begin aggressively shoving or applying pressure with the shoulders. They also attempt to strike blows with their tusks on the opponents shoulder to flanks. Biting at the fore leg, neck, and ears is also attempted at this time. Such biting is sometimes realized as a charge from the side, proceeding directly at the opponent. The fight continues until one of boars is overwhelmed and breaks off the contact and flees. The winner typically pursues the loser for a short distance before terminating the chase.

Such fighting between males can be intense, with either or both combatants getting injured, or possible even killed (Conley et al. 1972, Jezierski 1977, Henry and Conley 1978, Snethlage 1982, Goulding 2003). There is a much higher risk of injury among wild pigs than in fighting in antlered and horned game species (Walther 1984). These fights are also a very preoccupying activity. For example, two adult boars (one weighing $69 \mathrm{~kg}$ and the other $95 \mathrm{~kg}$ ) were shot and killed on the SRS after being approached at a very close distance by a hunter while the two animals were in the process of fighting (J. J. Mayer, unpubl. data). 
Maternal Behavior - The behavior of mature sows in farrowing and caring for their young parallels that of their domestic counterparts (Graves 1984). This summary encompasses the spectrum of maternal behavior from pre-parturition nest building through the weaning of the litter.

Pregnant sows build farrowing nests within $24 \mathrm{~h}$ prior to giving birth to their litters. The primary function of this structure has been theorized as providing the neonates with protection from inclement weather conditions (Mayer et al. 2002). The combined presence of the sow, the nest, and huddling behavior exhibited by piglets in farrowing nests has been shown to enable young piglets to survive very cold air temperatures (Kurz 1971). This would be especially important in locations where the peak farrowing period is during December to February. However, even wild sows in captivity can lose their piglets during very cold weather (Hedgier 1964, Martys 1982). In a few instances, a smaller, younger sow was observed working together with the pregnant sow to build the nest. It was presumed that the smaller animal was an offspring of the larger sow from a previous litter (Ickes 2001). These smaller females may even remain with the larger sows through the birth and the subsequent use of and later departure from the farrowing nest (R. K. Abernethy, pers. comm., J. J. Mayer, unpubl. data). The nest is used for a period of between one to three days following the birth of the litter (Martys, 1991). In addition, since these females make foraging trips away from their litters during the first week following the birth, the nest has also been suggested to serve as protective camouflage for hiding the newborn piglets from potential predators. The characteristics of a wild pig farrowing nest are typically round to oval in shape (on average approx. $145 \mathrm{~cm}$ long and 81 $\mathrm{cm}$ wide), built in an excavated depression, and normally, but not always, lined with floral/bedding material (Mayer et al. 2002). These structures can have a dome-like cover or roof (up to $120 \mathrm{~cm}$ in height); this is especially true in colder climates. Nests are larger in habitats with less overhead cover and in colder climates (Mayer et al. 2002). Larger sows built significantly longer and higher nests than their smaller counterparts. Nesting materials used are varied and consist of plant species that are readily available and gathered from within approximately $20 \mathrm{~m}$ of the nests. However, some sows will travel more than $50 \mathrm{~m}$ to collect the nesting materials. For example, larger, older sows were shown to travel significantly further to collect these materials for their nests than did smaller, younger sows (Mayer et al. 2002). Farrowing nests can also be built immediately next to trees, logs, boulders or other natural structures for either shelter or protection. The location and cover associated with farrowing nests is variable. Mayer et al. (2002) reported that nests were most often built in forested habitats on level terrain. Hanson and Karstad (1959) stated that farrowing nests were located in shaded areas on high ground. Fernández-Llario (2004) found that farrowing nests were constructed in places with abundant plant cover, water nearby, and a warmer temperature than other locations nearby. Diong (1973), Covacevich (1976) and Imaizumi and Chabata (1977) all described wild pig farrowing nests constructed in tall grassland habitats. Pavlov (1980) reported that sows would build nests in growing cereal crops over $60 \mathrm{~cm}$ in height if the fields were left undisturbed.

The birth of the piglets takes place in the sow's farrowing nest. The sow is restless or nervous just prior to beginning to give birth to her litter. The sow may also crawl under or burrow into the bedding material in the nest at that time. The young are typically born with the sow lying on her side (i.e., either left or right). However, some births can take place with the sow lying on her ventrum or even standing up. Farrowing in wild pigs can last for 2-5 hours, with approximately 15-20 minutes between the birth of each neonate. Martys (1982) reported that the average time required for the birth of a whole litter was 199 minutes. The overall duration of farrowing tends to increase with the age of the sow. Vigorous wagging of the sow's tail has been reported to precede the birth of each piglet. This interval increases with the birth of each piglet. The piglets can be born in either a cephalic or breech presentation. Wild piglets are precocial, being very active and standing within seconds or minutes after birth. After each piglet's birth, the sow may sit up or stand, possibly even moving around the farrowing area, or simply remain still in the nest. Shivering, shaking or trembling by the sow is also observed between the births. With the exception of an infrequent individual grunt, the sow typically makes no sounds or vocalizations during farrowing. The umbilical cords are separated by either the young repeatedly struggling to reach the teats or the sow's movements (e.g., standing up or turning). The sow usually pays little attention to her neonates until the last one is born. For example, she typically does not assist the neonates in their efforts to clean themselves of the remaining fetal membranes. After birth, the neonates begin to actively seek out the teats to begin suckling. Some can even be actively or trying to nurse as the latter piglets are being born. Following completion of births, the sow may or may not consume the blood, fluids, or placental material left in the nest. If conducted, this behavior would collectively serve to avoid attracting predators to the nest, allow the sow to obtain 
important nutrients, and keep the nest clean (Hafez et al. 1962, Hediger 1968, Bourlière 1970, Frädrich 1974, Martys 1982, Graves 1984). Any piglet carcasses from either stillbirths or postnatal mortalities may also be eaten by the sow (J. J. Mayer, unpubl. data).

Unlike most ungulates, neonatal wild pigs do not follow the mother following birth. The piglets will stay within or immediately around the farrowing nest for the first 1-2 weeks of life (Fig. 1). During that time, the sow will make periodic but infrequent foraging trips away from the nest. The sow will stay in close physical contact with her litter to keep them warm, as well as near the nest to protect them from potential predators. She will move the young with her snout to clear a space to lie down to nurse them (Frädrich 1974). The characteristics of nursing behavior in wild pigs are similar to that described in the domestic sow (Horrell 1997). After lying in suitable space, the sow will invite the young to begin nursing through repeated mixed soft squeals and grunts. The piglets will then begin nursing on a specific teat selected during the first few days of life, seldom if ever drinking from other teats (Frädrich 1974, Graves 1984). After a week of so, the sow will begin to lead the piglets away in a close group from the nest to forage. For a short time, she may return them to the nest to rest or nurse. Eventually, the family group will expand their foraging range progressively further away from the nest site (Frädrich 1974). The sow will continue to lead and protect her litter through weaning and up to their dispersal away from the family group.

The reported bravery exhibited by wild sows defending their young is legendary in anecdotal accounts (Stephen 1968). Frädrich (1974) noted that the younger the litter was, the more ready the sow was to defend them. He further noted that if a predator seizes a piglet out of an assemblage of two or more family groups, that intruder will potentially be attacked by all of the sows present which have young. Eguchi et al. (2000) reported that captive sows showed increased aggressive immediately after farrowing. However, other accounts indicate that wild sows will readily abandon her litter and retreat into dense cover rather than defend her young when the human observer continued to approach. For example, from observations made at several locations (e.g., SRS; Ossabaw Island, Georgia; Collier and Hendry counties, Florida; and Aransas National Wildlife Refuge, Texas), these accounts would in practice appear to be exaggerated. In eighteen instances during which a sow stood her ground, sometimes giving a single growl or roar, when being approached by the author, the sow abandoned her litter and retreated into dense cover rather than defend her young when that human observer continued to approach (J. J. Mayer, unpubl. data). Kurz (1971) reported warning growls and threatening charges by nesting sows. However, he also stated that these sows would then lead their litters away from the human observer after a short period of time rather than trying to chase off the human with prolonged attacks. The same was true for sows which had litters of piglets either in nests or with them and were bayed by hunting dogs. In all cases, if the sow could escape the dogs, she would abandon the piglets and flee. It is likely that in most of these cases, the sow would later return to the location where she had left the piglets in an effort to find them. However, no observations were made to substantiate this supposition.

Resting/Loafing Beds - In order to protect themselves during periods of extended rest, wild pigs establish and use sheltered bedding areas. This usually entails the construction of loafing or resting beds (Frädrich 1974). Loafing or resting beds are similar to but are less complex than farrowing nests. These beds are used by either adult and/or immature animals for resting. Frequently used by single animals, wild pigs can have up to 15 individuals in one bed (Frädrich 1984). Wild pigs are "contact" animals at rest, trying to be in as close physical contact with conspecifics in these beds as possible (Hediger 1964, 1968). Typically, wild pig loafing or resting beds are simply shallow depressions in the ground, which may or may not be lined with bedding material (Hanson and Karstad 1959, Bourlière 1970, Mayer et al. 2002). The composition of these beds varies considerably, depending upon the season and the location of the structure (Conley et al. 1972). Similar to farrowing nests, beds are often made immediately adjacent to a protective structure or object (e.g., large tree, log, boulder, or overhanging rock/cliff) (Graves 1984). When available, shallow caves can also serve as sites for beds (Nichols 1962). Occasionally, a loafing bed will be encountered in late fall, winter, or early spring which will be lined with a large amount of plant material (Conley et al. 1972, Mayer et al. 2002). Such cold-weather beds can consist of large piles of bedding material (Graves 1984). Loafing or resting beds can be used more than once, with some individuals returning to use a specific bed repeated times (Frädrich 1984). Once flushed from a bed, wild pigs may not return to them for some time (Waithman 2001). 
Mannerisms and Attitudes - An individual wild pig's mood or momentary temperament can generally be determined by their physical posture or body language at any particular time. The different mannerisms and postures described for wild pigs (e.g., Gundlach 1968, Barrett 1971, Frädrich 1974, Beuerle 1975, Baber 1977, Graves 1984, Briedermann 1986) include the following:

- Aggressive posture - erect or bristling of the mane, ears cocked forward (even in animals with droop ears, although it is a little more difficult to discern), stiff-legged and jerky walk, open mouth, lowing roar.

- Threatening charge - typically follows the aggressive posture, the male will charge a short distance toward the opponent or threat, with an open or snapping mouth. A loud, deep, and rapid staccato of "woof-woof-woof" is heard during the charge. The threatening charge ends suddenly in a stiff legged stop just short of the target being intimidated.

- Submissive posture - head pointed downward or held low, facing slightly away from dominant animal. If the dominant animal persists in the threat, the subordinate animal will lie down on its abdomen with its head and neck flat on the ground. The dominant animal may walk toward and around the laying animal. The subordinate animal may be squealing throughout this interaction.

- Curiosity or alert posture - facing directly at source of curiosity, head bobbing, entailing the animal lowering its head and then suddenly lifting it to an upright posture, looking directly at the source. Occasionally, the animal may look away during the point when the head is lowered. This bobbing sequence may be repeated several times until the animal identifies the source as a potentially threatening or non-threatening object. No vocalizations heard during this posture. A wild pig in the curiosity or alert posture may also exhibit erect bristles along the middorsum.

- Play among juveniles - this activity can take a variety of forms. It often resembles the fighting that takes place between adult males (Crouch 1983). Typically involves a fair amount of shoving and chasing between participants. Frädrich (1974) described three types of play in young wild pigs including social play, solitary play and play with objects.

Vigilance Behavior - The group size in wild pigs appears to have an influence on vigilance behavior (i.e., visual scanning to detect for or enable the escape from predators). Quenette and Gerard (1992) investigated the vigilance behaviour of captive wild pigs at feeding points using films. The results showed that individual vigilance decreased with increasing group size. This behavioral variation was markedly different between solitary individuals and any of the group sizes (i.e., two or more animals). Quenette and Desportes (1992) found similar vigilance behaviors among free-ranging wild pigs in the Camargue National Reserve in France.

Vocalizations - A number of vocalizations have been identified for wild pigs (e.g., Nichols 1962, Barrett 1971, Kurz 1971, Baber 1977, Crouch 1983, Hughes 1985). In general, these consist of grunts, woofs, squeals, snarls, and snorts. Females and young are typically heard more often than are males (Nichols 1962, Frädrich 1974). Descriptions of the seven different general types of vocalizations are presented in the following paragraphs. The information presented in these descriptions were based on the author's field observations of wild and captive animals made between 1982 and 2004, and those reported in the literature:

- Loud Woof(s) or Grunt(s) - This is probably the most common type of vocalization heard by people encountering wild pigs on the SRS. This is because most of these encounters involve an unexpected confrontation between human and wild pig. In those situations, this vocalization functions as an alarm call given by a surprised animal (Baber 1977). In group situations, this would warn the other members of the group to be alert and prepared to take flight from a potential threat. This can also be heard immediately before a cornered or startled pig charges a human (Nichols 1962, J. W. Reiner, pers. comm.). Loud woofs or grunts are also heard as aggressive vocalizations during male-male fighting. This vocalization can be made by any age or either sex. It is low-pitched, loud woof or grunt emitted once or several times in quick succession. The outcome (i.e., "flight or fight") of these encounters depends upon the age of the animal and the distance to the threat. This vocalization is also heard as a warning grunt or grunts by a sow to her piglets upon the mother detecting a threat (Barrett 1971, Kurz 1971, Frädrich 1974, Crouch 1983, Hughes 1985). Typically, the piglets respond by either crouching motionless or flee, usually in 


\section{Wild Pigs}

the direction of the signaling adult (Crouch 1983). The alarmed sow would often grunt and run, still grunting, and would be followed by the rest of the group (Hughes 1985). It can also be heard as a series of loud rapid grunts when a new animal joins a group (Barrett 1971).

- Squeal - This is typically a distress or submission vocalization made during both the intraspecific and interspecific interactions of wild pigs (Barrett 1971, Baber 1977). This call can be made by any animal, but is more commonly heard among immature or subordinate individuals. This vocalization is a loud, high-pitched piercing squeal repeated continuously until the threat ceases. Squealing most often functions in the establishment of dominance order and as a distress reaction to immediate danger. Mature males can also make low squeals when fighting other males or when courting a sow in estrous (Nichols 1962). Soft or low-volume squealing can be made by animals displaced in competitive feeding interactions.

- Roar or Growl - This is a soft to loud, low-pitched lowing roar or groaning bellow that is heard during male-male interactions within breeding groups (Barrett 1971) and when intruders approach a sow and her litter in an occupied nest site (Kurz 1971). It is therefore typically made by only mature males or females. In the first situation, this call would probably function as a threat signal to another animal during the establishment of dominance order between breeding males. In the latter instance, such a vocalization would function as a threat signal to an intruder or potential predator.

- General Contact Grunting - This is type of vocalization is made by any members of a group when these animals are out of visual contact with one another. It is a series of low-pitched, soft grunts that are repeated frequently or in some instances, almost continuously (Nichols 1962, Barrett 1971, Baber 1977, Hughes 1985). It functions to maintain the group within vocal contact with each other, and therefore, to keep the group from becoming separated.

- Low Grunt - This vocalization consists of a single low-pitched grunt, which is made by one animal during the act of displacing another animal in a feeding situation. It is apparently an assertion of dominance to a competing animal, and is heard during feeding group interactions. This may also be exhibited as a short series of rapid low grunts when a competitor for food approaches too close (Frädrich 1974). Mature males can emit low series of grunts when pursuing a sow (Barrett 1971, Kramer 1971).

- Nursing Grunt(s) - These soft rhythmic grunts, which are repeated in a rapid series, are made by nursing sows at the beginning of and during nursing of her litter of piglets (Barrett 1971, Crouch 1983). The piglets respond to this call by starting to nurse after the sow assumes the nursing posture. The function would be to solicit the litter to begin and continue nursing (Frädrich 1974, Graves 1984). This vocalization is also used to coax very young piglets to leave the farrowing nest for the first time and follow the sow (Hafez et al. 1962).

- Feeding Solicitation Grunt(s) - These calls are heard by young wild piglets which are attempting to nurse from a sow (Barrett 1971, Crouch 1983), animals trying to feed in the presence of a dominant animal, or from any animals in captive situations when trying to solicit feeding from a caretaker. The vocalization consists of mixed series of rapid soft squeals and low grunts. In the wild situation, the sow would respond by lying down and beginning to nurse.

- Teeth Clacking or Popping - Not truly a vocalization, this sound is caused by tooth impacts (primarily the canines or tusks) through rapidly champing of the jaws (Graves 1984). Mostly heard among mature males during aggressive interactions, it can consist of either single or a few multiple mouth impacts. This functions as a warning or threat during aggressive encounters between conspecifics or against potential predators.

Wallowing -Wild pigs wallow in order to lower body temperature and as a protective measure against insects (Conley et al. 1972, Eisenberg and Lockhart 1972, Frädrich 1974). Wild pigs use mud wallows 
year-round, with no seasonality of general use having been observed (Belden and Pelton 1974). However, wallows are used most frequently during the summer months when these sites are important to animals trying to behaviorally reduce their heat load (Crouch 1983). In addition, wallowing would also function to immobilize ectoparasites, which could then be mechanically removed through rubbing against trees or posts after wallowing. Certain mud wallows are used over long periods of time. Other wallows are very temporary in nature, drying up after only one spring or summer of use. Typically, wallows consist of a shallow, muddy depression that is oval to oblong in shape (Fig. 2), and are 0.6-2.2 m long, 0.3-1.5 m wide and approximately $0.2 \mathrm{~m}$ deep (Belden and Pelton 1974). Some wallows are sufficiently large enough to be used concurrently by more than one animal. Mud wallows are found almost anywhere that the wild pigs can find a low wet spot. This can include both shaded and open habitats. For that reason, most wallows are located in or adjacent to riparian or bottomland habitat. Unusual locations (e.g., deep ruts or low-lying spots in unpaved jeep trails, and within drainage ditches) have also been observed. Stegeman (1938) even reported wild pigs breaking through the ice to wallow during the winter. Wallows appear to normally be made in areas with overstory vegetation present, but not in areas of dense understory cover. In areas where open water sources are not available, wild pigs will also drink at wallows (Frädrich 1984). Scent marking is also reported to done at and around wallows (Eisenberg and Lockhart 1972, Frädrich 1984, Graves 1984). As such, wallowing may also have a territorial function among males during the peak of breeding (Corbet 1966). Fernández-Llario (2005) also reported an increased incidence of wallowing by larger and older males during the peak breeding season.

Rubbing - Wild pigs frequently rub up against either natural or manmade objects. The function of this behavior is to provide comfort, remove excess mud, remove hair and mechanically rid the body of ectoparasites (Conley et al. 1972, Graves 1984). Rubs can involve almost any upright sturdy object, including trees (both pines and hardwoods), telephone poles, fence and sign posts, rocks and boulders, and other manmade structures (e.g., walls and buildings). In most cases there is an association between rubs and mud wallows, such that if a wallow exists, rubs will also be present in the immediate vicinity. Wild pigs often suffer from substantial infestations of ticks and hog lice (Haematopinus suis). The combination of wallowing in mud and rubbing off that mud serves to immobilize and then mechanically remove these parasites. The tree rubs around mud wallows (uncluding both pines and hardwoods) can vary in size from trees from 2 to $234 \mathrm{~cm}$ in the diameter at breast height (J. J. Mayer, unpubl. data). Isolated rubs (e.g., pines and creosoted poles or posts) not associated with wallows are also used. Stegeman (1938) reported that, although other species of trees were used, wild pigs in east Tennessee usually chose pitch pine ( $P$. rigida) of less than $15 \mathrm{~cm}$ in diameter for rubbing. In addition to medium- to large-sized pine trees (Pinus spp.), wild pigs also rub on creosoted telephone poles and fence posts. The pine resin or pole/post creosote apparently either serves to repel ticks and hog lice (Kramer 1971, J. J. Mayer, unpubl. data). Muddy, smoothly-rubbed bands on trees, poles, or posts are located between 10 and $94 \mathrm{~cm}$ above the ground (Stegeman 1938), and often completely encircle the structure being rubbed. Wild pig rubs on trees as high as $140 \mathrm{~cm}$ have been reported (Rutledge 1965). Bristles or guard hairs from this species are also frequently found in the mud or rough surface of structures being rubbed. Wild pigs have been reported to travel long distances to a particular pine tree or telephone pole to use as a rubbing post. In some cases, certain trees were used so often that the bark is completely rubbed off (Kramer 1971). Stegeman (1938) noted that the rubbing was so severe on several trees ranging from 3 to $20 \mathrm{~cm}$ in diameter that the trees were killed. A few pine trees at the SRS have been killed by this type of excessive use; however, the frequency of that impact is uncommon (F. A. Brooks, pers. comm.).

Symbiotic Grooming Behavior - Several species of birds have been reported to physically forage on or groom wild pigs for ectoparasites. These have variously included Florida scrub jays (Aphelocoma coerulescens), common crows (Corvus brachyrhynchos), common mynahs (Acridotheres tristis), carrion crows (Corvus corone cornix), and black-billed magpies (Pica pica). This behavior has involved the wild pigs being grooming while either standing or lying down. In some instances, the standing wild pigs were moving about foraging with the birds "riding" on their backs. Some pigs even appeared to solicit such grooming, by walking over to the birds in question and then lying down on their sides and waiting for the birds to begin grooming. This symbiotic behavior has reportedly involved both immature and mature wild pigs (Eisenberg and Lockhart 1972, Baber and Morris 1980, Kilham 1982, Massei and Genov 1995). 
Scent Marking - Wild pigs have and use a number of types of scent glands (Fig. 3). The basic structure and function of the primary types of scent glands (i.e., metacarpal glands, preorbital glands, preputial gland, and tusk/lip glands) used by these animals are discussed in the following paragraphs.

Metacarpal glands are a series of two to nine small but visible, shallow pores or pockets on the back part of the front feet (Groves and Giles 1989, Farnesi et al. 1999, Bacchetta et al. 2007). These glands are located in a line roughly parallel to the length of the forelimbs in the area overlying the posterior face of the metacarpal bones of the forefeet (Fig. 3). The pores of the metacarpal glands are lined with different types of cells (mainly apocrine tissue) that produce or facilitate the movement of a chemical scent toward the gland's opening (Farnesi et al. 1999, Heise-Pavlov et al. 2005). These glands are found in both females and males. Heise-Pavlov et al. (2005) reported a bilateral asymmetry in females (i.e., significantly larger on the right leg), and sexual dimorphism in size between males and females on the left limbs (i.e., males were larger). In addition, the glands were larger in sexually mature/reproductively-active females. No seasonal variation is size is observed in the males (Heise-Pavlov et al. 2005). In contrast, Bacchetta et al. (2007) found significant differences in size between immatures and adults of both sexes, but no sexually dimorphic differences in adults. However, when all specimens were pooled, Bacchetta et al. (2007) reported that males had more developed and functional glands than females, with the oldest males having the highest values of gland surface, gland thickness and tubule diameter. Marking with the metacarpal glands is performed by the animal leaning forward and pawing the ground with the bottoms of its front feet; this action is somewhat reminiscent of a house cat stretching forward and clawing at a carpet with its front paws (Fig. 4). Boars mark with their metacarpal glands when they are participating in breeding groups or when they detect the presence of scent marking by another boar (Mayer and Brisbin 1986). Bacchetta et al. (2007) suggested that these glands play a relevant role in social communication by producing chemical signals involved in territorial definition as well as reproduction. Because the size of these glands and the testes weights and testosterone serum levels were not correlated, Heise-Pavlov et al. (2005) suggested that the metacarpal glands were not involved in advertising dominance in males. Heise-Pavlov et al. (2005) further suggested that these glands are involved in a defensive behavior in reproductive females, but not in the identification of the mother by her piglets.

The preorbital glands consist of a small secretory orifice located immediately in front of the eyes (Fig. 3). The highest ranking sows in a matriarchal group of wild boar in Germany were found to use their preorbital glands to mark trees about 14 days before they come into heat to signal the presence of receptive females in the near future (Meynhardt 1982).

The preputial gland is an outpocket or blind sac (technically referred to as a diverticulum) connected to the preputial area near the end of the penis (Fig. 3). This gland is easily identified as the large swollen area near the distal end of the penis when skinning out a boar. Both urine and cells shed from the walls of the urine canal and prepuce collect in this blind sac. There are also large sebaceous and sweat glands surrounding the entrance of the diverticulum. The preputial fluid also contains a pheromone called "muskone" (Barrett 1978). Collectively, all of this results in the production of the foul-smelling fluid that humans detect as the "boar odor" that is released whenever a mature male wild pig urinates upwind. It is also believed that the male pheromone that elicits the "mating stance" in females originates from the preputial gland (Hafez et al. 1962). Boars either intentionally or inadvertently mark with this gland as a result of muscle contractions in the preputial area whenever they urinate. Such scent marking is also observed in conjunction with metacarpal gland marking, usually after the boar has marked the spot with its metacarpal glands.

The tusk/lip glands are a scattered group of microscopic secretory glands found in the upper lip above the tusks or canine teeth in boars (Fig. 3). Boars mark with these glands by rubbing their lips against an object or by chomping their jaws to produce foamed saliva which contains the scent (Diong 1982). As a byproduct of contact, boars rub this scented saliva on sows during courtship or on rivals during fighting. Such saliva can also be left or marked on scent posts, including such objects as branches, tree trunks, or large leaves. The most infamous manner in which boars mark with these glands is when they "tusk" a tree (i.e., mark a tree with their tusk glands by rubbing the glands up and down against the tree, and inadvertently mar the tree with their canines). Tusking can vary from a single slash to trees that have a significant belt of bark on the trunk slashed away. Vigorous tusking can also result in a trench being 
created around the base of the tree by the boar doing the marking (Graves 1984). Stegeman (1938) reported that only pine trees in east Tennessee were found to have been tusked by wild pigs. Boars typically tend to tusk trees when in solitary situations and produce foamed saliva during social interactions. However, tusking trees can also be done by boars in mixed groups containing an estrous sow (Diong 1982). Tusking can also be associated with rubs (Stegeman 1938, Conley et al. 1972).

Wild pigs also have proctoideal glands (i.e., located at the entrance to the rectum), perineal glands (i.e., located between anus and genital region), mandibular or mental glands (i.e., consisting of numerous tubular glands in a swelling, marked by vibrissae, between the two halves of the jaw; reported to double in size during peak breeding), and rhinarial glands (i.e., located in the midline of the upper part of the rhinarial disc). All of these secrete or produce odorous compounds, which may or may not function in scent marking (Getty 1975, Groves and Giles 1989).

Senses - Of the five primary senses, wild pigs tend to use four of these (i.e., smell, sight, hearing and touch) in their daily existence. These are briefly discussed in the following paragraphs:

- Smell - Wild pigs excel at the sense of smell (Frädrich 1974). It has been estimated that when conditions are optimal, wild pigs can detect human scent downwind from a distance of 500 to 600 meters (Banoğlu 1952). It also allows these animals to detect the presence of fungi and other food resources buried below ground level (up to approx. 25 feet deep; Shephard 1994). Few other animals have as well evolved and refined a sense of smell as do swine. The olfactory region of the brain is extensive in correlation with the large size of the olfactory bulbs (Moulton 1967, Getty 1975). This enhanced sense often comes into play as means of finding food as well as avoiding enemies.

- Sight - Wild pigs are credited anecdotally with good, but not great eyesight. This species has a field of vision of approximately 260 to 275 degrees. Swine may also have a binocular field of vision covering a combined span of 30 to 50 degrees ahead of them (Getty 1975). In open areas where they are hunted, wild pigs have been observed to recognize and flee from an approaching man or vehicle from more than $1.5 \mathrm{~km}$ away (Kramer 1971).

- Hearing - Seems to be the least developed of the senses among wild pigs. These animals seem to depend on this sense less than either smell or sight. The auditory sense in wild pigs appears to play its highest role in detecting the presence of other animals in thick cover. Hearing something, a wild pig will freeze or go into the alert posture until determining the nature or source of the sound detected. Conversely, this sense is useful for maintaining close proximity by groups in thick cover through use of the general contact grunting vocalization.

- Touch - Sense of touch within wild pigs is centered around the rhinarial pad and the mouth. In addition to housing a highly-developed olfactory organ, the nose, primarily the area around the rhinarial pad, encompasses a very receptive tactile sensory system. In this species, the cortical area of the brain associated with the snout is proportionately larger than in any other ungulate (Moulton 1967). Not having manual dexterity in the form of a fingered hand, wild pigs use their rhinarial pad and mouth to "touch" or "pick up and feel" objects. Investigatory bites or chewing is not uncommon when pigs are presented with an object that is unknown to them. 


\section{Wild Pigs}

Table 1. Listing of home ranges sizes reported for wild pigs from different locations. Data are separated by sex.

\begin{tabular}{|c|c|c|c|}
\hline \multirow[t]{2}{*}{ Location } & \multicolumn{2}{|c|}{$\begin{array}{c}\text { Home Range Size - in } \mathrm{km}^{2} \\
\text { (Sample Size) }\end{array}$} & \multirow[t]{2}{*}{ Reference } \\
\hline & Female & Male & \\
\hline $\begin{array}{c}\text { Davis Mountains, Jeff } \\
\text { Davis County, TX, USA }\end{array}$ & $34.0(8)$ & $48.3(10)$ & Adkins and Harveson 2007 \\
\hline $\begin{array}{c}\text { Santa Catalina Island, CA, } \\
\text { USA }\end{array}$ & $0.7(4)$ & $1.4(6)$ & Baber and Coblentz 1986 \\
\hline $\begin{array}{c}\text { Dye Creek Ranch, CA, } \\
\text { USA }\end{array}$ & $10-25$ & $50+$ & Barrett 1978 \\
\hline Tuscany, Italy & $4.7(5)^{\mathrm{a}}$ & $13.4(3)^{\mathrm{a}}$ & Boitani et al. 1994 \\
\hline $\begin{array}{c}\text { Northern Territory, } \\
\text { Australia }\end{array}$ & $24.1(6)$ & $33.5(6)$ & Caley 1993 \\
\hline Galapagos Island, Ecuador & $0.9(3)$ & $1.6(4)$ & Coblentz and Baber 1987 \\
\hline $\begin{array}{c}\text { Savannah River Plant, SC, } \\
\text { USA }\end{array}$ & $7.9(4)$ & $14.0(3)$ & Crouch 1983 \\
\hline $\begin{array}{c}\text { Savannah River Plant, SC, } \\
\text { USA }\end{array}$ & $7.9(4)$ & $14.0(3)$ & Crouch 1983 \\
\hline $\begin{array}{c}\text { Northwest New South } \\
\text { Wales, Australia }\end{array}$ & $4.9-8.1$ & $8.9-11.6$ & Dexter 1995 \\
\hline $\begin{array}{c}\text { Kipahula Valley, Maui, HI, } \\
\text { USA }\end{array}$ & $1.1(4)$ & $2.0(5)$ & Diong 1982 \\
\hline $\begin{array}{c}\text { Congaree National Park, } \\
\text { SC, USA }\end{array}$ & $1.9(9)$ & $2.2(7)$ & Friebel and Jodice 2009 \\
\hline $\begin{array}{c}\text { Lowndes County Wildlife } \\
\text { Management Area, AL, } \\
\text { USA }\end{array}$ & $4.0(6)$ & $4.0(5)$ & Gaston et al. 2008 \\
\hline $\begin{array}{c}\text { New South Wales, } \\
\text { Australia }\end{array}$ & $5-20$ & $10-50$ & Giles 1978 \\
\hline $\begin{array}{c}\text { Yantabulla, New South } \\
\text { Wales, Australia }\end{array}$ & $3.4(4)$ & $15.1(3)$ & Giles 1980 \\
\hline $\begin{array}{c}\text { Warren, New South Wales, } \\
\text { Australia }\end{array}$ & 6.2 & 43 & Giles 1980 \\
\hline $\begin{array}{c}\text { Dye Creek Ranch, CA, } \\
\text { USA }\end{array}$ & $1.5(3)$ & - & Grover 1983 \\
\hline $\begin{array}{c}\text { Savannah River Plant, SC, } \\
\text { USA }\end{array}$ & $5.7(5)$ & $13.8(6)$ & Hughes 1985 \\
\hline $\begin{array}{c}\text { Savannah River Plant, SC, } \\
\text { USA }\end{array}$ & $4.4(1)$ & $5.3(4)$ & Kurz and Marchinton 1972 \\
\hline Forêt de Chizē, France & $1.5-4.1(5)$ & $7.0(1)$ & Mauget 1980 \\
\hline $\begin{array}{c}\text { Savannah River Site, SC, } \\
\text { USA }\end{array}$ & $2.5(2)$ & $4.0(2)$ & J. J. Mayer, unpubl. data \\
\hline Mt. Harte, New Zealand & $0.3-1.2(4)$ & $0.4-2.1(3)$ & McIlroy 1989 \\
\hline $\begin{array}{c}\text { Namadgi National Park, } \\
\text { ACT, Australia }\end{array}$ & $1.5-5.5$ & $1.4-6.6$ & $\begin{array}{c}\text { McIlroy and Saillard 1989, } \\
\text { McIlroy } 1989\end{array}$ \\
\hline
\end{tabular}


Table 1. Listing of home ranges sizes reported for wild pigs from different locations. Data are separated by sex. (Continued)

\begin{tabular}{|c|c|c|c|}
\hline \multirow[t]{2}{*}{ Location } & \multicolumn{2}{|c|}{$\begin{array}{c}\text { Home Range Size - in } \mathrm{km}^{2} \\
\text { (Sample Size) }\end{array}$} & \multirow[t]{2}{*}{ Reference } \\
\hline & Female & Male & \\
\hline $\begin{array}{l}\text { TXU Corporation's Big } \\
\text { Brown Mine, TX, USA }\end{array}$ & $6.5(10)$ & $15.8(6)$ & Mersinger and Silvy 2007 \\
\hline $\begin{array}{c}\text { Northeast Queensland, } \\
\text { Australia }\end{array}$ & 2.4 (19) & $9.0(22)$ & Mitchell 1999 \\
\hline Tuscany, Italy & $3.8(5)$ & $11.5(5)$ & Morini et al. 1995 \\
\hline $\begin{array}{c}\text { Girilambone, New South } \\
\text { Wales, Australia }\end{array}$ & 18 & - & Pavlov 1980 \\
\hline $\begin{array}{c}\text { Kosciusko National Park, } \\
\text { New South Wales, } \\
\text { Australia }\end{array}$ & $10.2(8)$ & $34.6(12)$ & Saunders 1988 \\
\hline $\begin{array}{c}\text { Sunny Corner, New South } \\
\text { Wales, Australia }\end{array}$ & $4.9(5)$ & $10.7(7)$ & $\begin{array}{c}\text { Saunders 1988, Saunders and Kay } \\
1991\end{array}$ \\
\hline $\begin{array}{c}\text { Kosciusko National Park, } \\
\text { New South Wales, } \\
\text { Australia }\end{array}$ & $11.1(6)$ & $35.0(8)$ & Saunders and Kay 1996 \\
\hline GSMNP, NC/TN, USA & $2.7-3.5(4)$ & $3.8-3.9(9)$ & Singer et al. 1981 \\
\hline $\begin{array}{c}\text { Santa Cruz Island, CA, } \\
\text { USA }\end{array}$ & $1.0(5)$ & $1.4(5)$ & Sterner 1990 \\
\hline Hobcaw Barony, SC, USA & $1.8(3)$ & $2.3(3)$ & Wood and Brenneman 1980 \\
\hline
\end{tabular}




\section{Wild Pigs}

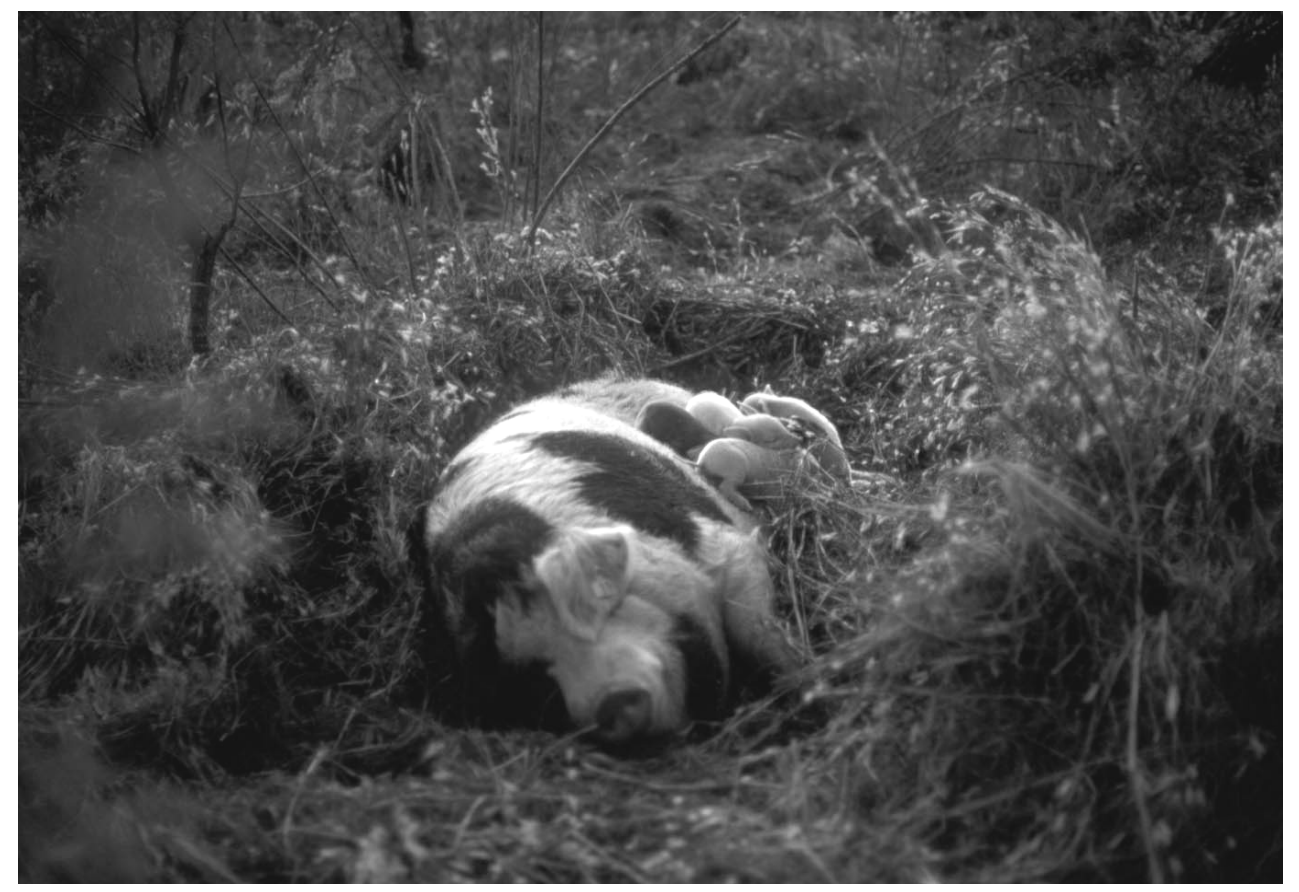

Fig. 1. Feral sow with a two-day old litter of neonatal piglets in the farrowing nest in an open field.

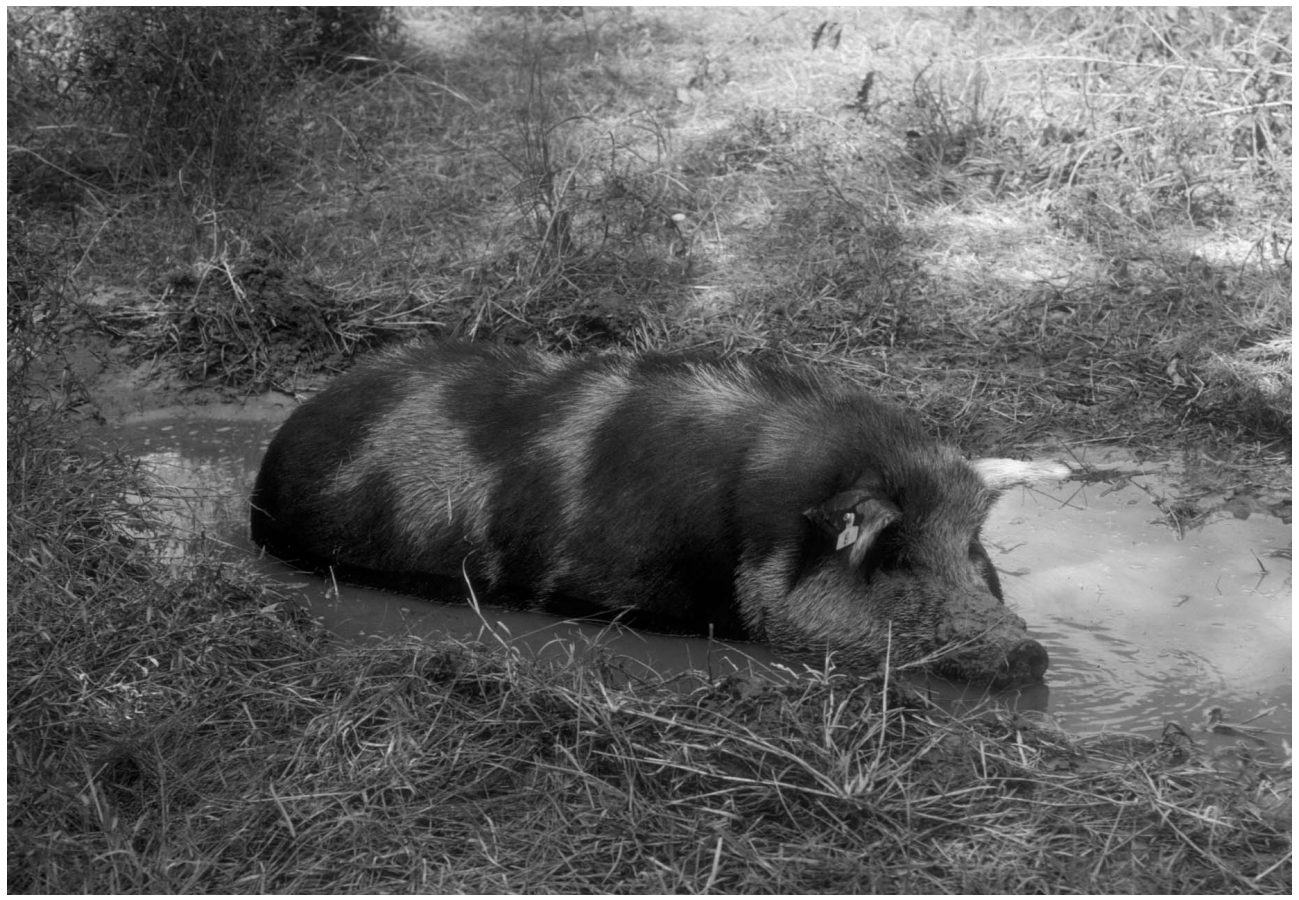

Fig. 2. Wild pig using a wallow that is oblong-shaped. 
SRNL-RP-2009-00869
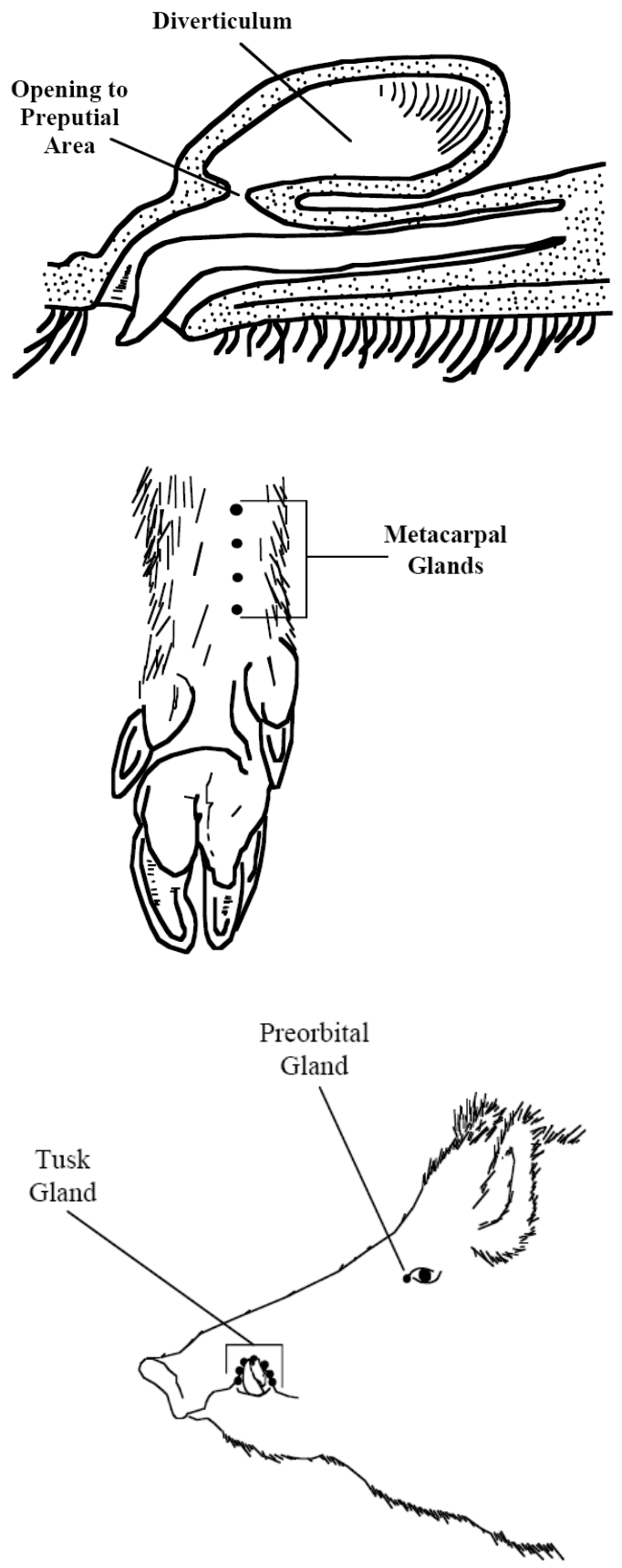

Fig. 3. Illustrations showing the four most commonly used scent glands in wild pigs including the preputial gland or diverticulum (top), metacarpal glands (middle), preorbital gland (bottom), and tusk gland (bottom). 


\section{Wild Pigs}
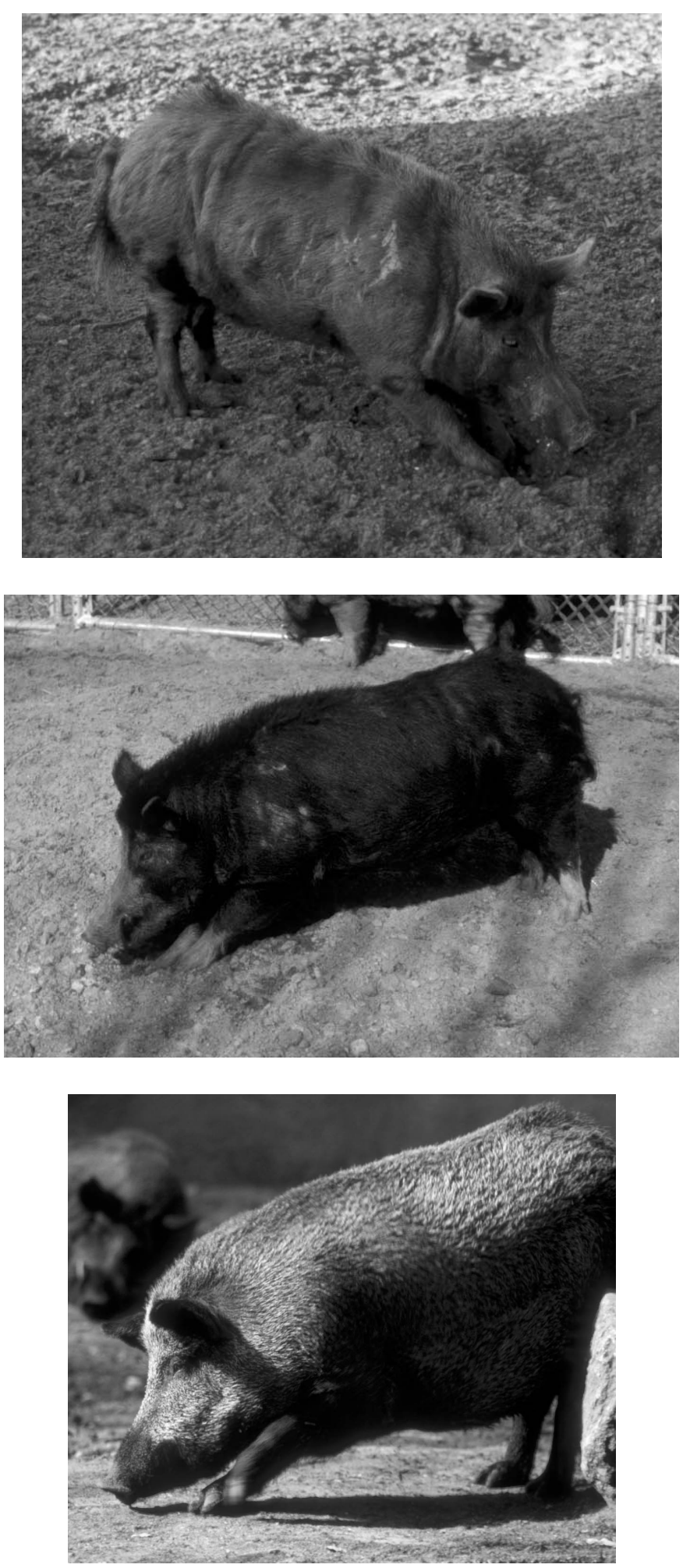

Fig. 4. Captive wild pigs scent-marking with their metacarpal glands. The top two photos are of adult boars, and the bottom photo is of an adult sow. 


\section{Literature Cited}

Adkins, R. N., and L. A. Harveson. 2006. Summer diets of feral hogs in the Davis Mountains, Texas. The Southwestern Naturalist, 51(4):578-580.

2007. Demographic and spatial characteristics of feral hogs in the Chihuahuan Desert, Texas. Human-Wildlife Conflicts, 1(2):152-160.

Andrzejewski, R., and W. Jezierski. 1978. Management of a wild boar population and its effects on commercial land. Acta Theriologica, 23(19):309-339.

Baber, D. W. 1977. Social organization and behavior in the feral hog. M.S. Thesis, Florida Institute of Technology, Melborne, Florida.

Baber, D. W., and B. E. Coblentz. 1986. Density, home range, habitat use and reproduction of feral pigs on Santa Catalina Island. Journal of Mammalogy, 67(3):512-525.

Baber, D. W., and J. G. Morris. 1980. Florida scrub jays foraging from feral hogs. Auk, 97(1):202.

Bacchetta, R., P. Mantecca, L. Lattuada, F. Quaglia, G. Vailati, and M. Apollonio. 2007. The carpal gland in wild swine: Functional evaluations. Italian Journal of Zoology, 74(1):7-12.

Banoğlu, N. A. 1952. Turkey: A sportsman’s paradise. The Press, Broadcasting, and Tourism Department, Ankara, Turkey.

Barrett, R. H. 1971. Ecology of the feral hog in Tehama County, California. Ph.D. Dissertation, University of California, Berkeley, California.

. 1978. The feral hog on the Dye Creek Ranch, California. Hilgardia, 46(9):283-355.

1982. Habitat preferences of feral hogs, deer, and cattle on a Sierra Foothill range. Journal of Range Management, 35(3):342-346.

Barrette, C. 1986. Fighting behavior of wild Sus scrofa. Journal of Mammalogy, 67(1):177-179.

Baubet, E., C. Bonenfant, and S. Brandt. 2004. Diet of the wild boar in the French Alps. Galemys, 16(Special Edition):99-111.

Belden, R. C., and M. R. Pelton. 1976. Wallows of the European wild hog in the mountains of east Tennessee. Journal of the Tennessee Academy of Sciences, 51(3):91-93.

Beuerle, W. 1975. Freilanduntersuchungen zum Kampf- und Sexualverhalten des Europaischen Wildschweines (Sus scrofa L.). Zeitschrift fur Tierpsychologie, 39(1-5):211-258.

Boitani, L., L. Mattei, D. Nonis, and F. Corsi. 1994. Spatial and activity patterns of wild boars in Tuscany, Italy. Journal of Mammalogy, 75(3):600-612.

Bourlière, F. 1970. The natural history of mammals. Alfred A. Knopf, New York, New York.

Braza, F., and F. Alvarez. 1989. Utilisation de l'habitat et organisation sociale du sanglier (Sus scrofa L.) a Donana (Sud-Ouest de l'Espagne). Canadian Journal of Zoology, 67(8):2047-2051.

Briedermann, L. 1986. Schwarzwild. VEB Deutscher Landwirtschaftsverlag, Berlin, Democratic Republic of Germany. 


\section{Wild Pigs}

Caley, P. 1993. Population dynamics of feral pigs (Sus scrofa) in a tropical riverine habitat complex. Wildlife Research, 20(5):625-636.

1997. Movements, activity patterns, and habitat use of feral pigs (Sus scrofa) in a tropical habitat. Wildlife Research, 24(1):77-87.

Cargnelutti, B., F. Spitz, and G. Valet. 1992. Analysis of the dispersion of wild boar (Sus scrofa) in southern France. Pp. 423-425. In F. Spitz, G. Janeau, G. Gonzalez, and S. Aulagnier (eds.), Ongules/Ungulates 91: Proceedings of the international symposium. Toulouse, France, September 2-6, 1991, Societe Francaise pour l'Etude et la Protection des Mammiferes, and Toulose: Institut de Recherche sur les Grands Mammiferes, Paris \& Toulouse, France.

Challies, C. N. 1975. Feral pigs (Sus scrofa) on Auckland Island: Status and effects on vegetation and nesting sea birds. New Zealand Journal of Zoology, 2(4):479-490.

Choquenot, D., J. McIlroy, and T. Korn. 1996. Managing vertebrate pests: Feral pigs. Bureau of Rural Sciences, Australian Government Publishing Service, Canberra, Australia.

Coblentz, B. E., and D. W. Baber. 1987. Biology and control of feral pigs on Isla Santiago, Galapagos, Ecuador. Journal of Applied Ecology, 24(2):403-418.

Conley, R. H., V. G. Henry, and G. H. Matschke. 1972. Final report for the European hog research project W-34. Tennessee Game and Fish Commission, Nashville, Tennessee.

Corbet, G. 1966. The terrestrial mammals of Western Europe. Dufour Editions, Philadelphia, Pennsylvania.

Covacevich, J. 1976. A nest constructed by wild pigs. Victorian Naturalist, 93:25-27.

Crouch, L. C. 1983. Movements of and habitat utilization by feral hogs at the Savannah River Plant, South Carolina. M.S. Thesis, Clemson University, Clemson, South Carolina.

Dardaillon, M. 1988. Wild boar social groupings and their seasonal changes in the Camargue, southern France. Zeitschrift fur Saugetierkunde, 53(1):22-30.

Dardaillon, M., and G. Beugnon. 1987. The influence of some environmental characteristics on the movements of wild boar, Sus scrofa. Biology of Behavior, 12(2):82-92.

de Poncins, V. E. 1914. How wild boars fight. Journal of the Bombay Natural History Society, 22:791-793.

DEFRA (Department for Environment, Food and Rural Affairs). 2004. The ecology and management of wild boar in southern England. Central Science Laboratory, Hutton, York, United Kingdom.

Dexter, N. 1995. The behaviour of feral pigs in north-west New South Wales and its implications for the epidemiology of foot and mouth disease. Ph.D. Dissertation. University of New England, Armidale, Australia.

. 1998. The influence of pasture distribution and temperature on habitat selection by feral pigs in a semi-arid environment. Wildlife Research, 25(5):547-559.

Dickson, J. G., J. J. Mayer, and J. D. Dickson. 2001. Wild hogs. Pp. 191-192, 201-208. In J. G. Dickson (ed.), Wildlife of Southern forests: Habitat \& management. Hancock House Publishers, Blaine, Washington.

Diong, C. H. 1973. Studies of the Malaysian wild pig in Perak and Jahore. Malayan Nature Journal, 26(3/4):120-151. 
1982. Population biology and management of the feral pig (Sus scrofa L.) in Kipahula Valley, Maui. Ph.D. Dissertation, University of Hawaii, Honolulu, Hawaii.

Duncan, R. W. 1974. Reproductive biology of the European wild hog (Sus scrofa) in the Great Smoky Mountains National Park. M.S. Thesis, University of Tennessee, Knoxville, Tennessee.

Durio, P., D. Fogliato, A. Perrone, and N. Tessarin. 1995. The autumn diet of the wild boar (Sus scrofa) in an alpine valley. Preliminary results. Journal of Mountain Ecology (Ibex), 3:180-183.

Eguchi, Y., T. Tanaka, and T. Yoshimoto. 2000. Behavioral responses of Japanese wild boars to the person in attendance during the pre- and post-farrowing periods under captive conditions. Animal Science Journal, 71(5):509-514.

Eisenberg, J. F. 1981. The Mammalian Radiations: An Analysis of Trends in Evolution, Adaptation, and Behavior. The University of Chicago Press, Chicago, Illinois.

Eisenberg, J. F., and M. C. Lockhart. 1972. An ecological reconnaissance of Wilpattu National Park, Ceylon. Smithsonian Contributions to Zoology 101:1-118.

Eisenberg, J. F., and G. M. McKay. 1974. Comparison of ungulate adaptations in the New World and Old World Tropical Forests with special reference to Ceylon and the rainforests of Central America. Pp. 585-602. In V. Geist and F.R. Walther (eds.). The Behaviour of Ungulates and its Relation to Management. International Union for the Conservation of Nature and Natural Resources, Morges, Switzerland.

Elman, R. 1974. The hunter's field guide to the game birds and animals of North America. Alfred A. Knopf. New York, New York.

Farnesi, R. M., D. Vagnetti, and S. Tei. 1999. Morphological and ultrastructural study of carpal organ in adult female wild swine. Anatomia, Histologia, Embryologia, 28(1):31-37.

Fernández-Llario, P. 2004. Environmental correlates of nest site selection by wild boar Sus scrofa. Acta Theriologica, 49(3):383-392.

. 2005. The sexual function of wallowing in male wild boar (Sus scrofa). Journal of Ethology, 23:9-14.

Fernández-Llario, P., J. Carranza, and S. J. Hidalgo De Trucios. 1996. Social organization of the wild boar (Sus scrofa) in Donana National Park. Miscellania Zoologica (Barcelona), 19(2):9-18.

Frädrich, H. 1974. A comparison of behaviour in the Suidae. Pp. 133-143. In V. Geist and F. R. Walther (eds.), The behavior of ungulates and its relation to management. International Union for the Conservation of Nature and Natural Resources, Morges, Switzerland.

. 1984. Swine and peccaries. Pp. 76-108. In B. Grzimek (ed.), Grzimek's animal life encyclopedia. Volume 13: Mammals IV. Van Nostrand Reinhold Company, New York.

Friebel, B. A., and P. G. R. Jodice. 2009. Home range and habitat use of feral hogs in Congaree National Park, South Carolina. Human-Wildlife Conflicts, 3(1):49-63.

Gaston, W., J. B. Armstrong, W. Arjo and H. L. Stribling. 2008. Home range and habitat use of feral hogs (Sus scrofa) on Lowndes County WMA, Alabama. Pp. 1-17. In S. M. Vantassel (ed.), 2008 National conference on feral hogs. St. Louis, Missouri. http://digitalcommons.unl.edu/feralhog/6

Getty, R. 1975. Sisson and Grossman's the anatomy of the domestic animals. W. B. Saunders Company, Philadelphia, Pennsylvania. 


\section{Wild Pigs}

Giles, J. R. 1977. Control of feral pigs. Wool Technology and Sheepbreeding, 25(2):29-31.

. 1980. The ecology of feral pigs in western New South Wales. Ph.D. Dissertation, Sydney University, Sydney, Australia.

Goulding, M. J. 2003. Wild boar in Britain. Whittet Books, Ltd., Suffolk, United Kingdom.

Graves, H. B. 1984. Behaviour and ecology of wild and feral swine (Sus scrofa). Journal of Animal Science, 58(2):482-492.

Graves, H. B., and K. L. Graves. 1977. Some observations on biobehavioral adaptations of swine. Pp. 103-110. In G. W. Wood (ed.), Research and management of wild hog populations. Belle Baruch Forest Science Institute of Clemson University, Georgetown, South Carolina.

Grover, A. M. 1983. The home range, habitat utilization, group behavior and food habits of the feral hog (Sus scrofa) in northern California. M.S. Thesis, California State University, Sacramento, California.

Gundlach, H. 1968. Brutfursorge, Brutpflege Verhaltensontogenese und Tagesperiodik beim Europaischen Wildschwein (Sus scrofa L.). Zeitschrift fur Tierpsychologie, 25(8):955-995.

Hafez, E. S. E., L. J. Sumpton, and J. S. Jakway. 1962. The behaviour of swine. Pp. 334-369. In E. S. E. Hafez (ed.). The behaviour of domestic animals. The Williams \& Wilkins Company, Baltimore, Maryland.

Hanson, R. P., and L. Karstad. 1959. Feral swine in the southeastern United States. Journal of Wildlife Management, 23(1):64-74.

Hediger, H. 1964. Wild animals in captivity: an Outline of the biology of zoological gardens. Dover Publications, Inc., New York, New York.

1968. The psychology and behaviour of animals in zoos and circuses. Dover Publications, Inc., New York, New York.

Heise-Pavlov, S., P. Heise-Pavlov, and A. Bradley. 2005. Carpal glands in feral pigs (Sus domesticus) in tropical lowland rainforest in north-east Queensland, Australia. Journal of Zoology, 266:73-80.

Hennig, R. 1981. Schwarzwild: Biologie - Verhalten, Hege und Jagd. BVL Verlagsgesellschaft, München, West Germany.

Henry, V. G., and R. H. Conley. 1978. Survival and mortality of European wild hogs. Proceedings of the Annual Conference of the Southeastern Association of Fish \& Wildlife Agencies, 32:93-99.

Horrell, I. 1997. The characteristics of suckling in wild boar. Applied Animal Behaviour Science, 53(4):271-277.

Hughes, T. W. 1985. Home range, habitat utilization, and pig survival of feral swine on the Savannah River Plant. M.S. Thesis, Clemson University, Clemson, South Carolina.

Ickes, K. L. 2001. The effects of wild pigs (Sus scrofa) on woody understory vegetation in a lowland rain forest of Malaysia. Ph.D. Dissertation, Louisiana State University, Baton Rouge, Louisiana.

Imaizumi, T., and T. Chabata. 1977. Notes on the nest for reproduction of Ryukyu wild boar, Sus riukiuanus (in Japanese with English summary). Journal of the Mammalogical Society of Japan, 7(2):111-113. 
SRNL-RP-2009-00869

Jezierski, W. 1977. Longevity and mortality rate in a population of wild boar. Acta Theriologica, 22(24):337-348.

Kaminski, G., S. Brandt, E. Baubet, and C. Baudoin. 2005. Life-history patterns in female wild boars (Sus scrofa): Mother-daughter postweaning associations. Canadian Journal of Zoology, 83(3):474-480.

Kellogg, R. 1939. Annotated list of Tennessee mammals. Proceedings of the United States National Museum, 86(3051):245-303.

Kilham, L. 1982. Cleaning/feeding symbioses of common crows with cattle and feral hogs. Journal of Field Ornithology, 53(3):275-276.

Kramer, R. J. 1971. Hawaiian Land Mammals. Charles E. Tuttle Company, Rutland, Vermont.

Kurz, J. C. 1971. A study of feral hog movements and ecology on the Savannah River Plant, South Carolina. M.S. Thesis, University of Georgia, Athens, Georgia.

Kurz, J. C., and R. L. Marchinton. 1972. Radiotelemetry studies of feral hogs in South Carolina. Journal of Wildlife Management, 36(4):1240-1248.

Land Protection. 2001. NRM Facts: Control of feral pigs declared. QNRM01278. Department of Natural Resources and Mines, The State of Queensland, Brisbane, Australia.

Lapidge, S. J., B. Cowled and M. Smith. 2004. Ecology, genetics and socio-biology: Practical tools in the design of target-specific feral pig baits and baiting procedures. Proceedings of the Vertebrate Pest Conference, 21:317-322.

Laurance, W. F., and G. N. Harrington. 1997. Ecological associations of feeding sites of feral pigs in the Queensland wet tropics. Wildlife Research, 24(5):579-590.

Lekagul, B., and J. A. McNeely. 1988. Mammals of Thailand. $2^{\text {nd }}$ Edition. Saha Karn Bhaet Co., Bangkok, Thailand.

Lemel, J., J. Truve, and B. Soderberg. 2003. Variation in ranging and activity behaviour of European wild boar Sus scrofa in Sweden. Wildlife Biology, 9 (Suppl. 1):29-36.

Maillard, D. and P. Fournier. 1995. Effects of shooting with hounds on size of resting range of wild boar (Sus scrofa L.) groups in mediterranean habitat. Journal of Mountain Ecology (Ibex), 3:102-107.

Martys, M. 1982. Gehegebeobachtungen zur Geburts- und Reproduktionsbiologie des Europaischen Wildschweines (Sus scrofa L.). Zeitschrift fur Saugetierkunde, 47(2):100-113.

1991. Monographie des eurasiatischen Wildschweines (Sus scrofa). Bongo, 18(1991):8-20.

Massei, G., and P. Genov. 1995. Observations of black-billed magpie (Pica pica) and carrion crow (Corvus corone cornix) grooming wild boar (Sus scrofa). Journal of Zoology (London), 236(2):338-341.

Massei, G., P. V. Genov, B. W. Staines, and M. L. Gorman. 1997. Factors influencing home range and activity of wild boar, Sus scrofa, in a mediterranean coastal area. Journal of Zoology, 242(3):411-423.

Matschke, G. H., and J. P. Hardister. 1966. Movements of transplanted European wild boar in North Carolina and Tennessee. Proceedings of the Annual Conference of the Southeastern Association of Fish \& Wildlife Agencies, 20:74-84. 


\section{Wild Pigs}

Mauget, R. 1980. Regulations ecologiques, comportementales et physiologiques (fonction de reproduction), de l'adaptation du sanglier, Sus scrofa L., au Milieu. Ph.D. Dissertation, L' Universite Francois Rabelais de Tours, Orleans, France.

Mayer, J. J., and I. L. Brisbin, Jr. 1991. Wild pigs in the United States: Their history, comparative morphology, and current status. The University of Georgia Press, Athens, Georgia.

Mayer, J. J., F. D. Martin, and I. L. Brisbin, Jr. 2002. Characteristics of wild pig farrowing nests and beds in the upper Coastal Plain of South Carolina. Applied Animal Behaviour Science, 78(1):1-17.

Mcllroy, J. C. 1989. Aspects of the ecology of feral pigs (Sus scrofa) in the Murchison area, New Zealand. New Zealand Journal of Ecology, 12:11-22.

McIlroy, J. C., and R. J. Saillard. 1989. The effect of hunting with dogs on the numbers and movements of feral pigs, Sus scrofa, and the subsequent success of poisoning exercises in Namadgi National Park, A.C.T. Australian Wildlife Research, 16(3):353-363.

Mersinger, R. C., and N. J. Silvy. 2007. Range size, habitat use, and dial activity of feral hogs on reclaimed surface-mined lands in east Texas. Human-Wildlife Conflicts, 1(2):161-167.

Meynhardt, H. 1982. Schwarzwild-Report: Mein Leben unter Wildschweinen. Verlag J. Neumann, Leipzig, East Germany.

Mitchell, J. 1999. Ecology of feral pigs in the Wet Tropics. Pp. 43-47. In C. N. Johnson (ed.), Feral pigs: Pest status and prospects for control. Proceedings of a feral pig workshop. James Cook University, Cairns, March. Research Report No. 13. Cooperative Research Centre for Tropical Rainforest Ecology and Management, Cairns, Australia.

Mitchell, J., and R. Mayer. 1997. Diggings by feral pigs within the Wet Tropics World Hertitage Area of North Queensland. Wildlife Research, 24:591-601.

Morini, P., L. Boitani, L. Mattei, and B. Zagarese. 1995. Space use by pen-raised wild boars (Sus scrofa) released in Tuscany (central Italy) - II. Home range. Journal of Mountain Ecology (Ibex), 3:112-116.

Moulton, D. G. 1967. Olfaction in mammals. Zoologist, 7:421-429.

Nasimovic, A. A. 1966. Wildschwein. Pp. 53-83. In V. G. Heptner, A. A. Nasimovic, and A. G. Bannikov. (eds.). Die Säugetiere der Sowjetunion. Bd. 1. Paarhufer und Unpaarhufer. VEB Gustav Fischer Verlag, Jena, German Democratic Republic.

Nichols, L., Jr. 1962. Ecology of the wild pig. Federal Aid in Wildlife Restoration Final Report Project W5-R-13. Hawaii Department of Land and Natural Resources, Division of Fish and Game, Honolulu, Hawaii.

Nowak, R. M. 1999. Walker's mammals of the world. 2 volumes. The Johns Hopkins University Press, Baltimore, Maryland.

Oloff, H. B. 1951. Zur Biologie und Okologie des Wildschweines. Beitrag zur Tierkunde und Tierzucht (Frankfurt am Main), 2(1):1-95.

Pavlov, P. M. 1980. The diet and general ecology of the feral pig (Sus scrofa) at Girilambone, N. S. W. M.S. Thesis, Monash University, Melbourne, Australia.

Pine, D. S., and G. L. Gerdes. 1973. Wild pigs in Monterey County, California. California Fish and Game, 59(2):126-137. 
Pei, K. J. C. 2006. Present status of the Formosan wild boar (Sus scrofa taivanus) in the Kenting National Park, southern Taiwan. Suiform Soundings, 6(1):9-10.

Prater, S. H. 1965. The book of Indian animals. Bombay Natural History Society, Bombay, India.

Pullar, E. M. 1950. The wild (feral) pigs of Australia and their role in the spread of infectious diseases. Australian Veterinary Journal, 25(4):99-110.

Quenette, P. Y., and J. P. Desportes. 1992. Temporal and sequential structure of vigilance behavior of wild boars (Sus scrofa). Journal of Mammalogy, 73(3):535-540. (Behavior)

Quenette, P. Y., and J. F. Gerard. 1992. From individual to collective vigilance in wild boar (Sus scrofa). Canadian Journal of Zoology, 70(8):1632-1635.

Rolls, E. C. 1969. They all ran wild: The story of pests on the land in Australia. Angus and Robertson Publishers. London, United Kingdom.

Rue, L. L., III. 1968. Sportsman's guide to game animals: A field book to North American species. Harper \& Row, New York.

Robb, B. 1989. Hunting wild boar in California. Larsen's Outdoor Publishing, Lakeland, Florida.

Saunders, G. 1988. The ecology and management of feral pigs in New South Wales. M.S. Thesis, Macquarie University, Ryde, Australia.

Saunders, G., and B. Kay. 1991. Movements of feral pigs at Sunny Corner, New South Wales. Wildlife Research, 18:49-61.

Saunders, G., and B. Kay. 1996. Movement and home ranges of feral pigs (Sus scrofa) in Kosciusko National Park, New South Wales. Wildlife Research, 23(6):711-719.

Saunders, G., and S. McLeod. 1999. Predicting home range size from the body mass or population densities of feral pigs, Sus scrofa (Artiodactyla: Suidae). Australian Journal of Ecology, 24(5):538-543.

Schauss, M. E. 1980. Population dynamics and movements of wild pigs in Grant Park. M.A. Thesis, San Jose State University, San Jose, California.

Schortemeyer, J. L., L. L. Hamilton, R. E. Johnson, and D. R. Progulske, Jr. 1985. Everglades hog study XVI - dispersal and survival of resident and stocked wild hogs in the Everglades, Project W-41, Final Job Performance Report. Florida Game and Fresh Water Fish Commission, Naples, Florida.

Shaffer, M. L. 1976. Behavior of the European wild boar (Sus scrofa) in the Great Smoky Mountains National Park. M.S. Thesis, Duke University, Durham, North Carolina.

Shepherd, N. 1994. "Are You a Potential Potbellied Pig Parent?" http://potbellypigs.com/htowning.htm.

Singer, F. J., B. B. Ackerman, M. E. Harmon, and A. R. Tipton. 1978. Part I. Census, trapping, and population biology of European wild boar - 1977. Pp. 1-93. In Studies of European wild boar in the Great Smoky Mountains National Park: 1st annual report; a report for the Superintendent. Uplands Field Research Laboratory, Great Smoky Mountains National Park, Gatlinburg, Tennessee.

Singer, F. J., D. K. Otto, A. R. Tipton, and C. P. Hable. 1981. Home range, movements and habitat use of European wild boar in Tennessee. Journal of Wildlife Management, 45(2):343-353.

Sludskii, A. A. 1956. Kaban: Ekologia i chozjajstvennoe znacenie. Akademii Nauk Kazachskoi SSR, Alma-Ata, Kazakhstan S.S.R. 


\section{Wild Pigs}

Snethlage, K. 1982. Das Schwarzwild. 7th Edition. Verlag Paul Parey, Hamburg and Berlin, West Germany.

Sodeikat, G., and K. Pohlmeyer. 2003. Escape movements of family groups of wild boar Sus scrofa influenced by drive hunts in Lower Saxony, Germany. Wildlife Biology, 9(Suppl. 1):43-49.

. 2004. Escape movements of wild boar piglets (Sus scrofa L.) after trapping, marking and releasing. Galemys, 16(No. Especial):185-193.

Sparklin, W. D. 2009. Territoriality and habitat selection of feral pigs on Fort Benning, Georgia, USA. M.S. Thesis, The University of Montana, Missoula, Montana.

Spencer, P. B. S., S. J. Lapidge, J. O. Hampton, and J. R. Pluske. 2005. The sociogenetic structure of a controlled feral pig population. Wildlife Research, 32(4):297-304.

Spitz, F. 1986. Current state of knowledge of wild boar biology. Pig News and Information, 7(2):171-175.

Spitz, F., and G. Janeau. 1990. Spatial strategies: An attempt to classify daily movements of wild boar. Acta Theriologica, 35(1-2):129-149.

. 1995. Daily selection of habitat in wild boar (Sus scrofa). Journal of Zoology (London), 237(3):423-434.

Stegeman, L. J. 1938. The European wild boar in the Cherokee National Forest, Tennessee. Journal of Mammalogy, 19(3):279-290.

Stephen, D. 1968. Encyclopedia of animals. St. Martin’s Press, Inc., New York, New York.

Sterner, J. D. 1990. Population characteristics, home range, and habitat use of feral pigs on Santa Cruz Island, California. M.S. Thesis, University of California at Berkeley, Berkeley, California.

Sweeney, J. M. 1970. Preliminary investigation of a feral hog (Sus scrofa) population on the Savannah River Plant, South Carolina. M.S. Thesis, University of Georgia, Athens, Georgia.

Sweeney, J. M., J. R. Sweeney, and S. W. Sweeney. 2003. Feral hog, Sus scrofa. Pp. 1164-1179. In G. A. Feldhammer, B. C. Thompson, and J. A. Chapman (eds.), Wild mammals of North America: Biology, management, and conservation. The Johns Hopkins Univ. Press, Baltimore, Maryland.

USDA (U. S. Department of Agriculture). 1981. European boar (Section 410). Pp. 1-7. In Wildlife habitat management handbook: Southern Region. FSH 2609.23R. U. S. Department of Agriculture, U. S. Forest Service, Atlanta, Georgia.

Truvé, J., and J. Lemel. 2003: Timing and distance of natal dispersal for wild boar Sus scrofa in Sweden. Wildlife Biology, 9(Suppl. 1):51-57.

Van Vuren, D. 1984. Diurnal activity and habitat used by feral pigs on Santa Cruz Island, California. California Fish and Game, 70(3):140-144.

Vaughn, T. A. 1986. Mammalogy. 3rd Edition. Harcourt Brace Jovanovich College Publishers, New York, New York.

Waithman, J. 2001. Guide to hunting wild pigs in California. California Department of Fish and Game, Wildlife Programs Branch, Sacramento, California. 
Walther, F. R. 1984. Communication and expression in hoofed mammals. Indiana University Press, Bloomington, Indiana.

Wodzicki, K. A. 1950. Introduced mammals in new Zealand, an ecological and economic survey. Bulletin No. 98. New Zealand Department of Science, Industry and Research, Wellington, New Zealand.

Wood, G. W., and R. E. Brenneman. 1977. Research and management of feral hogs on Hobcaw Barony. Pp. 23-35. In G. W. Wood (ed.), Research and management of wild hog populations. Belle Baruch Forest Science Institute of Clemson University, Georgetown, South Carolina.

1980. Feral hog movements and habitat use in South Carolina. Journal of Wildlife Management, 44(2):420-427. 
Wild Pigs

\section{Biology of Wild Pigs:}

\section{Wild Pig Food Habits}

Stephen S. Ditchkoff and John J. Mayer

School of Forestry and Wildlife Sciences, Auburn University, Auburn, Alabama 36849 (SSD)

Savannah River National Laboratory, Savannah River Nuclear Solutions, LLC, Savannah River Site, Aiken, South Carolina 29808 (JJM)

\section{Introduction}

Wild pigs (Sus scrofa) are omnivorous and generally opportunistic in their food habits (Sweeney et al. 2003). The ability of this species to survive on almost anything edible is one of the primary factors that led to the globally common use of free-ranging husbandry practices with the domestic component of S. scrofa. It is also one of the main reasons why this species has been so successful as an invasive species in establishing new wild-living populations in non-native areas. In spite of being omnivorous, studies have shown that the year-round diet of wild pigs contains a predominance of plant material (Table 1). However, algae, fungi and animals, as well as other materials, are also included in the list of items eaten by this suid. The specific composition of the diet of any one wild pig population is largely dependent upon what foods are available in the local area at any point in time. The season or time of year typically determines the bulk of their diet. In addition, these animals tend to maximize the intake of a preferred food resource when it is encountered. This adaptability can occasionally result in abrupt and radical seasonal changes in diet being observed as new forage species become available (Barrett 1978).

In addition to contributing to the species' capabilities as an environmental generalist, the diverse spectrum of potential forage resources used by wild pigs also increases their potential to impact natural and manmade environments. In any one area, wild pigs have been reported to feed on hundreds of different kinds of organisms (e.g., Genov 1981a, Thomson and Challies 1988, Schley and Roper 2003; Table 2). Understanding the species that wild pigs might forage on could be useful in trying to control or reduce potential impacts. Such knowledge is also required to understand the ecological influences of the feeding behavior of these animals in both native and introduced areas, as well as their role within the local food chain (Chimera et al. 1995, Baubet et al. 2004).

The purpose of this paper is to provide a general overview of wild pig food habits. Several topical areas were focused on and addressed in this review, including plant consumption, algae consumption, fungi consumption, animal consumption, other material ingestion, seasonal dietary variation, nutritional aspects of the diet, and the effect of diet on productivity. In addition to that obtained from the scientific and popular literature, data or information on wild pig food habits from the Savannah River Site (SRS) in Aiken, Barnwell and Allendale counties, South Carolina, has also been included.

\section{Results/Discussion}

The wild pig's alimentary tract is identical to that of its domestic counterpart. The stomach is a simple, non-ruminating structure. It is technically two-chambered with a small blind pouch or diverticulum, having a total capacity in adults of approximately 5 to 8 liters (Briedermann 1986). Typically, these animals can daily eat between 3 and $5 \%$ of their total body mass (Bodenchuk 2008). Pinna et al. (2007) reported that the mean $\mathrm{pH}$ of wild pig stomach contents was 3.8. The colon is spirally coiled with a caecum at the anterior end of the large intestine. The wild pig digestive tract is capable of adequately digesting and utilizing plant, algal, fungal and animal matter. However, it has a poor capacity for breaking down cellulose and hemicellulose, structural carbohydrates that form the nutritional basis for ruminants (e.g., bovids, cervids, etc.). Suids cannot effectively digest these structural carbohydrates relative to ruminants 
because: (1) they do not possess the bacteria/protozoan-filled 4-chambered stomach system of the ruminant that digests forage through fermentation, and (2) their digestive strategy is to maximize forage intake and gut transit time. Rather, wild pigs possess a stomach that relies on gastric secretions and enzymes for digestion, and the point where fermentation can take place (i.e., caecum and colon) is located behind the primary structure responsible for nutrient absorption (i.e., small intestine). Additionally, fermentation is a relatively slow digestive process, and the rapid passage rate of digesta does not allow for efficient fermentation. As a result, wild pigs tend to select forages that are easily digestible and low in structural carbohydrates.

The reported dietary variation between the sexes or age classes in wild pigs has not been consistent among populations. In general, most studies (e.g., Wood and Roark 1980, Scott and Pelton 1975, Durio et al. 1995, Loggins et al. 2002, Adkins and Harveson. 2006, Skewes et al. 2007) have found no difference in the diet with respect to either sex or age. Similarly, Barrett (1978) found no apparent variation in food habits between the sexes or age classes with one exception. He observed that adult boars tended to eat more carrion than other hogs due to their ability to dominate a carcass. Adult boars also tend to be more mobile than either sows or younger males. This would probably further increase their chances of encountering and utilizing carrion as a food resource. In contrast to these other studies, Dardaillon (1989), Abaigar (1993) and Groot Bruiderink et al. (1994) all reported that a greater proportion of animal material was found in the stomachs of young wild pigs compared to adults. Dardaillon (1989) also found a greater overall diversity of foods in the stomachs of younger individuals. The latter broad dietary diversity was suggested as an advantage for young and inexperienced individuals still learning to cope with fluctuations in food availability in the local area.

Thomson and Challies (1988) characterized three general types of foraging used by wild pigs: (1) browsing and grazing - leaves, fronds, stems, etc.; (2) foraging on the ground - fruits of woody species, fungi, small animals, vertebrate carrion, etc.; and (3) rooting - rhizomes, tubers, bulbs, corms, invertebrate larvae, small fossorial vertebrates, etc. Wild pigs normally rely upon their keen sense of smell to identify potential food items. Most forage resources that they consume will be at or near ground level (Table 3). Additionally, wild pigs are extremely adept at locating and obtaining potential forages below the soil surface by rooting, and much of their diet is obtained in this manner. With the use of their snout and strong neck muscles, they are able to overturn large amounts of soil material. Depending upon forage type, as well as soil density, moisture level, and compaction, they may obtain forages from a few centimeters up to a meter or more below the soil surface. This difference between above and below ground foraging varies by season and location with respect to resources that are available (Table 3).

Plant Consumption - Floral material makes up the majority (approx. 88\%) of a wild pig's dietary composition and is consumed year-round. This plant forage composition can vary from 57 to $99 \%$ of an animal's diet (Table 1), and seasonally can be as great as 100\% (Klaa 1992). The list of plant species consumed by wild pigs is considerable (Table 2), and the main plant food categories include fruits, seeds, leaves, stems, shoots, bulbs, tubers, and roots. The makeup of these basic types of plant foods varies by location (Table 3). The general plant taxa consumed by these animals collectively includes Bryphytes (i.e., mosses), Pteridophytes (i.e., ferns and horsetails), Pinophytes (i.e., conifers) and Magnoliophytes (i.e., flowering plants).

Native plants represent the majority of the wild pig diet. However, pigs will be highly selective of which plant species they consume, the time of year that particular species are consumed, and what plant parts are consumed. Plant phenology influences forage selection, varying from seeds or newly emerged sprouts to plants that have entered senescence (Howe et al. 1981). Plant species/part selectivity will be a function of digestibility and availability. Normally, preferred plant parts are fruits, seeds, bulbs, tubers, and roots (see Tables 2 and 3) as these structures are normally low in structural carbohydrates and are easily digested. The high composition of simple sugars, starches, and lipids, and relatively low concentrations of plant defensive compounds that may inhibit digestion cause them to be highly desirable.

Of the various species of plants consumed, mast (e.g., acorns, beechnuts, chestnuts, and hickory nuts) appears to be most important and preferred (Barrett 1978, Henry and Conley 1972, Sweeney et al. 2003). The same is true for populations in their native range (e.g., Sjarmidi et al. 1992, Fournier-Chambrillon et al. 


\section{Wild Pigs}

1995, Durio et al. 1995, Groot Bruinderink and Hazebroek. 1995, Schley and Roper 2003, Irizar et al. 2004). This is evidenced by both the preponderant usage of this food when available and the effect that abundance of this resource has on reproductive success within a population (Matschke 1964, Schley and Roper 2003). In fact, wild pigs will consume acorns for as long as this forage resource is available (Fournier-Chambrillon et al. 1995). This preference holds true more than for any other forage resource used by these animals (Henry and Conley 1972). Its use can reach $90 \%$ in volume and $100 \%$ in occurrence in the wild pig's seasonal diet (Henry and Conley 1972, Ackerman et al. 1978, Irizar et al. 2004). Hard and soft mast crops represent forages that are very high in energy, and when available can often be found in large quantities. While mast is a pulse resource and somewhat unpredictable from year to year, normally there is some form of mast available during late summer through mid-winter of each year in most areas. Although typically obtained through shallow rooting in the leaf litter, wild pigs will also obtain hard and soft mast by exploiting subsurface hoards collected by mammals (e.g., squirrels and small rodents) when encountered (Focardi et al. 2000). The consumption of these caches by wild pigs throughout winter may negatively affect productivity of local populations of these species of small mammals.

Subsurface herbaceous materials (e.g., roots, tubers, bulbs, etc.) are widespread and important staples in wild pig diets throughout their distribution. In general, wild pigs tend to prefer fleshy roots or corms to woody roots (Howe et al. 1981). Subsurface foraging by wild pigs increases with altitude, with roots constituting $71 \%$ of the diet in areas of the French Alps above 1,900 m (Baubet et al. 2004). At higher elevations, where mainly pastures or open meadows occur, roots are an even more important part of the diet. More specifically, rooting for subsurface herbaceous materials is the only way to readily access foods in these higher elevations during winter months (Baubet et al. 2004). Roots also become important during fall and winter when mast crops fail (Scott and Pelton 1975, Wood and Roark 1980, Baber and Coblentz 1987). In contrast to the widespread use of this general forage resource, Irizar et al. (2004) found no evidence of any belowground herbaceous material in the fall and winter diets of wild pigs in northern Spain.

Because of their relatively high digestibility and their high concentration of individual plants, agricultural crops are a highly preferred food source for wild pigs when available. Consumption of agricultural crops encompasses a variety of forage resources including grains/cereals (e.g., wheat, sorghum, barley, hay, rye, oats, millet, maize/corn, and rice), vegetables (e.g., various potatoes, yams, squash, turnips, rutabagas, beets, cassava, lettuce, cabbage, beans, peas, soybeans, and artichokes), fruits (e.g., pumpkins, grapes, blueberries, pineapples, avocadoes, bananas, apples, various citrus species, watermelons, cantaloupes, and coconuts), and other crops (e.g., cotton, linseed, sunflower, peanuts, almonds, oilseed/rapeseed, groundnuts, pecans, clover, thyme, basil, oil palms, sugar cane, rubber seeds, padi, and turf/sod/pasturage) (Diong 1973, Tisdell 1982, Brooks et al. 1988, Stevens 1996, Devine 1999, Schley and Roper 2003, Mapston 2004, J. J. Mayer, unpubl. data). The use of agricultural crops as a forage resource by wild pigs varies, ranging from nothing up to $71 \%$ of the plant material consumed (Genov 1981a, Irizar et al. 2004). In most locations where these foods are available, the use of agricultural crops typically ranges from about $30-50 \%$ of the plant volume eaten (Fournier-Chambrillon et al. 1995, Herrero et al. 2004, Giménez-Anaya et al. 2008). In discussing this variation, Sjarmidi et al. (1992), Wlazelko and Labudzki (1992) and Fournier-Chambrillon et al. (1995) all suggested that when natural foods are in abundance, wild pigs will not use agricultural crops. Soybeans, peanuts, and other leguminous species are highly desirable because of their extremely high protein levels. When available, wild pigs will visit agricultural fields with highprotein species on a daily/nightly basis and can cause significant amounts of damage and crop loss. Genov (1981b) reported that $90 \%$ of damage by wild pigs to agricultural crops in Poland were to potato, rye and oat fields. In addition to those agricultural crops that are high in protein, wild pigs will readily consume corn, sorghum, wheat, rice, and other grain crops that are carbohydrate-based.

Wild pigs can have negative impacts on pine and hardwood timber production in some areas through direct foraging on those commercial species. Plantings of longleaf pine (Pinus palustris) seedlings have been documented to receive significant damage due to foraging by wild pigs (Lipscomb 1989). Wild pigs are attracted to the starchy bark of the root of longleaf seedlings, and an individual pig can destroy 200-1,000 planted longleaf seedlings in a single day (Wakeley 1954). Wood and Roark (1980) observed that wild pigs typically do not completely ingest the seedling roots, but rather chew the root, swallow the sap and starches, and then spit out the chewed woody tissues before moving on to the next seedling. Such foraging 
can also include the roots of seedling slash pines ( $P$. elliotti), loblolly pines ( $P$. taeda), and pitch pines $(P$. rigida), although this is relatively uncommon. Wild pig damage has also been reported to hardwood/deciduous tree species. Similar to pines, wild pigs also dig up and consume the root stock of planted hardwood seedlings (Mayer et al. 2000). Wild boar have been found to selectively forage on the germinating seedlings and saplings of oak and beech species, having a special interest in the highly digestible and protein rich roots in late winter and spring (Groot Bruinderink and Hazebroek 1996).

Wildlife plantings or food plots (e.g., millet, winter wheat, clover, etc.) intended for native game species are normally very attractive to wild pigs and can receive significant damage due to foraging and rooting in the plots (Hanson and Karstad 1959, J. J. Mayer, unpubl. data). Wild pigs will also readily consume supplemental feed and bait (e.g., shelled corn) placed for native game species during fall and winter months (Fournier-Chambrillon et al. 1995, Taylor and Hellgren 1997). This type of opportunistic foraging would also include the use of bait lines set up at wild pig traps, which can often entail these animals not entering the associated traps and being caught. In some situations, the intense use of these resources can result in these food items comprising between $20-40 \%$ of the seasonal diet of these animals (Fournier-Chambrillon et al. 1995, Taylor and Hellgren 1997, Herrero et al. 2004, Adkins and Harveson 2006).

Algae Consumption - Where available (e.g., on oceanic islands and in coastal habitats), algae in the form of green and brown seaweeds found on exposed shores are opportunistically consumed by wild pigs. Challies (1975) and Chimera et al. (1995) reported that seaweed composition in the diet of wild pigs in coastal areas on Auckland Island, New Zealand, was $0.2 \%$ and $15 \%$, respectively, by volume. Working at the same location, Rudge (1976) speculated that the presence of seaweed in wild pig diets was probably due to these animals eating the regurgitation of New Zealand sea lions (Neophoca hookeri) rather than the pigs foraging on the algae themselves. The frequency of occurrence in wild pig stomach was also low (i.e., 2-6\%) (Rudge 1976, Chimera et al. 1995). In general, given the limited areas within the species range for such opportunistic foraging of seaweeds, algae would be a minor component of the overall wild pig diet.

Fungi Consumption - Wild pigs eat fungi (i.e., the fruiting bodies), but typically this is a small component of their diet (approx. 2\%). The amount of fungi consumed depends upon availability of other forage resources. Fungi can be found in the diet year-round, and has variously been reported to be most frequent in winter (Genov 1981a), spring (Springer 1975, Baron 1979) and summer (Ackerman et al. 1978, Wood and Roark 1980). Skewes et al. (2007) found an overall greater proportion by volume (i.e., 15.9\%) of fungi in the diet of wild pigs in Chile than had been reported elsewhere, while both Springer (1975) and Ackerman et al. (1978) found seasonal peaks of fungi consumption of $14.6 \%$ and $18.6 \%$, respectively. Other studies (e.g., Springer 1975, Genard et al. 1988, Abaigar 1993, Fournier-Chambrillon et al. 1995, Skewes et al. 2007) have reported a fairly high frequency of occurrence of fungi remains (i.e., up to $69 \%$ ) in wild pig stomachs. In contrast, a few studies did not report consumption of any fungi by these animals (e.g., Dardaillon 1987, Massei et al. 1996). Because of the high digestibility of fungi, Schley and Roper (2003) suggested that such differences could result from the presence of fungi only being found if eaten relatively recently by the wild pigs whose stomachs were being examined.

Animal Consumption - Like plants and fungi, animal material (i.e., invertebrates and vertebrates) is consumed year-round (Scott and Pelton 1975). The list of animals consumed by wild pigs includes earthworms, arachnids, crustaceans, insects, myriapods, gastropods, nematodes, fish, amphibians, reptiles, birds and mammals, and can include the egg, larval/immature and adult forms of various species (Table 2). Compared to plants, animal material typically makes up a smaller percentage of the dietary composition (approx. 10\%). However, all 40 studies listed in Table 1 reported at least some animal matter composition in the wild pig diet. While the composition by volume in the diet can be low (e.g., 5-8\%), the frequency of occurrence within the stomachs examined is often very high (e.g., 80-90\%) (Rudge 1976, Diong 1982, Herrero et al. 2004, Irizar et al. 2004, Giménez-Anaya et al. 2008). It has been suggested that food habits studies of wild pigs may under represent the percentage of animal matter in the diet (Hahn et al. 1998, Loggins et al. 2002). Rapid digestion of soft tissues often causes animal matter to be overlooked when conducting an analysis of stomach contents or feces (Klaa 1992, Fournier-Chambrillon et al. 1995, Schley and Roper 2003). Unless exoskeleton, bones, scales, feathers, hair, or remains are present, documentation may not occur. 


\section{Wild Pigs}

The presence of animal matter in a wild pig's diet has been reported to be due more to availability and accessibility rather than prey selection (Klaa 1992). However, Fournier-Chambrillon et al. (1995) stated that the presence of at least some animal foods in the wild pig's diet was indispensable. Ingestion of these high-protein foods may be important for growth and survival in wild pigs (Schley and Roper 2003). In fact, studies have shown that wild pigs intentionally deprived of animal proteins will lose weight over time (Klaa 1992). Wilcox and Van Vuren (2009) reported that wild pigs found with vertebrate prey in their stomachs were in poorer physical condition (i.e., based on rump fat thickness) than pigs whose stomachs did not contain vertebrate prey. These authors further suggested that protein deficiency may be an important factor influencing the predation of vertebrates by wild pigs, particularly for females facing the physiological cost of pregnancy.

Typically, more invertebrate than vertebrate remains are found in the stomachs of wild pigs (Henry and Conley 1972, Scott and Pelton 1975, Skewes et al. 2007; Table 4). Invertebrates were found in all 40 studies reviewed. Typically, either insects or annelids are the most common general types of invertebrates eaten by wild pigs, followed by myriapods, crustaceans, gastropods and other taxa (e.g., nematodes, arachnids, etc.) (Klaa 1992, Schley and Roper 2003). Invertebrates are consumed by wild pigs year-round (Springer 1975).

Within the invertebrate portion of the wild pig diet, insects usually comprise the majority of the volume reported. Frequency of occurrence has been reported to be as high as 100\% (Ackerman et al. 1978). Although they can consume any life stage (e.g., larval, pupae, instars, adults), most of the remains found in wild pig stomachs and scats are larval forms. The spectrum of insect taxa consumed by wild pigs is more diverse than in any other invertebrate group consumed, encompassing at least 6 Orders and 24 Families (Table 2).

Because of their high protein content, earthworms are frequently reported to be found in wild pig diets (e.g., Giffin 1970, Challies 1975, Scott and Pelton 1975, Wood and Roark 1980, Howe et al. 1981, Fournier-Chambrillon et al. 1995, Massei et al. 1996, Baubet et al. 2004). In some extreme cases, annelids are the most important animal food eaten by wild pigs (Challies 1975, Diong 1982, Asahi 1995). The frequency of occurrence for earthworms has been reported to be as high as almost $90 \%$ in wild pig stomachs (Diong 1982). As many as 300 earthworms have been found in a single wild pig stomach (Hanson and Karstad 1959). Earthworms are consumed year-round, with some seasonal variation observed. Fournier-Chambrillon et al. (1995) noted that earthworm consumption by wild pigs was related to the amount of rainfall, reporting that volume was greatest in winter, but frequency of occurrence was greatest in the fall. They further reported that earthworms were absent in wild pig stomachs during the summer months. In contrast, Baubet et al. (2004) reported that earthworm use by wild pigs as a food resource in alpine areas was least in winter. These authors further explained that earthworms are less accessible during winter months because of snow cover and the deeper depths that these worms retreat to during the colder months in these habitats (Baubet et al. 2003, 2004).

Most $(86 \%)$ of the 40 studies reviewed listed vertebrates as consumed by wild pigs. Typically, this consists of either whole small vertebrates or carrion of larger animals. The intentional predation of small vertebrates does occur (Loggins et al. 2002). Both male and female wild pigs use vertebrates as a forage resource, and they are consumed during every season (Springer 1975). This type of predation has been reported to be most frequent from the summer through the winter months (Breidermann 1976, Tucak 1996, Wilcox and Van Vuren 2009). Stomachs of wild pigs have been found with multiple individuals (e.g., 2 to 49) of small vertebrate prey (e.g., anurans, rodents) in them (Schneider 1975, Wilcox and Van Vuren 2009, Jolley et al. In Press). Many of the vertebrate prey examined appear to have been taken during active predation by the wild pigs (Wilcox and Van Vuren 2009). In fact, Loggins et al. (2002) reported that one wild pig was observed standing motionless for over 20 minutes above a ground squirrel burrow, apparently waiting for the opportunity to catch one of these rodents. Some of the vertebrate prey were fossorial or semi-fossorial, suggesting that these animals were taken opportunistically by pigs during rooting or grazing (Wilcox and Van Vuren 2009). There have been cases where pigs consumed more than just the prey species. For example, Giménez-Anaya et al. (2008) reported that one wild pig even had a common moorhen (Gallinula chloropus), that bird's nest and the nest of a purple gallinule (Porphyrio porphyrio) in 
SRNL-RP-2009-00869

its stomach. Schley and Roper (2003) reported that amphibians and reptiles were generally not taken in large volumes.

Wild pigs can also be voracious predators of larger animals, preying on several species of domestic livestock and wild game. However, Wood and Barrett (1979) stated that both witnessed attacks and the actual killing of these larger species are rare. In spite of that fact, such predation does still occur. Hennig (1981) reported that wild pigs will directly kill and consume roe deer fawns (Capreolus capreolus). Pavlov and Hone (1982) described the predation of lambs by wild pigs. Beach (1993) reported that livestock losses to wild pigs in Texas included lambs, adult sheep, kid goats, adult goats, calves, and exotic game species. Several authors (e.g., Rutledge 1970, Springer 1975, Jolley 2007) have reported predation of white-tailed deer fawns by wild pigs. In addition, the surplus killing of sheep and goats by wild pigs in small fenced enclosures has been observed in Edward's Plateau, Texas (R. F. Smart, pers. comm.). Often such attacks are the result of a momentary opportunity. In a heretofore unreported type of predation, three feral hogs were observed to attack, kill and partially consume an adult Rio Grande wild turkey hen on a wildlife food plot on the King Ranch, Texas, where all four animals had been feeding together in close proximity only moments before the attack (T. C. Urban, pers. comm.).

Wild pigs will readily consume animal carrion (e.g., Giffin 1970, Rudge 1976, Barrett 1978, Everitt and Alaniz 1980, Thomson and Challies 1988, DeVault and Rhodes 2002). In fact, the presence of large vertebrate material in most studies has normally been assumed to have been taken as carrion (Schley and Roper 2003). Wilcox and van Vuren (2009) defined the basis for identifying vertebrate remains as carrion in a wild pig stomach as the presence of dehydrated tissue, the odor of decomposition, and tissue being infested with maggots. Although usually not a major component, vertebrate carrion can make up to $12.4 \%$ of the wild pig diet (Thomson and Challies 1988). Wild pigs have been reported to scavenge on vertebrate carrion varying in size from as small as rodents (DeVault and Rhodes 2002) up to carcasses as large as ungulates and pinnepeds (Rudge 1976, Thomson and Challies 1988). In fact, wild pigs have even been documented to opportunistically forage on human remains in post-combat situations and from accidental or medically-related fatalities occurring in rural areas (Williams et al. 1998, Rockenbach 2005). Fish found in wild pig diets are usually opportunistically consumed as carrion when encountered washed up dead on shores or in dried-up pools and drainage channels (Baron 1979, Schley and Roper 2003). Wild pigs will also occasionally feed on weathered skeletons of both wild pigs and other vertebrates as a calcium source (Rudge 1976, Diong 1982).

Much consumption of animal matter is likely opportunistic and a result of randomly discovering prey during foraging bouts. As a result, their impact on most species is likely negligible. However, some researchers have suggested that feral pigs may have negative consequences for local populations of some reptile and amphibian species. Jolley et al. (In Press) suggested that high rates of consumption of pulsebreeding, adult amphibians could have negative consequences for local populations. Consumption of eggs of ground-nesting reptiles is also reported to be a threat to some species (Coblentz and Baber 1987, Oliver and Brisbin 1993, Taylor and Hellgren 1997). While not well documented, consumption of eggs of ground-nesting birds could have negative impacts on some species as well.

Ingestion of Other Material - In addition to plants, algae, fungi and animals, wild pigs have been found to ingest other materials (e.g., miscellaneous biotic matter, garbage, soil). Rudge (1976) found that most of the wild pig stomachs examined on Auckland Island contained such materials. In some cases, these materials are incidentally ingested during either rooting or surface foraging. For example, reported biotic materials that were probably incidentally ingested included pieces/lumps of wood, peat and lichen (Henry and Conley 1972, Rudge 1976). In other instances, the consumption of these materials is intentional. In either case, these items tend to make up a very small portion of their diet by volume $(<1 \%)$.

Wild pigs have been reported to feed on garbage or refuse in several locations (e.g., Hanson and Karstad 1959, Henry and Conley 1972, Scott and Pelton 1975, Ackerman et al. 1978, Erkinaro et al. 1982, Herrero et al. 2004, Giménez-Anaya et al. 2008). This has been documented to include both edible (e.g., discarded food waste) as well as inedible (e.g., plastic, rubber bands) refuse. Henry and Conley (1972) specifically noted that wild pigs foraged in local garbage pits in eastern Tennessee, with garbage composing up to $11.8 \%$ of the volume of the annual fall diet in these animals in that area. However, the authors did not 


\section{Wild Pigs}

consider garbage to be an important source of food for these animals. Based on anecdotal observations, Hanson and Karstad (1959) reported that garbage was superior to shelled corn as trap bait. More recent studies (e.g., Wathen et al. 1988) have shown the opposite to be true. The Three Rivers Solid Waste Authority regional landfill located on the SRS has recently reported large numbers of wild pigs rooting up and foraging in the facility's sanitary solid/household waste disposal cells. As many as 100 wild pigs at a time were observed foraging for garbage there at night during the spring and early summer of 2009 (J. J. Mayer, unpubl. data).

Incidental consumption of trace amounts of soil/sand and rocks/gravel by wild pigs as a result of rooting has been reported previously (e.g., Baker 1975, Scott and Pelton 1975, Rudge 1976, Ackerman et al. 1978, Klaa 1992, Durio et al. 1995). These geological materials have been reported to be present in trace amounts up to $5.3 \%$ of the annual diet by volume (Ackerman et al. 1978, Durio et al. 1995). On a monthly basis, this volume has been reported to be as high as 9.9\% (Klaa 1992). Based on estimates made using acid-insoluble ash content of wild pig scats collected at the SRS, Beyer et al. (1994) estimated that $2.3 \%$ of the diet of these animals consisted of soil. Similar amounts (i.e., 3.3-8.0\%) of soil ingestion have also been reported for domestic swine (Fries et al. 1982).

Seasonal Dietary Variation - Throughout their range, the diet of wild pigs varies by season. This variation is primarily a function of availability and abundance of local plant and animal communities (Klaa 1992, Sjarmidi et al. 1992). Globally, similar food types (e.g., plants, animal matter, roots, etc.) tend to be consumed during the same season, with local variation based on species composition. Preferences among food items do occur as evidenced by a few items making up most of the seasonal diets in these animals locally (Everitt and Alaniz 1980). In addition, the seasonal effect or change in the diet is not always consistent between years (Taylor and Hellgren 1997). In contrast to data from most studies, Loggins et al. (2002) reported that the diet of wild pigs in a central California coastal area was similar among all seasons, except for the fall, when acorns were the predominate food item.

Along with availability, phenology (often influenced by precipitation) and nutrition levels in different plant parts changes seasonally, and consumption by wild pigs changes accordingly. In general, there is extensive use of seasonally available fruits, regardless of location (Thomson and Challies 1988). However, roots were the most consistent food item consumed all year. Genov (1981a) further reported that the frequency of consumption of aboveground plant material was greatest in spring and least in winter, while the reverse occurred for subsurface plant material. Diong (1982) reported that, with the exception of two food items, seasonal variation was not apparent in the diet of wilds pigs in the Kipahulu Valley. This was driven by seasonal availability of these two plant species (i.e., tree ferns, Cibotium sp., and strawberry guava, Psidium cattleianum). Baber and Coblentz (1987) reported that seeds, fruits and roots were used more during the dry season (June through December), while the use of grasses and forbs was greatest in the wet season (January through May) on Santa Catalina Island.

In comparing the different studies on food habits of wild pigs, the consumption of animal material varied greatly between seasons. The use of animal matter by wild pigs is a function of seasonal availability and whether particular species tend to be available as pulse resources, or consistently throughout the year. For example, Jolley et al. (In Press) reported that consumption of herpetofauna occurred in two major pulses (July-August and December-January), which was most likely driven by availability. Baber and Coblentz (1987) noted that insect consumption did not vary between seasons. The use of carrion can increase during fall and winter due to greater availability of carcasses and entrails generated by sporthunting activities.

Most studies (e.g., Pine and Gerdes 1973, Wood and Roark 1980) have reported that wild pig diets during winter months are dominated by either mast or roots. During years of mast failure, roots become the dominant forage resource (Scott and Pelton 1975), while mast predominates in the diet during years of high mast production. Giménez-Anaya et al. (2008) stated that agricultural crops were less available in the winter, so wild pigs turned to consuming more subsurface parts of non-agricultural plants. FournierChambrillon et al. (1995) reported that animal matter is consumed during winter, but like the rest of the year, plant items are the most abundant forage resources in the diet. In contrast, Hanson and Karstad (1959) found that winter foods of wild pigs in the Coastal Plain of Georgia consisted of only plant material. 
During spring, new growth of grasses and other vegetation becomes much more important as it is lower in structural carbohydrates at this time of year and more easily digestible. Scott and Pelton (1975) reported that grass made up $86.7 \%$ of the spring diet. Wood and Roark (1980) also found that herbage/foliage consumption was greatest in spring. Eriksson and Petrov (1995) found that rooting was low during the spring months, most likely because of high availability of protein-rich, above-ground plant parts. Hanson and Karstad (1959) reported that animal material increased in the spring as well.

In general, grasses and new vegetative growth remain important during summer (Pine and Gerdes 1973, Scott and Pelton 1975, Wood and Roark 1980). In addition, insect availability and soft mast production are generally greatest during summer, and the diet of wild pigs reflects this availability. Some roots are also used, especially during dry periods.

During fall, hard mast again becomes a major component of the diet (Pine and Gerdes 1973, Wood and Roark 1980). During years of mast failure, roots are again the prominent forage resource (Scott and Pelton 1975). At this time, there also tends to be very little vegetative growth, so plant material above the soil surface decreases in importance. Eriksson and Petrov (1995) found that rooting increased to a peak in the fall and remained important for acquiring food during the winter months.

Nutritional Aspects of Diet - Nutritional condition of wild pigs varies seasonally. In most cases, it can be expected to be poorest during winter because of poor availability of food resources. However, during years with exceptional hard mast production, pig populations can be found to be in exceptional condition during winter. In general, nutritional condition of wild pigs is greatest during spring, when there is a flush of new vegetative growth, and fall, when hard mast is available in large quantities. Nutritional condition can vary during summer, as this is the time of year when drought can significantly reduce food availability.

Depending upon the area, wild pigs will consume at least one energy-rich plant food (e.g., acorns, beechnuts, chestnuts, pine seeds, olives, cereal grains, or other crops) (Schley and Roper 2003). Nutrient levels vary considerably by forage type. Fruits contain high concentrations of readily digestible carbohydrates (sugars and starch) relative to green foliage. Some fruits are especially high in lipids that provide readily available energy. Foliage contains more protein than fruits, but the high concentration of structural carbohydrates (e.g., cellulose and hemicelluloses) reduces its digestibility. Some fruits contain large seed capsules, which could provide proteins if consumed by wild pigs along with the fleshy pulp. However, fruits serve primarily as a source of energy. Supplemental feeds (e.g., shelled corn) can be high in carbohydrates but low in proteins.

Like other wildlife species, protein intake is a critical component of the diet. High protein levels are necessary during gestation and lactation, and for adequate growth of piglets. If intake of crude protein falls below $15 \%$ of the diet, lactation can be significantly reduced and result in poor survival of piglets. Because protein tends to be the most limiting nutrient in terrestrial ecosystems, wild pigs will selectively forage for foods that are high in protein. It is this protein demand that causes pigs to be so destructive to some agricultural crops (e.g., peanuts, soybeans, etc.). Additionally, because animal matter has such a high protein content, wild pigs will opportunistically take advantage of whatever animal matter they can consume. Wild pigs may have to compensate by searching more for insect larvae and roots. A similar effect occurs during good mast years (Groot Bruinderink et al. 1994). Wild pigs may have to increase their animal intake to compensate for the low protein content of acorns (Loggins et al. 2002). For example, Barrett (1978) stated that dietary deficiencies in the summer months, especially for protein, markedly affected young and lactating pigs in the foothills subpopulation on the Dye Creek Ranch, California. Similar protein deficiencies occurred during the fall.

The time of greatest nutrient demand for wild pigs is during lactation and the last month of gestation. Lactation is considered to be the greatest nutrient demand realized by any mammalian species. Lactating sows require up to three times the energy/protein of non-breeding sows. If energetic requirements are not met by dietary intake, they must be met by mobilizing fat reserves, which can later lead to poor condition and negatively influence the chances of successful breeding during later litters. During the last month of gestation, pregnant sows require twice the digestible energy of non-breeding sows. 


\section{Wild Pigs}

Effect of Diet on Productivity - The wild pig is a species that utilizes a wide variety of forage resources. Because they are generalist feeders, they can successfully survive in most any area as long as there is adequate water, and productivity of available habitats is not limiting to a large mammal. The productivity of wild pigs will ultimately be a function of availability of adequate nutrition to support their prolific breeding potential. Because their rate of reproduction is much greater than other large mammals, they tend to be particularly susceptible to climatic/landscape events (e.g., drought, mast failure) that negatively influence availability of food. Their high rate of reproduction can result in more animals than the habitat can sustain when forage availability drops significantly, and this can result in measurable declines in population size. However, their high rate of reproduction also ensures that populations will rapidly rebound when the nutritional environment returns to normal. Geisser and Reyer (2005) reported that food and temperature were important factors affecting the fluctuations in wild pig density. Enhanced food availability is likely to boost reproductive success through younger age at first reproduction, larger litter size and earlier onset of estrous within a season.

\section{Summary}

While our understanding of the food habits of wild pigs is generally sound, the impacts that wild pigs have on vegetative communities and animal species due to foraging is only poorly understood. Measurable impacts on native species of plants and animals have been documented, but the long-term impacts on local populations have yet to be thoroughly examined. A more complete understanding of these impacts will require long term studies and significant effort. It is in this area that the greatest gap in our knowledge regarding food habits of wild pigs exists. 
Table 1. Percent composition of material by volume in wild pig diets from various locations.

\begin{tabular}{|c|c|c|c|c|c|}
\hline \multirow{2}{*}{ Location } & \multicolumn{4}{|c|}{ Percent Composition of Diet } & \multirow{2}{*}{ Reference } \\
\hline & Plant & Fungi & Animal & Other $^{\mathrm{a}}$ & \\
\hline Doñana National Park, Spain & $88^{\mathrm{c}}$ & 8 & 3 & 1 & Abáigar 1993 \\
\hline $\begin{array}{c}\text { Great Smoky Mountains } \\
\text { National Park, NC and TN, } \\
\text { USA }\end{array}$ & $84.6-99.3^{\mathrm{b}}$ & $0-18.6^{\mathrm{b}}$ & $0.7-10.8^{\mathrm{b}}$ & Trace & $\begin{array}{c}\text { Ackerman et al. } \\
1978\end{array}$ \\
\hline Davis Mountains, TX, USA & $97.5^{\mathrm{c}}$ & - & $2.5^{\mathrm{c}}$ & - & $\begin{array}{c}\text { Adkins and } \\
\text { Harveson. } 2006\end{array}$ \\
\hline $\begin{array}{l}\text { Horn Island, Gulf Islands } \\
\text { National Seashore, MS, USA }\end{array}$ & $77.5^{\mathrm{c}}$ & $3.8^{\mathrm{c}}$ & $18.8^{\mathrm{c}}$ & - & Baron 1979 \\
\hline $\begin{array}{l}\text { Dye Creek Ranch, Tehama } \\
\text { County, CA, USA }\end{array}$ & 98.4 & - & 1.6 & - & Barrett 1978 \\
\hline $\begin{array}{l}\text { Maurienne Valley, Savoie } \\
\text { Department, France }\end{array}$ & 92 & 1 & 1 & 6 & $\begin{array}{l}\text { Baubet et al. } \\
\quad 2004\end{array}$ \\
\hline East Germany & $95-96$ & - & $4-5$ & - & $\begin{array}{l}\text { Briedermann } \\
1976\end{array}$ \\
\hline Auckland Island, New Zealand & $63-72^{\mathrm{d}}$ & - & $28-37$ & - & Challies 1975 \\
\hline Auckland Island, New Zealand & $63.1^{\mathrm{cd}}$ & 3.7 & 33.2 & - & $\begin{array}{l}\text { Chimera et al. } \\
1995\end{array}$ \\
\hline $\begin{array}{c}\text { Temperate Monte Desert } \\
\text { Reserve of Ñacuñen, Mendoza, } \\
\text { Argentina }\end{array}$ & 95 & - & 5 & - & $\begin{array}{l}\text { Cuevas et al. } \\
2007\end{array}$ \\
\hline $\begin{array}{l}\text { Kipahulu Valley, Maui, HI, } \\
\text { USA }\end{array}$ & 93.2 & - & 6.8 & - & Diong 1982 \\
\hline $\begin{array}{l}\text { Varaita Valley, Cuneo } \\
\text { Province, Italy }\end{array}$ & 87.5 & - & 7.2 & 5.3 & Durio et al. 1995 \\
\hline $\begin{array}{c}\text { Area around Chernobyl } \\
\text { powerplant, Polesie Region, } \\
\text { Ukraine }\end{array}$ & $91.3^{\mathrm{c}}$ & $\sim 0.2^{\mathrm{c}}$ & $8.3^{\mathrm{c}}$ & $\sim 0.2^{\mathrm{c}}$ & $\begin{array}{l}\text { Eriksson and } \\
\text { Petrov } 1995\end{array}$ \\
\hline $\begin{array}{c}\text { Yturria Ranch, Willacy County, } \\
\text { TX, USA }\end{array}$ & 95.2 & - & 4.8 & - & $\begin{array}{l}\text { Everitt and } \\
\text { Alaniz } 1980\end{array}$ \\
\hline Herault Department, France & 94 & 2 & 3 & 1 & $\begin{array}{l}\text { Fournier- } \\
\text { Chambrillon et } \\
\text { al. } 1995\end{array}$ \\
\hline $\begin{array}{l}\text { Natural Park of Aiguamolls de } \\
\text { l' Emporda, Catalonia, Spain }\end{array}$ & 94.0 & - & 5.6 & $<0.01$ & $\begin{array}{l}\text { Giménez-Anaya } \\
\text { et al. } 2008\end{array}$ \\
\hline $\begin{array}{l}\text { Northeastern and Western } \\
\text { Poland }\end{array}$ & 88.3 & 0.8 & 10.9 & - & Genov 1981a \\
\hline Island of Hawaii, HI, USA & $93-96^{\mathrm{bc}}$ & - & $4-7^{\mathrm{bc}}$ & - & Giffin 1970 \\
\hline Mendocino County, CA, USA & $71.5^{\mathrm{cd}}$ & - & $28.5^{\mathrm{c}}$ & - & Grover 1983 \\
\hline Poland & 92.6 & - & 7.4 & - & Haber 1966 \\
\hline $\begin{array}{c}\text { Tellico Wildlife Management } \\
\text { Area, TN, USA }\end{array}$ & 89.4 & - & 6.4 & 4.2 & $\begin{array}{l}\text { Henry and } \\
\text { Conley } 1972\end{array}$ \\
\hline $\begin{array}{l}\text { Natural Park of Aiguamolls de } \\
\text { l' Emporda, Catalonia, Spain }\end{array}$ & 91.9 & - & 8.1 & Trace & $\begin{array}{l}\text { Herrero et al. } \\
\quad 2004\end{array}$ \\
\hline
\end{tabular}




\section{Wild Pigs}

Table 1. Percent composition of material by volume in wild pig diets from various locations (Continued).

\begin{tabular}{|c|c|c|c|c|c|}
\hline \multirow{2}{*}{ Location } & \multicolumn{4}{|c|}{ Percent Composition of Diet } & \multirow{2}{*}{ Reference } \\
\hline & Plant $^{\mathrm{d}}$ & Fungi & Animal & Other $^{\mathrm{a}}$ & \\
\hline $\begin{array}{c}\text { Great Smoky Mountains } \\
\text { National Park, NC and TN, } \\
\text { USA }\end{array}$ & 98 & - & 2 & - & Howe et al. 1981 \\
\hline $\begin{array}{l}\text { Gipuzkoa and Bizbaia } \\
\text { provinces, Spain }\end{array}$ & 94.1 & - & 5.9 & - & Irizar et al. 2004 \\
\hline Czechoslovakia & 85.8 & - & 14.2 & - & Janda 1958 \\
\hline National Park of Chrea, Algeria & 95 & - & 1 & 4 & Klaa 1992 \\
\hline $\begin{array}{c}\text { Bialowieza Primeval Forest, } \\
\text { USSR }\end{array}$ & 95.7 & - & 4.3 & - & Kozlo 1975 \\
\hline $\begin{array}{c}\text { Bialowieza Primeval Forest, } \\
\text { Poland }\end{array}$ & 87.6 & - & 12.4 & - & Lebedeva 1956 \\
\hline Södermanland, Sweden & 86 & - & 14 & - & Lemel 1999 \\
\hline Maremma Natural Park, Italy & 86.3 & - & 13.7 & - & $\begin{array}{c}\text { Massei et al. } \\
1996\end{array}$ \\
\hline $\begin{array}{c}\text { Girilambone, New South } \\
\text { Wales, Australia }\end{array}$ & $82-86^{b}$ & - & $13.9-17.7^{\mathrm{b}}$ & - & Pavlov 1980 \\
\hline $\begin{array}{l}\text { Monterey, San Luis Obispo and } \\
\text { San Benito counties, CA, USA }\end{array}$ & $80.9-94.2^{b}$ & - & $5.8-19.1^{b}$ & - & $\begin{array}{c}\text { Pine and Gerdes } \\
1973\end{array}$ \\
\hline $\begin{array}{c}\text { Bialowieza Primeval Forest, } \\
\text { Poland }\end{array}$ & 86.7 & - & 13.3 & - & Sablina 1955 \\
\hline Great Smoky Mountains & 99.1 & - & 0.3 & 0.2 & Scott and Pelton \\
\hline $\begin{array}{c}\text { National Park, NC and TN, } \\
\text { USA }\end{array}$ & & & & & 1975 \\
\hline South-central Chile & 57.2 & 15.9 & 16.1 & - & $\begin{array}{l}\text { Skewes et al. } \\
2007\end{array}$ \\
\hline $\begin{array}{l}\text { Herault and Aude Departments, } \\
\text { France }\end{array}$ & 96.1 & - & 3.7 & 0.2 & $\begin{array}{l}\text { Sjarmidi et al. } \\
1992\end{array}$ \\
\hline $\begin{array}{c}\text { Aransas National Wildlife } \\
\text { Refuge, TX, USA }\end{array}$ & $75-83.9^{b}$ & $1.7-14.6^{\mathrm{b}}$ & $16.1-25^{b}$ & - & Springer 1975 \\
\hline South Texas Plains, TX, USA & 93 & - & 6.7 & 0.3 & $\begin{array}{c}\text { Taylor and } \\
\text { Hellgren } 1997\end{array}$ \\
\hline $\begin{array}{l}\text { Urewera Ranges, North Island, } \\
\text { New Zealand }\end{array}$ & $70.9^{\mathrm{c}}$ & 0.8 & $28.3^{\mathrm{c}}$ & - & $\begin{array}{l}\text { Thomson and } \\
\text { Challies } 1988\end{array}$ \\
\hline Hobcaw Barony, SC, USA & $83.0-97.4^{\mathrm{bc}}$ & $0.8-11.7^{\mathrm{bc}}$ & $1.3-5.6^{b c}$ & - & $\begin{array}{l}\text { Wood and Roark } \\
1980\end{array}$ \\
\hline
\end{tabular}

\footnotetext{
${ }^{\mathrm{a}}$ Includes, debris, garbage, lichen, rocks/gravel, soil/sand, etc.

${ }^{\mathrm{b}}$ Annual, seasonal or location variation

${ }^{\mathrm{c}}$ Calculated from reference

${ }^{\mathrm{d}}$ Volumes also include some algae and/or fungi
} 
SRNL-RP-2009-00869

Table 2. Listing of plants, fungi and animals consumed by wild pigs in the continental United States.

$\begin{array}{lcc}\text { Taxonomic Group or } & \text { State(s) Reported } & \text { Reference(s) } \\ \text { Scientific Name } & \text { From } & \\ \text { (Common name) } & \text { Part(s) Consumed } & \end{array}$

\section{Plants}

\begin{tabular}{|c|c|c|c|}
\hline \multicolumn{4}{|l|}{ Alismataceae } \\
\hline $\begin{array}{l}\text { Sagittaria platyphylla (delta } \\
\text { arrowhead) }\end{array}$ & leaves, stems, and tubers & GA & Hanson and Karstad 1959 \\
\hline Echinodorus rostratus (burhead) & leaves and stems & $\mathrm{TX}$ & Everitt and Alaniz 1980 \\
\hline \multicolumn{4}{|l|}{ Alliaceae } \\
\hline Allium canadense (wild onion) & leaves and stems & $\mathrm{TX}$ & Springer 1975 \\
\hline \multicolumn{4}{|l|}{ Amaranthaceae } \\
\hline $\begin{array}{l}\text { Amaranthus blitoides (creeping } \\
\text { amaranth) }\end{array}$ & fruits and seeds & $\mathrm{NC}, \mathrm{TN}$ & Scott and Pelton 1975 \\
\hline \multicolumn{4}{|l|}{ Anacardiaceae } \\
\hline Rhus diversiloba (poison oak) & fruits, seeds and leaves & $\mathrm{CA}$ & $\begin{array}{l}\text { Pine and Gerdes 1973, } \\
\text { Barrett } 1978\end{array}$ \\
\hline Rhus integrifolia (lemonade sumac) & fruits, seeds and stems & CA & Baber and Coblentz 1987 \\
\hline \multicolumn{4}{|l|}{ Apiaceae } \\
\hline Bowlesia incana (hoary bowlesia) & leaves and stems & $\mathrm{CA}$ & Baber and Coblentz 1987 \\
\hline Hydrocotyle sp. (pennywort) & leaves and stems & TX & Springer 1975 \\
\hline $\begin{array}{l}\text { Hydrocotyle bonariensis (largeleaf } \\
\text { pennywort) }\end{array}$ & leaves and stems & MS & Baron 1979 \\
\hline \multicolumn{4}{|l|}{ Aquifoliaceae } \\
\hline Ilex opaca (American holly) & fruits and seeds & $\mathrm{NC}, \mathrm{TN}$ & Scott and Pelton 1975 \\
\hline \multicolumn{4}{|l|}{ Arecaceae } \\
\hline Sabal palmetto (cabbage palm) & roots and fruits & MS & Baron 1979 \\
\hline Serenoa repens (saw palmetto) & fronds & FL & Thompson 1977 \\
\hline \multicolumn{4}{|l|}{ Asteraceae } \\
\hline $\begin{array}{l}\text { Ambrosia psilostachya (western } \\
\text { ragweed) }\end{array}$ & leaves and stems & $\mathrm{TX}$ & Everitt and Alaniz 1980 \\
\hline Aster sp. (aster) & leaves and stems & $\mathrm{NC}, \mathrm{TN}$ & Ackerman et al. 1978 \\
\hline Aster divaricatus (eastern star) & leaves and stems & $\mathrm{NC}, \mathrm{TN}$ & Howe et al. 1981 \\
\hline Carduus sp. (thistle) & leaves and stems & $\mathrm{SC}$ & Wood and Roark 1980 \\
\hline $\begin{array}{l}\text { Centaurea melitensis (Maltas } \\
\text { knapweed) }\end{array}$ & leaves and stems & CA & Baber and Coblentz 1987 \\
\hline Cirisium sp. (thistle) & seeds and leaves & CA & Pine and Gerdes 1973 \\
\hline $\begin{array}{l}\text { Eupatorium rugosum (white } \\
\text { snakeroot) }\end{array}$ & leaves, stems and roots & $\mathrm{NC}, \mathrm{TN}$ & $\begin{array}{l}\text { Conley et al. 1972, Scott } \\
\text { and Pelton 1975, } \\
\text { Ackerman et al. } 1978\end{array}$ \\
\hline Helianthus sp. (sunflower) & leaves and stems & $\mathrm{TX}$ & Ilse and Hellgren 1995 \\
\hline Prenanthes sp. (rattlesnakeroot) & leaves and stems & $\mathrm{NC}, \mathrm{TN}$ & Ackerman et al. 1978 \\
\hline $\begin{array}{l}\text { Prenanthes altissima (tall } \\
\text { rattlesnakeroot) }\end{array}$ & leaves and stems & $\mathrm{NC}, \mathrm{TN}$ & Howe et al. 1981 \\
\hline $\begin{array}{l}\text { Solidago curtisii (mountain } \\
\text { decumbent goldenrod) }\end{array}$ & leaves and stems & $\mathrm{NC}, \mathrm{TN}$ & Howe et al. 1981 \\
\hline
\end{tabular}




\section{Wild Pigs}

Table 2. Listing of plants, fungi and animals consumed by wild pigs in the continental United States (Continued).

Taxonomic Group or Scientific Name

(Common name)

Part(s) Consumed State(s) Reported

Reference(s)

Sonchus asper (prickly sowthistle) leaves and stems

CA

From
Baber and Coblentz 1987

Wood and Roark 1980

Conley et al. 1972

Baber and Coblentz 1987

Conley et al. 1972

Baber and Coblentz 1987

Baber and Coblentz 1987

Baber and Coblentz 1987
Sisymbrium offinale (common leaves and stems

hedgemustard)

Cactaceae

Opuntia sp. (prickly pear cactus)

leaves, stems, fruits and seeds

fruits and seeds

Sambucus mexicana (Mexican elder)

\section{Caryophyllaceae}

Stellaria pubera (great chick weed)

\section{Chenopodiaceae}

Salsola kali (common Russian thistle)

\section{Convolvulaceae}

Ipomoea stolonifera (fiddle-leaf leaves and stems morning glory)

\section{Cornaceae}

Nyssa sylvatica (water tupelo)
Nyssa sylvatica var. biflora (swamp tupelo)

\section{Cyperaceae}

Carex sp. (sedge)

Cypernius esculentus (chufa) leaves and stems

leaves and stems

fruits and seeds seedling roots

leaves and stems

tubers and roots
CA, MS, SC, TX

CA

Baber and Coblentz 1987

1979, Baber and Coblentz Helloren 1997, J. J. Mayer unpubl. data
Ackerman et al. 1978, Howe et al. 1981

Baber and Coblentz 1987

Baron 1979

Wood and Roark 1980

$\begin{array}{ll}\text { SC } & \text { Mood and Roark } \\ \text { SC al } 2000\end{array}$

CA

MS

NC, TN

$\mathrm{TN}$
Ackerman et al. 1978, Howe et al. 1981 Conley et al. 1972 
Table 2. Listing of plants, fungi and animals consumed by wild pigs in the continental United States (Continued).

\begin{tabular}{|c|c|c|c|}
\hline $\begin{array}{l}\text { Taxonomic Group or } \\
\text { Scientific Name } \\
\text { (Common name) }\end{array}$ & Part(s) Consumed & $\begin{array}{l}\text { State(s) Reported } \\
\text { From }\end{array}$ & Reference(s) \\
\hline Cyperus sp. (sedges) & $\begin{array}{l}\text { leaves, stems, tubers and } \\
\text { roots }\end{array}$ & MS, SC, TX & $\begin{array}{l}\text { Kurz 1971, Springer 1975, } \\
\text { Baron 1979, Everitt and } \\
\text { Alaniz 1980, Wood and } \\
\text { Roark } 1980\end{array}$ \\
\hline Cyperus esculentus (nut grass) & roots & $\mathrm{SC}$ & Wood and Roark 1980 \\
\hline Eleocharis sp. (spikesedge) & roots & MS, TX & Springer 1975, Baron 1979 \\
\hline Heleocharis palustris (spikerush) & fruits and seeds & $\mathrm{CA}$ & Pine and Gerdes 1973 \\
\hline $\begin{array}{l}\text { Scirpus americanus (three-square } \\
\text { bulrush) }\end{array}$ & roots & $\mathrm{TX}$ & Springer 1975 \\
\hline $\begin{array}{l}\text { Scirpus californicus (California } \\
\text { bulrush) }\end{array}$ & roots & $\mathrm{TX}$ & Springer 1975 \\
\hline Tradescanthia micrantha (cherisse) & leaves and stems & $\mathrm{TX}$ & Everitt and Alaniz 1980 \\
\hline \multicolumn{4}{|l|}{ Dioscoreaceae } \\
\hline Dioscorea sp. (wild yam) & roots & $\mathrm{NC}, \mathrm{TN}$ & $\begin{array}{l}\text { Conley et al. 1972, Scott } \\
\text { and Pelton } 1975\end{array}$ \\
\hline Dioscorea batatas (Chinese yam) & roots and tubers & $\mathrm{NC}, \mathrm{TN}$ & Ackerman et al. 1978 \\
\hline \multicolumn{4}{|l|}{ Dryopteridaceae } \\
\hline Cystopteris bulbifera (bulbet-fern) & roots & $\mathrm{TN}$ & Conley et al. 1972 \\
\hline $\begin{array}{l}\text { Polystichum acrostichoides } \\
\text { (Christmas fern) }\end{array}$ & roots and shoots & $\mathrm{NC}, \mathrm{TN}$ & $\begin{array}{l}\text { Conley et al. 1972, Scott } \\
\text { and Pelton } 1975\end{array}$ \\
\hline \multicolumn{4}{|l|}{ Ebenaceae } \\
\hline $\begin{array}{l}\text { Diospyros texana (Texas } \\
\text { persimmon) }\end{array}$ & $\begin{array}{l}\text { fruits, seeds, leaves and } \\
\text { stems }\end{array}$ & $\mathrm{TX}$ & $\begin{array}{l}\text { Hellgren and Holzem } \\
\text { 1992, Ilse and Hellgren } \\
\text { 1995 }\end{array}$ \\
\hline $\begin{array}{l}\text { Diospyros virginiana (common } \\
\text { persimmon) }\end{array}$ & fruits and seeds & $\mathrm{SC}, \mathrm{TX}$ & $\begin{array}{l}\text { Springer 1975, J. J. Mayer, } \\
\text { unpubl. data }\end{array}$ \\
\hline \multicolumn{4}{|l|}{ Ericaceae } \\
\hline Arctostaphylos sp. (manzanita) & fruits and seeds & $\mathrm{CA}$ & $\begin{array}{l}\text { Pine and Gerdes 1973, } \\
\text { Barrett 1978, Baber and } \\
\text { Coblentz 1987, de Nevers } \\
1993\end{array}$ \\
\hline $\begin{array}{l}\text { Arctostaphylos manzanita } \\
\text { (manzanita) }\end{array}$ & fruits and seeds & $\mathrm{CA}$ & Grover 1983 \\
\hline Gaylussacia sp. (huckleberry) & fruits and seeds & $\mathrm{NC}, \mathrm{TN}$ & $\begin{array}{l}\text { Conley et al. 1972, Henry } \\
\text { and Conley 1972, Scott and } \\
\text { Pelton } 1975\end{array}$ \\
\hline Vaccinium sp. (blueberry) & $\begin{array}{l}\text { leaves, stems, fruits and } \\
\text { seeds }\end{array}$ & $\mathrm{NC}, \mathrm{TN}$ & $\begin{array}{l}\text { Conley et al. 1972, Scott } \\
\text { and Pelton 1975, Howe et } \\
\text { al. } 1981\end{array}$ \\
\hline $\begin{array}{l}\text { Vaccinium corymbosum (highbush } \\
\text { blueberry) }\end{array}$ & $\begin{array}{l}\text { leaves, stems, fruits and } \\
\text { seeds }\end{array}$ & $\mathrm{NC}, \mathrm{TN}$ & Ackerman et al. 1978 \\
\hline $\begin{array}{l}\text { Vaccinium hirsutum (hairy } \\
\text { blueberry) }\end{array}$ & $\begin{array}{l}\text { leaves, stems, fruits and } \\
\text { seeds }\end{array}$ & $\mathrm{NC}, \mathrm{TN}$ & Ackerman et al. 1978 \\
\hline
\end{tabular}




\section{Wild Pigs}

Table 2. Listing of plants, fungi and animals consumed by wild pigs in the continental United States (Continued).

Taxonomic Group or Scientific Name

(Common name)

Part(s) Consumed State(s) Reported From
Reference(s)

\section{Fabaceae \\ Acacia berlandieri (guajillo) \\ Acacia farnesiana (huisache) Edicago hispida (bur clover) Lotus argophylus ornithopos (silver deervetch) \\ Lotus strigosus (bristle deervetch) Medicago polymorpha (burclover) Melilotus alba (wild sweet clover) Trifolium repens (white clover) Trifolium sp. (clover) \\ Acacia farnesiana (huisache) Lithocarpus densiflorum (tanbark oak) \\ Quercus sp. (oaks)}

fruits and seeds

fruits and seeds fruits, seeds and leaves

leaves and stems

leaves and stems

leaves and stems

leaves

leaves and stems

leaves and stems

fruits and seeds

fruits and seeds

fruits, seeds and leaves

\section{TX}

TX

CA

CA

CA

CA

TN

CA

CA, NC, TN

TX

CA

CA, GA, NC, SC, TN, TX
Quercus agrifolia (coast live oak) Quercus douglassi (blue oak) Quercus dumosa (scrub oak) Quercus falcata var. pagodaefolia (cherrybark oak)

Quercus lobata (valley oak)

Quercus michanxii (swamp chestnut oak)

Quercus virginiana (live oak)

\section{Geraniaceae}

Erodium sp. (filaree)

Geranium maculatum (spotted geranium) fruits and seeds

fruits and seeds

fruits and seeds

seedling roots

fruits and seeds

seedling roots

fruits and seeds

leaves and stems

leaves and stems
CA

$\mathrm{CA}$

CA

$\mathrm{SC}$

CA

$\mathrm{SC}$

TX

CA

$\mathrm{NC}, \mathrm{TN}$
Hellgren and Holzem 1992, Taylor and Hellgren 1997

Hellgren and Holzem 1992

Pine and Gerdes 1973

Baber and Coblentz 1987

Baber and Coblentz 1987

Baber and Coblentz 1987

Conley et al. 1972

Barrett 1978

Conley et al. 1972, Pine and Gerdes 1973, Scott and Pelton 1975, Ackerman et al. 1978

Hellgren and Holzem 1992

Pine and Gerdes 1973

Hanson and Karstad 1959, Kurz 1971, Conley et al. 1972, Henry and Conley 1972, Pine and Gerdes 1973, Scott and Pelton 1975, Springer 1975, Ackerman et al. 1978, Barrett 1978, Wood and Roark 1980, Grover 1983, Baber and Coblentz 1987, de Nevers 1993, Loggins et al. 2002

Peart 1993

Chipping 1993

Peart 1993

Mayer et al 2000

Chipping 1993

Mayer et al 2000

Everitt and Alaniz 1980

Barrett 1978, Pine and Gerdes 1973, Baber and Coblentz 1987

Ackerman et al. 1978 
Table 2. Listing of plants, fungi and animals consumed by wild pigs in the continental United States (Continued).

Taxonomic Group or Scientific Name

(Common name)

Part(s) Consumed State(s) Reported From

Reference(s)

\section{Hamamelidaceae \\ Liquidambar styraciflua (sweetgum) \\ Hydrophyllaceae \\ Pholistoma racemosa (racemed fiestaflower) \\ Juglandaceae \\ Carya sp. (hickories) \\ Carya aquatica (water hickory) Carya illinoensis (pecan) Juglans nigra (black walnut)}

\section{Juncaceae \\ Juncus effuses (common rush) \\ Lamiaceae \\ Marrubium vulgare (common horehound) \\ Lauraceae \\ Persea americana (avocado) \\ Umbellularia californica \\ (California bay fruit)}

\section{Leguminosae \\ Prosopis sp. (mesquite)}

\author{
Liliaceae \\ Lilliaceae (lily - general) \\ Brodiaea sp. (brodiaea) \\ Dichelostemma pulchellum \\ (purplehead brodiaea) \\ Disporum lanuginosum (yellow \\ fairy bells) \\ Erythronium americanum (fawn \\ lilly) \\ Lilium sp. (lily) \\ Smilacina racemosa (false \\ Solomon's seal)
}

roots

leaves and stems

fruits and seeds

seedling roots

fruits and seeds

fruits

$\mathrm{SC}$

$\mathrm{SC}$

$\mathrm{NC}, \mathrm{SC}, \mathrm{TN}$ roots

leaves and stems

fallen ripe fruits

fruits and seeds

fruits and seeds

TX

$\begin{array}{ll}\text { corms, bulbs and leaves } & \mathrm{CA} \\ \begin{array}{l}\text { corms } \\ \text { roots }\end{array} & \mathrm{CA} \\ \text { leaves and stems } & \mathrm{CA}, \mathrm{TN} \\ \text { roots and tubers } & \mathrm{NC}, \mathrm{TN} \\ \text { leaves and stems } & \mathrm{NC}, \mathrm{TN} \\ \text { leaves and stems } & \mathrm{NC}, \mathrm{TN}\end{array}$

Conley et al. 1972

Baber and Coblentz 1987

Conley et al. 1972, Henry and Conley 1972, Scott and Pelton 1975, Wood and Roark 1980

Mayer et al 2000

J. J. Mayer, unpubl. data Conley et al. 1972, Scott and Pelton 1975,

Ackerman et al. 1978, J. J.

Mayer, unpubl. data

J. J. Mayer, unpubl. data

Baber and Coblentz 1987

J. J. Mayer, unpubl. data Pine and Gerdes 1973

Hellgren and Holzem 1992, Taylor and Hellgren 1997

Pine and Gerdes 1973, de Nevers 1993

Pine and Gerdes 1973

Baber and Coblentz 1987

Howe et al. 1981

Ackerman et al. 1978, Howe et al. 1981

Ackerman et al. 1978

Ackerman et al. 1978 


\section{Wild Pigs}

Table 2. Listing of plants, fungi and animals consumed by wild pigs in the continental United States (Continued).

Taxonomic Group or Scientific Name

(Common name)

Part(s) Consumed State(s) Reported

From
Reference(s)

\begin{tabular}{|c|c|c|c|}
\hline \multicolumn{4}{|l|}{ Magnoliaceae } \\
\hline $\begin{array}{l}\text { Liriodendron tulipifera (tulip } \\
\text { poplar) }\end{array}$ & $\begin{array}{l}\text { leaves, stems, fruits and } \\
\text { seeds }\end{array}$ & $\mathrm{NC}, \mathrm{TN}$ & Scott and Pelton 1975 \\
\hline \multicolumn{4}{|l|}{ Malvaceae } \\
\hline Malva parviflora (little mallow) & leaves and stems & CA & Baber and Coblentz 1987 \\
\hline Malvastrum sp. (mallow) & leaves and stems & $\mathrm{TX}$ & Ilse and Hellgren 1995 \\
\hline \multicolumn{4}{|l|}{ Marsileaceae } \\
\hline Marsilea macropoda (water clover) & leaves and stems & $\mathrm{TX}$ & Everitt and Alaniz 1980 \\
\hline \multicolumn{4}{|l|}{ Nelumbonaceae } \\
\hline Nelumbo lutea (water lotus) & exposed rhizomes & $\mathrm{SC}$ & Whicker 1991 \\
\hline \multicolumn{4}{|l|}{ Nymphaeaceae } \\
\hline Nymphaea odorata (water lilly) & exposed rhizomes & $\mathrm{SC}$ & Whicker 1991 \\
\hline \multicolumn{4}{|l|}{ Oleaceae } \\
\hline Fraxinus americana (white ash) & fruits and seeds & $\mathrm{TN}$ & Henry and Conley 1972 \\
\hline \multicolumn{4}{|l|}{ Orchidaceae } \\
\hline Calypso bulbosa (Calypso orchid) & bulbs & CA & Chipping 1993 \\
\hline \multicolumn{4}{|l|}{ Oxalidaceae } \\
\hline $\begin{array}{l}\text { Oxalis montana (mountain } \\
\text { woodsorrel) }\end{array}$ & leaves and stems & $\mathrm{NC}, \mathrm{TN}$ & Ackerman et al. 1978 \\
\hline \multicolumn{4}{|l|}{ Phytolaccaceae } \\
\hline Phytolacca americana (pokeweed) & roots & $\mathrm{TN}$ & Conley et al. 1972 \\
\hline \multicolumn{4}{|l|}{ Pinaceae } \\
\hline Pinus sp. (pines) & leaves, roots and bark & $\mathrm{MS}, \mathrm{NC}, \mathrm{SC}, \mathrm{TN}$ & $\begin{array}{l}\text { Sweeney 1970, Henry and } \\
\text { Conley 1972, Scott and } \\
\text { Pelton 1975, Ackerman et } \\
\text { al. 1978, Baron } 1979\end{array}$ \\
\hline Pinus elliotti (slash pines) & roots and bark & $\mathrm{SC}$ & Mayer et al 2000 \\
\hline Pinus palustris (longleaf pines) & roots and bark & GA, SC & $\begin{array}{l}\text { Hanson and Karstad 1959, } \\
\text { Mayer et al } 2000\end{array}$ \\
\hline Pinus rigida (pitch pines) & roots and bark & $\mathrm{TN}$ & Conley et al. 1972 \\
\hline Pinus strobus (white pine) & roots & $\mathrm{TN}$ & Conley et al. 1972 \\
\hline Pinus taeda (loblolly pines) & roots and bark & $\mathrm{SC}$ & Mayer et al 2000 \\
\hline $\begin{array}{l}\text { Tsuga canadensis (eastern } \\
\text { hemlock) }\end{array}$ & leaves, stems and roots & $\mathrm{NC}, \mathrm{TN}$ & $\begin{array}{l}\text { Conley et al. 1972, Henry } \\
\text { and Conley 1972, Scott and } \\
\text { Pelton } 1975\end{array}$ \\
\hline \multicolumn{4}{|l|}{ Plantaginaceae } \\
\hline Plantago erecta (dotseed plantain) & leaves and stems & CA & Baber and Coblentz 1987 \\
\hline
\end{tabular}


Table 2. Listing of plants, fungi and animals consumed by wild pigs in the continental United States (Continued).

Taxonomic Group or Scientific Name (Common name)
Part(s) Consumed State(s) Reported From
Reference(s)

\begin{tabular}{|c|c|c|c|}
\hline \multicolumn{4}{|l|}{ Poaceae } \\
\hline Poaceae (grass - general) & leaves and stems & $\mathrm{CA}, \mathrm{NC}, \mathrm{TN}$ & $\begin{array}{l}\text { Pine and Gerdes } 1973, \\
\text { Scott and Pelton 1975, } \\
\text { Barrett 1978, Grover 1983, } \\
\text { de Nevers } 1993\end{array}$ \\
\hline Agrostis diegoensis (thin bentgrass) & leaves and stems & $\mathrm{CA}$ & Baber and Coblentz 1987 \\
\hline $\begin{array}{l}\text { Andropogon maritimus (beard } \\
\text { grass) }\end{array}$ & leaves and stems & MS & Baron 1979 \\
\hline Arundinaria gigantia (switch cane) & leaves & $\mathrm{SC}$ & J. J. Mayer, unpubl. data \\
\hline Avena barbata (wild oat) & $\begin{array}{l}\text { fruits, seeds leaves and } \\
\text { stems }\end{array}$ & CA & $\begin{array}{l}\text { Pine and Gerdes 1973, } \\
\text { Barrett 1978, Baber and } \\
\text { Coblentz } 1987\end{array}$ \\
\hline Avena fatua (wild oat) & $\begin{array}{l}\text { fruits, seeds leaves and } \\
\text { stems }\end{array}$ & CA & Pine and Gerdes 1973 \\
\hline Avena sativa (oats) & seed & $\mathrm{TN}$ & Conley et al. 1972 \\
\hline Bromus sp. (annual brome grass) & leaves and stems & $\mathrm{CA}$ & Baber and Coblentz 1987 \\
\hline Bromus mollis (soft chess) & fruits and seeds & CA & Barrett 1978 \\
\hline Bromus rigidus (rip-gut) & fruits and seeds & $\mathrm{CA}$ & Pine and Gerdes 1973 \\
\hline Cynodon dactylon (Bermuda grass) & leaves, stems and roots & $\mathrm{SC}, \mathrm{TX}$ & $\begin{array}{l}\text { Springer } 1975 \text {, Wood and } \\
\text { Roark } 1980\end{array}$ \\
\hline Dactylis glomerata (orchard grass) & leaves & $\mathrm{TN}$ & Conley et al. 1972 \\
\hline Digitaria sp. (crabgrass) & roots & $\mathrm{SC}$ & Wood and Roark 1980 \\
\hline $\begin{array}{l}\text { Digitaria adscendens (common } \\
\text { crabgrass) }\end{array}$ & leaves and stems & $\mathrm{TX}$ & Springer 1975 \\
\hline Eremochloa sp. (centipede grass) & roots & $\mathrm{SC}$ & J. J. Mayer, unpubl. data \\
\hline Festuca sp. (fescue) & seeds and leaves & CA, TN & $\begin{array}{l}\text { Conley et al. 1972, Barrett } \\
1978\end{array}$ \\
\hline Holcus lanatus (velvet grass) & leaves & $\mathrm{TN}$ & Conley et al. 1972 \\
\hline $\begin{array}{l}\text { Hordeum glaucum (glaucous } \\
\text { barley) }\end{array}$ & leaves and stems & $\mathrm{CA}$ & Baber and Coblentz 1987 \\
\hline $\begin{array}{l}\text { Hordeum leporinium (rabbit } \\
\text { barley) }\end{array}$ & leaves and stems & $\mathrm{CA}$ & Baber and Coblentz 1987 \\
\hline Hordeum vulgare (barley) & fruits and seeds & $\mathrm{CA}$ & Pine and Gerdes 1973 \\
\hline $\begin{array}{l}\text { Lamarkia aurea (common } \\
\text { goldentop) }\end{array}$ & leaves and stems & $\mathrm{CA}$ & Baber and Coblentz 1987 \\
\hline Leersia hexandra (cutgrass) & leaves and stems & $\mathrm{TX}$ & Springer 1975 \\
\hline Lolium sp. (rye grass) & $\begin{array}{l}\text { fruits, seeds, and fresh } \\
\text { shoots and rhizomes }\end{array}$ & $\mathrm{CA}, \mathrm{SC}$ & $\begin{array}{l}\text { Pine and Gerdes 1973, J. J. } \\
\text { Mayer, unpubl. data }\end{array}$ \\
\hline $\begin{array}{l}\text { Melica imperfecta (coastrange } \\
\text { melic) }\end{array}$ & leaves and stems & $\mathrm{CA}$ & Baber and Coblentz 1987 \\
\hline $\begin{array}{l}\text { Muhlenbergia microsperma } \\
\text { (littleseed muhly) }\end{array}$ & leaves and stems & CA & Baber and Coblentz 1987 \\
\hline Panicum sp. (panic grasses) & leaves and stems & $\mathrm{SC}$ & Wood and Roark 1980 \\
\hline Panicum miliaceum (millet) & seed heads and fresh shoots & $\mathrm{SC}$ & J. J. Mayer, unpubl. data \\
\hline Panicum repens (torpedograss) & leaves and stems & MS & Baron 1979 \\
\hline $\begin{array}{l}\text { Panicum tenerum (bluejoint } \\
\text { panicgrass) }\end{array}$ & leaves and stems & MS & Baron 1979 \\
\hline $\begin{array}{l}\text { Paspalum floridanum (Florida } \\
\text { paspalum) }\end{array}$ & leaves and stems & MS & Baron 1979 \\
\hline Paspalum lividum (longtom) & leaves and stems & $\mathrm{TX}$ & Everitt and Alaniz 1980 \\
\hline
\end{tabular}




\section{Wild Pigs}

Table 2. Listing of plants, fungi and animals consumed by wild pigs in the continental United States (Continued).

Taxonomic Group or Scientific Name

(Common name)

Part(s) Consumed State(s) Reported From
Reference(s)

\begin{tabular}{|c|c|c|c|}
\hline Paspalum notatum (bahia grass) & roots & $\mathrm{SC}$ & J. J. Mayer, unpubl. data \\
\hline Poa sp. (bluegrass) & leaves & $\mathrm{TN}$ & Conley et al. 1972 \\
\hline Poa annua (annual blugrass) & leaves and stems & $\mathrm{CA}$ & Baber and Coblentz 1987 \\
\hline Poa scabrella (pine blugrass) & leaves and stems & $\mathrm{CA}$ & Baber and Coblentz 1987 \\
\hline Sorghum sp. (sorghum grass) & fruits and seeds & $\mathrm{TX}$ & Springer 1975 \\
\hline Sorghum halepense (Johnson grass) & roots & $\mathrm{SC}$ & Wood and Roark 1980 \\
\hline Sorghum vulgare (dwarf milo) & seed heads & $\mathrm{TN}$ & Conley et al. 1972 \\
\hline $\begin{array}{l}\text { Spartina cynosuroides (big } \\
\text { cordgrass) }\end{array}$ & roots & $\mathrm{SC}$ & Wood and Roark 1980 \\
\hline Sporobolus sp. (dropseed) & leaves and stems & $\mathrm{TX}$ & Ilse and Hellgren 1995 \\
\hline $\begin{array}{l}\text { Stenotaphrum secundatum (St. } \\
\text { Augustine grass) }\end{array}$ & leaves and stems & $\mathrm{TX}$ & Springer 1975 \\
\hline Stipa sp. (needlegrass) & leaves and stems & $\mathrm{CA}$ & Baber and Coblentz 1987 \\
\hline Triticum sp. (winter wheat) & seed heads and fresh shoots & $\mathrm{SC}$ & J. J. Mayer, unpubl. data \\
\hline Triticum aestivum (wheat) & leaves & $\mathrm{TN}$ & Conley et al. 1972 \\
\hline $\begin{array}{l}\text { Vulpia megalura (foxtail annual } \\
\text { fescue) }\end{array}$ & leaves and stems & CA & Baber and Coblentz 1987 \\
\hline Zea mays (corn) & $\begin{array}{l}\text { leaves, stems, fruits and } \\
\text { seeds }\end{array}$ & $\mathrm{GA}, \mathrm{SC}, \mathrm{TN}, \mathrm{TX}$ & $\begin{array}{l}\text { Conley et al. 1972, Taylor } \\
\text { and Hellgren 1997, J. J. } \\
\text { Mayer, unpubl. data }\end{array}$ \\
\hline Zizania aquatica (wild rice) & $\begin{array}{l}\text { leaves, stems, tubers and } \\
\text { roots }\end{array}$ & $\mathrm{SC}$ & Wood and Roark 1980 \\
\hline $\begin{array}{l}\text { Zizaniopsis maliacea (southern } \\
\text { wild rice) }\end{array}$ & $\begin{array}{l}\text { leaves, stems, tubers and } \\
\text { roots }\end{array}$ & $\mathrm{SC}$ & Wood and Roark 1980 \\
\hline \multicolumn{4}{|l|}{ Polemoniaceae } \\
\hline $\begin{array}{l}\text { Gila angelensis (Australian } \\
\text { saltgrass) }\end{array}$ & leaves and stems & $\mathrm{CA}$ & Baber and Coblentz 1987 \\
\hline \multicolumn{4}{|l|}{ Polygonaceae } \\
\hline $\begin{array}{l}\text { Rumex acetosella (common sheep } \\
\text { sorrel) }\end{array}$ & leaves and stems & $\mathrm{NC}, \mathrm{TN}$ & Ackerman et al. 1978 \\
\hline \multicolumn{4}{|l|}{ Pontederiaceae } \\
\hline Pontederia cordata (pickerelweed) & leaves and stems & GA, TX & $\begin{array}{l}\text { Hanson and Karstad 1959, } \\
\text { Springer } 1975\end{array}$ \\
\hline \multicolumn{4}{|l|}{ Portulacaceae } \\
\hline $\begin{array}{l}\text { Claytonia perfoliata (miner's } \\
\text { lettuce) }\end{array}$ & leaves and stems & $\mathrm{CA}$ & Baber and Coblentz 1987 \\
\hline Claytonia virginica (spring beauty) & corms, leaves and stems & $\mathrm{NC}, \mathrm{TN}$ & $\begin{array}{l}\text { Ackerman et al. 1978, } \\
\text { Howe et al. } 1981\end{array}$ \\
\hline Montia perfoloata (miner's lettuce) & seeds and leaves & $\mathrm{CA}$ & Pine and Gerdes 1973 \\
\hline Portulaca mundula (mossrose) & leaves and stems & $\mathrm{TX}$ & Everitt and Alaniz 1980 \\
\hline \multicolumn{4}{|l|}{ Ranunculaceae } \\
\hline Thalictrum sp. (meadow rue) & leaves and stems & $\mathrm{NC}, \mathrm{TN}$ & Ackerman et al. 1978 \\
\hline
\end{tabular}


Table 2. Listing of plants, fungi and animals consumed by wild pigs in the continental United States (Continued).

Taxonomic Group or Scientific Name

(Common name)

Part(s) Consumed State(s) Reported From
Reference(s)

\begin{tabular}{|c|c|c|c|}
\hline \multicolumn{4}{|l|}{ Rosaceae } \\
\hline Amelanchier laevis (serviceberry) & fruits and seeds & $\mathrm{NC}, \mathrm{TN}$ & $\begin{array}{l}\text { Ackerman et al. 1978, } \\
\text { Howe et al. } 1981\end{array}$ \\
\hline $\begin{array}{l}\text { Chanomeles lagenaria (Japanese } \\
\text { quince) }\end{array}$ & fruits and seeds & $\mathrm{NC}, \mathrm{TN}$ & Ackerman et al. 1978 \\
\hline Crataegus canadensis (hawthorn) & fruit & $\mathrm{TN}$ & Conley et al. 1972 \\
\hline $\begin{array}{l}\text { Malus sp. (wild and domestic } \\
\text { apple, crabapple) }\end{array}$ & fruits and seeds & $\mathrm{NC}, \mathrm{TN}$ & $\begin{array}{l}\text { Scott and Pelton } 1975 \text {, } \\
\text { Ackerman et al. } 1978\end{array}$ \\
\hline $\begin{array}{l}\text { Photinia arbutifolia } \\
\text { (Christmasberry or toyon) }\end{array}$ & fruits, seeds and stems & $\mathrm{CA}$ & $\begin{array}{l}\text { Pine and Gerdes 1973, } \\
\text { Baber and Coblentz } 1987\end{array}$ \\
\hline Potentilla sp. (cinquefoil) & leaves and stems & $\mathrm{NC}, \mathrm{TN}$ & Ackerman et al. 1978 \\
\hline Prunus sp. (common plum) & fruits and seeds & $\mathrm{NC}, \mathrm{SC}, \mathrm{TN}$ & $\begin{array}{l}\text { Kurz 1971, Scott and } \\
\text { Pelton } 1975\end{array}$ \\
\hline $\begin{array}{l}\text { Prunus ilicifolia lyonii (Catalina } \\
\text { cherry) }\end{array}$ & fruits and seeds & $\mathrm{CA}$ & Baber and Coblentz 1987 \\
\hline $\begin{array}{l}\text { Prunus illicifolia (holly-leaf } \\
\text { cherry) }\end{array}$ & fruits and seeds & $\mathrm{CA}$ & Pine and Gerdes 1973 \\
\hline Pyrus malus (domestic apple) & fruit & $\mathrm{TN}$ & Conley et al. 1972 \\
\hline Rubus sp. (blackberry) & fruits, tubers and roots & $\mathrm{SC}, \mathrm{TN}$ & $\begin{array}{l}\text { Kurz 1971, Conley et al. } \\
\text { 1972, Scott and Pelton } \\
\text { 1975, Wood and Roark } \\
1980\end{array}$ \\
\hline $\begin{array}{l}\text { Rubus canadensis (smooth } \\
\text { blackberry) }\end{array}$ & fruits, tubers and roots & $\mathrm{NC}, \mathrm{TN}$ & Howe et al. 1981 \\
\hline \multicolumn{4}{|l|}{ Rubiaceae } \\
\hline $\begin{array}{l}\text { Galim aparine (catchweed } \\
\text { bedstraw) }\end{array}$ & leaves and stems & $\mathrm{CA}$ & Baber and Coblentz 1987 \\
\hline Mitchella repens (partridge berry) & fruits & $\mathrm{TN}$ & Conley et al. 1972 \\
\hline \multicolumn{4}{|l|}{ Ruscaceae } \\
\hline $\begin{array}{l}\text { Polygonatum biflora (Solomon's } \\
\text { seal) }\end{array}$ & leaves and stems & $\mathrm{NC}, \mathrm{TN}$ & Ackerman et al. 1978 \\
\hline \multicolumn{4}{|l|}{ Santalaceae } \\
\hline Pyrularia pubera (buffalo-nut) & fruits and seeds & $\mathrm{NC}, \mathrm{TN}$ & Scott and Pelton 1975 \\
\hline \multicolumn{4}{|l|}{ Saururaceae } \\
\hline Saururus cernuus (lizard's tail) & roots & $\mathrm{SC}$ & Wood and Roark 1980 \\
\hline \multicolumn{4}{|l|}{ Scrophulariaceae } \\
\hline Bacopa monnieri (water hyssop) & leaves and stems & $\mathrm{TX}$ & Springer 1975 \\
\hline \multicolumn{4}{|l|}{ Smilacaceae } \\
\hline Smilax sp. (greenbrier or catbrier) & tubers and roots & $\mathrm{NC}, \mathrm{SC}, \mathrm{TN}, \mathrm{TX}$ & $\begin{array}{l}\text { Kurz 1971, Conley et al. } \\
\text { 1972, Scott and Pelton } \\
\text { 1975, Springer } 1975\end{array}$ \\
\hline $\begin{array}{l}\text { Smilax rotundifolia (roundleaf } \\
\text { greenbrier) }\end{array}$ & leaves and stems & $\mathrm{NC}, \mathrm{TN}$ & Ackerman et al. 1978 \\
\hline
\end{tabular}




\section{Wild Pigs}

Table 2. Listing of plants, fungi and animals consumed by wild pigs in the continental United States (Continued).

Taxonomic Group or Scientific Name

(Common name)
Part(s) Consumed State(s) Reported

From
Reference(s)

\begin{tabular}{|c|c|c|c|}
\hline \multicolumn{4}{|l|}{ Solanaceae } \\
\hline Datura sp. (thorn apple) & fruit & $\mathrm{TN}$ & Conley et al. 1972 \\
\hline \multicolumn{4}{|l|}{ Styracaceae } \\
\hline Halesia carolina (silverbell) & fruit & $\mathrm{TN}$ & Conley et al. 1972 \\
\hline \multicolumn{4}{|l|}{ Trilliaceae } \\
\hline Trillium sp. (trillium) & leaves, stems and roots & $\mathrm{NC}, \mathrm{TN}$ & Ackerman et al. 1978 \\
\hline Trillium erectum (red trillium) & leaves, stems and roots & $\mathrm{NC}, \mathrm{TN}$ & Howe et al. 1981 \\
\hline \multicolumn{4}{|l|}{ Typhaceae } \\
\hline Typha sp. (cattail) & roots & CA, TX & $\begin{array}{l}\text { Springer 1975, Baber and } \\
\text { Coblentz } 1987\end{array}$ \\
\hline Typha latifolia (common cattail) & exposed rhizomes & $\mathrm{SC}$ & Whicker 1991 \\
\hline \multicolumn{4}{|l|}{ Urticaceae } \\
\hline Laportea canadensis (wood nettle) & leaves and stems & $\mathrm{NC}, \mathrm{TN}$ & $\begin{array}{l}\text { Scott and Pelton } 1975, \\
\text { Ackerman et al. } 1978, \\
\text { Howe et al. } 1981\end{array}$ \\
\hline Urtica chamaedryoides (nettle) & leaves and stems & $\mathrm{TX}$ & Everitt and Alaniz 1980 \\
\hline \multicolumn{4}{|l|}{ Verbenaceae } \\
\hline Phyla incisa (frog-fruit) & leaves and stems & $\mathrm{TX}$ & $\begin{array}{l}\text { Springer } 1975 \text {, Everitt and } \\
\text { Alaniz } 1980\end{array}$ \\
\hline Phyla nodiflora (turkey-tangle) & leaves and stems & $\mathrm{TX}$ & Everitt and Alaniz 1980 \\
\hline \multicolumn{4}{|l|}{ Violaceae } \\
\hline Viola sp. (violet) & $\begin{array}{l}\text { leaves, stems, tubers and } \\
\text { roots }\end{array}$ & $\mathrm{NC}, \mathrm{TN}$ & $\begin{array}{l}\text { Conley et al. 1972, Scott } \\
\text { and Pelton 1975, } \\
\text { Ackerman et al. 1978, } \\
\text { Howe et al. } 1981\end{array}$ \\
\hline \multicolumn{4}{|l|}{ Vitaceae } \\
\hline Vitis sp. (muscadine or wild grape) & fruits and seeds & $\mathrm{NC}, \mathrm{SC}, \mathrm{TN}, \mathrm{TX}$ & $\begin{array}{l}\text { Conley et al. 1972, Henry } \\
\text { and Conley 1972, Scott and } \\
\text { Pelton 1975, Springer } \\
\text { 1975, Wood and Roark } \\
\text { 1980, Kroll } 1986\end{array}$ \\
\hline \multicolumn{4}{|l|}{ Fungi } \\
\hline Fungi (mushrooms) & fruiting body & $\begin{array}{l}\text { CA, MS, NC, SC, } \\
\text { TN, TX }\end{array}$ & $\begin{array}{l}\text { Pine and Gerdes 1973, } \\
\text { Springer 1975, Ackerman } \\
\text { et al. 1978, Baron } 1979 \text {, } \\
\text { Wood and Roark } 1980\end{array}$ \\
\hline
\end{tabular}

\section{Animals}

\section{Invrtebrates}


Table 2. Listing of plants, fungi and animals consumed by wild pigs in the continental United States (Continued).

Taxonomic Group or Scientific Name

(Common name)

Part(s) Consumed State(s) Reported

Reference(s)

\begin{tabular}{|c|c|c|c|}
\hline \multicolumn{4}{|l|}{ Annelida } \\
\hline Hirudinidae (leech) & entire organism & $\mathrm{TX}$ & Springer 1975 \\
\hline Oligochaeta (earthworms) & entire organism & $\mathrm{CA}, \mathrm{NC}, \mathrm{TN}$ & $\begin{array}{l}\text { Ackerman et al. 1978, de } \\
\text { Nevers } 1993\end{array}$ \\
\hline Lumbricidae (earthworms) & entire organism & $\mathrm{SC}$ & Wood and Roark 1980 \\
\hline Annelida sp. (earthworm) & entire organism & $\mathrm{CA}, \mathrm{NC}, \mathrm{TN}, \mathrm{TX}$ & $\begin{array}{l}\text { Pine and Gerdes 1973, } \\
\text { Scott and Pelton 1975, } \\
\text { Springer 1975, Barrett } \\
1978\end{array}$ \\
\hline Lumbricoides sp. (earthworms) & entire organism & GA & Hanson and Karstad 1959 \\
\hline Lumbricus sp. (earthworms) & entire organism & CA, TN TX & $\begin{array}{l}\text { Conley et al. 1972, Henry } \\
\text { and Conley 1972, Kroll } \\
\text { 1986, Loggins et al. } 2002\end{array}$ \\
\hline Pheretima diffringens (earthworms) & entire organism & GA & Hanson and Karstad 1959 \\
\hline \multicolumn{4}{|l|}{ Arthropoda } \\
\hline Arthropoda (arthropods - general) & entire organism & $\mathrm{TX}$ & Ilse and Hellgren 1995 \\
\hline \multicolumn{4}{|l|}{ Arachnida } \\
\hline Aranea (spider) & entire organism & $\mathrm{CA}$ & Grover 1983 \\
\hline Ixodoidea (tick) & entire organism & $\mathrm{TX}$ & Springer 1975 \\
\hline \multicolumn{4}{|l|}{ Crustacea } \\
\hline Decapoda (crayfish) & entire organism & $\mathrm{NC}, \mathrm{TN}$ & Ackerman et al. 1978 \\
\hline Astacidae (crayfish) & entire organism & $\mathrm{TN}$ & $\begin{array}{l}\text { Conley et al. 1972, Henry } \\
\text { and Conley } 1972\end{array}$ \\
\hline Cambarus sp. (crayfish) & entire organism & $\mathrm{TX}$ & Springer 1975 \\
\hline Brachyura (crab) & entire organism & MS & Baron 1979 \\
\hline Callinectes sapidus (blue crab) & entire organism & MS & Baron 1979 \\
\hline Uca sp. (fiddler crab) & entire organism & GA, SC & $\begin{array}{l}\text { Hanson and Karstad 1959, } \\
\text { Wood and Roark } 1980\end{array}$ \\
\hline \multicolumn{4}{|l|}{ Insecta } \\
\hline Insecta (insects - general) & $\begin{array}{l}\text { larvae/adults/entire } \\
\text { organism }\end{array}$ & CA, MS, TN & $\begin{array}{l}\text { Stegeman 1938, Barrett } \\
\text { 1978, Baron 1979, Grover } \\
\text { 1983, Baber and Coblentz } \\
1987\end{array}$ \\
\hline Alleculidae (comb-clawed beetles) & larvae/entire organism & $\mathrm{TN}$ & $\begin{array}{l}\text { Conley et al. } 1972, \text { Henry } \\
\text { and Conley } 1972\end{array}$ \\
\hline Bibionidae (march flies) & larvae/entire organism & $\mathrm{NC}, \mathrm{TN}, \mathrm{TX}$ & $\begin{array}{l}\text { Conley et al. 1972, Henry } \\
\text { and Conley 1972, Springer } \\
\text { 1975, Ackerman et al. } \\
1978\end{array}$ \\
\hline Caelifera (grasshopper) & entire organism & $\mathrm{CA}, \mathrm{TX}$ & $\begin{array}{l}\text { Springer 1975, Grover } \\
1983\end{array}$ \\
\hline $\begin{array}{l}\text { Brachystola magna (lubber } \\
\text { grasshopper) }\end{array}$ & entire organism & GA & Hanson and Karstad 1959 \\
\hline Calliphoridae (blow flies) & larvae/entire organism & $\mathrm{TN}, \mathrm{TX}$ & $\begin{array}{l}\text { Conley et al. 1972, Henry } \\
\text { and Conley 1972, Springer } \\
1975\end{array}$ \\
\hline
\end{tabular}




\section{Wild Pigs}

Table 2. Listing of plants, fungi and animals consumed by wild pigs in the continental United States (Continued).

Taxonomic Group or Scientific Name (Common name)
Part(s) Consumed State(s) Reported From
Reference(s)

\begin{abstract}
Carabidae (ground beetles )
Coleoptera (beetles - general)
\end{abstract}

Corydalidae (hellgrammites) Curculionidae (true or snout weevils)

Diptera (flies)

Dolichopodidae (long-legged flies) Elateridae (click beetles)

Empididae (dance flies)

Formicidae (ants - general)

Geometridae (measuring worms)

Helicoverpa zea (corn earworm) Lepidoptera (moths and butterflies)

Meloidae (blister beetles)

Mutillidae (mutillid wasps)

Noctuidae (miller moths)

Odonata (dragonflies and damsel flies)

Phasmidae (walking sticks, stick insects)

Phengodidae (glowworms)

Rhagionidae (snipe flies)

Scarabacidae (lamellicron beetles)

Sialidae (alderflies)

Sphingidae (hawkmoths) entire organism

adult and larvae/entire organism

larvae/entire organism larvae/entire organism

larvae/adult/entire organism

entire organism larvae/entire organism

entire organism

entire organism

larvae/entire organism

larvae/entire organism

larvae, pupae/entire organism

entire organism adult/entire organism

larvae/entire organism

larvae/entire organism

entire organism

larvae/entire organism

larvae/entire organism

larvae/entire organism

larvae/entire organism

TN

larvae/entire organism
NC, TN, TX

$\mathrm{NC}, \mathrm{TN}$

CA, MS, NC, SC, TN

$\mathrm{NC}, \mathrm{TN}$

NC, TN, TX

$\mathrm{NC}, \mathrm{TN}$

TN

NC, TN

$\mathrm{NC}, \mathrm{TN}$

TN

NC, TN

TN, TX

$\mathrm{NC}, \mathrm{TN}$

TN

TN

TN, TX

NC, TN

TN

TN

SC, TN, TX
Ackerman et al. 1978, Howe et al. 1981

Conley et al. 1972, Henry and Conley 1972, Scott and Pelton 1975, Baron 1979, Wood and Roark 1980, Grover 1983

Ackerman et al. 1978 Conley et al. 1972, Henry and Conley 1972, Springer 1975, Ackerman et al. 1978

Conley et al. 1972, Henry and Conley 1972, Scott and Pelton 1975, Springer 1975, Howe et al. 1981 Ackerman et al. 1978 Conley et al. 1972, Henry and Conley 1972

Ackerman et al. 1978

Ackerman et al. 1978 Conley et al. 1972, Henry and Conley 1972

Ackerman et al. 1978 Conley et al. 1972, Henry and Conley 1972, Springer 1975, Taylor and Hellgren 1997

Ackerman et al. 1978

Conley et al. 1972, Henry

and Conley 1972

Conley et al. 1972, Henry and Conley 1972

Conley et al. 1972, Henry and Conley 1972, Springer 1975

Ackerman et al. 1978

Conley et al. 1972, Henry and Conley 1972

Conley et al. 1972, Henry and Conley 1972

Conley et al. 1972, Henry and Conley 1972, Springer 1975, Wood and Roark 1980

Conley et al. 1972, Henry and Conley 1972

Ackerman et al. 1978 
Table 2. Listing of plants, fungi and animals consumed by wild pigs in the continental United States (Continued).

Taxonomic Group or Scientific Name (Common name)

Part(s) Consumed State(s) Reported From
Reference(s)
Tabanidae (deer flies)

Tenebrionidae (darkling beetles)

Tipulidae (crane flies)

Trupaneidae (fruit flies)

\section{Myriapoda}

Diplopoda (millipedes)

Juliformia (millipede)

Polydesmoidae (millipedes)

Chilopoda (centipedes)

Geophilidae (centipedes)

Scolopendromorpha (centipedes)

Scolopendridae (centipedes)

\section{Mollusk}

Gastropoda (snails)

Polygridae (land snails)

Pelecypoda (clams and mussels)

Elliptio icterina (variable spike mussel)

Uniomerus carolinianus (Florida pondhorn)

\section{Nematode}

Nematoda (roundworms)

\section{Vertebrates}

\section{Fish}

Osteichthyes (fish - general)

Gambusia sp. (topminnows)

\section{Amphibians}

Anura (frogs - general)

Hyla sp. (tree frog) larvae/entire organism

$\mathrm{NC}, \mathrm{TN}$

larvae/entire organism

$\mathrm{NC}, \mathrm{TN}$

larvae/entire organism

NC, TN, TX

larvae/entire organism

TN

adult/entire organism

TN

entire organism

entire organism

entire organism

entire organism

entire organism

entire organism

entire organism

entire organism

entire organism

entire organism

entire organism

entire organism

$\mathrm{MS}, \mathrm{NC}, \mathrm{TN}$

$\mathrm{NC}, \mathrm{TN}$

$\mathrm{NC}, \mathrm{TN}$

$\mathrm{SC}$

$\mathrm{NC}, \mathrm{TN}$

$\mathrm{SC}$

NC, TN

$\mathrm{NC}, \mathrm{TN}$

$\mathrm{SC}$

$\mathrm{SC}$

$\mathrm{SC}$
Conley et al. 1972, Henry and Conley 1972, Ackerman et al. 1978 Conley et al. 1972, Henry and Conley 1972, Ackerman et al. 1978 Conley et al. 1972, Henry and Conley 1972, Scott and Pelton 1975, Springer 1975, Ackerman et al. 1978

Conley et al. 1972, Henry and Conley 1972

Conley et al. 1972, Henry and Conley 1972

CA, NC, TN, TX

Ackerman et al. 1978

Ackerman et al. 1978

Conley et al. 1972, Henry and Conley 1972, Scott and Pelton 1975, Springer 1975, de Nevers 1993

Wood and Roark 1980

Ackerman et al. 1978

Wood and Roark 1980

Ackerman et al. 1978

Howe et al. 1981

Wood and Roark 1980

Zengel and Conner 2008

Zengel and Conner 2008

Ackerman et al. 1978, Baron 1979

\section{carrion}

MS

Baron 1979

entire organism

TX

Springer 1975

entire organism

GA, TN

entire organism
GA
Stegeman 1938, Hanson and Karstad 1959

Jolly et al. In Press 


\section{Wild Pigs}

Table 2. Listing of plants, fungi and animals consumed by wild pigs in the continental United States (Continued).

Taxonomic Group or Scientific Name

(Common name)

Part(s) Consumed State(s) Reported

From
Reference(s)

\begin{tabular}{|c|c|c|c|}
\hline $\begin{array}{l}\text { Pseudacris regilla (Pacific } \\
\text { treefrog) }\end{array}$ & entire organism & $\mathrm{CA}$ & $\begin{array}{l}\text { Wilcox and Van Vuren } \\
2009\end{array}$ \\
\hline $\begin{array}{l}\text { Rana berlandieri (Rio Grande } \\
\text { leopard frog) }\end{array}$ & entire organism & $\mathrm{TX}$ & Springer 1975 \\
\hline $\begin{array}{l}\text { Rana pipiens shenocephala } \\
\text { (southern leopard frog) }\end{array}$ & entire organism & $\mathrm{SC}$ & Wood and Roark 1980 \\
\hline Rana sylvatica (wood frog) & eggs & $\mathrm{TN}$ & Conley et al. 1972 \\
\hline $\begin{array}{l}\text { Scaphiopus holbrooki (spadefoot } \\
\text { toad) }\end{array}$ & entire organism & GA & Jolly et al. In Press \\
\hline Caudata (salamanders - general) & entire organism & $\mathrm{NC}, \mathrm{TN}$ & $\begin{array}{l}\text { Scott and Pelton } 1975 \text {, } \\
\text { Ackerman et al. } 1978\end{array}$ \\
\hline $\begin{array}{l}\text { Ambystoma maculatum (spotted } \\
\text { salamander) }\end{array}$ & entire organism & $\mathrm{SC}$ & Sweeney 1970 \\
\hline $\begin{array}{l}\text { Desmognathus ochrophaeus } \\
\text { carolinensis (Carolina mountain } \\
\text { dusky salamander) }\end{array}$ & entire organism & $\mathrm{NC}, \mathrm{TN}$ & Ackerman et al. 1978 \\
\hline $\begin{array}{l}\text { Eurycea bislineata wilderae (Blue } \\
\text { Ridge two-lined salamander ) }\end{array}$ & entire organism & $\mathrm{NC}, \mathrm{TN}$ & Ackerman et al. 1978 \\
\hline $\begin{array}{l}\text { Leurognathus marmoratus } \\
\text { intermedius (shovel-nosed } \\
\text { salamander) }\end{array}$ & entire organism & $\mathrm{NC}, \mathrm{TN}$ & Ackerman et al. 1978 \\
\hline $\begin{array}{l}\text { Plethodontidae (lungless } \\
\text { salamanaders) }\end{array}$ & entire organism & $\mathrm{NC}, \mathrm{TN}$ & Howe et al. 1981 \\
\hline $\begin{array}{l}\text { Plethodon cinereus cinereus (red- } \\
\text { backed salamander ) }\end{array}$ & entire organism & $\mathrm{NC}, \mathrm{TN}$ & Ackerman et al. 1978 \\
\hline $\begin{array}{l}\text { Plethodon glutinosus (slimy } \\
\text { salamander) }\end{array}$ & entire organism & $\mathrm{SC}$ & Sweeney 1970 \\
\hline $\begin{array}{l}\text { Plethodon jordani jordani (Jordan's } \\
\text { salamander) }\end{array}$ & entire organism & $\mathrm{NC}, \mathrm{TN}$ & Ackerman et al. 1978 \\
\hline $\begin{array}{l}\text { Plethodon wrighti (pygmy } \\
\text { salamander) }\end{array}$ & entire organism & $\mathrm{NC}, \mathrm{TN}$ & Ackerman et al. 1978 \\
\hline $\begin{array}{l}\text { Pseudotriton ruber schencki } \\
\text { (black-chinned red salamander) }\end{array}$ & entire organism & $\mathrm{NC}, \mathrm{TN}$ & Ackerman et al. 1978 \\
\hline \multicolumn{4}{|l|}{ Reptiles } \\
\hline $\begin{array}{l}\text { Alligator mississippiensis } \\
\text { (American alligator) }\end{array}$ & eggs & FL, LA & $\begin{array}{l}\text { Neill 1971, McIlhenny } \\
\text { 1976, Mazzotti and Brandt } \\
1994\end{array}$ \\
\hline Testudines (turtle - general) & $\begin{array}{l}\text { eggs, hatchlings, entire } \\
\text { organism }\end{array}$ & $\mathrm{GA}, \mathrm{NC}, \mathrm{TN}$ & $\begin{array}{l}\text { Hanson and Karstad 1959, } \\
\text { Ackerman et al. } 1978\end{array}$ \\
\hline $\begin{array}{l}\text { Caretta caretta (loggerhead sea } \\
\text { turtle) }\end{array}$ & eggs and hatchlings & FL, GA & $\begin{array}{l}\text { Thompson 1977, Mayer } \\
\text { and Brisbin 1995, Hayes et } \\
\text { al. } 1996\end{array}$ \\
\hline $\begin{array}{l}\text { Chelonia mydas (Atlantic green } \\
\text { turtle) }\end{array}$ & eggs and hatchlings & FL & NMFS and USFWS 1991 \\
\hline $\begin{array}{l}\text { Gopherus berlandieri (Texas } \\
\text { tortoise) }\end{array}$ & entire organism & $\mathrm{TX}$ & Taylor and Hellgren 1997 \\
\hline $\begin{array}{l}\text { Lepidochelys kempii (Kemp's } \\
\text { Ridley sea turtle) }\end{array}$ & eggs & $\mathrm{TX}$ & Diaz 2008 \\
\hline
\end{tabular}


Table 2. Listing of plants, fungi and animals consumed by wild pigs in the continental United States (Continued).

Taxonomic Group or Scientific Name (Common name)
Part(s) Consumed
State(s) Reported From
Reference(s)

Terrapene carolina carolina
(eastern box turtle)
Lacertilia (lizard - general)
Anolis carolinensis (green anole)
Cnemidophorus sexlineatus (prairie
racerunner lizard)
Gerrhonotus multicarinatus
(alligator lizard)
Ophisaurus ventralis (eastern glass
lizard)
Phrynosoma cornutum (Texas
horned lizard)
Sceloporus occidentalis (western
fence lizard)
Sceloporus undulatus (eastern
fence lizard)
Xantusia riversiana (island night
lizard)
Serpentes (snakes - general)

Terrapene carolina carolina

Anolis carolinensis (green anole)

Cnemidophorus sexlineatus (prairie

(alligator lizard) lizard)

Phrynosoma cornutum (Texas

Sceloporus occidentalis (western

fence lizard)

Sceloporus undulatus (eastern ence lizard)

Serpentes (snakes - general)

shell fragment
entire organism
entire organism
entire organism
entire organism
entire organism
entire organism
entire organism
entire organism
entire organism
entire organism

Coluber constrictor (eastern racer)

Contia tenuis (sharp-tailed snake)

Crotalus sp. (rattlesnake)

Crotalus viridis (western

rattlesnake)

Diadophis punctatus (ringneck

snake)

Storeria occipitomaculata (redbellied snake)

Thomnophis sirtalis (eastern garter snake)

\section{Birds}

Aves (birds - general)

Bonasa umbellus (ruffed grouse)

Callipepla californica (California quail)

Colinus virginianus (northern bobwhite)

Geococcyx californianus

(roadrunner)
$\mathrm{NC}, \mathrm{TN}$

TN

GA, SC

TX

CA

$\mathrm{SC}$

TX

CA

GA

CA

GA, MS, NC, SC, TN, TX

CA

CA

CA

entire organism

entire organism

$\mathrm{CA}$

entire organism

CA

entire organism

GA

entire organism

$\mathrm{SC}$

MS, NC, TN, TX

TN

eggs
entire organism

CA

eggs

TX

entire organism
Ackerman et al. 1978

Stegeman 1938

Wood and Roark 1980, Jolly et al. In Press Taylor and Hellgren 1997

de Nevers 1993

Wood and Roark 1980

Taylor and Hellgren 1997

Grover 1983

Jolly et al. In Press

National Fish and Wildlife Laboratory 1980

Hanson and Karstad 1959, Sweeney 1970, Scott and Pelton 1975, Springer 1975, Ackerman et al. 1978, Baron 1979

Wilcox and Van Vuren 2009

Wilcox and Van Vuren 2009

Grover 1983

Wilcox and Van Vuren 2009

de Nevers 1993

Jolly et al. In Press

Wood and Roark 1980

Scott and Pelton 1975, Springer 1975, Ackerman et al. 1978, Baron 1979 Henry 1969 Wilcox and Van Vuren 2009

Tolleson et al. 1993

Taylor and Hellgren 1997 


\section{Wild Pigs}

Table 2. Listing of plants, fungi and animals consumed by wild pigs in the continental United States (Continued).

Taxonomic Group or Scientific Name (Common name)
Part(s) Consumed State(s) Reported From
Reference(s)

Melanerpes formicivorus (acorn
woodpecker)
Meleagris gallopavo (wild turkey)
Phalaenoptilus nuttallii (common
poorwill)
Pipilo crissalis (California towhee)
Richmondena cardinalis (cardinal)
Thryomanes bewickii (Bewick's
wren)
Zenaidura macroura (mourning
dove)
Mammals
Mammalia (mammals - general)
Didelphis virginiana (opossum)
Sorex sp. (shrew)
Sorex trowbridgii (Trowbridge's
shrew )
Scapanus latimanus (broad-footed
mole)
Dasypus novemcinctus (nine-
banded armadillo)
Sylvilagus bachmani (brush rabbit)
Sylvilagus floridanus (eastern
cottontail)
Rodentia (rodent - general)

Citellus beecheyi (ground squirrel) Microtus californicus (California vole)

Microtus sp. (voles)

Ondatra zibethicus (muskrat)

Neotoma fuscipes (dusky-footed woodrat)

Peromyscus sp. (deer mice)

Peromyscus maniculatus (deer mouse)

Peromyscus truei (piñon mouse)

Reithrodontomys megalotis (western harvest mouse)

\begin{tabular}{|c|c|c|}
\hline entire organism & $\mathrm{CA}$ & $\begin{array}{l}\text { Wilcox and Van Vuren } \\
2009\end{array}$ \\
\hline eggs and entire organism & $\mathrm{SC}, \mathrm{TN}, \mathrm{TX}$ & $\begin{array}{l}\text { Henry } 1969, \text { J. J. Mayer, } \\
\text { unpubl. data }\end{array}$ \\
\hline carrion & CA & $\begin{array}{l}\text { Wilcox and Van Vuren } \\
2009\end{array}$ \\
\hline entire organism & $\mathrm{CA}$ & $\begin{array}{l}\text { Wilcox and Van Vuren } \\
2009\end{array}$ \\
\hline entire organism & $\mathrm{TX}$ & Taylor and Hellgren 1997 \\
\hline entire organism & CA & $\begin{array}{l}\text { Wilcox and Van Vuren } \\
2009\end{array}$ \\
\hline carrion & $\mathrm{TX}$ & Taylor and Hellgren 1997 \\
\hline entire organism, carrion & $\mathrm{CA}, \mathrm{NC}, \mathrm{TN}$ & $\begin{array}{l}\text { Scott and Pelton } 1975 \text {, } \\
\text { Ackerman et al. 1978, } \\
\text { Grover } 1983\end{array}$ \\
\hline carrion & $\mathrm{TX}$ & Taylor and Hellgren 1997 \\
\hline entire organism & $\mathrm{NC}, \mathrm{TN}$ & Ackerman et al. 1978 \\
\hline entire organism & $\mathrm{CA}$ & $\begin{array}{l}\text { Wilcox and Van Vuren } \\
2009\end{array}$ \\
\hline entire organism & $\mathrm{CA}$ & $\begin{array}{l}\text { Wilcox and Van Vuren } \\
2009\end{array}$ \\
\hline entire organism & $\mathrm{TX}$ & Kroll 1986 \\
\hline carrion & $\mathrm{CA}$ & $\begin{array}{l}\text { Wilcox and Van Vuren } \\
2009\end{array}$ \\
\hline carrion & $\mathrm{TX}$ & Taylor and Hellgren 1997 \\
\hline entire organism, carrion & GA, SC, TX & $\begin{array}{l}\text { Hanson and Karstad } 1959, \\
\text { Springer 1975, DeVault } \\
\text { and Rhodes } 2002\end{array}$ \\
\hline carrion & $\mathrm{CA}$ & Pine and Gerdes 1973 \\
\hline entire organism & $\mathrm{CA}$ & $\begin{array}{l}\text { Wilcox and Van Vuren } \\
2009\end{array}$ \\
\hline entire organism & $\mathrm{CA}$ & Loggins et al. 2002 \\
\hline entire organism & MS & Hanson and Karstad 1959 \\
\hline entire organism & $\mathrm{CA}$ & $\begin{array}{l}\text { Wilcox and Van Vuren } \\
2009\end{array}$ \\
\hline entire organism & NC, SC, TN, TX & $\begin{array}{l}\text { Ackerman et al. 1978, } \\
\text { Wood and Roark 1980, } \\
\text { Taylor and Hellgren } 1997\end{array}$ \\
\hline entire organism & $\mathrm{CA}$ & $\begin{array}{l}\text { Wilcox and Van Vuren } \\
2009\end{array}$ \\
\hline entire organism & $\mathrm{CA}$ & $\begin{array}{l}\text { Wilcox and Van Vuren } \\
2009\end{array}$ \\
\hline entire organism & CA & $\begin{array}{l}\text { Wilcox and Van Vuren } \\
2009\end{array}$ \\
\hline
\end{tabular}

entire organism

ggs and entire organism

carrion

entire organism

$\mathrm{NC}, \mathrm{TN}$

entire organism

entire organism

carrion

$\mathrm{CA}$

CA

MS

NC, SC, TN, TX

CA

$\mathrm{CA}$
Scott and Pelton 1975 Grover 1983

Ackerman et al. 1978

Wilcox and Van Vuren

Wilcox and Van Vuren

2009

Wilcox and Van Vuren 2009

Hanson and Karstad 1959, Springer 1975, DeVault

Pine and Gerdes 1973

2009

Lanson and Karstad 2009 Taylor and Hellgren 1997 2009

2009 2009 
SRNL-RP-2009-00869

Table 2. Listing of plants, fungi and animals consumed by wild pigs in the continental United States (Continued).

\begin{tabular}{|c|c|c|c|}
\hline $\begin{array}{l}\text { Taxonomic Group or } \\
\text { Scientific Name } \\
\text { (Common name) }\end{array}$ & Part(s) Consumed & $\begin{array}{l}\text { State(s) Reported } \\
\text { From }\end{array}$ & Reference(s) \\
\hline $\begin{array}{l}\text { Spermophilus beecheyi (California } \\
\text { ground squirrel) }\end{array}$ & entire organism & $\mathrm{CA}$ & $\begin{array}{l}\text { Loggins et al. 2002, } \\
\text { Wilcox and Van Vuren } \\
2009\end{array}$ \\
\hline Tamias striatus (eastern chipmunk) & entire organism & $\mathrm{TN}$ & Stegeman 1938 \\
\hline $\begin{array}{l}\text { Thomomys bottae (Botta's pocket } \\
\text { gopher) }\end{array}$ & carrion & $\mathrm{CA}$ & $\begin{array}{l}\text { Pine and Gerdes 1973, } \\
\text { Wilcox and Van Vuren } \\
2009\end{array}$ \\
\hline Sus scrofa (wild pig) & carrion & GA, TX & $\begin{array}{l}\text { Hanson and Karstad 1959, } \\
\text { Hellgren and Holzem } \\
\text { 1992, Taylor and Hellgren } \\
1997\end{array}$ \\
\hline Axis axis (chital or axis deer) & carrion & $\mathrm{TX}$ & J. J. Mayer, unpubl. data \\
\hline Bos taurus (domestic cattle) & $\begin{array}{l}\text { carrion, calves/entire } \\
\text { organism }\end{array}$ & CA, FL, TX & $\begin{array}{l}\text { Towne and Wentworth } \\
\text { 1950, Springer 1975, } \\
\text { Barrett 1978, J. J. Mayer, } \\
\text { unpubl. data }\end{array}$ \\
\hline Capra hircus (domestic goat) & $\begin{array}{l}\text { carrion, kids/entire } \\
\text { organism }\end{array}$ & $\mathrm{TX}$ & $\begin{array}{l}\text { Mayer and Brisbin 1991, } \\
\text { Beach 1993, Littauer } 1993\end{array}$ \\
\hline $\begin{array}{l}\text { Odocoileous hemionus } \\
\text { (mule/black-tailed deer) }\end{array}$ & carrion & $\mathrm{CA}$ & $\begin{array}{l}\text { Pine and Gerdes 1973, } \\
\text { Grover 1983, Loggins et al. } \\
\text { 2002, Wilcox and Van } \\
\text { Vuren } 2009\end{array}$ \\
\hline $\begin{array}{l}\text { Odocoileous virginianus (white- } \\
\text { tailed deer) }\end{array}$ & $\begin{array}{l}\text { carrion, fawns/entire } \\
\text { organism }\end{array}$ & $\mathrm{SC}, \mathrm{TX}$ & $\begin{array}{l}\text { Rutledge 1970, Springer } \\
\text { 1975, Hellgren and } \\
\text { Holzem 1992, Beach 1993, } \\
\text { Taylor and Hellgren 1997, } \\
\text { Jolley 2007, J. J. Mayer, } \\
\text { unpubl. data }\end{array}$ \\
\hline Ovis aries (domestic sheep) & $\begin{array}{l}\text { carrion, lambs/entire } \\
\text { organism }\end{array}$ & $\mathrm{CA}, \mathrm{SC}, \mathrm{TX}$ & $\begin{array}{l}\text { Rutledge 1970, Barrett } \\
\text { 1978, Beach 1993, Littauer } \\
1993\end{array}$ \\
\hline
\end{tabular}




\section{Wild Pigs}

Table 3. Comparison of the plant material composition found in wild pig diets. Data are grouped as: (1) fruits and seeds, (2) aboveground herbaceous material (leaves, stems, shoots, etc.), and (3) belowground herbaceous material (roots, tubers, bulbs, corms, etc.), each presented as percent volume (Vol) and percent frequency of occurrence (Occur) in the diet at each location.

\begin{tabular}{|c|c|c|c|c|c|c|c|}
\hline \multirow{2}{*}{ Location } & \multicolumn{2}{|c|}{ Fruits and Seeds } & \multicolumn{2}{|c|}{$\begin{array}{l}\text { Aboveground } \\
\text { Herbaceous }\end{array}$} & \multicolumn{2}{|c|}{$\begin{array}{l}\text { Belowground } \\
\text { Herbaceous }\end{array}$} & \multirow{2}{*}{ Reference } \\
\hline & Vol & Occur & Vol & Occur & Vol & Occur & \\
\hline Great Smoky Mountains & $55.2-$ & 67- & $2.8-$ & $80-$ & $\operatorname{tr}-$ & $50-80^{\mathrm{a}}$ & Ackerman et al. 1978 \\
\hline $\begin{array}{c}\text { National Park, NC and TN, } \\
\text { USA }\end{array}$ & $89.5^{\mathrm{a}}$ & $100^{\mathrm{a}}$ & $28.9^{\mathrm{a}}$ & $100^{\mathrm{a}}$ & $13.2^{\mathrm{a}}$ & & \\
\hline $\begin{array}{c}\text { Davis Mountains, TX, } \\
\text { USA }\end{array}$ & 3.9 & NR & 38.6 & NR & 34.3 & NR & $\begin{array}{c}\text { Adkins and Harvesor } \\
2006\end{array}$ \\
\hline $\begin{array}{c}\text { Santa Catalina Island, CA, } \\
\text { USA }\end{array}$ & $\begin{array}{l}32.0- \\
57.2^{\mathrm{a}}\end{array}$ & $\begin{array}{l}94.7- \\
100.0^{\mathrm{a}}\end{array}$ & $\begin{array}{l}29.1- \\
60.2^{\mathrm{ab}}\end{array}$ & $\begin{array}{l}94.7- \\
97.4^{\mathrm{ab}}\end{array}$ & $\begin{array}{l}2.2- \\
8.5^{\mathrm{a}}\end{array}$ & $\begin{array}{l}28.9- \\
65.8^{\mathrm{a}}\end{array}$ & $\begin{array}{c}\text { Baber and Coblentz } \\
1987\end{array}$ \\
\hline $\begin{array}{l}\text { Maurienne Valley, Savoie } \\
\text { Department, France }\end{array}$ & $36^{\mathrm{b}}$ & NR & 17 & 98 & 39 & 97 & Baubet et al. 2004 \\
\hline $\begin{array}{l}\text { Area around Chernobyl } \\
\text { powerplant, Polesie } \\
\text { Region, Ukraine }\end{array}$ & $0-47^{\mathrm{ab}}$ & NR & $9-81^{\mathrm{ab}}$ & NR & $1-41^{\mathrm{ab}}$ & NR & $\begin{array}{c}\text { Eriksson and Petrov } \\
1995\end{array}$ \\
\hline $\begin{array}{c}\text { Kipahulu Valley, Maui, } \\
\text { HI, USA }\end{array}$ & 28.4 & 57.1 & $58.9^{\mathrm{b}}$ & 71.4 & 3.1 & 32.1 & Diong 1982 \\
\hline $\begin{array}{c}\text { Natural Park of } \\
\text { Aiguamolls de l' Emporda, } \\
\text { Catalonia, Spain }\end{array}$ & $44.2^{\mathrm{b}}$ & NR & $12.1^{\mathrm{b}}$ & NR & 33.0 & 57.8 & $\begin{array}{c}\text { Giménez-Anaya et } \\
\text { al. } 2008\end{array}$ \\
\hline $\begin{array}{c}\text { Tellico Wildlife } \\
\text { Management Area, TN, } \\
\text { USA }\end{array}$ & $83.6^{\mathrm{b}}$ & NR & $2.5^{\mathrm{b}}$ & NR & 3.3 & 57.5 & $\begin{array}{l}\text { Henry and Conley } \\
1972\end{array}$ \\
\hline $\begin{array}{l}\text { Natural Park of } \\
\text { Aiguamolls de l' Emporda, } \\
\text { Catalonia, Spain }\end{array}$ & $51.9^{\mathrm{b}}$ & NR & 13.9 & 62.2 & 17.4 & 29.7 & Herrero et al. 2004 \\
\hline $\begin{array}{c}\text { Great Smoky Mountains } \\
\text { National Park, NC and TN, } \\
\text { USA }\end{array}$ & 3.1 & NR & 55.3 & NR & 40.2 & NR & Howe et al. 1981 \\
\hline $\begin{array}{c}\text { Great Smoky Mountains } \\
\text { National Park, NC and TN, } \\
\text { USA }\end{array}$ & $24.4^{\mathrm{b}}$ & NR & $30.0^{\mathrm{b}}$ & NR & 44.7 & NR & $\begin{array}{l}\text { Scott and Pelton } \\
1975\end{array}$ \\
\hline $\begin{array}{c}\text { South Texas Plains, TX, } \\
\text { USA }\end{array}$ & $34.4^{\mathrm{b}}$ & NR & $41.3^{\mathrm{b}}$ & NR & 17.3 & 73.5 & $\begin{array}{c}\text { Taylor and Hellgren } \\
1997\end{array}$ \\
\hline $\begin{array}{l}\text { Urewera Ranges, North } \\
\text { Island, New Zealand }\end{array}$ & $35.9^{\mathrm{b}}$ & NR & $11.6^{\mathrm{b}}$ & NR & $17.4^{\mathrm{b}}$ & NR & $\begin{array}{l}\text { Thomson and } \\
\text { Challies } 1988\end{array}$ \\
\hline Hobcaw Barony, SC, USA & $\begin{array}{l}9.2^{-} \\
83.7^{\mathrm{a}}\end{array}$ & $54-94^{\mathrm{a}}$ & $\begin{array}{c}9.5- \\
51.4^{\mathrm{a}}\end{array}$ & 100 & $\begin{array}{l}2.2- \\
38.0^{\mathrm{a}}\end{array}$ & $44-95^{\mathrm{a}}$ & $\begin{array}{c}\text { Wood and Roark } \\
1980\end{array}$ \\
\hline
\end{tabular}

${ }^{\mathrm{a}}$ Annual, seasonal or location variation

${ }^{\mathrm{b}}$ Calculated from reference 
Table 4. Comparison of the dietary composition of invertebrate and vertebrate prey in wild pigs. Data are presented as percent volume (Vol) and percent frequency of occurrence (Occur) in the diet at each location.

\begin{tabular}{|c|c|c|c|c|c|}
\hline \multirow{2}{*}{ Location } & \multicolumn{2}{|c|}{ Invertebrates } & \multicolumn{2}{|c|}{ Vertebrates } & \multirow[t]{2}{*}{ Reference(s) } \\
\hline & Vol & Occur & Vol & Occur & \\
\hline Doñana National Park, Spain & 3 & 64 & $<1$ & 27 & Abáigar 1993 \\
\hline $\begin{array}{c}\text { Great Smoky Mountains } \\
\text { National Park, NC and TN, } \\
\text { USA }\end{array}$ & $\operatorname{Tr}-8.2^{\mathrm{a}}$ & 100 & $\operatorname{Tr}-2.6^{\mathrm{a}}$ & $20-60^{\mathrm{a}}$ & Ackerman et al. 1978 \\
\hline Davis Mountains, TX, USA & 1.3 & NR & 0.7 & NR & $\begin{array}{c}\text { Adkins and Harveson } \\
2006\end{array}$ \\
\hline Santa Catalina Island, CA, USA & $1.7-3.2^{\mathrm{a}}$ & $23.7-49.4^{\mathrm{a}}$ & Trace & 8.9 & $\begin{array}{c}\text { Baber and Coblentz } \\
1987\end{array}$ \\
\hline $\begin{array}{l}\text { Maurienne Valley, Savoie } \\
\text { Department, France }\end{array}$ & 1.0 & 75 & 0 & - & Baubet et al. 2004 \\
\hline Horn Island, MS, USA & $4.4^{\mathrm{b}}$ & $80^{\mathrm{b}}$ & $14.6^{\mathrm{b}}$ & $60^{\mathrm{b}}$ & Baron 1979 \\
\hline Auckland Island, New Zealand & 27.8 & 76 & 5.4 & 12 & Chimera et al. 1995 \\
\hline Temperate Monte Desert & 4.0 & NR & 1.0 & NR & Cuevas et al. 2007 \\
\hline \multicolumn{6}{|l|}{$\begin{array}{c}\text { Reserve of Ñacuñen, Mendoza, } \\
\text { Argentina }\end{array}$} \\
\hline $\begin{array}{c}\text { Kipahulu Valley, Maui, HI, } \\
\text { USA }\end{array}$ & 6.8 & 89.2 & 0 & - & Diong 1982 \\
\hline $\begin{array}{l}\text { Varaita Valley, Cuneo } \\
\text { Province, Italy }\end{array}$ & 1.1 & 65 & 6.1 & 65 & Durio et al. 1995 \\
\hline $\begin{array}{c}\text { Yturria Ranch, Willacy County, } \\
\text { TX, USA }\end{array}$ & 0.5 & NR & 4.3 & 10 & $\begin{array}{c}\text { Everitt and Alaniz } \\
1980\end{array}$ \\
\hline Herault Department, France & 3 & 88 & 0 & - & $\begin{array}{c}\text { Fournier- } \\
\text { Chambrillon et al. } \\
1995\end{array}$ \\
\hline $\begin{array}{l}\text { Natural Park of Aiguamolls de } \\
\text { l' Emporda, Catalonia, Spain }\end{array}$ & 3.4 & 75.4 & 3.3 & 24.6 & $\begin{array}{l}\text { Giménez-Anaya et } \\
\text { al. } 2008\end{array}$ \\
\hline $\begin{array}{c}\text { Tellico Wildlife Management } \\
\text { Area, TN, USA }\end{array}$ & 5.4 & 86.3 & 1.0 & 30.1 & $\begin{array}{l}\text { Henry and Conley } \\
1972\end{array}$ \\
\hline $\begin{array}{l}\text { Natural Park of Aiguamolls de } \\
\text { l' Emporda, Catalonia, Spain }\end{array}$ & 3.2 & 28.0 & 4.9 & 32.4 & Herrero et al. 2004 \\
\hline $\begin{array}{c}\text { Great Smoky Mountains } \\
\text { National Park, NC and TN, } \\
\text { USA }\end{array}$ & 1.1 & NR & 0.5 & NR & Howe et al. 1981 \\
\hline $\begin{array}{l}\text { Gipuzkoa and Bizbaia } \\
\text { provinces, Spain }\end{array}$ & 1.8 & 67.4 & 3.2 & 41.9 & Irizar et al. 2004 \\
\hline National Park of Chrea, Algeria & 1.0 & NR & 0 & - & Klaa 1992 \\
\hline Great Smoky Mountains & 0.2 & 52.3 & Trace & 23.4 & Scott and Pelton \\
\hline $\begin{array}{c}\text { National Park, NC and TN, } \\
\text { USA }\end{array}$ & & & & & 1975 \\
\hline $\begin{array}{l}\text { Herault and Aude Departments, } \\
\text { France }\end{array}$ & 2.1 & NR & 1.6 & NR & Sjarmidi et al. 1992 \\
\hline South-central Chile & 7.4 & NR & 8.7 & NR & Skewes et al. 2007 \\
\hline
\end{tabular}




\section{Wild Pigs}

Table 4. Comparison of the dietary composition of invertebrate and vertebrate prey in wild pigs. Data are presented as percent volume (Vol) and percent frequency of occurrence (Occur) in the diet at each location. (Continued)

\begin{tabular}{|c|c|c|c|c|c|}
\hline \multirow{2}{*}{ Location } & \multicolumn{2}{|c|}{ Invertebrates } & \multicolumn{2}{|c|}{ Vertebrates } & \multirow[t]{2}{*}{ Reference(s) } \\
\hline & Vol & Occur & Vol & Occur & \\
\hline South Texas Plains, TX, USA & 2.4 & 28 & 4.2 & 23 & $\begin{array}{c}\text { Taylor and Hellgren } \\
1997\end{array}$ \\
\hline $\begin{array}{l}\text { Urewera Ranges, North Island, } \\
\text { New Zealand }\end{array}$ & 13.2 & 79 & $12.4^{\mathrm{b}}$ & 45 & $\begin{array}{l}\text { Thomson and } \\
\text { Challies } 1988\end{array}$ \\
\hline $\begin{array}{c}\text { Diablo Range, Santa Clara } \\
\text { County, CA, USA }\end{array}$ & NR & NR & NR & 40.4 & $\begin{array}{l}\text { Wilcox and Van } \\
\text { Vuren } 2009\end{array}$ \\
\hline Hobcaw Barony, SC, USA & $0.6-2.8^{\mathrm{a}}$ & $85^{\mathrm{a}}$ & $0.7-2.8^{\mathrm{a}}$ & 24 & $\begin{array}{l}\text { Wood and Roark } \\
1980\end{array}$ \\
\hline
\end{tabular}

${ }^{\text {a }}$ Annual, seasonal or location variation

${ }^{\mathrm{b}}$ Calculated from reference

Table 5. Chemical constituents of tropical and temperate fruits and other items likely to be eaten by wild pigs (Choquenot et al. 1996).

Constituent (\% dry matter)

Food

Item

Crude Protein Sugars and Starch Cellulose

Tropical and Temperate

Fruits

3-12

$12-78$

1-8

Seeds

3-15

Grasses

4-17

2-16

3-19

$15-40$

Forbs

4-35

2-18

6-33

Tropical Trees and Shrubs

Young leaves

Mature leaves

General

Bulbs

Legumes

Earthworms

Insects

Carrion (cow)
7-55

5-36

0-33

1-15

6-25

11-30
12-15

24-25

54-80

60

57 
SRNL-RP-2009-00869

Table 6. Daily nutrient requirements of domestic pigs for different weight classes (Barrett 1978).

\begin{tabular}{|c|c|c|c|c|c|c|}
\hline \multirow[t]{2}{*}{ Daily Nutrient Requirement } & \multicolumn{3}{|c|}{ Growing Pigs } & \multirow{2}{*}{$\begin{array}{c}\begin{array}{c}\text { Breeding } \\
\text { Sows }\end{array} \\
\begin{array}{c}110-160 \\
\mathrm{~kg}\end{array}\end{array}$} & \multirow{2}{*}{$\begin{array}{c}\begin{array}{c}\text { Lactating } \\
\text { Sows }\end{array} \\
\begin{array}{c}136-200 \\
\mathrm{~kg}\end{array}\end{array}$} & \multirow{2}{*}{$\begin{array}{c}\text { Boars } \\
110- \\
180 \mathrm{~kg}\end{array}$} \\
\hline & $5-10 \mathrm{~kg}$ & $\begin{array}{l}10-20 \\
\mathrm{~kg}\end{array}$ & $\begin{array}{c}20-35 \\
\mathrm{~kg}\end{array}$ & & & \\
\hline \multicolumn{7}{|l|}{ Digestible Energy } \\
\hline $\begin{array}{l}\text { Kilocalories per kilogram } \\
\text { forage }\end{array}$ & 3,500 & 3,500 & 3,300 & 3,300 & 3,300 & 3,300 \\
\hline Kilocalories per day & 2,100 & 4,370 & 5,610 & 6,600 & 16,500 & 8,250 \\
\hline \multicolumn{7}{|l|}{ Total Feed } \\
\hline Air dry weight (in kg) & 0.6 & 1.3 & 1.7 & 2.0 & 5.0 & 2.5 \\
\hline \multicolumn{7}{|l|}{ Crude Protein } \\
\hline Percentage of diet & 22 & 18 & 16 & 14 & 15 & 14 \\
\hline Grams per day & 132 & 225 & 272 & 280 & 750 & 350 \\
\hline
\end{tabular}




\section{Wild Pigs}

\section{Literature Cited}

Abáigar, T. 1993. Regimen alimentario del jabali (Sus scrofa, L. 1758) en el sudeste iberico. Donana, Acta Vertebrata, 20(1):35-48.

Ackerman, B. B., M. E. Harmon, and F. J. Singer. 1978. Part II. Seasonal food habits of European wild boar - 1977. Pp. 94-137. In F. J. Singer (ed.), Studies of European wild boar in the Great Smoky Mountains National Park: 1st annual report; a report for the Superintendent. Uplands Field Research Laboratory, Great Smoky Mountains National Park, Gatlinburg, Tennessee.

Adkins, R. N., and L. A. Harveson. 2006. Summer diets of feral hogs in the Davis Mountains, Texas. The Southwestern Naturalist 51(4):578-580.

Asahi, M. 1995. Stomach contents of Japanese wild boar in winter. Journal of Mountain Ecology (Ibex), 3:184-185.

Baber, D. W., and B. E. Coblentz. 1987. Diet, nutrition and conception in feral pigs on Santa Catalina Island. Journal of Wildlife Management, 51(2):306-317.

Baker, J. K. 1975. The feral pig in Hawaii Volcanoes National Park. Transactions of the California-Nevada Section of the Wildlife Society, 22:74-80.

Baron, J. S. 1979. Vegetation damage by feral hogs on Horn Island, Gulf Islands National Seashore, Mississippi. M.S. Thesis, University of Wisconsin - Madison, Madison, Wisconsin.

Barrett, R. H. 1978. The feral hog on the Dye Creek Ranch, California. Hilgardia, 46(9):283-355.

Baubet, E., Y. Ropert-Coudert, and S. Brandt. 2003. Seasonal and annual variation in earthworm consumption by wild boar (Sus scrofa scrofa L.). Wildlife Research, 30(2):179-186.

Baubet, E., C. Bonenfant, and S. Brandt. 2004. Diet of the wild boar in the French Alps. Galemys, 16(Special Edition):99-111.

Beach, R. 1993. Depredation problems involving feral hogs. Pp. 67-75. In C. W. Hanselka and J. F. Cadenhead (eds.), Feral swine: A compendium for resource managers. Texas Agricultural Extension Service, Kerrville, Texas.

Beyer, W. N., E. E. Connor, and S. Gerould. 1994. Estimates of soil ingestion by wildlife. Journal of Wildlife Management, 58(2):375-382.

Bodenchuk, M. J. 2008. Feral hog management: Tying performance measures to resources protected. 4 pp. In S. M. Vantassel (ed.), 2008 National conference on feral hogs. St. Louis, Missouri. http://digitalcommons.unl.edu/feralhog/8

Briedermann, L. 1976. Ergebisse einer Inhaltsanalyse von 665 Wildschweinmagen. Der Zoologische Garten, 46(3):157-185.

1986. Schwarzwild. VEB Deutscher Landwirtschaftsverlag, Berlin, Democratic Republic of Germany.

Brooks, J. E., E. Ahmad, and I. Hussain. 1988. Characteristics of damage by vertebrate pests to groundnuts in Pakistan. Proceedings of the Vertebrate Pest Conference, 13:129-133.

Challies, C. N. 1975. Feral pigs (Sus scrofa) on Auckland Island: Status and effects on vegetation and nesting sea birds. New Zealand Journal of Zoology, 2(4):479-490. 
Chimera, C., M. C. Coleman, and J. P. Parkes. 1995. Diet of feral goats and feral pigs on Auckland Island, New Zealand. New Zealand Journal of Ecology, 19:203-207.

Chipping, D. H. 1993. Impacts of wild pig on native vegetation. Pp. 4. In W. Tietje and R. Barrett (eds.), The wild pig in California oak woodland: Ecology and economics. University of California, Berkeley, Berkeley, California.

Choquenot, D., J. McIlroy, and T. Korn. 1996. Managing vertebrate pests: Feral pigs. Bureau of Rural Sciences, Australian Government Publishing Service, Canberra, Australia.

Coblentz, B. E., and D. W. Baber. 1987. Biology and control of feral pigs on Isla Santiago, Galapagos, Ecuador. Journal of Applied Ecology, 24(2):403-418.

Conley, R. H., V. G. Henry, and G. H. Matschke. 1972. Final report for the European hog research project W-34. Tennessee Game and Fish Commission, Nashville, Tennessee.

Cuevas, F. A. Novillo, M. Dacar, B. Bender, C. Campos, and R. A. Ojeda. 2007. Ecology of wild boar, Sus scrofa, in the Temperate Monte Desert Reserve (MAB) of Ñacuñen, Argentina. Grupo de Investigaciones de la Biodiversidad (GiB), IADIZA, CONICET, CRICYT, Mendoza, Argentina.

Dardaillon, M. 1987. Seasonal feeding habits of the wild boar in a mediterranean wetland, the Camargue (southern France). Acta Theriologica, 32(23):389-401.

1989. Age class influences on feeding choices of free-ranging wild boars (Sus scrofa). Canadian Journal of Zoology, 67(11):2792-2796.

de Nevers, G. 1993. What is feral hog damage? Pp. 9-10. In W. Tietje and R. Barrett (eds.), The wild pig in California oak woodland: Ecology and economics, University of California, Berkeley, Berkeley, California.

DeVault, T. L., and O. E. Rhodes, Jr. 2002. Identification of vertebrate scavengers of small mammal carcasses in a forested landscape. Acta Theriologica, 47:185-192.

Devine, R. S. 1999. Alien invasion: America's battle with non-native animals and plants. National Geographic Society, Washington, DC.

Diaz, A. 2008. Managing the feral hog menace on Matagorda Island National Wildlife Refuge. Fish \& Wildlife Journal. U. S. Fish and Wildlife Service, Department of the Interior, Washington, D.C.

Diong, C. H. 1973. Studies of the Malaysian wild pig in Perak and Jahore. Malayan Nature Journal, 26(3/4):120-151.

1982. Population biology and management of the feral pig (Sus scrofa L.) in Kipahula Valley, Maui. Ph.D. Dissertation, University of Hawaii, Honolulu, Hawaii.

Durio, P., D. Fogliato, A. Perrone, and N. Tessarin. 1995. The autumn diet of the wild boar (Sus scrofa) in an alpine valley. Preliminary results. Journal of Mountain Ecology (Ibex), 3:180-183.

Eriksson, O., and M. Petrov. 1995. Wild boars (Sus scrofa scrofa L.) around Chernobyl, Ukraine. Seasonal feed choice in an environment under transition - A baseline study. Journal of Mountain Ecology (Ibex), 3:171-173.

Erkinaro, E., K. Heikura, E. Lindgren, E. Pulliainen, and S. Sulkava. 1982. Occurrence and spread of the wild boar (Sus scrofa) in eastern Fennoscandia (in English with Finnish summary). Memoranda Societas Fauna et Flora Fennica, 58(2):39-47. 


\section{Wild Pigs}

Everitt, J. H., and M. A. Alaniz. 1980. Fall and winter diets of feral pigs in south Texas. Journal of Range Management, 33(2):126-129.

Focardi, S., D. Capizzi, and D. Monetti. 2000. Competition for acorns among wild boar (Sus scrofa) and small mammals in a Mediterranean woodland. Journal of Zoology 250(3):329-334.

Fournier-Chambrillon, C., D. Maillard, and P. Fournier. 1995. Diet of the wild boar (Sus scrofa L.) inhabiting the Montpellier garrigue. Journal of Mountain Ecology (Ibex), 3:174-179.

Fries, G. F., G. S. Marrow and P. A. Snow. 1982. Soil ingestion by swine as a route of contaminant exposure. Environmental Chemistry, 1:201-204.

Geisser, H., and H. U. Reyer. 2005. The influence of food and temperature on population density of wild boar Sus scrofa in the Thurgau (Switzerland). Journal of Zoology, 267(1):89-96.

Genard, M., F. Lescourret, and G. Durrieu. 1988. Mycophagie chez le sanglier et hypotheses sur son role dans la dissemination des spores de champignons hypoges. Canadian Journal of Zoology, 66(10):23242327.

Genov, P. 1981a. Food composition of wild boar in North-eastern and Western Poland. Acta Theriologica, 26(10):185-205.

. 1981b. Significance of natural biocenoses and agrocenoses as the source of food for wild boar (Sus scrofa L.). Ekologia Polska, 29(1):117-136.

Giffin, J. G. 1970. Feral game mammal survey: Feral pig survey (Hawaii), Project No. W-5-R-21, Job No. 46 (21). State of Hawaii, Division of Fish and Game, Honolulu, Hawaii.

Giménez-Anaya, A., J. Herrero, C. Rosell, S. Couto, and A. García-Serrano. 2008. Food habits of wild boars (Sus scrofa) in a Mediterranean coastal wetland. Wetlands, 28(1):197-203.

Groot Bruinderink, G. W. T. A., and E. Hazebroek. 1995. Modelling carrying capacity for wild boar Sus scrofa scrofa in a forest/heathland ecosystem. Wildlife Biology, 1(2):81-87.

. 1996. Wild boar (Sus scrofa) rooting and forest regeneration on podzolic soils in the Netherlands. Forest Ecology and Management, 88(1-2):71-80.

Groot Bruinderink, G. W. T. A., E. Hazebroek, and H. van der Voot. 1994. Diet and condition of wild boar, Sus scrofa scrofa, without supplementary feeding. Journal of Zoology, 233(4):631-648.

Grover, A. M. 1983. The home range, habitat utilization, group behavior and food habits of the feral hog (Sus scrofa) in northern California. M.S. Thesis, California State University, Sacramento, California.

Haber, A. 1966. Pozywienie dzika. Lowiec Polski, 14(1281):2-3.

Hahn, N., D. Eisfeld, P Havet, E. Taran, and J. C. Berthos. 1998. Diet and habitat use of wild boar (Sus scrofa) in SW-Germany. Gibier et Fauna Sauvage, 15(2):595-606.

Hanson, R. P., and L. Karstad. 1959. Feral swine in the southeastern United States. Journal of Wildlife Management, 23(1):64-74.

Hayes, R. B., N. B. Marsh, and G. A. Bishop. 1996. Sea turtle nest depredation by a feral hog: A learned behavior. Pp. 129-134. In J. A. Keinath, D. E. Barnard, J. A. Musick, and B. A. Bell (eds.), Proceedings of the fifteenth annual symposium on sea turtle biology and conservation. NOAA Technical Memorandum MNFS-SEFSC 387, Hilton Head Island, South Carolina. 
Hellgren, E. C., and A. M. Holzem. 1992. Feral hog food habits in the western Rio Grande Plains. Texas Parks and Wildl. Dept., Austin, Texas.

Hennig, R. 1981. Schwarzwild: Biologie - Verhalten, Hege und Jagd. BVL Verlagsgesellschaft, Munchen, West Germany.

Henry, V. G. 1969. Predation on dummy nests of ground-nesting birds in the southern Appalachians. Journal of Wildlife Management 33(1):169-172.

Henry, V. G., and R. H. Conley. 1972. Fall foods of the European wild hogs in the southern Appalachians. Journal of Wildlife Management, 36(3):854-860.

Herrero, J., S. Couto, C. Rosell, and P. Arias. 2004. Preliminary data on the diet of wild boar living in a Mediterranean coastal wetland. Galemys, 16(Numero Especial):115-123.

Howe, T. D., F. J. Singer, and B. B. Ackerman. 1981. Forage relationships of European wild boar invading northern hardwood forests. Journal of Wildlife Management, 45(3):748-754.

Ilse, L. M., and E. C. Hellgren. 1995. Resource partitioning by sympatric populations of collared peccaries and feral hogs in southern Texas. Journal of Mammalogy, 76(3):784-799.

Irizar, I., N. A. Laskurain, and J. Herrero. 2004. Wild boar frugivory in the Atlantic Basque Country. Galemys, 16(Numero Especial):125-133.

Janda, M. 1958. Die Nahrung des Schwarzwildes (Sus scrofa) im Mittelgebirgsgebiet von Stiavnica. Saugetierkundliche Mittilungen, 6(2):67-74.

Jolley, D. B. 2007. Reproduction and herpetofauna depredation of feral pigs at Fort Benning, Georgia. M.S. Thesis, Auburn University, Auburn, Alabama.

Jolley, D. B., S. S. Ditchkoff, W. D. Sparklin, L. B. Hanson, M. S. Mitchell, and J. B. Grand. In Press. An estimate of herpetofauna depredation by a population of wild pigs. Journal of Mammalogy.

Klaa, K. 1992. The diet of wild boar (Sus scrofa L.) in the National Park of Chrea (Algeria). Pp. 403-407. In F. Spitz, G. Janeau, G. Gonzalez, and S. Aulagnier (eds.), Ongules/Ungulates 91: Proceedings of the international symposium. Toulouse, France, September 2-6, 1991. Societe Francaise pour l'Etude et la Protection des Mammiferes, and Toulose: Institut de Recherche sur les Grands Mammiferes, Paris \& Toulouse, France.

Kozlo, P. G. 1975. Dikiy Kaban. Izdatel'stovo Uradzhai, Minsk, U.S.S.R.

Kroll, J. C. 1986. Interspecific competition between feral hogs and white-tailed deer in the post oak savannah region of Texas. F. A. Proj. W-109-R-8 Job. No. 44, Final Perf. Report. Texas Parks and Wildlife Department, Austin, Texas.

Kurz, J. C. 1971. A study of feral hog movements and ecology on the Savannah River Plant, South Carolina. M.S. Thesis, University of Georgia, Athens, Georgia.

Lebedeva, L. S. 1956. O sostave letnich kormov kabana v wysokogornoj zonie Kavkaskogo zapovednika. Uchenye Zapiski Moskovskaya Gosudarstvennyi Pedagogicheskii Instituta Zoologii, 61(1):4-6.

Lemel, J. 1999. Populationstillvaxt, dynamik och spridning hos Vildsvinet, Sus scrofa, i mellersta Sverige. Slutrapport till Naturvardsverket/Jagareforbundet, Stockholm, Sweden.

Lipscomb, D. J. 1989. Impacts of feral hogs on longleaf pine regeneration. Southern Journal of Applied Forestry 13(4):177-181. 


\section{Wild Pigs}

Littauer, G. A. 1993. Control techniques for feral hogs. Pp. 139-148. In C. W. Hanselka and J. F. Cadenhead (eds.), Feral swine: A compendium for resource managers. Texas Agricultural Extension Service, Kerrville, Texas.

Loggins, R. E., J. T. Wilcox, D. H. V. Vuren, and R. A. Sweitzer. 2002. Seasonal diet of wild pigs in oak woodlands of the central coast region of California. California Fish and Game 88(1):28-34.

Mapston, M. E. 2004. Feral hogs in Texas. Document No. B-6149 5-04. Wildlife Services, Texas Cooperative Extension, Texas A\&M University, College Station, Texas.

Massei, G., P. V. Genov, and B. W. Staines. 1996. Diet, food availability and reproduction of wild boar in a mediterranean coastal area. Acta Theriologica, 41(3):307-320.

Matschke, G. H. 1964. The influence of oak mast on European wild hog reproduction. Proceedings of the Annual Conference of the Southeastern Association of Game and Fish Commissioners, 18:35-39.

Mayer, J. J., and I. L. Brisbin, Jr. 1991. Wild pigs in the United States: Their history, comparative morphology, and current status. The University of Georgia Press, Athens, Georgia.

1995. Feral swine and their role in the conservation of global livestock genetic diversity. Pp. 175179. In R. D. Crawford, E. E. Lister, and J. T. Buckley (eds.), Proceedings of the third global conference on conservation of domestic animal genetic resources. Rare Breeds International, Warwickshire, England, U.K.

Mayer, J. J., E. A. Nelson, and L. D. Wike. 2000. Selective depredation of planted hardwood seedlings by wild pigs in a wetland restoration area. Ecological Engineering, 15(Supplement 1):S79-S85.

Mazzotti, F. J. and L. A. Brandt. 1994. Ecology of the American alligator in a seasonally fluctuating environment. Pp. 485-506. In S. M. Davis and J. C. Ogden (eds.). Everglades: The ecosystem and its restoration. CRC Press, Boca Raton, Florida.

McIlhenny, E. A. 1976. The alligator's life history. Society for the Study of Amphibians and Reptiles. Lawrence, Kansas.

National Fish and Wildlife Laboratory. 1980. Selected vertebrate endangered species of the seacoast of the United States. FWS/OBS-80/01. Biological Services Program, U. S. Fish and Wildlife Service, Department of the Interior, Washington, D.C.

NMFS and USFWS (National Marine Fisheries Service and U.S. Fish and Wildlife Service). 1991. Recovery plan for U.S. population of Atlantic green turtle. National Marine Fisheries Service, Washington, D.C.

Neill, W. T. 1971. The last of the ruling reptiles: Alligators, crocodiles, and their kin. Columbia University Press, New York.

Oliver, W. L. R., and I. L. Brisbin, Jr. 1993. Introduced and feral pigs: Problems, policy, and priorities. Pp. 179-191. In W. L. R. Oliver (ed.), Pigs, peccaries and hippos: Status survey and conservation action plan. International Union for the Conservation of Nature and Natural Resources, Gland, Switzerland.

Pavlov, P. M. 1980. The diet and general ecology of the feral pig (Sus scrofa) at Girilambone, N. S. W. M.S. Thesis, Monash University, Melbourne, Australia.

Pavlov, P. M., and J. Hone. 1982. The behavior of feral pigs, Sus scrofa, in flocks of lambing ewes. Australian Wildlife Research, 9(1):101-109. 
Peart, D. 1993. Impact of feral pig activity on vegetation composition associated with Quercus agrifolia on Santa Cruz Island, California. Pp. 12-13. In W. Tietje and R. Barrett (eds.), The wild pig in California oak woodland: Ecology and economics. University of California, Berkeley, Berkeley, California.

Pine, D. S., and G. L. Gerdes. 1973. Wild pigs in Monterey County, California. California Fish and Game, 59(2):126-137.

Pinna, W., G. Nieddu, G. Moniello, and M.G. Cappai. 2007. Vegetable and animal food sorts found in the gastric content of Sardinian Wild Boar (Sus scrofa meridionalis). Journal of Animal Physiology \& Animal Nutrition, 91(5-6): 252-255.

Rockenbach, S. I. 2005. "War upon our border": War and society in two Ohio valley communities, 18611865. Ph.D. Dissertation, University of Cincinnati, Cincinnati, Ohio.

Rudge, M. R. 1976. A note on the food of feral pigs (Sus scrofa) of Auckland Island. Proceedings of the New Zealand Ecological Society, 23:83-84.

Rutledge, A. 1970. The woods and wild things I remember. R. L. Bryan Company, Columbia, South Carolina.

Sablina, T. B. 1955. Kopytnye Belovezhskoi Pushchi (Ungulates of the Bialowieza Preserve). Akademeiia Nauk SRR. Institut Morfologii Zhivotnykh, 15:1-191.

Schley, L., and T. J. Roper. 2003. Diet of wild boar Sus scrofa in Western Europe, with particular reference to consumption of agricultural crops. Mammal Review, 33(1):43-56.

Schneider, E. 1975. Mause in Magen eines Wildschweines (Sus scrofa L.). Zeitschrift fur Jagdwissenschaft, 21(3):190-192.

Scott, C. D., and M. R. Pelton. 1975. Seasonal food habits of the European wild hog in the Great Smoky Mountains National Park. Proceedings of the Annual Conference of the Southeastern Association of Fish \& Wildlife Agencies, 29:585-593.

Sjarmidi, A., F. Spitz, and G. Valet. 1992. Food resource use by wild boar in southern France. Pp. 171-173. In F. Spitz, G. Janeau, G. Gonzalez, and S. Aulagnier (eds.), Ongules/Ungulates 91: Proceedings of the international symposium. Toulouse, France, September 2-6, 1991. Societe Francaise pour l'Etude et la Protection des Mammiferes, and Toulouse: Institut de Recherche sur les Grands Mammiferes, Paris \& Toulouse, France.

Skewes, O., R. Rodriguez, and F. M. Jaksic. 2007. Ecologia trofica del jabali europeo (Sus scrofa) silvestre en Chile. Revista Chilena de Historia Natural 80: 295-307.

Springer, M. D. 1975. Food habits of wild hogs on the Texas Gulf Coast. M.S. Thesis, Texas A\&M University, College Station, Texas.

Stegeman, L. J. 1938. The European wild boar in the Cherokee National Forest, Tennessee. Journal of Mammalogy, 19(3):279-290.

Stevens, R. L. 1996. The feral hog in Oklahoma. Samuel Roberts Noble Foundation, Ardmore, Oklahoma.

Sweeney, J. R., J. M. Sweeney, and S. W. Sweeney. 2003. Feral hog, Sus scrofa. Pp. 1164-1179. In G. A. Feldhammer, B. C. Thompson, and J. A. Chapman (eds.), Wild mammals of North America: Biology, management, and conservation. The Johns Hopkins Univ. Press, Baltimore, Maryland.

Taylor, R. B., and E. C. Hellgren. 1997. Diet of feral hogs in western South Texas plains. The Southwest Naturalist, 42(1):33-39. 


\section{Wild Pigs}

Thompson, R. L. 1977. Feral hogs on national wildlife refuges. Pp. 11-15. In G. W. Wood (ed.), Research and management of wild hog populations. Belle Baruch Forest Science Institute of Clemson University, Georgetown, South Carolina.

Thomson, C., and C. N. Challies. 1988. Diet of feral pigs in the podocarp-tawa forests of the Urewera Ranges. New Zealand Journal of Ecology, 11:73-78.

Tisdell, C. A. 1982. Wild pigs: Environmental pest or economic resource? Pergamon Press, New York.

Tolleson, D., D. Rollins, W. Pinchak, M. Ivy, and A. Hierman. 1993. Impact of feral hogs on groundnesting gamebirds. Pp. 76-83. In C. W. Hanselka and J. F. Cadenhead (eds.), Feral swine: A compendium for resource managers. Texas Agricultural Extension Service, Kerrville, Texas.

Towne, C. W., and E. N. Wentworth. 1950. Pigs from cave to cornbelt. University of Oklahoma Press, Norman, Oklahoma.

Tucak, Z. 1996. Mageninhaltsuntersuchungen von Schwarzwild (Sus scrofa L.) im ungegatterten Teil des Waldjagdrevieres Belje in Baranja. Zeitschrift fur Jagdwissenschaft, 42(3):165-172.

Wakeley, P. C. 1954. Planting the southern pines. Forest Service, U.S. Department of Agriculture, Washington, D.C.

Wathen, G., J. Thomas, and J. Farmer. 1988. European wild hog bait enhancement study - Final report. Research/Resource Management Report Series, U. S. Department of the Interior, National Park Service, Southeast Region, Atlanta, Georgia.

Whicker, F. W. 1991. Observations on the Par Pond drawdown: A summary to-date. Savannah River Ecology Laboratory, Aiken, SC.

Wilcox, J. T., and D. H. Van Vuren. 2009. Wild pigs as predators in oak woodlands of California. Journal of Mammalogy, 90(1):114-118.

Williams, D. J., A. J. Ansford, D. S. Priday, and A. S. Forrest. 1998. Forensic Pathology: Colour Guide. Elsevier Health Services, Elsevier Press, New York.

Wlazelko, M., and L. Labudzki. 1992. Uber die Nahrungskomponenten und die trophische Stellung des Schwarzwildes im Forschungsgebiet Zielonka. Zeitschrift fur Jagdwissenschaft, 38:81-87.

Wood, G. W., and R. H. Barrett. 1979. Status of wild pigs in the United States. Wildlife Society Bulletin, 7(4):237-246.

Wood, G. W., and D. N. Roark. 1980. Food habits of feral hogs in coastal South Carolina. Journal of Wildlife Management, 44(2):506-511.

Zengel, S. A., and W. H. Conner. 2008. Could wild pigs impact water quality and aquatic biota in floodplain wetland and stream habitats at Congaree National Park, South Carolina? 5 pp. In Proceedings of the 2008 South Carolina Water Resources Conference, Charleston, South Carolina. 
SRNL-RP-2009-00869

This page left blank intentionally 
Wild Pigs

\section{Biology of Wild Pigs:}

\section{Wild Pig Physiological Ecology}

Stam M. Zervanos

Pennsylvania State University/Berks, P.O. Box 7009, Reading, Pennsylvania 19610-6009

\section{Introduction}

Understanding the physiological parameters under which animals live and survive is critical to their management. Physiological ecology data can be used to determine limits of geographical distribution, plus estimate carrying capacity and population growth (McNab 2002). Physiological information on wild pigs, however, is limited. Thus, one must rely on the plethora of data available for the domestic pig and assume they apply to wild pigs in their natural environment. This is not always feasible, because for wild pigs other factors such as predators, competition, and activity patterns associated with searching for food and reproduction can significantly alter the application of domestic pig results (Mount 1968). In this report, I will use published data from wild pigs and fill in major gaps from domestic pig studies, where the comparison seems justified.

This report focuses on basic physiological information associated with energy intake and expenditure, salt and water balance, and ecological energetics. For the purposes of this discussion, the term "wild pig" includes feral hogs, wild boars, and feral hog x wild boar hybrids (Mayer and Brisbin 1991), with the understanding there may be subtle differences in physiological parameters.

\section{Energy Balance}

The total energy budget for an animal is a balance between intake and utilization, where:

$$
\text { Total forage energy intake }=\text { metabolism }+ \text { production }+ \text { excretory energy loss }
$$

Metabolism can further be divided into energy for maintenance (including basal metabolism and thermoregulation) and activity (mostly locomotion). Production includes energy for growth and for reproduction. Excretory energy loss can be divided into urinary and fecal energy loss (for this discussion I will ignore urinary loss).

Forage Energy Intake - The efficiency of forage energy intake for an herbivore is based on the amount of the available forage consumed in a given period of time less the energy involved in grazing (Canas et al. 2003). Because wild pigs are broad-spectrum feeders, it is difficult to get an accurate perspective on forage intake efficiency in the field (Oliver and Brisbin 1993). In addition, there are physiological and landscape constraints on efficiency. For example, pigs lack sweat glands and can die if exposed for extended periods to full or partial sun at temperatures above $23^{\circ} \mathrm{C}$ (Porter and Gates 1969). Thus, foraging in open fields is constrained by time (Dexter 1999, Armstrong and Robertson 2000, Canas et al. 2003, Choquenot and Ruscoe 2003). The landscape also poses constraints. Choquenot and Ruscoe (2003) suggest that because wild pigs require riverine woodlands to thermoregulate when radiant heat loads are high, their foraging efficiency declines as the proximity of food resources to riverine woodlands increases. Refuge habitats, such as riverine woodlands, also play a role in reproduction, juvenile survival, and predator avoidance (including hunters). Finally, the efficiency of forage intake is also influenced by the quality and quantity of food resources in a given area. As would be expected, the higher the quality and/or quantity, the higher the efficiency of intake (Dexter 1999, Armstrong and Robertson 2000, Canas et al. 2003). 
Overall, lab studies have proven more productive in assessing food intake, although applying the results to field conditions may not always be practical. In particular, lab studies have demonstrated the effect of various environmental factors on food consumption. Seasonal changes in food consumption were observed in young captive wild pigs fed ad libitum over a two-year period (Pepin and Mauget 1989). During both years, food intake was high during autumn and decreased during winter. In part, this may be related to the effects of photoperiod on food consumption. Weiler et al. (1996) found that wild boars increased food consumption with increasing day length, reached a maximum during decreasing day length, and reached its lowest level under short-day conditions. This seasonal change in food consumption may reflect photoperiod-induced changes in gonadal hormones in wild boars (Clause and Weiler 1994). Estrogens and androgen levels influence food consumption. During summer, when these hormones are low, food consumption is high, matching summer food availability. In winter, when food availability is low and reproduction is most active, food intake is depressed by the high estrogen and androgen levels (Clause and Weiler 1994). However, this may not totally apply to wild pigs from domestic stock origins, which are capable of year-round reproduction (Comer and Mayer, this volume).

Ambient temperature and water availability also influence food intake. Young domestic pigs maintained at $33^{\circ} \mathrm{C}$ decrease food consumption by $30 \%$ compared to those maintained at $23^{\circ} \mathrm{C}$ (Collin et al. 2001a, b). Campbell and Taverner (1988) found similar results with young pigs maintained at $14^{\circ} \mathrm{C}$ and $32^{\circ} \mathrm{C}$. At high temperatures, reduced food intake would result in lower heat production associated with feeding and digestion, thus facilitating thermoregulation (Collin et al. 2001a). Comparing domestic pigs with captive wild pigs from Ossabaw Island, Georgia, Zervanos et al. (1983) demonstrated an inverse relationship between consumption of domestic hog feed and the salt content (between 0.5 and $6.0 \%$ ) of the feed. Under ad libitum water conditions, consumption decreased between 13 and 24\% for both domestic and wild pigs. When water was limited, a 3.0\% salt content reduced consumption by $42 \%$ for domestic pigs and $54 \%$ for wild pigs. Reduced consumption would help reduce the amount of water required to excrete the excess salt.

Assimilation of Energy - The energy that is absorbed into the body during digestion is known as the assimilated energy (or metabolizable energy intake). It is equal to the forge energy intake less the fecal energy loss plus metabolic costs associated with the digestive and absorptive processes. The degree to which forage is assimilated into the animal is based on its digestibility. One important factor that determines digestibility is the fiber content of the forage. In herbivores microbes in the gut help to digest some of the fiber. Pigs use microbes in their cecum and colon to extract energy from a fibrous diet. Van Wieren (2000) found that European wild boars were better able to digest fibrous forages, such as acorns, than domestic pigs (Although this may not apply to fiber content of commercial feeds; Hodgkinson et al. 2008). This adaptation would allow wild boars to extract more energy from their natural forage. Whether this applies to "feral" pigs, still needs to be determined. Using commercial feeds, Zervanos et al. 1983 found no difference in assimilation rates between domestic and feral pigs, $87.8 \%$ and $85.1 \%$ respectively. In addition, both groups exhibited significantly lower assimilation efficiency when water stressed. This suggests that the digestive processes between domestic pigs and formally domestic (feral) pigs are not significantly different. In another study, Elston et al. (2005) found no difference in assimilation rates of commercial feed components between wild pigs and collared peccaries.

Assimilated Energy Expenditure - Assimilated energy is the energy available for both metabolic and production expenditures. Over the long term, all must be in balance:

$$
\text { Assimilated energy }=\text { metabolic energy expenditure }+ \text { production energy expenditure }
$$

If assimilated energy decreases, then one or both of the expenditures must decrease and vice-versa. Metabolic energy expenditures include energy needed for basal metabolism (measured as the basil metabolic rate (BMR) or standard metabolic rate (SMR)), locomotion, and thermoregulation. Although there have been numerous metabolic studies on domestic pig (e.g., Kleiber 1965, Mount 1968, Noblet et al. 1997, Noblet et al.1999, Quiniou et al. 2001, Chwalibog et al. 2005), there is virtually no information on metabolic rates for wild pigs. 


\section{Wild Pigs}

Field Metabolic Rates - (FMR) The FMR is a measurement of all of the metabolic expenditures, and to some extent the production expenditure, of a free-living animal. One was to measure FMR is to use isotopes of molecules associated with metabolism (Nagy 1975, 1987, Zervanos and Day 1977, McNab 2002). Using isotope field study data Nagy (1987) found that FMR for mammalian herbivores correlated strongly to body mass with a slope $=0.73$. Thus, FMR can be estimated for a mammalian herbivore such as a wild pig by using a basic allometric equation:

$$
y=a x b
$$

where: $y=\mathrm{FMR}$ in $\mathrm{kJ} /$ day; $a=$ regression coefficient $5.95 ; x=$ mass in $\mathrm{g}$; and $b=$ slope 0.73 . In addition, assuming an assimilation rate of $80 \%$ and substituting a coefficient of 0.58 in the above equation an estimate of the feeding rate in $g$ dry wt/day can be estimated (Nagy 1987). I will use this equation to calculate energy and carrying capacities for wild pigs later.

Basil Metabolic Rate - The same basic regression equation can be used to estimate the BMR for a largesized grazing mammal such as a wild pig by substituting: $y=\mathrm{BMR}$ in $\mathrm{mlO} 2 / \mathrm{g} / \mathrm{h} ; a=2.26 ; x=$ mass in g; and $b=0.81$ (McNab 1988). Assuming anaerobic glycolysis is negligible, $\mathrm{mlO} 2$ can be converted to $\mathrm{J}$ by using the energetic equivalent: $1 \mathrm{ml} \mathrm{O} 2=20.1 \mathrm{~J}$. BMR, unlike the FMR, is the energy utilized when the animal is completely at rest and hence does not include the energy needed for activities such as locomotion or energy for thermoregulation.

Energy of Locomotion - For wild pigs, the major form of locomotion occurs during grazing. The amount of grazing energy required varies based on forage availability. If forage is sparse, the locomotion cost associated with grazing and associated stress is high, whereas, if forage density is high, grazing energy drops substantially (Armstrong and Robertson 2000, Canas et al. 2003). To illustrate this, Canas et al. (2003) present data for a variety of mammals, including wild boars. For boars at low forage availability of $2,000 \mathrm{~mJ} / \mathrm{ha}$, the estimated cost of grazing approaches $130 \mathrm{~kJ} / \mathrm{kg}$ body mass. At forage availability of $16,000 \mathrm{~mJ} / \mathrm{ha}$, cost of grazing decreases to $30 \mathrm{~kJ} / \mathrm{kg}$.

Another way to estimate the cost of locomotion is to determine the rate of movement and apply an allometric equation developed by Taylor et al (1982) for animal terrestrial locomotion. For mammals:

$$
\text { Energy of Locomotion }=10.7 \mathrm{Mb}-0.316 \cdot \mathrm{vg}+6.03 \mathrm{Mb}-0.303
$$

Where Locomotion Energy is in watts $/ \mathrm{kg} ; \mathrm{Mb}=$ body mass in $\mathrm{kg} ; \mathrm{vg}=$ speed in $\mathrm{m} / \mathrm{s}$; ( $\mathrm{s}=$ seconds). Using data from Ilse and Hellgren (1995a), we can apply this equation to estimate the energy of locomotion of wild pigs inhabiting a rangeland of mixed honey mesquite and live-oak in Texas. They estimated the wild pigs moved at a rate of $113.6 \mathrm{~m} / \mathrm{h}(0.032 \mathrm{~m} / \mathrm{s})$. Assuming an average mass of $75 \mathrm{~kg}$ for an adult male (Ilse and Hellgren 1995b) and using the above equation, the locomotion energy requirement would be 1.72 watts $/ \mathrm{kg}$.

Thermoregulation - Animals must remain in thermal equilibrium with their environment to survive; that is, thermal energy in must equal thermal energy out. Although thermal equilibrium is a complex process, a simple equation will aid our discussion:

$$
M+R+C d+C v=E-R-C d-C v
$$

Where $M$ is the metabolic heat production; $R$ is the radiant heat gain $(+)$ or loss $(-) ; E$ is the evaporative heat loss; $C d$ is the conductive heat gain or loss; and $C v$ is the convective heat gain or loss. Based on this thermal equilibrium principle, Porter and Gates (1969) estimated the climate conditions for survival of domestic pigs ("climate space"). They concluded that at wind speeds of $100 \mathrm{~cm} / \mathrm{s}$, light colored pigs could not survive full sun at ambient temperatures $\left(\mathrm{T}_{\mathrm{a}}\right)$ above $23^{\circ} \mathrm{C}$; partial shade at Ta above $35^{\circ} \mathrm{C}$; and full shade at Ta above $40^{\circ} \mathrm{C}$. Fur color would make a noticeable difference. A dark color pig, because of the increase in radiant heat absorption, would be more heat stressed in full or partial sun. Pigs lack any meaningful fur insulation. Under winter conditions, in still air they could survive a $\mathrm{T}_{\mathrm{a}}$ of $-27^{\circ} \mathrm{C}$, but only $15^{\circ} \mathrm{C}$ at wind speeds of $1,000 \mathrm{~cm} / \mathrm{s}$ (Porter and Gates 1969). However, this would require a significant 
increase in metabolic energy expenditure (Verstegen and Close 1994). Because pigs have a reduced ability to produce additional metabolic heat through non-shivering thermogenesis, newborn pigs have difficulty surviving cold temperatures (Herpin et al. 2002). Wild pigs compensate for this problem by furrowing and by reproducing during warmer seasons.

The skin of pigs is poorly vascularized and possesses no sweat glands, thus compounding the problem of high temperatures. They rely on panting to increase heat loss through evaporation. In one study, young pigs exposed to high humidity and $\mathrm{T}_{\mathrm{a}}$ above $22^{\circ} \mathrm{C}$, increased respiratory rate in response to the heat stress -- the higher the humidity, the higher the respiratory rate (Ingram 1965).

Overall, it would seem that pigs are poorly adapted to withstand climate extremes. The range of temperatures for thermal comfort for domestic pigs appears to be narrow, between $23^{\circ} \mathrm{C}$ and $25^{\circ} \mathrm{C}$ (Quiniou et al. 2001). One way to compensate for their reduced thermoregulatory abilities is to use behavioral adaptations, such as seeking shade and wallowing. For example, Ilse and Hellgren (1995b) suggested that wild pigs in south Texas, because they required more shade for thermoregulation, selected bedding sites with higher canopy cover then collard peccaries. Fernandez-Llario (2005) acknowledged the use of wallowing by wild boar for thermoregulation, in addition to serving a sexual function for male boars.

\section{Production Energy Expenditure}

Growth - During the growth phase of mammals, a high percentage of assimilated energy is channeled to support the increase in body size (McNab 2002). Under ideal conditions, domestic pigs can channel as much a $32 \%$ of their assimilated energy into growth (fat and protein) (Verstegen and Close 1994). However, this will vary based on how much of the assimilated energy is used for metabolic energy expenditures such as thermoregulation and locomotion. For example, because of the increase energy demands required to maintain thermal balance, both low and high temperatures have a negative affect on the overall growth of domestic pigs (Close and Stanier 1984, Christon 1988, Verstegen and Close 1994).

As expected, growth is maximized under optimal energy intake. This rarely occurs in the wild, as there are seasonal, habitat, and climate conditions that limit food availability. It has been well documented that declines in energy and nutritional values of forage result in deceased growth in wild boars (Wolkers et al. 1994, Spitz et al. 1998). There is also evidence that annual endogenous cycles in food consumption play a role in growth rates (Spitz et al. 1998). Increased food intake in autumn corresponded to increased growth of young female wild boars (Pepin and Mauget 1989). These endogenous feeding cycles are also linked to the annual reproductive cycle of wild boars. Decreasing day length optimizes reproductive preparations during fall/winter in males and females. Thus, by fall, if food supply is not limited, they reach their maximum mass and begin gonadal development in preparation for mating (Pepin and Mauget 1989, Claus and Weiler 1994). In addition, survival is enhanced by hormonal changes that anticipate seasonal changes in temperature and food supply, and thus, help regulate annual growth patterns. Seasonal changes in hormones, such as gonadal steroids and growth hormone (GH) appear to control the seasonal growth pattern of wild boars. With increasing day length $\mathrm{GH}$ levels rise and facilitate protein synthesis, particularly for muscle build up. In winter, high GH levels help with fat catabolism, thus providing energy during periods of low food availability (Claus and Weiler 1994).

Lipid metabolism is an important aspect of growth. It has been well studied and documented for domestic pigs (For a review see Mersmann 1986); however, there are very few studies on lipid dynamics of wild pigs and boars. The effect of temperature is of particular interest. At low temperature, fat deposition decreases as more energy is consumed by metabolic heat production (Mount 1968). However, at high temperatures, fat deposits actually increase in growing pigs (Kouba et al. 2001). They concluded that this was the result of a reduction in thyroid activity in response to high temperature. As thyroid activity decreased, metabolic heat production decreased, as an adaptation to heat stress. The result was an increase in energy available for fat deposition. Whether these results on domestic pigs can be applied to wild pigs is uncertain without further study.

Reproduction - The energetic cost of reproduction is difficult to assess. Much of the cost is related to factors that are not easily determined such as the type of mating behavior (defending territories, defending 


\section{Wild Pigs}

dominance, finding mates, etc.) and the costs of gestation, lactation, and rearing young (McNab 2002). One indices of reproduction cost is litter size. Wild pigs produce large litters that average between 5 to 8 young (Read and Harvey 1989, Mauget 1991, Taylor et al. 1998). Compared to other ungulates, these numbers are high and result in high reproductive energy costs. The overall litter size for wild pigs is influenced by several factors, especially body size. Larger females tend to have larger litters (FernandezLlario and Mateos-Quesada 1998). Taylor et al. (1998) found that older wild pigs in Texas had larger litter sizes than yearlings. Older females would tend to be large with higher energy stores (particularly fat) and thus able to provide for more young during gestation and lactation. The reproductive biology of wild pigs is fully discussed in another chapter of this volume.

\section{Water and Salt Balance}

As is the case with energy balance, water and salt (ionic) intake and output must be in balance in order to ensure survival. The physiological processes involved in maintaining mammalian water and ionic balances are interconnected. Thus, any discussion of mechanisms employed to maintain water balance must also take into account their impact on ionic regulation and vice-versa.

\section{Water balance}

Water gain - Water is gained through drinking fluids, ingested as preformed water in food, and generated from the metabolic breakdown of organic molecules during aerobic metabolism. Water intake from drinking varies according to ambient temperature, foods eaten, salt intake, etc. Domestic pigs will increase water consumption by $40 \%$ when the ambient temperature is raised from $20^{\circ} \mathrm{C}$ to $30^{\circ} \mathrm{C}$ (Mount 1968). Domestic pigs will also increase drinking with increasing salt content of food (Hagsten and Perry 1976). Zervanos et al. (1983) found that wild pigs from Ossabaw Island, Georgia also increased their water intake with increasing salt content of feed. Under the same salt regimes, wild pigs drank significantly less water per kg of mass per day than did the domestic pigs (Fig. 1). The amount of drinking also depends on the amount of preformed water consumed. Drier forages such as dried grasses contain less preformed water than items such as fruits, thus, necessitating an increase in drinking to compensate. Metabolism is the other source of water gain, but contributes relatively small amounts to the water content of pigs. The amount of net gain from metabolism depends on the metabolic rate and organic molecule being oxidized. Carbohydrates produce the most water $(0.70 \mathrm{~g} / \mathrm{L} \mathrm{O} 2)$, followed by fats $(0.53 \mathrm{~g} / \mathrm{L} \mathrm{O} 2)$, and then proteins (0.42 g/L O2) (McNab 2002).

Water loss - Water is lost by evaporation from the skin and respiratory tract, and from the loss of urine and feces. Since pigs do not sweat, evaporative water loss occurs primarily through respiration. However, some evaporation does occur through the skin and aids in temperature regulation (Ingram 1965, Mount 1968). At warm temperatures pigs increase respiration rate (pant) and thus increase heat loss through respiratory evaporation (Mount 1968). Similar respiratory increases occur under high humidity (Ingram 1965). Although not a direct avenue of water loss, wallowing by pigs would also help to increase heat loss by evaporation from the skin.

Renal excretory water loss will be discussed in the next section. Few studies are available on fecal water loss for pigs. Zervanos et al. (1983) found that fecal water loss in both domestic and wild pigs decreased under water restriction. This is not uncommon for mammals (Maloiy and Taylor 1971, MacFarlane 1964) and would be expected as less water is being ingested

\section{Salt and ion balance}

In mammals, the kidney plays a major role in salt and water balance. The mammalian nephron has a unique structure, the loop of Henle. It functions as a countercurrent multiplier creating an osmotic gradient within the kidney that enables the kidney produce concentrated urine. In general, the longer the loop and the higher percentage of long loops, the greater the concentrating ability of the nephron. Since the longer loops extend into the medulla of the kidney, it is possible to estimate the concentrating ability of the kidney by using the relative medullary thickness (RMT) (Sperber 1944) as an index. A number of ecophysiological comparisons have established that mammals from drier habitats have higher RMT's than 
those from moist habitats (McNab 2002, Zervanos 2002). Sperber (1944) determined the RMT of domestic pigs to be 1.6, whereas Zervanos and Naveh (1988) found values of 2.70 for wild pigs living in Georgia. Gabor et al. (1997) found similar results $(\mathrm{RMT}=2.82)$ for wild pigs living in Texas. It appears that wild pigs have better kidney concentrating abilities than their domestic counterparts. The difference may be in response to the greater environmental stress experienced in the wild. Zervanos and Naveh (1988) raised Ossabaw Island wild pigs from birth under ad libitum food and water conditions. On Ossabaw Island, wild pigs are under water stress due to their high salt diet. Zervanos and Naveh (1988) found that the captiveraised Ossabaw pigs had significantly lower RMT's (2.35) than their wild-living counterparts. They concluded that the difference was due to acclimatization. The higher overall RMT values for wild pigs enables them to produce a more concentrated urine $(1,040 \mathrm{mOsm})$ than domestic pigs $(712 \mathrm{mOsm})$ when water-stressed (Zervanos et al. 1983). The higher concentrating ability allows for better excretion of excess ions (Table 1) and lower urinary water loss (Fig. 1). However, the RMT values and kidney concentrating abilities for wild pig (2.35 to 2.82) are relatively low compared to other more xeric adapted mammals. Gabor et al. 1997 compared the RMT values for sympatric populations of collared peccaries and wild pigs in southern Texas. Collared peccaries had significantly higher RMT (3.67) than the wild pigs (2.82). They concluded that the better kidney concentrating ability of peccaries was a competitive advantage over wild pigs in water-limited environments. This is further supported by Ilse and Hellgren (1995a), who observed that wild pigs selected more mesic habitats than did peccaries.

Since pigs have mesic evolutionary origins, they have limited plasticity to better adapt to arid environments. Although wild pigs are superior to domestic pigs, they still are not well adapted for conservating of water (Zervanos et al. 1983). They require a source of free water to survive (Gabor et al. 1997, Choquenot and Ruscoe 2003).

\section{Ecological Energetics}

Estimating energy budgets for free-ranging animals is extremely difficult. Armstrong and Robertson (2000) present an excellent summary of factors that affect energy budget estimates. These include cost of thermoregulation under various conditions of temperature, insulation, wind, and precipitation; cost of grazing under various forage densities, digestibility, terrain; and cost of sheltering behavior. These are all difficult to measure and no published method or model is perfect. The following are examples of approaches that can be used.

\section{Estimating Population Growth}

Population growth is related to forage intake. This relationship was estimated for wild pigs in Australia by Choquenot and Ruscoe (2003) using the linear regression equation:

$$
r=-0.193+(0.007 x I R)
$$

where $r$ is the population rate of increase and $I R$ is the rate of pasture intake in $\mathrm{g} / \mathrm{kg} 0.75$ body mass/day. They estimated that $r$ would be maximum when $I R$ was at $58 \mathrm{~g} / \mathrm{kg} 0.75 /$ day at a forage density of 1000 $\mathrm{kg} / \mathrm{ha}$. This would occur under ideal grazing conditions. The rate of pasture intake (IR) is directly influenced by factors affecting grazing efficiency. These would include pasture biomass, inter- and intraspecific competition for forage, and proximity of forage to the refuge such as riverine woodlands used by pigs (Choquenot and Ruscoe (2003).

\section{Estimating carrying capacity}

The impact of a population on a habitat can be inferred by its size and the per capita demand of resources. A critical resource is forage biomass. Using equation 3 and population data from Ilse and Hellgren (1995b), the amount of forage biomass required by the population of wild hogs within their study site can be calculated. Ilse and Hellgren (1995b) estimated the population size of wild pigs at the Welder Wildlife Refuge, Sinton, Texas to be 9.5 pigs $/ \mathrm{km} 2$, with an average body mass of $69 \mathrm{~kg}$ (males and females). Using the allometric equation (3) for FMR; FMR $=5.95$ (mass0.73) we get $20,271 \mathrm{~kJ} / \mathrm{day} / \mathrm{pig}$ or for the entire population $192,575 \mathrm{~kJ} / \mathrm{day} / \mathrm{km} 2$. Assuming an assimilation rate of $80 \%$ and substituting a coefficient of 


\section{Wild Pigs}

0.58 in the above equation, an estimate of the feeding rate is $1,976 \mathrm{~g}$ dry wt/day/pig or on a population basis, $18,772 \mathrm{~g}$ dry wt/day/km2.

These examples illustrate how knowledge of the physiological parameters under which animals live and survive is critical in applying principles of ecological energetics to management issues. Unfortunately, such applications are limited because of the paucity of information on wild pig eco-physiology. Hopefully this review will help stimulate further studies.

Acknowledgement - I wish to acknowledge the valuable assistance of Neil Hadley in the review of this manuscript. His comments and advice were instrumental in improving the final draft. 
Table 1. Comparison between domestic and wild pig urine concentrations of sodium, chloride, and potassium ions in relation to dietary intake of sodium chloride. Mean $\pm \mathrm{SE}, \mathrm{LW}=$ Limited drinking water. (Data from Zervanos et al. 1983).

\begin{tabular}{|c|c|c|c|c|c|c|}
\hline \multirow[t]{2}{*}{$\begin{array}{l}\text { Salt in Diet } \\
(\% \mathrm{NaCl})\end{array}$} & \multicolumn{2}{|c|}{$\mathrm{Na}+($ meq/l) } & \multicolumn{2}{|c|}{$\mathrm{Cl}^{-}$(meq/l) } & \multicolumn{2}{|c|}{$\mathrm{K}+(\mathrm{meq} / \mathrm{l})$} \\
\hline & Domestic & Wild & Domestic & Wild & Domestic & Wild \\
\hline 0.5 & $29.7 \pm 7.2$ & $52.6 \pm 16.2$ & $64.3 \pm 7.2$ & $134.3 \pm 26.0$ & $51.0 \pm 13.0$ & $105.9 \pm 12.6$ \\
\hline 3.0 & $94.5 \pm 13.4$ & $165.1 \pm 9.5$ & $157.4 \pm 27.2$ & $226.6 \pm 30.1$ & $29.3 \pm 4.7$ & $61.7 \pm 8.5$ \\
\hline 6.0 & $103.2 \pm 26.0$ & $157.7 \pm 15.2$ & $143.4 \pm 16.7$ & $306.1 \pm 4.3$ & $18.1 \pm 2.3$ & $42.9 \pm 5.0$ \\
\hline $3.0 \mathrm{LW}$ & $194.1 \pm 32.1$ & $218.4 \pm 19.2$ & $260.8 \pm 34.1$ & $315.6 \pm 34.8$ & $47.6 \pm 8.4$ & $74.5 \pm 2.4$ \\
\hline
\end{tabular}


Wild Pigs

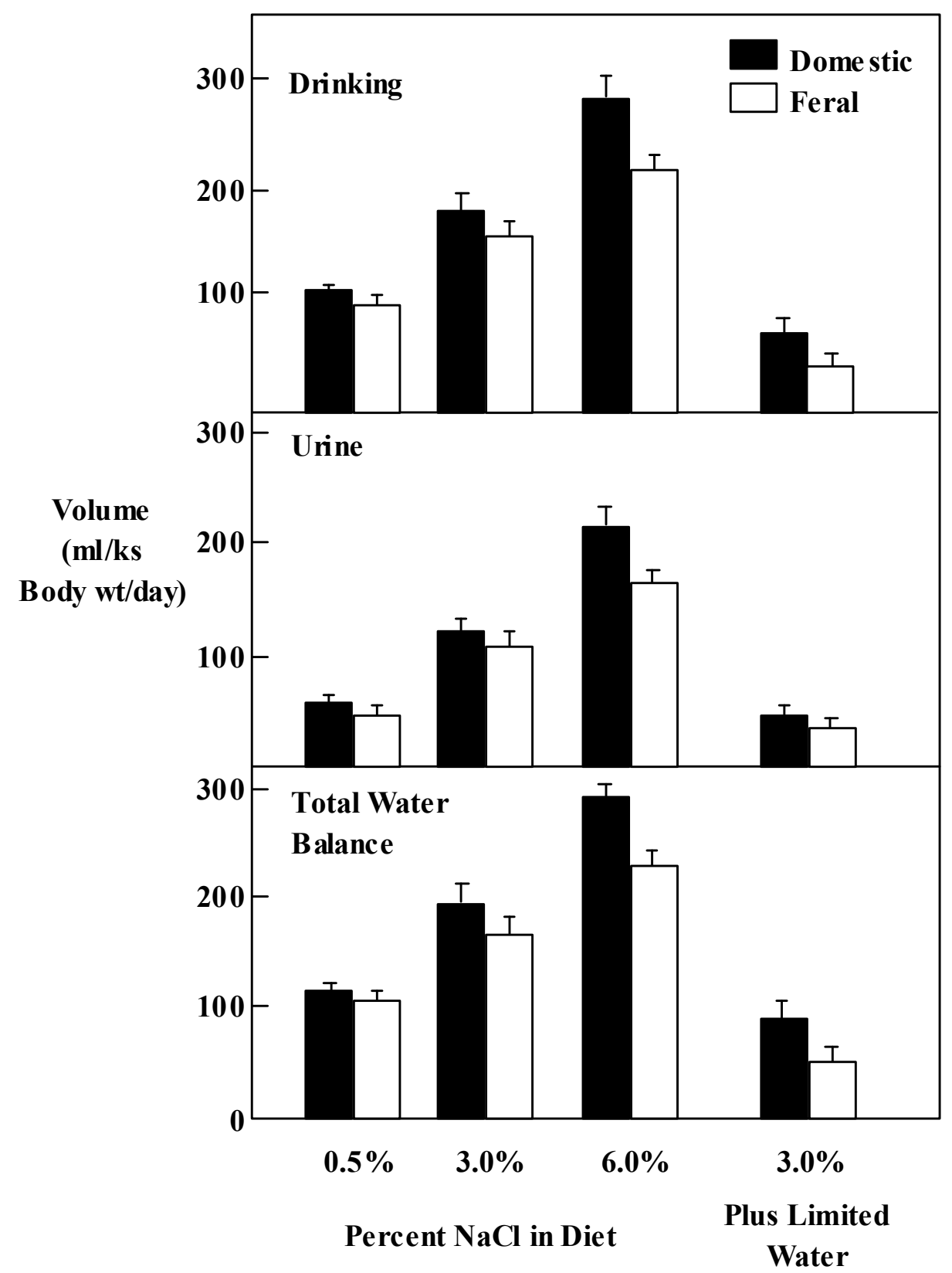

Fig. 1. Water balance of feral and domestic pigs under various salt diets. Drinking was the major avenue of water gain, where as urine production was the major avenue of water loss. (Figure from Zervanos et al. 1983). 


\section{Literature Cited}

Armstrong, H. M. and A. Robertson. 2000. Energetics of free-ranging large herbivores: When should costs affect foraging behavior. Canadian Journal of Zoology, 78:1604-1615.

Campbell, R. G. and M. R. Taverner. 1988. Relationship between energy intake and protein and energy metabolism, growth, and body composition of pigs kept at 14 or $32^{\circ} \mathrm{C}$ from 9 to $20 \mathrm{~kg}$. Livestock Production Science, 18:289-303.

Canas C. R., R. A. Quiroz, C. Leon-Velarde, A. Posadas, and J. Osorio. 2003. Quantifying energy dissipation by grazing animals in harsh environments. Journal of Theoretical Biology, 225:351-359.

Choquenot, D. and W. A. Ruscoe. 2003. Landscape complementation and food of large herbivores: habitatrelated constraints on the foraging efficiency of wild pigs. Journal of Animal Ecology, 72:14-26.

Christon, R. 1988. The effect of tropical ambient temperature on growth and metabolism in pigs. Journal of Animal Science, 66:3112-3123.

Chwalibog, A., K. Jakobsen, A. H. Tauson, and G. Thorbek. 2005. Energy metabolism and nutrient oxidation in young pigs and rats during feeding, starvation, and re-feeding. Comparative Biochemistry and Physiology, (A), 140:299-307.

Claus, R., and U. Weiler. 1994 Endocrine regulation of growth and metabolism in the pig: A review. Livestock Production Science, 37:245-260.

Close, W. H., and M. W. Stanier. 1984. Effects of plane of nutrition and environmental temperature in the growth and development of early weaned piglet. 2. Energy metabolism. Animal Production, 38:221231 .

Collin, A., J. van Milgen, S. Dubois, and J. Noblet. 2001. Effect of high temperature and feeding level on energy utilization in piglets. Journal of Animal Science, 79:1849-1857.

Collin, A., J. van Milgen, and J. Le Dividich. 2001. Modelling the effect of high, constant temperature on food intake in young growing pigs. Animal Science, 72:519-527.

Dexter, N. 1999. The influence of pasture distribution and temperature on habitat selection by feral pigs in a semi-arid environment. Wildlife Research, 25:547-559.

Elston, J. J., E. A. Klinksiek, and D. G. Hewitt. 2005. Digestive efficiency of collared peccaries and wild pigs. Southwestern Naturalist, 50:515-519.

Fernandez-Llario, P. 2005. The sexual function of wallowing in male wild boar (Sus scrofa). Journal of Ethology, 23:9-14.

Fernandez-Llario, P., ad P. Mateos-Quesada. 1998. Body size and reproductive parameters in the wild boar Sus scrofa. Acta Theriologica, 43:439-444.

Gabor, T. M., E. C. Hellgren, and N. J. Silvy. 1997. Renal morphology of sympatric suiforms: implications for competition. Journal of Mammalogy, 78:1089-1095.

Hagsten, I., and T. W. Perry. 1976. Evolution of dietary salt levels for swine. I. Effect on gain, water consumption and efficiency of feed conversion. Journal of Animal Science 42(5):1187-1190.

Herpin, P., M. Damon, and J. Le Dividich. 2002. Development of thermoregulation and neonatal survival in pigs. Livestock Production Science, 78:25-45. 


\section{Wild Pigs}

Hodgkinson, S. M., M. Schmidt, and N. Ulloa. 2008. Comparison of the digestible energy content of maize, oats, and alfalfa between European wild boar (Sus scrofa L.) and Landrace x Large White pig (Sus scrofa domesticus). Animal Feed Science and Technology, 144:167-173.

Ilse, L.M., and E. C. Hellgren. 1995a. Resource partitioning by sympatric populations of collared peccaries and feral hogs in southern Texas. Journal of Mammalogy, 76:784-799.

. 1995b. Spatial use and group dynamics of sympatric collared peccaries and feral hogs in southern Texas. Journal of Mammalogy, 76:993-1002.

Ingram, D. L. 1965. The effect of humidity on temperature regulation and cutaneous water loss in the young pig. Research in Veterinary Science, 6:9-17.

Kleiber, M. 1965. Metabolic body size. Pp 427-435. In K. L. Blaxter (ed.), Energy Metabolism in Farm Animals, EAAP Publ., vol. 11. Academic Press, London, UK.

Kouba, M., D. Hermier, and J. Le Dividich. 2001. Influence of a high ambient temperature on lipid metabolism in the growing pig. Journal of Animal Science, 79:81-87.

MacFarlane, W. V. 1964. Terrestrial animals in dry heat: ungulates. Pp. 509-531. In D. B. Dill (ed.), Handbook of Physiology Environment Vol. 4. American Physiological Society, Washington, D. C.

Maloiy, G. M. O., and C. R. Taylor. 1971. Water requirements of African goats and haired-sheep. Journal of Agricultural Science, 77:203-208.

Mauget, R. 1991. Reproductive biology of the wild Suidae. Pp. 49-64. In R. H. Barrett and F. Spitz, (eds.), Biology of Suidae. Reliure AGECO, Grenoble, France.

Mayer, J. J., and I. L. Brisbin, Jr.. 1991. Wild Pigs in the United States: Their history, comparative morphology, and current status. University of Georgia Press, Athens, Georgia.

McNab, B. K. 2002. The physiological ecology of vertebrates. Cornell University Press, Ithaca, New York. 1988. Complications inherent in scaling basil rate of metabolism in mammals. Quarterly Review of Biology, 63:25-54.

Mersmann, H. J. 1986. Lipid metabolism in swine. In H. C. Stanton and H. J. Mersmann (eds.), CRC Swine in Cardovascular Research (vol.1). CRC Press, Boca Raton, Florida.

Mount, L. E. 1968. The climatic physiology of the pig. Edwards Arnold, London.

Nagy, K. A. 1987. Field metabolic rate and food requirement scaling in mammals and birds. Ecological Monographs, 57(2):111-128.

1975. Water and energy budgets of free-living animals: measurements using isotopically labelled water. Pp. 227-245. In N. F. Hadley (ed.). Environmental physiology of desert organisms. Dowden, Hutchinson, and Ross, Stroudsburg, Pennsylvania.

Noblet, J., J. Y. Dourmand, M. Etienne, and J. LeDividich. 1997. Energy metabolism in pregnant sows and newborn pigs. Journal of Animal Science, 75:2708-2714.

Noblet, J. C. Karege, S. Dubois, and J. van Milgen. 1999. Metabolic utilization of energy and maintenance requirements in growing pigs: Effects of sex and genotype. Journal of Animal Science, 77:1208-1216. 
Oliver, W. L. R., and I. L. Brisbin, Jr. 1993. Introduced and feral pigs: Problems, policy, and priorities. Pp. 179-191. In W. R. Oliver (ed.), Pigs, peccaries, and hippos. International Union for Conservation of Nature and Natural Resources (IUCN). Gland, Switzerland.

Pepin, D., and R. Mauget. 1989. The effect of planes of nutrition on growth and attainment of puberty in female wild boars raise in captivity. Animal Reproduction Science, 20:71-77.

Porter, W. G., and D. M. Gates. 1969. Thermodynamic equilibria of animals with environment. Ecological Monographs, 39:245-270.

Quiniou, N., J. Noblet, J. van Milgen, and S. Dubois. 2001. Modelling heat production and energy balance in group-housed growing pigs exposed to cold or hot ambient temperatures. British Journal of Nutrition, 85:97-106.

Read, A. F., and P. H. Harvey. 1989. Life history differences among the eutherian radiations. Journal of Zoology (London), 219:329-353.

Sperber, I. 1944. Studies on the mammalian kidney. Zoological Bidrag Uppsala, 22:249-431.

Spitz, F., G. Valet, and I. L. Brisbin, Jr. 1998. Variations in body mass of wild boars from southern France. Journal of Mammalogy, 79:251-259.

Taylor, C. R., N. C. Heglund, and G. M. O. Maloiy. 1982. Energetics and mechanics of terrestrial locomotion: Metabolic energy consumption as a function of speed and body size in birds and mammals. Journal of Experimental Biology, 97:1-21.

Taylor, R. B., E. C. Hellgren, T. M. Gabor, and L. M. Ilse. 1998. Reproduction of feral pigs in southern Texas. Journal of Mammalogy, 79:1325-1331.

van Wieren, S. E. 2000. Digestibility and voluntary intake of roughages by wild boar and Meishan pigs. Animal Science, 71:149-156.

Verstegen, M. W. A., and W. H. Close. 1994. The environment and the growing pigs. Pp. 333-353. In D. J. A. Cole, J. Wiseman, and M. A. Varley (eds.), Principles of pig science. Nottingham University Press, Nottingham, UK.

Weiler, U., R. Claus, M. Dehnhard, and S. Hofacker. 1996. Influence of the photoperiod and a light reverse program on metabolically active hormones and food intake in domestic pigs compared with a wild boar. Canadian Journal of Animal Science, 76:531-539.

Wolkers, J., T. Wensing, J. T. Schonewille, and A. T. Van-Klooser. 1994. Undernutrition in relation to changed tissue composition in wild boar (Sus scrofa). Comparative Biochemistry and Physiology, (A), 108:623-628.

Zervanos, S. M., 2002. Renal structural adaptations among the three species of peccary. The Southwestern Naturalist, 47 (4):527-531.

Zervanos, S. M., and S. Naveh, 1988. Renal structural flexibility in response to environmental water stress in feral hogs. Journal of Experimental Zoology, 247:285-288.

Zervanos, S. M. W. D. McCort and H. B. Graves, 1983. Salt and water balance of feral versus domestic Hampshire hogs. Physiological Zoology, 56 (1):67-77.

Zervanos, S. M., and J. L. Day, 1977. Water and energy requirements of captive and free-living collared peccaries (Tayassu tajacu). Journal of Wildlife Management, 41:527-532. 
Wild Pigs

\section{Biology of Wild Pigs:}

\section{Wild Pig Population Biology}

John J. Mayer

Savannah River National Laboratory, Savannah River Nuclear Solutions, LLC, Savannah River Site, Aiken, South Carolina 29808

\section{Introduction}

In both the native and introduced portions of the species range, wild pig (Sus scrofa) populations have been reported to fluctuate greatly in size (Hanson and Karstad 1959, Jedrzejewska et al. 1997, Massei et al. 1997, Cahill and Llimona 2004, Geisser and Reyer 2005). Such changes are due to interactive variations in climatic, anthropogenic, epidemic and, to a certain degree, biocentric factors (Lozan 1995). Such external influences can result in high levels of mortality being realized within a wild pig population. However, because of their high reproductive potential (Comer and Mayer this volume), wild pig populations are resilient with the ability to rapidly recover from such dramatic reductions. Because of this, wild pig population sizes can oscillate widely over the short term, being more responsive/reactive to these external forces rather than multiannual cyclic in nature. Understanding the population demographics and dynamics of this invasive species is critical to being able to successfully manage or control local numbers of these animals.

The aforementioned broad changes in abundance have been exhibited by wild pig populations for a long time. During the past few centuries, some populations have been greatly reduced as a result of both habitat loss and overhunting. A few native populations were even completely extirpated; some as early as the $17^{\text {th }}$ Century. In contrast to these decreases, there have also been recent increases of wild pigs within the existing species range. These latter increases have been largely due to supplementary feeding, increased protection/regulated hunting, reduced predation, warmer winter/spring temperatures and changes in land use practices (Clutton-Brock 1981, Genov 1981, Tisdell 1982, Sáez-Royuela and Telleria 1986, Oliver et al. 1993, Goulding 2003, DEFRA 2004, Geisser and Reyer 2005, Fernández et al. 2006). In addition, wild pigs have recently been introduced into various unoccupied areas within the species global distribution (Mayer and Brisbin 1991, Gipson et al. 1998, Goulding 2003). Within the past decade, the observed widespread trend among wild pig populations in North America, Europe and western Asia has been to increase in both numbers and range (DEFRA 2004, Geisser and Reyer 2005, Rosvold and Andersen 2008).

The purpose of this paper is to provide a general overview on the population biology of wild pigs. This review focuses on basic population parameters including: sex and age demographics, density, rate of increase, longevity, fecundity, mortality, dispersal, population models and management. The intent of this review is to provide a basic understanding of wild pig population dynamics within the context of better supporting the management of these animals in control scenarios. In addition to that obtained from the scientific and popular literature, data or information on wild pig population biology from the Savannah River Site (SRS) in Aiken, Barnwell and Allendale counties, South Carolina, has also been included as appropriate.

\section{Results/Discussion}

Sex and Age Demographics - As a general statement, the overall postnatal male-to-female sex ratio is typically not significantly different from parity (i.e., 1:1); but within some populations, this ratio has been reported to be biased toward one sex or the other. Of the sex ratios listed for the 53 wild pig populations included in Table 1, most (70\%) were not significantly different from parity, while $17 \%$ and $13 \%$ were significantly biased $(p<0.05)$ towards males and females, respectively. However, it should be noted that 
most of these post-natal sex ratios were based on harvest data/numbers (e.g., from trapping, shooting and dogging), which may also be inherently biased toward one sex or the other (see Mayer this volume Comparison of Five Harvest Techniques for Wild Pigs). In addition, the reported sex ratios have also varied between age classes within a population. For example, Andrzejewski and Jezierski (1978), Henry and Conley (1978), Dardaillon (1984) and Garzon-Heydt (1992) all reported that the sex ratio became more female-biased with age. In contrast to these findings, Giles (1980) found that the sex ratios for wild pigs from New South Wales, Australia, were significantly biased toward males in all age classes. Belden and Frankenberger (1989) reported that in hunted populations, the younger age classes were male biased while the adult age class was female biased. Both Jezierski (1977) and Giles (1980) noted a higher mortality among males during the first three to four years of life, which would account for such a difference. Belden and Frankenberger (1989) also reported that in unhunted populations, the adult sex ratio was either 1:1 or slightly biased towards males. Belden and Frankenberger (1990) hypothesized that such a slight male bias in the adult age class would be due to mortality in mature females resulting from pregnancy or farrowing complications or problems. Over a seven-year period, Boitani et al. (1995) found that the sex ratios of piglets and adults varied, but that the ratios for yearlings were consistently male-biased. In a similar time period, Fernandez-Llario and Mateos-Quesada (2003) found that the age-specific sex ratio did not change between years or seasons within wild pig populations in Spain. For a sample of 636 wild pigs from the Hakalau Forest National Wildlife Refuge in Hawaii, Hess et al. (2006) found no significant differences between the sexes for six age classes (i.e., 0-8, 9-16, 17-24, 25-32, 33-38 and >39 mo. of age).

As in most large mammal populations (Caughley 1978), the population age structure for wild pigs within each age class decreases with increasing age (Table 2). The approximate age class percentages found within a population would be as follows: $0-1 \mathrm{yr} .-57 \%$; $1-2$ yrs. $-20 \%$; and $>2$ yrs. $-23 \%$. The increase in that last category would result from the cumulative total of several year classes (i.e., the sum of the 2-3 yrs, 3-4 yrs, 4-5 yrs, and etc.). Changes in the aforementioned demographics can occur in a population due to a variety of factors such as either biased hunter harvest for a specific size class or sex (e.g., selection of larger individuals or trophy males) or severe environmental conditions (e.g., extreme winter conditions, limited forage resources) that would select against very young, pregnant/lactating females or very old animals.

The sex and age class composition of a theoretical population of 1,000 wild pigs on the SRS is provided in Table 3. The numbers within each sex and age class grouping were based on data collected from and modeling done on the SRS wild pig population (J. J. Mayer, unpubl. data).

Density - Among wild pig populations, the density estimates vary from as low as 0.04 up to as many as 115 animals per square kilometer (Table 4). Most of these estimates (49\%) were between one and three animals per $\mathrm{km}^{2}$. As in other wildlife species, density in any one area is determined by a suite of local variables that collectively define the area's carrying capacity. For wild pigs, such variables would include presence of surface water, habitat, climatic conditions, food availability, and level of predation (i.e., both natural and manmade harvest). In addition, Wilson (2005) stated that feral pigs tend to live at higher densities than do Eurasian wild boar.

Among the aforementioned local variables determining wild pig density, water is probably the most critical from a long term perspective. This is especially true for wild pigs inhabiting arid areas (Baber and Coblentz 1986). In fact, the local absence of some form of available surface water will effectively prevent wild pigs from existing in that area (Dickson et al. 2001).

Habitat use in wild pigs throughout their range is strongly associated with cover, especially forested habitat (DEFRA 2004). There is also a preference for deciduous over conifer forests (Goulding et al. 1998). In general, higher densities are seen in mesic, forested areas while much lower estimates are reported in arid, shrub-scrub or steppe habitats. In addition, because such variables are not uniform over an area, local densities tend to be patchy. That variation between localized habitat types accounts for the broad ranges reported for the densities in some populations (e.g., Baber and Coblentz 1986, Caley 1993, Diong 1982).

With respect to varying climatic conditions, the winter and spring temperatures are positively correlated with density (Geisser and Reyer 2005, Melis et al. 2006), while the amount of snow depth is negatively correlated with density (Jedrzejewska et al. 1997). In general, any type of extreme weather (e.g., flooding, 


\section{Wild Pigs}

drought, severe winter conditions) that has the potential to either force animals to move or increase mortality will have an effect on density.

The abundance of forage resources also plays a significant role in wild pig densities (Melis et al. 2006). Given the link between food and reproduction in this species, as food availability is enhanced, reproductive success increases (Geisser and Reyer 2005); this then results in an increase in density. In natural situations, forage resources are strongly tied to both habitat type and climate. However, supplemental feeding and access to crops can also increase the density of wild pigs in an area (Groot Bruinderink et al. 1993, DEFRA 2004).

Although natural predation typically plays a minor role (Sweeney et al. 2003), the harvest by man can have a noticeable impact on the wild pig density within a given area. Sweitzer et al. (2000) reported lower densities in intensely hunted areas compared to lightly or unhunted areas in California. Similarly, Jedrzejewska et al. (1994) found that wild pig densities were higher in unhunted versus hunted portions of the Bialowieza Primeval Forest in Poland. At the SRS where wild pigs have been intensively hunted and trapped annually for over five decades, the densities have ranged from 1.0 up to 5.9 (Kurz and Marchinton 1972, Mayer 2005).

Rates of Increase - Both the observed instantaneous (r) and finite $(\lambda)$ rates of increase have been reported for a few wild pig populations. Using data reported in the literature, Bratton (1974) gave these rates for two locations in the USSR as follows: Bialowieza Primeval Forest $-r=1.02 /$ year, $\lambda=2.77 /$ year; Crimea Region - $\mathrm{r}=0.41 /$ year, $\lambda=1.51 /$ year. Hone and Pederson (1980) reported similar rates for a population in New South Wales, Australia: $\mathrm{r}=0.57 /$ year, $\lambda=1.77 /$ year. Giles (1999), also using published data from the literature, calculated rates for two locations in Australia as follows: the wet tropics - $r=0.78 /$ year, $\lambda=2.18$ /year; Macquarie Marshes - $\mathrm{r}=1.34$ /year, $\lambda=4.0$ /year. Based on computer modeling of a wild pig population over a ten-year period, Tipton (1977) reported rates of increase as $\mathrm{r}=0.30 /$ year and $\lambda=1.35 /$ year. The observed rate of increase (r) can be used to calculate the number of pigs that would have to be killed to keep a population stable. If $\mathrm{N}$ is the average population size throughout the year, then the number required to be killed would be $\mathrm{rN}$ (Hone and Pederson 1980). Based on the average of these r values, this would be between 50 to $60 \%$ removal per year to keep a population stable and not increasing.

Longevity - Age specific survival and mortality rates for wild pigs have been determined through several studies (e.g., Ashby and Santiapillai 1991, Barrett, 1978, Henry and Conley 1978, Jezierski 1977). In general, species in the Family Suidae are unique among the large precocious mammals in that they have a high natality combined with a very high mortality rate during the first year of life (Andrzejewski and Jezierski 1978, Jezierski 1977). Estimates of $80 \%$ or higher mortality within the first year of life have been reported for wild S. scrofa (e.g., Ashby and Santiapillai 1991, Barrett, 1978, Giles 1980). Then, between the first and fourth years of life, the cohort-specific mortality rates drops to about $30 \%$ to $40 \%$, with the greatest life expectancy in the one- and then two-year old animals (Fig. 1, Table 5). From the fifth year on, the annual mortality rate increases to $50 \%$ or higher. Typically, most wild pigs do not last more than six to eight years of age in the wild (Barrett 1978, Conley et al. 1972). The maximum lifespan for most wild pig populations is estimated to be 9-10 years of age, with exceptional instances of individuals reaching 12-14 years (Henry and Conley 1978, Jezierski 1977, Dzieciolowski et al. 1992). The life table for a hypothetical wild pig population is provided in Table 5.

The high mortality rate among the younger age classes in wild pigs results in a typical expected longevity of about 18 to 25 months (Briedermann 1986). Similar to other demographic parameters for wild pigs, this estimate has been reported to vary among populations (Table 6). Although variable, in most instances, the reported life expectancy for males is slightly shorter than that for females. For example, Boitani et al. (1995) found that life expectancy was slightly higher for females compared to males for all of the age classes. Jezierski (1977) and Henry and Conley (1978) both reported that the mortality rates of females and males differed, with males having higher rates, typically during the first four years of life (Jezierski 1977, Giles 1980). After the sixth year, females reportedly died at a higher rate than males (Jezierski 1977).

In spite of having a seemingly short average lifespan, the potential does exist for wild pigs to reach considerably more advanced ages. The oldest known free-ranging wild pig was feral sow in New Zealand, 
which was documented to be 14 years old (Dzieciolowski et al. 1992). Typically, old pigs starve to death when excess tooth wear begins to interfere with mastication (Groves and Giles 1989). Barrett (1978) stated that tooth deterioration was apparently the most important cause of death from old age. There is a positive correlation between tooth abscesses and age class in wild pigs (Barrett 1978, Samuel and Woodall 1988). In addition, Jezierski (1977) suggested the inability of animals six years or more in age to successfully withstand harsh environmental extremes (e.g., extreme cold temperatures and snow depth) as a leading cause of death in these older individuals.

Like most large mammals, wild pigs have been known to last longer in captivity with the benefits of the care and maintenance by their human keepers. The two oldest captive wild pig specimens that I have personally examined were a 15-year, 3-month old female Eurasian wild boar from the National Zoo in Washington, D.C., and a 17-year, 2-month old male Eurasian wild boar from the Philadelphia Zoo. The sow had none of her premolars and molars remaining, while the male had a full compliment of teeth, although these were badly worn. Mann (1934) also reported that the National Zoo sow had been incredibly diseased internally at the time of her death. One captive female Eurasian wild boar in London's Regent's Park Zoological Garden lived to be 19 years, 6 months, and 6 days old (Flower 1931). An anecdotal record exists for this species stretching the maximum known life span to 27 years in captivity (Nowak 1999).

Fecundity - Wild pigs are typically an r-selected species with a high reproductive potential (Geisser and Reyer 2005). The general reproductive biology of this species was reviewed by Comer and Mayer (this volume). Because of this high reproductive potential, wild pig populations have a great capacity for increase, even when the mortality rate of young is high. For example, when only $10 \%$ of pigs survive their first year, the population can still increase by $21 \%$ in one year (Groves and Giles 1989).

In general, litter size in wild pigs is positively correlated with age of the sow (Table 7). Sludskii (1956) noted that the first one or two litters were smaller than the subsequent litters. Hess et al. (2006) reported that the mean numbers of corpora lutea, embryos/fetuses and lactating teats from feral sows on Hawaii all increased with age. Baber and Coblentz (1986) reported that mean litter size peaked at 2-3 years of age on Santa Catalina Island, and then decreased. Barrett (1978) reported that this increase continued to the 4-5 year-old age class. In contrast to these findings, Dzieciolowski et al. (1992) reported that fetal litter size did not significantly differ with the age of the sow in New Zealand populations. Giles (1980) found that the fetal litter size was significantly correlated to the sow's age in some locations in New South Wales, but not in others. However, within the population that had the largest sample size (i.e., Yantabulla), Giles (1980) reported that pregnant sows over fours years of age had significantly more fetuses than any other age group. The percent of sows that are pregnant within each age class also usually increases with age (Table 8). In addition, Groot Bruinderink et al. (1994) reported that litter sizes and the proportion of sows that were pregnant varied from year to year and were higher in good mast years.

Typically, sows in most wild pig population produce between one and two litters a year. The mean incidence of pregnancy in wild pig populations has been variously reported as 0.84 up to 2.0 litters per year (Barrett 1978, Saunders 1988). Physiologically, wild sows should be capable of producing three litters in a 14-16 month time period. This has been documented to occur in captive animals (Dzieciolowski et al. 1992), but not in wild females to date.

Mortality - The mortality rate in wild pigs is variable, but very much related to age (Jezierski 1977). Most mortality is known to occur between birth and one month of age (Barrett 1978, Náhlik and Sándor 2003). Depending upon the various extrinsic factors impacting a specific population, the mortality rate can be highly variable between the sexes and among the age classes (Jezierski 1977). The causes of mortality in wild pigs can be either natural or manmade. Mortality can vary among seasons (Hayes 2007), and peak mortality typically coincides with post-farrowing periods (Henry and Conley 1978). Often, the realized mortality is the result of combined causes rather than a single factor. For example, Wodzicki (1950) suggested that significant mortality among piglets born in the fall and winter might occur because of adverse weather conditions and shortage of food. In an extreme example of mortality within a wild pig population, Cabon (1958) reported that two-thirds of the wild boar population (both sexes and all age classes) inhabiting the Bialowieza Primeval Forest died during the severe winter of 1955-56. 


\section{Wild Pigs}

As previously stated, the mortality rate is highest in the juvenile age classes. In addition, juvenile mortality is highly variable, and can range from $10-15 \%$ under favorable conditions to 90 or even $100 \%$ during periods of harsh conditions (e.g., floods, droughts, and severe winter conditions) (Master 1979, Giles 1980, Saunders 1988, Groves and Giles 1989). Both Eisenberg and Lockhart (1972) and Náhlik and Sándor (2003) reported a $50 \%$ mortality in the first four months of life. Juvenile mortality was estimated at $58 \%$ on Santa Catalina Island by the 7-19 week age class (Baber and Coblentz 1986). Barrett (1978) estimated that $70-90 \%$ of pigs at Dye Creek Ranch died before 6 months of age.

In contrast to the juveniles, mortality rates among adult wild pigs are much less variable. Adult mortality rates range from 15 to $50 \%$ depending upon food availability and quality, predators (including hunting pressure) and disease (McGaw and Mitchell 1998). Generally, the mortality rate of adults contributes little to the fluctuations in the population. In severe winters with low forage availability, the survival rate of the adults seems to have the largest impact on the population growth rate (Bieber and Ruf 2005).

In general, the causes of mortality in wild pigs can be grouped into two basic categories, either natural or manmade causes. Manmade causes usually result in a higher percent of the annual mortality than do natural causes (Rosvold and Andersen 2008). A listing of both of these categories of mortality is provided in Table 9.

The natural causes of mortality in this species would include accidents and injuries, starvation, predation, parasites, diseases, and tooth deterioration (Barrett 1978). Accidents and injuries would variously encompass piglet mortality due to stillbirths, crushing and/or suffocation in the farrowing nest, trampling by adults in large social groups, and injuries due to adult aggression, as well as drowning; intraspecific fighting (e.g., among mature males), and temperature-related mortality. Typically a combination of the aforementioned list of natural causes contributes to the attrition in any one population. For example, Rakov (1970) reported that mortality among wild boar in the Amur Territory of the USSR resulted, in order, from combined severe winter weather/reduction of food, then disease and finally predation. Woodall (1983) found that mortality among wild pigs in Queensland, Australia, was significantly related to predation by dingoes and low rainfall, which resulted in reduced food supply. Jedrzejewska et al. (1992) and Okarma et al. (1995) noted that disease followed by starvation were two most important natural mortality factors for wild pigs in Poland. In addition, starvation or parasites can also serve as indirect causes of death, predisposing animals to other forms of mortality such as predation or disease.

Manmade causes of mortality among wild pigs can be significant. Being a popular big game species, the major cause of wild pig mortality in most areas of Europe and North America is from hunting (Okarma et al. 1995, Sweeney et al. 2003). For example, 94\% of the wild pig mortality in Sweden is from hunting (Rosvold and Andersen 2008). Based on several estimates (e.g., Pine and Gerdes 1973, Spitz et al. 1984, Barrett 1978, J. J. Mayer unpubl. data), the mean sport hunting harvest normally removes about $20 \%$ $( \pm 1 \mathrm{SD}=10$ to $30 \%)$ of the population annually. At the same time, Jedrzejewska et al. (1997) noted that wild pigs were less sensitive to heavy hunting pressure compared to other ungulates because of their high reproductive rate. Further, Herrero et al. (2008) noted that wild pig populations in Europe have continued to increase in spite of the concurrent high hunting pressure. The other manmade cause of mortality in wild pigs is from vehicle collisions; however, this involves a much smaller proportion of the population (Mayer and Johns 2007).

An extreme example of manmade mortality in wild pigs would be eradication programs; the goals of which would be the complete elimination of all of the animals found in a given area. Typically, such programs have been successful (i.e., $100 \%$ mortality of the population) on either barrier or offshore islands (e.g., Mayer and Brisbin 1991, Kessler 2002, Schuyler et al. 2002, Cruz et al. 2005, Ramsey et al. 2008). However, mainland examples of successful eradication programs also exist (e.g., Brown 1985, Barrett et al. 1988, Richardson et al. 1997, Lohraff 2008, McCann and Garcelon 2008).

Dispersal - Wild pigs can be a very mobile species. Cargnelutti et al. (1992) found that, although wild pigs are largely sedentary, long distance dispersion occurred more often in this species than for any other European ungulate. Dispersal can be from either a natal site or a release location, and can be either as individuals or groups (Goulding et al. 1998). Under normal conditions, dispersal reaches its maximum at 
the age when sexual maturity is occurring. Truvé and Lemel (2003) determined that dispersal in boars begins at 10 months of age, reaching a maximum dispersal rate at 13 months, and that dispersal ceases at the age of 16 months. The mean dispersal distance at that age is $16.6 \mathrm{~km}$ from their natal sites. In wild sows, the corresponding ages were 7.9 and 11 months, with a dispersal distance of $4.5 \mathrm{~km}$. Dispersal of released pen-raised wild pigs ranged up to $15.7 \mathrm{~km}$ away from the release site over several years (Igo et al. 1979). Within a population in Poland, emigration accounted for disappearance of 12-32\% of two- to five-year old animals (Jezierski 1977). Truvé et al. (2004) reported that in both sexes, dispersal distance was not correlated with population density, but the proportion of individuals dispersing tended to be negatively correlated with density. However, long distance dispersal may be related to habitat parameters, density and hunting pressure (Janeau and Spitz 1990, Goulding et al. 1998). Invasions into new habitats are sporadic and further distances are often traveled in times of food shortage (Goulding et al. 1998). Often, wild pigs will disperse from an area prior to the depletion of locally available forage resources. As such, these animals disperse when in physically good condition, which results in a lower mortality rate (Saez-Royuela and Telleria 1986).

Related to dispersal, the rate of spread or range expansion in wild pigs has been reported by several sources (Table 9). However, because of the frequent migration in wild pigs, it is difficult to estimate what their natural rate of spread would be (Jakšić et al. 2002).

Population Models - Three different population models have been specifically developed toward supporting the management of wild pig populations. Tipton (1977) developed a modified matrix structure of the Leslie Matrix model. Simulations were conducted to (1) develop optimal harvest and control strategies, and (2) determine the effects of food abundance on litter size and percent breeding against different control programs. It was determined that the population could be maintained at a stable level if all $(100 \%)$ of the animals 2.5 years of age and older were removed and $49 \%$ of 2-2.5 age class were taken each season. The optimal control strategy was to reduce the $0.5-1$ age class by $60 \%$ and the $2.5+$ age class by $40 \%$ by hunting during spring and fall. In the second set of simulations, maximum reduction in population size was achieved by hunting every spring. Tipton (1977) further pointed out the need to better understand the population processes and the accuracy of the input data in modeling simulations for this species. Dearden (1984) discussed the ongoing modification of the Program ONEPOP to model wild pig populations (i.e., renamed as HOGPOP). This interactive model was to be used for testing harvest rate in managing the wild pig population in the Great Smoky Mountains National Park. Dearden (1984) also pointed out the need for more population information on wild pigs. Barrett (1999) developed a spreadsheet-based model, the Wild Boar Population Model (POPMODWB), to simulate the dynamics of a wild pig population, particularly one subjected to seasonal harvest. The primary use was to judge the effects of proposed harvest schemes on the population. Both the assumptions and instructions for running this model using Excel97 V.5-30-99 were provided.

Management - A wild pig population reportedly has the potential to double and triple in size within 4 and 12 months, respectively (Pavlov 1980, Barrett and Birmingham 1994, Waithman 2001). Because of this growth potential, wild pig populations can be very difficult to manage in control scenarios. Even with newly introduced populations, once the animals are established in an area, wild pigs can increase rapidly (Choquenot et al. 1996). In addition, wild pig populations respond to high mortality, such as that caused by intensive lethal removal programs, by increasing the reproductive rate through increased fecundity and higher frequency of breeding in 8-10 month-old females (DEFRA 2004). Even with a 90\% mortality rate, the breeding population can still increase 33\% annually (Wood and Barrett 1979). When left completely unchecked, this growth rate within wild pig populations can literally be explosive. Giles (1976) reported that a $70 \%$ harvest was necessary to reduce a wild pig population over 12 months. Using regression equations, Hess et al. (2006) found that 70-71\% of an area's wild pigs had to be removed to reduce the population by 50\% in each successive year. Similarly, Barrett and Stone (1983) found that a 60-80\% annual removal was necessary to maintain a wild pig population at $50 \%$ of their equilibrium density. However, using model simulations of population recovery rates, Dzieciolowski et al. (1992) predicted that a wild pig population reduced by $70 \%$ in one year would recover to its original size in 30 months, $80 \%$ in 35 months, $90 \%$ in 45 months, and 95\% in 55 months. From a control perspective, Hone and Robards (1980) calculated that an ongoing 70\% annual reduction would eliminate a theoretical population of 1,000 wild pigs in a nine year period of time. 


\section{Wild Pigs}

Because of such daunting statistics, it is necessary that control programs for wild pigs be ongoing until success is achieved (Wood et al. 1992, Barrett and Birmingham 1994). The management strategy for areas with an established population of wild pigs would be as follows:

- Implement and maintain an ongoing directed control program (typically this entails the use of a combination of lethal removal techniques)

- Set a goal to work toward eradication (this may not be either feasible or realistic, but will still ultimately serve to control the numbers of these animals)

- Do not periodically back off of control efforts

- Consider the use of fencing for critical or sensitive areas/habitats

Delaying or postponing the control activities (e.g., to save money) for even a matter of several months can result in substantial increases in the local numbers of these animals. The money saved initially by such delays is lost by the increased efforts required to get the numbers back to where they were before the delay was implemented.

Given the recent trends in illegal/clandestine releases of these animals into new areas, land and resource managers of properties that do not have any wild pigs also need to actively manage against the presence of these animals. The management strategy for areas with no wild pigs would be as follows:

- Set a goal to stay "pig free" (consider fencing if applicable)

- Monitor the area regularly for wild pig field sign (this can be accomplished while conducting daily or routine property management activities)

- If wild pigs appear, implement a rapid response eradication effort (it is both easier and less expensive to remove a few wild pigs as opposed to removing a lot of them)

- Once pigs have appeared, do not wait until these animals become a problem to begin control activities

The primary mistake that land owners and government agencies make with respect to newly established wild pig populations is to ignore the presence of these animals until their numbers increase to the level that problems and damage begin to occur. Once the wild pigs in an area have passed that threshold, the cost for controlling those animals goes up and the chances of achieving success in managing them go down. To miss that small window of opportunity will become increasingly more costly in both dollars and damage as time passes.

The presence of wild pigs in area constitutes a multi-faceted problem. Rapid eradication is recommended for newly-established populations. For existing populations, ongoing control must be conducted to keep the numbers of these animals in check or eliminate the population all together. In general, the population dynamics exhibited by this invasive species make wild pigs a challenge to manage successfully. In spite of a few successful eradication programs, it is unlikely that wild pigs can be exterminated in most areas where they occur (Barrett and Birmingham 1994).

\section{Summary}

The population biology of wild pigs is unique among most large mammals. Having a high reproductive potential with a concurrent high mortality rate caused population of these animals to fluctuate in response to a combination of several factors (e.g., density, food availability, severe weather conditions). The variability of the demographics (e.g., sex ratio, age class composition, mean lifespan) and other parameters (e.g., density, rate of increase, dispersal) of these populations reflects these broad oscillations in size. This versatility combined with their being adaptive generalists have made both native and introduced populations of wild pigs very successful throughout the non-polar regions of the world. Recent factors (e.g., supplemental feeding, reduced predation/hunting, milder temperatures) have contributed to the increase in numbers and longevity of local animals that has resulted in the currently observed global 
expansion of this species in the wild. Along with this has come an increase in the damage done by these animals to both natural and anthropogenic habitats.

Because of their high reproductive potential, wild pigs have the ability to reach large numbers of individuals in a local population in a very short period of time (Geisser and Reyer 2005). Studies have shown that it is necessary to remove 50 to $70 \%$ of a wild pig population annually to keep the numbers stable to decreasing. Under most circumstances, for both economical and logistical reasons, that is a complicated if not impossible goal to achieve year after year. Given the difficulties in managing these populations, land owners must generally accept the fact that, if they already have these animals on their lands, they will always have some wild pigs and should therefore plan for a long-term control program (Barrett and Birmingham 1994). 


\section{Wild Pigs}

Table 1. Listing of postnatal sex ratios reported for various wild pig populations.

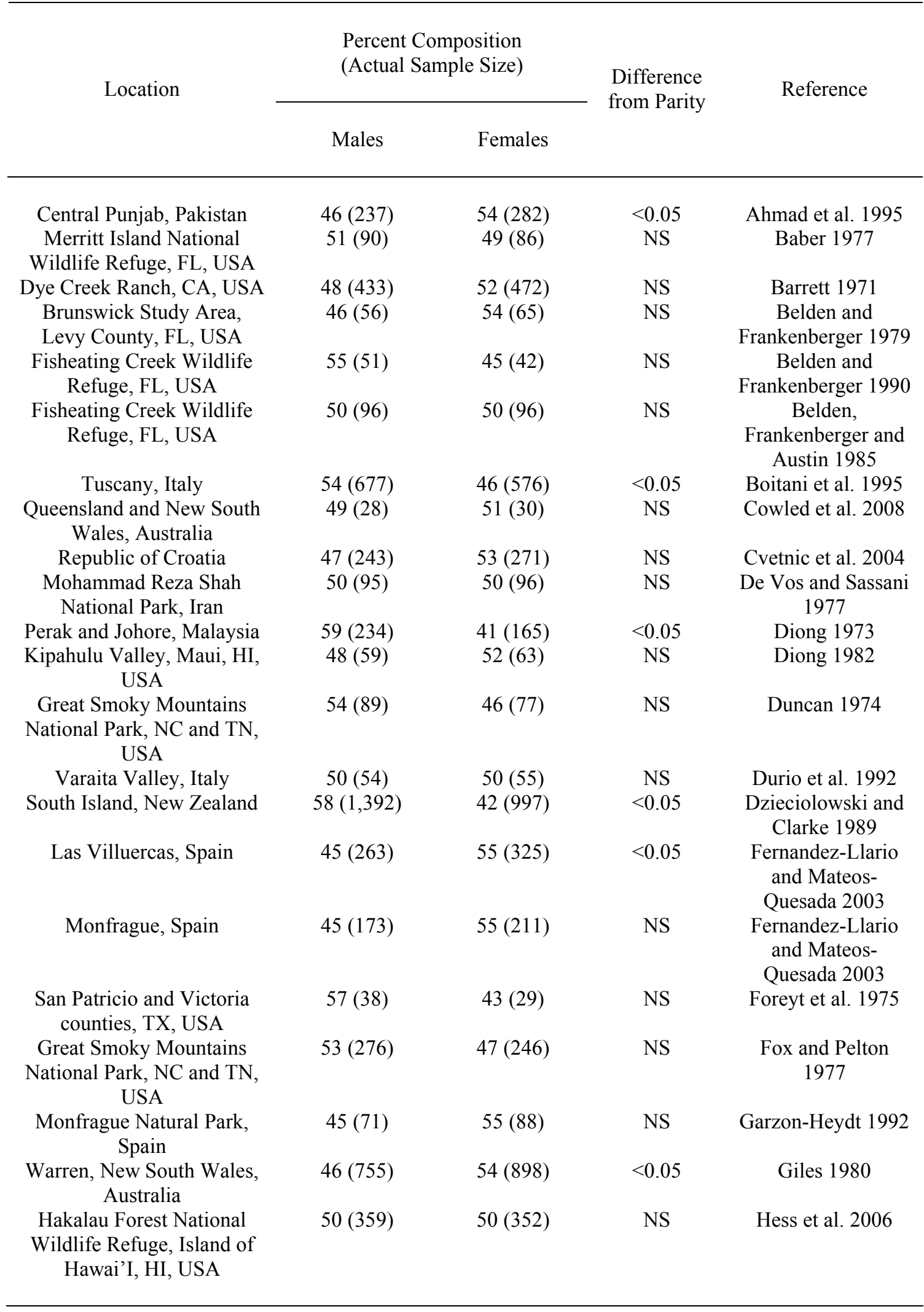


Table 1. Listing of postnatal sex ratios reported for various wild pig populations. (Continued)

\begin{tabular}{|c|c|c|c|c|}
\hline \multirow{2}{*}{ Location } & \multicolumn{2}{|c|}{$\begin{array}{l}\text { Percent Composition } \\
\text { (Actual Sample Size) }\end{array}$} & \multirow{2}{*}{$\begin{array}{l}\text { Difference } \\
\text { from Parity }\end{array}$} & \multirow{2}{*}{ Reference } \\
\hline & Males & Females & & \\
\hline $\begin{array}{c}\text { Welder Wildlife Refuge, } \\
\text { TX, USA }\end{array}$ & $44(14)$ & $56(18)$ & NS & $\begin{array}{c}\text { Ilse and Hellgren } \\
1995\end{array}$ \\
\hline $\begin{array}{l}\text { Sarigan Island, Mariana } \\
\text { Islands }\end{array}$ & $33(18)$ & $67(37)$ & $<0.05$ & Kessler 2002 \\
\hline $\begin{array}{l}\text { Iwami District, Shimane } \\
\text { Prefecture, Japan }\end{array}$ & $53(89)$ & $47(78)$ & NS & Kodera 2005 \\
\hline $\begin{array}{c}\text { Noorama, Queensland, } \\
\text { Australia }\end{array}$ & $120(42)$ & $165(58)$ & $<0.05$ & Lapidge et al. 2004 \\
\hline $\begin{array}{c}\text { Fort Hunter Liggett, CA, } \\
\text { USA }\end{array}$ & $46(91)$ & $54(105)$ & NS & Mansfield 1978 \\
\hline $\begin{array}{l}\text { Maremma Natural Park, } \\
\text { Italy }\end{array}$ & $50(330)$ & $50(330)$ & NS & $\begin{array}{c}\text { Massei and Tonini } \\
1992\end{array}$ \\
\hline $\begin{array}{c}\text { Savannah River Site, SC, } \\
\text { USA }\end{array}$ & $52(5,608)$ & $48(5,171)$ & $<0.05$ & $\begin{array}{l}\text { J. J. Mayer, unpubl. } \\
\text { data }\end{array}$ \\
\hline Ticino, Switzerland & $50(263)$ & $50(258)$ & NS & Moretti 1995 \\
\hline $\begin{array}{l}\text { Girilambone, New South } \\
\text { Wales, Australia }\end{array}$ & $51(105)$ & $49(99)$ & NS & Pavlov 1980 \\
\hline Cape Tribulation National & $32(12)$ & $68(25)$ & $<0.05$ & Pavlov and \\
\hline Park, Queensland, Australia & & & & Edwards 1995 \\
\hline $\begin{array}{c}\text { Great Smoky Mountains } \\
\text { National Park, NC and TN, } \\
\text { USA }\end{array}$ & $44(1,102)$ & $56(1,391)$ & $<0.05$ & $\begin{array}{l}\text { Peine and Farmer } \\
1990\end{array}$ \\
\hline Kazakstan, USSR & $51(132)$ & $59(137)$ & NS & Pfeffer 1960 \\
\hline Monterey County, CA. USA & $52(84)$ & $48(79)$ & NS & $\begin{array}{l}\text { Pine and Gerdes } \\
1973\end{array}$ \\
\hline $\begin{array}{l}\text { Kosciusko National Park, } \\
\text { New South Wales, Australia }\end{array}$ & $50(106)$ & $50(106)$ & NS & Saunders 1993 \\
\hline $\begin{array}{l}\text { Oxley Station, New South } \\
\text { Wales, Australia }\end{array}$ & $54(898)$ & $46(755)$ & $<0.05$ & $\begin{array}{c}\text { Saunders and Giles } \\
1995\end{array}$ \\
\hline $\begin{array}{l}\text { Big Cypress National } \\
\text { Preserve, FL, USA }\end{array}$ & $53(258)$ & $47(230)$ & NS & $\begin{array}{l}\text { Schortemeyer and } \\
\text { McCown } 1988\end{array}$ \\
\hline $\begin{array}{c}\text { Santa Catalina Island, CA, } \\
\text { USA }\end{array}$ & $52(2,845)$ & $48(2,664)$ & $<0.05$ & Schuyler et al. 2002 \\
\hline $\begin{array}{c}\text { Great Smoky Mountains } \\
\text { National Park, NC and TN, } \\
\text { USA }\end{array}$ & $54(298)$ & $46(252)$ & $<0.05$ & $\begin{array}{c}\text { Singer and } \\
\text { Ackerman } 1981\end{array}$ \\
\hline $\begin{array}{c}\text { Cumberland Island, GA, } \\
\text { USA }\end{array}$ & $49(290)$ & $51(300)$ & NS & $\begin{array}{c}\text { Singer and } \\
\text { Stoneburner } 1979\end{array}$ \\
\hline Lowery Saxony, Germany & $47(60)$ & $53(68)$ & NS & $\begin{array}{l}\text { Sodeikat and } \\
\text { Pohlmeyer } 2002\end{array}$ \\
\hline $\begin{array}{c}\text { Fort Benning, Georgia, } \\
\text { USA }\end{array}$ & $51(93)$ & $49(89)$ & NS & Sparklin 2009 \\
\hline $\begin{array}{c}\text { Muir, Western Australia, } \\
\text { Australia }\end{array}$ & $47(47)$ & $53(54)$ & NS & Spencer et al. 2006 \\
\hline
\end{tabular}




\section{Wild Pigs}

Table 1. Listing of postnatal sex ratios reported for various wild pig populations. (Continued)

\begin{tabular}{|c|c|c|c|c|}
\hline \multirow{2}{*}{ Location } & \multicolumn{2}{|c|}{$\begin{array}{l}\text { Percent Composition } \\
\text { (Actual Sample Size) }\end{array}$} & \multirow{2}{*}{$\begin{array}{l}\text { Difference } \\
\text { from Parity }\end{array}$} & \multirow{2}{*}{ Reference } \\
\hline & Males & Females & & \\
\hline $\begin{array}{l}\text { Northhampton, Western } \\
\text { Australia, Australia }\end{array}$ & $18(53)$ & $16(47)$ & NS & Spencer et al. 2006 \\
\hline $\begin{array}{c}\text { Noorama, Queensland, } \\
\text { Australia }\end{array}$ & $62(43)$ & $83(57)$ & NS & Spencer et al. 2006 \\
\hline $\begin{array}{c}\text { Cape York, Queensland, } \\
\text { Australia }\end{array}$ & $50(7)$ & $50(7)$ & NS & Spencer et al. 2006 \\
\hline Papua New Guinea & $16(62)$ & $10(38)$ & NS & Spencer et al. 2006 \\
\hline $\begin{array}{l}\text { Aransas National Wildlife } \\
\text { Refuge, TX, USA }\end{array}$ & $52(58)$ & $48(54)$ & NS & Springer 1975 \\
\hline Santa Cruz Island, CA, USA & $57(117)$ & $43(88)$ & $<0.05$ & Sterner 1990 \\
\hline $\begin{array}{c}\text { Savannah River Plant, SC, } \\
\text { USA }\end{array}$ & $53(41)$ & $47(36)$ & NS & Sweeney 1970 \\
\hline $\begin{array}{c}\text { Great Smoky Mountains } \\
\text { National Park, NC and TN, } \\
\text { USA }\end{array}$ & $53(772)$ & 47 (687) & $<0.05$ & Tate 1984 \\
\hline Hobcaw Barony, SC, USA & $53(125)$ & $47(110)$ & NS & $\begin{array}{c}\text { Wood and } \\
\text { Brenneman } 1977\end{array}$ \\
\hline
\end{tabular}


Table 2. Listing of age class percent composition reported for various wild pig populations. The percent composition for five of the populations have the 0-1 yr. and 1-2 yr old age class categories combined.

\begin{tabular}{|c|c|c|c|c|}
\hline \multirow{2}{*}{ Location } & \multicolumn{3}{|c|}{$\begin{array}{l}\text { Percent Composition of Age } \\
\text { Classes in Population }\end{array}$} & \multirow{2}{*}{ Reference } \\
\hline & $0-1 \mathrm{yr}$ & $1-2 \mathrm{yr}$ & $>2 \mathrm{yr}$ & \\
\hline Poland & \multicolumn{2}{|c|}{77.7} & 22.3 & $\begin{array}{c}\text { Andrzejewski and Jezierski } \\
1978\end{array}$ \\
\hline Dye Creek Ranch, CA, USA & 48.8 & 22.8 & 28.4 & Barrett 1978 \\
\hline Camargue National Reserve, France & \multicolumn{2}{|c|}{79.1} & 20.9 & Dardaillon 1984 \\
\hline Kipahulu Valley, Maui, HI, USA & 41.7 & 22.9 & 35.4 & Diong 1982 \\
\hline Monfrague Natural Park, Spain & \multicolumn{2}{|c|}{68.5} & 31.5 & Garzon-Heydt 1992 \\
\hline $\begin{array}{c}\text { Warren, New South Wales, } \\
\text { Australia }^{\text {a }}\end{array}$ & 77.6 & 8.8 & 13.6 & Giles 1980 \\
\hline Tellico WMA, TN, USA ${ }^{a}$ & 51.3 & 25 & 23.7 & Henry and Conley 1978 \\
\hline New South Wales, Australia ${ }^{a}$ & 63.1 & 14.3 & 22.6 & Hone and Pederson 1980 \\
\hline Savannah River Site, SC, USA & 57.3 & 16.1 & 26.6 & J. J. Mayer Unpubl. data \\
\hline Kampinos National Park, Poland ${ }^{\mathrm{a}}$ & 52.9 & 27.4 & 19.7 & Jezierski 1977 \\
\hline Foret d' Chize, France & \multicolumn{2}{|c|}{75.7} & 24.3 & Mauget 1980 \\
\hline Ticino, Switzerland ${ }^{\mathrm{a}}$ & 46 & 36 & 18 & Moretti 1995 \\
\hline Western Switzerland & 45 & 28 & 27 & Neet 1995 \\
\hline Kazakstan, USSR $^{\mathrm{a}}$ & \multicolumn{2}{|c|}{63} & 37 & Pfeffer 1960 \\
\hline Monterey County, CA, USA ${ }^{\mathrm{a}}$ & 68.4 & 16.3 & 15.3 & Pine and Gerdes 1973 \\
\hline $\begin{array}{l}\text { Kosciusko National Park, New } \\
\text { South Wales, Australia }\end{array}$ & 73.2 & 10.8 & 16 & Saunders 1988 \\
\hline Cumberland Island, GA, USA ${ }^{a}$ & 62 & 26 & 13 & Singer and Stoneburner 1979 \\
\hline
\end{tabular}

${ }^{a}$ Percentages calculated from reference.

Table 3. Composition of a theoretical population of 1,000 wild pigs on the Savannah River Site, South Carolina. Numbers are broken down by age class, sex and percentage within each sex and the total population.

\begin{tabular}{ccccccc}
\hline $\begin{array}{c}\text { Age Class } \\
\text { (in years) }\end{array}$ & $\begin{array}{c}\text { Number of } \\
\text { Females }\end{array}$ & $\begin{array}{c}\text { Percent of } \\
\text { Total } \\
\text { Females }\end{array}$ & $\begin{array}{c}\text { Percent of } \\
\text { Total } \\
\text { Population }\end{array}$ & $\begin{array}{c}\text { Number of } \\
\text { Males }\end{array}$ & $\begin{array}{c}\text { Percent of } \\
\text { Total Males }\end{array}$ & $\begin{array}{c}\text { Percent of } \\
\text { Total } \\
\text { Population }\end{array}$ \\
\hline $0-1$ & 300 & 56.5 & 30.0 & 273 & 58.2 & 27.3 \\
$1-2$ & 86 & 16.2 & 8.6 & 75 & 16.0 & 7.5 \\
$2-3$ & 59 & 11.1 & 5.9 & 51 & 10.9 & 5.1 \\
$3-4$ & 40 & 7.5 & 4.0 & 33 & 7.0 & 3.3 \\
$4-5$ & 23 & 4.3 & 2.3 & 18 & 3.8 & 1.8 \\
$5-6$ & 13 & 2.4 & 1.3 & 11 & 2.3 & 1.1 \\
$>6$ & 10 & 1.9 & 1.0 & 8 & 1.7 & 0.8 \\
All Ages & 531 & 100.0 & 53.1 & 469 & 100.0 & 46.9 \\
\hline
\end{tabular}




\section{Wild Pigs}

Table 4. Listing of density estimates reported for various wild pig populations.

\begin{tabular}{|c|c|c|}
\hline Location & $\begin{array}{c}\text { Density } \\
\text { (in wild pigs per } \mathrm{km}^{2} \text { ) }\end{array}$ & Reference \\
\hline Hawaii Volcanoes National Park, HI, USA & $0.7-6.5$ & Anderson and Stone 1994 \\
\hline Haleakala National Park, HI, USA & $1.3-1.8$ & Anderson and Stone 1994 \\
\hline $\begin{array}{c}\text { 'Ola’a Unit, Hawaii Volcanoes National } \\
\text { Park, HI, USA }\end{array}$ & $4.8-5.1$ & Anderson and Stone 1994 \\
\hline $\begin{array}{c}\text { Puhimau Unit, Hawaii Volcanoes National } \\
\text { Park, HI, USA }\end{array}$ & 6.5 & Anderson and Stone 1994 \\
\hline $\begin{array}{c}\text { Kipuka Kulalio Unit, Hawaii Volcanoes } \\
\text { National Park, HI, USA }\end{array}$ & 5 & Anderson and Stone 1994 \\
\hline Kampinoski National Park, Poland & 10 & $\begin{array}{c}\text { Andrzejewski and Jezierski } \\
1978\end{array}$ \\
\hline Santa Catalina Island, CA, USA & $21-34$ & Baber and Coblentz 1986 \\
\hline Galapagos Islands, Ecuador & $25-30$ & Baber and Coblentz 1986 \\
\hline Dye Creek Ranch, CA, USA & $5-8$ & Barrett 1978 \\
\hline Gir Forest, Gujarat, India & 0.08 & Berwick and Jordan 1971 \\
\hline $\begin{array}{l}\text { Douglas-Daly District, Northern Territory, } \\
\text { Australia }\end{array}$ & $0.8-3.5$ & Caley 1993 \\
\hline Southwestern Queensland, Australia & 0.09 & Cowled et al. 2006 \\
\hline Southwestern Queensland, Australia & 0.1 & Cowled et al. 2006 \\
\hline Mt. Meiron Region, Israel & 3.2 & Cnaani 1972 \\
\hline Savannah River Plant, SC, USA & 1.4 & Crouch 1983 \\
\hline Camargue National Reserve, France & $0.6-2.9$ & Dardaillon 1986 \\
\hline Aurukun, Queensland, Australia & $1-20$ & Dexter 1990 \\
\hline $\begin{array}{l}\text { Nocoleche Nature Reserve, New South } \\
\text { Wales, Australia }\end{array}$ & $0.2-1.5$ & Dexter 1995 \\
\hline Paroo River, New South Wales, Australia & $0.2-1.2$ & Dexter 1995 \\
\hline $\begin{array}{c}\text { Royal Karnali-Bardia Wildlife Reserve, } \\
\text { Nepal }\end{array}$ & $3.8-4.2$ & Dinerstein 1980 \\
\hline Dindings District, Perak, Malaysia & 0.8 & Diong 1973 \\
\hline Kipahulu Valley, Maui, HI, USA & $22-52$ & Diong 1982 \\
\hline Wilpattu National Park, Sri Lanka & $0.3-1.2$ & Eisenberg and Lockhart 1972 \\
\hline Eastern U.S.S.R. & $0.1-0.2$ & Fadeyev 1973 \\
\hline Poland & $1.8-2.0$ & Fruzinski 1992 \\
\hline Chaparral WMA, TX, USA & 5.5 & Gabor et al. 2001 \\
\hline Monfrague Natural Park, Spain & 3.1 & Garzon-Heydt 1992 \\
\hline Hawaii, HI, USA & $32-58$ & Giffin 1974 \\
\hline Warren, New South Wales, Australia & $8.0-17.5$ & Giles 1980 \\
\hline Yantabulla, New South Wales, Australia & $0.2-0.8$ & Giles 1980 \\
\hline $\begin{array}{c}\text { Fort Benning Military Reservation, GA, } \\
\text { USA }\end{array}$ & 4.0 & Hanson 2006 \\
\hline Lower Coastal Plain, FL and GA, USA & 3.9 & Hanson and Karstad 1959 \\
\hline $\begin{array}{c}\text { Fort Stewart Military Reservation, GA, } \\
\text { USA }\end{array}$ & 29-39 & Hanson and Karstad 1959 \\
\hline Canton of Geneva, Switzerland & $10.0-10.6$ & Hebeisen et al. 2008 \\
\hline $\begin{array}{l}\text { Hakalau Forest National Wildlife Refuge, } \\
\text { Island of Hawai'I, HI, USA }\end{array}$ & 12.1 & Hess et al. 2006 \\
\hline
\end{tabular}


Table 4. Listing of density estimates reported for various wild pig populations. (Continued)

\begin{tabular}{|c|c|c|}
\hline Location & $\begin{array}{l}\text { Density } \\
\text { (in wild pigs per } \mathrm{km}^{2} \text { ) }\end{array}$ & Reference \\
\hline $\begin{array}{c}\text { Adelaide River, Northern Territory, } \\
\text { Australia }\end{array}$ & $1.2-10.9$ & Hone 1990a \\
\hline Mary River, Northern Territory, Australia & 6.1 & Hone $1990 b$ \\
\hline $\begin{array}{c}\text { Namadgi National Park, Australian Capital } \\
\text { Territory, Australia }\end{array}$ & 1.7 & Hone 2002 \\
\hline Udjung Kulon National Park, Java & 7.7 & Hoogerwerf 1970 \\
\hline Pasoh Forest Reserve, Malaysia & $27-47$ & Ickes 2001 \\
\hline Welder Wildlife Refuge, TX, USA & 9.5 & Ilse and Hellgren 1995 \\
\hline Changa Manga Forest, Pakistan & 10.4 & Inayatullah 1973 \\
\hline $\begin{array}{c}\text { Central mountain region of Stiavnica, } \\
\text { Czechoslovakia }\end{array}$ & 3.1 & Janda 1958 \\
\hline Arc en Barrois, France & 10 & Janeau and Spitz 1990 \\
\hline Carmargue, France & 1 & Janeau and Spitz 1990 \\
\hline Dhuits, France & 8 & Janeau and Spitz 1990 \\
\hline Gresigne, France & 2 & Janeau and Spitz 1990 \\
\hline Herault, France & 7 & Janeau and Spitz 1990 \\
\hline Lauragais, France & 0.1 & Janeau and Spitz 1990 \\
\hline Petite Pierre, France & 5 & Janeau and Spitz 1990 \\
\hline Bialowieza Primeval Forest, Poland & $3.5-11.9$ & Jedrzejewski et al. 1994 \\
\hline Savannah River Plant, SC, USA & $1.2-4.2$ & Jenkins and Provost 1964 \\
\hline Nagarahole National Park, India & 4.2 & Karanth and Sunquist 1992 \\
\hline Sarigan Island, Mariana Islands & 0.4 & Kessler 2002 \\
\hline Gir Forest, Gujarat, India & $<1.0$ & Khan et al. 1996 \\
\hline Savannah River Plant, SC, USA & 1.2 & Kight 1962 \\
\hline $\begin{array}{c}\text { Bialowieza Primeval Forest, Urodzaj SSR, } \\
\text { USSR }\end{array}$ & $1.2-1.9$ & Kozlo 1970 \\
\hline Savannah River Plant, SC, USA & 5.9 & Kurz and Marchinton 1972 \\
\hline Noorama area, Queensland, Australia & 0.1 & Lapidge et al. 2004 \\
\hline Collier and Hendry Counties, FL, USA & $0.4-27$ & Law Environmental 1988 \\
\hline Germany & 5.6 & Leopold 1936 \\
\hline Poland (three regions) & $1.2-1.8$ & Mackin 1970 \\
\hline Maremma Natural Park, Italy & $5.1-6.1$ & Massei and Tonini 1992 \\
\hline $\begin{array}{c}\text { Bahía Samborombón Conservation Area, } \\
\text { Argentina }\end{array}$ & 1.7 & Merino and Carpinetti 2003 \\
\hline Western Australia, Australia & $1-4$ & Masters 1979 \\
\hline Savannah River Site, SC, USA & 1.0 & Mayer 2005 \\
\hline Aurukun, Queensland, Australia & $1-40$ & McGaw and Mitchell 1998 \\
\hline Lilyvale, Queensland, Australia & 4.2 & McGaw and Mitchell 1998 \\
\hline Mt. Harte, New Zealand & $12.5-43$ & McIlroy 1989 \\
\hline Gal Oya National Park, Sri Lanka & 0.6 & McKay 1973 \\
\hline $\begin{array}{c}\text { Namadgi National Park, Australian Capital } \\
\text { Territory, Australia }\end{array}$ & 1.8 & McIlroy et al. 1989 \\
\hline $\begin{array}{l}\text { Lakefield National Park, Queensland, } \\
\text { Australia }\end{array}$ & 4 & Mitchell 1998 \\
\hline Northeastern Queensland, Australia & 2 & Mitchell 1999 \\
\hline Hawaii, HI, USA & 48.0 & Nichols 1962 \\
\hline
\end{tabular}




\section{Wild Pigs}

Table 4. Listing of density estimates reported for various wild pig populations. (Continued)

\begin{tabular}{|c|c|c|}
\hline Location & $\begin{array}{l}\text { Density } \\
\text { (in wild pigs per } \mathrm{km}^{2} \text { ) }\end{array}$ & Reference \\
\hline Germany & $0.04-7.7$ & Oloff 1951 \\
\hline Dye Creek Ranch, CA, USA & 5.0 & Patten 1974 \\
\hline Udjung Kulon National Park, Java & $27-32$ & Pauwels 1980 \\
\hline Girilambone, New South Wales, Australia & 5.0 & Pavlov 1980 \\
\hline $\begin{array}{c}\text { Namadgi National Park, Australian Capital } \\
\text { Territory, Australia }\end{array}$ & 1.4 & Pech and McIlroy 1990 \\
\hline Monterey County, CA, USA & $0.5-0.8$ & Pine and Gerdes 1973 \\
\hline Dulów, Poland & 1.6 & Pucek et al. 1975 \\
\hline Józefów, Poland & 0.1 & Pucek et al. 1975 \\
\hline Pszczyna, Poland & 1.6 & Pucek et al. 1975 \\
\hline Augustów, Poland & 0.9 & Pucek et al. 1975 \\
\hline Smolniki, Poland & 2.4 & Pucek et al. 1975 \\
\hline Zielonka, Poland & 2.0 & Pucek et al. 1975 \\
\hline Kapaiga, Northern Territory, Australia & $<1$ & Ridpath 1991 \\
\hline Armenia, Azerbajdzhanskoj SSR, USSR & 6.9 & Safarov 1960 \\
\hline Ruhuna National Park, Sri Lanka & 0.7 & $\begin{array}{l}\text { Santiapillai and Chambers } \\
\qquad 1980\end{array}$ \\
\hline $\begin{array}{c}\text { Macquarie Marshes, New South Wales, } \\
\text { Australia }\end{array}$ & 10.3 & Saunders and Bryant 1988 \\
\hline $\begin{array}{c}\text { Kosciusko National Park, New South } \\
\text { Wales, Australia }\end{array}$ & 1.6 & Saunders and Giles 1995 \\
\hline Oxley Station, New South Wales, Australia & 10 & Saunders and Giles 1995 \\
\hline Oxley Station, New South Wales, Australia & 10 & Saunders and Giles 1995 \\
\hline $\begin{array}{c}\text { Sunny Corner, New South Wales, } \\
\text { Australia }\end{array}$ & 2 & Saunders and Kay 1990 \\
\hline Kanha National Park, India & 1.2 & Schaller 1967 \\
\hline Grant Park, Santa Clara County, CA, USA & 3.6 & Schauss 1980 \\
\hline Royal Chitwan National Park, Nepal & 5.8 & Seidensticker 1976 \\
\hline Punjab, Pakistan & $32-72$ & Shafi and Khokhar 1986 \\
\hline $\begin{array}{l}\text { Great Smoky Mountains National Park, } \\
\text { NC and TN, USA }\end{array}$ & $7.6-9.2$ & Singer 1981 \\
\hline Cumberland Island, GA, USA & $3.1-4.6$ & Singer and Stoneburner 1979 \\
\hline Thatta, Pakistan & 3.7 & Smiet et al. 1979 \\
\hline Kaziranga Wildlife Sanctuary, Assam & $1.3-1.5$ & Spillett 1967a \\
\hline Jaldapara Wildlife Sanctuary, India & $1.2-1.4$ & Spillett $1967 b$ \\
\hline Keoladeo Ghana Sanctuary, India & 2.9 & Spillett $1967 \mathrm{c}$ \\
\hline Europe & $<5$ & Spitz 1986 \\
\hline Gresigne Region, France & $<3$ & Spitz et al. 1984 \\
\hline $\begin{array}{c}\text { Huai Kha Khaeng Wildlife Sanctuary, } \\
\text { Thailand }\end{array}$ & $<0.5$ & Srikosamatara 1993 \\
\hline Flinders Island, Tasmania, Australia & $0.5-3.0$ & Statham and Middleton 1987 \\
\hline Santa Cruz Island, CA, USA & $14.4-23.9$ & Sterner 1990 \\
\hline $\begin{array}{c}\text { Hawaii Volcanoes and Haleakala National } \\
\text { Parks, HI, USA }\end{array}$ & $1-30$ & Stone 1985 \\
\hline Savannah River Plant, SC, USA & $3.8-5.0$ & Sweeney 1970 \\
\hline Lake Sonoma, CA, USA & $0.4-2.4$ & Sweitzer et al. 2000 \\
\hline
\end{tabular}


Table 4. Listing of density estimates reported for various wild pig populations. (Continued)

\begin{tabular}{ccc}
\hline Location & $\begin{array}{c}\text { Density } \\
\text { (in wild pigs per km }{ }^{2} \text { ) }\end{array}$ & Reference \\
\hline Bradford Ranch, CA, USA & & \\
USA & $0.5-1.7$ & Sweitzer et al. 2000 \\
Sweitzer et al. 2000 & \\
Austin Creek State Recreation Area, CA, & $0.9-3.0$ & Sweitzer et al. 2000 \\
Ranch San Carlos, CA, USA & & Sweitzer et al. 2000 \\
Chimney Rock Ranch, CA, USA & $0.7-2.2$ & Sweitzer et al. 2000 \\
Henry Coe State Park, CA, USA & 0.8 & Sweitzer et al. 2000 \\
Salt Lake Ranch, CA, USA & $2.4-5.6$ & Tate 1984 \\
Great Smoky Mountains National Park, & $1.2-3.0$ & Thomson 1922 \\
NC and TN, USA & $2-9$ & Vtorov 1993 \\
New Zealand & & Welander 1995 \\
Wilson 2005 \\
Hawaii Volcanoes National Park, HI, USA & 25.0 & Wilson et al. 1987 \\
Tullgarn Nature Reserve, Sweden & 20 & Wodzicki 1950 \\
Dorset, England, United Kingdom & $5-10$ & \\
Goondiwindi, Queensland, Australia & 1.1 & $0.1-3.9$ \\
New Zealand & $35-115$ & \\
\end{tabular}

Table 5. Life table for a hypothetical wild pig population. Based on composite data from Barrett (1978), Ashby and Santiapillai (1991), J. J. Mayer, unpubl. data, Jezierski (1977), Henry and Conley (1978), Saunders (1988), Diong (1982), Boitani et al. (1995), and Moretti (1995). The statistics included are as follows: $x$ - age (in years); $n_{x}$ - census size; $l_{x}$ - survival; $d_{x}$ - mortality; $q_{x}-$ proportionate mortality rate; $L_{x}$ - midpoint survivorship; $T_{x}$ - total number of age categories left to be lived by all individuals who survive to the beginning of age category; and $e_{x}$ - life expectancy (in years).

\begin{tabular}{cccccccc}
\hline$x$ & $n_{x}$ & $l_{x}$ & $d_{x}$ & $q_{x}$ & $L_{x}$ & $T_{x}$ & $e_{x}$ \\
\hline 0 & 1,000 & 1.000 & 709 & 70.9 & 0.646 & 1.177 & 1.18 \\
1 & 291 & 0.291 & 122 & 41.9 & 0.230 & 0.532 & 1.83 \\
2 & 169 & 0.169 & 69 & 40.8 & 0.135 & 0.302 & 1.78 \\
3 & 100 & 0.100 & 46 & 46.0 & 0.077 & 0.167 & 1.67 \\
4 & 54 & 0.054 & 22 & 40.7 & 0.043 & 0.090 & 1.67 \\
5 & 32 & 0.032 & 16 & 50.0 & 0.024 & 0.047 & 1.47 \\
6 & 16 & 0.016 & 8 & 50.0 & 0.012 & 0.023 & 1.44 \\
7 & 8 & 0.008 & 4 & 50.0 & 0.006 & 0.011 & 1.37 \\
8 & 4 & 0.004 & 2 & 50.0 & 0.003 & 0.005 & 1.25 \\
9 & 2 & 0.002 & 1 & 50.0 & 0.002 & 0.002 & 1.00 \\
10 & 1 & 0.001 & 1 & 100.0 & 0.001 & 0.000 & 0.50 \\
\end{tabular}




\section{Wild Pigs}

Table 6. Mean life expectancy (i.e., lifespan) estimates reported for wild pig populations.

\begin{tabular}{|c|c|c|c|c|}
\hline \multirow{2}{*}{ Location } & \multicolumn{3}{|c|}{ Mean Lifespan (in months) } & \multirow{2}{*}{ Reference } \\
\hline & Female & Male & Both & \\
\hline Dye Creek Ranch, CA, USA & - & - & 10 & Barrett's 1978 \\
\hline Kipahulu Valley, Maui, HI, USA & - & - & 19.1 & Diong 1982 \\
\hline Doñana National Park, Spain & - & - & 21.6 & Fernandez-Llario 1996 \\
\hline Las Villuercas, Spain & $21.2^{\mathrm{a}}$ & $21.4^{\mathrm{a}}$ & $21.4^{\mathrm{a}}$ & $\begin{array}{l}\text { Fernandez-Llario and } \\
\text { Mateos-Quesada } 2003\end{array}$ \\
\hline Monfrague, Spain & $25.7^{\mathrm{a}}$ & $24.6^{\mathrm{a}}$ & $25.3^{\mathrm{a}}$ & $\begin{array}{l}\text { Fernandez-Llario and } \\
\text { Mateos-Quesada } 2003\end{array}$ \\
\hline Poland & $19.2^{\mathrm{a}}$ & $15.6^{\mathrm{a}}$ & $18^{\mathrm{a}}$ & Fruzinski 1992 \\
\hline Monfrague Natural Park, Spain & 24.9 & 21.9 & 22.8 & Garzon-Heydt 1992 \\
\hline $\begin{array}{c}\text { Fort Benning Military Reservation, } \\
\text { GA, USA }\end{array}$ & 10.4 & - & 8.8 & Hanson 2006 \\
\hline $\begin{array}{c}\text { Tellico Wildlife Management Area, } \\
\text { TN, USA }\end{array}$ & $18.2^{\mathrm{a}}$ & $16.6^{\mathrm{a}}$ & $17.5^{\mathrm{a}}$ & Henry and Conley 1978 \\
\hline Savannah River Site, SC, USA & 19.9 & 19.2 & 19.6 & $\begin{array}{l}\text { J. J. Mayer, unpubl. } \\
\text { data }\end{array}$ \\
\hline Kampinos National Park, Poland & 25 & 21 & 23 & Jezierski 1977 \\
\hline Noorama area, Queensland, Australia & - & - & 9 & Lapidge et al. 2004 \\
\hline
\end{tabular}


Table 7. Comparison of mean fetal litter size among the female age classes in wild pigs.

\begin{tabular}{|c|c|c|c|c|}
\hline \multirow{2}{*}{ Location } & \multicolumn{3}{|c|}{$\begin{array}{l}\text { Mean Fetal Litter Size per } \\
\text { Sow's Age Grouping }\end{array}$} & \multirow{2}{*}{ Reference } \\
\hline & $0-1 \mathrm{yr}$ & $1-2 \mathrm{yr}$ & $>2 \mathrm{yr}$ & \\
\hline Central Punjab, Pakistan & 4.9 & 4.7 & $6.7-7.1$ & Ahmad et al. 1995 \\
\hline East Germany & 3.7 & 5.6 & 6.8 & Ahrens 1984 \\
\hline Canton du Jura, Switzerland & 4.7 & 6.1 & 7.3 & Baettig 1985 \\
\hline East Germany & $3.2-4.6$ & $4.5-6.7$ & $6.2-6.8$ & Briedermann 1971 \\
\hline Savannah River Site, SC, USA & 4.9 & 5.4 & $6.0-6.9$ & $\begin{array}{l}\text { Comer and Mayer (this } \\
\text { volume) }\end{array}$ \\
\hline $\begin{array}{c}\text { Mohammad Reza Shah National Park, } \\
\text { Iran }\end{array}$ & 4.2 & 5.6 & 6.5 & De Vos and Sassani 1977 \\
\hline Perak and Johore, Malaysia & - & 3.5 & 4.0 & Diong 1973 \\
\hline Kipahulu Valley, Maui, HI, USA & 3.5 & 5.8 & $4.7-6.8$ & Diong 1982 \\
\hline Portugal & 3.2 & 3.6 & 4.5 & Fonseca et al. 2004 \\
\hline Western Poland & 3.9 & 4.3 & 6.3 & Fruzinski 1995 \\
\hline Southeastern Niedersachsen, Germany & 5.2 & 6.7 & 7.6 & Gethöffer 2005 \\
\hline $\begin{array}{l}\text { Western Eifel, Rheinland-Pfalz, } \\
\text { Germany }\end{array}$ & $4.4-4.6$ & $4.6-6.1$ & $6.4-6.9$ & Gethöffer 2005 \\
\hline $\begin{array}{l}\text { Pfälzerwald, Rheinland-Pfalz, } \\
\text { Germany }\end{array}$ & 4.5 & $5.0-5.3$ & $5.7-7.5$ & Gethöffer 2005 \\
\hline $\begin{array}{c}\text { Yantabulla, New South Wales, } \\
\text { Australia }\end{array}$ & 4.8 & 5.9 & $6.3-7.6$ & Giles 1980 \\
\hline Warren, New South Wales, Australia & 4.7 & 5.9 & $6.6-8.1$ & Giles 1980 \\
\hline Moree, New South Wales, Australia & 6.0 & 4.6 & $5.5-7.0$ & Giles 1980 \\
\hline $\begin{array}{c}\text { Tablelands, New South Wales, } \\
\text { Australia }\end{array}$ & 4.7 & 5.7 & $6.0-8.6$ & Giles 1980 \\
\hline $\begin{array}{l}\text { Hakalau Forest National Wildlife } \\
\text { Refuge, Island of Hawai'I, HI, USA }\end{array}$ & 5.3 & 6.6 & 7.0 & Hess et al. 2006 \\
\hline Ticino, Switzerland & 3.8 & 5.4 & 5.7 & Moretti 1995 \\
\hline East Germany & 4.4 & 5.7 & 6.5 & Stubbe and Stubbe 1977 \\
\hline Western South Texas Plains, TX, USA & 4.8 & 4.4 & 6.3 & Taylor et al. 1998 \\
\hline Gulf Coast Prairies, TX, USA & 5.0 & 4.7 & 5.6 & Taylor et al. 1998 \\
\hline
\end{tabular}




\section{Wild Pigs}

Table 8. Comparison of percent of pregnant sows among the female age classes in wild pigs.

\begin{tabular}{|c|c|c|c|c|}
\hline \multirow{2}{*}{ Location } & \multicolumn{3}{|c|}{$\begin{array}{l}\text { Percent of Pregnant Sows } \\
\text { within Each Age Grouping }\end{array}$} & \multirow{2}{*}{ Reference } \\
\hline & $0-1 \mathrm{yr}$ & $1-2 \mathrm{yr}$ & $>2 \mathrm{yr}$ & \\
\hline Central Punjab, Pakistan & 24.1 & 28.0 & $43.3^{\mathrm{a}}$ & Ahmad et al. 1995 \\
\hline Perak and Johore, Malaysia & - & $47.0^{\mathrm{a}}$ & $44.7^{\mathrm{a}}$ & Diong 1973 \\
\hline Southeastern Niedersachsen, Germany & 35.0 & 15.8 & 49.2 & Gethöffer 2005 \\
\hline $\begin{array}{l}\text { Western Eifel, Rheinland-Pfalz, } \\
\text { Germany }\end{array}$ & 36.6 & 13.1 & 50.3 & Gethöffer 2005 \\
\hline $\begin{array}{c}\text { Yantabulla, New South Wales, } \\
\text { Australia }\end{array}$ & $20.0^{\mathrm{a}}$ & $77.7^{\mathrm{a}}$ & $76.3^{\mathrm{a}}$ & Giles 1980 \\
\hline Warren and Moree, NSW, Australia & $31.4^{\mathrm{a}}$ & $81.0^{\mathrm{a}}$ & $72.3^{\mathrm{a}}$ & Giles 1980 \\
\hline Hakalau Forest National Wildlife & $6.8^{\mathrm{a}}$ & $22.2^{\mathrm{a}}$ & $38.1^{\mathrm{a}}$ & Hess et al. 2006 \\
\hline \multicolumn{5}{|l|}{ Refuge, Island of Hawai'I, HI, USA } \\
\hline Savannah River Site, SC, USA & 10.0 & 28.7 & 39.3 & J. J. Mayer, unpubl. data \\
\hline Ticino, Switzerland & 63.0 & 100.0 & 100.0 & Moretti 1995 \\
\hline $\begin{array}{c}\text { Great Smoky Mountains National } \\
\text { Park, NC and TN, USA }\end{array}$ & - & $14.3^{\mathrm{a}}$ & $15.4^{\mathrm{a}}$ & Singer et al. 1978 \\
\hline Western South Texas Plains, TX, USA & 12.0 & 21.2 & 37.9 & Taylor et al. 1998 \\
\hline Gulf Coast Prairies, TX, USA & $7.1^{\mathrm{a}}$ & $50.0^{\mathrm{a}}$ & $78.3^{\mathrm{a}}$ & Taylor et al. 1998 \\
\hline
\end{tabular}

${ }^{\mathrm{a}}$ Calculated from reference. 
Table 9. Listing of natural and manmade mortality causes for wild pigs and the percentage or component of the population impacted. The list is separated into natural and manmade causes.

\begin{tabular}{|c|c|c|c|}
\hline \multirow{2}{*}{ Mortality Cause } & \multicolumn{2}{|c|}{ Impacted by Mortality } & \multirow{2}{*}{ Reference } \\
\hline & Percent of Population & Component of Population & \\
\hline \multicolumn{4}{|c|}{ Natural Causes } \\
\hline Accidents/Injuries & $1-14^{\mathrm{ab}}$ & $\begin{array}{l}\text { Both sexes and all age } \\
\text { classes; most important } \\
\text { cause of piglet mortality }\end{array}$ & $\begin{array}{c}\text { Conley et al. } 1972 \text {, } \\
\text { Barrett } 1978\end{array}$ \\
\hline Starvation & $1-66$ & $\begin{array}{l}\text { Both sexes and all age } \\
\text { classes; mostly younger } \\
\text { animals }\end{array}$ & $\begin{array}{c}\text { Cabon 1958, Jezierski } \\
\text { 1977, Barrett } 1978\end{array}$ \\
\hline Predation & $2-16^{\mathrm{c}}$ & $\begin{array}{l}\text { Both sexes and all age } \\
\text { classes; mostly younger } \\
\text { animals }\end{array}$ & $\begin{array}{c}\text { Jedrzejewska et al. 1994, } \\
\text { Jdrzejewski et al. 2000, } \\
\text { Okarma 1995, Sweeney } \\
\text { et al. } 2003\end{array}$ \\
\hline Parasites & $<1$ & $\begin{array}{c}\text { Both sexes and all age } \\
\text { classes }\end{array}$ & $\begin{array}{c}\text { Barrett 1978, Diong } \\
1982\end{array}$ \\
\hline Diseases & $1-9^{\mathrm{ab}}$ & $\begin{array}{c}\text { Both sexes and all age } \\
\text { classes; mostly young and } \\
\text { very old animals }\end{array}$ & Conley et al. 1972 \\
\hline Tooth Deterioration & $1-4^{b}$ & $\begin{array}{l}\text { Both sexes; most } \\
\text { important cause of death } \\
\text { from old age }\end{array}$ & Barrett 1978 \\
\hline \multicolumn{4}{|c|}{ Manmade Causes } \\
\hline $\begin{array}{l}\text { Recreational } \\
\text { Hunting }\end{array}$ & $2-40$ & $\begin{array}{l}\text { Both sexes and all age } \\
\text { classes; mostly younger } \\
\text { animals }\end{array}$ & $\begin{array}{l}\text { Ueckermann 1972, De } \\
\text { Vos and Sassani 1977, } \\
\text { Spitz et al. 1984, J. J. } \\
\text { Mayer, unpubl. data }\end{array}$ \\
\hline Vehicle Collisions & $0.1-5$ & $\begin{array}{l}\text { Both sexes and all age } \\
\text { classes; mostly yearlings, } \\
\text { subadults and adults }\end{array}$ & Mayer and Johns 2007 \\
\hline
\end{tabular}

\footnotetext{
${ }^{\mathrm{a}}$ Based on data from captive animals

${ }^{\mathrm{b}}$ Based on approximate percentage of population comprised by impacted animals

${ }^{\mathrm{c}}$ Calculated from reference
} 


\section{Wild Pigs}

Table 10. Listing of the mean annual rates of spread or range expansion for wild pigs from several locations. These rates are given as either distance or area.

\begin{tabular}{|c|c|c|c|}
\hline \multirow{2}{*}{ Location } & \multicolumn{2}{|c|}{$\begin{array}{l}\text { Mean Rate of Spread or } \\
\text { Range Expansion }\end{array}$} & \multirow{2}{*}{ Reference } \\
\hline & $\begin{array}{l}\text { Distance } \\
\text { (in } \mathrm{km} / \mathrm{yr} \text { ) }\end{array}$ & $\begin{array}{c}\text { Area } \\
\text { (in } \mathrm{km}^{2} / \mathrm{yr} \text { ) }\end{array}$ & \\
\hline Dye Creek Ranch, CA, USA & - & $5-8$ & Barrett 1978 \\
\hline Auckland Island, New Zealand & 0.67 & - & Challies 1975 \\
\hline Northern Territory, Australia & 2 & - & Choquenot et al. 1996 \\
\hline Kipahulu Valley, Maui, HI, USA & $0.45-0.76$ & - & Diong 1982 \\
\hline Eastern Fennoscandia, Finland & 50 & - & Erkinaro et al. 1982 \\
\hline $\begin{array}{c}\text { Namadgi National Park, Australian } \\
\text { Capital Territory, Australia }\end{array}$ & 4 & - & Hone and Stone 1989 \\
\hline Baltic Region, USSR & $4-5$ & - & Ling 1955 \\
\hline Savannah River Site, SC, USA & - & 4.5 & J. J. Mayer, unpubl. data \\
\hline $\begin{array}{c}\text { Great Smoky Mountains National Park, } \\
\text { NC and TN, USA }\end{array}$ & $1.8-8.0$ & - & Singer 1976 \\
\hline $\begin{array}{c}\text { Great Smoky Mountains National Park, } \\
\text { NC and TN, USA }\end{array}$ & 2.75 & - & Singer 1981 \\
\hline Monterey County, CA, USA & $8.4^{\mathrm{a}}$ & - & $\begin{array}{l}\text { von Bloeker 1938, Mayer } \\
\text { and Brisbin } 1991\end{array}$ \\
\hline
\end{tabular}

${ }^{\mathrm{a}}$ Calculated from reference. 


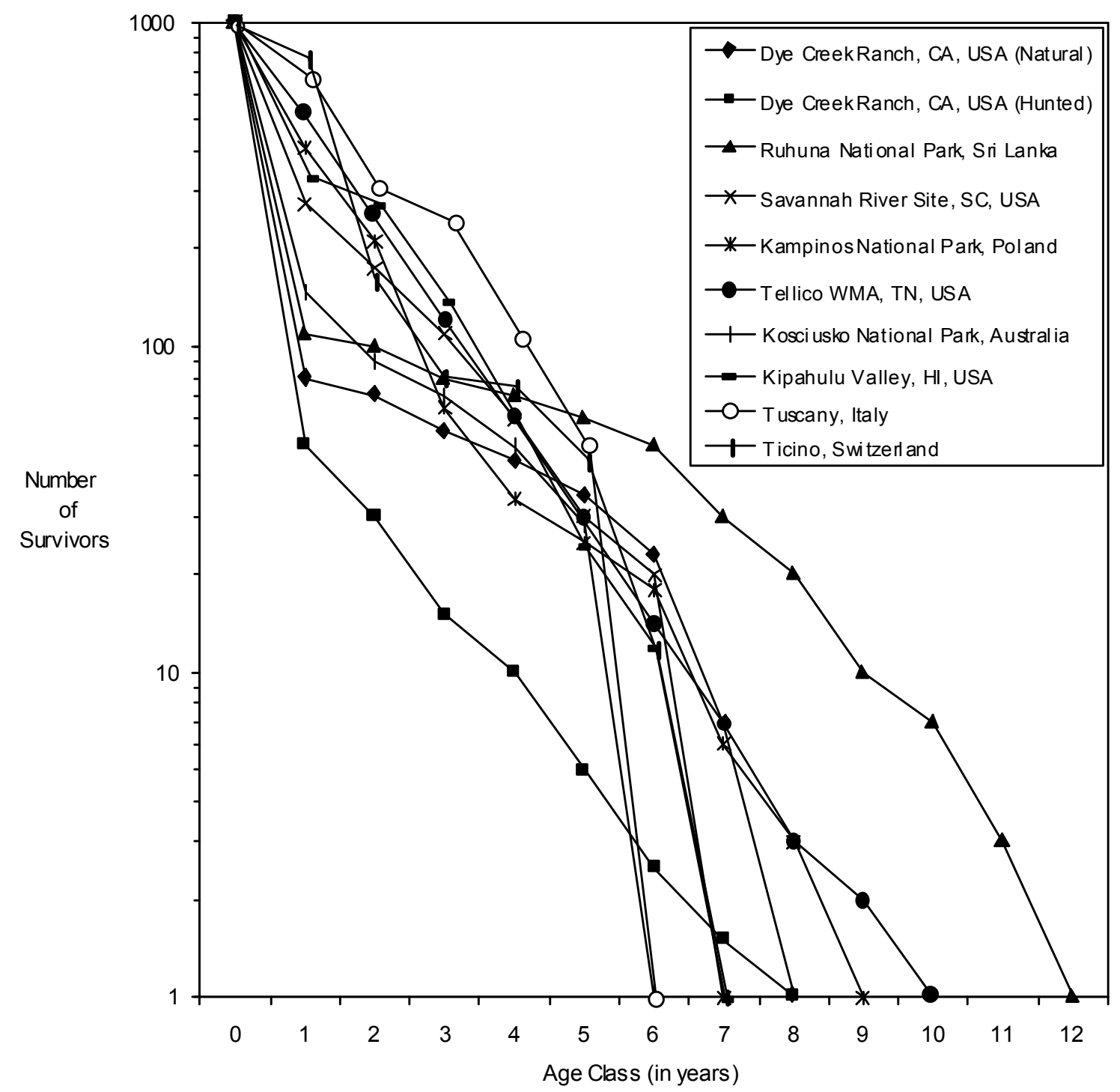

Fig. 1. Comparison of survival curves from ten wild pig populations. Survival curves were taken or calculated from the following sources: Dye Creek Ranch (Natural and Hunted)- Barrett (1978); Ruhuna National Park - Ashby and Santiapillai (1991); Savannah River Site - J. J. Mayer, unpubl. data; Kampinos National Park - Jezierski (1977); Tellico WMA - Henry and Conley (1978); Kosciusko National Park - Saunders (1988), Kipahulu Valley - Diong (1982), Tuscany - Boitani et al. (1995), and Ticino - Moretti (1995). 


\section{Wild Pigs}

\section{Literature Cited}

Ahmad, E., J. E. Brooks, I. Hussain, and M. H. Khan. 1995. Reproduction in Eurasian wild boar in central Punjab, Pakistan. Acta Theriologica, 40(2):163-173.

Ahrens, M. 1984. Erganzende Untersuchungen zum Reproduktionsgeschehen beim Schwarzwild. Beitrage zur Jagd- und Wildforschung, 13(8):231-243.

Anderson, S. J., and C. P. Stone. 1994. Indexing sizes of feral pig populations in a variety of Hawaiian natural areas. Transactions of the Western Section of the Wildlife Society, 30:26-39.

Andrzejewski, R., and W. Jezierski. 1978. Management of a wild boar population and its effects on commercial land. Acta Theriologica, 23(19):309-339.

Ashby, K. R., and C. Santiapillai. 1991. Population age structure of the wild pig Sus scrofa in Ruhuna National Park, Sri Lanka. Pp. 533-535. In B. Bobek, K. Perzanowski, and W. L. Regelin (eds.), Global trends in wildlife management. Transactions of the 18th International Congress of Game Biologists, Vol. I., Swiat Press, Krakow-Warsaw, Poland.

Baber, D. W. 1977. Social organization and behavior in the feral hog. M.S. Thesis, Florida Institute of Technology, Melborne, Florida.

Baber, D. W., and B. E. Coblentz. 1986. Density, home range, habitat use and reproduction of feral pigs on Santa Catalina Island. Journal of Mammalogy, 67(3):512-525.

Baettig, M. 1985. Rapporto sulla situazione del cinghiale nel Malcantone nell'anno 1984. Il Cacciatore Ticinese, 9:167-170.

Barrett, R. H. 1971. Ecology of the feral hog in Tehama County, California. Ph.D. Dissertation, University of California, Berkeley, California.

Barrett, R. H. 1978. The feral hog on the Dye Creek Ranch, California. Hilgardia, 46(9):283-355.

Barrett, R. H. 1999. The wild boar population model workbook for Excel97 V.5-30-99. Pp. 42-45. In Proceedings of the feral swine symposium. June 2-3. Texas Animal Health Commission, Fort Worth, Texas.

Barrett, R. H., and G. H. Birmingham. 1994. Wild pigs. Pp. D65-D70. In S. E. Hygnstrom, R. M. Timm, and G. E. Larson (eds.), Prevention and control of wildlife damage. 2 volumes; Great Plains Agricultural Council, Univ. of Nebraska, Lincoln, Nebraska.

Barrett, R. H., B. L. Goatcher, P. J. Gogan, and E. L. Fitzhugh. 1988. Removing feral pigs from Annadel State Park. Transactions of the California-Nevada Section of the Wildlife Society, 24:47-52.

Barrett, R. H., and C. P. Stone. 1993. Hunting as a control method for wild pigs in Hawaii Volcanoes National Park: A report for resource management. Research Division, Hawaii Volcanoes National Park, National Park Service, U. S. Department of the Interior, Hawaii National Park. Hawaii.

Belden, R. C., and W. B. Frankenberger. 1979. Brunswick hog study. Final performance report, P-R Project W-41-R, Study No. XIII-B-1. Florida Fresh Water Fish and Game Commission Wildlife Research Laboratory, Gainesville, Florida.

Belden, R. C., and W. B. Frankenberger. 1989. History and biology of feral swine. Pp. 3-10. In N. Black (ed.), Proceedings: Feral pig symposium. April 27-29, Orlando, Florida. Livestock Conservation Institute, Madison, Wisconsin. 
Belden, R. C., and W. B. Frankenberger. 1990. Biology of a feral hog population in south central Florida. Proceedings of the Annual Conference of the Southeastern Association of Fish \& Wildlife Agencies, 44:231-249.

Belden, R. C., W. B. Frankenberger, and D. H. Austin. 1985. A simulated harvest study of feral hogs in Florida. Final performance report, P-R Project W-41-R, Study No. XIII-FEC. Florida Fresh Water Fish and Game Commission Wildlife Research Laboratory, Gainesville, Florida.

Berwick, S. H., and P. A. Jordan. 1971. First report of the Yale-Bombay Natural History Society studies of wild ungulates at the Gir Forest, Gujarat, India. Journal of the Bombay Natural History Society, 68(2):412-423.

Bieber, C., and T. Ruf. 2005. Population dynamics in wild boar Sus scrofa: Ecology, elasticity of growth rate and implications for the management of pulsed resource consumers. Journal of Applied Ecology, 42(6):1203-1213.

Boitani, L., P. Trapanese, and L. Mattei. 1995. Demographic patterns of a wild boar (Sus scrofa L.) population in Tuscany, Italy. Journal of Mountain Ecology (Ibex), 3:197-201.

Bratton, S. P. 1974. An integrated ecological approach to the management of European wild boar (Sus scrofa) in GRSM. NPS-SER Management Report No. 3. Uplands Field Research Laboratory, Great Smoky Mountains National Park, Gatlinburg, Tennessee.

Briedermann, L. 1986. Schwarzwild. VEB Deutscher Landwirtschaftsverlag, Berlin, Democratic Republic of Germany.

Brown, L. N. 1985. Elimination of a small feral swine population in an urbanizing section of central Florida. Florida Scientist, 48(2):120-123.

Cabon, K. 1958. Das Massensterben von Wildschweinen im Naturstaatspark von Bialowieza im Winter 1955/56. Acta Theriologica, 2(4)71-82.

Cahill, S., and F. Llimona. 2004. Demographics of a wild boar Sus scrofa Linnaeus, 1758 population in a metropolitan park in Barcelona. Galemys, 16(Numero Especial):37-52.

Caley, P. 1993. Population dynamics of feral pigs (Sus scrofa) in a tropical riverine habitat complex. Wildlife Research, 20(5):625-636.

Cargnelutti, B., F. Spitz, and G. Valet. 1992. Analysis of the dispersion of wild boar (Sus scrofa) in southern France. Pp. 423-425. In F. Spitz, G. Janeau, G. Gonzalez, and S. Aulagnier (eds.), Ongules/Ungulates 91: Proceedings of the international symposium. Toulouse, France, September 2-6, 1991, Societe Francaise pour l'Etude et la Protection des Mammiferes, and Toulose: Institut de Recherche sur les Grands Mammiferes, Paris \& Toulouse, France.

Caughley, G. 1978. Analysis of vertebrate populations. John Wiley \& Sons, New York.

Choquenot, D., J. McIlroy, and T. Korn. 1996. Managing vertebrate pests: Feral pigs. Bureau of Rural Sciences, Australian Government Publishing Service, Canberra, Australia.

Clutton-Brock, J. 1981. Domesticated animals from early times. University of Texas Press, Austin, Texas.

Conley, R. H., V. G. Henry, and G. H. Matschke. 1972. Final report for the European hog research project W-34. Tennessee Game and Fish Commission, Nashville, Tennessee. 


\section{Wild Pigs}

Cowled, B. D., J. Aldenhoven, I. O. A. Odeh, T. Garrett, C. Moran, and S. J. Lapidge. 2008. Feral pig population structuring in the rangelands of eastern Australia: Applications for designing adaptive management units. Conservation Genetics, 9:211-224.

Cowled, B. D., S. J. Lapidge, J. O. Hampton, and P. B. S. Spencer. 2006. Measuring the demographic and genetic effects of pest control in a highly persecuted feral pig population. Journal of Wildlife Management, 70(6):1690-1697.

Crouch, L. C. 1983. Movements of and habitat utilization by feral hogs at the Savannah River Plant, South Carolina. M.S. Thesis, Clemson University, Clemson, South Carolina.

Cruz, F., C. J. Donlan, K. Campbell, and V. Carrion. 2005. Conservation action in the Galapagos: Feral pig (Sus scrofa) eradication from Santiago Island. Biological Conservation, 121(3):473-478.

Cvetnic, Z., J. Toncic, S. Spicic, M. Lojkic, S. Terzic, L. Jemersic, A. Humski, S. Curic, M. Mitak, and B. Habrun. 2004. Brucellosis in wild boar (Sus scrofa) in the Republic of Croatia. Veterinarni Medicina, 49(4):115-122.

Dardaillon, M. 1984. Organisation sociale et reproduction chez le sanglier en Camargue. Pp. 159-165. In F. Spitz and D. Pepin (eds.), Symposium International sur le Sanglier. Les Colloques de l'INRA 22, INRA, Toulouse, France.

1986. Seasonal variation in habitat selection and spatial distribution of wild boar (Sus scrofa) in the Camargue, southern France. Behavioural Processes, 13(3):251-268.

de Vos, A., and A. Sassani. 1977. Eine Studie der Population des Schwarzwildes (Sus scrofa) in dem Mohammad Reza Shah Nationalpark [A wild boar (Sus scrofa) population study in Mohammed Reza Shah National Park]. Zeitschrift fur Jagdwissenschaft, 23(3):113-126.

Dearden, B. 1984. Modeling hog populations. Pp. 30-31. In J. Tate (ed.), Techniques for controlling wild hogs in the Great Smoky Mountains National Park. Proceedings of a workshop, November 29-30. Research/Resources Mgmt. Rpt. SRE-72. U. S. Department of the Interior, National Park Service, Southeast Regional Office, Atlanta, Georgia.

DEFRA (Department for Environment, Food and Rural Affairs). 2004. The ecology and management of wild boar in southern England. Central Science Laboratory, Hutton, York, United Kingdom.

Dexter, N. 1990. Population density and management of feral pigs at Aurukun, North Queensland. Report R/11/90. Bureau of Resource Sciences, Canberra, Australia.

1995. The behaviour of feral pigs in north-west New South Wales and its implications for the epidemiology of foot and mouth disease. Ph.D. Dissertation. University of New England, Armidale, Australia.

Dickson, J. G., J. J. Mayer, and J. D. Dickson. 2001. Wild hogs. Pp. 191-192, 201-208. In J. G. Dickson (ed.), Wildlife of Southern forests: Habitat \& management. Hancock House Publishers, Blaine, Washington.

Dinerstein, E. 1980. An ecological survey of Royal Karnali-Bardia wildlife reserve, Nepal, Part III: Ungulate populations. Biological Conservation, 18:5-38.

Diong, C. H. 1973. Studies of the Malaysian wild pig in Perak and Jahore. Malayan Nature Journal, 26(3/4):120-151.

1982. Population biology and management of the feral pig (Sus scrofa L.) in Kipahula Valley, Maui. Ph.D. Dissertation, University of Hawaii, Honolulu, Hawaii. 
Duncan, R. W. 1974. Reproductive biology of the European wild hog (Sus scrofa) in the Great Smoky Mountains National Park. M.S. Thesis, University of Tennessee, Knoxville, Tennessee.

Durio, P., U. Gallo Orsi, E. Macchi, and A. Perrone. 1992. Monthly birth distribution and structure of an Alpine population of wild boar (Sus scrofa) in north-west Italy. Pp. 395-397. In F. Spitz, G. Janeau, G. Gonzalez, and S. Aulagnier (eds.), Ongules/Ungulates 91: Proceedings of the international symposium. Toulouse, France, September 2-6, 1991. Societe Francaise pour l'Etude et la Protection des Mammiferes, and Toulose: Institut de Recherche sur les Grands Mammiferes, Paris \& Toulouse, France.

Dzieciolowski, R. M., and C. M. H. Clarke. 1989. Age structure and sex ratio in a population of harvested feral pigs in New Zealand. Acta Theriologica, 34(38):525-536.

Dzieciolowski, R. M., C. M. H. Clarke, and C. M. Frampton. 1992. Reproductive characteristics of feral pigs in New Zealand. Acta Theriologica, 37(3):259-270.

Eisenberg, J. F., and M. C. Lockhart. 1972. An ecological reconnaissance of Wilpattu National Park, Ceylon. Smithsonian Contributions to Zoology 101:1-118.

Erkinaro, E., K. Heikura, E. Lindgren, E. Pulliainen, and S. Sulkava. 1982. Occurrence and spread of the wild boar (Sus scrofa) in eastern Fennoscandia (in English with Finnish summary). Memoranda Societas Fauna et Flora Fennica, 58(2):39-47.

Fadeyev, E. V. 1973. Dinamika chslennosti kabana (Sus scrofa) v Europeiskoi Rossii. Zoologicheskii Zhurnal, 52(8):1214-1219.

Fernández, N., S. Kramer-Schadt, and H. Thulke. 2006. Viability and risk assessment in species restoration: planning reintroductions for the wild boar, a potential disease reservoir. Ecology and Society, 11(1):1-6.

Fernandez-Llario, P. 1996. Ecologia del jabali en Donana: Parametros reproductivos e impacto ambiental. Ph.D. Dissertation, Universidad de Extremadura, Cacerces, Spain.

Fernandez-Llario, P., and P. Mateos-Quesada. 2003. Population structure of the wild boar (Sus scrofa) in two Mediterranean habitats in the western Iberian Peninsula. Folia Zoologica, 52(2):143-148.

Flower, S. S. 1931. Contributions to our knowledge of the duration of life in vertebrate animals. Proceedings of the Zoological Society of London, 5:145-234.

Fonseca, C., P. Santos, A. Monzon, P. Bento, A. A. Da Silva, J. Alves, A. Silverio, A. M. V. M. Soares and F. Petrucci-Fonseca. 2004. Reproduction in the wild boar (Sus scrofa Linnaeus, 1758) populations of Portugal. Galemys, 16(Special Issue):53-65.

Foreyt, W. J., A. C. Todd, and K. Foreyt. 1975. Fascioloides magna (Bassi, 1875) in feral swine from southern Texas. Journal of Wildlife Diseases, 11(4):554-559.

Fox, J. R., and M. R. Pelton. 1977. An evaluation of control techniques for the European wild hog in the Great Smoky Mountains National Park. Pp. 53-66. In G. W. Wood (ed.), Research and management of wild hog populations. Belle Baruch Forest Science Institute of Clemson University, Georgetown, South Carolina.

Fruzinski, B. 1992. Dzik. Wydawnictwo Cedrus, Warsaw, Poland.

1995. Situation of wild boar populations in western Poland. Journal of Mountain Ecology (Ibex), $3: 186-187$. 


\section{Wild Pigs}

Gabor, T. M., E. C. Hellgren, and N. J. Silvy. 2001. Multi-scale habitat partitioning in sympatric suiforms. Journal of Wildlife Management, 65(1):99-110.

Garzon-Heydt, P. 1992. Study of a population of wild boar Sus scrofa castilianus Thomas, 1912 in Spain, based on hunting data. Pp. 489-492. In B. Bobek, K. Perzanowski, and W. L. Regelin (eds.), Global trends in wildlife management. Transactions of the 18th International Congress of Game Biologists, Vol. II. Swiat Press, Krakow-Warsaw, Poland.

Geisser, H., and H. U. Reyer. 2005. The influence of food and temperature on population density of wild boar Sus scrofa in the Thurgau (Switzerland). Journal of Zoology, 267(1):89-96.

Genov, P. 1981. Die Verbreigtung des Schwarzwildes (Sus scrofa L.) in Eurasiens und seine Ampassung au die Nahrungsverhaltnisse. Zeitschrift für Jagdwissenschaft, 27(4):221-231.

Gethöffer, F. 2005. Reproduktionsparameter und Saisonalitat der Fortpflanzung des Wildschweins (Sus scrofa) in drei Untersuchungsgebieten Deutschlands. DVM, Institut fur Wildtierforschung an der Tierarztlichen Hochschule Hannover, Hannover, Germany.

Giffin, J. G. 1974. Population density of feral pigs in representative rain forests on the Island of Hawaii, Project No. W-15-4, Job No. IV-G (1). Hawaii Division of Fish and Game, Honolulu, Hawaii.

Giles, J. R. 1976. Feral pigs and agriculture. Pp. 125-128. In Agriculture, forestry and wildlife: Conflict or coexistence? Proceedings of a workshop. University of New England, Armidale, Australia.

1980. The ecology of feral pigs in western New South Wales. Ph.D. Dissertation, Sydney University, Sydney, Australia.

1999. The dynamics of feral pig populations in Australia: Implications for management. Pp. 39-42. In C. N. Johnson (ed.), Feral pigs: Pest status and prospects for control. Proceedings of a feral pig workshop. James Cook University, Cairns, March. Research Report No. 13. Cooperative Research Centre for Tropical Rainforest Ecology and Management, Cairns, Australia.

Gipson P. S., B. Hlavachick, and T. Berger. 1998. Range expansion by wild hogs across the central United States. Wildlife Society Bulletin, 26:279-286.

Goulding, M. J. 2003. Wild boar in Britain. Whittet Books, Ltd., Suffolk, United Kingdom.

Goulding, M. J., G. Smith, and S. J. Baker. 1998. Current status and potential impact of wild boar (Sus scrofa) in the English countryside: A risk assessment. Central Science Laboratory, Ministry of Agriculture, Fisheries and Food, London, England.

Groot Bruinderink, G., E. Hazebroek, and H. van der Voot. 1993. Density-dependent resource limitation in non-supplementarily fed wild boar. Pp. 327-331. In Forests and wildlife: towards the 21 st Century $21^{\text {st }}$ Congress, August. Halifax; Canada.

Groot Bruinderink, G. W. T. A., E. Hazebroek, and H. van der Voot. 1994. Diet and condition of wild boar, Sus scrofa scrofa, without supplementary feeding. Journal of Zoology, 233(4):631-648.

Groves, C. P., and J. Giles. 1989. Suidae. Pp. 1044-1049. In D. W. Walton and B. J. Richardson (eds.), Fauna of Australia, Mammalia Vol. 1b. Australian Government Publishing Service, Canberra, Australia.

Hanson, L. B. 2006. Demography of feral pig population at Fort Benning, Georgia. MS Thesis, Auburn University, Auburn, Alabama. 
Hanson, R. P., and L. Karstad. 1959. Feral swine in the southeastern United States. Journal of Wildlife Management, 23(1):64-74.

Hayes, R. C. 2007. Feral hogs in central Mississippi: Home range, habitat use and survival. M.S. Thesis, Mississippi State University, Mississippi State, Mississippi.

Hebeisen, C., J. Fattebert, E. Baubet, and C. Fischer. 2008. Estimating wild boar (Sus scrofa) abundance and density using capture-resights in Canton of Geneva, Switzerland. European Journal of Wildlife Research, 54(3):391-401.

Henry, V. G., and R. H. Conley. 1978. Survival and mortality of European wild hogs. Proceedings of the Annual Conference of the Southeastern Association of Fish \& Wildlife Agencies, 32:93-99.

Herrero, J., A. García-Serrano, and R. García-Gonzalez. 2008. Reproductive and demographic parameters in two Iberian wild boar Sus scrofa populations. Acta Theriologica, 53(4):355-364.

Hess, S. C., J. J. Jeffrey, D. L. Ball, and L. Babich. 2006. Efficacy of feral pig removals at Hakalau Forest National Wildlife Refuge. Transactions of the Western Section of the Wildlife Society, 42:53-67.

Hone, J. 1990a. Note on seasonal changes in population density of feral pigs in three tropical habitats. Australian Wildlife Research, 17(2):131-134.

. 1990b. How many feral pigs in Australia? Australian Wildlife Research, 17:571-572.

2002. Feral pigs in Namadgi National Park, Australia: Dynamics, impacts and management. Biological Conservation, 105(2):231-242.

Hone, J., and H. Pederson. 1980. Changes in a feral pig population after poisoning. Proceedings of the Vertebrate Pest Control Conference, 9:176-182.

Hone, J., and G. E. Robards. 1980. Feral pigs: Ecology and control. Wool Technology and Sheepbreeding, 28(4):7-11.

Hoogerwerf, A. 1970. Part III. Wild boar. Pp. 330-349. In Udjunkulon. E. J. Brill, London, U.K.

Ickes, K. L. 2001. The effects of wild pigs (Sus scrofa) on woody understory vegetation in a lowland rain forest of Malaysia. Ph.D. Dissertation, Louisiana State University, Baton Rouge, Louisiana.

Igo, W. K., T. J. Allen, and E. P. Michael. 1979. Observations on European wild boars released in southern West Virginia. Proceedings of the Annual Conference of the Southeastern Association of Fish \& Wildlife Agencies, 33:313-317.

Ilse, L. M., and E. C. Hellgren. 1995. Spatial use and group dynamics of sympatric collared peccaries and feral hogs in southern Texas. Journal of Mammalogy, 76(4):993-1002.

Inayatullah, C. 1973. Wild boar in West Pakistan. Bulletin No. 1. Pakistan Forest Institute, Peshawar, Pakistan.

Jakšić, F. M., J. A. Iriarte, J. E. Jimenez, and D. R. Martinez. 2002. Invaders without frontiers: Crossborder invasions of exotic mammals. Biological Invasions, 4(1-1):157-173.

Janda, M. 1958. Die Nahrung des Schwarzwildes (Sus scrofa) im Mittelgebirgsgebiet von Stiavnica. Saugetierkundliche Mittilungen, 6(2):67-74.

Janeau, G., and F. Spitz. 1990. Dispersal in relation to density in wild boar. Transactions of the Congress of the International Union of Game Biologists, 19:59-62. 


\section{Wild Pigs}

Jedrzejewska, B., H. Okarma, W. Jedrzejewski, and L. Milkowski. 1994. Effects of exploitation and protection on forest structure, ungulate density and wolf predation in Bialowieza Primeval Forest, Poland. Journal of Applied Ecology, 31:664-676.

Jedrzejewska, B., W. Jederzejewski, A. N. Bunevich, L. Milkowski, and Z. A. Krasinski. 1997. Factors shaping population densities and increase rates of ungulates in Bialowieza Primeval Forest (Poland and Belarus) in the 19th and 20th centuries. Acta Theriologica 42:399-451.

Jedrzejewski, W., B. Jedrzejewska, H. Okarma, and A. L. Ruprecht. 1992. Wolf predation and snow cover as mortality factors in the ungulate community of the Bialowieza National Park, Poland. Oecologia, 90:27-36.

Jedrzejewski, W., B. Jedrzejewska, H. Okarma, K. Schmidt, K. Zub, and M. Musiani. 2000. Prey selection and predation by wolves in Bialowieza Primal Forest, Poland. Journal of Mammalogy, 81(1):197-212.

Jenkins, J. H., and E. E. Provost. 1964. The population status of the larger vertebrates on the Atomic Energy Commission Savannah River Plant site. Office of Technical Services, Department of Commerce, Washington, DC.

Jezierski, W. 1977. Longevity and mortality rate in a population of wild boar. Acta Theriologica, 22(24):337-348.

Karanth, K. U., and M. E. Sunquist. 1992. Population structure, density and biomass of large herbivores in the tropical forests of Nagarahole, India. Journal of Tropical Ecology, 8:21-35.

Kessler, C. C. 2002. Eradication of feral goats and pigs and consequences for other biota on Sarigan Island, Commonwealth of the Northern Mariana Islands. Pp. 132-140. In C. R. Veitch and M. N. Clout (eds.), Turning the tide: The eradication of invasive species. IUCN SSC Invasive Species Specialist Group, International Union for the Conservation of Nature and Natural Resources, Cambridge, United Kingdom.

Khan, J. A., R. Chellam, W. A. Rodgers, and A. J. T. Johnsingh. 1996. Ungulate densities and biomass in the tropical dry deciduous forests of Gir, Gujarat, India. Journal of Tropical Ecology, 12:149-162.

Kight, J. 1962. An Ecological Study of the Bobcat, Lynx rufus (Schreber), in West-central South Carolina. M.S. Thesis, Univ. Georgia, Athens.

Kodera, Y. 2005. Survival analysis of wild boars (Sus scrofa) in Iwami District, western Japan. Suiform Soundings, 5(2):11-13.

Kozlo, P. G. 1970. Faktory opredeljajuscie dinamiku cislennosti kabana (Sus scrofa) w Belovezskoj Pusci. Zoologicheskii Zhurnal, 49(3):422-430.

Kurz, J. C., and R. L. Marchinton. 1972. Radiotelemetry studies of feral hogs in South Carolina. Journal of Wildlife Management, 36(4):1240-1248.

Lapidge, S. J., B. Cowled and M. Smith. 2004. Ecology, genetics and socio-biology: Practical tools in the design of target-specific feral pig baits and baiting procedures. Proceedings of the Vertebrate Pest Conference, 21:317-322.

Law Environmental. 1988. Wildlife assessment study of citrus grove development tracts. Law Environmental, Inc., Kennesaw, Georgia.

Leopold, A. 1936. Deer and Dauerwild in Germany, 2. Ecology and Policy. Journal of Forestry, 34(5):460-466. 
Ling, H. 1955. Metssea (Sus scrofa) areaalipiiri muutused Noukoguole Baltimaadel viimastel sajanditel. Loodusuurijate Leltsi Aastaraamat, 48(1955):176-200.

Lohraff, K. 2008. Fort Leonard Wood, Missouri: A feral hog eradication success story. 18 pp. In S. M. Vantassel (ed.), 2008 National conference on feral hogs. St. Louis, Missouri. http://digitalcommons.unl.edu/feralhog/5

Lozan, M. 1995. Factors that limit the number of wild boars (Sus scrofa L.) in the Republic of Moldova. Journal of Mountain Ecology (Ibex), 3:211.

Mackin, R. 1970. Dynamics of damage caused by wild boar to different agricultural crops. Acta Theriologica, 15(27):447-458.

Mann, W. M. 1934. Wild animals in and out of the zoo. Vol. 6. Smithsonian Scientific Series, Inc., New York.

Mansfield, T. M. 1978. Wild pig management on a California public hunting area. Transactions of the California-Nevada Section of the Wildlife Society, 25:187-201.

Massei, G., P. V. Genov, B. W. Staines, and M. L. Gorman. 1997. Mortality of wild boar, Sus scrofa, in a Mediterranean area in relation to sex and age. Journal of Zoology, 242: 394-400.

Massei, G., and L. Tonini. 1992. The management of wild boar in the Maremma Natural Park. Pp. 443-445. In F. Spitz, G. Janeau, G. Gonzalez, and S. Aulagnier (eds.), Ongules/Ungulates 91: Proceedings of the international symposium. Toulouse, France, September 2-6, 1991. Societe Francaise pour l'Etude et la Protection des Mammiferes, and Toulose: Institut de Recherche sur les Grands Mammiferes, Paris \& Toulouse, France.

Masters, K. B. 1979. Feral pigs in south-west of Western Australia. Final report to feral pig committee. Agricultural Protection Board, Department of Conservation and Land Management, Government of Western Australia, Perth, Australia.

Mauget, R. 1980. Ŕegulations ecologiques, comportementales et physiologiques (fonction de reproduction), de l'adaptation du sanglier, Sus scrofa L., au Milieu. Ph.D. Dissertation, L' Universite Francois Rabelais de Tours, Orleans, France.

Mayer, J. J. 2005. Wild hog. pp. 372-377. In J. C. Kilgo and J. I. Blake (eds.), Ecology and management of a forested landscape: Fifty years on the Savannah River Site. Island Press, Corvela, California.

Mayer, J. J., and I. L. Brisbin, Jr. 1991. Wild pigs in the United States: Their history, comparative morphology, and current status. The University of Georgia Press, Athens, Georgia.

Mayer, J. J., and P. E. Johns. 2007. Characterization of Wild Pig-Vehicle Collisions. Proceedings of the Wildlife Damage Management Conference, 12:175-187.

McCann, B. E., and D. K. Garcelon. 2008. Eradication of feral pigs from Pinnacles National Monument. Journal of Wildlife Management, 72(6):1287-1295.

McGaw, C. C., and J. Mitchell. 1998. Feral pigs (Sus scrofa) in Queensland. Pest status review series. Land Protection, Department of Natural Resources and Mines, Queensland Government, Coorparoo, Australia.

McKay, G. M. 1973. Behavior and ecology of the Asiatic elephant in Southeastern Ceylon. Smithsonian Contributions to Zoology, 125:1-113. 


\section{Wild Pigs}

Mcllroy, J. C. 1989. Aspects of the ecology of feral pigs (Sus scrofa) in the Murchison area, New Zealand. New Zealand Journal of Ecology, 12:11-22.

McIlroy, J. C., M. Braysher, and G. R. Saunders. 1989. The effectiveness of a warfarin poisoning campaign against feral pigs, Sus scrofa, in Namadgi National Park, A.C.T. Australian Wildlife Research, 16(2):195-202.

Melis, C., P. A. Szafrańska, B. Jędrzejewska, and K. Bartoń. 2006. Biogeographical variation in the population density of wild boar (Sus scrofa) in western Eurasia. Journal of Biogeography, 33(5):803-811.

Merino, M. L., and B. N. Carpinetti. 2003. Feral pig Sus scrofa population estimates in Bahia Samborombon Conservation Area, Buenos Aires Province, Argentina. Journal of Neotropical Mammalogy, 10(2):269-275.

Mitchell, J. 1998. The effectiveness of aerial baiting for control of feral pigs (Sus scrofa) in North Queensland. Wildlife Research, 25(3):297-303.

Mitchell, J. 1999. Ecology of feral pigs in the Wet Tropics. Pp. 43-47. In C. N. Johnson (ed.), Feral pigs: Pest status and prospects for control. Proceedings of a feral pig workshop. James Cook University, Cairns, March. Research Report No. 13. Cooperative Research Centre for Tropical Rainforest Ecology and Management, Cairns, Australia.

Moretti, M. 1995. Birth distribution, structure and dynamics of a hunted mountain population of wild boars (Sus scrofa L.), Ticino, Switzerland. Journal of Mountain Ecology (Ibex), 3:192-196.

Náhlik, A., and G. Sándor. 2003: Birth rate and offspring survival in a free-ranging wild boar Sus scrofa population. Wildlife Biology, 9(Suppl.1):37-42.

Neet, C. 1995. Population dynamics and management of Sus scrofa in Western Switzerland: A statistical modeling approach. Journal of Mountain Ecology (Ibex), 3:188-191.

Nichols, L., Jr. 1962. Ecology of the wild pig. Federal Aid in Wildlife Restoration Final Report Project W5-R-13. Hawaii Department of Land and Natural Resources, Division of Fish and Game, Honolulu, Hawaii.

Nowak, R. M. 1999. Walker's mammals of the world. $6^{\text {th }}$ Edition. The Johns Hopkins University Press, Baltimore, Maryland. Two Vol.

Okarma, H. 1995. The trophic ecology of wolves and their predatory role in ungulate communities of forest ecosystems in europe. Acta Theriologica, 40(4):335-386.

Okarma, H., B. Jedrzejewska, W. Jedrzejewski, Z. A. Krasinski, and L. Milkowski. 1995. The roles of predation, snow cover, acorn crop, and man-related factors on ungulate mortality in Bialowieza Primeval Forest, Poland. Acta Theriologica, 40(2):197-217.

Oliver, W. L. R., I. L. Brisbin, Jr., and S. Takahashi. 1993. The Eurasian wild pig (Sus scrofa). Pp. 112-121. In W. L. R. Oliver (ed.), Pigs, peccaries and hippos: Status survey and conservation action plan. International Union for the Conservation of Nature and Natural Resources, Gland, Switzerland.

Oloff, H. B. 1951. Zur Biologie und Okologie des Wildschweines. Beitrag zur Tierkunde und Tierzucht, 2(1):1-95.

Patten, D. C. 1974. Feral hogs: Boon or burden? Proceedings of the Vertebrate Pest Conference, 6:210-216. 
Pauwels, W. 1980. Study of Sus scrofa vittatus, its ecology and behavior in Ujung Kulon Nature Reserve, Java, Indonesia. Ph.D. Dissertation. University of Basel, Switzerland.

Pavlov, P. M. 1980. The diet and general ecology of the feral pig (Sus scrofa) at Girilambone, N. S. W. M.S. Thesis, Monash University, Melbourne, Australia.

Pavlov, P. M., and E. C. Edwards. 1995. Feral pig ecology in Cape Tribulation National Park, North Queensland, Australia. Journal of Mountain Ecology (Ibex), 3:148-151.

Pech, R. P., and J. C. McIlroy. 1990. A model of the velocity of advance of foot-and-mouth disease in feral pigs. Journal of Applied Ecology, 27:635-650.

Peine, J. D., and J. A. Farmer. 1990. Wild hog management program at Great Smoky Mountains National Park. Proceedings of the Vertebrate Pest Conference, 14:221-227.

Pfeffer, P. 1960. L'ecologie du sanglier in Asie Central d'apres les researches d'A. A. Sloudsky. Revue d'Ecologie (La Terre et la Vie), 108:368-372.

Pine, D. S., and G. L. Gerdes. 1973. Wild pigs in Monterey County, California. California Fish and Game, 59(2):126-137.

Pucek, Z., B. Bobek, L. Łabudzki, L. Miłkowski, K. Morow, and A. Tomek. 1975. Estimates of density and numbers of ungulates. Polish Ecological Studies, 1:121-136.

Pullar, E. M. 1953. The wild (feral) pigs of Australia: Their origin, distribution and economic importance. Memoirs of the National Museum Melbourne, 18:7-23.

Rakov, N. V. 1970. O fakorakh smertnosti kabana i ego vzaimootnosheniyakh S Khshchnikami v Priamure. Zoologicheskii Zhurnal, 49(8):1220-1228.

Ramsey, D. S. L., J. Parkes, and S. A. Morrison 2008. Quantifying eradication success: The removal of feral pigs from Santa Cruz Island, California. Conservation Biology, 23(2):449-459.

Richardson, C. D., P. S. Gipson, D. P. Jones, and J. C. Luchsinger. 1997. Extirpation of a recently established feral pig population in Kansas. Proceedings of the Eastern Wildlife Damage Management Conference, 7:100-103.

Ridpath, M. G. 1991. Feral mammals and their environment. Pp. 169-191. In C. D. Hayes, M. G. Ridpath, M. A. J. Williams and A. A. Balkema (eds.). Monsoonal Australia: Landscape, ecology and man in the northern lowlands. Rotterdam, Netherlands.

Rosvold, J., and R. Andersen. 2008. Wild boar in Norway - Is climate a limiting factor? Norges teknisknaturvitenskapelige universitet, Vitenskapsmuseet, Seksjon for naturhistorie, Trondheim, Norway.

Safarov, M. A. 1960. Census method for wild boar in Azerbaidjan (in Russian with an English summary). Izvestiya Akademii nauk Azerbajdzhanskoj SSR. Seriya biologicheskikh nauk, 1:125-128.

Samuel, J. L., and P. F. Woodall. 1988. Periodontal disease in feral pigs (Sus scrofa) from Queensland, Australia. Journal of Wildlife Diseases, 24(2):201-206.

Santiapillai, C., and M. R. Chambers. 1980. Aspects of the population dynamics of the wild pig (Sus scrofa Linnaeus, 1758) in the Ruhuna National Park, Sri Lanka. Spixiana, 3:239-250.

Saunders, G. 1988. The ecology and management of feral pigs in New South Wales. M.S. Thesis, Macquarie University, Ryde, Australia. 


\section{Wild Pigs}

Saunders, G. 1993. The demography of feral pigs (Sus scrofa) in Kosciusko National Park. Wildlife Research, 20(5):559-569.

Saunders, G., and H. Bryant. 1988. The evaluation of a feral pig eradication program during a simulated exotic disease outbreak. Australian Wildlife Research, 15(1):73-81.

Saunders, G., and J. R. Giles. 1995. Ecological comparison of two wild pig populations in semi-arid and sub-alpine Australia. Journal Mountain Ecology (Ibex), 3:152-155.

Saunders, G., and B. Kay. 1990. Movements of feral pigs at Sunny Corner, New South Wales. Wildlife Research, 18:49-61.

Schaller, G. B. 1967. The deer and the tiger: A study of wildlife in India University of Chicago Press, Chicago.

Schauss, M. E. 1980. Population dynamics and movements of wild pigs in Grant Park. M.A. Thesis, San Jose State University, San Jose, California.

Schortemeyer, J. L., and J. W. McCown. 1988. Big Cypress National Preserve Deer and Hog Annual Report. Florida Game and Fresh Water Fish Commission, Naples, Florida.

Schuyler, P. T., D. K. Garcelon, and S. Escover. 2002. Eradication of feral pigs (Sus scrofa) on Santa Catalina Island, California, USA. Pp. 274-286. In C. R. Veitch and M. N. Clout (eds.), Turning the tide: The eradication of invasive species. IUCN SSC Invasive Species Specialist Group, International Union for the Conservation of Nature and Natural Resources, Cambridge, United Kingdom.

Sáez-Royuela, C., and J. L. Telleria. 1986. The increased population of the wild boar (Sus scrofa L.) in Europe. Mammal Review, 16(2):97-101.

Seidensticker, J. 1976. Ungulate populations in Chitwan Valley, Nepal. Biological Conservation, 10:183-210.

Shafi, M. M., and A. R. Khokhar. 1986. Some observations on wild boar (Sus scrofa) and its control in sugarcane areas of Punjab, Pakistan. Journal of the Bombay Natural History Society, 83(1):63-67.

Singer, F. J. 1976. The European wild boar in the Great Smoky Mountains National Park: Problem analysis and proposed research. NPS-SER Management Report No. 6. Uplands Field Research Laboratory, Great Smoky Mountains National Park, Gatlinburg, Tennessee.

. 1981. Wild pig populations in the national parks. Environmental Management, 5(3):263-270.

Singer, F. J., and B. B. Ackerman. 1981. Food availability, reproduction and condition of European wild boar in Great Smoky Mountains National Park. Research/Resource Management Report No. 43. Uplands Field Research Laboratory, Great Smoky Mountains National Park, Gatlinburg, Tennessee.

Singer, F. J., and D. Stoneburner. 1979. Feral pig management. Memorandum N1615. Uplands Field Research Laboratory, Great Smoky Mountains National Park, Gatlinburg, Tennessee.

Sludskii, A. A. 1956. Kaban: Ekologia i chozjajstvennoe znacenie. Kazakhstan Academy of Sciences (Akademii Nauk Kazachskoi SSR), Alma-Ata, Kazakhstan S.S.R.

Smiet, A. C., G. W. Fulk, and S. B. Lathiya. 1979. Wild boar ecology in Thatta District: A preliminary study. Pakistan Journal of Zoology, 11(2):295-302. 
Sodeikat, G., and K. Pohlmeyer. 2002. Temporary home range modifications of wild boar family groups (Sus scrofa L.) caused by drive hunts in Lower Saxony (Germany). European Journal of Wildlife Research, 48(Supplement):161-166.

Sparklin, W. D. 2009. Territoriality and habitat selection of feral pigs on Fort Benning, Georgia, USA. M.S. Thesis, The University of Montana, Missoula, Montana.

Spencer, P. B. S., J. Hampton, S. J. Lapidge, J. Mitchell, J. Lee, and J. R. Pluske. 2006. An assessment of the genetic diversity and structure within and among populations of wild pigs (Sus scrofa) from Australia and Papua New Guinea, Journal of Genetics, 85(1):63-66.

Spillett, J. J. 1967a. A report on wild life surveys in North India and Southern Nepal: The Kaziranga Wild Life Sanctuary, Assam. Journal of the Bombay Natural History Society, 63:494-528.

Spillett, J. J. 1967b. A report on wild life surveys in North India and Southern Nepal: The Jaldapara Wild Life Sanctuary, West Bengal. Journal of the Bombay Natural History Society, 63:534-556.

Spillett, J. J. 1967c. A report on wild life surveys in North India and Southern Nepal: The large mammals of the Keoladeo Ghana Sanctuary, Rajasthan. Journal of the Bombay Natural History Society, 63:602-607.

Spitz, F. 1986. Current state of knowledge of wild boar biology. Pig News and Information, 7(2):171-175.

Spitz, F., G. Janeau, and G. Valet. 1984. Elements de demographie du sanglier (Sus scrofa) dans la Region de Gresigne. Acta Oecologica, 5(1):43-59.

Springer, M. D. 1975. Food habits of wild hogs on the Texas Gulf Coast. M.S. Thesis, Texas A\&M University, College Station, Texas.

Srikosamatara, S. 1993. Density and biomass of large herbivores and other mammals in a dry tropical forest, western Thailand. Journal of Tropical Ecology, 13:33-43.

Statham, M., and M. Middleton. 1987. Feral pigs on Flinders Island. Papers and Proceedings of the Royal Society of Tasmania, 121:121-124.

Stegeman, L. J. 1938. The European wild boar in the Cherokee National Forest, Tennessee. Journal of Mammalogy, 19(3):279-290.

Sterner, J. D. 1990. Population characteristics, home range, and habitat use of feral pigs on Santa Cruz Island, California. M.S. Thesis, University of California at Berkeley, Berkeley, California.

Stone, C. P. 1985. Feral pig (Sus scrofa) research and management in Hawai'i. National Park Service, Hawaii National Park, Hawaii.

Stubbe, W., and M. Stubbe. 1977. Vergleichende beitrage zur reproduktions und geburtsbiologie von Wild und Hausschewein Sus scrofa L., 1758. Beitrage zur Jagd- und Wildforschung, 10:153-179.

Sweeney, J. M. 1970. Preliminary investigation of a feral hog (Sus scrofa) population on the Savannah River Plant, South Carolina. M.S. Thesis, University of Georgia, Athens, Georgia.

Sweeney, J. R., J. M. Sweeney, and S. W. Sweeney. 2003. Feral hog, Sus scrofa. Pp. 1164-1179. In G. A. Feldhammer, B. C. Thompson, and J. A. Chapman (eds.), Wild mammals of North America: Biology, management, and conservation. The Johns Hopkins Univ. Press, Baltimore, Maryland. 


\section{Wild Pigs}

Sweitzer, R. A., D. Van Vuren, I. A. Gardner, W. M. Boyce, and J. D. Waithman. 2000. Estimating sizes of wild pig populations in the north and central coast regions of California. Journal of Wildlife Management, 64(2):531-543.

Tate, J. (ed.). 1984. Techniques for controlling wild hogs in the Great Smoky Mountains National Park. Proceedings of a workshop, November 29-30, Research/Resources Mgmt. Rpt. SRE-72. U. S. Department of the Interior, National Park Service, Southeast Regional Office, Atlanta, Georgia.

Taylor, R. B., E. C. Hellgren, T. M. Gabor, and L. M. Ilse. 1998. Reproduction of feral pigs in southern Texas. Journal of Mammalogy, 79(4):1325-1331.

Thomson, G. M. 1922. Pigs; wild boar (Sus scrofa). Pp. 33-39. In The naturalisation of animals \& plants in New Zealand. Cambridge University Press, London, England.

Tipton, A. R. 1977. The use of population models in research and management of wild hogs. Pp. 91-101. In G. W. Wood (ed.), Research and management of wild hog populations. Belle Baruch Forest Science Institute of Clemson University, Georgetown, South Carolina.

Tisdell, C. A. 1982. Wild pigs: Environmental pest or economic resource? Pergamon Press, New York.

Truvé, J., and J. Lemel. 2003: Timing and distance of natal dispersal for wild boar Sus scrofa in Sweden. Wildlife Biology, 9(Suppl. 1):51-57.

Truvé, J., J. Lemel, and B. Söderberg,. 2004. Dispersal in relation to population density in wild boar (Sus scrofa). Galemys, 16:75-82.

Vtorov, I. P. 1993. Feral pig removal: Effects on soil microarthropods in a Hawaiian rain forest. Journal of Wildlife Management, 57(4):875-880.

Waithman, J. 2001. Guide to hunting wild pigs in California. California Department of Fish and Game, Wildlife Programs Branch, Sacramento, California.

Welander, J. 1995. Are wild boars a future threat to the Swedish flora? Journal of Mountain Ecology (Ibex), 3:165-167.

Wilson, C. J. 2005. Feral wild boar in England: Status, impact and management. DEFRA, RDS National Wildlife Management Team, Exeter, United Kingdom.

Wilson, G. R., G. J. E. Hill, and A. Barnes. 1987. An aerial survey of feral pigs and emus in south eastern Queensland. Australian Wildlife Research, 14:515-520.

Wodzicki, K. A. 1950. Introduced mammals in new Zealand, an ecological and economic survey. Bulletin No. 98. New Zealand Department of Science, Industry and Research, Wellington, New Zealand.

Wood, G. W., and R. H. Barrett. 1979. Status of wild pigs in the United States. Wildlife Society Bulletin, 7(4):237-246.

Wood, G. W., and R. E. Brenneman. 1977. Research and management of feral hogs on Hobcaw Barony. Pp. 23-35. In G. W. Wood (ed.), Research and management of wild hog populations. Belle Baruch Forest Science Institute of Clemson University, Georgetown, South Carolina.

Wood, G. W., L. A. Woodward, D. C. Matthews, and J. R. Sweeney. 1992. Feral hog control efforts on a coastal South Carolina plantation. Proceedings of the Annual Conference of the Southeastern Association of Fish \& Wildlife Agencies, 46:167-178. 
SRNL-RP-2009-00869

This page left blank intentionally 
Wild Pigs

\section{Biology of Wild Pigs:}

\section{Natural Predators of Wild Pigs in the United States}

John J. Mayer

Savannah River National Laboratory, Savannah River Nuclear Solutions, LLC, Savannah River Site, Aiken, South Carolina 29808

\section{Introduction}

Globally, wild pigs (Sus scrofa) within their native range are preyed on by a number of natural (i.e., nonhuman) species of carnivores and omnivores (Table 1). In some instances, this predation can account for up to $25 \%$ of the annual natural mortality realized in these wild pig populations (Jedrzejewski et al. 1993). However, in the United States, man is the primary and most significant predator of wild pigs. Although natural predators exist, predation by these species is thought to generally play only a minor role in the mortality of wild pigs throughout their range in this country (Sweeney et al. 2003). Further, most of this predation is directed toward the younger age classes within a wild pig population (Barrett 1971).

The purpose of this review was to summarize in a more comprehensive manner both the documented and potential natural predators of wild pigs in the United States. The information provided in this paper is based on data both provided in the literature and that gathered by myself. Individual species accounts of the various natural predators are in the following section. In addition to the individual species accounts, large predators that have been documented as wild pig predators elsewhere and currently overlap the range of introduced wild pigs in this country are discussed as potential natural predators.

\section{Species Accounts}

American Alligator (Alligator mississippiensis) - Both anecdotal accounts (Rutledge 1965) and scientific investigations (Maehr et al. 1989, Shoop and Ruckdesche 1990, Wood and Brenneman 1977) document the predation of wild pigs by alligators. In general, this type of predation is largely limited to opportunistic situations. Wood and Brenneman (1977) noted that most alligator predation of wild pigs at Hobcaw Barony in coastal South Carolina took place in abandoned rice fields where the habitats of the two species overlapped. Hanson and Karstad (1959) described alligator predation of wild pigs as an "occasional" event. Alligators have been known to take a variety of sizes of pigs (Wood and Brenneman 1977). Further, being aquatic enables alligators to capture and kill very large pigs that are swimming in open water situations. McIlhenny (1976) reported large alligators killing in the water and later eating free-ranging domestic swine that weighed up to $227 \mathrm{~kg}$. The open water capture and drowning of wild pigs is probably the most common manner in which this type of predation occurs. On one occasion for example, a large alligator was observed to grab and drown a wild pig in a large reactor cooling reservoir on the Savannah River Site (SRS) in South Carolina after the pig had been chased into the water by hunting dogs (J. W. Reiner, pers. comm.). However, an alligator on Ossabaw Island was observed to rush, capture and then drown a wild pig which was standing on a ditch bank near the water's edge (R. E. Parker, pers. comm.). In contrast to this predator-prey relationship, Rutledge (1965) provided an anecdotal account of an almost 4.6 $\mathrm{m}$ long male alligator being killed by a large feral boar in the Santee River delta of South Carolina.

Turkey Vulture (Cathartes aura) - Primarily a scavenger, this vulture is also opportunistic in its foraging habits. In 1987, I observed the predation by three adult turkey vultures on a solitary small wild pig attempting to cross an open rangeland area near Immokalee in Collier County, Florida. The birds collectively flew in, surrounded, and stopped the piglet's escape with their outstretched wings. Using 
stabbing strikes with their beaks, the trio was then able to kill their victim, which they then consumed. The piglet was small and, by its lethargic behavior, did not appear to be completely healthy. Given the circumstances, predation of wild pigs by this avian scavenger would be a possible but extremely rare event.

Red-tailed Hawk (Buteo jamaicensis) - Although typically a predator of small birds and mammals, the red-tailed hawk will prey on small piglets given the right circumstances. This raptor has been observed on three occasions to capture, kill and feed on very small solitary wild piglets on Ossabaw Island off of the Georgia coast (R. E. Parker, pers. comm.). The more open habitat found on Ossabaw Island may have enabled the success of these predatory attempts. In addition, the small size and high percentage of solitary piglets within that wild pig population may account for these multiple observations of this type of predation (J. J. Mayer, unpubl. data). Orians and Kuhlman (1956) documented that red-tailed hawks will prey on domestic piglets, although this constituted a very small proportion of their diet by occurrence.

Golden Eagle (Aquila chrysaetos) - Typically a predator of small mammals taken on the ground, the golden eagle has been documented to opportunistically prey on wild piglets (Barrett 1971, Roemer et al. 2001). This is also true within the Eurasian portion of this raptor's species range (Seguin et al. 1998). In general, this type of predation is neither common nor widespread. However, the presence of a large prey base in the form of wild piglets has been theorized to have caused the establishment of nesting golden eagles on the California Channel Islands. When the islands' various wild pig populations were either eradicated (i.e., on Santa Rosa, San Clemente and Santa Catalina islands) or reduced (i.e., on Santa Cruz Island), the then resident golden eagles began to prey on the indigenous island foxes (Urocyon littoralis), almost driving this already threatened species to extinction (Roemer et al. 2001).

Owls (Strigiformes) - Stevens (1996) noted that owls have been reported as predators of small wild pigs and piglets. No further details were provided. Given its potential to prey on other animals of comparable size, the great horned owl (Bubo virginianus) would represent a potential predator of such small wild pigs. Briedermann (1986) noted that the Eurasian eagle owl (B. bubo), a species closely related the great horned owl, was a predator of wild piglets.

Feral Dog (Canis familiaris) - Present in most states (McKnight 1964), feral dogs represent a known predator of wild pigs in this country (Kramer 1971, Rue 1968, Tomich 1969). The predatory impact of feral dog packs would be mostly realized toward piglets and shoats (Elman 1974, Tomich 1969). Diong (1982) described the attempted predation by two feral dogs of a yearling sow on the Island of Maui, which was thwarted when that author intervened. In contrast to these reports, wild pigs as a species are at least perceived to be able to defend themselves against this canine predator. This ability was one of the primary reasons why the wildlife authorities in West Virginia stocked wild pigs in the southern portion of the state, where efforts to increase the white-tailed deer in this big game poor area of the state was thought to at least be in part hampered because of the presence of free-ranging or feral dogs (Igo 1977).

Coyote (Canis latrans) - A common native canid that has expanded its range throughout most of the continental United States, the coyote has been documented as preying on wild pigs in a number of locations (e.g., Barrett 1971, Taylor 1991, Kamler et al. 2002, Schrecengost et al. 2008). Most coyote predation of wild pigs is directed at younger or smaller animals (Bruce 1941). Overall, the predatory impact of coyote on wild pigs is unknown. There have been known instances of an increase in the coyote population as wild pig populations in that same area have increased (Stevens 1996). Schrecengost et al. (2008) reported that the occurrence of wild pig remains in coyote scats on the SRS corresponded to the peak control activities for this introduced ungulate, when wild pigs are killed and the carcass is left in the field. Wagner (1993) reported a similar peak occurrence of wild pig in the coyote diet in Mississippi during the peak in the local sport hunting for pigs. Both of these sources suggested that scavenging of carcasses was the primary source of wild pigs in these coyote diets. Feral hog remains were found in 12.7 percent of 1,042 coyote scats examined from the Dye Creek Ranch in northern California. Of those, piglet remains accounted for 95 percent of the wild pig material (Barrett 1971). These numbers included both direct predation as well as carrion scavenging. Because many of the coyote scats contained mummified piglet hide, and a fair amount of piglet carrion was available, Barrett (1971) felt that coyote predation was probably not a primary factor limiting the survival of young piglets. In contrast, coyote predation of piglets may be in part responsible 


\section{Wild Pigs}

for the reduction in wild pig numbers found in southern West Virginia (Hansroth 2001). However, there were no empirical data to corroborate this belief.

Red Wolf (Canis rufus) - Effectively extinct in recent times in the wild, the red wolf has been reintroduced onto Bull's Island, South Carolina, into the area encompassing the Alligator River National Wildlife Refuge (ARNWR) in eastern North Carolina, and into the Cades Cove area of the Great Smoky National Park (GSMNP). The family group in the GSMNP was observed to prey on the wild pigs inhabiting that portion of the park (V. G. Henry, pers. comm.). However, due to insufficient natural food sources, the red wolves in the GSMNP were removed from the wild in 1998. Davis (1978) reported that the red wolves in east Texas were known to prey on free-ranging domestic pigs. Unlikely to be returned to its historic numbers or density, the impact of the red wolf on wild pigs is likely to only be significant in localized areas of reintroduction efforts where both species occur. At present, no wild pigs are known to occur either on Bull's island or at the ARNWR.

Red Fox (Vulpes vulpes) - The red fox was reported by Stegeman (1938) and Conley et al. (1972) as having the potential to occasionally catch a very young piglet. No accounts exist specifically reporting predation of wild pigs by this species in the New World. However, Snethlage (1982), Briedermann (1986), Goergen (1974) and Kozlo (1975) all reported instances of predation on wild boar piglets by red fox in Eurasia.

Gray Fox (Urocyon cinereoargenteus) - Like the red fox, Stegeman (1938) also noted that this species might catch a very young piglet on occasion. Identified by wildlife researchers as a potential predator of young piglets in the Tennessee portion of the southern Appalachians (Conley et al. 1972), subsequent research showed that the only presence of wild pig in the diet of this small canid (29 percent occurrence of wild pig hairs in stomachs examined) was in the form of scavenging (Yoho and Pelton 1978). Bruce (1941) reported that piglets in the nest would be easy prey for a fox when the sow was away foraging.

Black Bear (Ursus americanus) - The black bear is known to prey on wild pigs of all ages (Stegeman 1938, Hamilton 1941, Conley et al. 1972, P. S. White, pers. comm.). Jenkins and Provost (1964) stated that this large carnivore may serve as a depressing effect on the wild pig numbers in areas where the two species overlap. Rue (1968) noted that domestic pigs were a preferred food of black bears, which reportedly would raid any pigsty that they located. However, Conley et al. (1972) speculated that black bears probably kill few if any wild pigs. These authors further noted that an adult wild pig would represent a formidable adversary for a black bear. In fact, a feral boar in the Okefenokee Swamp was reported to have killed a black bear in a fight between the two animals (Harper 1927). In addition, Turnbo (1988) reported anecdotal accounts of both feral and free-ranging domestic boars killing bears during fights in the Ozark Mountains of Arkansas in the 1880s. Being opportunistic, black bears have been reported to raid nylon net live traps used for wild pig control at high elevations in the GSMNP to obtain any trapped pigs contained within these devices (Coleman 1984).

Small Indian Mongoose (Herpestes auropunctatus) - Diong (1982) reported an attack of a solitary wild piglet by an adult small Indian mongoose on Maui. Although that author interrupted the attack, the piglet later died from its wounds in captivity after being caught for examination. The investigation of mongoose stomach contents from that same area revealed pig muscle and hair in five of the 18 stomachs analyzed. However, it was not possible to establish that this was not the result of carrion feeding as opposed to direct predation. Laycock (1966) and Kramer (1971) reported anecdotal accounts of this same species of viverrid preying on young domestic pigs in Jamaica.

Bobcat (Lynx rufus) - This small felid is found in most areas where introduced wild pig populations exist in this country. The predation of wild piglets by bobcats has been documented in both anecdotal (Blennerhasset 1907, Stegeman 1938, Young 1958) and scientific accounts (Kight 1964, Tewes et al. 1998). Hanson and Karstad (1959) reported that bobcats were important predators of young wild piglets in the southeast. Wood and Brenneman (1977) stated that bobcat predation only impacted wild pigs which were less than three to four months in age. These same authors also noted that finding wild pig hairs in bobcat scats was not uncommon. Kight (1962), in a study on bobcat food habits at the SRS, found that wild pigs only made up 0.6 percent of the diet by occurrence. Kight (1962) also implied that predation on 
the site's wild pigs by resident bobcats was directed at immature animals. Tewes et al. (1998) found wild pig remains in 15.4 percent of bobcat scats examined from the Lower Rio Grande valley in Texas.

Ocelot (Felis pardalis) - Although neither common nor widespread, this small Neotropical felid has been documented to prey of wild pigs in south Texas. Wild pig remains were found in 20.8 percent of ocelot scats examined from the Lower Rio Grande valley (Tewes et al. 1998). Davis (1978) also reported that ocelots were "fond" of young domestic pigs as prey in Texas in the early 1900s.

Mountain Lion (Puma concolor) - The mountain lion or cougar is found to overlap the range of wild pigs in the western states and in Florida. In both general regions, this cat has been documented to prey on introduced wild pigs (Bruce 1941, Cory 1896, Maehr et al. 1989). The target animals include both sexes and potentially any age class. Given the right situation, a mountain lion could catch and kill a fairly large sow or boar. Bruce (1941) reported mountain lions in California killing wild pigs weighing upwards of 136 $\mathrm{kg}$. On private ranch lands in south Florida, wild pigs constitute a large volume of prey in the diet of the Florida panther, based on 42 percent frequency of occurrence in scats. This varied within the panther's range in South Florida, with wild pigs constituting 58.7 and 22.7 percent of the estimated biomass consumed by these large cats north and south of $26^{\circ} 11^{\prime} \mathrm{N}$ latitude, respectively (Maehr et al. 1990). Hopkins (1989) found that wild pigs made up 5 to 20 percent of mountain lion scat samples from the Diablo Mountains in California. Wild pigs, however, only made up 2 percent of the actual kill recorded from the same study. The level of mountain lion use of wild pigs as a forage resource may be chiefly based on the density of these prey animals in a given area (Hopkins 1989). Craig (1986) reported that predation of wild pigs by mountain lions appeared to primarily occur during the wet season.

Wild Pig (Sus scrofa) - Cannibalism or predation of wild pigs by other individuals within that same population has been documented to occur (Barrett 1971, Wennrich 1976). Such intraspecific predation would be primarily directed at immature animals. The most likely instance would involve the predation of unattended newborn piglets by adult boars. The broad-spectrum impact of this type of predation is unknown. Based on extensive zoo experience with captive wild boar, Hediger (1968) believed that such reported predation of young piglets by adult boars was unfounded.

Potential Natural Predators - Based on their overlapping range with wild pigs in this country and the fact that these predators have been documented to prey on wild pigs elsewhere, four additional potential predators of wild pigs in this country would be the Burmese python (Python molurus bivittatus), gray wolf (Canis lupus), the lynx (Lynx lynx), and the jaguar (Panthera onca). Paragraphs summarizing the potential predation of wild pigs by these carnivores are included below.

The Burmese python has been established as an invasive species in South Florida. Although this snake has been documented as a predator of wild pigs elsewhere (Mehrtens 1987), the only food habits study conducted to date in Florida did not identify the presence of any wild pig material (Snow et al. 2007). However, that study was conducted in an area with low densities of wild pigs (i.e., Everglades National Park). Where Burmese pythons are found to the north of that location in Florida, the densities of wild pigs are much greater and, as such, pigs would represent a potential prey species for these large constrictors in those areas.

The gray wolf is a well-documented predator of wild boar in Eurasia (e.g., Briedermann 1986, Jedrzejewski et al. 1992, Jedrzejewski et al. 1994, Mattioli et al. 1995). This native canid currently overlaps the introduced distribution of wild pigs in Wisconsin. The potential for wolf predation of local wild pigs exists in these areas; however, none has been documented to date. Jedrzejewski et al. (1994) found the wolves took fewer wild boars than would be expected on a random basis. Okarma (1995) also noted wolves accounted for $16 \%$ of the natural mortality of wild boar in forested ecosystems in Europe. Kũbarsepp and Valdmann (2003) found that wild pigs were the main prey item for wolves in the Alampedja Nature Reserve in Estonia.

The lynx is currently sympatric in its distribution with that of scattered populations of introduced wild pigs in the states of Washington and Wisconsin. Briedermann (1986), Jedrzejewski et al. (1993), Kozlo (1975), and Rakov (1970) all documented predation of wild boar by lynx in Eurasia. However, this predation was 


\section{Wild Pigs}

made of immature animals and comprised only 1-3 percent of lynx's diet (Jedrzejewski et al. 1993, Kozlo 1975, Rakov 1970).

The jaguar is a rare wanderer north from its current range in Mexico. Recent sightings in the United States have included the Peloncillo Mountains in New Mexico (DOI 1997, Glenn 1996), which also has an established wild pig population (Mayer and Brisbin 1991). As a documented predator of introduced wild pigs in South America (Mondolfi and Hoogesteijn 1989), the jaguar could also potentially prey on wild pigs in the United States. However, because of the present extremely rare status of this large felid in the United States, the jaguar represents at most a negligible impact on wild pig populations in this country.

\section{Summary}

The list of known and potential natural predators of introduced wild pigs in the United States is longer than had been heretofore reported. However, because the predation by these species is largely opportunistic in nature, the impact on local wild pigs on an annual basis would be minor under most circumstances. Mountain lions appear to be the only predator that uses wild pigs as prey on a regular basis, the percentage of wild pigs in their diet appearing to be prey density dependent in any one given area. With the possible exceptions of the alligator and black bears, most other species identified above would constitute only an incidental or infrequent opportunistic predator of immature wild pigs. 
Table 1. List of natural predators of wild pigs within the native portion of the latter's species range.

\begin{tabular}{|c|c|c|c|}
\hline Common Name & Scientific Name & $\begin{array}{l}\text { Component of Wild Pig } \\
\text { Population Impacted }\end{array}$ & Reference \\
\hline \multicolumn{4}{|c|}{ Reptiles } \\
\hline Burmese Python & $\begin{array}{c}\text { Python molurus } \\
\text { bivittatus }\end{array}$ & $\begin{array}{l}\text { All age classes; mostly } \\
\text { immature animals }\end{array}$ & Mehrtens 1987 \\
\hline $\begin{array}{c}\text { Indian or Indian Rock } \\
\text { Python }\end{array}$ & Python molurus molurus & $\begin{array}{l}\text { All age classes; mostly } \\
\text { immature animals }\end{array}$ & Mehrtens 1987 \\
\hline Reticulated Python & Python reticulatus & $\begin{array}{l}\text { All age classes; mostly } \\
\text { immature animals }\end{array}$ & $\begin{array}{c}\text { Shine et al. 1998, Auliya } \\
\text { and Abel } 2000\end{array}$ \\
\hline Saltwater Crocodile & Crocodylus porosus & All age classes & $\begin{array}{l}\text { Messel and Vorlicek } \\
1989\end{array}$ \\
\hline Mugger Crocodile & Crocodylus palustris & All age classes & $\begin{array}{c}\text { Guggisburg 1972, } \\
\text { Whitaker and Whitaker } \\
1989\end{array}$ \\
\hline \multicolumn{4}{|c|}{ Birds } \\
\hline Eurasian Eagle Owl & Bubo bubo & Very young piglets & Briedermann 1986 \\
\hline Golden Eagle & Aquila chrysaetos & Very young piglets & Seguin et al. 1998 \\
\hline \multicolumn{4}{|c|}{ Mammals } \\
\hline Wolf & Canis lupus & $\begin{array}{l}\text { All age classes; mostly } \\
\text { immature animals }\end{array}$ & $\begin{array}{c}\text { Briedermann 1986, } \\
\text { Jedrzejewski et al. 1992, } \\
\text { 2000, Mattioli et al. } \\
\text { 1995, Głowaciński and } \\
\text { Profus } 1997\end{array}$ \\
\hline Red Fox & Vulpes vulpes & Very young piglets & $\begin{array}{c}\text { Snethlage } 1982, \\
\text { Briedermann 1986, } \\
\text { Goergen 1974, Kozlo } \\
1975\end{array}$ \\
\hline Dhole & Cuon alpinus & $\begin{array}{l}\text { All age classes; mostly } \\
\text { immature animals }\end{array}$ & $\begin{array}{l}\text { Prater 1965, Nowak } \\
\text { 1999, Grassman et al. } \\
2005\end{array}$ \\
\hline Brown Bear & Ursus arctos & All age classes & $\begin{array}{c}\text { Rakov 1963, Prater } \\
\text { 1965, Nasimovic 1966, } \\
\text { Danilov 1983, } \\
\text { Briedermann } 1986\end{array}$ \\
\hline
\end{tabular}




\section{Wild Pigs}

Table 1. List of natural predators of wild pigs within the native portion of the latter's species range. (Continued)

\begin{tabular}{|c|c|c|c|}
\hline Common Name & Scientific Name & $\begin{array}{l}\text { Component of Wild Pig } \\
\text { Population Impacted }\end{array}$ & Reference \\
\hline Asian Black Bear & Ursus thibetanus & All age classes & Prater 1965 \\
\hline Striped hyenas & Hyaena hyaena & $\begin{array}{l}\text { All age classes; mostly } \\
\text { immature animals }\end{array}$ & $\begin{array}{c}\text { Heptner and Sludskij } \\
1980\end{array}$ \\
\hline Yellow-throated Marten & Martes flavigula & Very young piglets & Nasimovic 1966 \\
\hline Snow Leopard & Uncia uncia & $\begin{array}{l}\text { All age classes; mostly } \\
\text { immature animals }\end{array}$ & $\begin{array}{l}\text { Nasimovic 1966, } \\
\text { Hemmer } 1972\end{array}$ \\
\hline Clouded Leopard & Neofelis nebulosa & $\begin{array}{l}\text { All age classes; mostly } \\
\text { immature animals }\end{array}$ & $\begin{array}{c}\text { Prater 1965, Nowak } \\
1999\end{array}$ \\
\hline Jungle Cat & Felis chaus & Very young piglets & Nasimovic 1966 \\
\hline Fishing Cat & Felis viverrina & Very young piglets & Nasimovic 1966 \\
\hline European Wildcat & Felis sylvestris & Very young piglets & Briedermann 1986 \\
\hline Leopard & Panthera pardis & All age classes & $\begin{array}{c}\text { Nasimovic 1966, Eaton } \\
\text { 1973, Grassman } 1999\end{array}$ \\
\hline Lynx & Lynx lynx & $\begin{array}{l}\text { Mostly immature } \\
\text { animals }\end{array}$ & $\begin{array}{c}\text { Nasimovic 1966, } \\
\text { Jedrzejewski et al. } 1993\end{array}$ \\
\hline Asiatic Lion & Panthera leo persica & All age classes & $\begin{array}{c}\text { Prater 1965, Mitra 2006, } \\
\text { Khalaf-von Jaffa } 2006\end{array}$ \\
\hline Tiger & Panthera tigris & All age classes & $\begin{array}{c}\text { Prater 1965, Nasimovic } \\
\text { 1966, Schaller 1967, } \\
\text { Mazák 1981, } \\
\text { Briedermann 1986, } \\
\text { Miquelle et al. 1996, } \\
\text { Biswas and Sankar 2002 }\end{array}$ \\
\hline
\end{tabular}




\section{Literature Cited}

Auliya, M., and F. Abel. 2000. Zur Taxonomie, geographischen Verbreitung und Nahrungsökologie des Netzpythons (Python reticulatus) - Teil 2 (Nahrungsökologie). Herpetofauna, 22(128):19-28.

Barrett, R. H. 1971. Ecology of the feral hog in Tehama County, California. Ph.D. Dissertation, University of California, Berkeley, California.

Biswas, S., and K. Sankar. 2002. Prey abundance and food habit of tigers (Panthera tigris tigris) in Pench National Park, Madhya Pradesh, India. Journal of Zoology, 256:411-420.

Blennerhasset, (NFN). 1907. Wildcat and boar. Forest \& Stream, 68(24):935.

Briedermann, L. 1986. Schwarzwild. VEB Deutscher Landwirtschaftsverlag, Berlin, Democratic Republic of Germany.

Bruce, J. 1941. Mostly about the habits of the wild boar. California Conservationist, 6(5):14, 21.

Coleman, S. 1984. Control efforts in Great Smoky Mountains National Park since 1978. Pp. 15-20. In J. Tate (ed.), Techniques for controlling wild hogs in the Great Smoky Mountains National Park. Proceedings of a workshop, November 29-30. Research/Resources Mgmt. Rpt. SRE-72. U. S. Department of the Interior, National Park Service, Southeast Regional Office, Atlanta, Georgia.

Conley, R. H., V. G. Henry, and G. H. Matschke. 1972. Final report for the European hog research project W-34. Tennessee Game and Fish Commission, Nashville, Tennessee.

Cory, C. B. 1896. Hunting and Fishing in Florida. Estes and Lauriat, Boston, Massachusetts.

Craig, D. L. 1986. The seasonal food habits in sympatric populations of puma (Puma concolor), coyote (Canis latrans), and bobcat (Lynx rufus) in the Diablo Range of California. M.A. Thesis, San Jose State University, San Jose, California.

Danilov, P. L. 1983. The brown bear (Ursus arctos L.) as a predator in the European taiga. Acta Zoologica Fennica, 174:159-160.

Davis, W. B. 1978. The mammals of Texas. Texas Parks and Wildlife Department Bulletin No. 41. Austin, Texas.

Diong, C. H. 1982. Population biology and management of the feral pig (Sus scrofa L.) in Kipahula Valley, Maui. Ph.D. Dissertation, University of Hawaii, Honolulu, Hawaii.

DOI (Department of the Interior). 1997. Final rule to extend endangered status for the jaguar in the United States. Federal Register, 62(140):39,147-39,157.

Elman, R. 1974. The hunter's field guide to the game birds and animals of North America. Alfred A. Knopf. New York, New York.

Glenn, W. 1996. Eyes of fire: Encounter with a borderlands jaguar. Printing Corner Press, El Paso, Texas.

Głowaciński, Z., and P. Profus. 1997. Potential impact of wolves Canis lupus on prey populations in eastern Poland. Biological Conservation, 80:99-106.

Goergen, R. 1974. Fuchs reisst Frischlinge. Wild und Hund, 76(23):547.

Grassman, L. I., Jr. 1999. Ecology and behavior of the Indochinese leopard in Kaeng Krachan National Park, Thailand. Natural History Bulletin of the Siam Society, 47:77-93. 


\section{Wild Pigs}

Grassman, L. I., Jr., M. E. Tewes, N. J. Silvy, and K. Kreetiyutanont. 2005. Spatial ecology and diet of the dhole Cuon alpinus (Canidae, Carnivora) in north central Thailand. Mammalia, 69(1):11-20.

Guggisburg, C. A. W. 1972. Crocodiles: Their natural history, folklore and conservation. Stackpole Books. Harrisburg, Pennsylvania.

Hamilton, W. J., Jr. 1941. Notes on some Mammals of Lee County, Fla. American Midland Naturalist, 25:686-691.

Hanson, R. P., and L. Karstad. 1959. Feral swine in the southeastern United States. Journal of Wildlife Management, 23(1):64-74.

Hansroth, A. 2001. Coyotes, habitat losses take toll on boar. Charleston Sunday Gazette-Mail, June 10:9E.

Harper, F. 1927. Mammals of the Okefenokee Swamp. Proceedings of the Boston Society of Natural History, 38:191-380.

Hediger, H. 1968. The psychology and behaviour or animals in zoos and circuses. Dover Publications, Inc., New York.

Heptner, V. G., and A. A. Sludskij. 1980. Die Säugetiere der Sowjetunion. Vol III: Raubtiere (Feloidea). VEB Gustav Fischer Verlag, Jena, Germany.

Hemmer, H. 1972. Uncia uncia. Mammalian Species, 20:1-5.

Hopkins, R. A. 1989. Ecology of the puma in the Diablo Range, California. Ph.D. Dissertation. University of California, Berkeley, California.

Igo, W. K. 1977. Wild Boar Thriving. Wonderful West Virginia, 40(12):12,14.

Jedrzejewska, B., H. Okarma, W. Jedrzejewski, and L. Milkowski. 1994. Effects of exploitation and protection on forest structure, ungulate density and wolf predation in Bialowieza Primeval Forest, Poland. Journal of Applied Ecology, 31:664-676.

Jedrzejewski, W., B. Jedrzejewska, H. Okarma, and A. L. Ruprecht. 1992. Wolf predation and snow cover as mortality factors in the ungulate community of the Bialowieza National Park, Poland. Oecologia, 90:27-36.

Jedrzejewski, W., K. Schmidt, L. Milkowski, B. Jedrzejewska, and H. Okarma. 1993. Foraging by lynx and its role in ungulate mortality: The local (Bialowieza Forest) and the Palearctic viewpoints. Acta Theriologica, 38:385-403.

Jenkins, J. H., and E. E. Provost. 1964. The population status of the larger vertebrates on the Atomic Energy Commission Savannah River Plant site. Office of Technical Services, Department of Commerce, Washington, DC.

Kamler, J. F., P. S. Gipson and C. C. Perchellet. 2002. Seasonal food habits of coyotes in northeastern Kansas. The Prairie Naturalist, 34(3/4):75-83.

Khalaf-von Jaffa, N. A. B. 2006. The Asiatic or Persian Lion (Panthera leo persica, Meyer 1826) in Palestine and the Arabian and Islamic Region. Gazelle (The Palestinian Biological Bulletin), 58:1-13.

Kight, J. 1962. An Ecological Study of the Bobcat, Lynx rufus (Schreber), in West-central South Carolina. M.S. Thesis, Univ. Georgia, Athens. 
Kozlo, P. G. 1975. Dikiy Kaban. Izdatel'stovo Uradzhai, Minsk, U.S.S.R.

Kramer, R. J. 1971. Hawaiian Land Mammals. Charles E. Tuttle Company, Rutland, Vermont.

Kũbarsepp, M., and H. Valdmann. 2003. Winter diet and movements of wolf (Canis lupus) in Alampedja Nature Reserve, Estonia. Acta Zoologica Lituanica, 13(1):28-33.

Laycock, G. 1966. The alien animals. The Natural History Press, Garden City, New York.

Maehr, D. S., R. C. Belden, E. D. Land, and L. Wilkins. 1990. Food habits of panthers in southwest Florida. Journal of Wildlife Management, 54(3):420-423.

Maehr, D. S., J. C. Roof, E. D. Land, J. W. McCown, R. C. Belden, and W. B. Frankenberger. 1989. Fates of wild hogs released into occupied Florida panther home range. Florida Field Naturalist, 17(2):42-43.

Mattioli, L., M. Apollonio, C. Lovari, N. Siemoni, and G. Crudele. 1995. Wild boar as the main prey species of wolf in an area of northern Apennines (Italy). Journal of Mountain Ecology (Ibex), 3:212.

Mazák, V. 1981. Panthera tigris. Mammalian Species, 152:1-8.

McIlhenny, E. A. 1976. The alligator's life history. Society for the Study of Amphibians and Reptiles. Lawrence, Kansas.

McKnight, T. 1964. Feral livestock in Anglo-America, University of California Publications in Geology, Vol. 16. University of California Press, Berkeley and Los Angeles, California.

Mehrtens, J. M. 1987. Living snakes of the world. Sterling Publishing Company, Inc., New York.

Messel, H., and G. C. Vorlicek. 1989. Ecology of Crocodylus porosus in northern Australia. Pp. 163-184. in P. Hall and R. Bryant (eds.) Crocodiles. Their ecology, management and conservation. A Special Publication of the IUCN/SSC Crocodile Specialist Group. IUCN, Gland, Switzerland.

Miquelle, D. G., E. N. Smirnov, H. G. Quigley, M. G. Hornocker, I. G. Nikolaev and E. N. Matyushkin. 1996. Food habits of Amur tigers in Sikhote-Alin Zapovednik and the Russian Far East, and implications for conservation. Journal of Wildlife Research, 1(2):138-147.

Mitra, S. 2006. Gir Forest and the Saga of the Asiatic Lion. Indus Publishing Company, New Delhi, India.

Mondolfi, E., and R. Hoogesteijn. 1989. Notes on the biology and status of the Jaguar in Venezuela. Pp. 85-123. In S. D. Miller and D. D. Everett (eds.), Cats of the World: Biology, Conservation and Management. National Wildlife Federation, Washington DC.

Nowak, R. M. 1999. Walker's mammals of the world. $6^{\text {th }}$ Edition. The Johns Hopkins University Press, Baltimore, Maryland. Two Vol.

Okarma, H. 1995. The trophic ecology of wolves and their predatory role in ungulate communities of forest ecosystems in europe. Acta Theriologica, 40(4):335-386.

Orians. G., and F. Kuhlman. 1956. Red-tailed hawk and horned owl populations in Wisconsin. Condor, $58: 371-385$.

Prater, S. H. 1965. The book of Indian animals. Bombay Natural History Society, Bombay, India.

Rakov, N. V. 1970. O fakorakh smertnosti kabana i ego vzaimootnosheniyakh S Khshchnikami v Priamure. Zoologicheskii Zhurnal, 49(8):1220-1228. 


\section{Wild Pigs}

Roemer, G. W., T. J. Coonan, D. K. Garcelon, J. Bascompte, and L. Laughrin. 2001. Feral pigs facilitate hyperpredation by golden eagles and indirectly cause the decline of the island fox. Animal Conservation, 4(4):307-318.

Rue, L. L., III. 1968. Sportsman's guide to game animals: A field book to North American species. Harper \& Row, New York.

Rutledge, A. 1965. Demons of the delta. Sports Afield, 153(5):69, 167-170.

Schrecengost, J. D., J. C. Kilgo, D. Mallard, H. S. Ray, and K. V. Miller, Karl. 2008. Seasonal food habits of the coyote in the South Carolina coastal plain. Southeastern Naturalist, 7(1):135-144.

Seguin J. F., P, Bayle, J. C. Thibault, J. Torre, and J. D. Vigne. 1998. A comparison of methods to evaluate the diet of golden eagles in Corsica. Journal of Raptor Research, 32(4):314-318.

Shine, R., P. S. Harlow, J. S. Keogh and Boeadi. 1998. The influence of sex and body size on food habits of a giant tropical snake, Python reticulatus. Functional Ecology, 12:248-258.

Shoop, C. R., and C. A. Ruckdeschel. 1990. Alligators as predators on terrestrial mammals. American Midland Naturalist, 124:407-412.

Snethlage, K. 1982. Das Schwarzwild. 7th Edition. Verlag Paul Parey, Hamburg and Berlin, West Germany.

Snow, R. W., M. L. Brien, M. S. Cherkiss, L. Wilkins, and F. J. Mazzotti. 2007. Dietary habits of Burmese python, Python molurus bivittatus, from Everglades National Park, Florida. Herpetological Bulletin, 101:5-7.

Stegeman, L. J. 1938. The European wild boar in the Cherokee National Forest, Tennessee. Journal of Mammalogy, 19(3):279-290.

Stevens, R. L. 1996. The feral hog in Oklahoma. Samuel Roberts Noble Foundation, Ardmore, Oklahoma.

Sweeney, J. M., and J. R. Sweeney. 1982. Feral hog. Pp. 1099-1113. In J. A. Chapman and G. A. Feldhammer (eds.), Wild mammals of North America: Biology, management, and economics. The Johns Hopkins Univ. Press, Baltimore, Maryland.

Taylor, R. 1991. The feral hog in Texas. PWD-BK-7100-195-10/91, Federal Aid Report Series No. 28, A contribution of Federal Aid (P-R) Project W-125-R. Texas Parks \& Wildlife Department, Austin, Texas.

Tewes, M. E., J. Young, L. L. Laack, and S. E. Hayslette. 1998. Dietary overlap of co-occurring ocelots and bobcats. Pp. 56-57. In Report of current research - July 1, 1997 to June 30, 1998. Caesar Kleberg Wildlife Research Institute, College of Agriculture and Human Sciences, Texas A\&M UniversityKingsville, Kingsville, Texas.

Tomich, P. Q. 1969. Mammals in Hawaii. $1^{\text {st }}$ Edition. Special Publication 57. Bishop Museum Press, Honolulu, Hawaii.

Turnbo, S. C. 1988. Turnbo's tales of the Ozarks: Bear stories. Edited By D. W. Allen. Arkansas Research, Conway, Arkansas.

Wagner, G. D. 1993. Coyote diet in areas of wild turkey abundance during the wild turkey reproductive season. M.S. Thesis, Mississippi State University, Mississippi State, Mississippi. 
Wennrich, G. 1976. Eine Bemerkung zum Kannibalismus bei Wildschweinen (Sus scrofa). Deutsche Tierärztliche Wochenschrift, 83(2):68.

Whitaker, R., and Z. Whitaker. 1989. Ecology of the mugger crocodile. Pp. 276-296. In IUCN Crocodilian Species Specialist Group. Crocodiles: Their ecology, management, and conservation. IUCN Publication New Series. International Union for the Conservation of Nature and Natural Resources, Gland, Switzerland.

Wood, G. W., and R. E. Brenneman. 1977. Research and management of feral hogs on Hobcaw Barony. Pp. 23-35. In G. W. Wood (ed.), Research and management of wild hog populations. Belle Baruch Forest Science Institute of Clemson University, Georgetown, South Carolina.

Yoho, N. S., and V. G. Henry. 1972. Foods of the gray fox (Urocyon cinereoargenteus) on European wild hog (Sus scrofa) range in east Tennessee. Journal of the Tennessee Academy of Sciences, 47(2):77-79.

Young, S. P. 1958. The Bobcat in North America. The Stackpole Company, Harrisburg, Pennsylvania. 
Wild Pigs

\section{Biology of Wild Pigs:}

\section{Wild Pig Field Sign}

John J. Mayer

Savannah River National Laboratory, Savannah River Nuclear Solutions, LLC, Savannah River Site, Aiken, South Carolina 29808

\section{Introduction}

The distribution of the introduced wild pigs (Sus scrofa) has recently been expanded in the United States (Gipson et al. 1998). This range increase is largely manmade, and is anticipated to encompass additional states in the near future. The control of new populations of this invasive species is most successful if such efforts can begin immediately following the establishment of these animals in an area. It is important, then, to be able to rapidly identify the presence of these animals in areas where wild pigs had heretofore been absent.

Wild pigs can be secretive in their behavior, shifting activity patterns to avoid being readily observable by humans (Goulding 2003). The presence of these animals in an area may therefore not be verifiable by the direct observations of either animals or their physical remains. However, the presence of wild pigs in an area can be readily identified from the field sign that these animals leave (Mayer and Brisbin 1991, Goulding 2001). In fact, wild pigs can leave a diverse variety of visible evidence or impacts. The ability to accurately make such identifications is vital to being able to verify the new presence of wild pigs in areas where control of these animals is desired. Further, the absence of such field sign would corroborate the successful removal of these animals following an eradication program. The purpose of this paper is to review these various types of field sign made by wild pigs.

The characterization of the different type of wild pig field sign were based on descriptions in the literature and field data collected by the author at the Savannah River Site (SRS), located in central western South Carolina. Information from the literature included data from North America as well as in the native range in Eurasia. Those observations not specifically credited to a cited reference were made by the author in the field.

\section{Results/Discussion}

The different types of field sign made by wild pigs are discussed in the following paragraphs:

Rooting - The most common and evident field sign created by wild pigs is rooting. This was the first field sign noted when the escaped wild boar began to establish themselves in southern England in the mid to late 1980s (Goulding 2003). Rooting is very simply the result of wild pigs foraging for food located in either the leaf litter or below the surface of the ground. These foods can variously include hard and soft mast, newly emergent tips of shoots, roots, tubers, bulbs, rhizomes, subterranean fungi, both adult and larval invertebrates, and even some smaller vertebrate species (Ditchkoff and Mayer, this volume). Rooting is typically conducted with the end of the animal's snout being used to excavate soil in a forward pushing/scooping motion. The animal's feet are infrequently used in a pawing motion to supplement the snout actions. Rooting is done by all wild pigs, regardless of sex or age. However, although wild piglets will root from their first day of life, adult wild pigs appeared to have been responsible for most of the rooting in a large forested area of the Netherlands (Groot Bruinderink and Hazebroek 1996). Rooted areas can be extensive, sometimes covering large areas or entire fields (Fig. 1). The size of the area rooted depends upon the number of wild pigs involved and the forage resource(s) being sought (Waithman 2001). 
However, caution should be used in attempting to estimate the number of wild pigs based on the amount of rooting; a few pigs can root up extremely large areas (Anon. 2003).

Rooting by this omnivorous species can take on a number of forms. The general type of wild pig rooting can be classified into one of three categories including: (1) pit rooting, (2) trench rooting, or (3) area rooting. Pit rooting involves the directed foraging for a specific localized food item. Such rooting can consist of a shallow hole down to a deep-sided crater, up to $120 \mathrm{~cm}$ in depth. Trench rooting consists of an elongate excavated ditch typically one or more meters in length. The last category, area rooting, entails large areas of continuous rooting. This can be from a few square meters up several hectares in size. Several factors are involved in this variability, including the target resource, and the age and social unit being occupied by an individual at the time of actively foraging. Adults of both sexes tend to root systematically in deep regular patterns. Subadults and yearlings root more shallow and irregular patches. Piglets and juveniles dig up shallow spots in an erratic and haphazard manner (USAREUR 1965, J. J. Mayer, unpubl. data). The three types of rooting also vary in depth. Groot Bruinderink and Hazebroek (1996) classified rooting into three types based on depth: superficial litter rooting, organic topsoil rooting, and mineral soil rooting. Of these, the superficial type was by far the predominant form of rooting. Barrett (1971) noted that a wild pig's manner of rooting was dependent not only upon the food being sought, but also on the moisture content of the soil. Other species [e.g., nine-banded armadillo (Dasypus novemcinctus), eastern gray squirrel (Sciurus carolinensis), and raccoon (Procyon lotor)] also excavate soil that can look similar to the variable rooting of wild pigs. The presence of tracks (see next section) can be used to confirm the species responsible for such digging activity.

The type of habitats where wild pigs will root is extremely variable and can be determined by several factors. For example, the location of rooting in different vegetation types in east Tennessee appeared to be related to elevational movement in response to changes in ambient temperatures, food availability, and farrowing activity (Belden and Pelton 1975). Rooting can be found in soils that range from relatively dry to completed inundated conditions. Zengel and Conner (2008) found a positive association between the frequency of rooting and the presence of coarse woody debris in floodplain wetland and stream habitats. Wilson (2003) found that most rooting by escaped wild boar in an agricultural area in southern England was concentrated in grasslands and fields with standing grain crops. Groot Bruinderink and Hazebroek (1996) found that the frequency of rooting was greater in deciduous forest as compared to coniferous forest and heathland. In east Tennessee, wild pigs rooted in hemlock (Tsuga spp.) and closed-type oak (Quercus spp.) forests in the spring, in northern hardwood forests during the warmer spring months and summer, and in the closed-type oak forests and open fields during the fall and winter (Belden and Pelton 1975). Barrett (1971) found that the mast crop appeared to affect the intensity of rooting in certain habitats. When the mast was good, rooting significantly increased in the oak thickets. During poor mast years, other habitats receive higher that expected rooting intensity.

Rooting is done year-round in search of food (Barrett 1971, Belden and Pelton 1975). However, depending upon the location, the frequency and intensity of rooting by wild pigs can be seasonal. In an agricultural area in England, most (74\%) rooting occurred between January through March (Wilson 2003). Within forests in the Netherlands, Groot Bruinderink and Hazebroek (1996) found no seasonal differences in rooting, but did find that rooting frequencies were higher in rich as opposed to poor mast years. Barrett (1971) found that rooting was heaviest in open habitats in the summer; this shifted in the late fall and winter to oak stands and around brush, where the pigs searched for insects and larvae. Ackerman et al. (1978) found that in fall and winter rooting in the Great Smoky Mountains National Park (GSMNP), only the litter layers were disturbed by searching for mast in all habitats except the successional tulip poplar (Liriodendron tulipifera) stands; in contrast, rooting during the spring and summer was at higher elevations and was much more extensive in nature.

Tracks - The tracks of a wild pig are typical of most large cloven-hoofed mammals. However, unlike most ungulate species, wild pig tracks are distinctive in that the lateral toes or dewclaws (i.e., digits 2 and 5) are evident in many of the prints left. This is a result of the lateral toes being located very low on each leg. The exception to this is on very hard ground; however, a very careful examination will usually result in at least a minor imprint of the lateral toes being found. Wild pig tracks tend to be more rounded or circular in general overall shape, being as long as they are wide (Fig. 2, Waithman 2001). Typically, the tracks of 
adult wild pigs range from 5 to $8 \mathrm{~cm}$ in length and 4 to $8 \mathrm{~cm}$ in width (Diong 1973). The central toes are large, with only a small space between them at the back. The inner and outer margins of the prints taper to form a somewhat pointed tip at the front of the track print. The lateral toe prints, generally triangular or crescent shaped, are located to the outside and behind the central toes. The hooves or toes on the front feet are slightly larger, being physically longer and proportionately wider than those of the rear feet. In addition, the lateral toes on the front feet are closer and slightly positioned more to the outside in comparison to those of the rear feet. The track of younger animals are simply smaller replicas of the adult tracks (i.e., varying from approximately 2 to $7 \mathrm{~cm}$ in both length and width, Diong 1973); however, except in soft substrates (e.g., deep mud or snow) the dewclaws are seldom present in the prints of piglets and shoats. Tracks of syndactylous or "mule-footed" wild pigs exhibit a single rounded central triangular print flanked by the lateral or dewclaw prints (Fig. 2).

When walking, wild pigs typically place their feet in a heel-to-toe pattern such that the hind prints often almost perfectly overlap the front prints. The front two toes tend to point outward from the medial line of the track pattern. The prints also straddle the medial line of the path being traveled. The spacing for these groups of tracks along this line typically ranges from 25 to $48 \mathrm{~cm}$, and would be dependent upon the size of the animal and the speed at which it was walking or trotting. When running, the tracks are often placed in groups of four with a further distinct pairing of the front and rear pairs. The hoof prints of a running pig are splayed widely and the lateral toes can be very distinct.

Tracks can also be used to determine a number of things about the animal that made them. For example, the tracks can be used to tell which direction the animal was heading, about what size the animal was, whether or not the animal was in a hurry, and, in combination with other factors (e.g., the presence of feeding sign or tracks of other animals), what the animal in question was generally doing. Based on the freshness of the tracks left, one can further estimate how recently the animal passed through the area being study. Both soil type and meteorological conditions should be taken into account when trying to "age" wild pig tracks.

Being found in the same habitats, wild pigs and deer (Odocoileus spp.) often use the same trails and leave tracks in the same general areas. The most significant differences used to distinguish wild pig tracks from deer tracks are the tips of the central toes and the presence of the dewclaws. The tips of deer hooves are pointed, and the angle of the toes forms a fairly distinct "V." Being more blunt/rounded and splayed away from the central line of the print, the central toes of wild pig tracks form a rounded "W." Deer tracks are also more elongate compared to the rounded/circular wild pig track. In mud or snow, and sometimes when the animal is running very fast, deer tracks can have dewclaw marks. However, the lateral toes on deer are almost in line with the central toes and are positioned higher up the limb. This difference is readily apparent when compared to the more closely positioned dewclaws to the central toes in a wild pig.

Trails - The game trails used by wild pigs are normally the same ones used by other big game occupying the local area. Visibly well worn or cleared paths through brush are the key to look for. These are most obvious when they intersect roads or other open habitats. The use of these trails by wild pigs is specifically confirmed by the presence of tracks. Barrett (1971) noted that wild pigs will continue to use defined trails or paths, even when they travel across wide, open areas. That author further noted that most wild pig trails follow the shortest possible route from one point of interest (e.g., bedding area, water source) to another, regardless of the topography or vegetation. Wild pigs will create shorter or lower-topped (i.e., tunnel) trails through thick underbrush than deer typically do. In some cases, trails may be exclusively used by wild pigs. For example, trails that go straight up a steep hill indicate the presence of wild pigs. Other animals tend to make trails that angle up such slopes (Kramer 1971, Waithman 2001).

Wild pigs will also variously use manmade hiking trails, foot paths, and unpaved secondary roads located within areas which they inhabit. The use of the latter thoroughfare is often more frequent than one might imagine. On the other hand, it is easy to understand that moving along an open roadway, even one that's unpaved is less demanding than moving through thick brush along a game trail through a thicket. In short, when wild pigs can take the easy route, they often will. Normally, these animals will enter one of these manmade roads on a game trail, traveling down the road for a short distance (e.g., up to approximately 50 to $100 \mathrm{~m}$ ), then exiting the road on another game trail. However, some individual wild pigs will also travel these secondary roads and jeep trails for considerable distances. A few wild pigs have been observed to 
travel up to one kilometer or more along such roadways on the SRS. Meandering down the road, these animals were noted to occasionally stop to apparently investigate potential foods before moving on.

Scats - The scats or droppings of a wild pig can vary widely depending on the material having been eaten and the size of the animal that produced it. In general, most are irregularly shaped lumps approximately 3-7 $\mathrm{cm}$ thick and 7-22 cm in length (Anon. 2003). The color may vary from light brown to black, and may have a purplish hue when fresh (Goulding 2003). Frequently, wild pig scats resemble a segmented sausage composed of compacted fecal material. The consistency of the scats will also vary with the foods being consumed. Oak acorns will produce scats which are hard and black in color, with scattered pieces of brown acorn shell present throughout the fecal material. Such scats dry very quickly after being produced. At the other extreme, persimmons (Diospyrus virginiana) or plums (Prunus spp.) will produce scats which are soft and lighter brown in color, with scattered fragments of black or reddish material present. These latter scats also remain moist longer. Most wild pig droppings are short-lived (Stevens 1996), turning gray over time and breaking into separate droppings (Goulding 2003). However, Hone and Martin (1998) found that some scat can persist up to 16 months in southeastern Australia, with over $50 \%$ disappearance within 2-5 months, depending upon the season.

Wallows - Because of the need to cool themselves and get relief from external parasites and biting insects, wild pigs use wallows (Fig. 3). Wallowing behavior occurs year-round (Belden and Pelton 1976, Stegeman 1938); however, it is especially pronounced in the summer months (Crouch 1983, Stevens 1996). Stegeman (1938) reported that wild pigs would even break ice to use wallows in the winter. Wallows can be present in almost any type of low-lying or wet areas. For example, Belden and Pelton (1976) reported that $57 \%$ of the wallows were found in muddy depressions in well-traveled foot trails, while the remaining $43 \%$ were found in and around small streams with slow-moving water. Stegeman (1938) described the location of wallows in eastern Tennessee as being near the upper ends of the higher coves, in shaded, cool and wet places. Kramer (1971) noted that in the ranch and pastureland areas in Hawaii, wild pigs form wallows in the soft mud along the edges of reservoirs. In the Hawaiian forests, wallows are found in patches of boggy ground, seep springs, and rain-created mud puddles. Seventy-one percent of the wallows found at the SRS were located in bottomland forest. Most of the remainder were located in wet areas in planted pine forest. Wallows have also been found in the deep ruts of unpaved secondary roads on SRS. Conley et al. (1972) also reported that wild pig wallows have been found in mud puddles in old roads as well as in the lateral drainage ditches along these roads.

The wallow itself is typically a shallow, muddy depression that is oval to oblong in shape (Belden and Pelton 1976). Depending on the substance involved, the sides of the wallow are often smooth where the animal has rolled (Goulding 2003). The shape is, of course, dependent upon the size of the animal or animals using any one specific wallow. The largest wallows appear to have been used by several animals at one time (Belden and Pelton 1976). Multiple wallows can also be found in close proximity to one another. For example, eleven distinct wallows were observed in an area approximately six $\mathrm{m}$ in diameter in a drying slough in the SRS riverswamp. Belden and Pelton (1976) reported the average size of wallows in east Tennessee as being $1.3 \mathrm{~m}$ long by $1.0 \mathrm{~m}$ wide by $0.2 \mathrm{~m}$ deep. These dimensions varied 0.6 to $2.2 \mathrm{~m}$ long and 0.3 to $1.5 \mathrm{~m}$ wide. At the SRS, 25 wild pig wallows ranged from 0.9 to $2.0 \mathrm{~m}$ long by 0.5 to $1.5 \mathrm{~m}$ wide. The seasonal location of wallows in the GSMNP corresponds to the elevational change in home range by the wild pigs in the park (Belden and Pelton 1976). All wallows have trails leading into or out of them. Mud is also almost always evident on the trees and vegetation that surround the trails entering or exiting the wallow. This mud is left by either casual contact or intentional rubbing. Stegeman (1938) described the vegetation around the wallow as being heavily trampled and smeared with mud. Some wallows are very temporary in nature, drying up after only one spring or summer of use. Certain wallows can receive use over extended periods. For example, one such wallow at the SRS has been repeatedly used by the local wild pigs for over 27 years.

Rubs - Wild pig rubs, although most often associated with wallows, can also be found alone. Rubs are, very simply, where wild pigs rub up against trees, fence posts, rocks, telephone poles, or other immovable objects (Figs. 4 and 5). Tree rubs are often found near trails that wild pigs use regularly (Barrett 1971, Waithman 2001), especially those near wallows (Stegeman 1938). Rubbing by wild pigs functions to scratch and remove mud, hair, and ectoparasites. Wild pigs often suffer from substantial infestations of hog 


\section{Wild Pigs}

lice (Haematopinus suis) and ticks. Wallowing in mud serves to immobilize these parasites, and rubbing then mechanically removes them. Wild pigs also rub on medium- to large-sized pine trees (Pinus spp.) and creosoted telephone poles and fence posts. The pine resin or pole/post creosote apparently either serves to repel or immobilize hog lice and ticks (Kramer 1971, J. J. Mayer, unpubl. data). Muddy, smoothly-rubbed bands on trees, poles, or posts are located between 10 and $94 \mathrm{~cm}$ above the ground (Stegeman 1938), and often completely encircle the structure being rubbed. Rutledge (1965) reported rubs in the Santee River delta of South Carolina being as high as $140 \mathrm{~cm}$ on trees. In addition, wild pig bristles are often found in the mud or are caught in the rough surface of the structure being rubbing. Wild pigs will travel long distances to a particular pine tree or telephone pole to use as a rubbing post. In some cases, certain trees were used so often that the bark is completely rubbed off (Kramer 1971). Stegeman (1938) noted that the rubbing was so severe on several trees ranging from 3 to $20 \mathrm{~cm}$ in diameter that the trees were killed. A few pine trees at the SRS have been girdled and killed by this type of excessive use, but the frequency of that impact is uncommon (F. A. Brooks, pers. comm.).

Stegeman (1938) reported that, although other species of trees were used, wild pigs in east Tennessee usually chose pitch pine ( $P$. rigida) of less than $15 \mathrm{~cm}$ in diameter for a rubbing tree. All of the wild pig wallows found on the SRS had rubs located in close proximity. These rubs varied from 2 to $125 \mathrm{~cm}$ in diameter at breast height, and included a variety of both pine and hardwood species. Typically, these rubs involved the trees that were located immediately adjacent to the wallow or trails leading into and out of the area, and were not limited to certain species. Isolated rubs at the SRS included only pines and creosoted fence posts and telephone poles.

The height of a muddy rub can give an indication of the relative height of the wild pig that created it (Stegeman 1938, Rutledge 1965, Waithman 2001). However, when pigs rub against an object, the animals tend to arch their backs giving a greater appearance to their height than the rub would indicate. Aggressive rubbing by very mud-coated pigs can also result in mud being flipped or thrown higher than the animal's back.

Feeding Sign - Being omnivorous in their food habits, wild pigs can leave a variety of other feeding sign. This would of course vary depending upon the resource(s) that any one animal is seeking. The most obvious would be rooting (see previous section on rooting). Direct foraging on agricultural crops (e.g., corn plants knocked down and trampled), pine/hardwood seedlings (i.e., plants rooting out of the ground and the root stock consumed, Mayer et al. 2000), lateral roots of pine trees, prickly pear cactus (Opuntia spp.) pads/fruits, the eggs of ground-nesting birds, turtles and crocodilians, and carrion can all be used to identify the presence of wild pigs. Wild pig tracks associated with the aforementioned feeding sign can be used to verify the identification of these animals. Foraging wild pigs will also displace and dig/chew into decomposing logs to locate insects and small vertebrates (Singer et al. 1984).

Scent Marks - Although wild pigs actively scent mark (Mayer and Brisbin 1986), the specific identification of these field sign can be difficult. Of the four types of scent marking commonly done by wild pigs, the only ones that leave readily-identifiable evidence are from using either the metacarpal or the tusk glands. Scent marking with the metacarpal glands results in a bare spot of ground with pawing marks in parallel positions in the open area. Unfortunately, having been created in much the same manner, this can be easily confused with a whitetail buck's scraping activity. Wild pig tracks within or in close association with the bare spot can distinguish between the two. Trees or other scent posts that have been marked with tusk glands can be similarly difficult to identify. Trees tusked by male wild pigs result in the bark being removed and the bare wood exposed. Goulding (2003) described frequent tusking as producing a distinct "paisley" pattern in the bark. Tusked trees, typically not very thick in diameter, are found along trails frequently by mature boars (Goulding 2003). A tusked tree is somewhat similar in appearance to buck rub (Fig. 6). The two differences are that scent posts tusked by boars are typically not as intensely cut up (i.e., with a shredded or frayed appearance to the bark) or as high up on the post as buck rubs. Both Barrett (1971) and Stegeman (1938) noted that tusked trees were usually rubbed as well. Tusking may also secondarily function to increase the resin flow of pines being rubbed.

Fence Crossings - Given strong neck muscles and the ability the lift heavy things with their snouts, wild pigs tend to create a lot of openings either under or through wire fences. Goulding (2003) described the 
opening as an arch, characteristic of having been made by wild pigs (Fig. 7). As these animals create and then use these crossings, bristles become caught in the twisted barbs of strand fencing or the joints on woven wire fences. Such hairs left at these crossings are clear evidence that wild pigs are present in the local area. However, given the durability of wild pig bristles, these hairs can last in these situations easily for several months. That being the case, it is recommended that all hairs present at crossings being monitored be removed when the fenced is checked. One should be careful when doing this to try to not touch the wire around the opening in the fence, inadvertently leaving human scent at the crossing. Periodic removal of the bristles present, in combination with the presence of other sign (e.g., tracks), will enable one to determine the how recently these fence crossing are being used. In addition to the bristles, mud can also be rubbed off on the wire bordering the openings of these fence crossings.

Nests and Beds - Wild pigs build two types of unique structures: (1) farrowing nests (Fig. 8), and (2) resting or loafing beds (Mayer et al. 2002). It is common in some areas to encounter both unoccupied nests and beds (Silver, 1974). Since these structures share some of the same general characteristics, it is not always possible to tell them apart (Mayer et al. 2002).

Farrowing nests are constructed by pregnant sows within $24 \mathrm{~h}$ prior to giving birth to their offspring (Mayer et al. 2002). The primary function of this type of structure has been theorized as providing the neonates with protection from inclement weather conditions (Briedermann 1986, Kurz, 1971, Nichols 1962). It can also serve as protective camouflage for hiding the newborn piglets from potential predators (Pullar, 1953; Crouch, 1983). The nests are typically round to oval in shape, and consist of a rooted-out area that is either unlined or lined with nesting material. Exceptions to this general shape included nests located between the root buttresses of large mature hardwood trees, where shapes (i.e., roughly triangular) were dictated by space available between the buttresses. The nests range in size from 1 to $2.5 \mathrm{~m}$ long and 0.5 to $2 \mathrm{~m}$ wide. Farrowing nests are consistently located in shallow depressions, approximately 4 to $18 \mathrm{~cm}$ deep, which are excavated by the sow. In general, the sows line the nests using material that was readily available in reasonably close proximity. These floral materials have variously included grass stems and leaves, reeds, fern fronds, tree/shrub leaves, pine straw, Spanish moss (Tillandsia usneoides), twigs/sticks, eastern hemlock (T. canadensis) boughs, and algaroba (Prosopis chilensis) branches and stems. This nesting material can vary from being non-existent up to a height of $1.2 \mathrm{~m}$. Some nests have dome-like covers made of vegetation. Nests found in either colder or more open habitats tend to be more elaborate than those found in warmer or more forested habitats, respectively. Nests are often constructed around or in conjunction with existing woody vegetation or structures (e.g., at the bases of large live trees, at the underside of the root mat of a large fallen tree, next to fallen tree trunks/logs, or in a manmade log pile). Sows most often select nest sites with protective overhead cover. Sows also often select secluded, undisturbed place with dense protective cover to build their farrowing nests. However, some nests are built in areas of open understory, which offer no visual protective cover or screening from potential predators (Mayer et al. 2002).

Wild pig resting or loafing beds are less complex than farrowing nests. These structures are used by either adult and/or immature animals for resting. As many as fifteen pigs have been observed occupying one bed (Frädrich 1984). The general shape of solitary beds is similar to that of the farrowing nests. The size and shape of the multiple-animal beds vary depending upon the number of wild pigs using the structure. In contrast to the farrowing nests, beds do not always consist of excavated depressions. Occasionally, a loafing bed will be encountered in late fall, winter, or early spring which will be lined with pine straw. One yearling boar was observed to be completely covered with pine straw in a loafing nest during the winter (Mayer et al. 2002).

\section{Summary}

In general, the more common the field sign, the higher the number of animals found in a given area. However, it is also disconcerting to note that very few wild pigs can generate an abundance of certain types of field sign (e.g., rooting). Further, caution should be exercised when isolated or minimal sign is located, especially those types of field sign that could have been made by other species. Confirmation of the presence of wild pigs in an area is best based on a combination of several types of field sign to corroborate the existence of these animals in areas where they have heretofore been absent. 


\section{Wild Pigs}
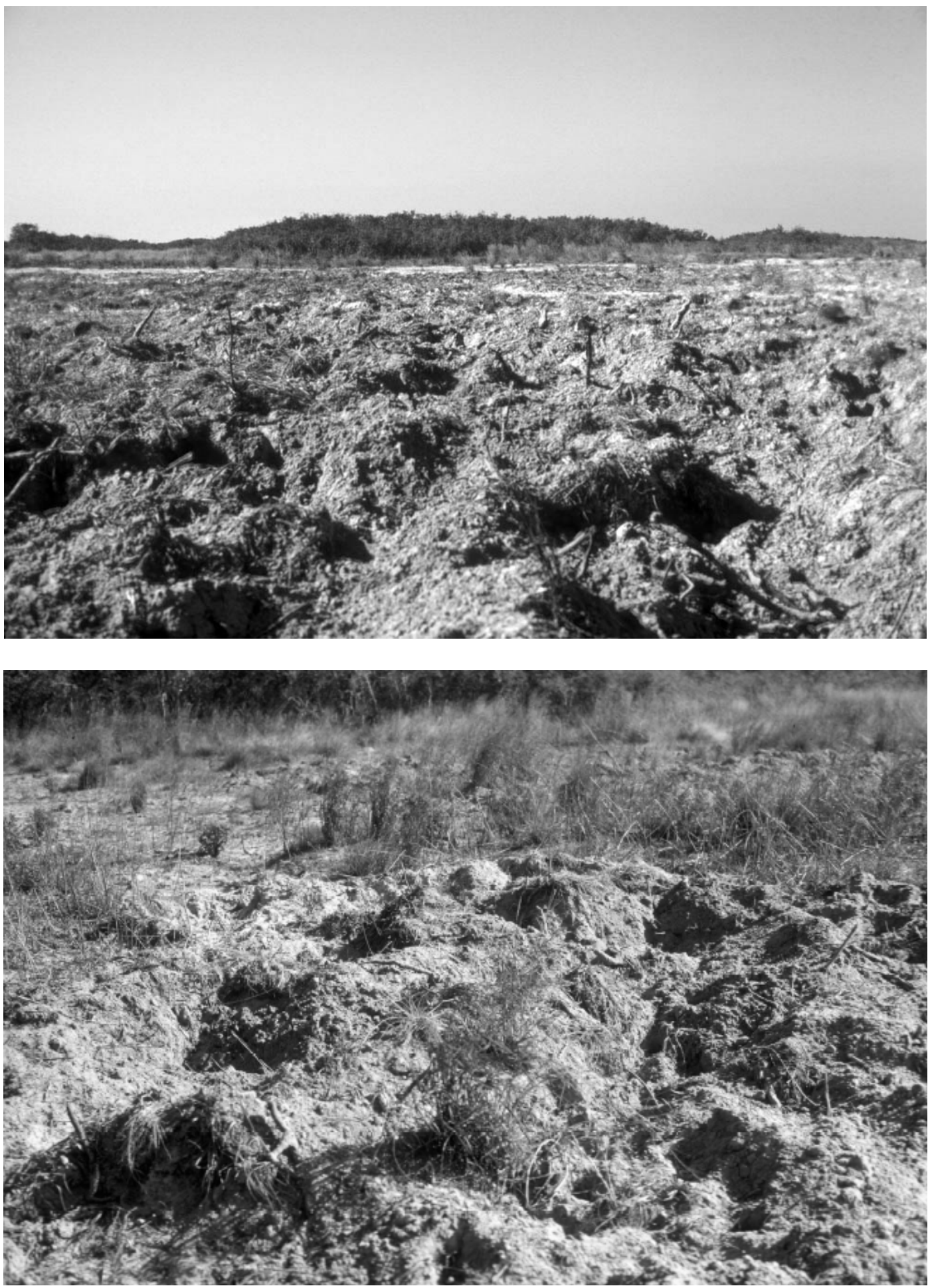

Fig. 1. Areas of wild pig rooting can be extensive. 


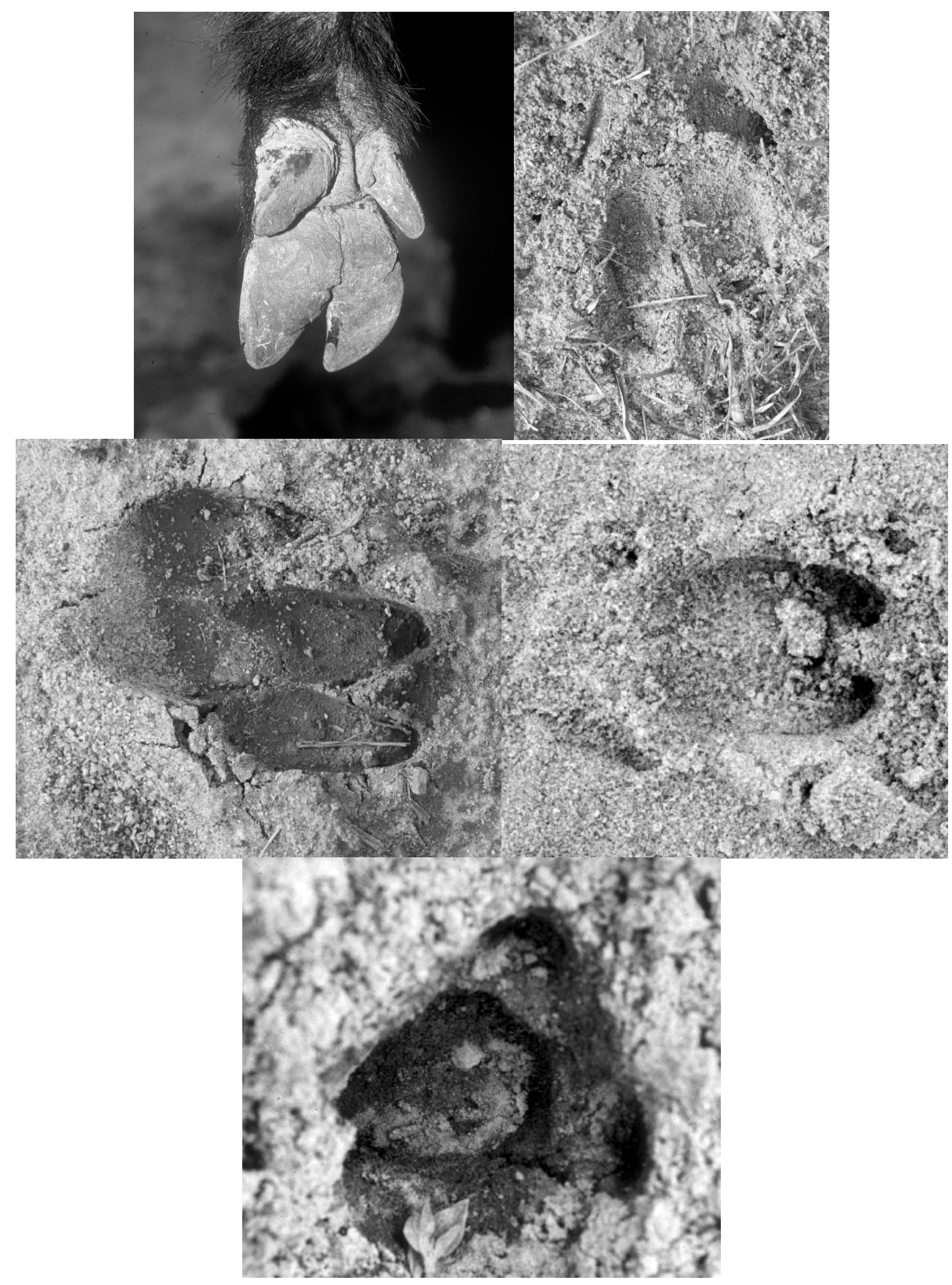

Fig. 2. Wild pig tracks can be variable. The top left photo is the forefoot of an adult boar. The top right, middle right and bottom photos show tracks with the lateral toe or dewclaw impressions visible in the track. The top right and both middle photos are of normal cloven-hoofed tracks; the bottom photo is of a syndactylous or "mule-footed" wild pig track. 
Wild Pigs
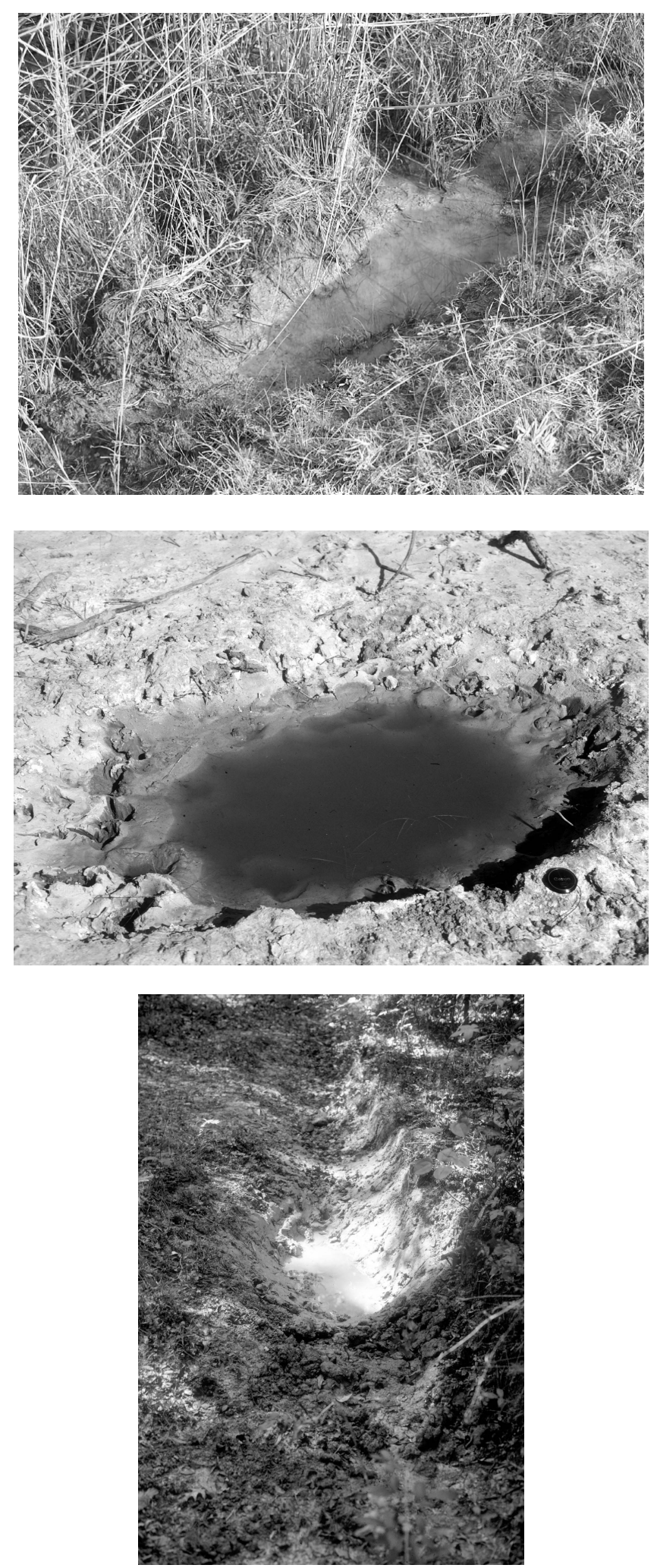

Fig. 3. Wild pig wallows. 


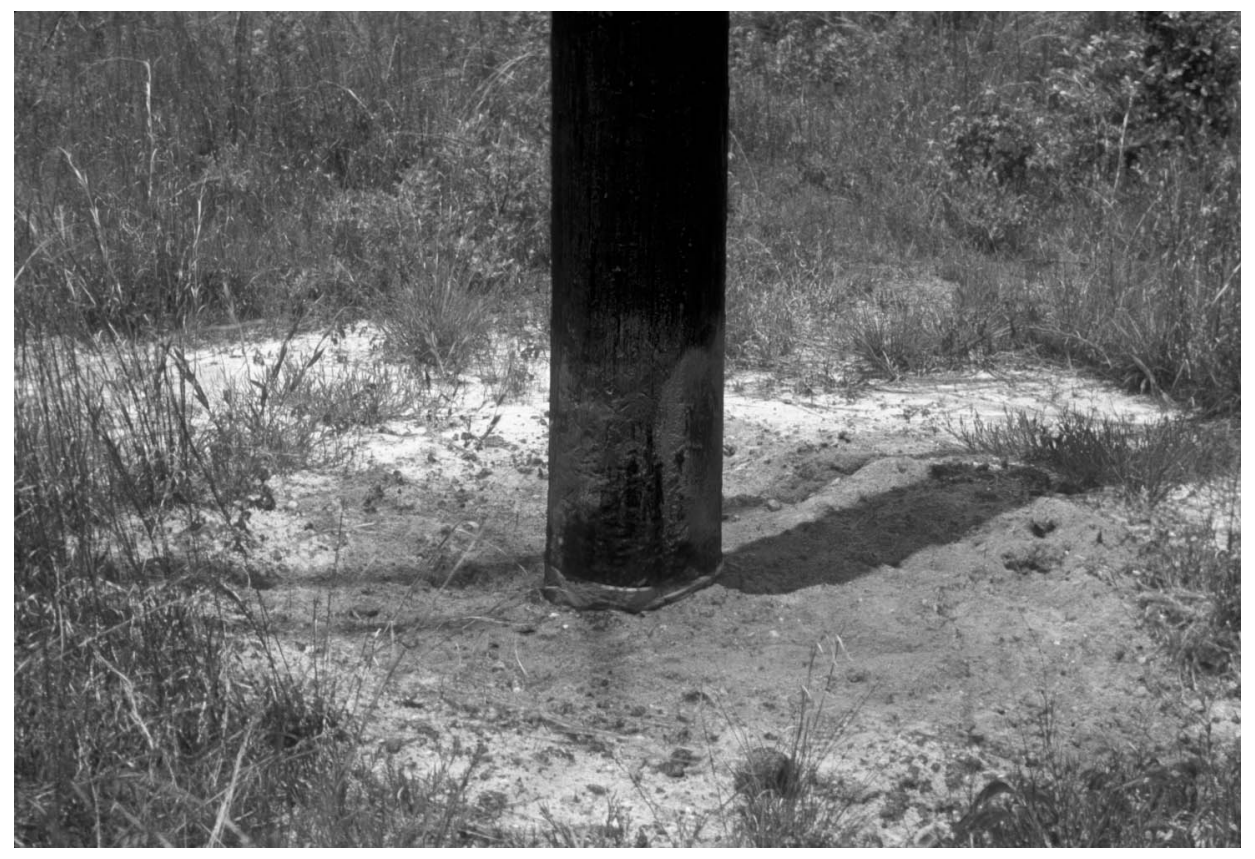

Fig. 4. Wild pig rub on a telephone pole.

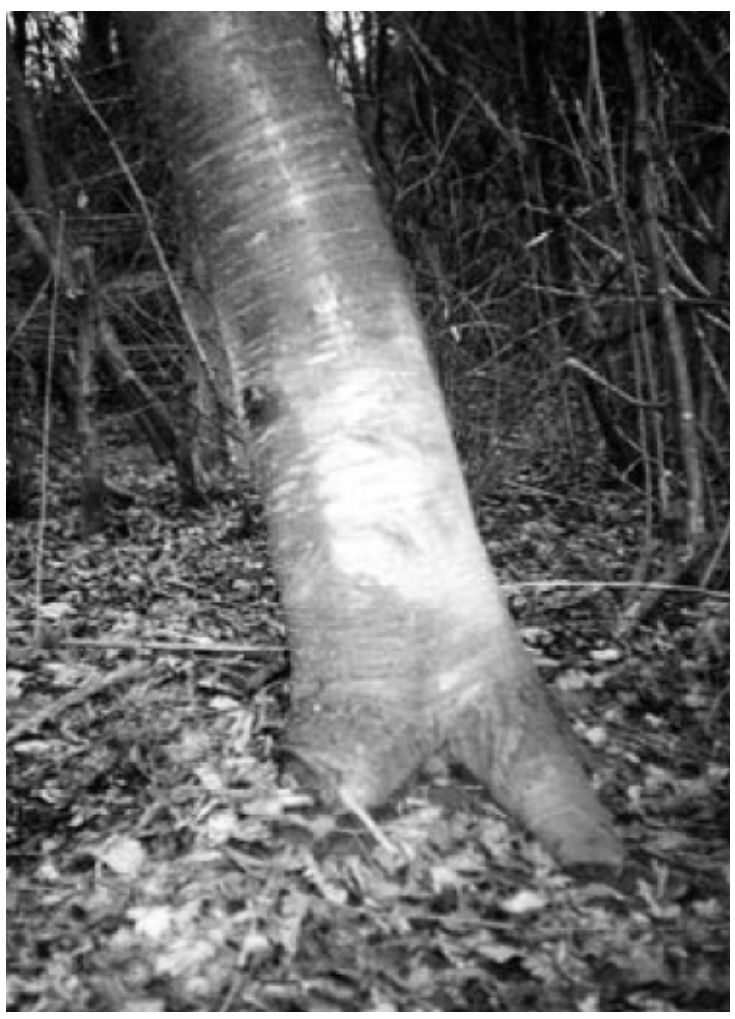

Fig. 5. Wild pig rub on a tree trunk. 


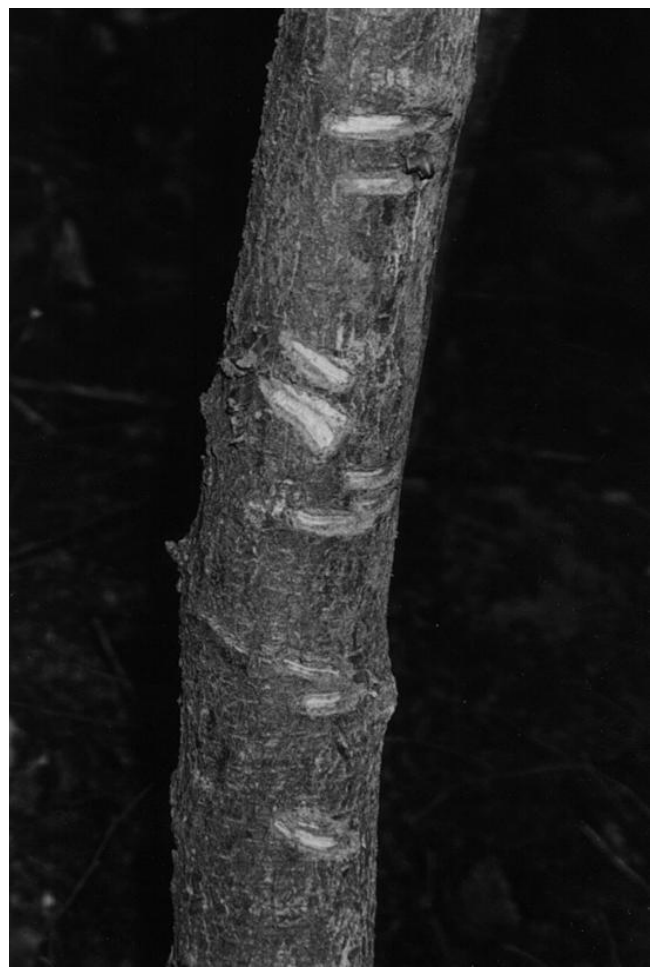

Fig. 6. Marks made on tree by wild pig tusking or scent marking with the tusk glands.

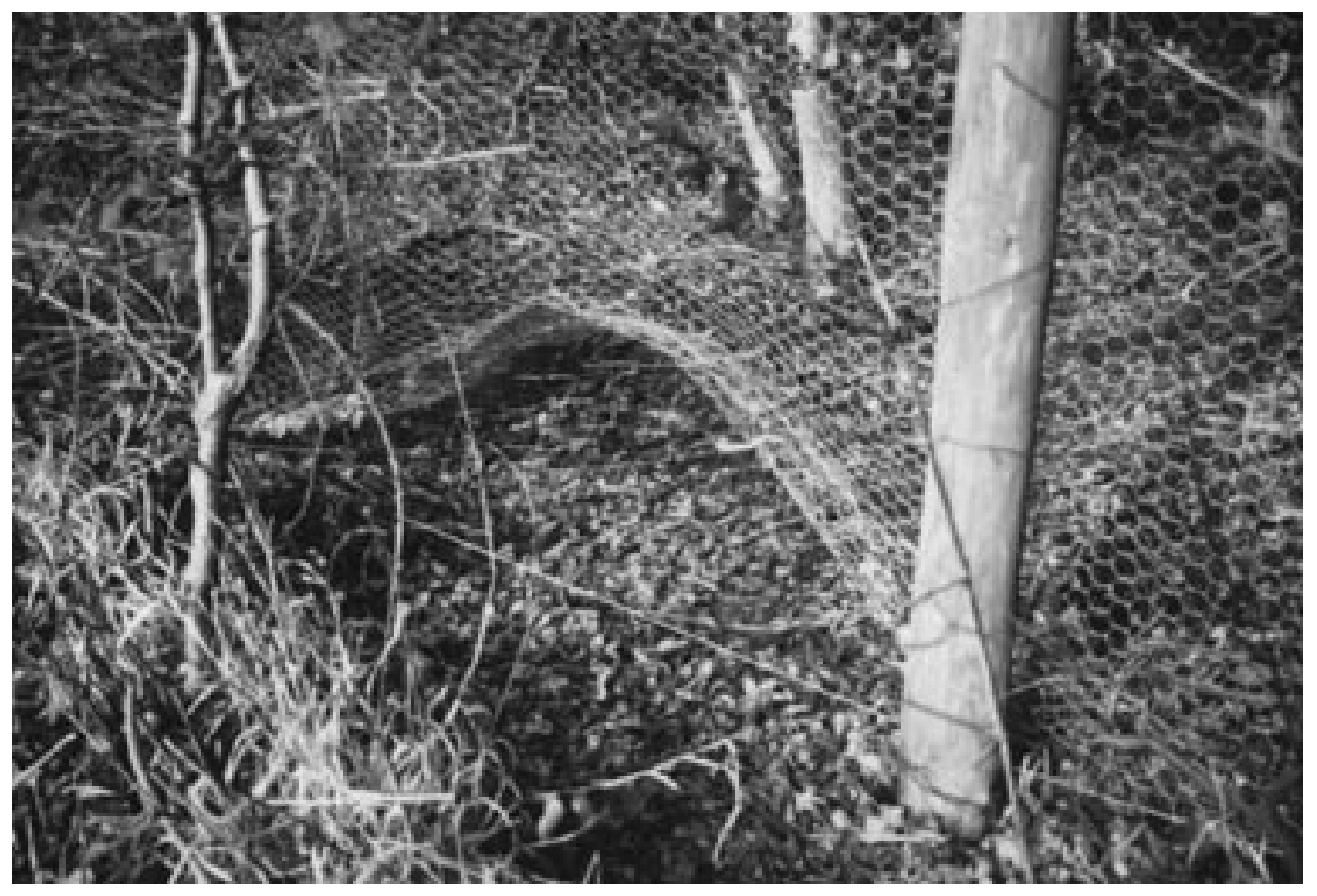

Fig. 7. Wild pig fence crossing. 

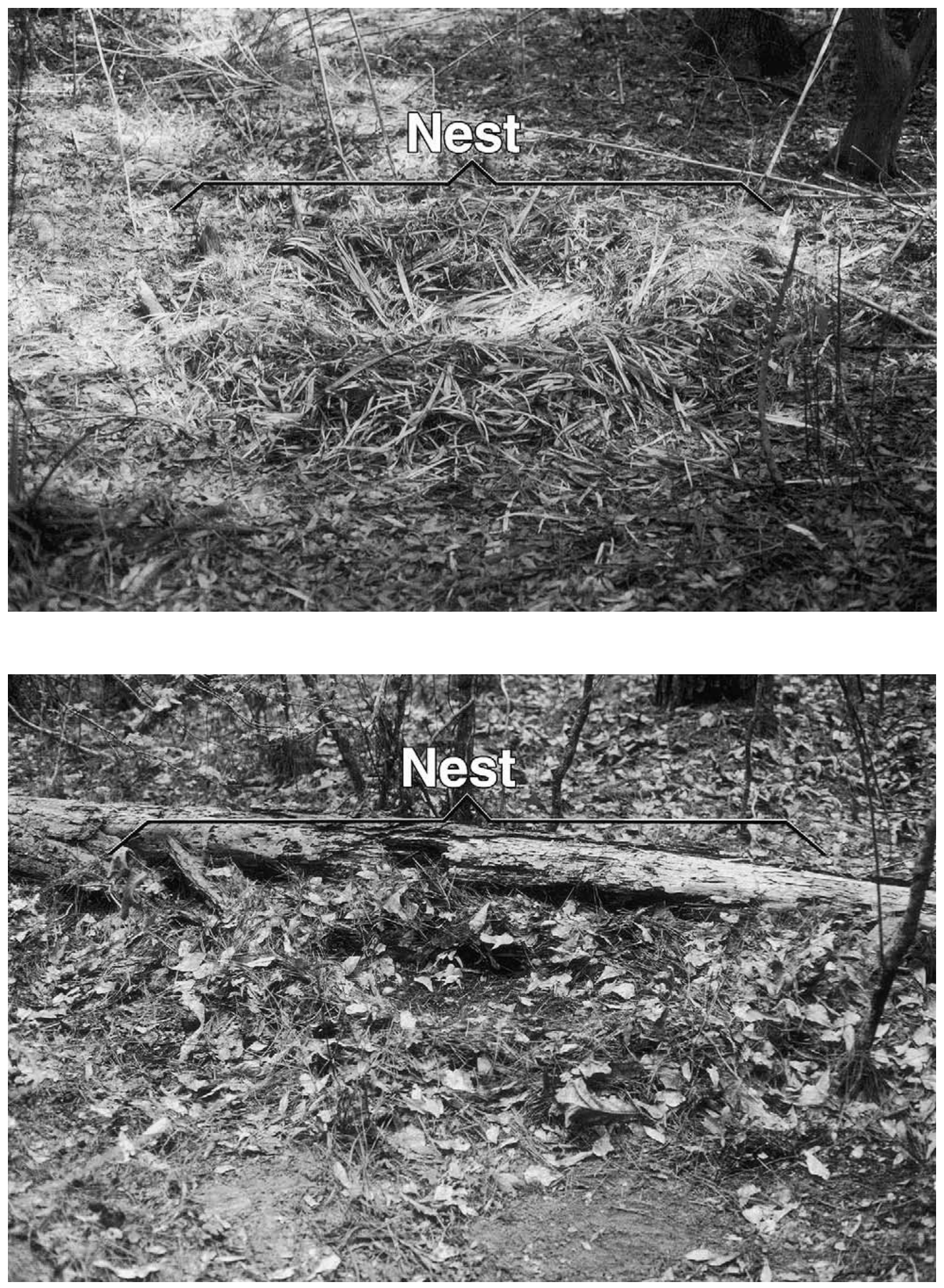

Fig. 8. Wild pig farrowing nests (Mayer et al. 2002). 


\section{Wild Pigs}

\section{Literature Cited}

Ackerman, B. B., M. E. Harmon, and F. J. Singer. 1978. Part II. Seasonal food habits of European wild boar - 1977. Pp. 94-137. In F. J. Singer (ed.), Studies of European wild boar in the Great Smoky Mountains National Park: $1^{\text {st }}$ annual report; a report for the Superintendent. Uplands Field Research Laboratory, Great Smoky Mountains National Park, Gatlinburg, Tennessee.

Anonymous. 2003. Feral pigs in Queensland - Distribution, ecology and impact. Pest Series: Pest Fact PA6 - QNRME01277, Department of Natural Resources and Mines, The State of Queensland, Brisbane, Australia.

Barrett, R. H. 1971. Ecology of the feral hog in Tehama County, California. Ph.D. Dissertation, University of California, Berkeley, California.

Belden, R. C., and M. R. Pelton. 1975. European wild hog rooting in the mountains of east Tennessee. Proceedings of the Annual Conference of the Southeastern Association of Game and Fish Commissioners, 29:665-671.

1976. Wallows of the European wild hog in the mountains of east Tennessee. Journal of the Tennessee Academy of Sciences, 51(3):91-93.

Briedermann, L. 1986. Schwarzwild. VEB Deutscher Landwirtschaftsverlag, Berlin, Democratic Republic of Germany.

Conley, R. H., V. G. Henry, and G. H. Matschke. 1972. Final report for the European hog research project W-34. Tennessee Game and Fish Commission, Nashville, Tennessee.

Crouch, L. C. 1983. Movements of and habitat utilization by feral hogs at the Savannah River Plant, South Carolina. M.S. Thesis, Clemson University, Clemson, South Carolina.

Diong, C. H. 1973. Studies of the Malaysian wild pig in Perak and Jahore. Malayan Nature Journal, 26(3/4):120-151.

Fradrich, H. 1984. Swine and peccaries. Pp. 76-108. In B. Grzimek (ed.), Grzimek's animal life encyclopedia. Volume 13: Mammals IV. Van Nostrand Reinhold Company, New York.

Gipson P. S., B. Hlavachick, and T. Berger. 1998. Range expansion by wild hogs across the central United States. Wildlife Society Bulletin, 26:279-286.

Goulding, M. 2001. Identification: Wild boar signs in southern England. British Wildlife, 13(1):38-41.

Goulding, M. J. 2003. Wild boar in Britain. Whittet Books, Ltd., Suffolk, United Kingdom.

Groot Bruinderink, G. W. T. A., and E. Hazebroek. 1996. Wild boar (Sus scrofa) rooting and forest regeneration on podzolic soils in the Netherlands. Forest Ecology and Management, 88(1-2):71-80.

Hone, J., and W. Martin. 1998. A study of dung decay and plot size for surveying feral pigs using dung counts. Wildlife Research, 25(3):255-260.

Kramer, R. J. 1971. Hawaiian Land Mammals. Charles E. Tuttle Company, Rutland, Vermont.

Kurz, J. C. 1971. A study of feral hog movements and ecology on the Savannah River Plant, South Carolina. M.S. Thesis, University of Georgia, Athens, Georgia.

Mayer, J. J., and I. L. Brisbin, Jr. 1986. A note on the scent marking behavior of two captive-reared feral boars. Applied Animal Behaviour Science, 16:85-90. 
1991. Wild pigs of the United States: Their history, comparative morphology, and current status. The University of Georgia Press, Athens, Georgia.

Mayer, J. J., F. D. Martin, and I. L. Brisbin, Jr. 2002. Characteristics of wild pig farrowing nests and beds in the upper Coastal Plain of South Carolina. Applied Animal Behaviour Science, 78(1):1-17.

Mayer, J. J., E. A. Nelson, and L. D. Wike. 2000. Selective depredation of planted hardwood seedlings by wild pigs in a wetland restoration area. Ecological Engineering, 15(Supplement 1):S79-S85.

Nichols, L., Jr. 1962. Ecology of the wild pig. Federal Aid in Wildlife Restoration Final Report Project W-5-R-13. Hawaii Department of Land and Natural Resources, Division of Fish and Game, Honolulu, Hawaii.

Pullar, E. M. 1953. The wild (feral) pigs of Australia: Their origin, distribution and economic importance. Memoirs of the National Museum Melbourne, 18:7-23.

Rutledge, A. 1965. Demons of the delta. Sports Afield, 153(5):69, 167-170.

Silver, H. 1974. A history of New Hampshire game and furbearers. Report No. 6. $2^{\text {nd }}$ Ed. New Hampshire Fish and Game Department, Concord, New Hampshire.

Singer, F. J., W. T. Swank, and E. E. C. Clebsch. 1984. The effects of wild pig rooting in a deciduous forest. Journal of Wildlife Management, 48(2):464-473.

Stegeman, L. J. 1938. The European wild boar in the Cherokee National Forest, Tennessee. Journal of Mammalogy, 19(3):279-290.

Stevens, R. L. 1996. The feral hog in Oklahoma. Samuel Roberts Noble Foundation, Ardmore, Oklahoma.

USAREUR (United States Army, Europe). 1965. Welfare, recreation, and morale: Guide to hunting in Germany. USAREUR Pamphlet N0. 28-148. Headquarters United States Army, Europe, APO, U. S. Forces, Heidelberg, West Germany.

Waithman, J. 2001. Guide to hunting wild pigs in California. California Department of Fish and Game, Wildlife Programs Branch, Sacramento, California.

Wilson, C. J. 2003. Rooting damage to farmland in Dorset, southern England, caused by feral wild boar Sus scrofa. Mammal Review, 34(4):331-335.

Zengel, S. A., and W. H. Conner. 2008. Could wild pigs impact water quality and aquatic biota in floodplain wetland and stream habitats at Congaree National Park, South Carolina? 5 pp. in Proceedings of the 2008 South Carolina Water Resources Conference, Charleston, South Carolina. http://www.clemson.edu/restoration/events/past_events/sc_water_resources/t2_proceedings_presentati ons/t2_zip/zengels.pdf 
Wild Pigs

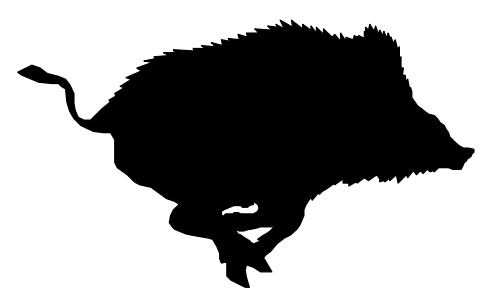

Part II

Wild Pig Damage 
SRNL-RP-2009-00869

This page left blank intentionally 
Wild Pigs

\section{Wild Pig Damage:}

\section{Overview of Wild Pig Damage}

John J. Mayer

Savannah River National Laboratory, Savannah River Nuclear Solutions, LLC, Savannah River Site, Aiken, South Carolina 29808

\section{Introduction}

In spite of the fact that wild pigs (Sus scrofa) have a lot of potential as a big game resource in the United States, these non-native animals are generally almost always classified as an undesirable invasive species. The primary reason for this frequently assigned designation is because of the magnitude of damage that these animals inflict upon their host environments. In addition, the magnitude of that damage is rivaled only by the diversity of the damage done. The annual economic loss due to wild pig damage to environmental and agricultural resources in this country added the cost of their control has collectively been estimated at $\$ 1.5$ billion (Pimentel 2007). Wild pig damage can variously include depredation of crops and livestock, spreading disease, property damage, attacks on humans, and more. Wild pigs have also been widely implicated in the declines and extinctions of numerous native species of flora and fauna worldwide (e.g., Bratton 1974, Roots 1976, Wiewandt 1977, Tisdell 1982, Lever 1985, Oliver and Brisbin 1993, Cuthbert 2002, LaPointe 2006). In fact, the Species Survival Commission of the World Conservation Union (IUCN) listed these animals as being among the 100 worst invasive alien species from around the world (Lowe et al. 2000).

The potential for environmental and economic impacts from wild pigs in any given area is high (Coblentz and Bouska 2004, Massei and Genov 2004). In fact, the spectrum of wild pig damage is not restricted to only the introduced portions of its global range. Even within its native range, this species is considered to be extremely destructive (e.g., Andrzejewski and Jezierski 1969, Mackin 1970, Holy 1983, Brooks et al. 1989, Labudzki 1991, Macchi et al. 1992, Meriggi and Sacchi 1992, Fico et al. 1993, Vassant 1994, Khokhar and Rizvi 1998, Calenge et al. 2004, Herrero et al. 2006). The ongoing debate about wild Sus scrofa being either a big game resource or an unwanted destructive pest also encompasses native populations of Eurasian wild boar (Tisdell 1982, Briedermann 1986).

Most of the damage caused by wild pigs is a result of their aggressive and widespread foraging activities. This primarily includes impacts resulting from either their rooting activities or the direct consumption of plant or animal material. Wild pigs are classified as opportunistic omnivores. The magnitude of the impacts of this generalist foraging behavior by wild pigs was best characterized by Rolls (1969) as follows: "Pigs are omnivorous beyond any reasonable interpretation of the meaning of the word. I can think of nothing that they will not eat and nothing that they do not seem to relish."

The purpose of this paper is to provide a summary overview of the existing literature on the damage caused by wild pigs. Although the primary focus is on the impacts of introduced populations of this species in non-native areas, descriptions of the negative impacts caused by Eurasian wild boar within native portions of the global range will also be presented. In addition to information obtained from the scientific and popular literature, data on wild pig damage from the Savannah River Site (SRS) in Aiken, Barnwell and Allendale counties, South Carolina, has also been included.

\section{Types of Damage}

The impacts that wild pigs have on the environment have been categorized into the following groupings: rooting, agricultural depredation, forestry depredation, disease vectors, predation, wallowing, competition, 
vehicle collisions, attacks on humans, property damage, alternative prey, and contaminate uptake. Each of these groupings is discussed separately below.

Rooting - This is the most widespread and observable type of damage done by wild pigs anywhere in the species range (Barrett and Birmingham 1994). Wild pigs root to obtain food (e.g., roots, tubers, fungi and fossorial/burrowing animals). In general, wild pig rooting breaks up and loosens the soil. Rooting among locations and habitats varies significantly in both the area and depth involved (Fig. 1). It can differ from shallow disturbance/displacement of leaf litter to substantial excavations, with the soil turned over, piled up, exposed to sunlight, and oxidized (Barrett 1971, Arrington et al. 1999). Similar to the rooting characteristics themselves, the resulting impacts vary with respect to the area and depth associated with this activity in a given location.

All wild pigs, regardless of sex and age, root in soils on a regular basis to find food. Wild pigs begin to root shortly after leaving the farrowing nest (Saint George 1973). Not only do all wild pigs root, but they root extensively on a frequent basis. In fact, a very small number of wild pigs can root up the soil over extremely large areas in a short time period (Anon. 2003). Anderson et al. (2007) estimated that one wild pig could root up slightly less than $2 \mathrm{~m}^{2}$ of soil in one minute. In addition, Hone (1999) noted that the frequency of pig rooting and the abundance of pigs in an area were positively related. Rooting activities occur throughout the year, but can vary with season, location, and both the abundance and type of food resource being sought (Barrett 1971, Belden and Pelton 1975, Ackerman et al. 1978, Groot Bruinderink and Hazebroek 1996a, Wilson 2003). For example, wild pigs rooting for mast (e.g., acorns, Quercus spp.) create widespread disturbance of the leaf litter during the fall and winter months. In contrast, foraging by these animals for subterranean fungi on the SRS has resulted in the excavation of specific, deep holes (e.g., up to $120 \mathrm{~cm}$ in depth) during the late spring and summer months (J. J. Mayer, unpubl. data).

Rooting by wild pigs modifies the chemistry and nutrient cycling within the soil column. It mixes the A1 and A2 soil horizons and reduces ground vegetative cover and leaf litter. Wild pig rooting in the Great Smoky Mountains National Park (GSMNP) was also found to accelerate the leaching of $\mathrm{Ca}, \mathrm{P}, \mathrm{Zn}, \mathrm{Cu}$, and $\mathrm{Mg}$ from the leaf litter and upper soil horizons (Singer et al. 1984). In addition, rooting by wild pigs may interfere with the decomposition cycle in soils by the widespread removal of earthworms (e.g., Lumbricus terrestris), a favorite food item, and by impacting the soil microbiota through extreme habitat alteration (Tisdell 1982). In contrast, Groot Bruinderink and Hazebroek (1996a) could not find any significant differences in soil characteristics between an area free of wild pigs for 60 years and an immediately adjacent area with ongoing wild pig rooting.

Wild pig rooting can also severely impact aquatic and wetland habitats. Wild pigs have a preference for these types of habitats (Crouch 1983, Sweeney et al. 2003). The destabilization of surface soils by wild pig rooting on sloped areas (e.g., along earthen dams and stream banks) can result in erosion and subsequent down-gradient sedimentation. Runoff and silt-loading into both standing and flowing aquatic systems can greatly degrade these habitats. Zengel and Conner (2008) reported that rooting disturbance in small linear cypress-tupelo sloughs and along small creeks in the Congaree National Park frequently approached $80-100 \%$, especially during the driest months. Chavarria et al. (2007) found $45 \%$ of floodplain in the Big Thicket National Preserve was damaged by wild pigs through rooting, wallows and trails. Rooting combined with both wallowing and defecating can threaten aquatic species (e.g. endemic populations of brook trout, Salvelinus fontinalis in the southern Appalachians) through siltation and contamination of stream water quality (Singer 1976, Ackerman et al. 1978, Howe et al. 1979). Such damage can include algae blooms, oxygen depletion, and fish kills (Mapston 2004). Kaller and Kelso (2006) found that such activity increased microbial pathogens while causing a reduction in certain invertebrate communities in coastal plain streams. This same combination of wild pig activities in and around stock ponds/tanks can also foul or sour drinking water for range livestock (Pullar 1950, Tisdell 1982, Mapston 2004).

Both understory and ground-story habitats can be severely impacted through wild pig rooting. This is primarily due to the extreme alteration and destructive modification that this activity has on these near-surface habitat types. For example, in intensively rooted stands on the GSMNP, $67 \%$ of all branches and logs $>2.5 \mathrm{~cm}$ in diameter were moved by wild pigs and another $10 \%$ broken apart. The unmoved logs were large and/or obviously heavy due to waterlogging or partial decomposition. However, even the large 


\section{Wild Pigs}

logs were ripped apart when decomposed. Wild pig rooting exposed 1,400-2,800 tree roots per hectare. Four percent of exposed roots were broken (Singer et al. 1984). Bratton (1975) found that wild pig rooting reduced species richness in the herbaceous understory in the GSMNP. The potential effects of rooting were found to vary among plant community types. In general, however, it was found to result in a decreased plant cover, reduction in litter-layer mass, and decreased food resources for macroinvertebrates (Arrington et al. 1999). Areas of disturbed soil can also be more susceptible to exotic plant species invasion or population expansion (Stone and Anderson 1988, Choquenot et al. 1996, Tierney and Cushman 2006). Small vertebrate species that occupy these forest floor habitats can also be impacted. For example, southern red-backed voles (Clethrionomys gapperi) and northern short-tailed shrews (Blarina brevicauda), two mammals that are dependent upon leaf litter for habitat, were nearly eliminated from intensively rooted areas in the GSMNP (Singer et al. 1984).

Rooting by these animals can also result in destruction to timber and agricultural crops (Arrington et al. 1999). Most of these specific impacts will be addressed in the following sections. In general, these impacts result from either exposure or actual damage to the roots systems or bases of these plants. With respect to impacts to timber management practices, rooting by wild pigs can also create difficulties in conducting prescribed burns in pine flatwoods by serving as fire breaks (J. Lipe, pers. comm.). Further, wild pig rooting reduces the availability of pasturage or rangeland forage, as well as promoting the spread of weeds through those livestock areas (Hone 1980, McGaw and Mitchell 1998, Luxton 1999).

In addition to impacting natural resources, wild pig rooting can cause irreversibly damage to sensitive archaeological sites and cultural resources. For example, wild pig rooting was found to have seriously degraded the scientific value of the archeological resources on Santa Cruz Island, California (NPS 2002). Wild pigs have also been observed to damage Native American Sacred Places and National Register eligible prehistoric sites on both the Caliente Mountain Wilderness Study Area and Carrizo Plain Natural Area in California (Van de Hoek 1993). Even shallow sub-surface rooting can disturb or modify the presence of both prehistoric and historic artifacts. Such uprooted or displaced materials could also be exposed to the elements, leading to direct degradation of the resources or possible loss due to runoff transport.

A variety of impacts to traffic and travel ways can also result from wild pig rooting. These would vary from causing injuries to persons/damage to vehicles traversing the route to actual damage to the thoroughfare itself. Being widespread, rooting can occur along vehicular (e.g., roads and railways) and pedestrian (e.g., hiking trails) passageways. Alongside of both paved roads and rail beds, wild pig rooting on the side slopes can sequentially lead to soil destabilization, erosion, gully formation on those slopes, and ultimately slumping of the road/rail beds. Wild pig rooting damage on the "crawlerway" has even caused problems for moving the space shuttle with the Crawler-Transporter between the Vehicle Assembly Building and launch pads 39A and 39B at the Kennedy Space Center (Anon. 1983). Rooting along unpaved thoroughfares (e.g., public and private secondary roads, jeep trails, farm roads, hiking and equestrian trails, and light aircraft landing strips) can represent both safety and usability impacts, which may also require maintenance to prevent further damage through erosion of soils in and adjacent to the passageway (Tisdell 1982). Rooting along foot paths and trails can presents a safety problem to both pedestrian traffic and livestock (Stevens 1996). Even in undeveloped areas on the SRS, rooting by wild pigs represents a hazard to site personnel traveling on foot. Because some of this rooting activity results in deep conical holes, the likelihood of tripping or falling exists for persons walking through an area rooted up by wild pigs. One site employee (i.e., a USFS timber cruiser) broke his foot as a consequence of such an accident (SRFS 1985).

Lastly, rooting by wild pigs has also been found to impact developed areas (e.g., Kotulski and König 2008). With the recent increase in the numbers of wild pigs in developed habitats (i.e., both urban and suburban areas), the incidents associated with these animals rooting up landscaped areas (e.g., lawns, parks, greenways, sports fields, golf courses and cemeteries) has also increased (Fig. 2).

Agricultural Depredation - Wild pigs are well known globally for depredation of and damage to almost any commercial crops (Tisdell 1982, Mapston 2004). For example, in Poland, 70\% of all crop damage caused by game animals is due to wild pigs (Mackin 1970). In the United States, this damage is realized as 
millions of dollars in losses annually. Most of this damage is caused by either direct feeding/chewing or trampling and rooting by foraging wild pigs. Kristiansson (1985) estimated that only 5-10\% of crop damage by wild pigs was due to actual consumption, the balance being due to trampling. In some cases, rooting around the base or root mat of larger plants (e.g., banana and apple trees) can cause damage through undermining (Tisdell 1982). Wild pigs will feed on most life stages of an agricultural crop, from seeds through mature plants (Mapston 2004). However, most of the depredations occur when the crops are nearly mature (Stevens 1996). Pavlov (1980) even reported that wild pigs would feed on grains stored in wire-mesh silos or bins if pig-proof fencing was not erected. Wild pigs will travel long distances to reach crops that have ripened or matured. Giles (1980) reported that feral hogs would move up to $10 \mathrm{~km}$ a day to forage on grain fields. Similarly, wild pigs on the Welder Wildlife Refuge in Texas seasonally move 8-11 $\mathrm{km}$ off of the refuge onto adjacent ranches to forage in ripening grain fields (Mayer and Brisbin 1991, L. W. Drawe, pers. comm.). Agricultural depredations by wild pigs encompass a variety of resources including grains/cereals (e.g., wheat, sorghum, barley, hay, rye, oats, millet, maize/corn, and rice), vegetables (e.g., various potatoes, yams, squash, turnips, rutabagas, beets, cassava, lettuce, cabbage, beans, peas, soybeans, and artichokes), fruits (e.g., pumpkins, grapes, blueberries, pineapples, avocadoes, bananas, apples, various citrus species, watermelons, cantaloupes, and coconuts), and other crops (e.g., cotton, linseed, sunflower, peanuts, almonds, oilseed/rapeseed, groundnuts, pecans, clover, thyme, basil, oil palms, sugar cane, rubber seeds, padi, and turf/sod/pasturage) (Diong 1973, Tisdell 1982, Brooks et al. 1988, Stevens 1996, Devine 1999, Schley and Roper 2003, Mapston 2004). Not all crops are equally impacted. For example, Pavlov (1980) showed that feral hogs in Australia had a preference for certain types of grain. Wheat and oats are preferred over rye and barley (DEFRA 2004). Crop losses typically vary depending upon location and season. For example, almost half of the annual losses of crops in Australia to wild pig depredation are wheat (Tisdell 1982). Wild pigs cause an estimated 20,000 tons of annual losses in sugarcane in Australia (Choquenot et al. 1996). Up to $40 \%$ of the loss of the sugarcane crop in Pakistan is due to wild pig depredation (Abbas et al. 2004). Pimentel et al. (2005) reported that one wild pig could cause up to $\$ 1,000$ in damage in one night. Reported losses for individual farmers in the United States have ranged as high as \$40,000 (Beach 1993). Crop depredation by wild pigs in some countries (e.g., France, Italy, Luxembourg and Poland) is so significant that the governments reimburse farmers to compensate them for these losses (DEFRA 2004).

Forestry Depredation - Similar to the impacts on agricultural resources, wild pigs also severely impact forestry and timber resources. Such impacts encompass a variety of forms such as girdling of mature pine trees (Pinus spp.) through rubbing, damage to the lateral roots of mature pine trees by rooting and chewing, and damage to the bark of trees by tusking (i.e., scent marking with the tusk glands) (Conley et al. 1972, Lucas 1977). As many as $90 \%$ of the pine trees at a nature preserve in California were impacted by wild pig girdling (Chipping 1993). However, the most widespread and economically costliest type of forest damage done by wild pigs is the depredation of planted pine seedlings. This has primarily involved the grass stage of longleaf pines ( $P$. palustris), but also included slash pines ( $P$. elliotti), loblolly pines $(P$. taeda), and pitch pines $(P$. rigida). Documented from several areas in the southeastern United States (Wahlenberg 1946, Wakely 1954, McKnight 1964, Wood and Lynn 1977, Belden and Frankenberger 1977, Lucas 1977, Wood and Brenneman 1977, Lipscomb 1989), this type of damage involves the seedlings being pulled out of the ground or rooted up by wild pigs, which then chew up the plant's rootstock and lower portion of the stem. Wild pigs will systematically go from one seedling to the next in one planted row after another in pine regeneration plots, ultimately depredating almost the entire crop (Lucas 1977, Thompson 1977, Wood and Brenneman 1977). Wild pigs have been observed destroying young trees at the rate of six per minute per animal, and sustained damage of as many as 400 to 1,000 seedlings per day has been recorded (Hopkins 1948, Wakely 1954). During the mid-1900s, in a period of intensive planting of longleaf and slash pine by the U.S. Forest Service, entire pine plantations in Alabama, Florida, Louisiana, and Mississippi were reported to be complete failures because of wild pig depredations (Wahlenberg 1946, Wakely 1954, Lucas 1977).

Wild pig damage has also been reported to hardwood/deciduous tree species. Similar to pines, wild pigs also dig up and consume the root stock of planted hardwood seedlings (Mayer et al. 2000). Wild boar have been found to selectively forage on the germinating seedlings and saplings of oak and beech species, having a special interest in the highly digestible and protein rich roots in the late winter and spring (Groot Bruinderink and Hazebroek 1996a). In general, regular rooting by wild pigs negatively affects the 


\section{Wild Pigs}

regeneration potential of many deciduous woody species. This is largely compensated for by the enormous overproduction of mast by the dominant woody species in forests inhabited by wild pigs. Rooting can cause juvenile plant mortality by mechanical damage and uprooting. However, this impact may be offset later by improved germination and growth conditions (Groot Bruinderink and Hazebroek 1996a).

Wild pigs also impact native herbaceous species. Bulb populations that did not evolve in the presence of intense pressure from rooting can be badly damaged or destroyed through foraging by this invasive species. Populations of rare Calypso orchid (Calypso bulbosa) were severely impacted by wild pig rooting in Marin County, California (Chipping 1993). A Turk's cap lily (Lilium superbum) population in the GSMNP was similar destroyed by wild pigs. In fact, about one third of the wildflowers listed as occurring in that park have been observed to be either uprooted or eaten by wild pigs (Bratton 1974). In fact, Beacham (1997) reported that wild pig rooting and foraging was one of the major factors that led to the extinction of four species of Hawaiian flowering lobelioids (Cyanea linearifolia, C. parrifolia, C. purpurellifolia, and $C$. pycnocarpa).

Wild pig damage to forestry resources has been documented to cause problems with the control of insect pests, invasive species, and pathogens. Wild pigs forage on and damage tree fern logs, which then became preferred breeding sites of mosquitoes (Culex spp.) in Hawaii. Therefore, Lease et al. (1996) found that wild pig control may also be an effective management tool for reducing mosquito populations in those areas. Wild pigs have even been identified as one of the primary agents of dispersing invasive plant species such as the strawberry guava (Psidium cattleianum), guava (Psidium guajava), kahili ginger (Hedychium gardnerianum), banana poke (Passiflora mollissima), fennel (Foeniculum vulgare), tropical soda apple (Solanum viarum), prickly-pear cactus (Opuntia spp.) and mesquite (Prosopis pallida) (Diong 1982, Layne 1997, Loope 1998, McIlroy 1999, Lynes and Campbell 2000, Gimeno and Vila. 2002, NPS 2002). Finally, in addition to the direct damage to floral species, wild pigs have been implicated in the transmission of plant diseases such as root rot fungus (Phytophthora cinnamomi) and other plant pathogens (McIlroy 1999, Anon. 2004).

Disease Vectors - In general, wild pigs are susceptible to a wide range of diseases, reportedly being able to carry at least 30 important viral and bacterial diseases (Hutton et al. 2006, Stallknecht and Little this volume). Some encompass the same suite of diseases that are specific to domestic swine, while others can also infect other wild and domestic mammals as well as man (Davis 1993). In general, wild pigs have the potential to contract and transmit all of the viral, bacterial and fungal diseases of domestic swine. Because of this, wild pigs have the potential to function as a disease reservoir which can impact nearby domestic swine herds (Payeur 1989, Davis 1993). It is also possible for domestic swine herds to infect local populations of wild pigs, as well as those wild pigs to infect local native game species (e.g., white-tailed deer, Odocoileus virgnianus). In addition, zoonotic pathogens, such as brucellosis and swine influenza, present potential human as well as livestock health problems. As such, diseases outbreaks due to wild pigs represent a substantial economic risk to the nation's economy (Witmer et al. 2003).

Diseases and pathogens that can infect wild pigs include but are not limited to the following: African swine fever, anthrax, avian tuberculosis, bovine herpesvirus, bovine tuberculosis, brucellosis (various), bubonic plague, chlamydiosis, classical swine fever (i.e., hog cholera), coronaviral infections, cysticercosis, echinococcosis, encephalomyocarditis, Erysipelothrix infections, Escherichia coli, foot-and-mouth disease, Helicobacter spp., Hepatitis E, influenza viruses (various), Japanese encephalitis, leptospirosis, louping-ill virus, malignant catarrhal fever, melioidosis, menangle virus, Mycobacterium spp., papillomavirus infections, parainfluenza virus, pasteurellosis, pestivirus infections, porcine circovirus, Porcine Dermatitis Nephropathy Syndrome (PDNS), porcine encephalomyelitis, porcine enterovirus, Porcine Reproductive and Respiratory Syndrome (PRRS), Postweaning Multisystemic Wasting Syndrome (PMWS), pseudorabies (Aujeszky's disease), Q-fever, rabies, reovirus, rinderpest, salmonellosis, San Miguel sea lion virus, sarcoptic mange, sparganosis, Streptococcus suis, swinepox virus, toxoplasmosis, transmissible gastroenteritis, trichinosis, tuberculosis (unspecified), tularemia, Venezuelan equine encephalitis, vesicular exanthema, vesicular stomatitis, and yersiniosis (Davidson and Nettles 1988, Mebus 1989, Nettles 1989, Davis 1993, Jessup and Swift 1993, Stevens 1996, Lee 1999, Shield 1999, Wahlstrom et al. 2003, Sonoda et al. 2004, Vicente et al. 2004, Wilson 2005, Trcka et al. 2006, Baums et al. 2007, Hall et al. 2008). Of 
these, swine brucellosis and pseudorabies are of particular concern within wild pig populations in the United States as a threat to domestic livestock (Nettles 1989, Payeur 1989, Davis 1993).

Swine brucellosis is a highly contagious infectious disease caused by the bacterium Brucella suis, of which there are Biotypes 1, 2,3 and 4. Several species of vertebrates including man can contract this disease. There is no cure for this disease in animals; humans are treated with very high doses of antibiotics for extended periods to hopefully clear the infection. Transmission between swine is through sexual contact or ingestion of recently discharged organisms in urine, aborted fetuses, etc. Brucellosis causes infectious abortions in pigs. Other symptoms include stillborn or weak pigs, infertility, testicular inflammation, and lameness. Unfortunately, these symptoms are not always evident; blood tests are the only reliable method of diagnosis. Swine brucellosis has been found in, but is not limited to, wild pig populations in Arkansas, California, Florida, Georgia, Hawaii, Louisiana, South Carolina, and Texas (Davidson and Nettles 1988, Davis 1993). Clay (2007) noted that brucellosis was reported in wild pig populations in at least 14 states. In 1974-5, 22\% of the human cases of brucellosis in Florida were from contact with wild pigs (Bigler et al. 1976). CDC (2009) reported that three hunters (i.e., one each from Florida, Pennsylvania and South Carolina) had contracted brucellosis from field dressing and butchering wild pigs in Florida during December of 2007.

Pseudorabies virus (PRV), also known as Aujeszky's disease, is an infectious viral disease that is caused by porcine herpesvirus 1. Although humans cannot be infected, PRV is found in several species of domestic carnivores and livestock as well as swine. There is no cure; population control is the only successful method of treatment. Transmission is through direct contact, aerosols, contaminated feed, water, infected tissue ingestion, or contaminated footwear, clothing or trailers. Symptoms include loss of appetite, excessive salivation, spasms, and convulsions. Infections in swine can vary from asymptomatic appearances to fatalities, depending upon the age of the pig (e.g., usually deadly among young pigs). Diagnosis is usually made on clinical signs and a variety of serological tests. PSV infections are widespread in the United States. Wild pig populations in numerous states have been shown to be positive for this disease (Davidson and Nettles 1988, Davis 1993). Corn et al. (2004) also demonstrated that PSV was persistent for long-term time periods in these populations.

Given the fact that wild pigs will forage, wallow and excrete in certain habitats, especially wetlands or waterways, the potential exists for these animals to be involved in the transmission of certain zoonotic pathogens to humans. Hampton et al. (2006) found several protozoan parasitic pathogens (i.e., Giardia spp., Cryptosporidium spp., Balatantidium coli and Entamoeba spp.) in wild pig feces collected in metropolitan drinking water catchment areas in Australia. Jay et al. (2007) investigated the involvement of wild pigs in the contamination of agricultural fields and surface waterways with Escherichia coli O157:H7 after a nationwide outbreak was traced to bagged spinach from California. E. coli $\mathrm{O} 157$ was cultured from both field-collected and colonic feces from wild pigs in the study area. In addition, the foodborne pathogen Campylobacter spp. was found in tissues and feces from the same wild pig population. The presence of these pathogens suggests that wild pigs may contribute to the microbial contamination of crops or the surrounding area under the right conditions (Jay and Wiscomb 2008).

Predation - In spite of being omnivorous, wild pigs are mostly herbivorous in their food habits; however, they do prey on a broad range of animal species (Barrett 1971, Diong 1973, Wood and Barrett 1979, Giles 1980). This variously includes egg, larval/immature, and adult forms of these different animals, as well as the remains or carcasses of many of these same species. With respect to the wild pig's consumption of animal matter, Rolls (1969) described it as "Pigs attack animals at any stage of life or death." Typically, however, this predation is directed at either young animals and less mobile species (Wood and Barrett 1979). Collectively, this extensive list includes numerous species of mollusks, annelids, arthropods, echinoderms, and vertebrates (e.g., Diong 1973, Rudge 1976, Wood and Barrett 1979). However, given the opportunistic nature of this foraging, the impact on any one species population is for the most part minor.

One of the most significant impacts of this type of wild pig foraging is the predation of the eggs and hatchlings of reptiles and birds. Examples of affected species would include crocodilians (e.g., Amercian alligator, Alligator mississippiensis), turtles (e.g., loggerhead sea turtle, Caretta caretta; green turtle, Chelonia mydas; Galápagos tortoise, Geochelone nigra), lizards (e.g., Mona ground iguana, Cyclura 


\section{Wild Pigs}

cornuta stejnegeri), and ground-nesting birds (e.g., wild turkey, Meleagris gallopavo; bobwhite quail, Colinus virginianus; ruffed grouse, Bonasa umbellus; woodcock, Scolopax rusticola, common pheasant, Phasianus colchicus). In some cases, this predation has seriously impacted a species' existence. In Europe, for example, it was noted that a decrease in the number of woodcock coincided with an increase in the wild pig populations (Schley and Roper 2003). Nest predation by wild pigs is cited as one of the causes for the decline of the Hawaiian goose or Nēnē (Branta sandvicensis) and the dark-rumped petrel (Pterodroma phaeopygia) on the Hawaiian Islands (Bryan 1937, Smith 1952, Lever 1985). Similar depredation was responsible for the decline of the endemic Auckland Island flightless teal (Anas aucklandica aucklandica) and the tuatara (Sphenodon punctatus) (Lever 1985). The Tristan Island hen (Gallinula nesiotis), Tahiti sandpiper (Prosobonia leucoptera) and Auckland Island merganser (Mergus australis) were all driven to extinction because of this type of depredation by introduced wild pigs on those oceanic archipelagos (Roots 1976, Beacham 1997).

Wild pigs can also be voracious predators of larger animals, preying on several species of both domestic livestock and wild game (e.g., Rutledge 1970, Springer 1975, Hennig 1981, Pavlov and Hone 1982, Beach 1993). In general, Wood and Barrett (1979) stated that both witnessed attacks and the actual killing of these larger species are rare. However, in spite of that fact, such predation does still occur. Wild pigs kill and eat up to 38 percent of newborn lambs born in some areas of Australia (e.g, Pavlov et al. 1981, Choquenot et al. 1997, Lapidge et al. 2006). In 1991, farmers and ranchers in Texas and California reported to USDA APHIS-ADC that a total of 1,473 sheep, goats, and exotic game animals had been killed on their lands by wild pigs (Barrett and Birmingham 1994). On one property in Australia, wild pigs were reported to have killed 3,000 lambs and weak ewes in one season (McKight 1976). This type of predation is conducted by both sexes of adult wild pigs. In some cases, individual adult boars became skilled repeated predators of lambs (Pavlov and Hone 1982). Pavlov (1980) reported that the hunting success for these pigs as $18 \%$. In an extreme anecdotal example, one boar had reportedly been credited with predating over 800 sheep and heifers in western Argentina before being killed itself (Capstick 1990). In addition, the surplus killing of sheep and goats by wild pigs in small fenced enclosures has been observed in Edward's Plateau, Texas (R. F. Smart, pers. comm.). Often such attacks are the result of a momentary opportunity. In a heretofore unreported type of predation, three feral hogs were observed to attack, kill and partially consume an adult Rio Grande wild turkey hen on a wildlife food plot on the King Ranch, Texas, where all four animals had been feeding together in close proximity only moments before the attack (T. C. Urban, pers. comm.).

Wallowing - Because these animals cannot cool themselves physiologically, wild pigs wallow throughout the year, especially during hot weather. Wallowing can contaminate water holes and negatively alter riparian habitats. Wallowing is often found in conjunction with rooting activity (see Rooting). Rooting combined with wallowing can affect ponds by muddying waters, creating algae blooms, creating bank erosion, destroying aquatic vegetation, and decreasing livestock use and fish production (Stevens 1996).

Competition - Being an introduced species, one of the major concerns about wild pigs has been competition with native species for available resources. Primarily associated with dietary overlap of the local mast crop, wild pigs are typically considered to compete with white-tailed deer, wild turkey, black bear, and both gray and fox squirrels. In addition, wild pigs have even been reported to aggressively exclude deer from feeding on acorns (Taylor and Hellgren 1997). However, previous research looking at such dietary overlaps (e.g., Springer 1975, Yarrow and Kroll 1989) has failed to indicate whether or not such competition for a limiting resource is occurring (Hellgren 1993). If such competitive impacts did exist, the effects would be worse during years of poor mast crops (Tate 1984). In fact, Yarrow (1987) suggested that in such times of low mast availability, competition from wild pigs for scarce resources may limit white-tailed deer populations The existence of general dietary overlap has also inferred or suggested forage resource competition between wild pigs and collared peccaries, range cattle, striped skunks, common opossums, red and gray foxes, raccoons, bobcats, muskrats, nutria, eastern cottontail, swamp rabbits, hawks, owls, sandhill cranes, and waterfowl (Conley et al. 1972, Bratton 1974a, 1974b, Thompson 1977, Baron 1979, Everitt and Alaniz 1980, Sweeney et al. 2003). Based on observations of interspecific aggression, competition for space between sympatric populations of wild pigs and collared peccaries is intense (Hellgren 1993). Wild pig use of salt/mineral blocks can impact both range livestock and native 
SRNL-RP-2009-00869

game species. Being scavengers, wild pigs also compete with coyotes, vultures and eagles for carrion (Zappacosta 2005).

Vehicle Collisions - Wild pig collisions with vehicles are known to occur in the United States (Thompson 1977, Synatzske 1993, Mayer and Johns 2007). As the numbers of these animals in this country have increased, the frequency of wild pig-vehicle collisions has increased concurrently. In some locations of high incidence for these accidents, wild pig crossing signs have been erected to warn motorists (Fig. 3). In general, wild pigs are large animals (e.g., 200+ $\mathrm{kg}$ ) with a relatively low center of gravity. As a consequence, collisions with these animals represent a serious safety hazard, and can result in personal injuries and fatalities for the human occupants of the vehicles involved (Briedermann 1986, ADAC 2002, Mayer and Johns 2007).

Collisions with wild pigs involve both sexes and all age classes of animals (Okarma et al. 1995, Groot Bruinderink and Hazebroek 1996b, Mayer and Johns 2007). The number of wild pig roadkills in an area is positively correlated to the local population numbers (Okarma et al. 1995, Groot Bruinderink and Hazebroek 1996b). However, the sex/age composition of the animals involved does not always reflect the population structure. Typically only one wild pig is involved in most collisions; however, multiple animal collisions (e.g., up to as many as 18 wild pigs in 1 collision) do take place (Goulding et al. 1998, MOSNEWS 2006, Mayer and Johns 2007, RIA Novosti 2007). The percentage of males was significantly higher in the single-animal accidents (Mayer and Johns 2007). The annual attrition resulting from vehicle collisions varies from 0.1 to 5.0\% of a population (Okarma et al. 1995, Groot Bruinderink and Hazebroek 1996b, Mayer and Johns 2007). Wild pig-vehicle collisions occur year-round and throughout the 24-hour daily time period. The frequency of these collisions is highest during the fall and winter months. Most accidents occur at night (Groot Bruinderink and Hazebroek 1996b, Inbar et al. 2002, Goulding 2003, Mayer and Johns 2007). Human injuries were infrequent but potentially serious. In collisions with wildlife in Israel, 78 percent of the accidents that resulted in human injuries and casualties involved wild boar (Inbar et al. 2002). In West Germany, personal injury involving collisions with wild boar encompassed 12.8 percent of the total accidents with big game animals (Briedermann 1986). The estimated annual cost of property damage and personal injury associated with wild pig-vehicle collisions in the United States is \$36 million (Mayer and Johns 2007).

In addition to collisions with motor vehicles, wild pigs have also been involved in collisions with both trains and aircraft. Collisions between wild pigs and trains have occurred in both Western Europe and Asia (Briedermann 1986, BBC News 2002). The author has examined two wild pigs that were hit and killed in collisions with trains. The first was an adult sow that was brought into the Hauptbahnhof in Giessen, West Germany, in the summer of 1968. The second was an adult male that was found next to the Steel Creek trestle on the SRS in the spring of 1991. In 1988, two wild pigs attempting to run across the runway at the Jacksonville International Airport, Florida, collided with an F-16 fighter jet that was attempting to takeoff, destroying the 16-million dollar aircraft in the subsequent crash (Anon. 1988). A similar accident happened a year earlier in Pakistan, with a wild boar colliding with another F-16 in the process of taking off, resulting in the nose wheel being knocked off and the jet being destroyed in the subsequent crash (Glazer 1987). Unlike the vehicular accidents, the collisions with these other modes of transportation are typically uncommon to extremely rare.

Attacks on Humans - Although rare, wild pig attacks on humans do occur. Documentation of such incidents date back to prehistoric times. These attacks have been reported from both the native and introduced portions of the species global range (Mayer 2008). Although in some cases these appeared to be unprovoked (Bowie 2004), most cases of attacks are caused by the pigs being either cornered, threatened or wounded (e.g., Barrett 1971, Rappaport 1984, WSRC 1994). In addition, the presence of dogs walking with their human owners has been suggested to represent a hazard with respect to instigating wild pig attacks (Goulding 2003). These incidents occur under both hunting and non-hunting circumstances (e.g., Bryan 1937, Barss and Ennis 1988, Gubler 1992, Hatake et al. 1995). The consequences of these attacks can be serious. Puncture wounds and lacerations on the human victims from such an attack can be extensive (Barss and Ennis 1988, Hatake et al. 1995). Bite wounds from wild pigs can also result in serious infections (Barss and Ennis 1988, Gubler 1992). Both hunters and non-hunters have been killed in attacks by wild pigs (Bryan 1937, Hatake et al. 1995). 
Property Damage - Wild pigs can cause a variety of property damage. Most of these impacts result from foraging activities by these animals. In the past, this type of impact was only observed in rural areas, however, there has been a recent increase in property damage by wild pigs in suburban or developed areas. Rooting can damage sprinkler and irrigation system pipes and floodgates (Tisdell 1982). In some instances, wild pigs will root up and break buried sprinkler and irrigation system pipes to access the water contained in those lines. Wild pigs do a lot of damage to fencing by creating holes or crossings through these barriers. Wild pigs have strong neck muscles and can push through or lift up even the sturdiest of fences. This behavior results in the tearing of the fence netting or mesh, deforming the wire, and weakening both wires and posts within the fence structure. This damage can allow livestock to escape/wander, gives access to predators, and can result in costly repairs (Mapston 2004). Damaging fences that were erected to exclude/control other pest species (e.g., rabbits, Oryctolagus cuniculus, and dingoes, Canis dingo) causes a further impact to the management of the local environment (Tisdell 1982). Lastly, wild pigs have been known to damage other property (e.g., scientific field equipment, miscellaneous yard/patio furniture and other items, flower boxes/pots, etc.) by knocking it over either accidentally or because of their curiosity (J. J. Mayer, unpubl. data).

Alternative Prey - Often cited as a positive attribute of these invasive animals, wild pigs can serve as prey for local predators. In some cases, wild pigs provide an alternative prey for predators in Australia such as dingoes and wedge-tailed eagles (Uroaëtus audax). It has been suggested that this may help reduce predation by these species on young domestic stock (Pullar 1953, McKnight 1976).

In contrast to this potential positive circumstance, a situation developed on California Channel Islands, where wild pigs serving as a prey species played a pivotal role in the catastrophic decline in populations of the endangered island fox (Urocyon littoralis). Golden eagles, formerly rare or occasional visitors to the Channel Islands, had taken up residence on the islands, attracted and sustained by the year-round supply of wild piglets. In addition to preying on the pigs and other feral ungulates on the islands, the golden eagles also began to prey on the island fox. When the wild pig numbers began to decline as a result of control activities, the eagles switched to prey more on the endangered foxes. The golden eagle predation has placed the island fox on the brink of extinction (Roemer et al. 2001, 2002).

Contaminant Uptake - Because wild pigs are harvested for consumption by the sport-hunting public, these animals have the potential to serve as agents or vectors for the introduction of contaminants (e.g., radionuclides, metals) into the human food chain. The incidental ingestion of soil during foraging (Beyer et al. 1994) along with the preference of these animals for wetland areas and drainages (Crouch 1983), where many such constituents are frequently present (either through mobilization and/or sequestration), increases the potential for uptake of contaminants (Stribling et al. 1986). Concerns over human contamination prompted monitoring and studies of the uptake of radionuclides by these animals at the SRS beginning in the early 1970s. In addition to contamination from nuclear production operations such as the SRS, radioactive atmospheric fallout from earlier weapons testing has also been deposited globally (Brisbin et al. 1977). Such impacts make this contamination concern widespread. For example, the Chernobyl nuclear reactor disaster in Belarus in 1986 resulted in increased radionuclide body burdens in wild boar populations as far away as Austria, Croatia and Germany (Kreuzer and Hecht 1988, Schonhofer and Tataruch 1988, Tataruch et al. 1996, Vilic et al. 2005). In addition to radionuclides, metals (e.g., cadmium, lead and mercury), organochlorine pesticides and polychlorinated biphenyls have all been documented as contaminants found in wild pig tissues (e.g., Rimkus and Wolf 1987, Falandysz and Kannan. 1992, Zasadowski 1994, Kuiters 1996, Hoshi et al. 1998, Santiago et al. 1998, Tyutikov 1999, 2000, Korenekova and Kottferova 2000, Dobrowolska and Melosik 2002, Sobańska 2005).

\section{Positive Impacts}

The effects of these introduced pigs on their natural and manmade host environments are not always negative. Activities by wild pigs have been attributed to having at least some positive effects. This would include such things as rooting activities aerating compacted forest floor soils, promoting the propagation and regeneration of certain tree species, and increasing the growth in other tree species (Lacki and Lancia 1986, Wilson 2005). Both Kotanen (1995) and Arrington et al. (1999) found that wild pig rooting led to an 
increase in species diversity in habitats in California and Florida, respectively. Similar increases in floral species diversity from rooting have also been reported from England and Sweden (Welander 1995, Wilson 2005). Wild pig rooting also decreases plant cover and breaks up dense mats of dead vegetation, thereby decreasing potential competition and increasing light penetration to the soil surface, which can trigger seed germination (Arrington et al. 1999). Wild pig rooting in marshes sometimes improves waterfowl habitat by enlarging the area of open water (McKnight 1964). Wild pigs also increase the local prey base available to some large predators (e.g., mountain lion, Puma concolor) (Hopkins 1989). Being active scavengers, wild pigs are quick to locate and consume carcasses, serving to remove them from an area (McKnight 1976, Tisdell 1982). In parts of Australia where sheep blowfly (Lucilia cuprina) control is an ongoing management issue, scavenging by wild pigs reduces the availability of carcasses that would facilitate the propagation of blowfly numbers (Pullar 1953, McKnight 1976, Roots 1976). Wild pigs also devour other pest species (e.g., larvae and adults of some insect pests, introduced rodents and rabbits, and invasive plants/weeds) (Pullar 1950, Briedermann 1967, Genov 1981, Tisdell 1982, Lever 1985, Brownlow 1994). However, the list of such positive consequences pales in comparison to the compilation of the negatives impacts.

\section{Summary}

The spectrum of damage caused by wild pigs highlights the need to be able to management such impacts, whether or not these animals are considered to be a big game resource. The successful management of a type of damage dictates a better understanding of that impact. Some forms of wild pig damage are well studied and documented, while other forms need to be better characterized before they can be successfully managed, controlled or eliminated.

The recent expansion of the wild pig populations in the United States brings to light a couple of choices. If a state with newly established populations of these animals takes the position that wild pigs are an unwanted invasive species that poses significant threats to both the natural and manmade environments, then that state can implement an aggressive removal program to eradicate these animals anywhere they are reported. On the other hand, if a state has elected to accept that these animals cannot be eradicated in either existing or new areas where they are found, then that state must accept the potential for damage and the cost of having to manage or control it. Again, the better that the different types of damage are characterized and understood, the better that these impacts can be successfully handled from both an economic and environmental perspective. 


\section{Wild Pigs}
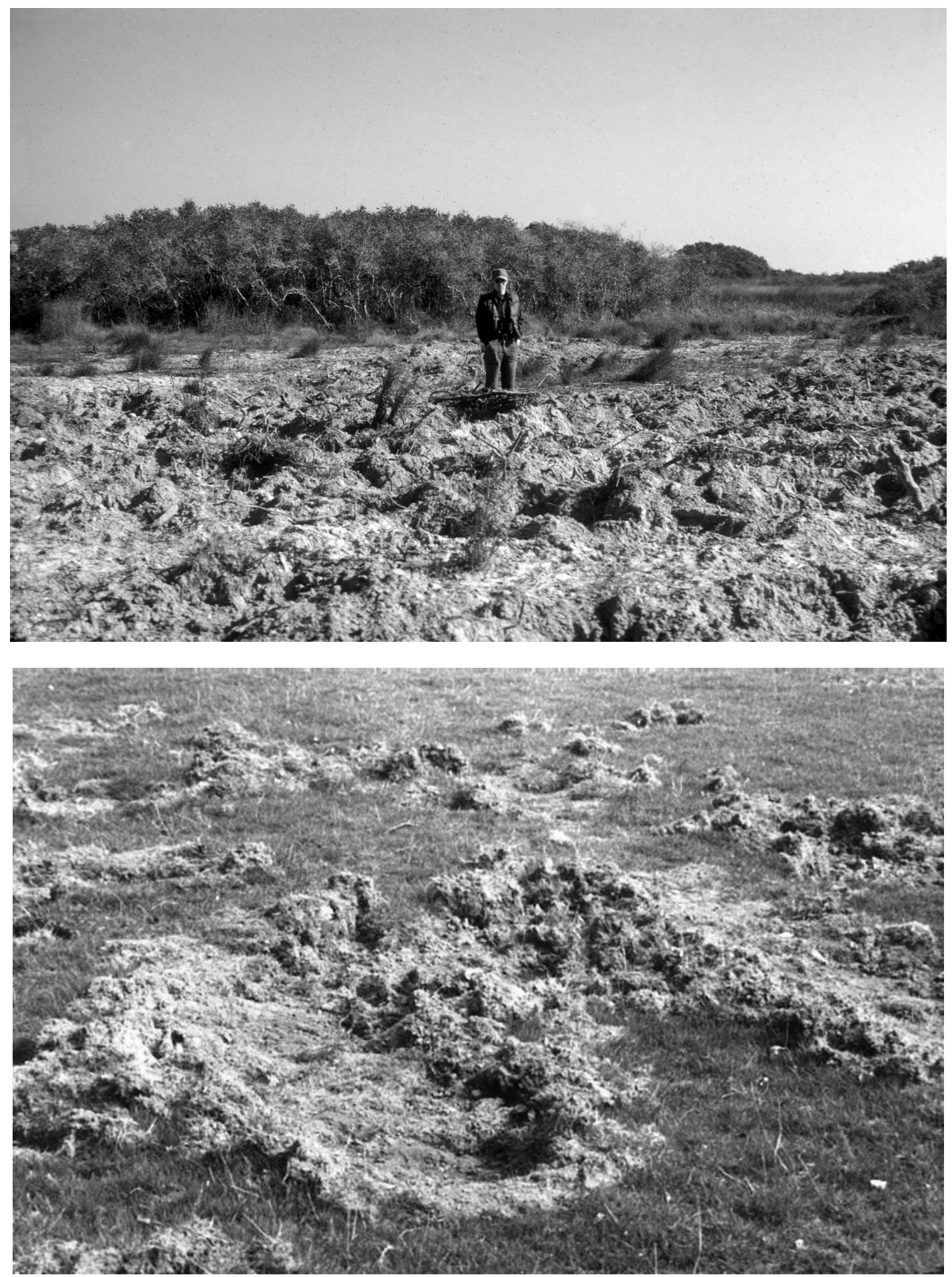

Fig. 1. Illustration of extensive rooting damage by wild pigs at the Aransas National Wildlife Refuge, Texas (top photo), and in an improved rangeland area in western South Carolina (bottom photo). 

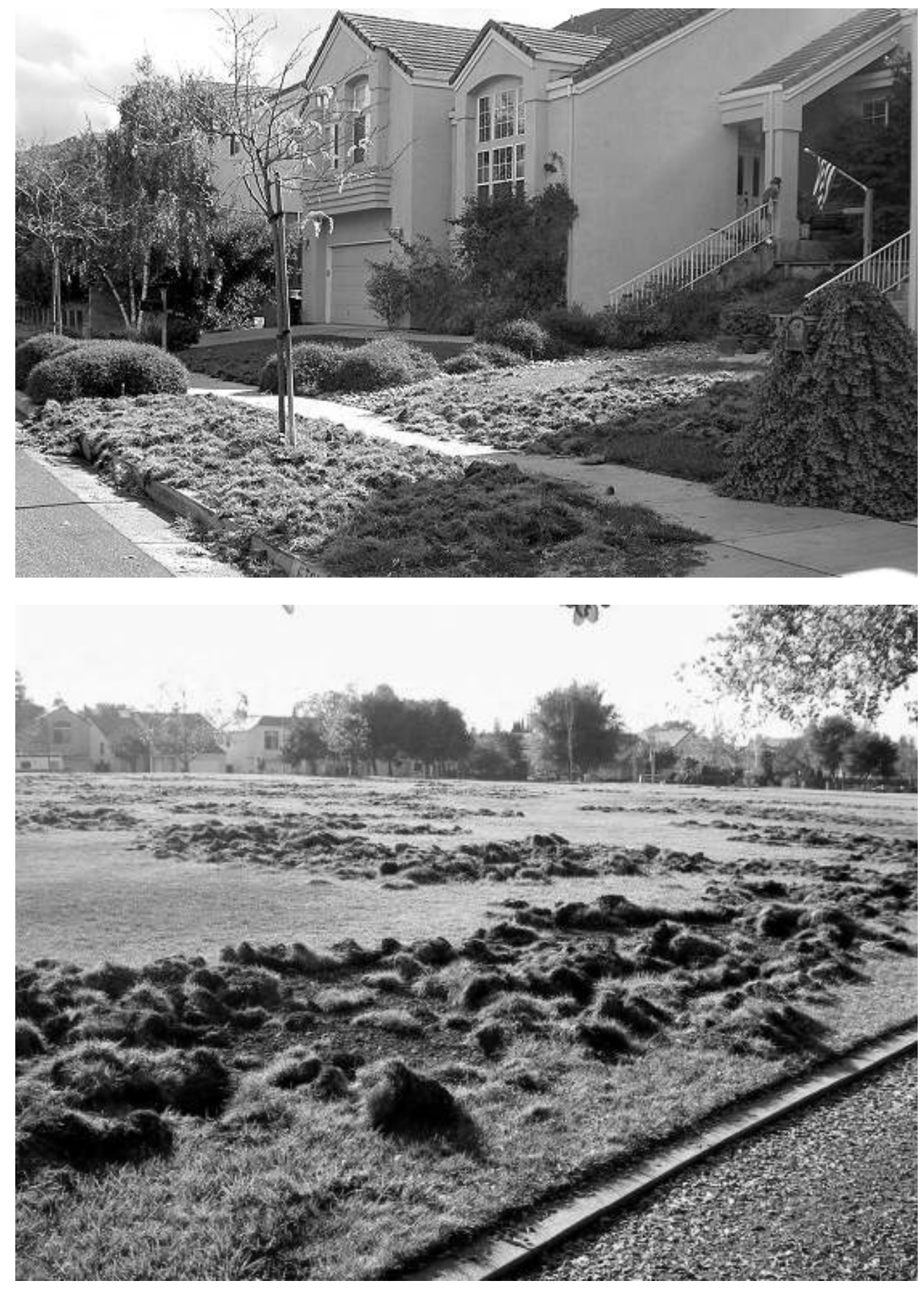

Fig. 2. Wild pig rooting damage on landscaped lawns in suburban developments in California. 


\section{Wild Pigs}
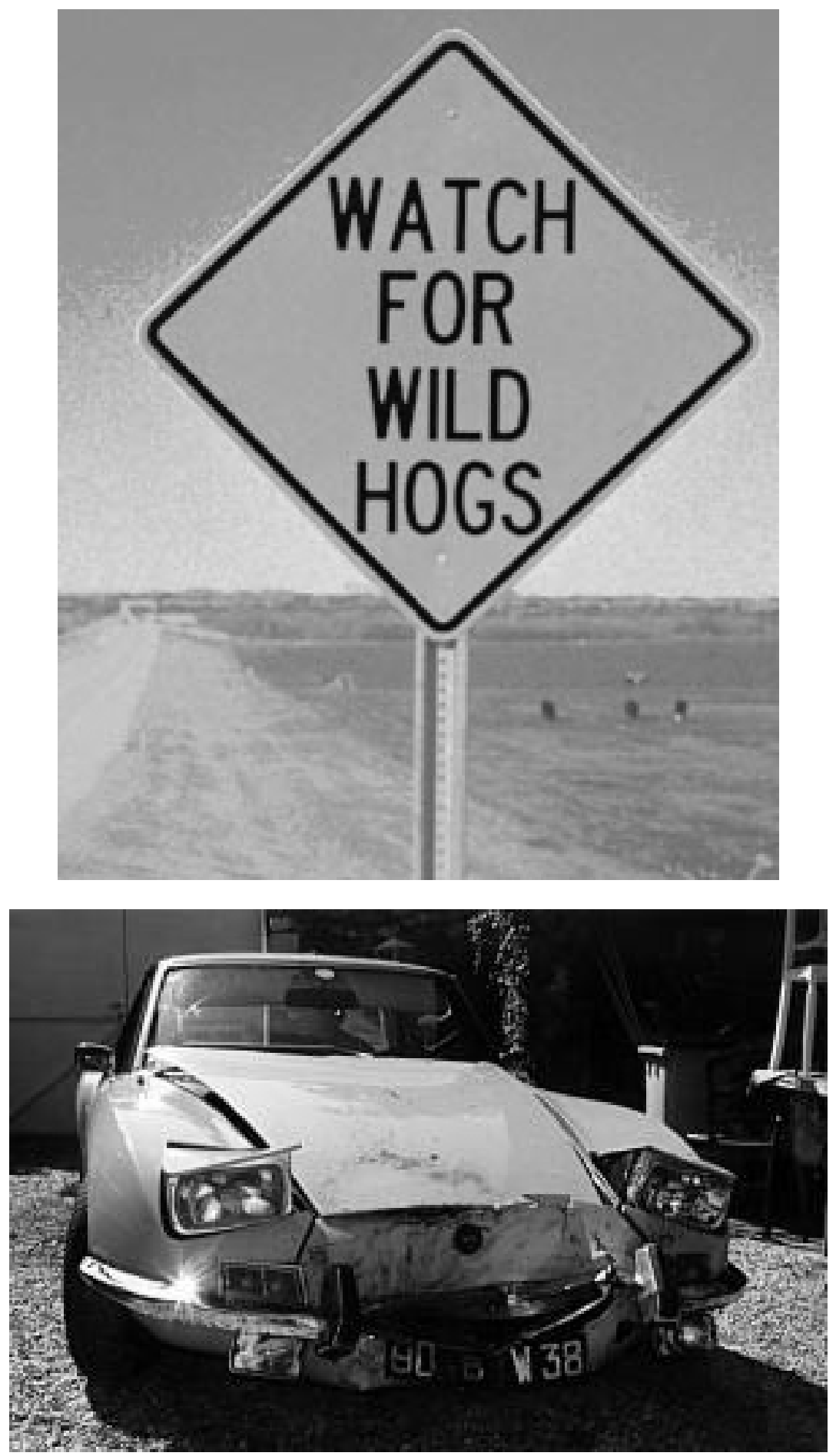

Fig. 3. Wild pig crossing warning sign in Texas (top photo), and the front end of a vehicle that was involved in a collision with a wild pig (bottom photo). 

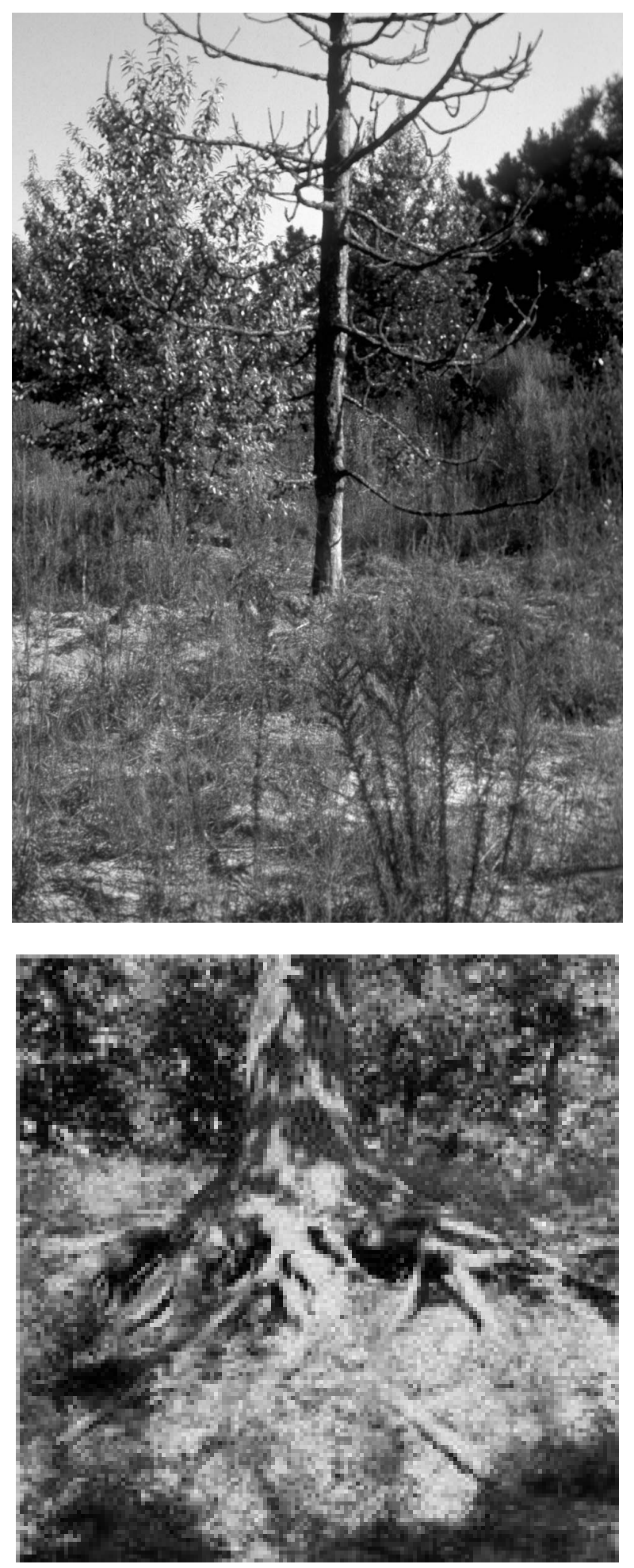

Figure 4. Pine tree killed by rubbing from wild pigs (top photo); tree roots exposed by wild pig rooting (bottom photo). 


\section{Wild Pigs}

\section{Literature Cited}

Abbas, M., S. H. Khan, R. A. Khan and M. Shahbaz. 2004. Impact of wild boar's habitat on sugarcane crop in Faisalabad Division. International Journal of Agriculture \& Biology, 6(2):420-421.

Ackerman, B. B., M. E. Harmon, and F. J. Singer. 1978. Part II. Seasonal food habits of European wild boar - 1977. Pp. 94-137. In F. J. Singer (ed.), Studies of European wild boar in the Great Smoky Mountains National Park: 1st annual report; a report for the Superintendent. Uplands Field Research Laboratory, Great Smoky Mountains National Park, Gatlinburg, Tennessee.

ADAC (Allgemeiner Deutscher Automobil-Club). 2002. Kollisionen mit Schwarzwild: Vorsicht vor Obelix Leibspeise. Weltzeit uhr. http://www.weltzeituhr.com/reise/kollisionen_mit_sc.shtml

Anderson, S., R. Hobdy, and K. Maly. 2007. The need for more effective ungulate control in Hawai'i. The Nature Conservancy of Hawai'i, Honolulu, Hawai'i.

Andrzejewski, R., and W. Jezierski. 1969. Zasady przeciwdzialania szkodom wyrzadzanym przez dziki. Lowiec Polski, 1(1340):4-60.

Anonymous. 1983. Space Center's problem pigs - A taste treat at Florida jail. The New York Times, September 12.

1988. Wild pigs cause jet to crash. The News \& Courier, Charleston, South Carolina, June 10:2A.

. 2003. Feral pigs in Queensland - Distribution, ecology and impact. Pest Series: Pest Fact PA6 QNRME01277, Department of Natural Resources and Mines, The State of Queensland, Brisbane, Australia.

2004. Feral pigs Sus scrofa. Queensland Pest Animal Strategies series. QNRME04066. Natural Resources, Mines and Energy, Land Protection Council, The State of Queensland, Coorparoo, Australia.

Baron, J. S. 1979. Vegetation damage by feral hogs on Horn Island, Gulf Islands National Seashore, Mississippi. M.S. Thesis, University of Wisconsin - Madison, Madison, Wisconsin.

Barrett, R. H. 1971. Ecology of the feral hog in Tehama County, California. Ph.D. Dissertation, University of California, Berkeley, California.

Barrett, R. H., and G. H. Birmingham. 1994. Wild pigs. Pp. D65-D70. In S. E. Hygnstrom, R. M. Timm, and G. E. Larson (eds.), Prevention and control of wildlife damage. 2 volumes; Great Plains Agricultural Council, Univ. of Nebraska, Lincoln, Nebraska.

Barss, P., and S. Ennis. 1988. Injuries caused by pigs in Papua New Guinea. Medical Journal of Australia, 149(11-12):649-656.

Baums, C. G., G. J. Verkühlen, T. Rehm, L. M. G. Silva, M. Beyerbach, K. Pohlmeyer, and P. ValentinWeigand. 2007. Prevalence of Streptococcus suis genotypes in wild boars of northwestern Germany. Applied and Environmental Microbiology, 73(3):711-717.

BBC News. 2002. Wild boar causes Japan rail crash. February 23. http://news.bbc.co.uk/1/hi/world/asiapacific/1837080.stm.

Beach, R. 1993. Depredation problems involving feral hogs. Pp. 67-75. In C. W. Hanselka and J. F. Cadenhead (eds.), Feral swine: A compendium for resource managers. Texas Agricultural Extension Service, Kerrville, Texas. 
Beacham, W. 1997. The World Wildlife Fund guide to extinct species of modern times. Beacham Publishing Corp., Osprey, Florida.

Belden, R. C., and W. B. Frankenberger. 1977. Management of feral hogs in Florida - Past, present and future. Pp. 5-10. In G. W. Wood (ed.), Research and management of wild hog populations. Belle Baruch Forest Science Institute of Clemson University, Georgetown, South Carolina.

Belden, R. C., and M. R. Pelton. 1975. European wild hog rooting in the mountains of east Tennessee. Proceedings of the Annual Conference of the Southeastern Association of Game and Fish Commissioners, 29:665-671.

1976. Wallows of the European wild hog in the mountains of east Tennessee. Journal of the Tennessee Academy of Sciences, 51(3):91-93.

Beyer, W. N., E. E. Connor, and S. Gerould. 1994. Estimates of soil ingestion by wildlife. Journal of Wildlife Management, 58(2):375-382.

Bigler, W. J., G. L. Hoff, W. H. Hemmert, J. A. Tomas, and H. T. Janowski. 1976. Trends in Brucellosis in Florida an epidemiological review. American Journal of Epidemiology, 105(3):245-251.

Bowie, C. 2004. Dog saves Edgefield man from wild hog attack. The Edgefield Advertiser, August 18:1.

Bratton, S. P. 1974. The effect of the European wild boar (Sus scrofa) on the high elevation vernal flora in Great Smoky Mountains National Park. Bulletin of the Torrey Botanical Club, 101(4):198-206.

. 1974. An integrated ecological approach to the management of European wild boar (Sus scrofa) in GRSM. NPS-SER Management Report No. 3. Uplands Field Research Laboratory, Great Smoky Mountains National Park, Gatlinburg, Tennessee.

. 1975. The effect of the European wild boar (Sus scrofa) on grey beech forest in the Great Smoky Mountains. Ecology, 56(6):1356-1366.

Briedermann, L. 1967. Die Nahrungskomponenten des Schwarzwildes (Sus s. scrofa 1959) in der mitteleuropaischen Kulturlandschaft. Transactions of the Congress of the International Union of Game Biologists, 7:207-213.

- 1986. Schwarzwild. VEB Deutscher Landwirtschaftsverlag, Berlin, Democratic Republic of Germany.

Brisbin, I. L. Jr., M. W. Smith and M. H. Smith. 1977. Feral swine studies at the Savannah River Ecology Laboratory: An overview of program goals and design. Pp. 71-90. In G. W. Wood (ed.), Research and management of wild hog populations. Belle Baruch Forest Science Institute of Clemson University, Georgetown, South Carolina.

Brooks, J. E., E. Ahmad, and I. Hussain. 1988. Characteristics of damage by vertebrate pests to groundnuts in Pakistan. Proceedings of the Vertebrate Pest Conference, 13:129-133.

. 1989. The agricultural importance of the wild boar (Sus scrofa L.) in Pakistan. Tropical Pest Management, 35(3):278-281.

Brownlow, M. J. C. 1994. Towards a framework of understanding for the integration of forestry with domestic pig (Sus scrofa domestica) and European wild boar (Sus scrofa scrofa) husbandry in the United Kingdom. Forestry, 67(3):189-218. 


\section{Wild Pigs}

Calenge, C., D. Maillard, P. Fournier, and C. Fouque. 2004. Efficiency of spreading maize in the garrigues to reduce wild boar (Sus scrofa) damage to Mediterranean vineyards. European Journal of Wildlife Research, 50(3):112-120.

Capstik, P. H. 1990. Death in a lonely land: More hunting, fishing, and shooting on five continents. St. Martin's Press, New York.

CDC (Centers for Disease Control and Prevention). 2009. Brucella suis infection associated with feral swine hunting - Three states, 2007-2008. Morbidity and Mortality Weekly Report, 58(22):618-621.

Chavarria, P. M., R. R. Lopez, G. Bowser and N. J. Silvy. 2007. A landscape-level survey of feral hog impacts to natural resources of the Big Thicket National Preserve. Human-Wildlife Conflicts, 1(2):199-204.

Chipping, D. H. 1993. Impacts of wild pig on native vegetation. Pp. 4. In W. Tietje and R. Barrett (eds.), The wild pig in California oak woodland: Ecology and economics. University of California, Berkeley, Berkeley, California.

Choquenot, D., B. Lukins, and G. Curran. 1997. Assessing lamb predation by feral pigs in Australia's semiarid rangelands. Journal of Applied Ecology, 34(6):1445-1454.

Choquenot, D., J. McIlroy, and T. Korn. 1996. Managing vertebrate pests: Feral pigs. Bureau of Rural Sciences, Australian Government Publishing Service, Canberra, Australia.

Clay, W. H. 2007. Hogs gone wild. Human-Wildlife Conflicts, 1(2):137-138.

Coblentz, B., and C. Bouska. 2004. Pest risk assessment for feral pigs in Oregon. Department of Fisheries and Wildlife, Oregon State University, Corvallis, Oregon.

Conley, R. H., V. G. Henry, and G. H. Matschke. 1972. Final report for the European hog research project W-34. Tennessee Game and Fish Commission, Nashville, Tennessee.

Corn, J. L., D. E. Stallknecht, N. M. Mechlin, M. P. Luttrell, and J. R. Fischer. 2004. Persistence of pseudorabies virus in feral swine populations. Journal of Wildlife Diseases, 40(2):307-310.

Crouch, L. C. 1983. Movements of and habitat utilization by feral hogs at the Savannah River Plant, South Carolina. M.S. Thesis, Clemson University, Clemson, South Carolina.

Cuthbert, R. 2002. The role of introduced mammals and inverse density-dependent predation in the conservation of Hutton's shearwater. Biological Conservation, 108(1):69-78.

Davidson, W. R., and V. F. Nettles. 1988. Field manual of wildlife diseases in the southeastern United States. Southeastern Cooperative Wildlife Disease Study, The University of Georgia, Athens, Georgia.

Davis, D. S. 1993. Feral hogs and disease: Implications for humans and livestock. Pp. 84-87. In C. W. Hanselka and J. F. Cadenhead (eds.), Feral swine: A compendium for resource managers. Texas Agricultural Extension Service, Kerrville, Texas.

DEFRA (Department for Environment, Food and Rural Affairs). 2004. The ecology and management of wild boar in southern England. Central Science Laboratory, Hutton, York, United Kingdom.

Devine, R. S. 1999. Alien invasion: America's battle with non-native animals and plants. National Geographic Society, Washington, DC.

Dobrowolska, A., and M. Melosik. 2002. Mercury contents in liver and kidneys of wild boar (Sus scrofa) and red deer (Cervus elaphus). Zeitschrift fur Jagdwissenschaft, 48:156-160. 
Diong, C. H. 1982. Population biology and management of the feral pig (Sus scrofa L.) in Kipahula Valley, Maui. Ph.D. Dissertation, University of Hawaii, Honolulu, Hawaii.

Everitt, J. H., and M. A. Alaniz. 1980. Fall and winter diets of feral pigs in south Texas. Journal of Range Management, 33(2):126-129.

Falandysz, J., and K. Kannan. 1992. Organochlorine pesticide and polychlorinated biphenyl residues in slaughtered and game animal fats from the northern part of Poland. Zeitschrift fur LebensmittelUntersuchung und -Forschung, 195(1):17-21.

Fico, R., G. Morosetti, and A. Giovannini. 1993. The impact of predators on livestock in the Abruzzo region of Italy. Revue Scientifique et Technique, 12(1):39-50.

Genov, P. 1981. Significance of natural biocenoses and agrocenoses as the source of food for wild boar (Sus scrofa L.). Ekologia Polska, 29(1):117-136.

Giles, J. R. 1980. The ecology of feral pigs in western New South Wales. Ph.D. Dissertation, Sydney University, Sydney, Australia.

Gimeno, I., and M. Vila. 2002. Recruitment of two Opuntia species invading abandoned olive groves. Acta Oecologica, 23(4):239-246.

Glazer, J. M. 1987. Boar wars: Geopolitics. The Harvard Crimson, April 10:2.

Goulding, M. J. 2003. Wild boar in Britain. Whittet Books, Ltd., Suffolk, United Kingdom.

Goulding, M. J., G. Smith, and S. J. Baker. 1998. Current status and potential impact of wild boar (Sus scrofa) in the English countryside: A risk assessment. Central Science Laboratory, Ministry of Agriculture, Fisheries and Food, London, England.

Groot Bruinderink, G. W. T. A., and E. Hazebroek. 1996a. Wild boar (Sus scrofa) rooting and forest regeneration on podzolic soils in the Netherlands. Forest Ecology and Management, 88(1-2):71-80.

1996b. Ungulate traffic collisions in Europe. Conservation Biology 10:1059-1067.

Hall, J. S., R. B. Minnis, T. A. Campbell, S. Barras, R. W. DeYoung, K. Pabilonia, M. L. Avery, H. Sullivan, L. Clark, and R. G. McLean. 2008. Influenza exposure in United States feral swine populations. Journal of Wildlife Diseases, 44(2):362-368.

Hampton, J., P. B. S. Spencer, A. D. Elliot, and R. C. A. Thompson. 2006. Prevalence of zoonotic pathogens from feral pigs in major public drinking water catchments in Western Australia. EcoHealth, 5(2):64-66.

Hellgren, E. C. 1993. Biology of feral hogs (Sus scrofa) in Texas. Pp. 50-58. In C. W. Hanselka and J. F. Cadenhead (eds.), Feral swine: A compendium for resource managers. Texas Agricultural Extension Service, Kerrville, Texas.

Hennig, R. 1981. Schwarzwild: Biologie - Verhalten, Hege und Jagd. BVL Verlagsgesellschaft, Munchen, West Germany.

Herrero, J., A. Garcia-Serrano, S. Couto, V. Ortuno, and R. Garcia-Gonzalez. 2006. Diet of wild boar Sus scrofa L. and crop damage in an intensive agroecosystem. European Journal of Wildlife Research, 52(4):245-250. 


\section{Wild Pigs}

Holy, J. 1983. Food ecology of boar from the viewpoint of damage to forestry and agriculture. Folia Venatoria, 13:51-63.

Hone, J. 1980. Effects of feral pig rooting on introduced and native pasture in north-eastern New South Wales. Journal of the Australian Institute of Agricultural Science, 46(2):130-132.

1999. Monitoring impacts and control of feral pigs: A case study in Namadgi National Park, A.C.T. Pp. 48-50. In C. N. Johnson (ed.), Feral pigs: Pest status and prospects for control. Proceedings of a feral pig workshop. James Cook University, Cairns, March. Research Report No. 13. Cooperative Research Centre for Tropical Rainforest Ecology and Management, Cairns, Australia.

Hopkins, R. A. 1989. Ecology of the puma in the Diablo Range, California. Ph.D. Dissertation. University of California, Berkeley, California.

Hopkins, W. 1948. Hogs or logs - Longleaf pine seedlings and range hogs won't grow together. Naval Stores Review, 57(43):12-13.

Hoshi, H., N. Minamoto, H. Iwata, K. Shiraki, R. Tatsukawa, S. Tanabe, S. Fujita, K. Hirai, and T. Kinjyo. 1998. Organochlorine pesticides and polychlorinated biphenyl congeners in wild terrestrial mammals and birds from Chubu region, Japan: Interspecies comparison of the residue levels and compositions. Chemosphere, 36(15):3211-3221.

Howe, T. D., F. J. Singer, and B. B. Ackerman. 1979. High elevation forage relationships of European wild boar invading Great Smoky Mountains. Report to the Superintendent. U. S. Department of the Interior, National Park Service, Great Smoky Mountains National Park, Gatlinburg, Tennessee.

Hutton, T., T. DeLiberto, S. Owen, and B. Morrison. 2006. Disease risks associated with increasing feral swine numbers and distribution in the United States. Wildlife and Fish Health Committee, Midwest Association of Fish and Wildlife Agencies, Rhinelander, Wisconsin.

Inbar, M., U. Shanas, and I. Izhaki. 2002. Characterization of road accidents in Israel involving larger mammals. Israel Journal of Zoology, 48:197-206.

Jay, M. T., M. Cooley, D. Carychao, G. W. Wiscomb, R. A. Sweitzer, L. Crawford-Miksza, J. A. Farrar, D. K. Lau, J. O'Connell, A. Millington, R. V. Asmundson, E. R. Atwill, and R. E. Mandrell. 2007. Escherichia coli O157:H7 in feral swine near spinach fields and cattle, central California coast. Emerging Infectious Diseases, 13(12):1908-1911.

Jay, M. T., and G. W. Wiscomb. 2008. Food safety risks and mitigation strategies for feral swine (Sus scrofa) near agriculture fields. Proceedings of the Vertebrate Pest Conference, 23:21-25.

Jessup, D. A., and P. Swift. 1993. Zoonotic diseases of California's wild hogs. Pp. 19-20. In W. Tietje and R. Barrett (eds.), The wild pig in California oak woodland: Ecology and economics. University of California, Berkeley, Berkeley, California.

Kaller, M. D., and W. E. Kelso. 2006. Swine activity alters invertebrate and microbial communities in a coastal plain watershed. American Midland Naturalist, 156(1):163-177.

Khokhar, A. R., and S. W. A. Rizvi. 1998. Productivity enhancement of rice crop yield through prevention of losses due to wild boars in Pakistan. Turkish Journal of Zoology, 22(2):167-174.

Korenekova, B., and J. Kottferova. 2000. Game as an indicator of environmental pollution by cadmium and lead. Journal of Trace and Microprobe Techniques, 18(4):571-575.

Kotanen, P. M. 1995. Responses of vegetation to a changing regime of disturbance: Effects of feral pigs in a California coastal prairie. Ecography, 18(2):190-199. 
Kotulski, Y., and A. König. 2008. Conflicts, crises and challenges: Wild boar in the Berlin City - A social empirical and statistical survey. Natura Croatica, 17(4):233-246.

Kreuzer, W., and H. Hecht. 1988. Radioactivity in Bavarian game from the reactor accident at Chernobyl. Archiv fur Lebensmittelhygiene, 39:57-84.

Kristiansson, H. 1985. Crop damage by wild boars in central Sweden. Transactions of the Congress of the International Union of Game Biologists, 17:605-609.

Kuiters, A. T. 1996. Accumulation of cadmium and lead in red deer and wild boar at the Veluwe, the Netherlands. The Veterinary Quarterly, 18(3): S134-S135.

Labudzki, L. 1991. Seasonal dynamics of damages by wild boar (Sus scrofa) to agricultural fields in westcentral Poland. Transactions of the Congress of the International Union of Game Biologists, 20(1):117-124.

Lapidge, S., D. Dall, R. Hunt, B. Cowled, M. Smith, and L. Staples. 2006. A review of the impact of sheep predators in Australia and new control methods under development. Proceedings of the Vertebrate Pest Conference, 22:258-263.

LaPointe, D. A. 2006. Feral pigs, introduced mosquitoes, and the decline of Hawai'i's native birds. Fact Sheet Report Number 2006-3029. USGS Information Services, Denver, Colorado.

Layne, J. N. 1997. Nonindigenous mammals. Pp. 157-186. In D. Simberloff, D. C. Schmitz and T. C. Brown (eds.). Strangers in paradise: Impact and management of nonindigenous species in Florida. Island Press, Washington, D.C.

Lease, J. K., R. J. Dusek, and C. T. Atkinson. 1996. Feral pig control is effective in reducing mosquito populations (abstract only). The 1996 Hawaii Conservation Conference, July 18-19, Honolulu, Hawaii.

Lee, J. 1999. Japanese encephalitis - A case study of exotic animal disease incursion. Pp. 21-26. In C. N. Johnson (ed.), Feral pigs: Pest status and prospects for control. Proceedings of a feral pig workshop. James Cook University, Cairns, March. Research Report No. 13. Cooperative Research Centre for Tropical Rainforest Ecology and Management, Cairns, Australia.

Lever, C. 1985. Naturalized mammals of the world. Longman, London, United Kingdom.

Lipscomb, D. J. 1989. Impacts of feral hogs on longleaf pine regeneration. Southern Journal of Applied Forestry, 13(4):177-181.

Loope, L. L. 1998. Hawaii and Pacific Islands. Pp. 747-774. In M. J. Mac, P. A. Opler, C. E. Puckett Haecker, and P. D. Doran (eds.). Status and Trends of the Nation's Biological Resources. Vol. 2. U. S. Department of the Interior, Geological Survey, Reston, Virginia.

Lowe S., M. Browne, S. Boudjelas, and M. De Poorter. 2000. 100 of the World's Worst Invasive Alien Species: A selection from the Global Invasive Species Database. Invasive Species Specialist Group, Species Survival Commission, World Conservation Union (IUCN), Auckland, New Zealand.

Lucas, E. G. 1977. Feral hogs - Problems and control on national forest lands. Pp. 17-21. In G. W. Wood (ed.), Research and management of wild hog populations. Belle Baruch Forest Science Institute of Clemson University, Georgetown, South Carolina.

Luxton, R. 1999. Economic impacts of feral pigs in the Wet Tropics. Pp. 11-13. In C. N. Johnson (ed.), Feral pigs: Pest status and prospects for control. Proceedings of a feral pig workshop. James Cook 


\section{Wild Pigs}

University, Cairns, March. Research Report No. 13. Cooperative Research Centre for Tropical Rainforest Ecology and Management, Cairns, Australia.

Lynes, B. C., and S. D. Campbell. 2000. Germination and viability of mesquite (Prosopis pallida) seed following ingestion and excretion by feral pigs (Sus scrofa). Tropical Grasslands Journal, 34(2):125-128.

Macchi, E., U. Gallo Orsi, A. Perrone, and P. Durio. 1992. Wild boar (Sus scrofa) damages in Cuneo Province (Piedmont, Italy NW). pp. 431-433. In F. Spitz, G. Janeau, G. Gonzalez, and S. Aulagnier (eds.), Ongules/Ungulates 91: Proceedings of the international symposium. Toulouse, France, September 2-6, 1991. Societe Francaise pour l'Etude et la Protection des Mammiferes, and Toulose: Institut de Recherche sur les Grands Mammiferes, Paris \& Toulouse, France.

Mackin, R. 1970. Dynamics of damage caused by wild boar to different agricultural crops. Acta Theriologica, 15(27):447-458.

Mapston, M. E. 2004. Feral hogs in Texas. Document No. B-6149 5-04. Wildlife Services, Texas Cooperative Extension, Texas A\&M University, College Station, Texas.

Massei, G., and P. V. Genov. 2004. The environmental impact of wild boar. Galemys, 16(no. especial):135145.

Mayer, J. J. 2008. Wild pig attacks on humans. 2008 National Conference on Feral Hogs, St. Louis, Missouri. April 13-15. Abstracts of Papers. p. 14.

Mayer, J. J., and P. E. Johns. 2007. Characterization of wild pig-vehicle collisions. Proceedings of the Wildlife Damage Management Conference, 12:175-187.

Mayer, J. J., E. A. Nelson, and L. D. Wike. 2000. Selective depredation of planted hardwood seedlings by wild pigs in a wetland restoration area. Ecological Engineering, 15(Supplement 1):S79-S85.

McGaw, C. C., and J. Mitchell. 1998. Feral pigs (Sus scrofa) in Queensland. Pest status review series. Land Protection, Department of Natural Resources and Mines, Queensland Government, Coorparoo, Australia.

McIlroy, J. C. 1999. Overview of the impact of feral pigs Sus scrofa on the Australian environment. Pp. 710. In C. N. Johnson (ed.), Feral pigs: Pest status and prospects for control. Proceedings of a feral pig workshop. James Cook University, Cairns, March. Research Report No. 13. Cooperative Research Centre for Tropical Rainforest Ecology and Management, Cairns, Australia.

McKnight, T. 1964. Feral livestock in Anglo-America, University of California Publications in Geology, Vol. 16. University of California Press, Berkeley, California.

1976. Friendly vermin: A survey of feral livestock in Australia, University of California Publications in Geology, Vol. 21. University of California Press, Berkeley, California.

Mebus, C. A. 1989. Potential role of feral pigs in the spread of foreign animal disease. Pp. 34-36. In N. Black (ed.), Proceedings: Feral pig symposium. April 27-29, Orlando, Florida. Livestock Conservation Institute, Madison, Wisconsin.

Meriggi, A., and O. Sacchi. 1992. Factors affecting damage by wild boars to cereal fields in northern Italy. Pp. 439-441. In F. Spitz, G. Janeau, G. Gonzalez, and S. Aulagnier (eds.), Ongules/Ungulates 91: Proceedings of the international symposium. Toulouse, France, September 2-6, 1991. Societe Francaise pour l'Etude et la Protection des Mammiferes, and Toulose: Institut de Recherche sur les Grands Mammiferes, Paris \& Toulouse, France. 
MOSNEWS (Moscow News Service). 2006. Estonian driver accidentally runs over 10 wild boars in one day. http://mosnews.com/news/2006/03/14/driveoverboars.shtml

Nettles, V. F. 1989. Disease of wild swine. Pp. 16-18. In N. Black (ed.), Proceedings: Feral pig symposium. April 27-29, Orlando, Florida. Livestock Conservation Institute, Madison, Wisconsin.

NPS (National Park Service). 2002. Santa Cruz Island primary restoration plan. Final Environmental Impact Statement. Channel Islands National Park, Santa Cruz Island, Santa Barbara County, California.

Okarma, H., B. Jedrzejewska, W. Jedrzejewski, Z. A. Krasinski, and L. Milkowski. 1995. The roles of predation, snow cover, acorn crop, and man-related factors on ungulate mortality in Bialowieza Primeval Forest, Poland. Acta Theriologica, 40(2):197-217.

Oliver, W. L. R., and I. L. Brisbin, Jr. 1993. Introduced and feral pigs: Problems, policy, and priorities. Pp. 179-191. In W. L. R. Oliver (ed.), Pigs, peccaries and hippos: Status survey and conservation action plan. International Union for the Conservation of Nature and Natural Resources, Gland, Switzerland.

Pavlov, P. M. 1980. The diet and general ecology of the feral pig (Sus scrofa) at Girilambone, N. S. W. M.S. Thesis, Monash University, Melbourne, Australia.

Pavlov, P. M., and J. Hone. 1982. The behavior of feral pigs, Sus scrofa, in flocks of lambing ewes. Australian Wildlife Research, 9(1):101-109.

Pavlov, P. M., J. Hone, R. J. Kilgour, and H. Pederson. 1981. Predation by feral pigs on Merino lambs at Nyngan, New South Wales. Australian Journal Experimental Agriculture and Animal Husbandry, 21:570-574.

Payeur, J. B. 1989. Feral swine: A potential threat to domestic cattle and swine. Pp. 19-33. In N. Black (ed.), Proceedings: Feral pig symposium. April 27-29, Orlando, Florida. Livestock Conservation Institute, Madison, Wisconsin.

Pimentel, D. 2007. Environmental and economic costs of vertebrate species invasions into the United States. Pp. 2-8. In G. W. Witmer, W. C. Pitt, and K. A. Fagerstone (eds). Managing vertebrate invasive species: Proceedings of an international symposium. USDA/APHIS Wildlife Services, National Wildlife Research Center, Fort Collins, Colorado.

Pimentel, D., R. Zuniga, and D. Morrison. 2005. Update on the environmental and economic costs associated with alien-invasive species in the United States. Ecological Economics, 52:273-288.

Pullar, E. M. 1950. The wild (feral) pigs of Australia and their role in the spread of infectious diseases. Australian Veterinary Journal, 25(4):99-110.

1953. The wild (feral) pigs of Australia: Their origin, distribution and economic importance. Memoirs of the National Museum Melbourne, 18:7-23.

RIA Novosti (Russian News and Information Service). 2007. Car crashes into herd of wild pigs in Central Russia. http://en.rian.ru/russia/20071024/85330518.html

Ricciuti, E. R. 1976. Killer animals. Walker Publishing Company, Inc., New York.

Rimkus, G., and M. Wolf. 1987. Schadstoffbelastung von Wild aus Schleswig-Holstein: 4. Blei-, Cadmium- und Quecksilbergehalte in Fleisch von Haar und Federwild. Fleischwirtschaft, 67(9):1150-1154. 


\section{Wild Pigs}

Roemer, G. W., T. J. Coonan, D. K. Garcelon, J. Bascompte, and L. Laughrin. 2001. Feral pigs facilitate hyperpredation by golden eagles and indirectly cause the decline of the island fox. Animal Conservation, 4(4):307-318.

Roemer, G. W., C. J. Donlan, and F. Courchamp. 2002. Golden eagles, feral pigs, and insular carnivores: How exotic species turn native predators into prey. Proceedings of the National Academy of Sciences, 99(2):791-796.

Rolls, E. C. 1969. They all ran wild: The story of pests on the land in Australia. Angus and Robertson Publishers. London, United Kingdom.

Roots, C. 1976. Animal invaders. Universe Book, New York.

Rudge, M. R. 1976. A note on the food of feral pigs (Sus scrofa) of Auckland Island. Proceedings of the New Zealand Ecological Society, 23:83-84.

Rutledge, A. 1970. The woods and wild things I remember. R. L. Bryan Company, Columbia, South Carolina.

Saint George, G. 1973. Shovel nose: Hungary's pugnacious wild boar. International Wildlife, 3(2):32-35.

Santiago, D., M. Motas-Guzman, A. Reja, P. Maria-Mojica, B. Rodero, and A. J. Garcia-Fernandez. 1998. Lead and cadmium in red deer and wild boar from Sierra Morena Mountains (Andalusia, Spain). Bulletin of Environmental Contamination and Toxicology, 61(6):730-737.

Schley, L., and T. J. Roper. 2003. Diet of wild boar Sus scrofa in Western Europe, with particular reference to consumption of agricultural crops. Mammal Review, 33(1):43-56.

Schonhofer, F., and F. Tataruch. 1988. Contamination of game in Austria after the Chernobyl accident. ESNA Proceedings of the Annual Meeting of Food Irradiation, 19:53-86.

Shield, J. 1999. Veterinary status of pigs on Cape York. Pp. 30-32. In C. N. Johnson (ed.), Feral pigs: Pest status and prospects for control. Proceedings of a feral pig workshop. James Cook University, Cairns, March. Research Report No. 13. Cooperative Research Centre for Tropical Rainforest Ecology and Management, Cairns, Australia.

Singer, F. J. 1976. The European wild boar in the Great Smoky Mountains National Park: Problem analysis and proposed research. NPS-SER Management Report No. 6. Uplands Field Research Laboratory, Great Smoky Mountains National Park, Gatlinburg, Tennessee.

Singer, F. J., W. T. Swank, and E. E. C. Clebsch. 1984. The effects of wild pig rooting in a deciduous forest. Journal of Wildlife Management, 48(2):464-473.

Smith, J. D. 1952. The Hawaiian goose (nēnē) restoration program. Journal of Wildlife Management, $16: 1-9$.

Sobańska, M. A. 2005. Wild boar hair (Sus scrofa) as a non-invasive indicator of mercury pollution. Science of the Total Environment, 339:81-88.

Sonoda, H., M. Abe, T. Sugimoto, Y. Sato, M. Bando, E. Fukui, et al. 2004. Prevalence of Hepatitis E virus (HEV) infection in wild boars and deer and genetic identification of a genotype $3 \mathrm{HEV}$ from a boar in Japan. Journal of Clinical Microbiology, 42:5371-5374.

Springer, M. D. 1975. Food habits of wild hogs on the Texas Gulf Coast. M.S. Thesis, Texas A\&M University, College Station, Texas. 
SRFS (Savannah River Forest Station). 1985. Feral Hog Trapping. Pp. 1-2. In Savannah River Forest Station. January 1985 Highlight Update: Forest Management and Research Progress. Savannah River Forest Station, Aiken, South Carolina.

Stevens, R. L. 1996. The feral hog in Oklahoma. Samuel Roberts Noble Foundation, Ardmore, Oklahoma.

Stone, C., and S. Anderson. 1988. Introduced animals in Hawaii's natural areas. Proceedings of the Vertebrate Pest Conference, 13:134-140.

Stribling, H. L., I. L. Brisbin, Jr., and J. R. Sweeney. 1986. Radiocesium concentrations in two populations of feral hogs. Health Physics, 50(6):852-854.

Sweeney, J. M., J. R. Sweeney, and S. W. Sweeney. 2003. Feral hog, Sus scrofa. Pp. 1164-1179. In G. A. Feldhammer, B. C. Thompson, and J. A. Chapman (eds.), Wild mammals of North America: Biology, management, and conservation. The Johns Hopkins Univ. Press, Baltimore, Maryland.

Synatzske, D. R. 1993. The ecological impacts of feral swine. Pp. 59-66. In C. W. Hanselka and J. F. Cadenhead (eds.), Feral swine: A compendium for resource managers. Texas Agricultural Extension Service, Kerrville, Texas.

Tataruch, F., E. Klansek, and F. Schonhofer. 1996. Radiocaesium levels in roe deer and wild boar in two large forest areas in Austria. Pp. 285-293. In M. Gerzabek, G. Desmet, B. J. Howard, G. Heinrich, and W. Schimmack (eds.), International symposium on ten years terrestrial radioecological research following the Chernobyl accident. Vienna, Austria, April 22-24. Proceedings of the international symposium on radioecology 1996. Berger, Horn, Austria.

Tate, J. (ed.). 1984. Techniques for controlling wild hogs in the Great Smoky Mountains National Park. Proceedings of a workshop, November 29-30, Research/Resources Mgmt. Rpt. SRE-72. U. S. Department of the Interior, National Park Service, Southeast Regional Office, Atlanta, Georgia.

Taylor, R. B., and E. C. Hellgren. 1997. Diet of feral hogs in western South Texas plains. The Southwest Naturalist, 42(1):33-39.

Thompson, R. L. 1977. Feral hogs on national wildlife refuges. Pp. 11-15. In G. W. Wood (ed.), Research and management of wild hog populations. Belle Baruch Forest Science Institute of Clemson University, Georgetown, South Carolina.

Tierney, T. A., and J. H. Cushman. 2006. Temporal changes in native and exotic vegetation and soil characteristics following disturbances by feral pigs in a California grassland. Biological Invasions, 8(5):1073-1089.

Tisdell, C. A. 1982. Wild pigs: Environmental pest or economic resource? Pergamon Press, New York.

Trcka, I., J. Lamka, R. Suchy, M. Kopecna, V. Beran, M. Moravkova, A. Horvathova, M. Bartos, I. Parmova, and I. Pavlik. 2006. Mycobacterial infections in European wild boar (Sus scrofa) in the Czech Republic during the years 2002 to 2005. Veterinarni Medicina, 51(5):320-332.

Tyutikov, S. F. 1999. Use of zoological indicators for detection of environmental pollution by firm chloroorganic pesticides. Selskokhozyaistvennaya Biologiya, 1999(4):112-114.

2000. Chemical elementary composition of organs of wild hoofed and farm animals. Russian Agricultural Sciences, 2000(6):34-36.

Van de Hoek, R. 1993. Impacts of feral pigs to the Caliente Mountain Wilderness Study Area and Carrizo Plain Natural Area, San Luis Obispo County, California. Pp. 14-15. In W. Tietje and R. Barrett (eds.), 


\section{Wild Pigs}

The wild pig in California oak woodland: Ecology and economics. University of California, Berkeley, Berkeley, California.

Vassant, J. 1994. Les techniques de prevention des degats de sanglier (Techniques for the prevention of wild boar damage). Bulletin Mensuel de l'Office National de la Chasse, 191:90-93.

Vicente, J., J. Segales, U. Hofle, M. Balasch, J. Plana-Duran, M. Domingo, and C. Gortazar. 2004. Epidemiological study on porcine circovirus type 2 (PCV2) infection in the European wild boar (Sus scrofa). Veterinary Research, 35(2):243-253.

Vilic, M., D. Barisic, P. Kraljevic, and S. Lulic. 2005. 137Cs concentration in meat of wild boars (Sus scrofa) in Croatia a decade and half after the Chernobyl accident. Journal of Environmental Radioactivity, 81(1):55-62.

Wahlenberg, W. G. 1946. The longleaf pine. C. L. Pack Forestry Foundation, Washington, DC.

Wahlström, H., E. Tysén, E. Olsson Engvall, B. Brändström, E. Eriksson, T. Mörner, and I. Vågsholm. 2003. Survey of Campylobacter species, VTEC O157 and Salmonella species in Swedish wildlife. The Veterinary Record, 153(3):74-80.

Wakely, P. C. 1954. Planting the Southern pine. Forest Service Agricultural Monograph, 18:1-233.

Welander, J. 1995. Are wild boars a future threat to the Swedish flora? Journal of Mountain Ecology (Ibex), 3:165-167.

Wiewandt, T. A. 1977. Unit plan for the management of Mona Island Forest Reserve. Forestry Task Force, Puerto Rico Dept. of Natural Resources, San Juan, Puerto Rico.

Wilson, C. J. 2004. Rooting damage to farmland in Dorset, southern England, caused by feral wild boar Sus scrofa. Mammal Review, 34(4):331-335.

2005. Feral wild boar in England: Status, impact and management. DEFRA, RDS National Wildlife Management Team, Exeter, United Kingdom.

Witmer, G. W., R. B. Sanders, and A. C. Taft. 2003. Feral swine - Are they a threat to livestock in the United States? Proceedings of the Wildlife Damage Management Conference, 10:316-325.

Wood, G. W., and R. H. Barrett. 1979. Status of wild pigs in the United States. Wildlife Society Bulletin, 7(4):237-246

Wood, G. W., and R. E. Brenneman. 1977. Research and management of feral hogs on Hobcaw Barony. Pp. 23-35. In G. W. Wood (ed.), Research and management of wild hog populations. Belle Baruch Forest Science Institute of Clemson University, Georgetown, South Carolina.

Wood, G. W., and T. E. Lynn, Jr. 1977. Wild hogs in southern forests. Southern Journal of Applied Forestry, 1(2):12-17.

Yarrow, G. K. 1987. The potential for interspecific resource competition between white-tailed deer and feral hogs in the post oak savannah region of Texas. Ph.D. Dissertation, Stephen F. Austin University, Nacogdoches, Texas.

Yarrow, G. K., and J. C. Kroll. 1989. Coexistence of white-tailed deer and feral hogs: Management implications (abstract only). Southeast Deer Study Group, 12:13-14.

Zasadowski, A. 1994. Polychlorinated biphenyls in the adipose tissue of wild boars and roe deer in the region of Warmia and Mazuria. Polish Journal of Environmental Studies, 3:43-45. 
Zappacosta, O. 2005. Wild pigs and plants. http://www.stanford.edu/ rawlings/pigs.htm

Zengel, S. A., and W. H. Conner. 2008. Could wild pigs impact water quality and aquatic biota in floodplain wetland and stream habitats at Congaree National Park, South Carolina? 5 pp. In Proceedings of the 2008 South Carolina Water Resources Conference, Charleston, South Carolina. http://www.clemson.edu/restoration/events/past_events/sc_water_resources/t2_proceedings_presentati ons/t2_zip/zengels.pdf 
Wild Pigs

\section{Wild Pig Damage:}

\section{Diseases and Parasites of Wild/Feral Swine}

David E. Stallknecht and Susan E. Little

Southeastern Cooperative Wildlife Disease Study, College of Veterinary Medicine, The University of Georgia, Athens GA 30602

\section{Introduction}

Wild and feral swine (Sus scrofa) populations have been linked to numerous diseases potentially affecting both domestic animals and public health. This association reflects a long history of interactions between humans and this species, and these interactions continue to provide opportunities for transmission of both new and old infectious agents between these populations. It is important to note that disease transmission often represent a "two way street", that is, a pathogen may originate from a wild population or it may be introduced into a wild population from either a domestic animal or even a human source. This simple concept has important implications to wildlife, domestic animal, and zoonotic disease epidemiology and management, and is becoming increasingly relevant with increasing domestic animal production, human population growth and expanding feral and wild swine populations worldwide. The objective of this review is to highlight some viral, bacterial, and parasitic diseases that have been associated with feral and wild swine populations and to discuss these diseases in relation to their epidemiology, their potential impacts to wildlife, domestic animal and human health, and the possibility for their control.

\section{Viral Diseases}

Pseudorabies (PR) (Aujesky's Disease): Pseuodrabies is caused by Suid herpesvirus 1 (PRV, Varicellovirus, Herpesviridae) and represents a significant disease of domestic swine and can cause fatal disease in many non-suid hosts. This disease has been all but eliminated from domestic swine herds in the United States; however, infection commonly occurs in feral swine populations.

With PR, swine represent the only documented reservoir for this virus and transmission and maintenance is accomplished through animal to animal contact and the establishment of latent and persistent infections. In wild swine populations, this contact transmission appears to be linked to reproductive behavior and is transmitted through sexual contact (Romero et al. 2001). This is in contrast to PR epidemiology in domestic swine herds where transmission is associated with both contact (nose to nose) and aerosols. Another importance difference in the epidemiology of this virus in domestic and feral populations relates to observed morbidity and morality. Infection in domestic swine often results in disease, especially among young pigs. There is no evidence to date suggesting that disease is associated with infection in feral or wild swine populations. These contrasts emphasize the danger in applying epidemiologic findings between very different animal populations even of the same species. It is likely that this virus evolved with Sus scrofa and under natural conditions these infections do not result in significant disease. In domestic swine reported disease may be more associated with confinement production and resulting changes in primary modes of transmission rather than increased species susceptibility.

There are numerous reports of infected wild and feral swine populations in Europe and North America and these are primarily based on serologic data (Van Der Leek et al. 1993a, Vincente et al. 2002, Zupancic et al. 2002).

Virus isolation also can be achieved but sampling (swabs) should be directed at reproductive tracts rather than nasal or tonsil swabs. In such surveys, it is very important to sample adults because infection is related to reproduction; prevalence of infection will be highest in the older age-classes. In infected 
populations, infections in older animals ( $>24$ months of age) can exceed $60 \%$. This virus appears to have a world-wide distribution in feral and wild swine populations.

The significance of PRV infections is not related to potential disease-related impacts on wild or feral populations. Rather, wild and feral swine represent a potential source of virus to domestic swine populations. The significance of PRV in wild and feral swine populations has increased greatly due to the recent success of PR control and eradication programs in domestic swine populations, and because of both range expansion and population increases of wild and feral swine populations which has increased the potential for feral and domestic swine contact.

Control of PR in feral swine populations is problematic. This disease is not density dependent and it is not likely that eradication could be achieved through population reductions. Due to latent infection and the high prevalence of infection that is often observed in infected herds, the probability of moving this virus with feral swine during translocation is high. In addition, no efficacious vaccines are available that could be effectively administered to wild populations. In fact, even in domestic swine herds, vaccination often proves ineffective if not supported by other control measures. The only rational course for action related to PRV control in feral swine populations is eradication of the infected population or control of movement to prevent establishment of new populations. Both of these will be extremely difficult to achieve.

Classical Swine Fever: Classical swine fever virus (CSFV, Pestivirus, Flaviviridae) is another example of a virus where Sus scrofa represents the only natural reservoir, and like PRV, infection with CSFV can result in persistent infection. Classical swine fever was successfully eradicated from domestic swine populations in the United States by 1976 through a program relying on vaccination and strict sanitary procedures. The disease also has been eradicated in Canada and Australia. It is interesting that evidence of CSFV has never been reported from any feral swine populations in the United States prior or subsequent to CSFV eradication in domestic swine. This is not the case in wild boar populations in Europe where CSFV has been confirmed by both virus isolation (Kaden et al. 2004) and detection of antibodies (Vincente et al. 2002, Zupancic et al. 2002.

Transmission of CSFV occurs by contact either through ingestion or introduction via mucous membranes or breaks in the skin. There is very limited evidence of mechanical vector transmission. Transmission from wild boar to domestic swine has been reported (Kaden and Lange 2004).

Control of CSFV in wild boar populations has been attempted through modification of hunting strategies with some success (Zanardi et al. 2003). In this case, hunting is directed at young susceptible animals rather than older immune animals. Oral vaccination of wild boar against CSFV has been suggested and field trials have been conducted with some success (Kaden et al. 2000).

Vesicular Stomatitis: Vesicular stomatitis (VS) in swine is caused by vesicular stomatitis virus New Jersey type (VSV-NJ) (Vesiculovirus, Rhabdoviridae); this virus represents an example of the potential role feral swine may play in the epidemiology of an important livestock disease. As a livestock disease, VS affects horses, cattle, and domestic swine, and in the latter two species, clinical disease is indistinguishable from foot and mouth disease. For this reason, the cost of this disease is more associated with a regulatory response than costs associated with actual livestock disease or direct production losses. Although considered exotic to the United States, a focus of VSV exists on Ossabaw Island, Georgia (Stallknecht et al. 1985). In the Southeast, prior to the 1960s, VS was endemic with reported outbreaks in livestock occurring annually.

The transmission VSV-NJ can be achieved by various routes including transmission by biological and mechanical vectors and direct contact (Mead et al. 2004). In general, it is believed that the virus is maintained in an enzootic vector/host cycle in nature. In contrast, once introduced into a livestock population, transmission is driven a variety of epizootic vectors or can occur by contact.

Feral swine have been useful in the study of VSV as an indicator species (Stallknecht et al. 1985). There is no evidence that they are involved in the natural maintenance cycle as they do not develop a viremia (Comer et al. 1995). Feral swine, however do represent a very susceptible species, and once infected, 


\section{Wild Pigs}

transmission can occur efficiently by contact (Stallknecht et al. 2001). Because of this, it has been suggested that feral swine represent a bridge between wild and farm environments and it may be significant that the cessation of VS outbreaks in the Southeast corresponded to the elimination of free-range swine management in this region (Stallknecht et al. 1993).

Because feral swine are only indirectly involved in the epidemiology of VS, control of this disease within free-ranging populations is not warranted. The risks associated with such infections are minimal relative to the very localized areas where this virus is known to exist within the United States, and to the fact that transmission to domestic swine can be eliminated by avoiding direct contact with feral animals. However, these minimal risks should be ignored when feral swine are transported from known endemic sites.

Feral Swine and Exotic Viral Diseases: There are several important livestock diseases that are not present within the United States, but if introduced, could involve both domestic and feral swine populations. These include vesicular exanthema, swine vesicular disease, foot and mouth disease, and African swine fever.

Vesicular exanthema is caused by vesicular exanthema of swine virus which represents at least 13 serotypes of closely related viruses of the genus Vesivirus in the family Caliciviridae. These viruses are of marine origin, but outbreaks have occurred in domestic swine in the United States between 1932 and 1959. It is believed that some these cases resulted from the feeding of infected fish or seal meat to domestic swine. Antibodies to these viruses have been detected in feral swine populations in California and such populations may represent a potential link between infected marine fish and mammals and domestic swine.

Swine vesicular disease is caused by a porcine variant of human coxsackie virus (Enterovirus). Disease in domestic swine has occurred in Europe and Asia but not in the United States. The reservoir for this virus and the potential for feral/wild seine involvement are not known.

Foot and mouth disease is a highly communicable livestock disease affecting cattle, sheep, domestic swine, and all other cloven hoofed animals and is caused by any of seven serologic types of foot and mouth disease virus (Aphthovirus, Picornaviridae). Transmission can occur via direct contact, aerosols, or indirectly through contact with contaminated materials and feed. Domestic swine can play an important role in foot and mouth outbreaks due to the fact that they have been associated with heavy viral shedding. There currently are no accounts of foot and mouth disease establishment in either feral or wild swine populations, but it is accepted that such populations would be susceptible. The critical question related to the establishment of this disease in feral/wild swine populations relates to opportunity for effective transmission and maintenance to occur at low density or in isolated populations with a limited number of susceptible individuals.

African swine fever is caused by African swine fever virus (Asfivirus, Asfarviridae). Members of the family Suidae represent the only susceptible species. This virus is maintained in a natural cycle in Africa involving wart hogs (Phacochoerus aethiopus) and soft ticks (Ornithodoros erraticus). The bush pig (Potamochoerus porcus) and giant forest hog (Hylochoerus meinertzhageni) also can serve as silent carriers. The virus has escaped into domestic swine populations outside of Africa on several occasions mostly associated with feeding of infected meat scrapes. Once introduced into a feral or wild swine population, this disease can be maintained by direct and indirect contact.

Should any of these diseases be introduced into the United States, eradication would be attempted and control of disease in feral swine populations would probably involve depopulations. Effective vaccines that could be effectively administered to feral swine populations currently are unavailable.

\section{Feral Swine and Indigenous Viral Diseases of Domestic Swine}

As previously stated, there also exists the potential for pathogen movement between domestic swine and feral populations, and as in the case with PRV and foreign animal diseases, feral swine could represent a potential reservoir for such diseases. Some examples of domestic swine diseases that may have been introduced to feral populations include swine influenza and porcine respiratory and reproductive syndrome (PRRS). 
Swine influenza is caused by several subtypes of influenza viruses (Orthomyxovirus, Orthomyxoviridae). Swine influenza viruses are established in domestic pig populations worldwide but there is little evidence of infection in feral or domestic swine populations. Antibodies to these viruses have been reported in feral swine populations in Kansas (Gipson et al. 1999) and wild boar in Spain (Vincente et al. 2002). Transmission occurs by contact or aerosol and infections are transient followed by a long-lasting immunity. For this reason, it is unknown if these viruses could persist in free-ranging swine populations especially in low density populations. In addition to these swine-adapted viruses, there are many other avian influenza viruses that are maintained in wild bird populations. As swine are important in the adaptations of avian viruses to mammalian hosts, it is possible that free-ranging populations could provide a potential intermediate mammalian host in the movement and adaptation of these viruses between avian reservoirs and domestic animal hosts. Very little work has been done to investigate this possibility.

Porcine respiratory and reproductive syndrome is caused by porcine respiratory and reproductive syndrome virus (Arterivirus, Arteriviridae). This is a relatively new domestic swine disease that was first reported in the United States in 1992 (Collins et al. 1992) and in Europe in 1993 (Wensvoort et al. 1993). There has been some suggestion that this virus originated from wild swine, especially in Europe, where antibodies to this virus have been reported (Plagemann 2003). However, there is little evidence that this virus is established in feral swine populations in the United States and it is likely that feral swine are not involved in the epidemiology of this disease in the this country. Serologic evidence of PRRS in feral swine in the United States is limited to a report of antibodies from feral swine in Oklahoma; antibody prevalence in this population was $2 \%$ (Saliki et al. 1998).

\section{Bacterial Diseases}

Brucellosis: Swine brucellosis is caused by Brucella suis, and the current situation related to brucellosis in feral and wild swine populations mirrors the previous discussion related to PRV. However, in addition to feral swine acting as a potential source of infection to domestic swine, this disease also is zoonotic and represents a significant public health threat to hunters or other humans who may have direct contact with these animals.

Brucella is transmitted through both direct and indirect contact and infections can be of long-term duration. Like PRV it is widely distributed in feral and wild swine populations (Van Der Leek et al. 1993b) and similar problems related to the control of this disease exist. Specifically, there is no information currently available to suggest that this disease is density dependent and the effectiveness of vaccines, although available for domestic animals, has not been demonstrated in the field.

Tuberculosis: Tuberculosis in feral and wild swine populations caused by Mycobacterium bovis represents both a threat to domestic animals and humans. This disease occurs locally and is generally associated with mixed wildlife and domestic reservoir species where swine are infected. Feral and wild swine, therefore, may represent a component of the reservoir. Feral swine have been shown to be infected with M. bovis in Europe (Serraino et al. 1999), Australia (McInerney et al. 1995), New Zealand (Nugent et al. 2002), and the United States (Hawaii) (Essey et al. 1983). Control has only been attempted through extreme population reductions and some limited success has been achieved (Essey et al. 1983).

Other bacterial diseases: There are numerous bacterial pathogens that can be associated with feral and wild swine populations. Leptosirosis, for example, commonly occurs in these populations (Vincente et al. 2002). Surveys for foodborne pathogens, such as species associated with Salmonella, Campylobacter, Yersinia, and numerous others have received limited attention but probably are well established in these populations. 


\section{Wild Pigs}

\section{Parasitic Diseases}

Feral swine are susceptible to infection with several protozoal and helminth parasites, including some that pose a zoonotic risk to people who inadvertently consume the infectious stages of these parasites in undercooked pork or in food or water contaminated with feces from an infected animal. Feral/wild swine populations acquire many of these parasites from humans or domestic animals but once infected these parasites can be maintained in these populations. Accordingly, control efforts must focus on the factors responsible for transmitting these parasites from humans and domestic animals to wild pigs, as well as attempting to control those parasites already established in feral swine populations. Strict attention to thorough cooking of pork, careful handling of carcasses when dressing feral pigs, and adherence to basic hygiene measures, such as hand washing, are also necessary to prevent zoonotic infection with these parasites.

\section{Feral Swine and Zoonotic Protozoa}

Feral swine may be infected with a number of different zoonotic protozoa including the intestinal protozoa Balantidium coli, Cryptosporidium parvum, and Giardia duodenalis, and the tissue-cyst forming Toxoplasma gondii. Clinical disease is rarely apparent in pigs infected with these protozoa (Bowman 2003). Balantidium coli is commonly found in domestic pigs, and has also been reported from feral pigs in several studies (Pakandl 1994, Nakauchi 1999, Solaymani-Mohammadi et al. 2004). Although disease due to $B$. coli is not seen in pigs, this parasite may cause enteritis in humans, non-human primates, and other mammals that ingest cysts (Kocan 2001). Human infection usually occurs following ingestion of cysts in fecal-contaminated water or through contact with infected pigs under conditions of poor hygiene. Disease may be exacerbated in immunocompromised patients or those with concurrent infections (Arean and Koppisch 1956).

Infection with both Cryptosporidium and Giardia is common in a wide variety of hosts, including humans, domestic mammals, and wild mammals; at least 79 hosts of $C$. parvum and 55 hosts of Giardia have been identified (Casemore et al. 1997, Olson and Buret 2001). In one study, 5\% of feral pigs surveyed were shedding infectious stages of C. parvum in their feces, and 8\% were shedding cysts of Giardia (Atwill et al. 1997). Infection with C. parvum, but not Giardia, is more common in younger pigs and in pigs from highdensity populations (Atwill et al. 1997). Humans and other animals become infected with C. parvum and Giardia when they ingest oocysts or cysts, respectively, directly from feces of an infected individual or in fecal-contaminated food or water. Human cases of both C. parvum and Giardia infection are commonly acquired from a human source of infection, but wild mammals, including feral pigs, can serve as secondary reservoir hosts and contribute to ground water contamination (Atwill et al. 1997, Olson and Buret 2001). Wild mammals in close proximity to human development or to contaminated agricultural effluent are more likely to become infected (Roach et al. 1993). Feral pigs prefer riparian habitats, and thus, once infected, may be more likely to deposit feces containing infectious stages in natural water systems (Atwill et al. 1997).

A wide range of mammals are susceptible to infection with Toxoplasma gondii, a coccidian parasite with a complex life cycle involving an intermediate host and a feline definitive host. Tissue cysts develop in the muscle of an animal that ingests either infectious, sporulated oocysts from a fecal-contaminated environment or infectious tissue cysts in the muscle of a systemically-infected intermediate host (Bowman 2003). Infection rates are amplified through the food chain; serosurveys for $T$. gondii show that herbivores have the lowest prevalence of exposure and carnivores have the highest exposure levels (Smith and Frenkel 1995). Accordingly, serosurvey has shown exposure rates in feral pigs approach 50\% (Gresham et al. 2002), but island populations of wild pigs where cats are rare or absent apparently have much lower exposure levels (Dubey et al. 1997). Human infection of $T$. gondii occurs following ingestion of tissue cysts in undercooked meat, and may result in a range of disease symptoms from clinically inapparent infection to severe toxoplasmosis (Frenkel 1988). All wild game meat, including that from wild pigs, should be thoroughly cooked prior to consumption. 
SRNL-RP-2009-00869

\section{Feral Swine and Zoonotic Helminths}

In areas where the parasites are endemic, wild pigs also may be infected with helminths that pose a risk of zoonotic infection, such as Trichinella spiralis, Taenia solium, and Spirometra. The source of infection to people for all of these helminths is ingestion of the infectious immature stages in undercooked meat. The immature worms may be grossly inapparent in the pig tissue, and inadvertent ingestion can occur even after close inspection of the flesh. Care must be taken to properly prepare and thoroughly cook all pig meat to insure helminth infection is not transmitted to people.

Trichinella spiralis and other Trichinella spp. are zoonotic nematodes that infect a wide variety of mammals. Historically T. spiralis infection was common in domestic pigs, and undercooked pork from domestic herds was a major source of trichinosis in people. However, the majority of infections in people in North America are now associated with ingestion of wild game (Roy et al. 2003). Trichinella spp. infection has been reported in wild pigs, and consumption of undercooked pork from feral swine has resulted in human disease (Jongwutiwes et al. 1998, Owen et al. 2000, Roy et al. 2003). While some reports state that the prevalence of Trichinella spp. infection in wild pigs, particularly in North America, appears low (Smith et al. 1982, Dick and Pozio 2001), a recent serologic survey found evidence of T. spiralis exposure in 39\% of feral pigs tested (Gresham et al. 2002). Animals become infected with Trichinella spp. when they ingest larvae in muscle tissue of another animal. Adult worms develop in the intestine and the viviparous females produce the next generation of larvae, which then invade the intestinal mucosa, migrate to skeletal muscle, and encyst within muscle cells until ingested by the next host (Bowman 2003). Infection may result in enteritis following larval penetration of intestinal mucosa or myositis due to inflammation in response to larvae in the muscles (Roberts and Janovy 2005). Control of T. spiralis focuses on avoiding consumption of infected animal tissue, or thoroughly cooking pork and other meat prior to ingestion (Bowman 2003).

Taenia solium is another zoonotic helminth which uses pigs as a primary intermediate host. While infection rates appear low, T. solium has been reported from wild pigs (Eslami and Farsad-Hamdi 1992). Humans serve as the normal definitive host of this tapeworm. Infection is contracted when people ingest larval cysticerci of $T$. solium in undercooked pork. Adult tapeworms then develop in the small intestine of the person, and eggs are passed in the feces. When these eggs are ingested by a pig, the immature tapeworms migrate to the muscles and form cysticerci to await ingestion by a human definitive host. However, when $T$. solium eggs are ingested by a person, the larval cysticerci may migrate aberrantly in the central nervous system of the human host, causing neurologic disease (Roberts and Janovy 2005). Control efforts for T. solium in endemic areas focus on treating infected people and pigs and educating the public about avoiding measly pork. Encouraging availability and appropriate use of toilet facilities to prevent deposition of human feces that may contain eggs of $T$. solium in areas frequented by pigs is also recommended (Garcia et al. 2003).

Wild pigs may also harbor immature larval stages, or spargana, of the pseudophylidean cestode Spirometra. In areas where this parasite is endemic in wildlife and domestic animals, such as Florida, infection in feral pigs is common, and in some localities, over $20 \%$ of feral hogs examined are infected (Gray et al. 1999, Bengtson and Rogers 2001). Pigs and other vertebrates, including people, become infected with Spirometra when they ingest the larval stages by inadvertently consuming an infected copepod first intermediate host in drinking water, or by eating undercooked meat of a vertebrate second intermediate host that contains the spargana. Adult cestodes develop in the intestine of the cat, dog, or other carnivore definitive host, and eggs are passed in the feces (Bowman et al. 2003). Clinical disease in people reflects the location of resultant spargana, and may include subcutaneous masses, ocular lesions, or infection of the central nervous system (Gray et al. 1999). Filtering water to remove infected copepods and thoroughly cooking meat prior to ingestion aid in preventing infection.

\section{Non-Zoonotic Helminths of Feral Swine}

Feral swine may also be infected with a wide variety of other helminths that do not pose a significant risk of infection to people. Examples of such helminths include lungworms in the genus Metastrongylus, the kidney worm Stephanurus dentatus, Ascaris suum, the common ascarid of pigs, Macracanthorhynchus 


\section{Wild Pigs}

hirudinaceus, a thorny-headed worm found in the small intestine of wild and domestic pigs, and Fasciola hepatica, a liver fluke of cattle that occasionally infects pigs (Prestwood et al. 1975, Smith et al. 1982). Pigs acquire Metastrongylus spp. lungworms upon ingestion of earthworm intermediate hosts; heavily infected pigs may develop verminous pneumonia (Bowman 2003). Stephanurus dentatus is transmitted to pigs by direct ingestion or skin penetration of larvae, or ingestion of infected earthworms. The larvae migrate through the liver and perirenal fat, ultimately developing as adults in the kidneys; eggs are passed in the urine. Pigs infected with $S$. dentatus may develop posterior paralysis due to migration of larvae in the spinal cord (Bowman 2003). Ascaris suum infection is seen in both young and adult wild pigs (Smith et al. 1982); infection is acquired by ingestion of larvated eggs from a contaminated environment. Pigs with heavy ascarid infections can develop hepatic fibrosis and interstitial pneumonia following migration of larval A. suum through the liver and lung (Bowman 2003). The thorny-headed worm of pigs, $M$. hirudinaceus, is acquired when pigs ingest infected beetle intermediate hosts. These parasites embed a heavily-armed proboscis in the small intestinal mucosa, which may lead to necrosis and subsequent peritonitis (Bowman et al. 2003). Wild pigs are occasionally infected with $F$. hepatica, a liver fluke of domestic cattle that may also infect people, upon ingestion of metacercaria on vegetation. However, the prevalence of $F$. hepatica in wild pigs is low, and these animals are not considered important in the epizootiology of this parasite (Smith et al. 1982). Infections with all of these helminths are long-lived, and both persistent infectious stages and/or intermediate hosts are commonly found in the environment. Thus, controlling helminth infections in wild pig populations is generally not feasible. 


\section{Literature Cited}

Arean, V., and E. Koppisch. 1956. Balantidiasis. A review and report of cases. American Journal of Pathology, 32:1089-1107.

Atwill, E. R., R. A. Sweitzer, M. G. Pereira, I. A. Gardner, D. Van Vuren, and W. M. Boyce. 1997. Prevalence of and associated risk factors for shedding Cryptosporidium parvum oocysts and Giardia cysts within feral pig populations in California. Applied and Environmental Microbiology, 63(10):3946-3949.

Bengtson, S. D., and F. Rogers. 2001. Prevalence of sparganosis by county of origin in Florida feral swine. Veterinary Parasitology, 97(3):239-242.

Bowman, D. D. 2003. Helminths. Pp 115-243. In D. D. Bowman (ed.), Georgis' Parasitology for Veterinarians. 8th Ed. W. B. Saunders, Philadelphia, Pennsylvania.

Casemore, D. P., S. E. Wright, and R. L. Coop. 1997. Cryptosporidiosis - Human and animal epidemiology. Pp 65-92. In R. Fayer (ed.), Cryptosporidium and Cryptosporidiosis. CRC Press, Inc., Boca Raton, Florida.

Comer, J. A., D. E. Stallknecht, and V. F. Nettles. 1995. Incompetence of domestic pigs as amplifying host of vesicular stomatitis virus for Lutzomyia shannoni (Diptera: Psychodidae). Journal of Medical Entomology, 32:741-744.

Collins, J. E., D. A. Benfield, W. T. Christinaon, L. Harris, J. C. Hennings, D. P. Shaw, S. M. Goyal, S. McCullough, R. B. Morrison, and H. S. Joo. 1992. Isolation of swine infertility and repiratory syndrome virus (isolate ATCC VR-2332) in North America and experimental reproduction of the disease in gnotobiotic pigs. Journal of Veterinary Diagnostic Investigation, 4:117-126.

Dick, T. A., and E. Pozio. 2001. Trichinella spp. and trichinellosis. Pp. 380-396. In W. M. Samuel, M. J. Pybus, and A. A. Kocan, (eds.). Parasitic Diseases of Wild Mammals, $2^{\text {nd }}$ Ed. Iowa State Press, Ames, Iowa.

Dubey, J. P., E. A. Rollor, K. Smith, O. C. Kwok, and P. Thulliez. 1997. Low seroprevalence of Toxoplasma gondii in feral pigs from a remote island lacking cats. Journal of Parasitology, 83(5):839-841.

Eslami, A., and S. Farsad-Hamdi. 1992. Helminth parasites of wild boar, Sus scrofa, in Iran. Journal of Wildlife Diseases, 28(2):316-318.

Essey, M. A., D. E. Stallknecht, E. M. Himes, and S. K. Harris. 1983. Follow-up survey of feral swine for Mycobacterium bovis on the Hawaiian island of Molokai. Proceedings of the Annual Meeting of the U. S. Animal Health Association, 87:589-595.

Frenkel, J. K. 1988. Pathophysiology of toxoplasmosis. Parasitology Today, 4(10):273-278.

Garcia, H. H., A. E. Gonzalez, C. A. Evans, and R. H. Gilman. 2003. Taenia solium cysticercosis. The Lancet, 362(9383):547-556.

Gipson, P. S., J. K. Veatch, R. S. Matlack, and D. P. Jones. 1999. Health status of a recently discovered population of feral swine in Kansas. Journal of Wildlife Diseases, 35(3):624-627.

Gray, M. L., F. Rogers, S. Little, M. Puette, D. Ambrose, and E. P. Hoberg. 1999. Sparganosis in feral hogs (Sus scrofa) from Florida: 222 cases and a review of the significance of the disease as a zoonosis. Journal of the American Veterinary Medical Association, 215(2):204-208. 


\section{Wild Pigs}

Gresham, C. S., C. A. Gresham, M. J. Duffy, C. T. Faulkner, and S. Patton. 2002. Increased prevalence of Brucella suis and pseudorabies virus antibodies in adults of an isolated feral swine population in coastal South Carolina. Journal of Wildlife Diseases, 38(3):653-656.

Jongwutiwes, S., N. Chantachum, P. Kraivichian, P. Siriyasatien, C. Putaporntip, A. Tamburrini, G. La Rosa, C. Sreesunpasirikul, P. Yingyourd, and E. Pozio. 1998. First outbreak of human trichinellosis caused by Trichinella pseudospiralis. Clinical Infectious Diseases, 26(1):111-115.

Kaden, V., E. Lange, U. Fischer, G. Strebelow, D. Paton, and S. Edwards. 2000. Oral immunization of wild boar against classical swine fever: Evaluation of the first field study in Germany. Veterinary Microbiology, 73(2/3):239-252.

Kaden, V., and E. Lange. 2004. Development of maternal antibodies after oral vaccination of young female wild boar against classical swine fever. Veterinary Microbiology, 103(1-2):115-119.

Kaden, V., E. Lange, U. Polster, R. Klopfleisch, and J. P. Teifke. 2004. Studies on the virulence of two field isolates of the classical swine fever virus genotype 2.3 rostock in wild boars of different age groups. Journal of Veterinary Medicine Series B, 51(5):202.

Kocan, A. A. 2001. Amebiasis, balantidiasis, and enteric trichomoniasis. Pp 397-399. In W. M. Samuel, M. J. Pybus, and A. A. Kocan (eds.). Parasitic Diseases of Wild Mammals. $2^{\text {nd }}$ Ed. Iowa State Press, Ames, Iowa.

McInerney, J., K. J. Small, and P. Caley. 1995. Prevalence of Mycobacterium bovis infection in feral pigs in the Northern Territory, Australia. Australian Veterinary Journal, 72(12):448-451.

Mead, D. G., E. W. Howerth, M. D. Murphy, E. W. Gray, R Noblet, and D. E Stallknecht. 2004. Black fly involvement in the epidemic transmission of Vesicular Stomatitis New Jersey Virus (Rhabdoviridae: Vesiculovirus). Vector Bourne Zoonotic Diseases, 4:351-359.

Nakauchi, K. 1999. The prevalence of Balantidium coli infection in fifty-six mammalian species. Journal of Veterinary Medical Science, 61(1):63-65.

Nugent, G., J. Whitford, and N. Young. 2002. Use of released pigs as sentinels for Mycobacterium bovis. Journal of Wildlife Diseases, 38:665-677.

Olson, M. E., and A. G. Buret. 2001. Giardia and giardiasis. Pp 399-416. In W. M. Samuel, M. J. Pybus, and A. A. Kocan (eds.). Parasitic Diseases of Wild Mammals. $2^{\text {nd }}$ Ed. Iowa State Press, Ames, Iowa.

Owen, I. L., L. D. Sims, M. C. Wigglesworth, and I. Puana. 2000. Trichinellosis in Papua New Guinea. Australian Veterinary Journal, 78(10):698-701.

Pakandl, M. 1994. The prevalence of intestinal protozoa in wild and domestic pigs. Veterinarni Medicina (Praha), 39(7):377-380.

Plagemann, P. G. W. 2003. Porcine reproductive and respiratory syndrome virus: origin hypothesis. Emerging Infectious Diseases, 9:903-908.

Prestwood, A. K., F. E. Kellogg, S. R. Pursglove, and F. A. Hayes. 1975. Helminth parasitisms among intermingling insular populations of white-tailed deer, feral cattle, and feral swine. Journal of the American Veterinary Medical Association, 166(8):787-789.

Roach, P. D., M. E. Olson, G. Whitley, and P. M. Wallis. 1993. Waterborne Giardia cysts and Cryptosporidium oocysts in the Yukon, Canada. Applied Environmental Microbiology, 59(1):67-73.

Roberts, L. S., and J. Janovy. 2005. Foundations of Parasitology. $7^{\text {th }}$ Ed., McGraw-Hill, New York. 
Romero, C. H., P. N. Meade, J. E. Shultz, H. Y. Chung, E. P. Gibbs, E. C. Hahn, and G. Lollis. 2001. Venereal transmission of pseudorabies viruses indigenous to feral swine. Journal of Wildlife Diseases, 37(2):289-296.

Roy, S. L., A. S. Lopez, and P. M. Schantz. 2003. Trichinellosis surveillance - United States, 1997-2001. MMWR Surveillance Summaries, 52(SS06):1-8.

Saliki, J. T., S. J. Rogers, and G. Eskew. 1998. Serosurvey of selected viral and bacterial diseases in wild swine from Oklahoma. Journal of Wildlife Diseases, 34(4):834-838.

Serraino, A., G. Marchetti, V. Sanguinetti, M. C. Rossi, R. G. Zanoni, L. Catozzi, A. Bandera, W. Dini, W. Mignone, F. Franzetti, and A. Gori. 1999. Monitoring of transmission of tuberculosis between wild boars and cattle: Genotypical analysis of strains by molecular epidemiology techniques. Journal of Clinical Microbiology, 37(9):2766-2771.

Smith, H. M., Jr., W. R. Davidson, V. F. Nettles, and R. R. Gerrish. 1982. Parasitisms among wild swine in southeastern United States. Journal of the American Veterinary Medical Association, 181(11):12811284.

Smith, D. D., and J. K. Frenkel. 1995. Prevalence of antibodies to Toxoplasma gondii in wild mammals of Missouri and east central Kansas: biologic and ecologic considerations of transmission. Journal of Wildlife Diseases, 31(1):15-21.

Solaymani-Mohammadi, S., M. Rezaian, H. Hooshyar, G. R. Mowlavi, Z. Babaei, and M. A. Anwar. 2004. Intestinal protozoa in wild boars (Sus scrofa) in western Iran. Journal of Wildlife Diseases, 40(4):801803.

Stallknecht, D. E., V. F. Nettles, W. O. Fletcher, and G. A. Erickson. 1985. Enzootic vesicular stomatitis New Jersey type in an insular feral swine population. American Journal of Epidemiology, 122(5):876883.

Stallknecht, D. E., D. M. Kavanaugh, J. L. Corn, K. A. Eernisse, J. A. Comer, and V. F. Nettles. 1993. Feral swine as a potential amplifying host for vesicular stomatitis virus New Jersey serotype on Ossabaw Island, Georgia. Journal of Wildlife Diseases, 29(3):377-383.

Stallknecht, D. E., D. E. Perzak, L. D. Bauer,, M. D. Murphy, and E. W. Howerth, 2001. Contact transmission of vesicular stomatitis virus New Jersey in pigs. American Journal of Veterinary Research, 62:516-520.

Van Der Leek, M. L., H. N. Becker, E. C. Pirtle, P. Humphrey, C. L. Adams, B. P. All, G. A. Erickson, R. C. Belden, W. B. Frankenberger, and E. P. J. Gibbs. 1993. Prevalence of pseudorabies (Aujeszky's disease) virus antibodies in feral swine in Florida. Journal of Wildlife Diseases, 29(3):403-409.

Van Der Leek, M. L., H. N. Becker, P. Humphrey, C. L. Adams, R. C. Belden, W. B. Frankenberger, and P. L. Nicoletti. 1993. Prevalence of Brucella sp. antibodies in feral swine in Florida. Journal of Wildlife Diseases, 29(3):410-415.

Vicente, J., L. Leon-Vizcaino, C. Gortazar, M. J. Cubero, M. Gonzalez, and P. Martin-Atance. 2002. Antibodies to selected viral and bacterial pathogens in European wild boars from southeastern Spain, Journal of Wildlife Diseases, 38(3):649-652.

Wensvoot, G. 1993. Lelystad virus and the porcine epidemic abortion and respiratory syndrome. Veterinary Research, 24:117-124. 


\section{Wild Pigs}

Zanardi, G., C. Macchi, C. Sacchi, and D. Rutili. 2003. Classical swine fever in wild boar in the Lombardy region of Italy from 1997 to 2002. The Veterinary Record, 152(15):461-465.

Zupancić, Z., B. Jukić, M. Lojkić, Z. Cac, L. Jemeršić, and V. Strarešina. 2002. Prevalence of antibodies to classical swine fever, Aujeszky's disease, porcine reproductive and respiratory syndrome, and bovine viral diarrhea viruses in wild boars in Croatia. Journal of Veterinary Medicine Series B, 49(5):253-256. 
SRNL-RP-2009-00869

This page left blank intentionally 
Wild Pigs

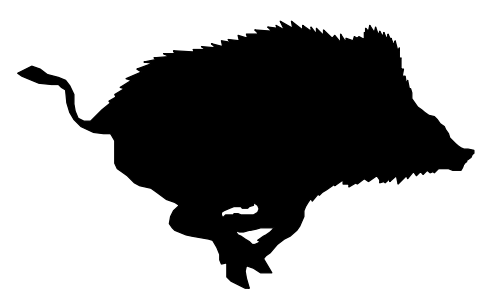

\section{Part III}

Control Techniques for Wild Pigs 
SRNL-RP-2009-00869

This page left blank intentionally 


\section{Control Techniques for Wild Pigs:}

\section{Wild Pig Trapping Techniques}

John J. Mayer and Paul E. Johns

Savannah River National Laboratory, Savannah River Nuclear Solutions, LLC, Savannah River Site, Aiken, South Carolina 29808 (JJM)

Carolina Wildlife Consultants, 2441 Williston Road, Aiken, South Carolina 29803 (PEJ)

\section{Introduction}

Trapping is a longstanding method for capturing wild pigs (Sus scrofa). This is due to the fact that this technique can be reasonable straightforward and inexpensive to implement, combined with the fact that wild pigs are also in general very trappable. Reported reductions of $70-80 \%$ in local wild pig populations have achieved through the use of trapping (Saunders et al. 1990, Vernes et al. 1999). The specific use of traps as a control technique for this invasive species has been extensively employed in both the United States and Australia (e.g., Barrett and Birmingham 1994, Caley 1999, Giles 1973). In fact, most wild pig control programs use trapping as either a standalone technique or in combination with other lethal removal methods (e.g., shooting, dogging, snaring). Because the animals are captured alive, this technique can also be used for research purposes (e.g., mark-recapture or radiotelemetry studies).

The extent of application and assortment of trap designs used to control wild pigs over the years have varied widely (Barrett and Birmingham 1994, Choquenot et al. 1996). The application of this technique is normally tailored to the specific control situation in question. Trapping is a flexible technique that can be fitted into routine site or property management activities, potentially making it economical in terms of both manpower and operating costs (Lukins 1989). Prior to implementation of a trapping program for wild pig, upfront planning involving several decisions about the specifics to employ are critical toward achieving the success of such a control effort. The only reasons that wild pigs would survive a trapping program would be due to of one or more of the following: (1) failure to find the bait, (2) not being willing to consume the bait, or (3) not being willing to enter the trap (Choquenot et al. 1993). Thoughtful planning with respect to trapping location, bait selection and trap design can overcome most of these.

The purpose of this paper is to review the various implementation options for this control technique. Specifically, this discussion will include sections on trap design, trapping program protocol, and advantages and disadvantages. These discussions included both results from a review of the literature as well as observations made in the field at the Savannah River Site (SRS), an $803 \mathrm{~km}^{2}$ federal nuclear facility located in west-central South Carolina. Other control techniques that capture wild pigs (e.g., snares, deadfalls) are often included under the heading of trapping; however, those techniques will not be addressed in this review.

\section{Results/Discussion}

\section{Trap Design}

The variety of trap designs used to catch wild pigs is extensive. All are principally an enclosed area with a one-way gate or entrance (Land Protection 2001). The only requirements that a trap design must achieve are that pigs must be able to enter relatively easily, and after the door is shut, the animals are not able to escape (Caley 1999). In general, there are two primary categories of traps, portable traps and fixed traps. Both have unique advantages and disadvantages toward the capture of these animals. In addition to the overall trap configuration, alternatives with respect to the choices of doors, triggers and tops further add to the options that one must consider in designing a wild pig trap. 
Portable Traps - This is the most common category of trap employed for the capture of wild pigs. Very simply, these traps are designed to be set up, used for a period time, and then disassembled and/or relocated to a new trapping site. Typically, these traps are of a small to medium size. Often portable traps consist of various components that must be assembled at the trapping location; but this is not always the case.

Portable wild pig traps are normally in one of two different designs: corral traps (e.g., panel or silo/continuous wire configurations) or box traps (Fig. 1). The size of any specific portable trap is somewhat dependent upon the design. The primary advantage of this trap type is the versatility in location. In addition, portable traps can be by design very light weight and capable of being set-up by one person. The primary disadvantage would be the limitation in overall trap size. Some portable trap designs are also not as sturdy or durable as fixed traps.

Panel traps consist of three or more connected panels or sections. The construction can be either metal or wood. Typically, however, the panels are welded metal frames (e.g., galvanized pipe) covered with welded or woven wire. Whichever the construction, the openings in the wire mesh or spaces between wooden boards should be small enough to prevent small piglets from escaping, especially near the bottom of the panel. The panels or sections are typically approximately 3 to $5 \mathrm{~m}$ in length and 1.5 to $2 \mathrm{~m}$ in height. The door can be a separate framed component connected to the ends of two of the panels or built into one of the panels/sections. Doors can be almost any design (e.g., drop, hinged or funnel/squeeze). Triggers normally include either root or trip-wire designs. The panels are connected together through a variety of means (e.g., pull pin metal hinges, metal hose clamps, cable ties, wire, or rope). Configurations can vary from triangles to multi-sided polygons (i.e., depending upon the number of panels employed). The base of panels should be anchored with either stakes, posts, or lines. The advantage of panel traps is the combined versatility of sturdiness and configuration options. Designs for the construction of panel traps for wild pigs can be found in Belden and Frankenberger (1977), Giles (1977), Sweitzer et al. (1997) and Caley (1999).

Silo traps are constructed using a roll of welded or woven wire fence. The fencing material used is approximately 10 to $15 \mathrm{~m}$ in length and 1.5 to $2 \mathrm{~m}$ in height, but can vary in size depending upon the trap configuration employed. Such configurations can include oval, heart-shaped, "figure 6," or other options. Again, the wire mesh should be small enough to prevent small piglets from escaping near the bottom of the wire. The traps should be supported and anchored using metal or wooden posts. The larger the silo trap configuration size, the more secure or sturdy these posts need to be. The wire fencing should also be anchored or staked to the ground. Doors can include any design (e.g., drop, hinged or funnel/squeeze). Silo trap designs are especially well-suited for the use of integral funnel/squeeze doors using a portion of the continuous fencing (e.g., the "figure 6" configuration). The use of triggers is also variable, and can include root or trip-wire designs when drop or hinged trap doors are included in the trap. The funnel/squeeze doors employ an integral metal or elastic spring closure system, and, as such, do not require a triggering set-up or device. The advantage of silo traps over other portable traps would be the ability to size/configure the trap to the physical constraints at a specific location. However, silo traps do take longer to set up and take down than do either panel or box traps. Illustrated designs for silo traps can be found in Giles (1973), Choquenot et al. (1996), Caley (1999), and Land Protection (2001).

Box traps for wild pigs can be in a variety of both shapes and sizes. In general, these traps consist of an enclosed unit with permanently connected sides, ends, bottom and top. However, some designs are made to be disassembled for relocation. The box trap construction can be either metal, wood or a combination of both. The sturdiest box traps for wild pigs are constructed welded metal frames covered with welded or woven wire. The size of box traps for wild pigs varies with the design, but is normally in the range of 1 to $3 \mathrm{~m}$ in height and width, and 2 to $4 \mathrm{~m}$ in length. The configuration is more often an elongate or rectangular shaped box, but can also include round or cylinder designs approximately 2 to $4 \mathrm{~m}$ in diameter. These cylinder designs have the advantage of being able to be rolled to the trap location. Ease of movement should be taken into account when building a box trap, since large box traps can be very heavy, making them difficult to handle and move, especially for one person. Depending upon the size and shape, box traps can be readily moved using either trucks or trailers. The doors tend to include either drop or hinged types. Some box trap designs even have a drop door at each end. Triggers used in box traps can be root, trip-wire or treadle designs. Because of the permanent construction, box traps do not need to be anchored or 


\section{Wild Pigs}

supported. The principal advantage of box traps would include a combination of sturdiness and ease of set-up. Designs for wild pig box traps can be found in Williamson and Pelton (1972), Giles (1973), Diong (1981) and Barrett and Birmingham (1994).

Fixed Traps - Compared to portable traps, the use of fixed traps for wild pigs tends to be employed much less in control programs. Fixed traps are permanently erected in areas of high wild pig density or usage. These traps can be closed/shutdown when the local pig activity decreases, and then readily baited and set when that activity increases. Unlike a portable trap, a fixed trap has a constant presence in the area where it is located, and, as such, does not represent a new or unknown object which the area's wild pigs could be wary of or must get used to. However, if the wild pigs leave or are eradicated in the surrounding area, a fixed trap would become useless.

Fixed traps for wild pigs all encompass one general design, corral traps. Similar to portable traps, fixed traps can be constructed of metal, wire, wood or combinations of these materials. The sides are typically braced using metal or wooden posts. In some instances, large trees can be used as additional bracing or support along the sides of the trap enclosure. Unlike portable traps, fixed traps can be extremely large because of the permanent placement of the structure. Most fixed traps are within the upper end of the size range for portable traps. However, larger fixed traps can encompass larger areas (e.g., 20 to $30 \mathrm{~m}$ or more on a side). Simply put, bigger traps can capture more pigs. According to Barrett and Birmingham (1994), large corral traps have been documented to capture up to 104 wild pigs in a single night. Some fixed traps also have very tall sides (e.g., upwards of $4 \mathrm{~m}$ in height). Doors on fixed traps can include any of the design options; most are variations of either drop or hinged door designs. Triggers employed on this type of trap are also variable. Triggers on extremely large fixed corral traps must be either located reasonably close to the door or employ electronic components capable of transmitting a signal from the trigger device back to the door release mechanism. Because of the permanent construction of these traps, the sides should not need additional anchoring or support. The advantages of fixed traps would include increased size and sturdiness of the structure, as well as the relative ease with which the trap can be activated (i.e., baited and set) or inactivated (i.e., closed or tied open).

Door Design - A properly functioning door is a key element of a wild pig trap (Choquenot et al. 1996). The doors for these traps typically fall into one of three general categories as follows: drop doors, hinged doors, and funnel/squeeze doors (Fig. 3). These three types have different applications and both advantages and disadvantages.

Drop doors, sometimes called guillotine doors, consist of a relatively heavy door panel falling inside a frame to completely seal the trap entrance. These doors can be made of either metal or wood. For example, 3/4-inch plywood panels sized to fit the opening and frame make very serviceable drop doors for a wild pig trap. A drop door can also be built using a four-sided metal frame covered by welded or woven wire. Drop doors are typically 0.5 to $1 \mathrm{~m}$ wide and 0.75 to $1.5 \mathrm{~m}$ in height. The door frame housing the tracks which enclose the door panel can also be either metal or wood construction. The drop door/frame housing can be a separate component or a part of either an individual panel or the entire trap. Various triggers can be used to activate a drop door. The activation mechanism can be through the release of either a pin or a line (i.e., rope or cable) holding the door open. Locking devices can also be installed on the door frame to prevent trapped pigs from lifting the door to escape. Drop door frames do not require a base or bottom component that spans the area between the sides of the frame. In addition, drop doors can be sized to accommodate the largest wild pigs. Both of these can be an advantage in successfully trapping a wild pig that does want to either step over something or scrape its back on the bottom of the door to enter the trap.

Hinged doors include either top- or side-hinged designs in several configurations. Although most often fabricated from metal components, hinged doors can be metal sheet, a four-sided metal frame with wire facing, or wood. The hinges can be metal bracket or piano hinges. Hinged doors can be either single- or double-panel designs, with single panels being hinged on the top or side and double panels being hinged on the sides. These doors vary from 0.5 to $1.5 \mathrm{~m}$ in both width and height. Top-hinged doors, also called root doors, close using gravity. Side-hinged doors close using metal springs, elastic straps, or balanced counter-weights. A squeeze configuration can also be used with side-hinged doors. Top-hinged doors 
normally close into an angle-iron frame that prevents pigs from being able to get their nose pad under the door's edge to lift it up and escape. Laying barbed wire along the inside lower portions of these doors can also serve the same function (Diong 1980). The spring or elastic components of side-hinged doors typically prevent the doors from being opened by trapped animals. Although normally not used, locking devices can be added to both designs. Although this option can include a separate or integral design, most are built into a panel or the trap itself. Top-hinged doors require a frame that the wild pigs must step over, while the bottom portion of a frame is optional with side-hinged doors. Any of the trigger options can be used with hinged doors. The activation mechanism typically entails the release of a line or prop (e.g., stick or rod) holding the door(s) open. One of the reported advantages of the top-hinged or root door is that additional animals can enter the trap after the initial wild pigs are captured. However, in two instances on the SRS, large sows, which were outside of the trap when the door dropped, pushed up the top-hinged doors from the outside to allow their trapped litters of piglets to escape.

The last basic door type, funnel or squeeze doors, are wire mesh fencing that pigs must push their way through to enter the trap. The sides of the funnel/squeeze door then close behind the animal. With the door not capable of being entered or opened from the trap interior, the animals are captured. These doors can either be extensions of the fencing comprising the side of the trap or standalone structures. In both designs, the corners of the funnel need to be supported by posts. In some designs, the sides of the funnel should also have this type of structural support. The front of the funnel is typically between 0.5 to $1 \mathrm{~m}$ wide. The height would be determined by the wire fencing used for the funnel or trap wall. The ends of the funnel fencing are tied together with wire or rope. This connection can also be spring-operated. Funnel/squeeze doors are most often used in silo trap designs. By design, these doors are physically opened by and then automatically closed behind the pigs, and therefore do not need a separate trigger mechanism. The advantage of this type of door is the simplicity of its design. The only disadvantage would be the inability to trap those wild pigs that are not willing to squeeze through a funnel-type entrance to enter the trap to access the bait.

Trigger Design - The type of trigger chosen depends upon the combination of trap and door designs to be used. Although other options are available, the most often used designs are trip wire, root and treadle triggers. Variations on these basic designs can be easily devised to suit specific trapping requirements.

The trip wire is a standard trigger used in trapping. It consists of a wire or rope anchored about $10-20 \mathrm{~cm}$ above the ground to a stake or post, and then stretched around one or more other stakes to the pull-pin or release lever. A similar impact-type of trigger, a stick or rod can also be used to prop the door open. In entering the trap, the wild pig impacts the wire or stick/rod with its leg or snout, either pulling the taut line and activating the release mechanism or releasing the door. Placement of the trip wire or stick/rod needs to ensure that the animal activating it will be well within the trap's interior and away from the door.

A root or root-bar trigger is most often used in wild pig traps and can be set up in a variety of configurations. Basically, this trigger design entails the placement of a $10-15 \mathrm{~cm}$ long stick or rod behind two angled shallow stakes or pins in the ground at the back of the trap. Notched stakes can also be used to hold the stick or rod. The trigger stick or rod is attached to a line connected under tension to the trap release mechanism. The stick or rod is then covered with bait. When a pig attempts to consume the bait, it pushes the stick or rod, releasing it from behind the shallow stakes or pins, which then releases the door.

A treadle trigger is typically used in box traps, but could be modified or configured to be used in other trap designs. A treadle employs a hinged side or end that can be either depressed or lifted depending upon the intended operation. Often, the placement and access to the bait would be the factor determining how the treadle should function. The treadle plate is then connected to a rod or line which triggers the activation mechanism (e.g., release pin or lever). The size of the treadle plate is variable, determined by the intended bait placement and overall trap design. Because of the motion required to activate the treadle, the mechanism needs to be firmly installed. This is the primary reason that this type of trigger is most often found in sturdy box-trap designs.

Tops on Traps - Wild pigs have the ability to jump or climb out of some traps with an open top (e.g., silo or corral traps). To counter this, tops can be built into a trap design (e.g., as seen in most box traps). 


\section{Wild Pigs}

Optional tops for corral traps would include lengths of light-wire mesh fencing (e.g., chicken wire), synthetic webbed netting, or rigid woven/welded wire panels. The specific trap design may also contribute to this problem. For example, the inside corners of three- or four-sided panel traps are easier for wild pigs to climb out of than are the comparable corners in either six- or eight-sided designs. In addition, if a four-sided panel trap is not firmly anchored to the ground, repeated attempts by large trapped wild pigs to climb out at one corner of the trap can move the overall trap from a square to a trapezoid configuration. The corners with the smaller angles are then easier for these animals to climb out of. Trap wall height can also alleviate the need for a top (e.g., by increasing the trap wall height to $2+\mathrm{m}$ ). Another option to prevent pigs from jumping or climbing over the trap walls entails fastening a long bar or rod parallel to each trap wall, approximately $20-30 \mathrm{~cm}$ out from the wall itself. These barriers should be firmly attached to the tops of the walls at each end (e.g., with wire, rope, cable ties or clamps).

\section{Trapping Program Protocol}

The success of wild pig trapping requires the proper initial planning prior to program implementation. This primarily includes making decisions with regard to various aspects of the program (e.g., what design and number of traps to use, when and where to put the traps, what type of bait to use, etc.). These programs should also be developed and sized based on the funding available. As such, the overall goal of the program needs to be defined at the start. For example, trapping programs can be implemented to either keep the local numbers in check or eradicate the entire population. Funding resources may dictate which of these options would be an achievable goal. The cost of trapping wild pigs has been reported to be vary between \$15 and \$500 per pig (Coblentz and Baber 1987, Coblentz and Bouske 2004). In addition, the cost per pig removed increases over time as the population decreases (Hone and Stone 1989). The first few pigs captured will cost in the tens of dollars, while the last animals out of the population will cost upwards of a thousand dollars or more per individual to remove. The planned application of this technique on a large population of wild pigs (e.g., 1,000+ animals) with complete eradication as the goal would be very expensive, and potentially cost prohibitive. Careful upfront decisions, knowledge and planning will go a long way toward ensuring the successful implementation of a wild pig trapping program. The following provides the planning sequence of decisions needed to implement a trapping program for wild pigs.

Goal - As noted above, the first component of implementing a wild pig trapping program is to determine the goal. Such a program goal can range from merely conducting a minimal level of removal up to complete elimination of the population in question. Trapping is a very effective way to reduce numbers of wild pigs where they are either present at low to moderate densities or concentrated in small areas (Giles 1977, Caley 1999, Vernes et al. 1999). As a standalone technique, trapping can be used to eradicate small, localized populations of wild pigs or as a means of removing the surviving animals from a large-scale lethal removal program (e.g., poisoning) over a larger area (Giles 1977, Choquenot et al. 1993, Land Protection 2001). On the other hand, trapping will not successfully serve as a standalone means to completely eliminate a very dense wild pig population that is dispersed over a large geographic area (Giles 1973). However, planned appropriately, trapping can be effectively used in conjunction with other lethal removal methods (e.g., dogging, shooting) over time to control a wild pig population (Diong 1980). It is best to minimize or completely discontinue dogging and shooting prior to and during trapping since such disturbances can cause wild pigs to scatter, as well as disturbing their foraging behavior and ability to find the bait (Choquenot et al. 1996, Land Protection 2001).

Location - Assuming that the property to be included in the trapping program is predetermined, then the specific locations in that area need to be evaluated for setting up the traps. There are several factors to consider in making that decision. First, trapping should be conducted in areas that wild pigs frequent regularly (e.g., near permanent water or dense cover along drainage corridors) (Giles 1977, Caley 1999). This can be confirmed by the presence of fresh field sign (e.g., tracks, scats, wallows, rooting). In fact, the presence of fresh wild pig sign in an area was an important variable in predicting trapping success (Giles 1973, Fox and Pelton 1977, Saunders et al. 1993, Caley 1994). If telemetry data are available for the area in question, Diong (1980) recommended the placement of traps in the core areas of the wild pig home ranges. The distance to water is another important consideration (Giles 1973, Caley 1999). Localized habitat parameters or characteristics should also be considered. Placement along tree lines maximized the potential for wild pigs finding bait and eating it (Saunders et al. 1993). Pigs may be more likely to enter a 
trap that is set in cover as opposed to one that is in the open (Caley 1999). Traps should also be placed in the shade where possible (i.e., it is more humane and pigs are less likely to try to escape) (Caley 1999). The entrances should be located along major pig trails (Giles 1977, Caley 1999). Diong (1980) found that muddy pools or ponded areas around the trap entrance caused some pigs to be reluctant to enter the trap. Finally, since traps must be checked frequently, accessibility to the trap sites is an important consideration for operating a trapping program (Choquenot et al. 1993). For that reason, it is often useful to locate traps next to or near roads. Traps that must be hiked into to reach and work may be very manpower intensive to operate.

Season - Season is the most important variable for predicting trapping success for wild pigs. This is probably the result of the large seasonal changes in food availability. Caley $(1994,1999)$ found that capture rates were highest during the dry season and lowest during the wet season of the year, presumably reflecting seasonal changes in food availability. Trapping is most successful when food resources are limited (Land Protection 2001). Competition with other forage resources (e.g., acorns) can make trapping success decline dramatically. Fox and Pelton (1977) found the highest rates of capture for trapping pigs in the southern Appalachians to be in the spring months and during August, November and December. Wyckoff et al. (2006) reported that trapping success was reduced during periods of extreme heat. In addition, trapping success is also best when pigs are moving most and therefore stand a better chance of encountering bait trails.

Type(s) and Number of Traps - Decisions regarding what type(s) of trap(s) and how many traps to use are primarily driven by the available resources (e.g., budget and manpower), program goal(s), and the size of the area(s) involved. With respect to what type or types of traps to use, there are important considerations regarding trap efficiency, durability, portability and flexibility that have to be made to support the program (Diong 1980). The knowledge and experience of the trapper(s) are also important in deciding upon a trap design. Because of the variation in individual trap wariness of pigs as well as the terrain and habitat types in a local area, the use of several types of traps can be more effective in trapping larger numbers of animals. The number of traps depends upon the size of the area to be trapped, the population density and distribution, as well as the average home range size of the wild pigs in the population in question (Diong 1980). In areas of high density, it is recommended that several traps be placed together to increase capture efficiency and success (Diong 1980).

Types of Baits - The variety of baits that have been used to trap wild pigs is extensive. For example, the reported list of successful baits has included shelled corn, soured corn (e.g., with lye and/or water), ear corn, corn oil and meal, fresh or fermented (e.g., soaked or boiled in water) grain (e.g., wheat, barley, sorghum or oats), soybeans, peanuts, peanut butter, garbage, vegetables, fruit (e.g., apples, bananas), commercial feed or pellets, whole fish, fish oil and meal, soured chicken mash, cut meat, and carrion. Shelled corn is considered to be the standard bait by most wild pig trappers, followed closely by soured corn. Commercially-produced baits pellets (e.g., PIGOUT®) are also available and have been successfully used (e.g., Cowled et al. 2006a, 2006b, Campbell and Long 2009). The best bait to use in a specific area can be regionally dependent. Whatever bait is chosen, it needs to be readily recognized by/attractive to the local animals, cheap to purchase, be easily handled, and have a long life in the trap (Giles 1973). Because of the pig's highly-developed sense of smell (Seamark 1999), the use of baits with increased odors can increase the trap harvest. For this reason, many wild pig trappers add an olfactory attractant to their baits such as raspberry or strawberry Jell-O, molasses, blood, bone meal, meat flavoring, synthetic fermented egg flavoring, cod-liver oil, rancid fish oil, beer, diesel fuel, or aromatic commercial chemicals (e.g., strawberry-, apple-, berry- and caramel-scented liquid domestic swine feed additives) (Eason and Henderson 1995, Campbell and Long 2008). Soaking corn in diesel fuel has also been reported by some trappers to reduce the capture of non-target species. However, trapping studies have not corroborated this belief (Wyckoff et al. 2006).

Trapping Operation - Once decisions have been made with respect to location, season, traps and bait, the actual trapping can begin. The trapping operation begins with pre-baiting an area, and then continues through setting up and beginning of trapping, and ultimately to the removal and disposition of the captured animals. 


\section{Wild Pigs}

The techniques used for baiting wild pigs are as variable as the trap designs. All trapping at a location should begin with pre-baiting. This entails the placement of bait at a potential trapping location, and then checking it periodically (e.g., once every 2-3 days) until wild pigs have found the bait and begin to consume it. Once this happens, it confirms two things: first, wild pigs are present in the area; and, second, those animals are willing to consume the bait offered. Setting up a trap without establishing those two points may ultimately be a waste of time.

Once the wild pigs are coming to the site and consuming the bait, the trap should be set up. This should be done during the middle of the day when the animals are least likely to be present. Giles (1977) suggesting leaving a new trap in an incomplete state for several days and to place bait in and about the trap so that pigs will become accustomed to feeding there. When the trap is set up, the door should be tied open. A bait trail should then be laid out starting from the original bait to the inside of the trap enclosure. This bait line is replenished daily. If the pigs are only eating up to the door of the trap, but are not entering the trap, cease placement of the bait outside of the trap. Place a large amount at the door, with a trail leading to a larger pile inside of the trap enclosure. If the pigs are still reluctant to enter the trap, relocate the large pile near the entrance or just inside of the trap enclosure. It is important to continue replenishing the bait to keep the pigs interested. Assuming that the bait represents a desirable resource and there is no competition from a naturally available resource (e.g., acorns), the wild pigs will eventually enter the trap. Once the pigs have started going into the trap and eating the bait, wait between one and seven days of free-feeding, and then the trap can be set.

The next step is to set the trigger device and trap door. The trap is then re-baited. The bait trail should now start inside of the door as a sparse trail leading to the triggering device. The bait is placed at the trigger to favor the animal releasing or activating the triggering device. If the pigs refuse to enter the trap with the bait starting at the door, place a short, sparse bait trail outside of the trap leading to the pile located just inside of the door. In larger corral traps, it is often possible to capture a group of animals. This is done by laying out the sparse bait trail leading to a large bait pile that is located away from the triggering device. A smaller amount of bait is then placed at the device itself. Most of the animals will then head to the large bait pile. The larger more aggressive animals will tend to exclude the younger, smaller ones from feeding there. Those animals will search around the trap enclosure, find the smaller pile at the triggering device, ultimately tripping the device and capturing the entire group. The traps should be set in the late afternoon or early evening. The traps should then be checked early the following morning. Wild pig traps must be checked daily to either be reset or replace bait as needed. If possible, traps should be initially checked from a distance. If several large pigs are in a trap, the sudden presence of a person or vehicle will frighten them and some may escape (Barrett and Birmingham 1994).

Once one or more wild pigs have been captured in the trap, the decision must be made as to the fate of those animals. The options are basically either kill/euthanize the animals or to capture them alive. Unless the animals are to be either removed live for further study or released as part of a telemetry or mark-recapture study, it is best to consider humanely sacrificing the animals following capture. In an effort to prevent the spread of diseases (e.g., brucellosis or pseudorabies), most states do not permit the relocation or release of trapped wild pigs back into the wild. If the animals are to be killed in the trap, the quickest method is to shoot them. Institutional Animal Care and Use Committee (IACUC) guidelines recommend the use of a large caliber center-fire round to the head as a humane form of euthanasia for this species. It is best to approach the trap slowly, and then shoot the largest animal first. Wait for the remaining animals to settle down after the first one is shot, then move on the next largest animal, and so on. Care and accuracy need to taken with shots on trapped animals so as not to only wound any of the pigs. In lieu of a firearm, euthanasia can also be accomplished through an overdose with an immobilization drug administered using a commercial pole syringe or dart gun. Because of the concern for blood in the trap causing other wild pigs to be reluctant to enter the enclosure, some trappers feel the need to clean any blood out of the trap before using it again. Often this means replacing the soil in the entire floor of the trap. This can be a laborious undertaking. For this reason, some trappers with that concern prefer to take the animals elsewhere to shoot them. To capture animals alive, the use of a pole syringe or dart gun to inject an immobilization drug can be employed. A pole snare or large net can be used to capture and remove smaller animals. 
Following the removal of the animals, the trap should be re-baited and reset. The trap should continue to be worked until the capture rate drops off. Tie the trap open and try using different bait for a few days. If the pigs begin to take that bait, begin the trapping process again. The trap should be moved when either no more bait is taken or no more pigs are caught. Make certain to start pre-baiting at another location before actually moving the trap (Hone 1984). If the trap is a fixed design, tie the door open and deactivate the triggering device until wild pigs reappear in the area.

\section{Advantages and Disadvantages}

The advantages and disadvantages of using traps to control wild pigs have been listed by Giles (1973), Barrett and Birmingham (1994), Choquenot et al. (1996) and Land Protection (2001). These advantages are as follows:

- Does not interfere with normal pig behavior in an area (unlike dogging and shooting)

- Unlike poisoning programs, the number of animals removed is known exactly and carcasses can be safely removed and disposed of

- Portable traps can be moved and re-used as necessary (good trapping makes use of opportunities as they arise)

- Designed properly, traps can be set up by one person

- $\quad$ Pigs cannot escape from a properly constructed trap

- Humane to both wild pigs and non-target species if routinely checked

- Dogs are not put at risk as they are with poisoning or dogging campaigns

- Can be incorporated into existing routine property management activities

- Landowners can offset the cost of trapping by selling trapped pigs

- $\quad$ Safest form of wild pig control; can be undertaken in densely populated (e.g., suburban or urban) areas

Disadvantages are as follows:

- Can be expensive to construct and maintain

- Can be manpower intensive; traps must be checked regularly

- $\quad$ Some wild pigs are trap shy (38\% in one study, Saunders et al. 1993); others are reluctant to walk on wire panels used in some trap flooring

- $\quad$ Potential for capturing non-target species

- $\quad$ Some trap can be tripped (by pigs, non-target species or humans) and the door closed, preventing the capture of any pigs

- $\quad$ Pigs may be able to escape from some trap designs

- Trapped pigs may be released by humans interfering with the trapping program

- Not practical for large-scale control programs

- $\quad$ Not effective when preferred natural foods are available

- Some trap designs require two or more people to set up

- Trapping fatigue: success will drop off over time if trapping is used for extended periods

Some of these disadvantages can be avoided or overcome with careful upfront planning.

\section{Conclusion}

Trapping is a useful technique for controlling wild pigs. It has a variety of both advantages and disadvantages. Upfront planning with respect to the application of this method in a given area for a defined purpose can greatly increase the success rate. Its versatility to apply as either a standalone technique or in conjunction with other techniques makes trapping a valuable option to use. In spite of the fact that it can be costly and manpower intensive if large numbers of traps are being used, trapping remains a core component of efforts for controlling this invasive species. 


\section{Wild Pigs}
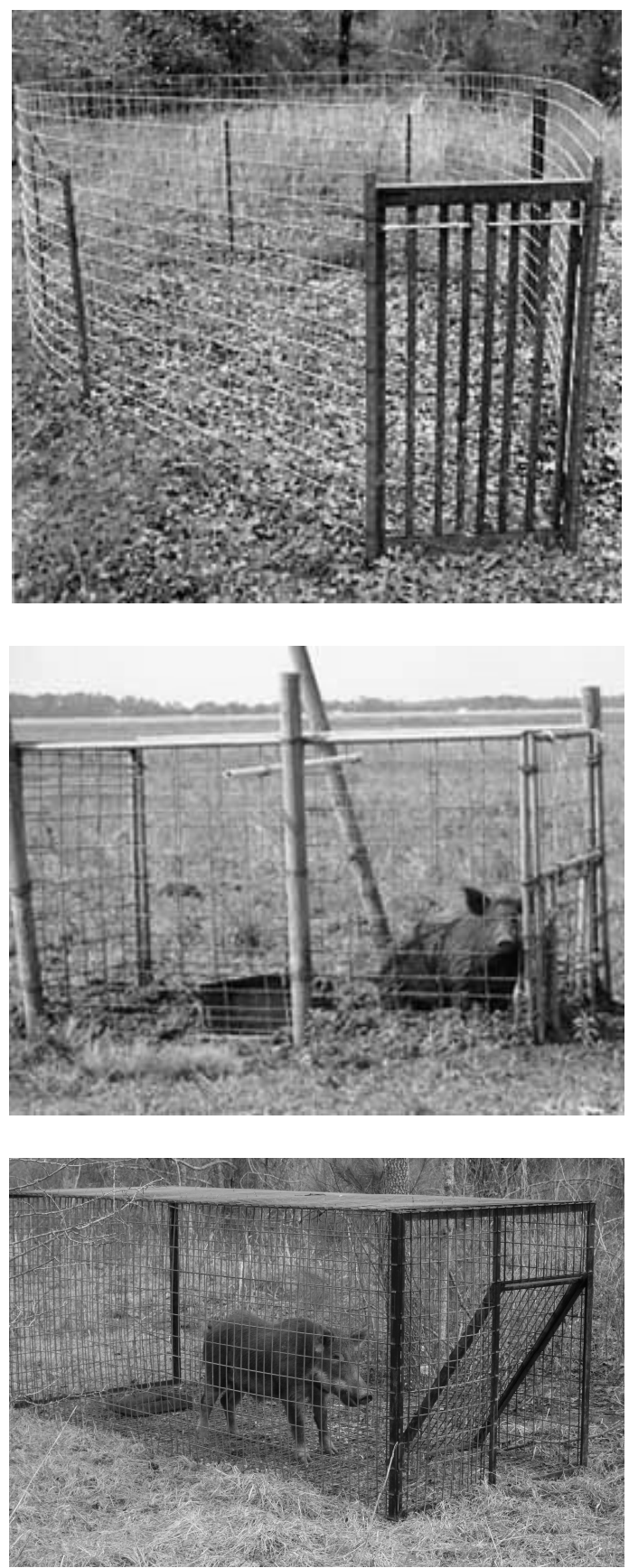

Fig. 1. Examples of three types of portable traps. These include: top - silo trap with side-hinged doors; middle - panel trap with a top-hinged door; and bottom - box trap with a top-hinged door. 

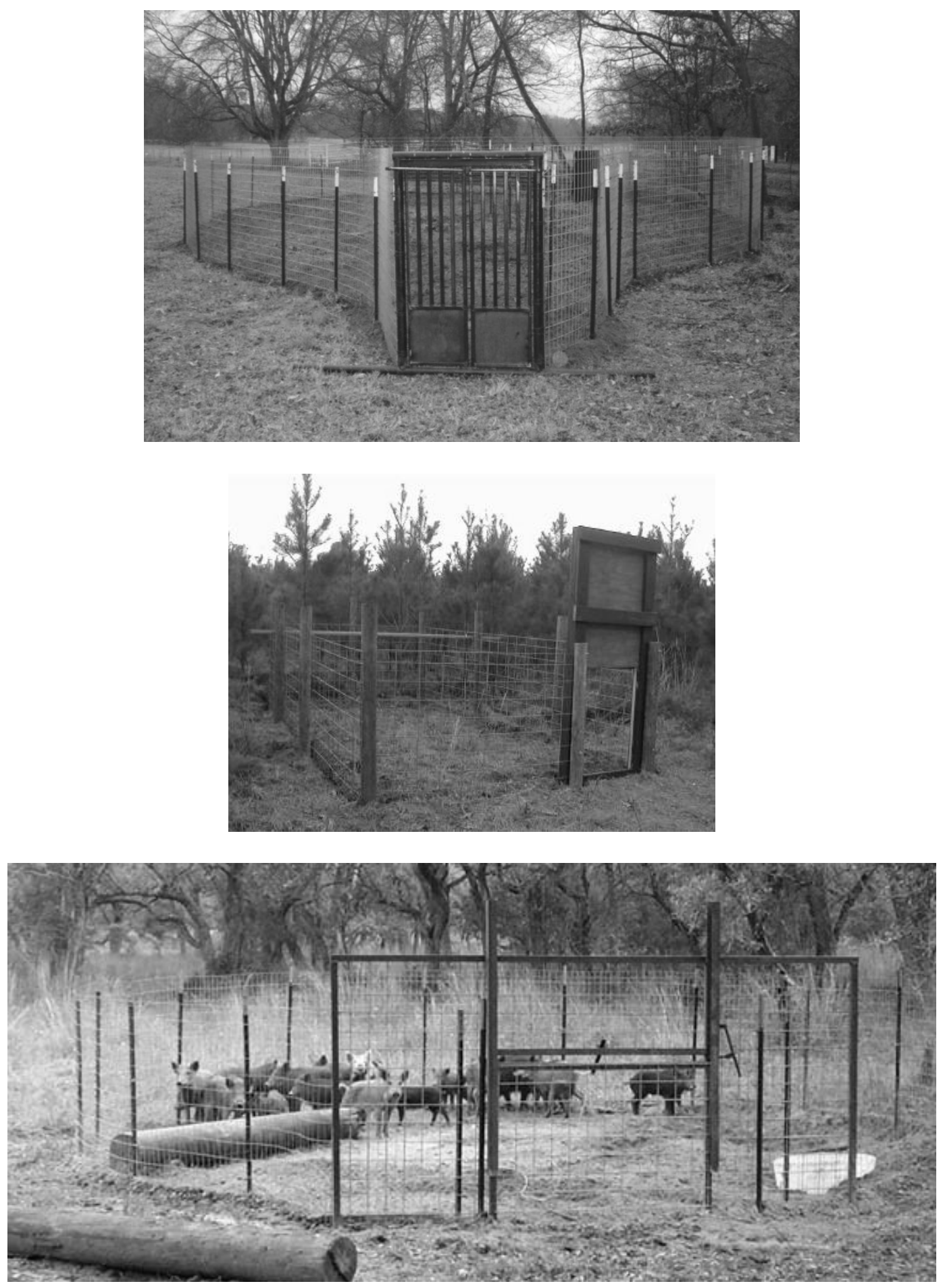

Fig. 2. Examples of three types of fixed traps. These are all wire-sided corral traps. The top design has side-hinged doors, while the middle and bottom designs have drop doors. 

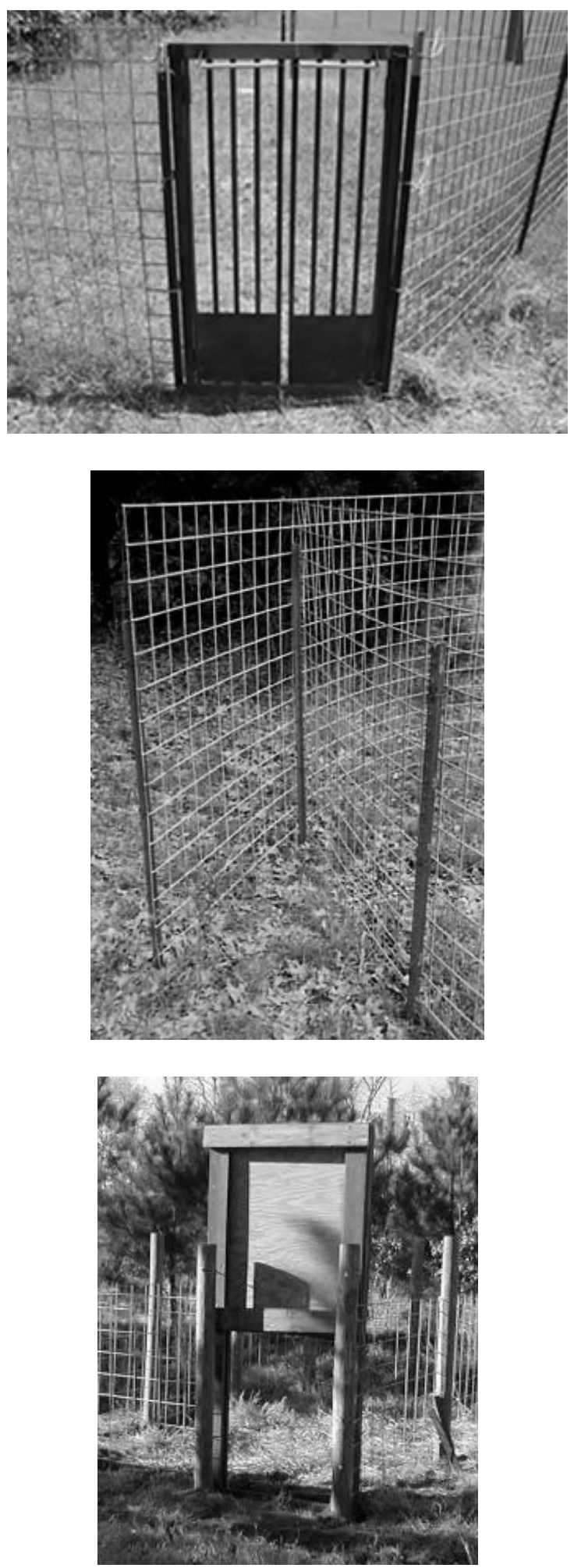

Fig. 3. Examples of the three types of doors for use on wild pig traps. These include: top - side hinged; middle - funnel/squeeze; and bottom - drop. 


\section{Literature Cited}

Barrett, R. H., and G. H. Birmingham. 1994. Wild pigs. Pp. D65-D70. In S. E. Hygnstrom, R. M. Timm, and G. E. Larson (eds.), Prevention and control of wildlife damage. 2 volumes; Great Plains Agricultural Council, Univ. of Nebraska, Lincoln, Nebraska.

Belden, R. C., and W. B. Frankenberger. 1977. A portable root-door hog trap. Proceedings of the Annual Conference of the Southeastern Association of Fish \& Wildlife Agencies, 31:123-125.

Caley, P. 1994. Factors affecting the success rate of traps for catching feral pigs in a tropical habitat. Wildlife Research, 21(3):287-292.

1999. Feral pig: Biology and control in the Northern Territory. Agnote 554, No. J52. Agdex No. 440/91. Parks and Wildlife Commission of the Northern Territory, Australia.

Campbell, T.A., and D.B. Long. 2008. Mammalian visitation to candidate feral swine attractants. Journal of Wildlife Management 72:305-309.

2009. Strawberry-flavored baits for pharmaceutical delivery to feral swine. Journal of Wildlife Management 73:615-619.

Choquenot, D., R. J. Kilgour, and B. S. Lukins. 1993. An evaluation of feral pig trapping. Wildlife Research, 20(1):15-22.

Choquenot, D., J. McIlroy, and T. Korn. 1996. Managing vertebrate pests: Feral pigs. Bureau of Rural Sciences, Australian Government Publishing Service, Canberra, Australia.

Coblentz, B. E., and D. W. Baber. 1987. Biology and control of feral pigs on Isla Santiago, Galapagos, Ecuador. Journal of Applied Ecology, 24(2):403-418.

Coblentz, B., and C. Bouska. 2004. Pest risk assessment for feral pigs in Oregon. Department of Fisheries and Wildlife, Oregon State University, Corvallis, Oregon.

Cowled, B. D., E. Gifford, M. Smith, L. Staples, and S. J. Lapidge. 2006a. Efficacy of manufactured PIGOUT ${ }^{\circledR}$ baits for localized control of feral pigs in the semi-arid Queensland rangelands. Wildlife Research 33:427-437.

Cowled, B. D., S. J. Lapidge, M. Smith, and L. Staples. 2006b. Attractiveness of a novel omnivore bait, PIGOUT®, to feral pigs (Sus scrofa) and assessment of risks of bait uptake by non-target species. Wildlife Research 33:651-660.

Diong, C. H. 1980. Responses of feral pigs to trap types and food baits. Proceedings of the Conference in Natural Sciences, Hawaii Volcanoes National Park, 3:91-100.

1981. A portable metal box trap for the live-capture of feral pigs. CPSU/UH Tech. Report 37. Department of Botany, University of Hawaii, Honolulu, Hawaii.

Eason, C. T., and R. J. Henderson. 1995. Part 3: Development of a toxic bait and baiting strategy for feral pig control. Pp. 24-33. In J. Coleman (ed.), Baits and baiting strategies for feral goats, pigs and cats. Department of Conservation, Wellington, New Zealand.

Fox, J. R., and M. R. Pelton. 1977. An evaluation of control techniques for the European wild hog in the Great Smoky Mountains National Park. Pp. 53-66. In G. W. Wood (ed.), Research and management of wild hog populations. Belle Baruch Forest Science Institute of Clemson University, Georgetown, South Carolina. 


\section{Wild Pigs}

Giles, J. R. 1973. Controlling feral pigs. Agricultural Gazette of New South Wales, 84(3):130-132.

1977. Control of feral pigs. Wool Technology and Sheepbreeding, 25(2):29-31.

Hone, J. 1984. Controlling feral pigs, Agfact A9.0.9. Agdex 673. New South Wales Department of Agriculture, Sydney, Australia.

Hone, J., and C. P. Stone. 1989. A comparison and evaluation of feral pig management in two national parks. Wildlife Society Bulletin, 17:419-425.

Land Protection. 2001. NRM Facts: Control of feral pigs declared. QNRM01278. Department of Natural Resources and Mines, The State of Queensland, Brisbane, Australia.

Lukins, B. S. 1989. Feral pigs: Trapping in New South Wales. Agfact A9.0.15. New South Wales Department of Agriculture, Sydney, Australia.

Saunders, G., B. Kay, and H. Nicol. 1993. Factors affecting bait uptake and trapping success for feral pigs (Sus scrofa) in Kosciusko National Park. Wildlife Research, 20(5):653-665.

Saunders, G., B. Kay, and R. Parker. 1990. Evaluation of a warfarin poisoning programme for feral pigs (Sus scrofa). Australian Wildlife Research, 17(5):525-533.

Seamark, R. F. 1999. Prospects for pig control: A biotechnology perspective. Pp. 63-64. In C. N. Johnson (ed.), Feral pigs: Pest status and prospects for control. Proceedings of a feral pig workshop. James Cook University, Cairns, March. Research Report No. 13. Cooperative Research Centre for Tropical Rainforest Ecology and Management, Cairns, Australia.

Sweitzer, R. A., I. A. Gardner, D. Van Vuren, B. J. Gonzales, and W. M. Boyce. 1997. A modified panel trap for capturing multiple wild pigs. Wildlife Society Bulletin, 25(3):699-705.

Vernes, K., C. N, Johnson, and J. Mitchell. 1999. The effectiveness of trapping in reducing pig abundance in the Wet Tropics of north Queensland. Pp 51-56. In C. N. Johnson (ed.), Feral pigs: Pest status and prospects for control. Proceedings of a feral pig workshop. James Cook University, Cairns, March. Research Report No. 13. Cooperative Research Centre for Tropical Rainforest Ecology and Management, Cairns, Australia.

Williamson, M. J., and M. R. Pelton. 1972. New design for a large portable mammal trap. Proceedings of the Annual Conference of the Southeastern Association of Game and Fish Commissioners, 25:315-322.

Wyckoff, A.C., S.E. Henke, T.A. Campbell and K.C. VerCauteren. 2006. Is trapping success of feral hogs dependent upon weather conditions? Proceedings of the Vertebrate Pest Conference 22:370-372. 
SRNL-RP-2009-00869

This page left blank intentionally 
Wild Pigs

\section{Control Techniques for Wild Pigs: \\ Use of Trained Hunting Dogs to Harvest or Control Wild Pigs}

John J. Mayer, Rollie E. Hamilton, and I. Lehr Brisbin, Jr.

Savannah River National Laboratory, Savannah River Nuclear Solutions, LLC, Savannah River Site, Aiken, South Carolina 29808 (JJM)

Wild Hog Control, 221 Project Road, Warrenville, South Carolina 29851 (REH)

Savannah River Ecology Laboratory, P. O. Drawer E, Aiken, South Carolina 29803 (ILB)

\section{Introduction}

The use of trained hunting dogs (a.k.a. "dogging") to locate and capture or "bay and catch" wild pigs (Sus scrofa) has been and continues to be one of the most successful methods for harvesting these animals. It is a popular sport hunting method as well as being a widely-used control or eradication technique for wild pigs (Choquenot et al. 1996, Dickson et al. 2001). The basic processes or methodologies used in this technique have remained effectively unchanged over the years. Dogging has withstood the passage of time, constituting a proven wild pig hunting method that dates back to the archaic societies in Eurasia (Towne and Wentworth 1950, Riddle 1987, Stevens 1996, Wendt 1996, Blüchel 1997). In the United States, it was often used during the Colonial period for the capture of both wild and free-ranged domestic pigs (Stevens 1983). It further has the added advantage of allowing the captured pig to be either sacrificed, released immediately or taken out live (Dickson et al. 2001).

To many hunters, the use of trained dogs is synonymous with hunting wild pigs (e.g., Cuthbertson 1968, Ellis 1988, Carr 1996). For these sportsmen, the latter is viewed as not being realistically possible without the former. In the United States, this component of the wild pig sport hunting public is the biggest and most devoted faction found. Dogging also represents a longstanding social combination or relationship between man and dog that has been successfully used in the pursuit of wild pigs since ancient times. For many sportsmen, it is considered to be the most exciting way to hunt wild pigs on either foot or horseback (McKenna 1966, Dickson et al. 2001).

In addition to being a popular hunting method, dogging is a widely employed as a removal technique for controlling local numbers of wild pigs. This is true for both the native and introduced portions of the species range (Tisdell 1982, Briedermann 1986). It can be used as a standalone application, or as a component of a management program using several control or removal techniques (Choquenot et al. 1996). In spite of this potential, dogging can also be expensive to implement if one chooses to do so from scratch. In addition, continuing to maintain a trained and effective pack of dogs for harvesting wild pigs can represent a significant ongoing expense following the initial expenditure. This is especially true if these dogs are used on a frequent basis. For most situations, it is probably much more cost effective to use a contractor or subcontractor to supply these technical capabilities for wild pig control rather than to attempt to do so internally within an organization, facility or site.

The purpose of this paper is to provide a summary overview of the use of dogs for harvesting and controlling wild pigs. Specifically, this discussion will include sections on types of dogs, training and testing of dogs, equipment used in dogging, typical hunt scenario, impacts to dogs, and advantages and disadvantages. This summary includes both results from both a review of the literature and observations collectively made in the field by the authors. 
SRNL-RP-2009-00869

\section{Results/Discussion}

In general, dogging is an effective technique to use for wild pig removal and eradication. However, the effectiveness of such programs depends largely on the skills of the hunters and dogs involved (McIlroy and Saillard 1989, Choquenot et al. 1996, Mapston 2004). In Annabel State Park, northern California, Barrett et al. (1988) noted that the pigs rarely escaped the dogs once the trail was struck by the pack. The social configuration of the pigs encountered during dogging efforts can also impact the successful application of this technique. For example, Caley and Ottley (1995) found that hunting dogs were successful on $88 \%$ of all occasions of catching or cornering solitary pigs when encountered, but that this rate rapidly declined as the group size of encountered pigs increased. In addition, they also determined that the mean maximum number of pigs that could be caught or cornered in any one encounter was about one pig per one dog. A trial conducted in the southwestern part of Western Australia showed that at least $30 \%$ of all wild pigs encountered escaped from the dogs. When groups of pigs were encountered during that trial, usually only one pig was caught (Oliver et al. 1992). Rizaldi et al. (2007) reported that the success rate increased when groups of pigs were encountered, especially sows with piglets.

The use of dogging can be limited seasonally in some areas. For example, during the hot and humid summer months at the Savannah River Site (SRS), South Carolina, the use of dogs to remove wild pigs can only be successfully conducted during the cooler morning hours (note: SRS access restrictions do not allow dogging at night). The impacts of both heat exhaustion and venomous snake bites on the dogs increased during the rest of the day at this location during that season. Because of these impacts and the limited time to use the dogs during any one day, the removal rate decreased dramatically compared to the cooler seasons. Often the wild pig control subcontractors at SRS have elected to not even attempt dogging during the hottest summer periods. Similar limitations and impacts have been noted for the use of dogging in Texas (Littauer 1993). In dogging for wild pigs on islands in the tropical western Pacific Ocean, it was found that the dogs could only chase a maximum of four pigs in a day before they were tired out (Kessler 2002). Schuyler et al. (2002) reported that dogging was less effective during the dry season because of the poorer conditions for holding the pig's scent and the impacts to the dogs from barbed seeds and grass flowering heads, which worked into the eyes, ears, foot pads and other open parts of the dogs, severely effecting or incapacitating them. In contrast, Barrett et al. (1988) reported that dogging at Annabel State Park was successful in removing pigs during all seasons; however, they did noted that it was not as efficient as trapping with respect to the overall numbers taken.

Dogging can also impact the local wild pig distribution by causing the pigs to scatter and disperse widely, making control efforts harder to use and less effective. For example, Maillard and Fournier (1995) showed that using trained hunting dogs is a significant factor of wild pig disturbance, such that wild pigs increase their range during seasons with hunting pressure from dogs. They found that animals subjected to high hunting pressure left their original territory, but returned later. It was also determined that, with little disturbance from hunting dogs, wild pigs stayed within their original ranges. Such potential disturbance impacts should be considered and taken into account when either implementing dogging as a standalone technique or in combination with other removal methods in the same location.

The application of dogging in wild pig control programs in some areas has run into obstacles involving controversy and public disapproval. Such issues have revolved around animal rights/humane concerns associated with dogs catching wild pigs, problems regarding the specific contracted personnel employed for the application of this control technique, and the potential impacts of the dogs on native wildlife species. Examples of sites where such problems have arisen would include the Great Smoky Mountains National Park and the Cumberland Island National Seashore (Anon. 1978, Coleman 1984, Anon. 1992).

\section{Types of Dogs}

A variety of dog breeds has been shown to be useful in hunting wild pigs (Littauer 1993). However, whatever the breed of any particular dog, the most important character is the ability of that animal to function in one of the three types of dogs, commonly referred to as "hog dogs," that are needed to hunt wild pigs. Because of their inherent characteristics, some breeds of dogs are better at one function or the other. For this reason, most hog dog are mixes of specific breeds rather than any one single pure breed. Many 


\section{Wild Pigs}

wild pig hunters go to great lengths to try to breed the perfect hog dog based on the combination of characteristics that they want in the final result. Local packs have been bred through many generations for scenting ability, stamina, good voice, pugnacity, strength, and the nimbleness to hold a pig at bay without being gored before the shot is made or the pig is thrown (Elman 1974). In most cases where the characteristics fit the job, the question is not so much "can," but rather, "will" the dog do the job. Many a promising hog dog has become worthless after being only slightly injured in a fight with a large boar, and subsequently refused to participate in future chases of wild pigs. To be good at hunting wild pigs, a dog must above all have courage and tenacity. With that foundation, the skills useful in this technique will be developed over time.

The number of the types or categories of dogs used to hunt wild pigs varies widely. Some sources have reported as many as six distinct types of hog dogs (i.e., strike, tracker, mouth, fighting, bay and catch dogs) (Conley et al. 1972). Typically, however, only three types are cited by most authorities (i.e., trail, bay and catch dogs; Fig. 1) (Littauer 1993). Some individual dogs can also adequately function in two of these types, and in a very few cases, even in all three types.

Trail Dogs - In the order of use during a hunt, the first type is the trail dog. As the name implies, the function of this dog is to initially detect the presence of a wild pig's scent and trail the pig until it is located. These dogs are also expected to wind wild pigs standing nearby. This can include the ability to wind a pig from either the back of a moving pickup or in a moving boat. Suffice it to say that the abilities here are centered around the nose and the stamina to trail a wild pig for potentially a number of kilometers through what can be very rugged country. Most hunters prefer a dog that trails silently until the pig stops or is "bayed up." A number of established hunting breeds can be used for this function. These would include Plott Hounds, American Foxhounds, Walker Foxhounds, Trigg Hounds, Staghounds, Norwegian Elk Hounds, Coonhounds (e.g., Bluetick, Redtick, Redbone, Black and Tan), Catahoula Leopard Hounds, Florida Cur, Yellow Blackmouthed Cur, Rhodesian Ridgebacks, Airedale, Wolfhounds, Border Collies, Blue Healers, Beagles, and various bird dog breeds (e.g., Pointer, Weimaraner, German Short-haired Pointer, Griffon). Unlike the next two types, the trail dogs are the dogs least likely to be either cut or gored during a hunt. Conley et al.'s (1972) strike, tracker and mouth dogs would all be considered to belong to the trail dog category.

Bay Dogs - Once the trail dogs have located and begun pursuing the wild pig, the next type, known as the bay dogs, takes over. The job of the bay dogs is, again as the name denotes, to bring the boar to bay. This can be either through stopping the boar by surrounding it or by backing it up against an object, like a large tree, rock or other barrier. The bay dogs accomplish this by convincing the pig that it cannot escape the dogs, and that it must stand and defend itself. This is done through combination of barking, biting, and making threatening rushes at the boar. In fact, Ishikawa et al. (2001) found that, in penned trials, both a dog's bark and focused gaze were adverse stimuli for wild pigs. Many of the same breeds commonly used as trail dogs will also serve adequately as bay dogs (e.g., Plott Hounds, Catahoula Leopard Hounds, the various Cur breeds, and Rhodesian Ridgebacks). This is especially true for the hound breeds. With the action getting closer, more bay dogs tend to get cut; although this is typically not a serious wound. The "fighting" dog defined by Conley et al. (1972) would be included in the "bay dog" classification.

Catch Dogs - The final type of hog dog is the catch dog. Of the three types, this is the one that really gets "up close and personal" with the boar. These dogs have the single-minded function of grabbing and holding the pig until the quarry is either caught and thrown or killed by the hunter. To accomplish this, these dogs tend to be larger in the shoulder, neck and head than the other two types. Typically, however, these dogs also do not tend to have the stamina seen in trail and bay dogs. Many hunters keep the catch dogs on a leash until the boar is bayed and then turn them loose to catch the pig. Good catch dogs are masters of the silent, quick rush into the standoff between dogs and pig, seeking to secure a firm hold with their teeth on an ear or side of the jowls. Other holds can be made (e.g., hip, tail or leg); but the ear and jowls provide the best hold allowing the hunter to grab the back legs and throw the pig. A poor hold can result in the boar being able to swing his head, either slashing (which results in long open gash wounds) or stabbing (which results in deep puncture wounds) the neck, shoulders or sides of the dogs attempting to hold on to the pig. The senior author once saw a dog grab a medium-sized sow by the front of the snout. The dog had firm hold, and the sow responded by biting and crushing the entire front third of the dog's 
SRNL-RP-2009-00869

lower jaw. That dog had to be euthanized at the local veterinarian's office; there wasn't much that the vet could do with the way that the sow had destroyed the dog's jaw. The breeds that work well as catch dogs are the bulldogs, such as the American Pitbull, American Staffordshire Terrier, Bull Terriers, Rottweiller, English Bulldog, and Argentine Dogo. Many hunters prefer to use catch dogs that are approximately half bulldog rather than pure breeds. Such crossbred dogs are reportedly easier handle and control (Stevens 1983). Catch dogs are the type of hog dog that sustains the injuries so commonly associated with the dogs used in hunting wild pigs. These are by far some of toughest hunting dogs that one will ever watch in action. They have the grit to hold on, while getting thrown and cut; and through all of that, they do not let go!

Pack Size - The size of the pack of hog dogs used varies with the hunter. It is commonly perceived that the larger the pack, the safer and more consistently successful it is. In fact, some hunters dislike fewer than 12 to 15 dogs. However, at least a few state laws limit the number of dogs that one can use to hunt wild pigs (Camp 1972, Elman 1974). Barrett et al. (1988) reported using packs of 3 to 6 dogs to remove wild pigs from Annabel State Park. The size of the pack employed will also depend upon the variety and skill of the dogs composing it. A few highly experienced, aggressive and skilled hog dogs can easily do the work of a much larger pack of inexperienced dogs.

\section{Training and Testing of Dogs}

Individual hunters vary widely as to how much time they spend training their dogs for the various skills used in hunting wild pigs. There is also a particularly high degree of variability in the amount of training that is usually devoted to dogs that are to be used in the various aspects of the hunt. For example, trail dogs generally receive the least amount of training and preparation for the work that they are expected to do. Typically this involves relying a great deal on the instinct of the individual dog, which is no doubt imparted largely through its genetics and breeding. Given that, the dog is then worked repeatedly over time with more experienced dogs to improve its abilities.

Like that of trail dogs, the work of bay/catch dogs also has a significant innate component. However formal training can refine this behavior to increase the usefulness of these types of dogs to the wild pig hunter. In particular, proper training can help to ensure that the bay/catch dog does not spontaneously attack the quarry until commanded to do so by the hunter. Even more importantly, proper training can facilitate the termination of baying and bring the dog back to the hunter on command if for some reason it becomes either unwise or unnecessary for the dog to attack and attempt to capture a particular pig. Training to attain this kind of control over a bay/catch dog is taught as part of the sport of schutzhund or protection dog training (Stevens 1983, O'Hanlon 1987). As part of this training, the dog is taught to search for the quarry, and when found, bring it to bay, or upon command from its handler, attack, bite and hold the quarry. The dog is also trained to leave/release the quarry and immediately return to the handler on verbal command. As such, the principles employed in schutzhund training can also be used to increase the degree of control that can be exercised over the work of catch dogs and thereby decrease the risk of serious injury to either the hunter or his dogs. Specifically, this kind of training could allow a hunter to verbally call-off his catch dog once it has seized a pig and control of the quarry has been achieved, which can help avoid the injuries to both dog and human that are often associated with the struggle to remove the catch dog by physical force.

Although schutzhund training typically involves one of the working breeds used in police work, this degree of both training and control has been successfully achieved with many of the kinds of dogs that are commonly used to capture and control wild pigs. For example, when patiently worked under the supervision of a skilled trainer using the techniques described by Stevens (1983) and O'Hanlon (1987), dogs of even the Pitbull breeds have proven capable of excelling in this kind of work. In fact, several American Staffordshire/American Pitbull Terriers have proven capable of distinguishing themselves in the highest levels of schutzhund competition, and defeating dogs of the standard police working breeds (Stevens 1983).

With sufficient training and testing of individual dogs by experienced handlers, some dogs have proven capable of capturing and controlling wild pigs without significant harm to the animal being captured. Such 


\section{Wild Pigs}

dogs can be valuable for research programs requiring multiple recaptures of the same free-ranging individual pig over time and in at least one case, in an effort to conserve an endangered species of wild pig, the Philippine Visayan warty pig (Sus cebifrons). The latter case involved the use of certain highly trained "elite" New Zealand pig dogs (Clarke 1991, 1993) in an effort to obtain wild breeding stock of this endangered suid for a program of captive breeding (Clarke 1992), which is now being undertaken in a number of zoos (Durham 2009).

\section{Equipment Used in Dogging Wild Pigs}

Dogging for wild pigs can entail the use of a variety of equipment. These items may be determined by either the manner in which one hunts wild pigs with trained dogs or for the sake of convenience and expedience while being in the field. Choices of the types and variety of such tools to employ in dogging are seemingly infinite, but generally include items in the areas of the following: (1) weapons to dispatch the pigs; (2) hunter/handler mobility; (3) protection of the dogs; and (4) miscellaneous equipment. These are discussed in the following paragraphs.

Weapons to Dispatch Wild Pigs - In hunting wild pigs with dogs, a variety of weapons have been historically employed for dispatching wild pigs including guns, bows, knives, swords and spears (Blüchel 1997, Dickson et al. 2001). In short, all of the aforementioned weapons will work. The choice of what weapon to use depends upon the hunter's preference/skill, the manner/location of hunting, and any applicable regulatory requirements (e.g., weapons restrictions) or ethical use/animal welfare issues (e.g., local Institutional Animal Care and Use Committee or IACUC guidelines). In general, most sources (e.g., Barrett et al. 1988) have reported that captured pigs can be humanely dispatched by a high-powered bullet to the brain. However, the use of firearms may not be possible if, for example, the removal effort is being conducted in a densely-settled suburban area. In addition, care must be taken if firearms are used to dispatch the pig, so that a dog is not accidentally shot while trying to hit an enraged large boar surrounded by a pack of dogs dashing and dodging in and out of the melee (Milek 1980).

Hunter/Handler Mobility - Most hunters that employ dogging to harvest wild pigs travel on foot. However, anyone who has followed a pack of hog dogs in pursuit of a large boar will readily testify that this is not an activity for someone not in good physical condition. Some chases can literally go for miles before the pig is either bayed up or lost. For this reason, many hunters prefer to use of horses or mules to follow their dogs. Many hunters also now use four-wheelers or all-terrain vehicles (ATVs). In some instances, pickup trucks, sport utility vehicles or boats can also be used to get to the location where the dogs have a pig bayed up. The choice of mobility will depend upon the terrain, property access and any applicable legal/regulatory restrictions.

Protection of the Dogs - With a highly skilled hog dog being difficult to either purchase or develop, many hunters use a variety of equipment to protect their dogs from injury. Generally, this includes some form of either cut vests or cut collars. Cuts vests are exactly what they sound like they should be, a material covering the lower part of the neck, entire chest, and upper abdomen of the dog to protect the animal from being either lacerated or punctured by the tusks of a boar or large sow (Fig. 2). The type of material used in cut vests varies from heavy leather to puncture-resistant synthetic materials such as kevlarß. The vest usually fastens with either buckles or ties. This "body armor" can be worth far more than the purchase value if it saves one's best dog from being permanently maimed or killed. Interesting enough, the practice of using body armor on hog dogs actually dates back to medieval times (Blüchel 1997). However, the material used for these early cut vests was either chain-mail or heavy cloth quilted with thick padding. Either of which would make fast moves or extended running on the part of the dogs very difficult if not next to impossible. In short, modern cut vests costing between fifty and several hundreds of dollars are cheap insurance for protecting a highly skilled, experienced hog dog worth several thousands of dollars. The other option to protect a valuable hog dog is to put one or more wide, sturdy leather collars around their necks. Known as "cut collars," these prevent the external carotid arteries or jugular veins from being lacerated or punctured during fights with large boars. When a catch dog has a boar by the ear, the boar will attempt to puncture or stab the dog (i.e., typically hitting them in the neck) with its tusks. Such blows can be rapidly fatal for the unfortunate dog upon which a boar has gotten a lucky stab. Many hunters also use these collars in conjunction with a cut vest. 
Miscellaneous Equipment - A variety of other equipment can also be employed when dogging for wild pigs. A recent increase has been seen in the use telemetry equipment to locate dogs that are working the surrounding area, and are out of sight from the hunters/handlers. It would be especially useful to have a radio collar on a trail dog that follows or pursues wild pigs silently. If the chase goes for miles or over several ridgetops, the sound of the dogs barking when they finally bay up cannot be heard. Use of a telemetry setup can allow the chase to be followed before the dogs get out of hearing range. To enable the handler to get tenacious catch dogs to release their hold on a pig, some hunters use a breaking or pry stick. These are typically wooden sticks or rods approximately $30 \mathrm{~cm}$ in length and $3 \mathrm{~cm}$ in diameter. A loop is often added near the base or handle portion of the rod to improve the holding capabilities by the hunter/handler. The breaking or pry stick is inserted between the upper and lower jaws of the dog's mouth and the pig, and the dog's hold on the pig is then carefully pried loose. At that point, the dog is led away by the collar and leashed to a tree or other anchoring point. Muzzles can also be used for some catch dogs to keep them under control prior to being released to catch a bayed pig. It can also serve to prevent the bulldogs from fighting with the other dogs.

Other equipment can include such items as walkie-talkies or cell phones (i.e., for handlers/hunters to stay in contact), multi-compartment dog boxes (i.e., for transporting dogs safely), and equipment/implements to tie up or "hog-tie" the pig. For pigs that are to be brought out alive (e.g., for research purposes), various hunters use rope (sturdy composition that will holds knots), heavy-duty cable ties, or even handcuffs/shackles. Immobilization drugs may also be appropriate for this task.

\section{Typical Hunt Scenario}

The pursuit or chase involved in dogging for wild pigs has been described in numerous accounts ranging for fiction to anecdotal to non-fiction (e.g., McNally 1955, Jones 1959, Cuthbertson 1968, Camp 1972, McGrail and McGrail 1969, Conley et al. 1972, Humphrey 1984, Capstick 1990, Littauer 1993, Carr 1996, Kessler 2002). The sequence of activities is relatively consistent, with personal preferences or variations incorporated as appropriate. Typically such hunts encompass two or more hunters/handlers and three or more dogs. The use of either less people or fewer dogs is awkward and can lead to potentially dangerous situations. Hunts can also be conducted during either daylight or nighttime hours; however, the difficulty and potential incidents increase after dark. Unless the local wild pigs have completely shifted their activity pattern in the area to be hunted (e.g., croplands) to nighttime hours, it is preferable to conduct dogging during daylight hours.

The hunting sequence, following the aforementioned pattern of use defined for the three types of dogs is described as follows. While moving through wild pig country, the dogs and hunters/handlers intensively search areas with fresh pig sign until a pig's scent trail is struck (Barrett et al. 1988). In areas that have experienced depredation, it is best to start the dogs at the site of the wild pig damage (Zwickel 1980). The trail dogs get a pig's scent and run off following the pig's trail. The pig, once it realizes that it is being pursued, will continue to move rapidly to stay ahead of the dogs in an effort to escape. The dogs, closing in on the pig, go through a repetitive sequence of the pig baying up, breaking loose from the dogs, and then continuing the pursuit until the pig is brought to bay again. The chase can vary from a few meters up to 30 to 50 kilometers, depending upon the terrain, the climatic conditions, the dogs involved and the pig being pursued (McKenna 1966, Elman 1974, Ricciutti 1976, Barrett et al. 1988). Jones (1959) reported that one boar in the southern Appalachians was even chased for 97 kilometers. Some chases have been known to last for as long as 12 hours (Conley et al. 1972). In some cases, the pig will outrun the dogs and escape. Other chases end up so far away that the hunters never know what the outcome was. In those instances, seriously wounded dogs may never be either recovered or found (Jones 1959). Typically, however, the pig is stopped and bayed up, usually against a protective backdrop (e.g., cliff, boulder, base of a large tree, or thick log) (Kessler 2002). Large boars will single-handedly take on a whole pack of dogs without hesitating (McKenna 1966). The bay dogs keep the pig corralled in that one spot. At that point, the process to be followed varies depending upon the preference of the hunter. The simplest option is for the hunter to shoot the bayed pig. Other hunters choose the option to turn the catch dogs loose and "catch" the pig so that it can be "thrown." In doing this, these hunters/handlers carefully wade into the scene of the pig being held securely by the catch dogs. Working their way toward the rear end of the pig, the hunter grabs 


\section{Wild Pigs}

the back legs of the pig, lifts them into the air and turns the pig on its side. The pig is then pinned to the ground at the shoulder and the front leg closest to the ground is lifted, thereby preventing the hog from getting a leg underneath to stand up. At that point, the hog is completely under the control of the hunter. The neck of a wild pig is too inflexible to allow the hog to reach back to the hunter. The hog can push with its back legs, but can only succeed in slowly spinning the hunter sitting or kneeling on its shoulder around in circles. The hunter has two options at that point, tie the legs of the animal to take it out of the woods alive or sacrifice it with the preferred weapon. The desired endpoint dictates the method of choice. Once a pig is thrown and under control, the dogs should be caught, put on a chain lead or lease, and either held by one of the other handlers or tied/anchored to a tree of other object to keep them in the area and preventing them from running off in pursuit of other wild pigs.

Another scenario (i.e., dog drives) involves using packs of hunting dogs to drive wild pigs through lines of shooters/hunters to be harvested. Such drive hunts typically use only trail dogs (e.g., hound breeds) to chase the wild pigs through the strategically positioned shooters. This is a common practice in many European countries. It has also been practiced on the SRS since 1965 (Mayer 2005).

\section{Impacts to Dogs}

The trained hunting dogs are frequently put at risk of injury with dogging for wild pigs (Fig. 3) (Stevens 1983, Mapston 2004). The mortality rate of hog dogs is high (Wooters 1975, Milek 1980). In fact, wild pigs take the greatest toll of hunting dogs of any big game in the United States. Some hunters realize annual losses to their packs of up to $40 \%$ (Camp 1972). The use of cut vests and collars can reduce the potential for some of these injuries; however, even dogs wearing those protective devices can be either lacerated or gored. For that reason, hunters/handlers using dogs to bay or catch wild pigs need to have a suture kit and antibiotics (i.e., topical or intramuscular) with them in the field at all times. Dogs that do get either lacerated or gored can then be sutured and treated on the scene prior to removing them back out of the field. The sooner the injuries are tended to, the sooner the dogs will heal and be able to hunt again.

Aside from injuries associated with the contact with wild pigs, dogs can also be negatively affected by being hunted in hot weather. As previously noted, dogs will readily succumb to heat stress if participating in a strenuous chase in hot and humid weather. During those climatic conditions, dogs should be hunted either in the cooler morning hours or at night.

Venomous snakes (e.g., pit vipers), which can be active during summer nights, can pose a hazard to dogs (Littauer 1993). Such encounters between dogs and snakes can even occur during summer days. Frequently bitten around the head or neck, these dogs should be removed to a veterinarian as soon as possible for treatment. Any collars or vests should also be removed so that constriction will not become a problem in conjunction with swelling tissues in the neck.

Although rarely encountered during hunts, American alligators (Alligator mississippiensis) can also represent a hazard to hog dogs in areas of the southern United States. Being found in habitats often used by wild pigs (e.g., swamps and bayous), alligators will readily attack and kill hunting dogs as prey if the opportunity presents itself. Such encounters usually occur when the dogs are swimming across open water. In these instances, the dogs are often out of the handler's direct control. As such, a sudden ambush attack on a dog by a large alligator cannot be successfully prevented (J. W. Reiner, pers. comm..).

Since some chases can cover long distances, it is very possible that the dogs will get out of sight of the handlers. Over extreme distances and in areas of thick cover, it is also possible for the dogs to get separated from the hunters or lost. Under such circumstances, the dogs may not be either found or recovered during the hunt. Dogs that are injured, succumb to heat stress or become frightened by aggressive pigs can also be lost. The use of telemetry equipment can enable one to find these dogs.

\section{Advantages and Disadvantages}

The advantages and disadvantages of using dogs to harvest/control wild pigs have been discussed by Tisdell (1982), Saunders and Bryant (1988), McIlroy and Saillard (1989), Caley (1999), Littauer (1993), 
Barrett and Birmingham (1994), Choquenot et al. (1996), and Land Protection (2001). These advantages of dogging are as follows:

- Can be employed during either daylight or nighttime hours

- Able to locate and flush wild pigs out of thick or dense cover to be bayed or caught

- Can be used for removing residual or surviving pigs after densities have been reduced by other forms of control (e.g., poisoning, shooting and trapping)

- Very successful when solitary pigs are encountered

- Can produce wild pig specimens from an area for sampling (e.g., disease testing) quicker than most other methods

- Possible to take many pigs in a very short period of time

- Can be used to take individual depredating pigs

Disadvantages of dogging are as follows:

- Generally not effective for ongoing large-scale reductions in populations

- Can have a negative impact on sheep enterprises or native fauna if the dogs become feral

- May not be possible to use in certain areas (e.g., suburban areas with lots of children and outside pets present; natural areas with obstacles involving controversy and public disapproval regarding the use of this technique)

- Success rate rapidly declines as the group size of pigs encountered increases

- Intensive hunting with dogs might cause pigs to disperse, making subsequent control more difficult

- The use of dogs to pursue, and hold pigs is considered inhumane by some private and public groups

- Dogs are often put at risk of injury or death

- Veterinary bills for treating injured dogs can be costly

- Often difficult to find and train good dogs

- Dogs cannot be used during extreme hot and humid weather conditions

\section{Summary}

Dogging is a popular age-old method for harvesting wild pigs that can be employed in management and control programs for these invasive species. This technique can be very effective, but dogging has its limitations. Although it can be used to remove a number of wild pigs that would be difficult to harvest otherwise, dogging can also be very expensive to implement. For limited application, the use of a contractor's or subcontractor's services for a dogging program to harvest or control wild pigs should be considered. It is best used as a component of a control program employing several lethal removal techniques (e.g., dogging in addition to shooting and trapping). 


\section{Wild Pigs}
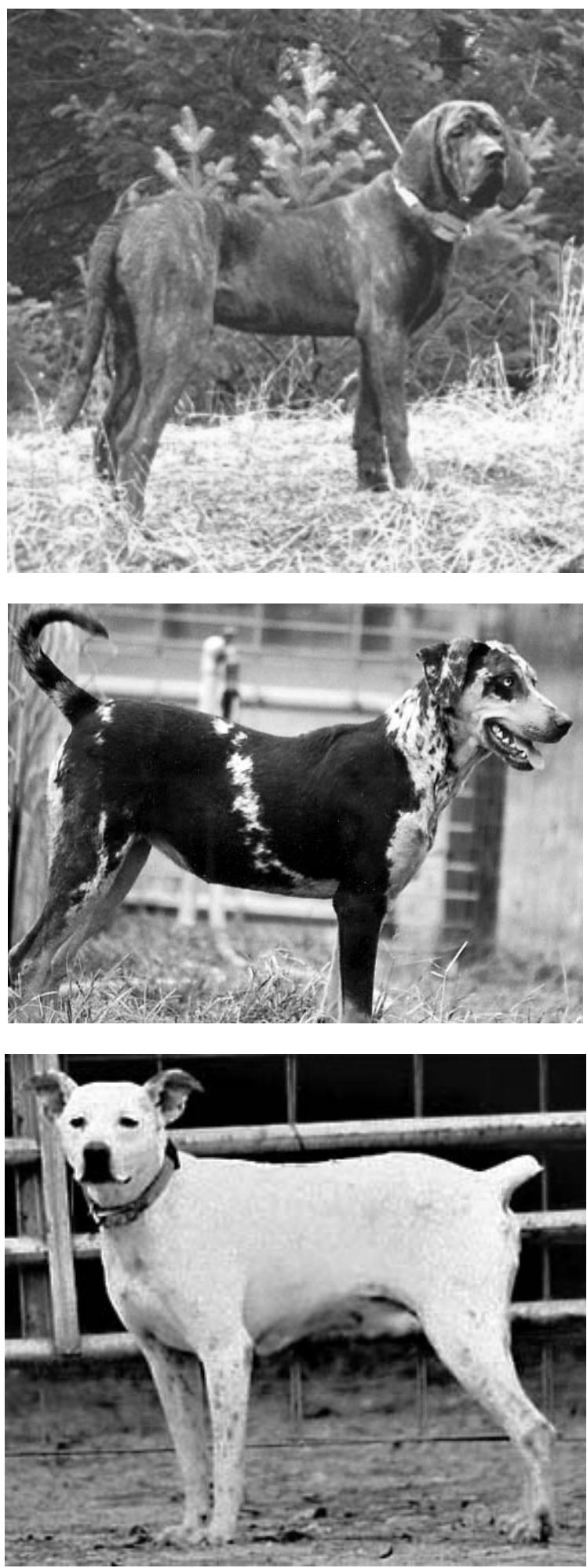

Fig. 1. Examples of a trail dog (top photo; Plott hound), a bay dog (middle photo; Catahoula leopard), and a catch dog (bottom photo; pitbull terrier). 

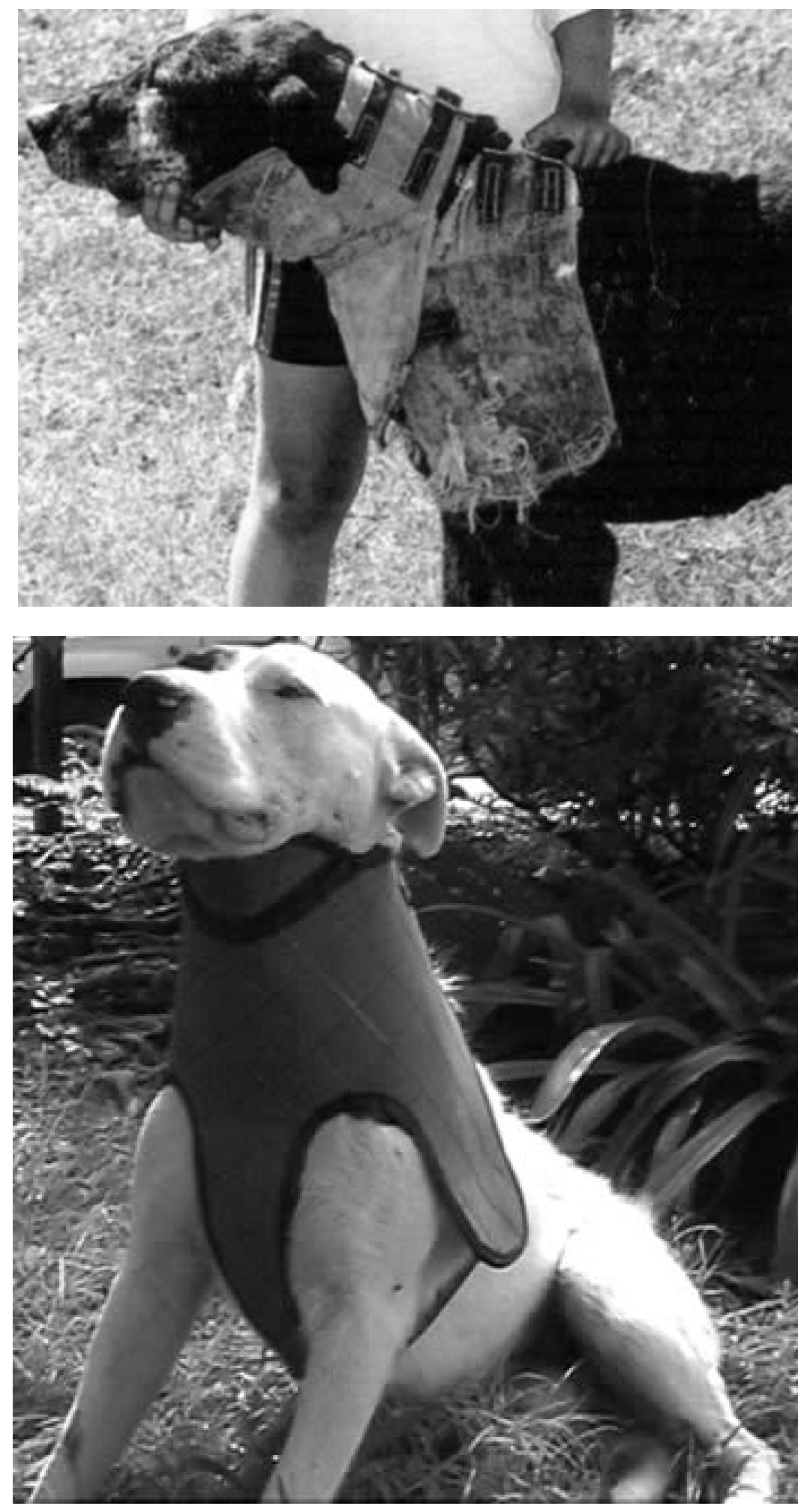

Fig. 2. Illustrations of cut vests used to protect hog dogs from being injured by wild pigs. 


\section{Wild Pigs}
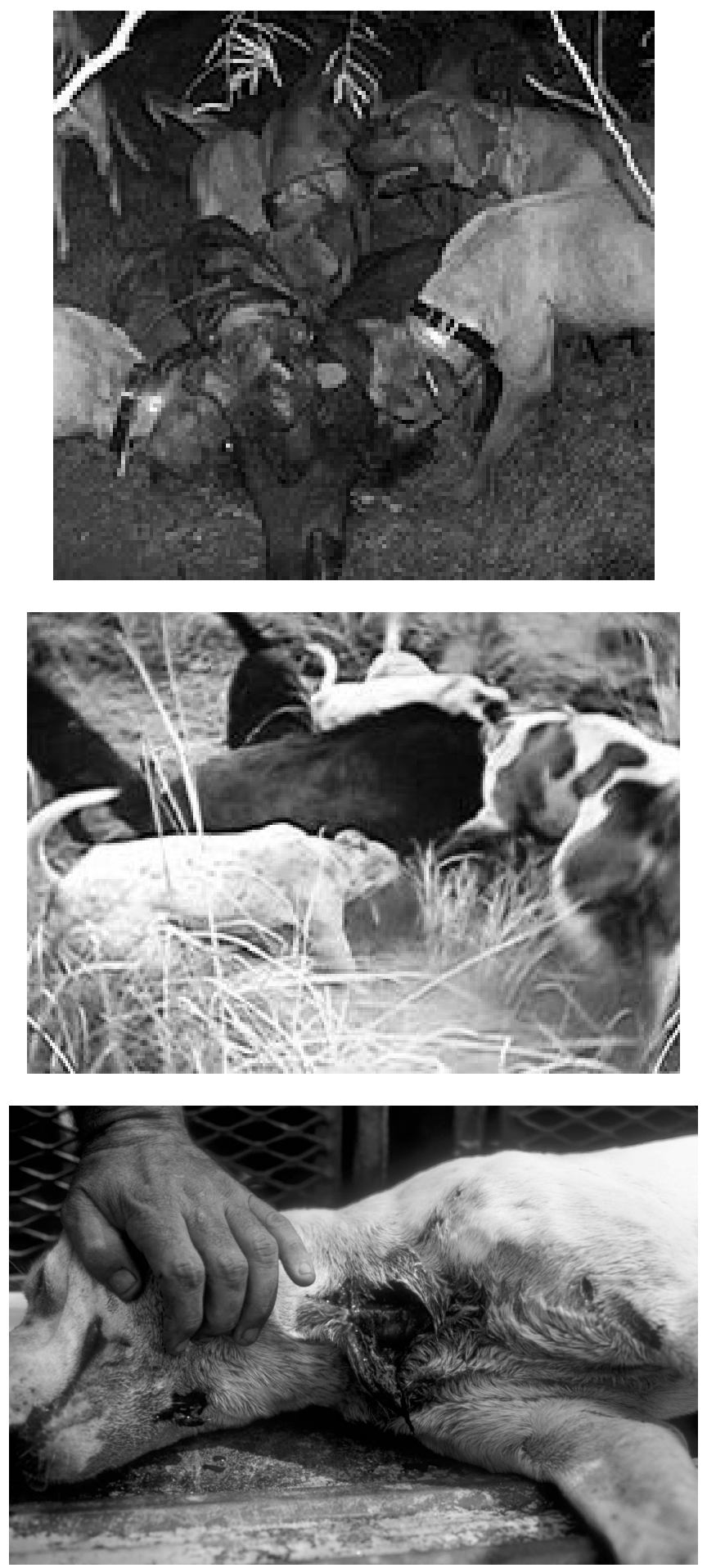

Fig. 3. Illustrations of wild pigs that have been "caught" by the catch dogs (top and middle photos), and injuries sustained by a catch dog, which in fact did live to hunt again (bottom photo). 
SRNL-RP-2009-00869

\section{Literature Cited}

Anonymous. 1978. The plundering pigs of the Smokies. National Parks and Conservation Magazine, 52(6):20-21.

1992. Dogs no longer catch hogs on Cumberland. Athens Banner-Herald, May 17.

Barrett, R. H., and G. H. Birmingham. 1994. Wild pigs. Pp. D65-D70. In S. E. Hygnstrom, R. M. Timm, and G. E. Larson (eds.), Prevention and control of wildlife damage. 2 volumes; Great Plains Agricultural Council, Univ. of Nebraska, Lincoln, Nebraska.

Barrett, R. H., B. L. Goatcher, P. J. Gogan, and E. L. Fitzhugh. 1988. Removing feral pigs from Annadel State Park. Transactions of the California-Nevada Section of the Wildlife Society, 24:47-52.

Blüchel, K. G. (ed.) 1997. Game and hunting. 2 Volumes. Konemann Velagsgesellschaft mbH, Köln, Germany.

Briedermann, L. 1986. Schwarzwild. VEB Deutscher Landwirtschaftsverlag, Berlin, Democratic Republic of Germany.

Caley, P. 1999. Feral pig: Biology and control in the Northern Territory. Agnote 554, No. J52. Agdex No. 440/91. Parks and Wildlife Commission of the Northern Territory, Australia.

Caley, P., and B. Ottley. 1995. The effectiveness of hunting dogs for removing feral pigs (Sus scrofa). Wildlife Research, 22(2):147-154.

Camp, R. R. (ed.) 1972. The new hunter's encyclopedia. $3^{\text {rd }}$ Ed. Stackpole Books, Harrisburg, Pennsylvania.

Capstick, P. H. 1990. Death in a lonely land: More hunting, fishing, and shooting on five continents. St. Martin's Press, New York.

Carr, R. 1996. The boar and the pig dog. Reed Publishing (NZ) Ltd., Auckland, New Zealand.

Choquenot, D., J. McIlroy, and T. Korn. 1996. Managing vertebrate pests: Feral pigs. Bureau of Rural Sciences, Australian Government Publishing Service, Canberra, Australia.

Clarke, C. M. H. 1991. Pig hunters and their dogs in the northern South Island, New Zealand: Characteristics and harvest efficiency. The New Zealand Geographer, 47(1):11-18.

1992. Visayan warty pig live-capture mission. Report to the Captive Breeding Specialist Group, Species Survival Commission, IUCN, The World Conservation Union. Apple Valley, Minnesota.

1993. The emerging role of elite New Zealand pig dogs for national and international pig control and conservation (abstract). Pp.52-53. In M. L. Augee (ed.), Abstracts of the Sixth International Theriological Congress, University of New South Wales, Sydney, Australia.

Coleman, S. 1984. Control efforts in Great Smoky Mountains National Park since 1978. Pp. 15-20. In J. Tate (ed.), Techniques for controlling wild hogs in the Great Smoky Mountains National Park. Proceedings of a workshop, November 29-30. Research/Resources Mgmt. Rpt. SRE-72. U. S. Department of the Interior, National Park Service, Southeast Regional Office, Atlanta, Georgia.

Conley, R. H., V. G. Henry, and G. H. Matschke. 1972. Final report for the European hog research project W-34. Tennessee Game and Fish Commission, Nashville, Tennessee.

Cuthbertson, K. 1968. Two dogs and a rifle. Reed Publishing (NZ) Ltd., Auckland, New Zealand. 


\section{Wild Pigs}

Dickson, J. G., J. J. Mayer, and J. D. Dickson. 2001. Wild hogs. Pp. 191-192, 201-208. In J. G. Dickson (ed.), Wildlife of Southern forests: Habitat \& management. Hancock House Publishers, Blaine, Washington.

Durham, M. 2009. On the cover. Connect: Association of Zoos \& Aquariums, July:1

Ellis, B. 1988. Hound dogs and tush hogs. Mississippi Outdoors, 51(6):10.

Elman, R. 1974. The hunter's field guide to the game birds and animals of North America. Alfred A. Knopf. New York, New York.

Humphrey, W. 1978. Home from the Hill. Dell Publishing Co., Inc., New York.

Ishikawa, K., Y. Eguchi, K. Uetake, and T. Tanaka. 2001. Domestic dog's behaviour in confrontation with wild boar - Utilization of dogs as aversive stimulus to wild boar. Animal Science Journal, 72(10):J594-J604.

Jones, P. 1959. The European wild boar in North Carolina. North Carolina Wildlife Resources Commission, Game Division, Raleigh, North Carolina.

Kessler, C. C. 2002. Eradication of feral goats and pigs and consequences for other biota on Sarigan Island, Commonwealth of the Northern Mariana Islands. Pp. 132-140. In C. R. Veitch and M. N. Clout (eds.), Turning the tide: The eradication of invasive species. IUCN SSC Invasive Species Specialist Group, International Union for the Conservation of Nature and Natural Resources, Cambridge, United Kingdom.

Land Protection. 2001. NRM Facts: Control of feral pigs declared. QNRM01278. Department of Natural Resources and Mines, The State of Queensland, Brisbane, Australia.

Littauer, G. A. 1993. Control techniques for feral hogs. Pp. 139-148. In C. W. Hanselka and J. F. Cadenhead (eds.), Feral swine: A compendium for resource managers. Texas Agricultural Extension Service, Kerrville, Texas.

Maillard, D. and P. Fournier. 1995. Effects of shooting with hounds on size of resting range of wild boar (Sus scrofa L.) groups in mediterranean habitat. Journal of Mountain Ecology (Ibex), 3:102-107.

Mapston, M. E. 2004. Feral hogs in Texas. Document No. B-6149 5-04. Wildlife Services, Texas Cooperative Extension, Texas A\&M University, College Station, Texas.

Mayer, J. J. 2005. Wild hog. pp. 372-377. In J. C. Kilgo and J. I. Blake (eds.), Ecology and management of a forested landscape: Fifty years on the Savannah River Site. Island Press, Corvela, California.

McGrail, J., and B. McGrail. 1969. The catch and the feast. Weybright and Talley, New York, New York.

McIlroy, J. C., and R. J. Saillard. 1989. The effect of hunting with dogs on the numbers and movements of feral pigs, Sus scrofa, and the subsequent success of poisoning exercises in Namadgi National Park, A.C.T. Australian Wildlife Research, 16(3):353-363.

McKenna, G. 1966. The killer boar. Pp. 118-121. In L. Koller (ed.), 101 hunting tips. Maco Publishing Co., Inc, New York, New York.

McNally, T. 1955. Too tough to squeal. Outdoor Life, 115(5):50-51, 111-115.

Milek, B. 1980. Rifles \& cartridges for North American game. Peterson Publishing Company, Los Angeles, California. 
O’Hanlon, J. 1987. Schutzhund: The working American Staffordshire Terrier. Pp. 40-48. In The American Staffordshire Terrier Annual. Hoflin Publishing Ltd., Wheat Ridge, Colorado.

Oliver, A. J., P. R. Marsack, P. R. Mawson, P. H. Coyle, R. D. Spencer, and K. R. Dean. 1992. Species management plan for feral pigs. Agricultural Protection Board, Government of Western Australia, Perth, Australia.

Ricciuti, E. R. 1976. Killer animals. Waller and Company, New York, New York.

Riddle, M. 1987. Dogs through history. Denlinger's Publishers Ltd., Fairfax, Virginia.

Rizaldi, (NFN), K. Watanabe, and A. Bakar. 2007. Communal hunting of wild boars (Sus scrofa) as a common practice in West Sumatra, Indonesia. Suiform Soundings, 7(1):25-30.

Saunders, G., and H. Bryant. 1988. The evaluation of a feral pig eradication program during a simulated exotic disease outbreak. Australian Wildlife Research, 15(1):73-81.

Schuyler, P. T., D. K. Garcelon, and S. Escover. 2002. Eradication of feral pigs (Sus scrofa) on Santa Catalina Island, California, USA. Pp. 274-286. In C. R. Veitch and M. N. Clout (eds.), Turning the tide: The eradication of invasive species. IUCN SSC Invasive Species Specialist Group, International Union for the Conservation of Nature and Natural Resources, Cambridge, United Kingdom.

Stevens, B. 1983. Dogs of velvet and steel. Pit bulls: A manual for owners. Herb Eaton Historical Publications \& Walsworth Publishing, Charlotte, North Carolina.

Stevens, R. L. 1996. The feral hog in Oklahoma. Samuel Roberts Noble Foundation, Ardmore, Oklahoma.

Tisdell, C. A. 1982. Wild pigs: Environmental pest or economic resource? Pergamon Press, New York.

Towne, C. W., and E. N. Wentworth. 1950. Pigs from cave to cornbelt. University of Oklahoma Press, Norman, Oklahoma.

Wendt, L. M. 1996. Dogs - A historical journey: The human/dog connection through the centuries. Howell Book House, New York.

Wooters, J. 1975. The Czar of swine. Pp. 62-64. In R. Elman and G. Peper (eds.), Hunting America's game animals \& birds. Winchester Press, New York.

Zwickel, F. C. 1980. Use of dogs in wildlife biology. Pp. 531-536. In S. D. Schemnitz (ed.), Wildlife management techniques manual. $4^{\text {th }}$ Edition. The Wildlife Society, Washington, D.C. 
Wild Pigs

\section{Control Techniques for Wild Pigs: \\ Efficacy of Shooting as a Control Method for Feral Hogs}

Doug M. Hoffman

USDA, APHIS, Wildlife Services, School of Forest Resources, Athens, GA 30602

\section{Introduction}

The mission of the U.S. Department of Agriculture's (USDA) Wildlife Services program is management of human-wildlife conflicts involving agriculture, health and safety, property and natural resources. USDA biologists respond to complaints involving feral hogs causing damage to crops; posing disease threats to livestock; threatening aircraft and automobile safety; damaging personal property; and negatively impacting threatened and endangered species. USDA provides assistance to resource owners in the form of technical guidance and direct implementation of proven management techniques. Federal and State wildlife agencies and private resource managers typically rely on trapping and hunting for maintenance of hog populations. I assessed the efficacy of shooting by trained personnel used as a primary method for reducing or eliminating localized hog populations.

\section{Methods}

Trained personnel with specific objectives have the potential to achieve significant harvest results in a relatively compressed time period when compared to recreational hunters. Personnel trained in shot placement can dispatch animals quickly and are capable of removing multiple hogs from a group with several well-placed shots. Hunting methods used in control operations range from stalking and stand hunting during daylight hours to use of specialized night vision equipment. Stalking allows personnel to cover extensive areas and search for habitats preferred by hogs. Walking slowly while scanning ahead enables the detection of animals and evaluation of activity. Hogs have an advanced olfactory sense, requiring planning stalking routes relative to wind directions. Stand hunting focuses on specific sites and limits the probability of encountering multiple animals.

Night vision equipment eliminates the need for continuous spotlighting which could spook hogs. Lights may be necessary for a short time to execute a shot, while advanced systems utilize laser sights to allow light-free shooting. The use of night vision is particularly effective in encountering specific animals that are suspected of frequenting sites nocturnally, rendering daytime efforts unsuccessful. Equipment is available in goggles, binoculars, monoculars and rifle scopes. The image quality is typically measured in Generations 1, 2 and 3. Generation 1 equipment produces minimal image clarity compared to Generation 3. Environmental conditions affect the ability of personnel using night vision to detect hogs. Dense vegetation offers more difficulty in detecting animals versus open areas like fields or beaches. Cost for night vision ranges from several hundred dollars for Generation 1 to several thousand dollars for Generation 3. Certain night vision and laser equipment is regulated and may be difficult for nongovernment resource managers to obtain. Hunting methods using night vision include shooting from stationary stands, stalking and use of vehicles and ATV's.

Aerial gunning involves the use of helicopters and fixed-wing aircraft equipped with a pilot and gunner flying at low altitudes in search of hogs. The success of aerial operations relies on large expanses of open habitat and has proven to be effective in Texas and Australia. Costs associated with aircraft rental in the U.S. range from $\$ 350$ to $\$ 650$ per hour for aircraft and pilot. 
SRNL-RP-2009-00869

The choice of firearms for lethal control of hogs depends on expected shot distance, vegetation density and hunting method. Animal weights may range from less than 10 pounds to over 300 pounds. Centerfire rifle calibers in .270 and larger loaded with moderate to heavy weight bullets (i.e. $\geq 130$ grains) will provide sufficient energy to effectively remove hogs of all sizes at long ranges. The use of shotguns in 12 gauge or larger bore loaded with buckshot or slugs is preferred by some shooters in dense vegetative cover where close range shooting is expected without advanced detection of animals.

\section{Results and Discussion}

Feral hog impacts to threatened and endangered plants and animals is common in the southeastern United States. Cumberland Island National Seashore, Georgia's southernmost barrier island, has a history of hogs dating back to the European settlers. The 34,000-acre island is an annual nesting site for several species of sea turtles. Since the National Park Service (NPS) began managing Cumberland Island's resources raccoon and hog depredation on sea turtle nests has been documented at levels exceeding 60\%. NPS contracted with USDA to assist with managing nest losses beginning in 2000. A USDA biologist utilized hunting during daylight hours and night vision to reduce local hog populations adjacent to turtle nesting areas. Intensive control efforts implemented for 43 days in 2001 and 19 days in 2002 resulted in the removal of 284 hogs. Sea turtle nest depredation rates went from $62 \%$ in 2000 to less than 5\% in 2002 . NPS began a hog eradication plan in 2003, including hiring a biologist to implement control methods. USDA continued assisting NPS in 2003 and 2004, with combined efforts resulting in the removal of over 600 hogs. Night vision has been instrumental in removing specific hogs depredating turtle nests. Trapping accounted for less than $20 \%$ of hogs removed from 2001 to 2004 . Public hunts have resulted in the removal of less than 100 hogs annually since 2000 .

Ossabaw Island, a 9,000-acre barrier island located off the Georgia coast near Savannah, also has a history of high hog populations and sea turtle nest depredations. The Georgia Department of Natural Resources (GADNR) requested USDA's assistance in 2000 prior to the onset of sea turtle nesting season. Seven USDA personnel removed 263 hogs by shooting over a 31/2-day period. GADNR hired a technician to continue hog management efforts with trapping and shooting after completion of USDA efforts. The island also has several public hunts annually.

USDA conducted a hog control operation for a major water treatment facility in west Georgia in 2002. Hog damage to nutrient recycling operations on this 1,000 -acre site had reached a level that the U. S. Environmental Protection Agency considered discontinuing operations until corrective actions were taken. Ten USDA personnel removed 101 hogs by shooting over a 4-day period. Follow-up measures involved removing an additional 32 hogs by trapping. Consultation with water treatment officials 1 year after the removal efforts revealed that no evidence of hogs had been noted.

Eglin Air Force Base, a 500,000-acre military site located in Florida, had growing concerns with hog damage to sensitive wetland areas. USDA initiated control efforts in 2003 and removed 341 hogs in 6 months. Trapping was the primary means of control (295 hogs removed). Shooting during daylight hours and at night with night vision equipment was utilized to remove hogs (46 hogs removed) from bombing ranges where unexploded ammo prevented use of traps. The Department of Defense has been pleased with the project and control efforts continue.

The USDA Wildlife Services program in Texas assists with managing hog populations causing damage to livestock and crops on multiple ranches encompassing large acreages. In 2003 USDA removed over 8,000 hogs in Texas with aerial shooting, snaring and trapping. Aerial shooting accounted for over 3,500 hogs, with snaring producing 3,100 hogs. One pilot logged 8 flights accounting for 24 hours flight time producing 466 hogs, equaling 19.4 hogs taken per hour.

\section{Management Implications}

Shooting by trained personnel can be effective in achieving significant population reduction in a short time period. However, successful control of feral hog populations relies on a resource manager's ability to utilize multiple control techniques in a variety of situations. Knowledge of hog biology and movement 


\section{Wild Pigs}

patterns in relation to food and water availability and habitat conditions is critical in planning a control operation. Feral hog reproductive capacity and mobility can present a challenge to resource managers in charge of large acreages. A comprehensive management plan incorporating trapping and shooting can be successful in maintaining low hog densities and possibly eradicate isolated hog populations altogether.

\section{Acknowledgments}

E. O’Connell, J. C. Griffin, B. R. Leland and J. B. Allen provided data on hog control projects, information on techniques and suggestions for the development of this manuscript. 
SRNL-RP-2009-00869

This page left blank intentionally 


\section{Control Techniques for Wild Pigs: \\ Contraception of Feral Pigs: A Potential Method for Population and Disease Control}

Lowell Miller, Gary Killian, Jack Rhyan, and Tommy Dees

USDA, APHIS, Wildlife Services, National Wildlife Research Center, 4101 LaPorte Ave, Ft. Collins, CO, 80521-2154, USA (LM and JR)

Almquist Research Center, The Pennsylvania State University, University Park, PA, 16802, USA (GK)

Bureau of Animal Disease Control, Florida Department of Agriculture and Consumer Services, Gainesville, FL, 32601, USA (TD)

\section{Introduction}

Overpopulation of feral swine raises concerns relating to damage of wild ecosystems and agricultural crops. Rooting and feeding behaviors can cause considerable damage to native vegetation as well as to forest plantings, row crops and pastures. Feral swine are also recognized as disease reservoirs for brucellosis and pseudorabies among other diseases, and their presence increases the risk of disease spread to other wildlife, domestic livestock and humans. Population reduction using contraceptives has the potential to reduce these disease concerns, since it appears that among feral swine, sexual activity and oral contact with reproductive discharges are the primary means of transmission of both brucellosis and pseudorabies.

The GnRH contraceptive vaccine has been studied in domestic and farm animals for potential as a nonsurgical castrating agent, and in swine to eliminate boar taint (Dunshea et al. 2001). In short-duration studies, GnRH vaccines have been evaluated as immunocastration agents in cattle (Adams and Adams 1992), horses (Rabb et al. 1990), and swine (Meloen et al. 1994, Oonk et al. 1998, Zeng et al. 2002, Miller et al. 2004b). Recently, we completed a long-term study using a GnRH vaccine on white-tailed deer, establishing its efficacy, safety and reversibility (Miller et al. 2000). Initial studies to test the contraceptive effect of the GnRH vaccine in pigs was performed in domestic pigs at Pennsylvania State University (unpublished). These studies demonstrated that the vaccine could contracept female pigs for up to three years (when the studies were terminated).

Effects of the GnRH on the male pigs were less consistent and did not last more than one year. Because of the encouraging results of the domestic pig study, the present study was undertaken to evaluate the effects of a single-shot GnRH vaccine on the reproductive physiology and contraception of male and female feral pigs (Sus scrofa).

\section{Materials and Methods}

The study was conducted on a farm near Gainesville, Florida. The site was a wooded area that included several outdoor pens to confine the feral swine. Wild pigs of unknown history were captured throughout Florida from January-March 2002 and brought to the study site for preliminary testing. Although no body weights were measured, estimates ranged from $7-32 \mathrm{~kg}$. Some pigs were obviously pregnant, and most were sexually mature, but some were immature at the start of the study. Initially, pigs were dewormed and tested for brucellosis and pseudorabies; positive reactors were eliminated from the study.

The GnRH vaccine was developed at the National Wildlife Research Center and has been used previously in white-tailed deer (Miller et al. 2000). A synthetic peptide of GnRH was conjugated to KLH and combined with AdjuVac ${ }^{\mathrm{TM}}$ adjuvant to prepare 1- $\mathrm{ml}$ vaccination doses. 
SRNL-RP-2009-00869

Pigs were segregated by sex and randomly assigned to two GnRH treatments, given as a single IM injection in the rump. Ten males and 9 females received $1000 \mu \mathrm{g}$ GnRH-KLH; 10 males and 9 females received $2000 \mu \mathrm{g}$ GnRH-KLH. Five males and 5 females served as untreated controls. On March 21, 2002, blood samples were taken and pigs were immunized. Males and females were segregated and also sorted into pens by large and small size. In mid-June 2002, approximately 12 weeks after immunization, blood samples were taken and males and females of all treatments were combined into two large breeding pens. Observations made throughout the study indicated some mounting and breeding activity. Females having litters during the 36-week study were recorded, as were those females that were pregnant at slaughter.

During the second week of December 2002, pigs were euthanized and blood and tissue samples were taken. Reproductive tracts were excised, and testes and ovaries were weighed. Pregnancy status of females was recorded. Blood serum samples were assayed for antibody titers and progesterone or testosterone concentrations as previously described (Miller and Killian 2001).

\section{Results}

Females given the $2000 \mu \mathrm{g}$ GnRH vaccine produced somewhat higher titers than those give the $1000 \mu \mathrm{g}$ GnRH dose 12 weeks after vaccination, but the $2000 \mu \mathrm{g}$ dose was clearly more effective in sustaining the antibody titer 36 weeks post-vaccination than the $1000 \mu \mathrm{g}$ dose. In contrast, the $1000 \mu \mathrm{g}$ GnRH vaccine in males was more effective in producing antibody titers at both 12 and 36 weeks than the $2000 \mu \mathrm{g}$ dose.

At slaughter, reproductive tracts were regressed and inactive in most of the GnRH vaccinated females, but not in the female controls. Regressed reproductive tracts appeared similar to those of pre-pubertal animals. Fully regressed testes were occasionally seen in the treated males, but intermediate stages of regression were most commonly observed in the treated males. Average weight of both ovaries at slaughter was similar for treated females, and less than controls. Mean weight of the testes in the treated males was less than the mean testes weight in control males. The decrease in weight was inversely proportional to the increase in antibody titer.

The ability of the GnRH vaccine to prevent pregnancy and furrowing prior to slaughter was evaluated by recording females who had litters during the 36-week study. Some of these females were pregnant at the start of the study based on their furrowing dates, whereas others became pregnant during the study. For purposes of treatment analysis, these observations are summarized as the number of females that did not give birth during the entire study and the number that were not pregnant at slaughter. As expected, all of the controls either gave birth during the study or were pregnant at slaughter. The $2000 \mu \mathrm{g}$ GnRH vaccine dose was very effective in preventing pregnancy. Only 1 of 9 treated females gave birth during the 36-week study and none of the female were pregnant at the time of slaughter. Of the females receiving the $1000 \mu \mathrm{g}$ GnRH vaccine, 5 of 9 gave birth during the 36-week period and 2 of 9 were pregnant at the time of slaughter, Some females were pregnant at the time of vaccination as evidenced by the time of farrowing. The higher vaccine dose may have prevented the further development of the fetuses, however, there were no aborted fetuses noted during the study. It is possible that in early pregnancy fetuses may have been reabsorbed.

Because of the cost of maintaining the wild pigs that study was terminated at 36 weeks. In a previous domestic pig study, however we have rendered female pigs infertile up to 3 years with a single GnRH injection. That study was terminated after 3 years because of the cost of maintaining the infertile pigs. Some may have been permanently infertile.

\section{Discussion}

GnRH as a Population Control Method - The present study demonstrated that the GnRH vaccine was effective in generating antibody titers in both male and female feral swine that altered several aspects of reproductive physiology. Effects included reduced ovarian and testicular weights, reduced plasma testosterone and progesterone concentrations, and reduced pregnancy rates in treated pigs compared to controls. The likely mechanism of action of the anti-GnRH titers produced by the vaccine is the inactivation of $\mathrm{GnRH}$ from the hypothalamus, and the resultant blockage of the normal stimulation of gonadotropic hormones, which regulate reproductive steroid and gamete production by the testes and 


\section{Wild Pigs}

ovaries (Miller et al. 2000). The effects we observed in the treated pigs in the present study are consistent with this mechanism of action.

In the context of contraception of feral swine, the most impressive results were obtained with the singleshot $2000 \mu \mathrm{g}$ GnRH vaccine given to the females. None of the females in this group were pregnant at slaughter, and only one of these females farrowed during the study. Because she farrowed in late November, we estimate she conceived in early August. Most of the females in the $2000 \mu \mathrm{g}$ group had reproductive tracts that were clearly regressed and ovaries that were inactive. Almost $80 \%$ of the females receiving the $1000 \mu \mathrm{g}$ GnRH vaccine were infertile at slaughter, whereas only about $45 \%$ remained infertile for the entire study. The differences observed between the two treatments are likely related to the greater anti-GnRH titers present at slaughter in the females receiving the $2000 \mu \mathrm{g}$ vaccine. It is noteworthy that while titers were similar between the two treatments 12 weeks after the vaccination, the titer was better sustained after 36 weeks in females receiving the $2000 \mu \mathrm{g}$ dose.

The physiological responses of males to the vaccine were generally less definitive than those observed in the females. The experimental design did not enable us to specifically test the fertility of individual males, because control and treated males were commingled with females. However, based on testicular weights taken at slaughter and serum testosterone values, we can make some inferences about the treatment effects on the males. Serum testosterone was clearly lower in both groups of treated males than in controls. Interestingly, reduction in testicular weight compared to the controls was greatest in males receiving the $1000 \mu \mathrm{g}$ treatment. This result is likely associated with higher anti-GnRH titers in the $1000 \mu \mathrm{g}$ vaccinetreated males throughout the study than in those receiving the $2000 \mu \mathrm{g}$ dose.

GnRH as a Disease Control Method - Evidence suggests that among feral swine sexual activity and oral contact with reproductive discharges are the primary means of transmission of both brucellosis (Anon. 1999) and pseudorabies (Romero et al. 2001). This is also the situation in the transmission of brucellosis in bison (Miller et al. 2004a). Our interest in evaluating GnRH as a disease control agent in both feral swine and bison is based on recent studies with deer, in which we demonstrated that both fertility and reproductive behavior are greatly diminished with the GnRH contraceptive vaccine (Miller et al. 2000).

In conclusion, this study has demonstrated that the single-shot GnRH vaccine was highly effective in reducing fertility of females during the 36-week period. Data from domestic pig studies at Pennsylvania State University suggest the contraceptive effect could last much longer; however circumstances prevented a longer study at the wild pig site. The vaccine also negatively impacted testis weight and serum testosterone in the males. These observations are significant in that most prior studies using GnRH vaccines required booster vaccinations to produce antibody titers sufficient to impair reproductive physiology. Longer studies will be needed to answer questions such as the long term duration of the contraceptive effects in free-ranging feral pigs. Future studies will be directed toward the development of an oral form of delivery for the $\mathrm{GnRH}$ vaccine to make it more practical for delivery in free-ranging feral pigs. 


\section{Literature Cited}

Adams, T. E., and B. M. Adams. 1992. Feedlot performance of steers and bulls actively immunized against gonadotropin-releasing hormone. Journal of Animal Science, 70:691-698.

Anonymous. 1999. Wild pigs: Hidden dangers for farmers and hunters. USDA-APHIS Information Bulletin No. 620.

Dunshea, F. R., C. Colantoni, K. Howard, I. McCauley, P. Jackson, K. A. Long, S. Lopaticki, E. A. Nugent, J. A. Simons, J. Walker, and D. P. Hennessy. 2001. Vaccination of boars with a GnRH vaccine (Improvac) eliminates boar taint and increases growth performance. Journal of Animal Science, 79:2524-2535.

Fagerstone, K. A., M. A. Coffey, P. D. Curtis, R. A. Dolbeer, G. J. Killian, L. A. Miller, and L. M. Wilmot. 2002. Wildlife fertility control. Wildlife Society Technical Review 02-2, Washington, D.C., USA.

Killian, G. J., L. A. Miller, J. Rhyan, T. Dees, D. Perry, and H. Doten. 2004. Evaluation of GnRH contraceptive vaccine in captive feral swine in Florida. Proceedings of the Wildlife Damage Management Conference, 10:128-133.

Miller, L. A., J. Rhyan, and M. Drew. 2004a. Contraception of bison by GnRH vaccine: A possible means of decreasing transmission of brucellosis in bison. Journal of Wildlife Diseases, 40:725-730.

Miller, L. A., J. Rhyan, G. J. Killian. 2004b. GonaCon, a versatile GnRH contraceptive for a large variety of pest animal problems. Proceedings of the Vertebrate Pest Conference, 21:269-273.

Miller, L. A. and G. J. Killian. 2001. Seven years of white-tailed deer immunocontraceptive research at Penn State University: A comparison of two vaccines. Proceedings of the Wildlife Damage Management Conference, 9:60-69.

Miller, L. A., B. E. Johns, and G. J. Killian. 2000. Immunocontraception of white-tailed deer with GnRH vaccine. American Journal of Reproductive Immunology, 44:266-274.

Meleon, R. H., J. A. Turkstra, H. Lankhof, W. C. Puijk, W. M. M. Schaaper, G. Dijkstra, C. J. G. Wensing, and R. B. Oonk. 1994. Efficient immunocastration of male piglets by immonuneutralization of $\mathrm{GnRH}$ using a new GnRH-like peptide. Vaccine, 12:741-6.

Oonk H. B., J. A. Turkstra, W. Schaaper, M. M. Erkens, M. H. Schuitemaker-deWeerd, A. van Nes, J. H. M. Verheijden, and R. H. Meloen. 1998. New GnRH-like peptide construct to optimize efficient immunocastration of male pigs by immunoneutralization of GnRH. Vaccine, 16:1074-1082.

Rabb M. H., D. L. Thompson, Jr., B. E. Barry, D. R. Colborn, K. E. Hehnke, and F. Garza, Jr. 1990. Effects of active immunization against GnRH on LH, FSH and Prolactin storage, secretion and response to their secretagogues in pony geldings. Journal of Animal Science, 68:3322-3329.

Romero, C. H., P. N. Meade, J. E. Shultz, H. Y. Chung, E. P. Gibbs, E. C. Hahn, and G. Lollis. 2001. Venereal transmission of pseudorabies viruses indigenous to feral swine. Journal of Wildlife Diseases, 37(2):289-296.

Zeng, X. Y., J. A. Turkstra, R. H. Meloen, X. Y. Liu, F. Q. Chen, W. M. M. Schaaper, H. B. Oonk, D. Z. Guo, and D. F. M. van de Wiel. 2002. Active immunization against gonadotrophin-releasing hormone in Chinese male pig: Effects of dose on antibody titer, hormone levels and sexual development. Animal Reproductive Science, 70:223-233. 
Wild Pigs

\section{Control Techniques for Wild Pigs:}

\section{Other Control Techniques for Wild Pigs}

John J. Mayer

Savannah River National Laboratory, Savannah River Nuclear Solutions, LLC, Savannah River Site, Aiken, South Carolina 29808

\section{Introduction}

The control techniques for wild pigs typically entail the use of methods for lethal removal. In the United States, the most commonly used lethal removal methods for the control of these invasive animals would include shooting, trapping and dogging (e. g., Coleman 1984, Barrett and Birmingham 1994, Stevens 1996, Mapston 2004). These techniques are also frequently used in other introduced as well as native portions of the species range (e.g., Diong 1973, Tisdell 1982, Briedermann 1986).

In spite of the prominent use of the three aforementioned techniques, other functional options are available for controlling wild pigs and the damage that these animals do. The most widely-used of these include exclusion, lethal removal and diversion methods. Exclusion simply entails the fencing out of wild pigs from areas to preclude the possibility of those animals causing damage or impacts there. The other lethal removal techniques include the use of toxins/poisons, Judas pigs and snaring to remove animals from the local population. Diversion consists of supplemental feeding to reduce the impacts on local economic or more important forage resources. All of these other methods have been shown to be useful in the control of wild pigs and their damage.

The purpose of this paper is to summarize the application of these additional techniques for controlling wild pigs and their damage. Each of these techniques will be addressed separately. This summary combines information from both a review of the literature as well as observations made by the author in the field.

\section{Results/Discussion}

Similar to the more commonly-used control techniques, these other alternatives can also be used as standalone options or in conjunction with a program employing several techniques. Another similarity among these various techniques is the list of advantages and disadvantages. Unlike the three popular lethal removal techniques, the application of these other control options tends to engage more issues or concerns with respect to extreme cost, public disapproval/objection, and legality. Such aspects can make these options difficult, if not impossible, to implement in some control programs.

Each of these other control techniques is addressed in the following paragraphs.

Fencing - The use of fencing to exclude wild pigs from areas of potential concern can be a very effective control technique to employ. However, with the requirement that such fencing must be "pig-proof," the cost of implementing this option (i.e., construction and maintenance) can be very high. This is especially true for fencing that encompasses a large area. For that reason, fencing is most practical to employ for excluding wild pigs from small areas (e.g., localized sensitive or fragile environments or habitats). Unfortunately, fencing seldom provides a permanent control, since wild pigs are persistent and will eventually find a way through almost any type of fence over time (Barrett and Birmingham 1994, Stevens 1996, Mapston 2004). Wild pigs will even aggressively charge an electrified fence to get through it (Land Protection 2001). In addition, such fencing is subjected to breaches caused by both manmade and natural incidents (e.g., vandalism, trees falling, washouts due to flash flooding, and vehicle collisions with the 
structure) that would enable wild pigs to cross the barrier. In general, Giles (1977) recommended that fencing be used in combination with other techniques for the control of wild pigs in an area.

A "pig-proof" fence is by definition a fence that will not allow a wild pig to cross either over, through, under or around the barrier. This requires that such a structure be tall enough (i.e., $90-100+\mathrm{cm}$ ), deep enough (i.e., $25-30+\mathrm{cm}$ ), and constructed of sturdy materials in such a manner so as to prohibit pigs from breaching the barricade (Fig. 1). The most successful fencing for excluding wild pigs includes a heavy/sturdy woven or mesh wire fence with the base buried in the ground in combination with one or more electric wires on the outside of the barrier (Littauer 1993, Barrett and Birmingham 1994, Stevens 1996, Caley 1999, Land Protection 2001, Mapston 2004). Even electric fencing constructed with just 1 to 3 strands of polywire will restrict wild pig movements compared to non-electric strand fencing (Reidy et al. 2008). Most successful fences incorporate woven/mesh fencing with two electrified wires, one 15 to $20 \mathrm{~cm}$ above the ground, and an earth wire just above the ground. That way, a pig trying to push under the fence will come in contact with both wires (Giles 1977). A single live wire can also be placed as an outrigger, approximately 20 to $30 \mathrm{~cm}$ above the ground and the same distance away from the fence. In very dry soil conditions, an earth wire may be positioned below the outrigger (Marsack 2000). Reidy et al. (2008) positioned the electrified strands above the ground in their study as follows: 1-strand $-20 \mathrm{~cm}$; 2 -strand -20 and $45 \mathrm{~cm}$; and 3-strand $-20,45$ and $71 \mathrm{~cm}$. Electric fencing for wild pigs should be energized to about 8,000 to 10,000 volts (Caley 1999). Existing plain or barbed-wire fences can be made pig-proof with the addition of one or more electrified wires (Marsack 2000). The primary challenge with electrical fencing is that it is difficult to maintain over large areas or long distances (Barrett and Birmingham 1994). Heavy posts (i.e., either metal or wooden) should be used to support a pig-proof fence. These posts should be spaced no more than $10 \mathrm{~m}$ apart, and even closer (1-5 m) if the terrain is rough (Barrett et al. 1988, Hone and Stone 1989, McGaw and Mitchell 1998, Caley 1999). Terrain is an important consideration with constructing pig-proof fencing. Canyons, creeks, ditches, etc. present problem areas in a proposed fence that wild pigs would be sure to find (Littauer 1993, Stevens 1996). Various designs for pig-proof fencing have been described (e.g., Tilley 1973, Hone and Atkinson 1983, Caley 1999, Vidrih and Trdan 2008).

The effectiveness of a pig-proof fence is related to how much is spent on erecting the structure, since research has showed that the most effective fences are also the most expensive (Land Protection 2001). Based on eight examples, the average cost of building pig-proof fencing is approximately $\$ 20-25,000$ per kilometer (Table 1). However, depending upon the terrain in the area being enclosed and the length of the proposed fence, the costs associated with this control method can be extremely prohibitive. Again, because of that, exclusion fences for wild pigs are most practical for use in protecting small areas. However, in some cases, such extreme costs may be justified to protect high-value agricultural crops or livestock, or in the event of a disease outbreak (Caley 1999, Marsack 2000).

To continue to be effective, the use of pig-proof fencing must be accompanied by diligent surveillance and maintenance. Fences need constant maintenance and vegetation must be regularly cleared from the vicinity of live wires to prevent short-circuits. Any breaches made by wild pigs through exclusion fencing should be repaired promptly before that path through the barrier becomes well established by the local animals. The most effective way to quickly remove pigs that have breached a fence and are still active within the enclosed area is to flush them out using dogs (Littauer 1993, Caley 1999, Marsack 2000). Similar to the cost of construction, the cost of fence surveillance and maintenance is not insignificant. Schuyler et al. (2002) reported that the annual of cost of maintenance and repairs for 24 kilometers of pig-proof fence on Santa Catalina Island, California, was $\$ 28,569$. Hone and Stone (1989) reported that one year of inspection and maintenance cost for 76 kilometers of pig-proof fence at the Hawaii Volcanoes National park was $\$ 25,000$.

Pig-proof fencing is most effective where construction and electrification take place before wild pig activity is well established in an area. Once pigs become accustomed to either traveling through or foraging in an area, such animals will be persistent in their attempts to breach a subsequently-erected fence line (Caley 1999, Marsack 2000, Land Protection 2001). For optimal effectiveness, electrified pig-proof fencing should be energized two to three weeks before the time when the pigs need to be excluded (e.g., prior a crop ripening or lambs being farrowed) (Giles 1977, Land Protection 2001). 
As stated previously, pig-proof fencing is generally not a practical control technique to employ for large areas. However, in certain instances, the use of fencing for expediting the lethal removal of wild pigs and then subsequently protecting large areas through exclusion is warranted. Such successful applications of this technique have been used for wild pig eradication in Annadel State Park, the Channel Islands and Pinnacles National Monument in California (Barrett et al. 1988, Sterner and Barrett 1991, McCabe 2001, Schuyler et al. 2002, National Park Service 2003). In all of these examples, the plan was to enclose a large area and then eradicate all wild pigs found in that enclosed area using lethal removal techniques (e.g., shooting, trapping, dogging). To ensure success using this method, thorough efforts should be taken to ensure that all pigs have been removed from the enclosed area (Giles 1977). Monitoring for wild pig sign after conclusion of the eradication program is the best way to corroborate the complete removal of all animals from the enclosed area.

The advantages and disadvantages for the use of fencing to exclude wild pigs are listed in Table 2.

Toxins/Poisoning - The use of toxins or poisons can be very effective for the lethal removal of wild pigs (e.g., Anon. 2001, Twigg et al. 2005, 2006). If properly used, poisoning can result in a rapid decrease in the targeted wild pig population. It is widely accepted as a control technique in Australia, especially in the rural communities (Choquenot et al. 1996). A variety of toxins, such as sodium monofluororacetate (Compound 1080), warfarin, yellow phosphorus (CSSP), organochloride insecticides and strychnine, have all been either tested or used in Australia for the control of wild pigs (Giles 1973, 1977, Hone and Pederson 1980, McIlroy et al. 1989, Choquenot et al. 1996). Sodium nitrite also has potential for use as an additional wild pig toxin (Cowled et al. 2008). Overall, campaigns using the aforementioned toxins have been generally successful in reducing the local numbers of wild pigs. In addition, studies have shown the use of toxicants is considerably cheaper than other control methods for wild pigs. Coblentz and Baber (1987) showed that poisoning with hidden baits would be eleven times cheaper than shooting and eighty times cheaper than trapping in terms of cost per pig removed. However, poisoning programs for wild pig control typically do not remove all of the animals in an area. Follow-up campaigns of more poisoning or other lethal removal techniques (e.g., shooting or dogging) are often required to get any residual animals (Giles 1973). The use of toxins can also encompass a versatility of application modes (e.g., ground or aerial). Where accessibility is limited, poisoning may be possible by utilizing aircraft to distribute the baits (Mitchell 1998).

Compound 1080, which is readily accepted by and effective on wild pigs (Hone and Kleba 1984), is the most common toxin used in Australia for the control of these animals. In fact, it is the only toxin recommended for use by the New South Wales Department of Agriculture. However, there are strict conditions for its use. Further, it can only be supplied by authorized government agents or vendors, and it is not available in the pure form to landowners (Giles 1977, Anon. 2001). Trials with 1080 were first conducted in New South Wales in 1973 (Choquenot et al. 1996). Vomiting is a common characteristic of 1080 poisoning in pigs. In various trials, vomiting occurred in between $20-98 \%$ of the pigs poisoned (McIlroy 1983, O'Brien 1988). Vomiting caused by 1080 poisoning can cause a secondary poisoning of a non-target species or result in non-lethal dosing of the target animals (Choquenot et al. 1996). Pigs surviving a sub-lethal dose of 1080 develop an aversion for the toxin, and are less susceptible to subsequent 1080 poisoning campaigns (O'Brien et al. 1986). Several anti-emetics (e.g., prochlorperazine, thiethylperazine and metoclopramide) have been tested to prevent vomiting after 1080 ingestion in pigs, but the results were inconclusive (Hone and Kleba 1984, Rathore 1985, O’Brien et al. 1986). The $\mathrm{LD}_{50}$ values for ingestion of 1080 during trials have varied from 1.03 up to $4.11 \mathrm{mg} / \mathrm{kg}$ live weight (Sheehan 1984, O'Brien 1988). This variation probably occurred because of differences in ambient temperatures occurring during the trials and different indices of vomiting by the pigs (Choquenot et al. 1996). One of the specific disadvantages of this compound is that it is highly toxic to canids. In addition, it is relatively quick acting and there is no antidote. Possibly due to the vomiting response, mortality after poisoning has been unacceptably low in some field situations (O'Brien et al. 1986).

Warfarin is an anticoagulant that is highly toxic and acceptable to wild pigs. It is relatively slow acting and has an effective antidote. However, to be effective, warfarin must be provided for an extended period of time (O'Brien et al. 1986, Choquenot et al. 1996). When used in such an extended poisoning campaign, the mortality rates in local populations have reportedly been very high (e.g., 87-94\%) (Hone and Kleba 1984, 
Hone 1987, Mcllroy et al. 1989). Hone and Stone (1989) reported a significant decrease at several sites in the Australian Capital Territory, where warfarin had been tested for use as a toxin for wild pigs. Warfarin has a latent period (i.e., initial exposure to mortality) of from 4-17 days in the wild (Hone and Mulligan 1982, Mcllroy et al. 1989). Penned studies have had a slightly more rapid onset of toxicity (e.g., 5-10 days) (Hone and Kleba 1984). Warfarin has an $\mathrm{LD}_{50}$ of $2.9 \mathrm{mg} / \mathrm{kg}$ live weight (O'Brien and Lukins 1990). Saunders et al. (1990) found that toxin residues declined over time in a 57-day poisoning campaign with warfarin, indicating that the potential for secondary poisonings was not an issue over extended periods. In addition, Poche (1998) reported that studies on wildlife indicated that secondary poisonings were not an issue with the use of warfarin. In spite of its potential, warfarin has not been registered for routine use in Australia. Issues with the slow death that occurs with anticoagulants and the impact on non-target species have been the primary animal welfare and environmental concerns, respectively (Choquenot et al. 1996).

CSSP is a yellow phosphorus-based pesticide that contains $4 \%$ active phosphorus. CSSP has been documented to be effective in killing wild pigs during poisoning campaigns. It is manufactured and widely used as a wild pig toxin in parts of eastern Australia. Its popularity is largely because of convenience, in that it can be purchased in quantity, stored for extended periods, and then used at some later date. Other toxins used on wild pigs (e.g., 1080) cannot be stored for later use (Choquenot et al. 1996). The $\mathrm{LD}_{50}$ for CSSP in pigs is $5.3 \mathrm{mg} / \mathrm{kg}$ live weight (O'Brien and Lukins 1990). With very large doses, wild pigs can die from shock within 6-12 hours of ingestion. If the dose is lower, animals may survive for a several days before dying from liver necrosis and heart failure. Most pigs die 2-4 days after ingestion. However, in some cases there may be a delay of up to 3 weeks before death occurs. Similar to warfarin, CSSP is considered to be less humane than 1080. During the time in which yellow phosphorus takes to kill, the animal experiences distress, disability and/or pain (Anon. 2001, Sharp and Saunders 2004).

The sequence for application of this technique is typically just a three-step process. First, the application site and the bait must be chosen. The site must have a sufficient wild pig density and level of activity to enable the majority of animals to find the bait. Similar to trapping, this would entail both looking for fresh pig sign (e.g., tracks, scats, wallows, rooting) and focusing on areas that wild pigs typically frequent (e.g., near permanent water or dense cover along drainage corridors). Again, with a similarity to trapping, the bait selected must be readily recognized by/attractive to the local animals. Baits typically include either grain or bran/pollard pellets impregnated with the poison. Such pellet baits are sometimes more readily accepted by pigs in areas where grain is not available (Giles 1977). Other materials such as high-protein content floral matter and meat have also commonly been used as baits (Giles 1973). The success of this technique depends upon the pigs being able to find the bait and then consume a sufficient amount to ingest a lethal dose. Careful selection of the bait can also preclude the unintentional poisoning of non-target species. Next, the area targeted for the poisoning campaign should be pre-fed with unpoisoned bait several days prior to the placement of the poisoned bait. One then waits until the pigs locate and consume the bait. Finally, once the pigs are consistently consuming the unpoisoned bait, it is replaced completely with the poisoned bait. When a free-feeding routine is established for the wild pigs in an area, these animals will feed regularly and keep non-target species away (Anon. 2001).

The specific placement of the bait can also be used to reduce the potential impacts on non-target species. Since pigs are one of the few animals that will dig up bait (Anon. 2001), it can also be placed in holes and lightly covered with soil, or completely buried just below the surface (McIlroy 1983). Some baits can be laid in furrows, while others can be placed at bait stations. When used in livestock areas (e.g., with cattle, sheep and horses), stock-proof enclosures can be constructed around the bait stations to allow pigs to enter, but exclude the other species of livestock (Giles 1977). A novel bait designed for wild pigs (i.e., PIGOUT $\left.{ }^{\circledR}\right)$ has also been developed and showed promise for effectiveness and reduced impacts to nontarget species (see Smith et al. 2005, Cowled et al. 2006a, 2006b).

Toxicants cannot currently be legally used for wild pig control in the U.S. and none are registered for that use at this time. The cost for the development and licensing of such a toxicant could be prohibitive. Problems associated with reducing impacts to non-target species and data registration compliance with the U. S. Environmental Protection Agency would significantly add to the cost. The estimated registration costs alone for a single chemical toxicant for wild pigs would range from $\$ 500,000$ to $\$ 3,000,000$ or more (Littauer 1993). 


\section{Wild Pigs}

The advantages and disadvantages for the use of toxins/poisons to control wild pigs are listed in Table 2.

Judas Pig Technique - Being highly social animals, solitary feral goats (Capra hircus) will actively seek groups of conspecifics to join up with. Because of this driven innate behavior, a control technique, referred to as the "Judas goat" method, was developed, which entails the use of individual feral goats fitted with radio collars to betray the locations of goat herds to facilitate shooting success (Taylor and Katahira 1988). Also being social animals, wild pigs have been suggested as candidates for the use of this technique (Pech et al. 1992, McIlroy and Gifford 1997). In contrast, Soule (1990) considered this technique inappropriate for use on pigs since these animals were not as gregarious as goats. In spite of that difference, both Bryan (1994) and Wilcox et al. (2004) found the Judas pig technique to be useful for eradicating small localized numbers of wild pigs. Wilcox et al. (2004) recommended that it be used in conjunction with other proven lethal removal techniques.

As described above, this technique entails fitting individual wild pigs with radio collars, and then releasing those animals back into the source population. After allowing the collared animals a sufficient amount of time to reestablish themselves within the social structure of the local population (e.g., one or more weeks), the animals are located using the telemetry equipment, and then personnel approach the location as close as possible and shoot any other wild pigs found in association with the transmittered animal. The Judas pig is then allowed to escape and the process is repeated at some periodic interval. In addition to shooting, one can also use trained hunting dogs to catch pigs that are found with the Judas animal. Once the eradication program has been completed, the Judas pig then is located and killed, and the radio collar is retrieved. A complete protocol for the application of the Judas pig technique for controlling wild pigs was described by Sharp and Saunders (2002). Trials evaluating the Judas pig technique to remove wild pigs have included both sexes, as well as immature and mature animals (e.g., McIlroy and Gifford 1997, Wilcox et al. 2004). The use of adult sows from within the targeted population is preferred for the Judas technique. Both wild pigs relocated from other areas and mature males took longer to contact other pigs and then only associated with them infrequently. Immature animals were also less effective in that they are often excluded from joining other family groups and tend to form temporary groups on their own (Sharp and Saunders 2002). It is also wise to sterilize matures females that are released as Judas pigs so that they do not continue to contribute to population recruitment. Wilcox et al. (2004) found that using the Judas pig technique, the transmittered pigs could be located in less than one hour.

A modification of this concept was used at the Savannah River Site in South Carolina in conjunction with the site's wild pig subcontract trapping program. A mature sow was captured in a large corral trap. That animal was ear-tagged and then kept in the trap enclosure for about two weeks with the door tied shut. The animal was fed and watered daily. The sow was then released from the trap, and the door was tied open. Food was provided in the open trap daily. After one week, the trap was set, and the next day, the tagged sow was captured along with several other pigs. The other animals were then killed and the tagged sow was released. The process was then repeated again. In over $70 \%$ of the subsequent captures in that trap, the tagged sow was present with other pigs. It was assumed that the sow joined with other pigs, and then led these animals back to the baited trap. This technique was used successfully for almost three months, after which time the sow did not return to the trap and was not seen again.

The advantages and disadvantages for the use of the Judas pig technique to control wild pigs are listed in Table 2 .

Snaring - Snaring is an age-old trapping method for animals (Bateman 1973) that can be effective for the removal of individual wild pigs. Snaring is very low in cost (i.e., equipment and manpower) compared to almost all other techniques used to control wild pigs. It is the single most important control technique used by the Texas Animal Damage Control Service (TADCS) in the sheep and goat producing areas of the state. Between 1983 and 1992, 55\% of the total number of wild pigs removed by TADCS was taken through the use of snares (Littauer 1993). Stone and Anderson (1988) reported that snares were used extensively for wild pig control in the Kipahulu Valley in Hawaii. Between March 1986 and January 1988, a total of 204 pigs were removed during 935,046 snare nights (i.e., 4,584 snare nights/pig). Muir and McEwen (2007) reported that snares had been more successful than either dogging or shooting in removing wild pigs from 
grain production areas in central Texas. In contrast, Coblentz and Baber (1987) reported that snares were ineffectively and costly compared to either shooting or baiting (poisoning) for removing pigs on Isla Santiago in the Galapagos.

The primary issue with the use of snares is the concern about the humanity of potentially slow strangulation over time as an acceptable lethal removal technique for pigs (Kaser 1993, PETA 1993). In addition, the potential also exists for snares to either kill or injure non-target species of livestock, pets or wildlife (Littauer 1993, Mapston 2004). Because of these issues, the use of snaring to remove wild pigs has been met with public opposition in some areas (Anderson and Stone 1993, Jeffery 1999).

A snare is basically a loop of steel cable, which is attached to a secure anchor point, and then placed in a location so that the loop catches the pig around the neck or base of the head as it passes through a small opening (Fig. 2). A snare is typically constructed of 3/32- or 1/8-inch aircraft-quality galvanized steel cable, with a locking device, which allows the loop to close but not easily open. The locking device can made out a heavy duty washer, angle bracket or small piece of angle iron. Commercial locking devices are also available (Littauer 1993). A swivel can also be incorporated into the snare to increase its effectiveness (typically at the base of the loop). The loop can also be connected to a 1-2 m long extension cable. The base end of the snaring device is then anchored to a tree, steel stake driven into the ground, or a drag. A suitable drag can be an uprooted stump, large log or similarly heavy object (Littauer 1993). Do not anchor the snare to a fence.

Snares are normally placed at fence crossings or trails that are used by wild pigs. Typically, the fence crossings are arches in the fence's wire mesh created by pigs lifting up and deforming the structure (Fig. 2). The loop of the snare is suspended from the upper wire of the opening with either U-shaped wire clips or small gauge copper wire. The loop is then positioned to encompass the opening. In trail sets, the loop (approximately $25-30 \mathrm{~cm}$ in diameter) is positioned about $18-20 \mathrm{~cm}$ off of the ground. Vegetation or other objects adjacent to the trail are used to suspend the snare loop. Fence snares are typically anchored to stationary objects, while trail snares are anchored to drags (Littauer 1993). The lack of defined trails or fence crossings can severely limit the usefulness of this technique (Kessler 2002).

Variations in the use the snare concept to catch wild pigs have also been reported. Barrett and Birmingham (1994) noted that leg snares could be used to catch pigs. The use of Aldrich spring-activated foot snares for wild pigs has also been reported, although without much success (Fox and Pelton 1977). Diong (1973) described the use of wire snares set over pits covered with metal plates attached to a triggering device to catch wild pigs in Malaysia. Kessler (2002) described a foot snare tied to an elastic tree branch and baited with split coconuts that was effective. Kodera (2005) reported the successful use of leg snares for the live capture of wild pigs for a survival analysis.

The advantages and disadvantages for the use of snares to control wild pigs are listed in Table 2.

Supplemental Feeding - Supplemental feeding has been widely used in Europe in attempts to divert wild pigs away from agricultural crops that could be damaged (Wilson 2005). The amount of wild pig damage to such agricultural fields is largely dependent upon the concurrent availability of local natural foods. When such natural foods (e.g., mast) are scarce, the impacts to agricultural crops increase (Mackin 1970, Andrzejewski and Jezierski 1978, Genov 1981). Therefore, these authors all advocated the use of supplemental feeding as a way to reduce crop damage by these animals. In contrast, other studies have suggested that this technique does not significantly reduce damage (Geisser et al. 1998) and may actually increase it (Groot Bruinderink et al. 1994). Vassant (1994) reported that, while supplementary feeding with corn in adjacent woodlands reduced the wild pig damage to local wheat fields by $70 \%$, the cost of that effort was very high. In comparing hunting, supplemental feeding and electrified fencing as ways to reduce wild pig crop damage, Geisser and Reyer (2004) found that hunting was the only effective method to employ. However, carefully targeted supplemental feeding during specific periods of vulnerability of highvalued crops may be appropriate in some circumstances (Wilson 2005).

Supplemental feeding can be in the form of either planted food plots or established feeding stations. Both agricultural crops (e.g., corn, grains/cereals and peanuts) and natural foods (e.g., grasses, clovers) can be 


\section{Wild Pigs}

used. Food plots are typically "sacrificial" crops that are planted away from the fields that are to be protected. Vassant (1994) noted that these were less successful at reducing damage than feeding stations. Supplemental feeding stations can entail of the use of stationary feeders (e.g., troughs or mechanical feeders) or broadcasting feed on the ground. Feeding stations should be located within natural areas and away from the vulnerable agricultural fields in an effort to keep the wild pigs finding and damaging the crops in question (Goulding et al. 1998).

In contrast to its use as a method to reduce crop damage, supplemental feeding also has the potential to increase the reproductive output and size of a wild pig population. For example, Nedzel'skii (2007) reported that supplemental winter feeding increased the reproductive output of female wild boar in the Russian Federation. This effect further increased with the age of the sow. In addition to increasing the carrying capacity in an area, supplemental feeding may also improve the survival of wild pigs (Wilson 2005). In areas where eradication of the local wild pig population is being undertaken, supplemental feeding efforts to reduce crop damage may be counterproductive.

The advantages and disadvantages of using supplemental feeding to control wild pig damage are listed in Table 2.

\section{Summary}

The other control techniques for exclusion, lethal removal or diversion of wild pigs described in this report provide more versatility for land and resource managers dealing with this destructive invasive species. Although neither these other techniques nor the more-commonly used methods (i.e., shooting, trapping and dogging) represent guaranteed options for successfully controlling wild pigs, collectively these alternatives can be used to manage the numbers of and damage done by these animals over time.

Each of these control techniques is best suited to use in certain situations or circumstances. With that in mind, these other options may work for a specific situation in which the standard techniques would not. For example, the Judas pig technique may enable the removal of wary remnant pigs that have survived excessive harvest pressure during a disease outbreak control program. Erecting pig-proof fencing may be the best manner in which to protect a small colony of endangered floral species from wild pigs that have been difficult to control through lethal removal.

A successfully-implemented management program for controlling wild pigs must be both flexible and adaptable in dealing with the changes that one encounters in both the behavioral and population parameters of a wild pig population over time. The strategic use of a single control technique or combination of various techniques at the right time will ensure that success. 
Table 1. List of the actual or estimated costs of installing fencing to exclude wild pigs. For each example, the costs are given in US dollars per kilometer.

\begin{tabular}{|c|c|c|c|}
\hline \multirow{2}{*}{ Location } & \multicolumn{2}{|c|}{ Cost (\$US per km) } & \multirow{2}{*}{ Reference } \\
\hline & Actual & Estimate & \\
\hline Anabelle State Park, CA, USA & $\$ 8,182^{\mathrm{a}}$ & & Barrett et al. 1988 \\
\hline Northern Territory, Australia & $\$ 2,100$ & & Caley 1999 \\
\hline Savannah River Site, SC, USA & & $\$ 45,000^{\mathrm{a}}$ & $\begin{array}{l}\text { L. L. Eldridge, pers. } \\
\text { comm. }\end{array}$ \\
\hline Australia & $\$ 2,500$ & & $\begin{array}{l}\text { Hone and Atkinson } \\
1983\end{array}$ \\
\hline $\begin{array}{c}\text { Hawaii Volcanoes National } \\
\text { Park, HI, USA }\end{array}$ & $\$ 14,000-24,000$ & & Hone and Stone 1989 \\
\hline Santa Cruz Island, CA, USA & $\$ 27,818^{a}$ & & $\begin{array}{l}\text { Kelly 2002, McCann } \\
\text { and Garcelon } 2008\end{array}$ \\
\hline $\begin{array}{c}\text { Natural Conservancy lands, HI, } \\
\text { USA }\end{array}$ & & $\$ 21,700-31,000^{\mathrm{a}}$ & Leone 2001 \\
\hline $\begin{array}{c}\text { Pinnacles National Monument, } \\
\text { CA, USA }\end{array}$ & $\$ 47,619^{a}$ & & $\begin{array}{c}\text { McCann and Garcelon } \\
2008\end{array}$ \\
\hline Santa Catalina Island, CA, USA & $\$ 36,439^{a}$ & & Schuyler et al. 2002 \\
\hline $\begin{array}{c}\text { Hawaii Volcanoes and } \\
\text { Haleakala National Parks, HI, } \\
\text { USA }\end{array}$ & $\$ 6,820-28,500$ & & $\begin{array}{l}\text { Stone and Anderson } \\
1988\end{array}$ \\
\hline
\end{tabular}




\section{Wild Pigs}

Table 2. List of advantages and disadvantages of employing fencing, toxins/poisons, Judas pig, snaring and supplemental feeding as wild pig control techniques.
Control Technique
Advantages
Disadvantages

Fencing

Toxins/Poisons

Judas Pig

Snaring
- Can be very effective, especially for smaller areas

- Low impact on non-target species

\section{May impede movement of non-target species}

- Requires constant maintenance

- Does not eliminate problem; merely shifts the location of the impacts

- Fences will eventually be breached

- Not practical for large-scale control

- Difficult to construct and maintain fencing in terrain with steep slopes (e.g., hills, ravines and gullies)

- Potential for primary poisoning of non-target species through ingestion of poisoned bait

- Proven lethal removal technique for wild pigs

- Widely accepted in rural communities in Australia for wild pig control

- Fast and effective initial removal of individuals from a population

- Can facilitate the ability to locate sparsely distributed or wary wild pigs that are difficult to find by other means

- Can assist in the eradication of small localized populations of wild pigs

- Can assist in the eradication of remnant survivors of previous control campaigns

- Inexpensive to implement and operate
Potential for secondary poisoning

of non-target species through ingestion of the carcasses of poisoned pigs

- Ingestion of non-fatal doses will reduce the number of pigs removed

- Development and registration of a new toxicant is expensive

Some toxins are considered to be inhumane, taking several days to kill, during which time the animal experiences distress, disability and/or pain

Unknown general level of effectiveness

- Requires expensive equipment and skilled personnel to implement

- Not effective to use for eradication of large populations of wild pigs

- $\quad$ May not be useful if animals are remaining in dense cover

- Can kill or injure non-target species 
Table 2. List of advantages and disadvantages of employing fencing, toxins/poisons, Judas pig, snaring and supplemental feeding as wild pig control techniques. (Continued)

\begin{tabular}{|c|c|c|}
\hline Control Technique & Advantages & Disadvantages \\
\hline Snaring (cont.) & $\begin{array}{c}\text { - } \quad \text { Can be very effective if properly } \\
\text { set }\end{array}$ & $\begin{array}{l}\text { - Strangulation is considered by some } \\
\text { to be an inhumane manner in which } \\
\text { to kill an animal } \\
\text { - } \quad \text { Large pigs can occasionally break } \\
\text { snares and escape } \\
\text { Only one pig can be caught at a } \\
\text { time } \\
\text { - Inappropriate for areas where fence } \\
\text { crossings or trail sets cannot be } \\
\text { used } \\
\text { If pigs are only using one fence } \\
\text { crossing to access a damage area, } \\
\text { eradication can take a considerable } \\
\text { period of time } \\
\text { Lack of defined pig trails and fence } \\
\text { crossings can limit the effectiveness }\end{array}$ \\
\hline Supplemental Feeding & $\begin{array}{l}\text { - Can locally reduce damage to } \\
\text { economically important crops } \\
\text { - May also benefit other species of } \\
\text { wildlife }\end{array}$ & $\begin{array}{l}\text { Can be costly to successfully } \\
\text { implement } \\
\text { - } \quad \text { Can result in an increase in the } \\
\text { local wild pig population } \\
\text { - May be ineffective at significantly } \\
\text { reducing damage }\end{array}$ \\
\hline
\end{tabular}



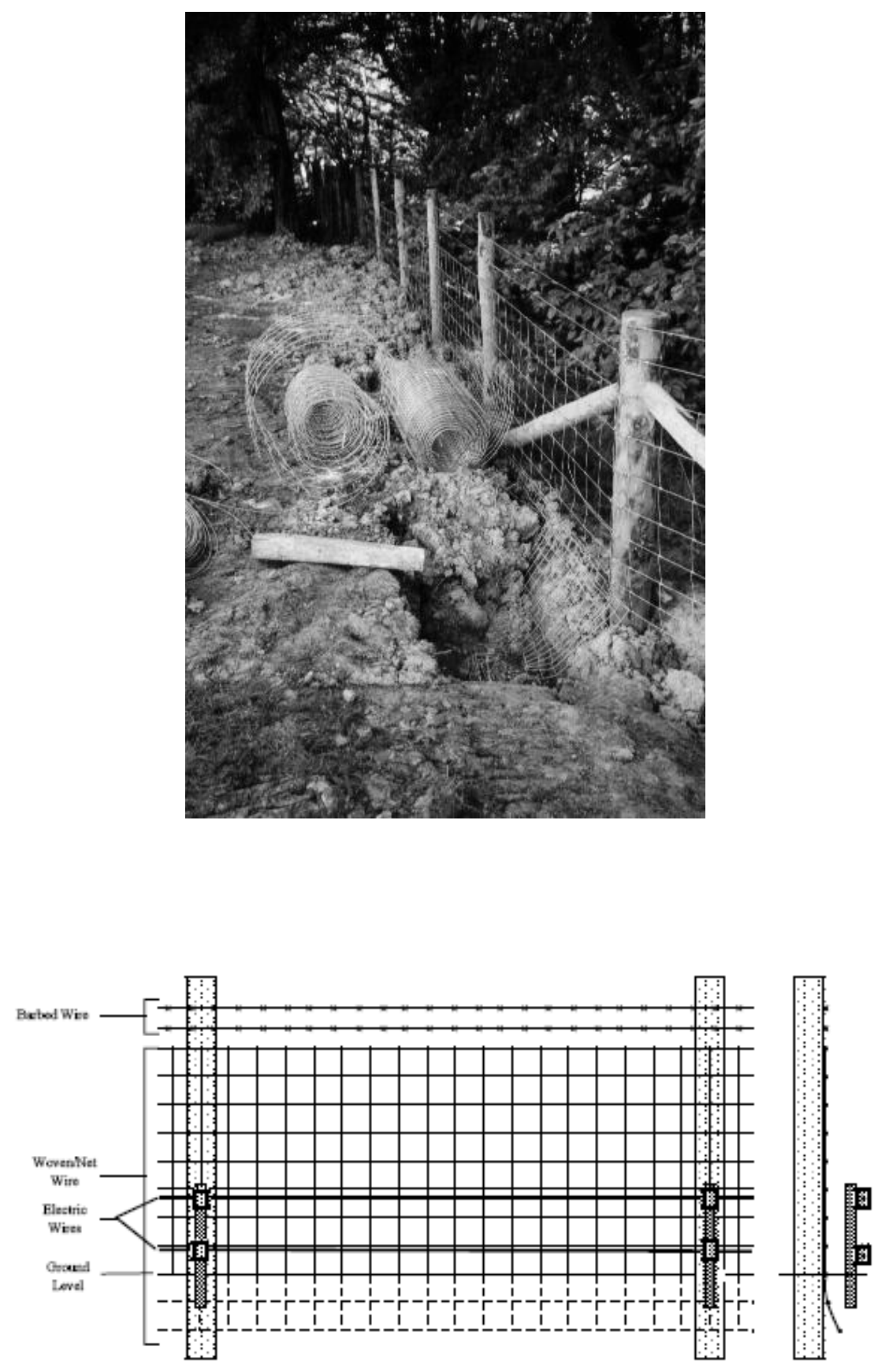

Fig. 1. Illustration of pig-proof fencing being installed (top) and schematic of components of pig-proof fence (bottom). 

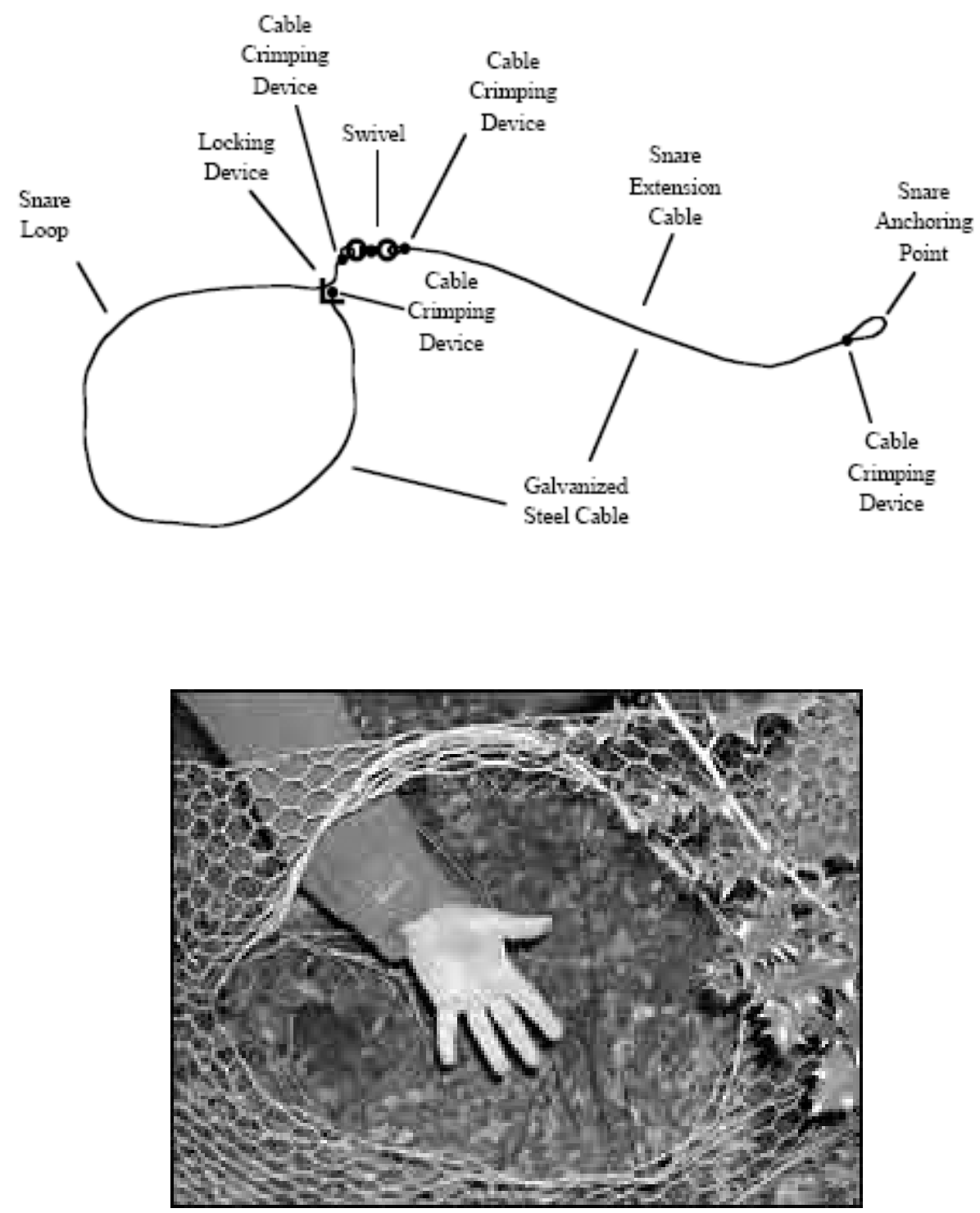

Fig. 2. Illustration of a snare for removing wild pigs (top) and the location in a fence crossing used by wild pigs where the snare should be placed (bottom). 


\section{Wild Pigs}

\section{Literature Cited}

Anderson, S. J., and C. P. Stone. 1993. Snaring to control feral pigs Sus scrofa in a remote Hawaiian rain forest. Biological Conservation, 63(3):195-201.

Andrzejewski, R., and W. Jezierski. 1978. Management of a wild boar population and its effects on commercial land. Acta Theriologica, 23(19):309-339.

Anonymous. 2001. Control of feral pigs. NRM Pest Fact PA7, Agdex 670, Department of Natural Resources and Mines, The State of Queensland, Brisbane, Australia.

Barrett, R. H., and G. H. Birmingham. 1994. Wild pigs. Pp. D65-D70. In S. E. Hygnstrom, R. M. Timm, and G. E. Larson (eds.), Prevention and control of wildlife damage. 2 volumes; Great Plains Agricultural Council, Univ. of Nebraska, Lincoln, Nebraska.

Barrett, R. H., B. L. Goatcher, P. J. Gogan, and E. L. Fitzhugh. 1988. Removing feral pigs from Annadel State Park. Transactions of the California-Nevada Section of the Wildlife Society, 24:47-52.

Bateman, J. A. 1973. Animal traps and trapping. Stackpole Books, Harrisburg, Pennsylvania.

Briedermann, L. 1986. Schwarzwild. VEB Deutscher Landwirtschaftsverlag, Berlin, Democratic Republic of Germany.

Bryan, R. 1994. Feral pigs in the red centre. Australian Ranger Bulletin, 28:30-31.

Caley, P. 1999. Feral pig: Biology and control in the Northern Territory. Agnote 554, No. J52. Agdex No. 440/91. Parks and Wildlife Commission of the Northern Territory, Australia.

Choquenot, D., J. McIlroy, and T. Korn. 1996. Managing vertebrate pests: Feral pigs. Bureau of Rural Sciences, Australian Government Publishing Service, Canberra, Australia.

Coblentz, B. E., and D. W. Baber. 1987. Biology and control of feral pigs on Isla Santiago, Galapagos, Ecuador. Journal of Applied Ecology, 24(2):403-418.

Coleman, S. 1984. Control efforts in Great Smoky Mountains National Park since 1978. Pp. 15-20. In J. Tate (ed.), Techniques for controlling wild hogs in the Great Smoky Mountains National Park. Proceedings of a workshop, November 29-30. Research/Resources Mgmt. Rpt. SRE-72. U. S. Department of the Interior, National Park Service, Southeast Regional Office, Atlanta, Georgia.

Cowled, B. D., E. Gifford, M. Smith, L. Staples, and S. J. Lapidge. 2006a. Efficacy of manufactured PIGOUT ${ }^{\circledR}$ baits for localised control of feral pigs in the semi-arid Queensland rangelands. Wildlife Research, 33:427-437.

Cowled, B. D., S. J. Lapidge, M. Smith, and L. Staples. 2006b. Attractiveness of a novel omnivore bait, PIGOUT®, to feral pigs (Sus scrofa) and assessment of risks of bait uptake by non-target species. Wildlife Research, 33:651-650.

Cowled, B. D., P. Elsworth and S. J. Lapidge. 2008. Additional toxins for feral pig (Sus scrofa) control: Identifying and testing Achilles' heels. Wildlife Research, 35(7):651-662.

Diong, C. H. 1973. Studies of the Malaysian wild pig in Perak and Jahore. Malayan Nature Journal, 26(3/4):120-151.

Fox, J. R., and M. R. Pelton. 1977. An evaluation of control techniques for the European wild hog in the Great Smoky Mountains National Park. Pp. 53-66. In G. W. Wood (ed.), Research and management of 
wild hog populations. Belle Baruch Forest Science Institute of Clemson University, Georgetown, South Carolina.

Geisser, H., P. Havet, E. Taran, and J. C. Berthos. 1998. The wild boar (Sus scrofa) in the Thurgau (northeastern Switzerland): Population status, damages and the influence of supplementary feeding on damage frequency (in French). Gibier et Faune Sauvage, 15(2):547-554.

Geisser, H., and H. U. Reyer. 2004. Efficacy of hunting, feeding, and fencing to reduce crop damage by wild boars. Journal of Wildlife Management, 68(4):939-946.

Genov, P. 1981. Significance of natural biocenoses and agrocenoses as the source of food for wild boar (Sus scrofa L.). Ekologia Polska, 29(1):117-136.

Giles, J. R. 1973. Controlling feral pigs. Agricultural Gazette of New South Wales, 84(3):130-132. . 1977. Control of feral pigs. Wool Technology and Sheepbreeding, 25(2):29-31.

Goulding, M. J., G. Smith, and S. J. Baker. 1998. Current status and potential impact of wild boar (Sus scrofa) in the English countryside: A risk assessment. Central Science Laboratory, Ministry of Agriculture, Fisheries and Food, London, England.

Groot Bruinderink, G. W. T. A., E. Hazebroek, and H. van der Voot. 1994. Diet and condition of wild boar, Sus scrofa scrofa, without supplementary feeding. Journal of Zoology, 233(4):631-648.

Hone, J. 1987. Theoretical and practical aspects of feral pig control. Ph.D. Dissertation, Australian National University, Canberra, Australia.

Hone, J., and W. Atkinson. 1983. Evaluation of fencing to control feral pig movement. Australian Wildlife Research, 10(3):499-505.

Hone, J., and R. Kleba. 1984. The toxicity and acceptability of warfarin and 1080 poison to penned feral pigs. Australian Wildlife Research, 11(1):103-111.

Hone, J., and H. Mulligan. 1982. Vertebrate pesticides. Science Bulletin No. 89. Division of Animal Production, New South Wales Department of Agriculture, Sydney, Australia.

Hone, J., and H. Pederson. 1980. Changes in a feral pig population after poisoning. Proceedings of the Vertebrate Pest Control Conference, 9:176-182.

Hone, J., and C. P. Stone. 1989. A comparison and evaluation of feral pig management in two national parks. Wildlife Society Bulletin, 17:419-425.

Jeffery, J. 1999. Snaring: Controversial but effective. Environment Hawai'i, 10:5.

Kaser, T. 1993. On the horns of a dilemma: more humane goat, pig control ordered. Honolulu Advertiser, Feb. 11:2.

Kelly, D. 2002. U.S. to aid island's war on wild pigs. Los Angeles Times, February 6:B-6.

Kessler, C. C. 2002. Eradication of feral goats and pigs and consequences for other biota on Sarigan Island, Commonwealth of the Northern Mariana Islands. Pp. 132-140. In C. R. Veitch and M. N. Clout (eds.), Turning the tide: The eradication of invasive species. IUCN SSC Invasive Species Specialist Group, International Union for the Conservation of Nature and Natural Resources, Cambridge, United Kingdom. 


\section{Wild Pigs}

Kodera, Y. 2005. Survival analysis of wild boars (Sus scrofa) in Iwami District, western Japan. Suiform Soundings, 5(2):11-13.

Land Protection. 2001. NRM Facts: Control of feral pigs declared. QNRM01278. Department of Natural Resources and Mines, The State of Queensland, Brisbane, Australia.

Leone, D. 2001. Wild pigs invade neighborhoods: Homeowners and hunters battle the porcine invasion. Honolulu Star-Bulletin, May 21.

Littauer, G. A. 1993. Control techniques for feral hogs. Pp. 139-148. In C. W. Hanselka and J. F. Cadenhead (eds.), Feral swine: A compendium for resource managers. Texas Agricultural Extension Service, Kerrville, Texas.

Mackin, R. 1970. Dynamics of damage caused by wild boar to different agricultural crops. Acta Theriologica, 15(27):447-458.

Mapston, M. E. 2004. Feral hogs in Texas. Document No. B-6149 5-04. Wildlife Services, Texas Cooperative Extension, Texas A\&M University, College Station, Texas.

Marsack, P. 2000. Biology and control of the feral pig. Infonote. Vertebrate Pest Research Services, Department of Agriculture, Western Australia. Perth, Australia.

McCabe, M. 2001. No one's rooting for these pigs: Pinnacles finishing 30-mile hog-proof fence. San Francisco Chronicle, December 1:A-13.

McCann, B. E., and D. K. Garcelon. 2008. Eradication of feral pigs from Pinnacles National Monument. Journal of Wildlife Management, 72(6):1287-1295.

McGaw, C. C., and J. Mitchell. 1998. Feral pigs (Sus scrofa) in Queensland. Pest status review series. Land Protection, Department of Natural Resources and Mines, Queensland Government, Coorparoo, Australia.

McIlroy, J. C. 1983. The sensitivity of Australian animals to poison. V. The sensitivity of feral pigs, Sus scrofa, to 1080 and its implications for poisoning campaigns. Australian Wildlife Research, 10(1):139148.

McIlroy, J. C., M. Braysher, and G. R. Saunders. 1989. The effectiveness of a warfarin poisoning campaign against feral pigs, Sus scrofa, in Namadgi National Park, A.C.T. Australian Wildlife Research, 16(2):195-202.

McIlroy, J. C., and E. J. Gifford. 1997. The "Judas" pig technique: A method that could enhance control programmes against feral pigs, Sus scrofa. Wildlife Research, 24(4):483-491.

Mitchell, J. 1998. The effectiveness of aerial baiting for control of feral pigs (Sus scrofa) in North Queensland. Wildlife Research, 25(3):297-303.

Muir, T. J., and G. McEwen. 2007. Methods and strategies for managing feral hog damage in grain production areas in central Texas. Pp. 445-450. In G. W. Witmer, W. C. Pitt and K. A. Fagerstone (eds.). Managing vertebrate invasive species: Proceedings of an international symposium. USDA/APHIS/WS, National Wildlife Research Center, Fort Collins, Colorado.

National Park Service. 2003. Pinnacles National Monument feral pig eradication plan: Environmental Assessment. Pinnacles National Monument, Paicines, California.

Nedzel'skii, E. M. 2007. Effect of supplemental winter feeding of ungulates on prolificacy. Russian Agricultural Sciences, 33(2):121-122. 
O'Brien, P. H. 1988. The toxicity of sodium monofluroacetate (Compound 1080) to captive feral pigs (Sus scrofa). Australian Wildlife Research, 15:163-170.

O'Brien, P. H., R. E. Kleba, J. A. Beck, and P. J. Baker. 1986. Vomiting by feral pigs after 1080 intoxication: Nontarget hazards and influence of anti-emetics. Wildlife Society Bulletin, 14(4):425432.

O'Brien, P. H., and B. S. Lukins. 1990. Comparative dose response relationships and acceptability of warfarin, Brodifacoum and Phosphorus to feral pigs. Australian Wildlife Research, 17:101-112.

Pech, R. P., J. C. McIlroy, M. F. Clough, and D. G. Green. 1992. A microcomputer model for predicting the spread and control of foot and mouth disease in feral pigs. Proceedings of the Vertebrate Pest Conference, 15:360-364.

PETA (People for the Ethical Treatment of Animals). 1993. On TNC's trail. PETA News, Fall:15.

Poche, R. 1998. Wildlife secondary toxicity studies with warfarin. The Probe: Newsletter of the National Animal Damage Control Association, 187:4.

Rathore, A. K. 1985. Use of metoclopramide to prevent 1080-induced emesis in wild pigs. Journal of Wildlife Management, 49(1):55-56.

Reidy, M. M., T. A. Campbell, and D. G. Hewitt. 2008. Evaluation of electric fencing to inhibit feral pig movements. Journal of Wildlife Management 72:1012-1018.

Saunders, G., B. Kay, and R. Parker. 1990. Evaluation of a warfarin poisoning programme for feral pigs (Sus scrofa). Australian Wildlife Research, 17(5):525-533.

Schuyler, P. T., D. K. Garcelon, and S. Escover. 2002. Eradication of feral pigs (Sus scrofa) on Santa Catalina Island, California, USA. Pp. 274-286. In C. R. Veitch and M. N. Clout (eds.), Turning the tide: The eradication of invasive species. IUCN SSC Invasive Species Specialist Group, International Union for the Conservation of Nature and Natural Resources, Cambridge, United Kingdom.

Sharp, T. and G. Saunders. 2002. Use of Judas pigs. SOP PIG004. Natural Heritage Trust, New South Wales, Sydney, Australia.

Sharp, T., and G. Saunders. 2004. Model code of practice for the humane control of feral pigs. Natural Heritage Trust, New South Wales, Sydney, Australia.

Sheehan, M. W. 1984. Field studies in the use of sodium monofluoroacetate, '1080', in the control of vertebrate vermin species in inland south east Queensland. M.V. Sc. Thesis, University of Queensland,

Smith, M., S. Lapidge, B. Cowled, and L. Staples. 2005. The design and development of PIGOUT® - A target-specific feral pig bait. Australasian Vertebrate Pest Conference, 13:129-134

Soule, M. E. 1990. The onslaught of alien species, and other challenges in the coming decades. Conservation Biology, 4:233-239.

Sterner, J. D., and R. H. Barrett. 1991. Removing feral pigs from Santa Cruz Island, California. Transactions of the Western Section the Wildlife Society, 27:47-53.

Stevens, R. L. 1996. The feral hog in Oklahoma. Samuel Roberts Noble Foundation, Ardmore, Oklahoma.

Stone, C., and S. Anderson. 1988. Introduced animals in Hawaii's natural areas. Proceedings of the Vertebrate Pest Conference, 13:134-140. 


\section{Wild Pigs}

Taylor, D., and L. Katahira. 1988. Radio telemetry as an aid in eradicating remnant feral goats. Wildlife Society Bulletin, 16:297-299.

Tilley, L. G. W. 1973. Pig fencing in Mossman. Cane Growers Quarterly Bulletin, 36(4):132-133.

Tisdell, C. A. 1982. Wild pigs: Environmental pest or economic resource? Pergamon Press, New York.

Twigg, L. E., T. Lowe, G. Martin, and M. Everett. 2005. Feral pigs in north-western Australia: Basic biology, bait consumption, and the efficacy of 1080 baits. Wildlife Research, 32(4):281-296.

2006. Feral pigs in north-western Australia: population recovery after 1080 baiting and further control. Wildlife Research, 33(5):417-425.

Vassant, J. 1994. L'agrinage dissuasive: Resultants d' experiences. Bulletin Mensuel de l'Office National de la Chasse, Numero Special: Gestion du Sanglier, 191:101-105.

Vidrih, M., and S. Trdan. 2008. Evaluation of different designs of temporary electric fence systems for the protection of maize against wild boar (Sus scrofa L., Mammalia, Suidae). Acta Agriculturae Slovenica, 91(2):343-349.

Wilcox, J. T., E. T. Ashehoug, C. A. Scott, and D. H. Van Vuren. 2004. A test of the Judas technique as a method for eradicating feral pigs. Transactions of the Western Section of the Wildlife Society, 40:120126.

Wilson, C. J. 2005. Feral wild boar in England: Status, impact and management. DEFRA, RDS National Wildlife Management Team, Exeter, United Kingdom. 
SRNL-RP-2009-00869

This page left blank intentionally 
Wild Pigs

\section{Control Techniques for Wild Pigs:}

\section{Comparison of Five Harvest Techniques for Wild Pigs}

John J. Mayer

Savannah River National Laboratory, Savannah River Nuclear Solutions, LLC, Savannah River Site, Aiken, South Carolina 29808

\section{Introduction}

Invasive animal species frequently have major negative economic consequences and adverse effects on native wildlife, plants, and habitats. Because of this, it is imperative to be able to identify means of controlling these populations so as to effectively reduce or minimize these impacts (Myers et al. 2000, Pimentel et al. 2005).

Introduced wild pigs (Sus scrofa) are one of the non-native animals most often cited as posing a threat to new host environments. These animals are currently found in more than 40 states within the United States and in at least 4 Canadian provinces. The impacts that this species has on both agricultural areas and wildlands are largely negative. Although these impacts are variable, the resulting effects are often significant and long lasting. Once established, populations of wild pigs are very difficult to control. In addition, because of their high reproductive potential, wild pigs have the capacity to recover quickly from control operations (Stewart 1989, Mayer and Brisbin 1991, Beach 1993, Littauer 1993, Thomas 1998, Gipson et al. 1998, Waithman et al. 1999). The ability to be able to implement effective and targeted control measures for newly established wild pig populations is crucial.

A variety of management methods (i.e., lethal removal techniques) have been used historically to control introduced wild pig populations. These have included live trapping, shooting, hunting with trained dogs (a.k.a., dogging), fencing, and snaring. The successful employment of each method can vary with the terrain, season, and local regulations (Barrett and Birmingham 1994). For example, although very inexpensive to employ and widely used in Australia (Hone and Pedersen 1980, Mcllroy et al. 1989), poisons (e.g., either Compound 1080 or Warfarin) for controlling wild pigs have not been approved for use in the United States (Littauer 1993). In spite of the extensive use of these various methods, little work has been done to determine the differential or selective effectiveness of these techniques on the various potential target groups (e.g., females vs. males; adult vs. immatures) within these populations.

The purpose of this study was to do a basic comparison of the harvest parameters resulting from the use of five wild pig control techniques. These data, compiled at one location over a thirty-five year period, were evaluated for significant differences within each method for taking the various components of the local wild pig population. Such information would be useful in determining what methods are best suited for controlling or harvesting specific target groups or segments within a wild pig population. In addition to these study goals, some general cost and manpower estimates were calculated for comparative purposes.

I would like to thank the U. S. Department of Energy's Savannah River Site for access to lands under their controls. I am especially grateful for the assistance of F. A. Brooks, M. E. Eller, G. E. Eller, D. T. Elliott, R. E. Hamilton, A. R. Harvey, W. L. Jarvis, P. E. Johns, E. T. LeMaster, D. A. Napier, and the late J. W. Reiner. Funding for this study was provided by the U. S. Department of Energy under contracts DE-AC0989SR18035 and DE-AC09-96SR18500 to the Washington Savannah River Company (formerly known as the Westinghouse Savannah River Company). 
SRNL-RP-2009-00869

\section{Study Area}

The study was conducted on the Savannah River Site (SRS), Aiken, Barnwell and Allendale counties, South Carolina. The SRS is an $803 \mathrm{~km}^{2}$ federal nuclear facility operated by the U. S. Department of Energy. Based on historical and morphological data, the SRS wild pig population is composed of animals with mixed wild boar/feral swine hybrid ancestry (Mayer and Brisbin 1991). The population estimate has varied recently between 800 and 2,000 individuals, with a mean density of 7.5 animals per hectare (J. J. Mayer, unpubl. data). The SRS contains greater than 90 percent forested habitats. Site land use is dominated by managed pine plantations. The SRS is transected by several stream drainage corridors occupied by bottomland hardwood forest and forested swamp. Pockets of upland hardwood forest and mixed pine/hardwood forest are scattered throughout the site (Workman and McLeod 1990).

\section{Methods}

Between 1968 and 2003, data were collected from a total of 8,793 wild pigs harvested on the SRS. The individual animals were taken using one of five control techniques including dogging, bait stations, opportunistic shooting, corral trapping, and public hunts. Dogging entails the use of trained trail, bay and catch dogs to capture wild pigs. Upon capture, the dogs' handlers immediately killed the pigs. The use of bait stations involved the placement of bait (i.e., shelled or soured corn) at locations with existing wild pig sign. These locations were then periodically checked, and any wild pigs seen at the bait station were dispatched with either a shotgun or high-powered rifle. Opportunistic shooting simply comprised of wild pigs serendipitously encountered in the study area being shot and killed with one of the aforementioned firearms. The corral trapping encompassed the use of $2.5 \times 2.5 \times 1.3$ m wooden or wire paneled corral traps to capture one or more wild pigs at a time. These traps employed either root door or drop door designs. These live traps were baited with either shelled or soured corn and checked on a daily basis when set. Animals caught in these traps were immediately dispatched as the traps were checked. The SRS public hunts (i.e., organized drive hunts using dogs) were conducted annually in the fall to control the onsite populations of both white-tailed deer (Odocoileus virginianus) and wild pigs. During these hunts, packs of trained dogs (typically deer or fox hounds) are used to drive the deer and wild pigs across lines of hunters standing on roads intersecting the hunt area. The hunters, using shotguns loaded with buckshot, are directed to harvest any deer or wild pig, regardless of age or sex. This technique was initially implemented as a management tool to control the site's deer population. It should be noted that, unlike during the use of dogging described above, the deer hunt dogs simply chase or drive the wild pigs within the hunt area. If the wild pigs bay up or refuse to be driven, the dogs used in these drive hunts typically will not remain with the bayed up pigs after a short period of time. In many instances, these wild pigs would avoid being killed because the hunters do not arrive on the scene soon enough to enable them to shoot the quarry.

The use of bait stations, opportunistic shooting, and corral trapping was conducted between 1968 and 2001 . Dogging was conducted concurrently with the aforementioned techniques from 1986 through 2003. The public hunts were conducted from 1968 through 2003; however, this was only during the months of October through December of each year.

For each animal taken, the following data were recorded: date of collection, harvest technique used, sex, and age class. In addition, 2,015 of the sexually-mature females (i.e., juveniles through adults) out of the total sample size included in the study had a pregnancy status recorded (i.e., pregnant or not pregnant). Age class categories included piglet, juvenile, yearling, subadult and adult, and were based on erupted dental patterns as described in Mayer and Brisbin (1991).

All statistical analyses were performed using the JMP ${ }^{\circledR}$ Version 4.0.2 software package (SAS Institute Inc. 2002). Chi Square tests were used to determine if a variable differed significantly from the expected/hypothetical probability. Statistical significance was accepted at $p<0.05$.

The composition (e.g., sex, age class) of these harvested animals was compared to a population model developed for this area (i.e., PIGPOP). PIGPOP is a spreadsheet-formatted lifetable-based population model estimating of the size and composition of the SRS wild pig population. The sex and age class percentage breakdown of the overall population derived from that model is given in Table 1. The 


\section{Wild Pigs}

pregnancy status was compared using age class and seasonal specific data known for this population (Table 2).

Average cost and level of effort (manpower) estimates were calculated for each control method. For the public hunts, the cost estimate, calculated as dollars per animal, was based on the total program cost published after each hunting season (e.g., WSRC 1990). The level of effort, calculated as manhours per animal, were derived from the same published annual reports. Comparable estimates for the other techniques (i.e., dogging, bait stations, opportunistic shooting, and corral trapping) were similarly calculated (i.e., dollars and manhours per animal harvested, respectively). These latter cost estimates were based on the estimated hourly subcontract cost (i.e., $\$ 11 / \mathrm{hr}$ ) multiplied by the number of animals harvested within a given time frame. The time frames used in these calculations were selected such that only one of the techniques was being conducted for that given period of cost. As such, these estimates were not based on the entire data set. An estimate of the mean manpower effort was determined based on the total personnel effort for the USFS-Savannah River Forest Station and the subcontractor for each technique. This collectively included administrative, preparation, travel and actual technique operational time. Again, this was based on selected time periods when only one of the techniques was being employed.

\section{Results}

The harvested sample for each control technique varied greatly, with dogging being the most successful method (4,398 animals or 50.0 percent of the total). The remaining techniques accounted for the following numbers of wild pigs: bait stations - 215 ( 2.5 percent), opportunistic shooting -434 (4.9 percent), corral trapping - 1,514 (17.2 percent), and public hunts - 2,232 (25.3 percent). The mean annual harvest by technique over the decade from 1992 to 2001 (during which all of the methods were conducted) was as follows: dogging - 432.4 (63.1 percent), bait stations - 17.2 (2.5 percent), opportunistic shooting - 33.8 (4.9 percent), corral trapping - 123.0 (17.9 percent), and public hunts - 79.3 (11.6 percent). These percentages generally follow the overall harvest breakdown with the exception of about a 10 percent increase in dogging and a comparable decrease in the public hunts.

With respect to the overall sample harvested, 47.1 percent $(4,025)$ consisted of females and 52.9 percent $(4,515)$ were males. The percent sexual composition of the sample differed significantly $\left(\chi^{2}=138.0, d f=1\right.$, $p<0.0001$ ) from that estimated for the population as a whole, with males being harvested at a greater rate than would have been expected. The age class breakdown (sexes combined) of the overall sample was as follows: piglet -41.4 percent $(3,638)$, juvenile -14.9 percent $(1,306)$, yearling -13.6 percent $(1,192)$, subadult -12.5 percent $(1,095)$, and adult -17.8 percent $(1,562)$. Similar to the overall sex ratio of harvested animals, the age class breakdown was also significantly different $\left(\chi^{2}=377.1, d f=4, p<0.0001\right)$ from the expected. The piglet, subadult and adult age classes were each harvested at slightly higher levels than would be found in the population as a whole, while the juvenile and yearling groupings were underharvested compared to what would have been present. In general, this would indicate an overall tendency using these methods collectively to remove the youngest as well as the more mature age classes from the population.

Of the 2,015 mature females that were checked for pregnancy status, 68.2 percent $(1,374)$ and 31.8 percent (641) were not pregnant and pregnant, respectively. This did not differ significantly from the expected overall pregnancy status percentages from the population (i.e., not pregnant -68.9 percent; pregnant -31.1 percent). When broken down by age class, the same comparison did not result in any significant differences within each of the age classes.

Dogging - Overall, in comparing the sex percentages in the harvest using this method to that of the population as a whole, males were taken at a significantly greater rate $\left(\chi^{2}=108.4, d f=1, p<0.0001\right)$ than would have been expected. When broken down by age class, this same significantly higher harvest of males was found within each age class (piglet $-\chi^{2}=30.39, d f=1, p<0.0001$; juvenile $-\chi^{2}=11.03, d f=1$, $p<0.0009$; yearling $-\chi^{2}=3.90, d f=1, p<0.05$; subadult $-\chi^{2}=7.65, d f=1, p<0.006$; and adult $-\chi^{2}=107.29, d f=1$, $p<0.0001)$. With the sexes combined, significantly more young animals were taken using this harvest technique $\left(\chi^{2}=770.71, d f=4, p<0.0001\right)$. The same was true for the sexes analyzed separately (i.e., female $\chi^{2}=365.59, d f=4, p<0.0001$; male $\left.-\chi^{2}=365.99, d f=4, p<0.0001\right)$, except that there were slightly more adult 
males taken than would have been expected. The pregnancy status for all of the age classes combined harvested using this method resulted in a significant higher frequency of females that were not pregnant $\left(\chi^{2}=13.96, d f=1, p<0.0002\right)$. When analyzed within age classes, significantly more non-pregnant females were found in the yearling $\left(\chi^{2}=6.95, d f=1, p<0.008\right)$ and adult $\left(\chi^{2}=9.06, d f=1, p<0.003\right)$ age classes.

Bait Stations - Of the comparisons for the wild pig harvest using this technique, only sex was found to be significantly different $\left(\chi^{2}=5.4, d f=2, p<0.02\right)$, with more males being taken. When the sex comparison was broken down by age class, the only significant increase was in the number of adult males harvested $\left(\chi^{2}=8.07, d f=1, p<0.005\right)$.

Opportunistic Shooting - In general, significantly more males $\left(\chi^{2}=14.18, d f=1, p<0.0002\right)$ were taken using this technique. Further breaking the sex comparison down by age class revealed significant higher numbers of males harvested for only for the juvenile $\left(\chi^{2}=8.85, d f=1, p<0.003\right)$ and yearling $\left(\chi^{2}=5.92, d f=1\right.$, $p<0.02)$ age classes. In addition, overall more young wild pigs were taken by this method than would have been expected if the harvest were random $\left(\chi^{2}=20.61, d f=4, p<0.0004\right)$. When broken down by sex, a similar significant bias toward a younger harvest was seen only for females $\left(\chi^{2}=18.08, d f=4, p<0.001\right)$. None of the pregnancy status comparisons for animals harvested using opportunistic shooting were found to be significantly different from the expected frequencies.

Corral Trapping - The overall comparison of the sex breakdown was significantly different for this technique, with more males being taken than would have been expected $\left(\chi^{2}=66.95, d f=1, p<0.0001\right)$. For the comparison within each age class, significantly more males were taken in all of the age classes (piglet $\chi^{2}=13.77, d f=1, p<0.0002$; juvenile $-\chi^{2}=12.31, d f=1, p<0.0005$; yearling $-\chi^{2}=9.04, d f=1, p<0.003$; subadult - $\chi^{2}=15.45, d f=1, p<0.0001$; and adult $-\chi^{2}=36.49, d f=1, p<0.0001$ ). Corral trapping resulted in a significantly higher harvest of younger animals (i.e., sexes combined $-\chi^{2}=154.79, d f=4, p<0.0001$; female $\chi^{2}=133.41, d f=4, p<0.0001$; male $\left.-\chi^{2}=44.60, d f=4, p<0.0001\right)$. Overall, corral trapping was biased toward harvesting non-pregnant females $\left(\chi^{2}=23.27, d f=1, p<0.0001\right)$. When analyzed separately, the only age class that was significantly different was the adults, with a significant increase in the frequency of non-pregnant individuals $\left(\chi^{2}=7.92, d f=1, p<0.005\right)$.

Public Hunts - No significant differences in harvest between the sexes were determined using this technique, either collectively or when broken down by age class. The age class structure of the public hunt/dog drive harvest was significantly older than the expected population age class structure $\left(\chi^{2}=969.45\right.$, $d f=4, p<0.0001$ ). This was also true for both sexes (i.e., female $-\chi^{2}=528.77, d f=4, p<0.0001$; male $\left.\chi^{2}=447.79, d f=4, p<0.0001\right)$. The public hunts harvested significantly more pregnant females than would have been expected $\left(\chi^{2}=15.29, d f=1, p<0.0001\right)$. The same was true for each of the age classes (i.e., juvenile $-\chi^{2}=8.32, d f=1, p<0.004$; yearling $-\chi^{2}=3.65, d f=1, p<0.05$; subadult $-\chi^{2}=12.79, d f=1, p<0.0003$; and adult $-\chi^{2}=13.89, d f=1, p<0.0002$ )

Cost and Level of Effort Estimates - A summary of the estimates for cost (dollars per pig) and level of effort (manhours per pig) are provided in Table 3. Of the five control techniques, dogging was both the most cost effective and level-of-effort efficient method. The cost estimates then increased from public hunts to corral trapping, opportunistic shooting, and finally bait stations. The level of effort increased from trapping to shooting, public hunts, and finally bait stations. The inconsistent order of ranking between cost and level of effort is a result of the different source data that were used for the public hunts compared to the other techniques. The four techniques that had a common estimating basis were ranked consistently for both parameters.

\section{Discussion}

The comparable harvest data from previous studies have been contradictory. The comparison of such information is further complicated by inconsistencies in the population densities, terrain, vegetative cover, and other site-specific factors among the different locations (Tate 1984, Barrett and Birmingham 1994).

With respect to the use of dogging, both Dzieciolowski and Clarke (1989) and Caley and Ottley (1995) identified that technique as being biased toward the harvest of males. Younger wild pigs were previously 


\section{Wild Pigs}

reported to be significantly more vulnerable to capture by hunting dogs than were the older age classes (Dzieciolowski and Clarke 1989, Katahire et al. 1993). These same biases were also found in the present study. In contrast, Barrett et al. (1988) found that dogging tended to select for adults.

The use of bait stations to target wild pigs for removal has been evaluated previously. A high percent of juveniles was observed in one baiting study in southern England. Other studies using baiting have shown a bias toward the female segment of the population (DEFRA 2004). In contrast, the present study only indicated the potential for the preferential removal of adult males. Similar to the ability of adult males to dominate the use of carcasses (Barrett 1978), these larger males may also do the same with bait piles that they encounter. That behavior would account for the higher number of adult males harvested using this technique.

Shooting has previously been reported to produce inconsistent results with respect to the component of a wild pig population harvested. However, it should be noted that "shooting" could collectively include a variety of formats (e.g., recreational hunting vs. professional control programs) and modes (e.g., still hunting on foot, shooting from an elevated stand, shooting from a vehicle, shooting from an aircraft, etc.). For example, shooting has been reported to be both female- (Korytin et al. 2002) and male-biased (Fox and Pelton 1977, Henry and Conley 1978). It has also been reported to be biased toward both younger (Dzieciolowski and Clarke 1989, Feichtner 1998) and older animals (Fox and Pelton 1977, Johnson et al. 1982, Tate 1984). The bias toward older wild pigs reported for shooting can result from a tendency toward shooting the largest animal in the group first (Fox and Pelton 1977, Pavlov 1980). The present study found significant biases toward the general harvest of males and younger animals. A further breakdown revealed an increased vulnerability of juvenile and yearling males to the use of this technique. Animals in these sex/age class groupings would have recently been weaned and would still be relatively inexperienced, as well as beginning to live a solitary existence. These factors in combination might make them more susceptible to harvest with this technique.

Trapping has been previously reported to be biased toward the harvest of both younger animals (Singer 1976, Barrett et al. 1988, Johnson et al. 1982, Mitchell 1998, DEFRA 2004) and females (Choquenot et al. 1993). The present study found a similar bias toward the removal of younger individuals, but also found that the trapping harvest favored males in general and specifically females that were not pregnant. Fox and Pelton (1977) found that trapping took a higher percentage of adult males.

From a population control perspective, it would make the most sense to target sexually mature females for removal. The sows in subadult and adult age classes have the highest annual reproductive potential because of higher litter sizes than in the younger age classes (Barrett 1978, Taylor et al. 1998). Since boars can be sexually mature as young as four to five months age, any males from the juvenile through adult age classes could potentially be contributing to recruitment within the subject population. Successful removal of adult boars would only result in the replacement of these dominant sires by the younger males that had previously been excluded from breeding because of male-male competition for females. Short of the removal of all males, the younger males replacing these previously dominant breeding individuals would make the removal of only more mature or older males ineffective. None of the techniques compared selectively removed the aforementioned targeted grouping (i.e., sexually mature females). The only technique that came close to this goal was the public hunts, which were selective toward older animals in general and specifically females that were pregnant. Unfortunately, this technique was not as effective as some of the other techniques (e.g., dogging) at removing large numbers of animals. In addition, Fernández-Llario et al. (2003) noted that the age composition of the wild pig harvest in such large drive hunts using dogs can vary depending upon the intensity/size of the hunt (i.e., number of dogs, number of hunters, area being hunted, etc.). Those authors found that the larger the hunt, the younger the age structure of the harvested wild pigs. On average, the public hunts on the SRS remove only about 8 percent of the population on an annual basis (J. J. Mayer, unpubl. data).

Although not analyzed for, it should be noted that the only technique that harvested any individuals that would be considered to be neonates (i.e., individuals in the piglet age class with at least a dried and still attached umbilicus and dried remnants of fetal membrane on the body or limbs) was dogging. This would be expected since this age class is the least mobile of all. In fact, given the sedentary nature of neonatal 
wild pigs (Mayer et al. 2002), the only other techniques evaluated that could even possibly take animals in this age class would be opportunistic shooting and public hunts.

Dogging has been reported as being capable of serving as a primary harvest technique to use in an area for removing wild pigs. In the Hawaii Volcanoes National Park, the use of hunting dogs is the principal means of controlling wild pigs (Katahira et al. 1993). The same is true for the wild pig control program at SRS.

Trapping has been cited as being both labor intensive and costly (Giles 1973, 1977, Coblentz and Baber 1987), especially when trying to control wild pigs with that technique over a large area. Trapping is also impractical in inaccessible areas (Saunders 1990). Other sources (e.g., Caley 1999) have reported that it is an effective means of harvesting wild pigs where these animals are present in low to moderate densities.

Bait stations and opportunistic shooting are both low overhead and maintenance. Although conducted throughout a good portion of the study period, both techniques accounted for only a low percentage of the animals harvested (i.e., $<8$ percent of total harvest). Shooting has been reported to not be a good stand-alone technique for controlling a wild pig population (Giles 1977). Other sources (e.g., Coblentz and Baber 1987) report it to be only moderately effective. Tate (1984) reported that shooting was more effective than trapping in the Great Smoky Mountains National Park, although trapping did account for a larger overall harvest within the park's wild pig control program. However, both techniques can be operated as minimum effort add-ons to the use of other techniques. This is especially true for control programs employing corral trapping. Bait stations can also be used as prebaiting sites for future corral trapping. In addition, the type of bait used should be carefully selected for both acceptance and olfactory attractiveness to the local wild pigs.

Seasonality can also affect the use of certain harvest techniques for wild pigs. Although not included in the analysis for this study, other authors have noted the increased success of one technique versus another during specific seasons. For example, Schuyler et al. (2002) found that trapping was more successful during the dry months when resource were low, while dogging was more effective during the winter months.

Cost and level of effort for lethal removal of wild pigs can be difficult to accurately determine. Previous estimates for cost and level of effort have been extremely variable (e.g., $\$ 2$ to $\$ 754$ per pig; 0.6 to 23 manhours per pig). This made the economic comparison of the use of the different techniques complicated. Again, site-specific variables play a significant role in the development of such estimates. In general, the more pigs that are removed, the higher the cost per pig. For example, there is a positive correlation between the removal cost per pig and the total number of pigs removed by a control program (Fig. 1). A comparable relationship for level of effort had a lower slope, but was still positive. It should also be noted that the cost of removing the last animal from a population is high (Hone and Stone 1989). Therefore, the larger the population, the greater the mean per-animal cost and level of effort needed to eradicate the entire population.

\section{Conclusion}

Based on the analysis of the harvest data, differential removal of components of the population was found to exist among the five techniques employed. Four of the techniques tended to select for males. Dogging, opportunistic shooting and corral trapping were all biased toward the harvest of younger animals, while the public hunts removed significantly older animals than would have been expected. In addition, dogging was the only technique to take neonates in the harvested sample. Females that were not pregnant were taken in higher proportion in the dogging and corral trapping harvest totals, while the public hunts took more pregnant females. In general, bait stations were not that successful, but did have potential for the removal of adult males.

With respect to targeting sexually mature females for removal, the only technique that even marginally had the potential to achieve this goal was the public hunts. However, this technique was not effective at the removal of large numbers of animals. As such, none of the five techniques appeared to have stand-alone 


\section{Wild Pigs}

potential to selectively removal the one sex-age class grouping that would likely have the highest impact on the annual recruitment within a wild pig population.

In general, the cost and level of effort of the five techniques mirrored the harvest total of each. Dogging was both the most cost effective and level of effort efficient. Bait stations were found to be the most expensive and manpower intensive method to use as a stand-alone technique. Because of the high cost and level of effort, both bait stations and opportunistic shooting would only be economically feasible to employ as add-on techniques to other programs (e.g., dogging and corral trapping).

Among the five techniques compared, there does not appear to be a single preferred harvest method to employ for controlling a wild pig population. As such, lethal removal programs for this species should employ a combination of these techniques. Based on the cost, level of effort and ability to remove large numbers of animals, dogging should be the primary technique to emphasize in these programs. This should be supplemented with trapping, opportunistic shooting and bait stations as appropriate. Public hunts can also be used, but the increased cost and inability to remove large numbers of wild pigs would limit the potential that this technique represents. 
Table 1. Percent composition of the SRS wild pig population by sex and age class as determined by the PIGPOP model. The age classes were based on erupted dental patterns as described in Mayer and Brisbin (1991).

\begin{tabular}{|c|c|c|c|c|c|c|c|}
\hline \multirow{2}{*}{$\begin{array}{l}\text { Age Class } \\
\text { (Approx. } \\
\text { Age) }\end{array}$} & \multicolumn{3}{|c|}{ Female } & \multicolumn{3}{|c|}{ Male } & \multirow{2}{*}{$\begin{array}{c}\text { Both } \\
\text { Percent } \\
\text { within } \\
\text { Population }\end{array}$} \\
\hline & $\begin{array}{l}\text { Percent } \\
\text { within } \\
\text { Sex }\end{array}$ & $\begin{array}{c}\text { Percent } \\
\text { within } \\
\text { Age } \\
\text { Class }\end{array}$ & $\begin{array}{c}\text { Percent } \\
\text { within } \\
\text { Population }\end{array}$ & $\begin{array}{c}\text { Percent } \\
\text { within } \\
\text { Sex }\end{array}$ & $\begin{array}{c}\text { Percent } \\
\text { within } \\
\text { Age } \\
\text { Class }\end{array}$ & $\begin{array}{c}\text { Percent } \\
\text { within } \\
\text { Population }\end{array}$ & \\
\hline $\begin{array}{c}\text { Piglet } \\
\text { (0-0.5 yr.) }\end{array}$ & 35.2 & 53.1 & 18.8 & 35.8 & 46.9 & 16.6 & 35.5 \\
\hline $\begin{array}{l}\text { Juvenile } \\
(0.5-1 \mathrm{yr} .)\end{array}$ & 21.3 & 52.2 & 11.4 & 22.4 & 47.8 & 10.4 & 21.8 \\
\hline $\begin{array}{l}\text { Yearling } \\
\text { (1-1.5 yr.) }\end{array}$ & 16.2 & 53.8 & 8.7 & 16 & 46.2 & 7.4 & 16.1 \\
\hline $\begin{array}{l}\text { Subadult } \\
\text { (1.5-3 yr.) }\end{array}$ & 11.1 & 54 & 5.9 & 10.9 & 46 & 5.1 & 11.1 \\
\hline $\begin{array}{c}\text { Adult } \\
(3 \mathrm{yr} .+)\end{array}$ & 16.2 & 55.6 & 8.7 & 14.9 & 44.4 & 6.9 & 15.6 \\
\hline All Ages & 100 & 53.5 & 53.5 & 100 & 46.5 & 46.5 & 100.0 \\
\hline
\end{tabular}

Table 2. Summary of age class specific pregnancy status frequencies observed in the SRS wild pig population (J. J. Mayer, unpubl. data). Percentages are given for the entire year and specifically for the SRS public hunt season (i.e., October through December).

\begin{tabular}{ccccc}
\hline & \multicolumn{2}{c}{ Entire Year } & \multicolumn{2}{c}{ Public Hunt Season } \\
Age Class & Not Pregnant & Pregnant & Not Pregnant & Pregnant \\
& 89.8 & 10.2 & 87.6 & 12.4 \\
Juvenile & 69.8 & 30.2 & 63.5 & 36.5 \\
Yearling & 66.5 & 33.5 & 66.8 & 33.2 \\
Subadult & 53.1 & 46.9 & 57.4 & 42.6 \\
Adult & 68.9 & 31.1 & 63.7 & 36.3 \\
All Ages & & & & \\
\hline
\end{tabular}




\section{Wild Pigs}

Table 3. Summary of cost and level of effort estimates for the five wild pig harvest techniques compared.

\begin{tabular}{ccc}
\hline Harvest Technique & $\begin{array}{c}\text { Cost Estimate } \\
\text { (Dollars per Wild Pig) }\end{array}$ & $\begin{array}{c}\text { Level of Effort } \\
\text { (Manhours per Wild Pig) }\end{array}$ \\
\hline Dogging & $\$ 88^{\mathrm{a}}$ & $8^{\mathrm{a}}$ \\
Bait Stations & $\$ 1,176^{\mathrm{a}}$ & $107^{\mathrm{a}}$ \\
Opportunistic Shooting & $\$ 830^{\mathrm{a}}$ & $75^{\mathrm{a}}$ \\
Corral Trapping & $\$ 319^{\mathrm{a}}$ & $29^{\mathrm{a}}$ \\
Public Hunts & $\$ 228^{\mathrm{b}}$ & $268^{\mathrm{b}}$ \\
\hline $\mathrm{a}-$ - Based on average annual subcontract program cost and level of effort &
\end{tabular}

Table 4. Summary of the results from the comparison of the five wild pig harvest techniques.

\begin{tabular}{cccccc}
\hline $\begin{array}{c}\text { Harvest } \\
\text { Parameter }\end{array}$ & Dogging & Bait Stations & $\begin{array}{c}\text { Harvest Technique } \\
\text { Opportunistic } \\
\text { Shooting }\end{array}$ & $\begin{array}{c}\text { Corral } \\
\text { Trapping }\end{array}$ & Public Hunts \\
\cline { 2 - 5 } Sex & Male & Male & Male & Male & NS \\
Age Class & Younger & NS & Younger & Younger & Older \\
$\begin{array}{c}\text { Pregnancy } \\
\text { Status }\end{array}$ & Not Pregnant & NS & NS & Not Pregnant & Pregnant \\
\hline a - Significantly more males taken in the adult age class & &
\end{tabular}


SRNL-RP-2009-00869

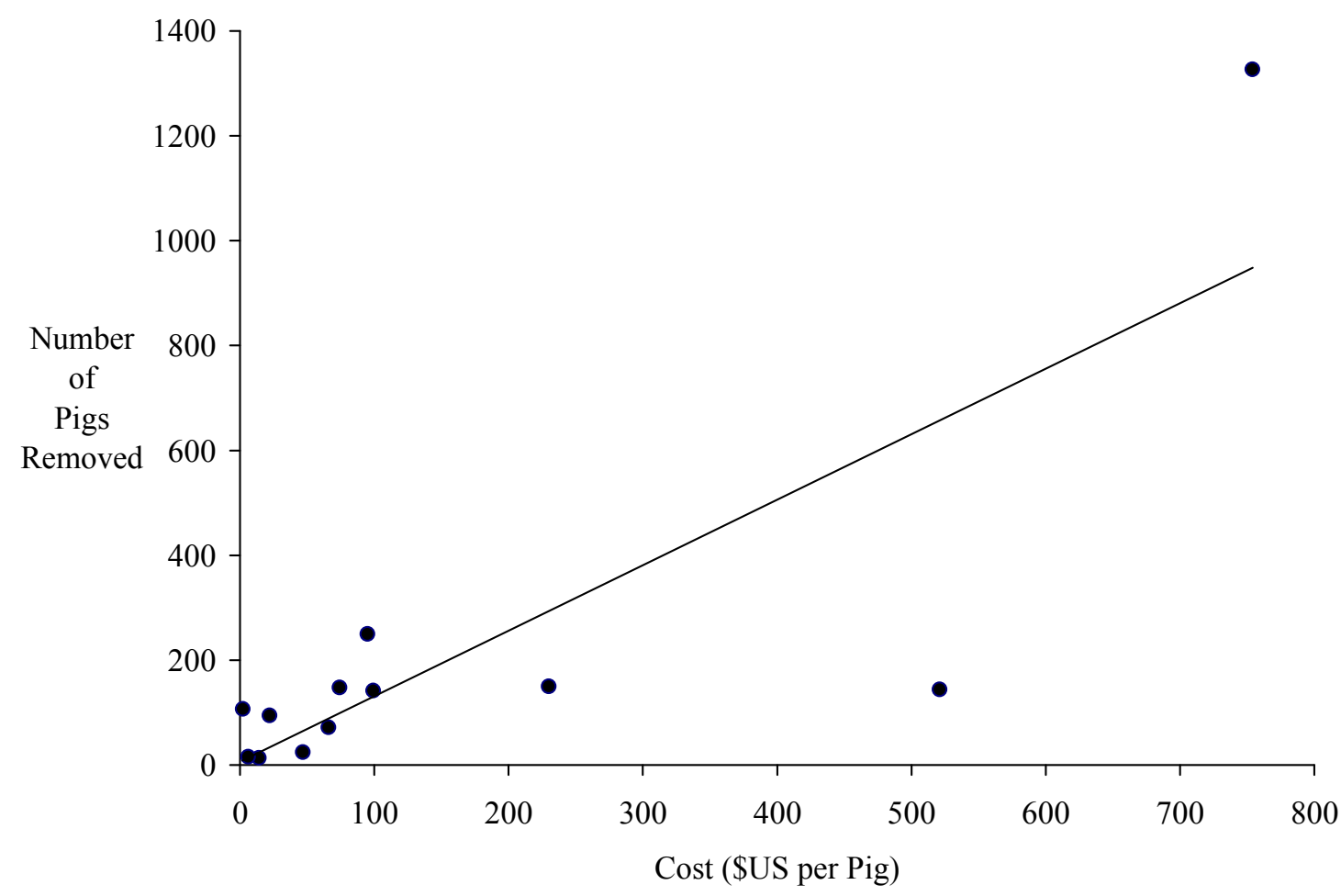

Fig. 1. Comparison of cost (dollars per pig removed) and the total number of wild pigs that the program removed. 


\section{Wild Pigs}

\section{Literature Cited}

Barrett, R. H. 1978. The feral hog on the Dye Creek Ranch, California. Hilgardia, 46(9):283-355.

Barrett, R. H., and G. H. Birmingham. 1994. Wild pigs. Pp. D65-D70. In S. E. Hygnstrom, R. M. Timm, and G. E. Larson (eds.), Prevention and control of wildlife damage. 2 volumes; Great Plains Agricultural Council, Univ. of Nebraska, Lincoln, Nebraska.

Barrett, R. H., B. L. Goatcher, P. J. Gogan, and E. L. Fitzhugh. 1988. Removing feral pigs from Annadel State Park. Transactions of the California-Nevada Section of the Wildlife Society, 24:47-52.

Beach, R. 1993. Depredation problems involving feral hogs. Pp. 67-75. In C. W. Hanselka and J. F. Cadenhead (eds.), Feral swine: A compendium for resource managers. Texas Agricultural Extension Service, Kerrville, Texas.

Caley, P. 1999. Feral pig: Biology and control in the Northern Territory. Agnote 554, No. J52. Agdex No. 440/91. Parks and Wildlife Commission of the Northern Territory, Australia.

Caley, P., and B. Ottley. 1995. The effectiveness of hunting dogs for removing feral pigs (Sus scrofa). Wildlife Research, 22(2):147-154.

Choquenot, D., R. J. Kilgour, and B. S. Lukins. 1993. An evaluation of feral pig trapping. Wildlife Research, 20:15-22.

Coblentz, B. E., and D. W. Baber. 1987. Biology and control of feral pigs on Isla Santiago, Galapagos, Ecuador. Journal of Applied Ecology, 24(2):403-418.

DEFRA (Department for Environment, Food and Rural Affairs). 2004. The ecology and management of wild boar in southern England. Central Science Laboratory, Hutton, York, United Kingdom.

Dzieciolowski, R. M., and C. M. H. Clarke. 1989. Age structure and sex ratio in a population of harvested feral pigs in New Zealand. Acta Theriologica, 34(38):525-536.

Feichtner, B. 1998. Ursachen der Streckenschwankungen beim Schwarzwild im Saarland. Zeitschrift für Jagdwissenschaft, 44(3):140-150.

Fernández-Llario, P., P. Mateos-Quesada, A. Silverio, and P. Santos. 2003. Habitat effects and shooting techniques on two wild boar (Sus scrofa) populations in Spain and Portugal. Zeitschrift fur Jagdwissenschaft, 49(2):120-129.

Fox, J. R., and M. R. Pelton. 1977. An evaluation of control techniques for the European wild hog in the Great Smoky Mountains National Park. Pp. 53-66. In G. W. Wood (ed.), Research and management of wild hog populations. Belle Baruch Forest Science Institute of Clemson University, Georgetown, South Carolina.

Giles, J. R. 1973. Controlling feral pigs. Agricultural Gazette of New South Wales, 84(3):130-132.

Giles, J. R. 1977. Control of feral pigs. Wool Technology and Sheepbreeding, 25(2):29-31.

Gipson P. S., B. Hlavachick, and T. Berger. 1998. Range expansion by wild hogs across the central United States. Wildlife Society Bulletin, 26:279-286.

Henry, V. G., and R. H. Conley. 1978. Survival and mortality of European wild hogs. Proceedings of the Annual Conference of the Southeastern Association of Fish \& Wildlife Agencies, 32:93-99. 
Hone, J., and H. Pederson. 1980. Changes in a feral pig population after poisoning. Proceedings of the Vertebrate Pest Control Conference, 9:176-182.

Hone, J., and C. P. Stone. 1989. A comparison and evaluation of feral pig management in two national parks. Wildlife Society Bulletin, 17:419-425.

Johnson, K. G., R. W. Duncan, and M. R. Pelton. 1982. Reproductive biology of European wild hogs in the Great Smoky Mountains National Park. Proceedings of the Annual Conference of the Southeastern Association of Fish \& Wildlife Agencies, 36:552-564.

Katahira, L. K., P. Finnegan, and C. P. Stone. 1993. Eradicating feral pigs in montane mesic habitat at Hawaii Volcanoes National Park. Wildlife Society Bulletin, 21(3):269-274.

Korytin, N. S., V. N. Bol'shakov, N. I. Markov, and N. L. Pogodin. 2002. The state of populations and selective hunting of game ungulates in the Middle Urals. Russian Journal of Ecology, 33(3):178-185.

Littauer, G. A. 1993. Control techniques for feral hogs. Pp. 139-148. In C. W. Hanselka and J. F. Cadenhead (eds.), Feral swine: A compendium for resource managers. Texas Agricultural Extension Service, Kerrville, Texas.

Mayer, J. J., and I. L. Brisbin, Jr. 1991. Wild pigs in the United States: Their history, comparative morphology, and current status. The University of Georgia Press, Athens.

Mayer, J. J., F. D. Martin, and I. L. Brisbin, Jr. 2002. Characteristics of wild pig farrowing nests and beds in the upper Coastal Plain of South Carolina. Applied Animal Behaviour Science, 78(1):1-17.

McIlroy, J. C., M. Braysher, and G. R. Saunders. 1989. The effectiveness of a warfarin poisoning campaign against feral pigs, Sus scrofa, in Namadgi National Park, A.C.T. Australian Wildlife Research, 16(2):195-202.

Mitchell, J. 1998. The effectiveness of aerial baiting for control of feral pigs (Sus scrofa) in North Queensland. Wildlife Research, 25(3):297-303.

Myers, J. H., D. Simberloff, A. M. Kuris, and J. R. Carey. 2000. Eradication revisited: Dealing with exotic species. Trends in Ecology and Evolution, 15(8):316-320.

Pavlov, P. M. 1980. The diet and general ecology of the feral pig (Sus scrofa) at Girilambone, N. S. W. M.S. Thesis, Monash University, Melbourne, Australia.

Pimentel, D., R. Zuniga, and D. Morrison. 2005. Update on the environmental and economic costs associated with alien-invasive species in the United States. Ecological Economics, 52:273-288.

SAS Institute Inc. 2002. JMP® Version 5 Statistics and Graphics Guide. SAS Institute Inc., Cary, North Carolina.

Saunders, G. 1990. Evaluation of feral pig management strategies in N.S.W., Australia. Transactions of the Congress of the International Union of Game Biologists, 19:337-339.

Schuyler, P. T., D. K. Garcelon, and S. Escover. 2002. Eradication of feral pigs (Sus scrofa) on Santa Catalina Island, California, USA. Pp. 274-286. In C. R. Veitch and M. N. Clout (eds.), Turning the tide: The eradication of invasive species. IUCN SSC Invasive Species Specialist Group, International Union for the Conservation of Nature and Natural Resources, Cambridge, United Kingdom.

Singer, F. J. 1976. The European wild boar in the Great Smoky Mountains National Park: Problem analysis and proposed research. NPS-SER Management Report No. 6. Uplands Field Research Laboratory, Great Smoky Mountains National Park, Gatlinburg, Tennessee. 


\section{Wild Pigs}

Stewart, W. C. 1989. Eradication. Pp. 63-69. In N. Black (ed.), Proceedings: Feral pig symposium. April 27-29, Orlando, Florida. Livestock Conservation Institute, Madison, Wisconsin.

Tate, J. (ed.). 1984. Techniques for controlling wild hogs in the Great Smoky Mountains National Park. Proceedings of a workshop, November 29-30, Research/Resources Mgmt. Rpt. SRE-72. U. S. Department of the Interior, National Park Service, Southeast Regional Office, Atlanta, Georgia.

Taylor, R. B., E. C. Hellgren, T. M. Gabor, and L. M. Ilse. 1998. Reproduction of feral pigs in southern Texas. Journal of Mammalogy, 79(4):1325-1331.

Thomas, L., Jr. 1998. Expanding wild hogs: Bad news or great hunting? Georgia Outdoor News, 12(12):12-15

Waithman, J. D., R. A. Sweitzer, J. Drew, A. J. Brinkhaus, I. A. Gardner, D. Van Vuren, and W. M. Boyce. 1999. Range expansion, population sizes, and management of wild pigs (Sus scrofa) in California. Journal of Wildlife Management, 63(1):298-308.

Workman, S. W., and K. W. McLeod. 1990. Vegetation of the Savannah River Site. SRO-NERP-19. Savannah River Ecology Laboratory, Aiken, South Carolina.

WSRC (Westinghouse Savannah River Company). 1990. Savannah River Site Deer Hunts (U) - 1990. Westinghouse Savannah River Company, Savannah River Site, Aiken, South Carolina. 
SRNL-RP-2009-00869

This page left blank intentionally 
Wild Pigs

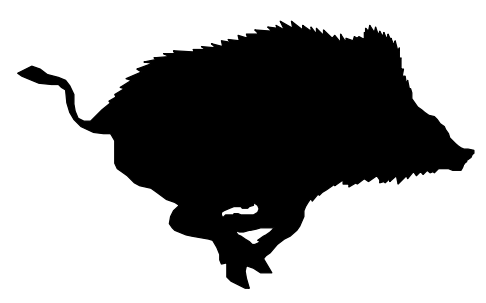

Part IV

Wild Pig

Management Case Studies 
Wild Pigs

This page left blank intentionally 
Wild Pigs

\section{Wild Pig Management Case Study: Savannah River Site}

John J. Mayer and Laurel A. Moore-Barnhill

Savannah River National Laboratory, Savannah River Nuclear Solutions, LLC, Savannah River Site, Aiken, South Carolina 29808 (JJM)

South Carolina Department of Natural Resources, P. O. Box 167, Columbia, South Carolina 29202

(LAMB)

\section{Introduction}

Wild pigs (Sus scrofa) have been present on the U. S. Department of Energy's (DOE's) Savannah River Site (SRS) since the establishment of that federal installation. As in other places where these animals have been introduced, the SRS wild pigs are considered to be an unwanted invasive species requiring ongoing control efforts. However, similar to public lands on which these animals are hunted, the sportsmen that participate in the fall public hunts on the SRS consider wild pigs to be a desirable big game species. Such a localized polarized controversy over these animals is a commonplace phenomenon.

The SRS is an $803 \mathrm{~km}^{2}$ nuclear production and research facility located in Aiken, Barnwell, and Allendale counties in the upper Coastal Plain region of western South Carolina (Fig. 1). The site borders the Savannah River for about 27 kilometers. The SRS was constructed during the 1950s to produce basic materials (e.g., plutonium-237 and tritium) used in nuclear weapons. The current site mission entails both environmental restoration/clean-up and waste management activities. The entire site has been closed to general public access since its establishment (Blake et al. 2005). Since 1952, when the U. S. Government acquired the SRS, forestry management practices and natural succession outside of the construction and operating areas on the site have resulted in increased ecological complexity and diversity of the property. At the time of acquisition, land use consisted of approximately 52 percent forest, 34 percent agricultural lands, and 14 percent floodplains and wetlands. The present SRS land use comprises 96 percent forested habitats or undeveloped lands. The dominant site land use is managed pine plantations consisting primarily of managed stands of loblolly pine (Pinus taeda), longleaf pine (P. palustris), and slash pine (P. elliotti). The site is transected by several stream drainage corridors occupied by bottomland hardwood forest and forested swamp. Pockets of upland hardwood forest and mixed pine/hardwood forest are scattered throughout the site (Imm and McLeod 2005).

\section{History of the SRS Wild Pigs}

As a non-native species, the presence of wild pigs on the SRS is solely attributable to both the accidental and intentional introduction of these animals by man. The sources of these animals have varied both prior to the establishment of the SRS and after the site became operational.

The initial SRS wild pig population stemmed from free-ranging and semi-wild domestic swine that were present in the area prior to the government purchase of the land. The first known presence of domestic swine on what is now the SRS dates back to the period of 1730 to 1750 from the colonial Dunbar House farm site located in the uplands between Steel Creek and Pen Branch (Reitz 1985). Later, between 1870 and 1900, Barnwell County ranked among the top five counties in the state in overall swine production (SRARP 1989). Considering that free-ranging was a widely-used method of rearing domestic swine in the southeastern United States during the late nineteenth century (Mayer and Brisbin 1991), it is likely that some of these locally-raised pigs might have been released into open range on lands presently encompassed by the SRS. In fact, the free-ranging of domestic swine in the Savannah River swamp between Upper Three Runs and Steel Creek was known to be a common practice in the late 1930s and throughout the 
1940s (H. W. Arnold, Sr., pers. comm., F. Foreman, pers. comm., P. Harrington, pers. comm., B. Schwartz, pers. comm.). When the site was purchased by the federal government in 1950, the resident farmers were given one year to capture and remove all of their free-ranging domestic swine. Large numbers could not be recovered by the end of 1951 and were left behind by their owners when the farmers were finally prohibited further access to the land in 1952. Jarrell Brown, one of the former landowners, claimed to have lost more than 100 domestic swine that he was unable to recapture (Jenkins and Provost 1964, J. H. Jenkins, pers. comm.). Since that time, these animals thrived and multiplied in the riverswamp portion of the site. By 1970, the distribution of the SRS wild pig population had expanded to include most of the hardwood bottomland forest and swamps along the Savannah River, the adjacent upland pine plantations, and the stream drainage corridors (Sweeney 1970, Kurz 1971, Kurz and Marchinton 1972).

In the mid 1970s, a small second subpopulation of wild pigs was discovered along the Upper Three Runs drainage just below U. S. Highway 278 in the central northern portion of the site. Several theories have been posed as to the origin of these animals, but none have been verified (Mayer and Brisbin 1983). However, based on morphological data (Mayer and Brisbin 1991), it was evident that this second subpopulation did not stem from the riverswamp subpopulation as was theorized by both Crouch (1983) and Hughes (1985). The upland wild pigs have since expanded their range toward the Savannah River at a rate of approximately 4,474 ha per year. Animals exhibiting the upland phenotype have since been collected in areas adjacent to the river.

During the 1983 SRS Fall Public Hunt, nine wild pigs were killed near the central western boundary of the site that were found to exhibit characteristics typical of Eurasian wild boar or wild boar/feral hog hybrids (Mayer 1984). The origin of these animals was traced to a release of wild pigs of mixed wild boar and feral hog ancestry onto private property, Cowden Plantation, which is adjacent to the SRS (Mayer and Brisbin 1991). In the late 1960s, Jarrell Brown, the owner of Cowden Plantation, acquired several wild pigs from an animal dealer in North Carolina, who had obtained his original stock from the hybrid wild pig population in the southern Appalachians (J. K. Jarrett, pers. comm.). These hybrid animals were released on the plantation in an effort to upgrade the feral hog population that was already present there (Mayer 1984). Since the release of the original animals, wild pigs exhibiting wild boar characteristics have spread throughout the Cowden Plantation wild pig population. Wild pigs showing these hybrid characteristics have continued to increase on the SRS, and by 1989, had expanded throughout the riverswamp portion of the site (Mayer and Brisbin 1991).

Aside from those introductions or releases which have had significant impacts on the composition of the SRS wild pig population, there also reportedly have been a number of small or limited introductions of swine onto the site during the past three decades that have had a questionable or undefined impact. These have included both illegal releases and immigrations from adjacent properties. These sources have encompassed a variety of swine, including additional stocks of wild boar/feral hog hybrids, all white domestic swine, mule-footed feral hogs, Vietnamese pot-bellied pigs, and Tamworth domestic swine. In addition, some movement of wild pigs occurs between the SRS and the Georgia side of the Savannah River. Wild pigs have been observed swimming across the river adjacent to SRS lands on a number of occasions (Mayer and Brisbin 1991). Unfortunately, although the Savannah River does not appear to present a barrier to the gene flow between populations on either side of the river, the impact of such movement on the SRS population is unknown (B. Schwartz, pers. comm., D. T. Elliott, pers. comm., J. W. Reiner, Sr., pers. comm., J. J. Mayer, unpubl. data).

With recent expansions of their distribution after 2002, wild pigs presently occupy approximately 91 percent of the area encompassed by the SRS boundaries, being documented in portions of all 46 SRS wildlife management units. Isolated sightings of wild pigs continue to be reported in areas of the site where these animals have heretofore not become established as of yet. The current sitewide average density of the SRS wild pigs is 1.0 animals $/ \mathrm{km}^{2}$ (Mayer 2005). The estimated mean annual population density has varied over the years from 1.0 up to 5.9 wild pigs $/ \mathrm{km}^{2}$ (Jenkins and Provost 1964, Mayer 2005).

The size of the SRS wild pig population has fluctuated greatly since the early 1950s. In 1952, a couple of hundred free-ranging pigs roamed the SRS riverswamp, upland areas bordering the swamp, and adjacent drainage corridors (Jenkins and Provost 1964, J. J. Mayer, unpubl. data). In the late 1960s, the SRS wild 


\section{Wild Pigs}

pig population was thought to fluctuate around a mode of 300 to 400 animals (Sweeney 1970). In 1981, SRS imposed a one-year moratorium on harvest of wild pigs during hunts in the river-swamp hunt compartments. This was done in an effort to protect several wild pigs that were instrumented with radiotracking collars as part of a telemetry study conducted by Clemson University. The moratorium, in addition to the concurrent expansion of the upland subpopulation, resulted in a subsequent doubling of SRS wild pig population (Mayer 2005). Based on an assumed annual harvest percentage (25\%), Savereno and Fendley (1988) derived a rough population estimate of 1,450 individuals using the previous year's harvest of 361 animals. The estimated size of the SRS wild pig population during the past 10 years has fluctuated between about 900 and 2,300 animals (Fig. 2).

\section{Damage/Impacts of SRS Wild Pigs}

Wild pigs are at present the most widespread and numerous invasive species on the SRS. Since the late $1950 \mathrm{~s}$, the principle perceived role of this animal in the SRS ecosystem has been that of a nuisance or pest species. This categorization has been the result of the damage that these mammals do on the site including the following: depredation of planted seedlings; rooting damage, vehicle collisions, depredation of wildlife food plots, radionuclide/contaminant uptake, and hazards to SRS personnel traveling on foot. Each of these types of damage is described in more detail in the following paragraphs:

Depredation of Planted Seedlings - Since the early 1950s, wild pigs have damaged planted pine seedlings on site. This type of damage has continued up through the present (J. G. Irwin, pers. comm.). The pigs dig up and consume the rootstocks of loblolly and longleaf pine seedlings. These animals will systematically go from one seedling to the next in one planted row after another in pine regeneration plots, ultimately depredating almost the entire crop. Similar depredations on planted hardwood seedlings recently occurred in a wetland restoration area. In addition, SRS wild pigs have been documented to uproot and strip the bark off of lateral roots of mature pines onsite (Mayer et al. 2000, Tofte 1959).

Rooting Damage - Rooting is most widespread and frequently observed kind of damage done by wild pigs on the SRS. This type of damage is the result of these animals foraging for tubers, roots and insect larvae. Excessive pig rooting can destabilize surface soils and increase soil erosion, damaging stream channels, seeded roadbeds, and ditch banks. Extensive erosion of this type has been observed on the steep slopes to the east of the Upper Three Runs drainage. Some rooting damage has been noted to occur to unsurfaced forestry roads on the SRS. Damage of this type has not been widespread, but it can be potentially dangerous to vehicular traffic. Rooting disturbance, along with direct foraging, may also negatively affect native plant communities (J. J. Mayer, unpubl. data).

Another area of damage due to rooting was to the former SCWMRD wild turkey food plots. In some instances, the wild pigs rooted holes which were almost a meter in depth. Extensive damage of this type has caused both difficulties in maintaining these food plots and to the equipment and operators attempting to till and plant the forage species (M. B. Caudell, pers. comm.).

Vehicle Collisions - As with the SRS white-tailed deer population, wild pigs have presented a collision hazard for SRS traffic since the 1960s. The SRS roads are subject to regular periods of heavy traffic during the morning and evening shift changes, which coincide with the daily activity peaks of wild pigs. Since 1991, an average of nine wild pig/vehicle collisions has taken place on the SRS per year. Recently, a record total of 23 such collisions occurred in 2003. These losses, however, only represent an average of 0.63 percent attrition within the SRS wild pig population on an annual basis (J. J. Mayer, unpubl. data).

Depredation of Wildlife Food Plots - During the 1970s and 1980s, extensive depredation by wild pigs occurred to the SCWMRD wild turkey food plots established on the SRS. These food plots were intended to provide both millet (Panicum miliaceum) and winter wheat (Triticum spp.) for the site's wild turkey population. The wild pigs readily ate the seed heads and fresh shoots, and quickly consumed all of the available food resources at these plots. The local wild pigs caused further problems by foraging on bait lines (i.e., shelled corn) intended to lure in wild turkeys onto the food plots to enable their later capture for relocation. Typically, the wild pigs would find the bait before the turkeys, necessitating continued rebaiting in order to eventually catch the birds (M. B. Caudell, pers. comm.). 
Radionuclide/Contaminant Uptake - Being present on a federal nuclear production facility, the wild pigs at SRS have been and continue to be exposed to radiological contaminants in the environment. This contamination is the result of both global atmospheric fallout and SRS operations. Because of their omnivorous food habits, wild pigs have the potential for realizing very high body burdens of certain radionuclides (Stribling 1978). Several studies have been conducted on the radionuclide body burdens found in the site's wild pigs since the late 1960s. Between 1971 and 2003, SRS wild pig body burdens have averaged approximately $4.3 \mathrm{pCi} / \mathrm{gm}$ wet weight, with a range from not detectable up to $75 \mathrm{pCi} / \mathrm{gm}$. During this timeframe, the annual means have been steadily decreasing (J. J. Mayer, unpubl. data). The primary concern surrounds those wild pigs harvested on site lands during the SRS fall deer hunts by the public. Before a pig is released to a hunter, a portable iodide detector is used to monitor the animal for radiocesium. These measurements are used to calculate a dose to the hunter for each individual animal and to track cumulative dose for the specific hunter. If the harvested animal exceeds a committed effective dose equivalent based on the weight of the animal and the hunter's past hunting history, the animal is not released for consumption by the public. To date, all of the wild pigs harvested at SRS during the fall hunts have been released to the public (D. A. Napier, pers. comm.).

Hazards to SRS Personnel Traveling on Foot - Confrontations between wild pigs and SRS employees walking in undeveloped areas of the site have been an ongoing problem since the site was established. Early anecdotal accounts exist of site personnel having been chased by wild pigs. In one instance during the 1950s, a DuPont Patrol officer was "treed" on top of his vehicle by a large boar that the officer had tried to chase out of a pine regeneration plot (B. Schwarz, pers. comm.). In 1991, two encounters in the field between SRS employees and wild pigs resulted in the employees getting injured. During the 1993 SRS Fall Hunts, a hunter was gored by a 79-kilogram adult boar after he had wounded the animal, and before it finally died of its wounds. In 1993, subcontract surveyors reported having been treed several times by wild pigs that were unexpectedly encountered in very close proximity in dense thickets during the survey line work being conducted in the SRS riverswamp. Rooting by wild pigs also presents a safety problem to site personnel traveling on foot. One site employee broke his foot as a consequence of such an accident (SRFS 1985).

Other minimal damage by these animals has been observed on SRS (e.g., girdling of individual tree through repeated rubbing behavior). In addition, although not specifically documented to date, SRS wild pigs would likely cause other types of damage associated with this introduced species elsewhere. This would include such general impact categories such as: competition with native fauna for forage resources; predation of native fauna and flora; and damage to trees through tusking behavior.

\section{Management/Control of SRS Wild Pigs}

Because of the damage that wild pigs cause, SRS has used a variety of control efforts to manage their population numbers. These activities have been conducted by several agencies operating on site with the common goal of reducing the number of animals present and thus the level of damage realized. The summary of the number of wild pigs killed during these efforts is presented in Table 1. These different programs, which began in 1952 and have variously continued up through the present, are described in the following paragraphs:

Early Trapping and Shooting By SRFS - The initial control activities involved a live-trapping program implemented by the Savannah River Plant Forestry Project. This program was started shortly after the operations began on site in 1952. This action was considered necessary at that time after numerous observations of depredation damage to planted seedlings (Jenkins and Provost 1964). The wild pigs were caught in wooden drop-door corral traps baited with shelled corn. The captured animals were collected and maintained in an old cypress-board sided barn until they were picked up and removed from the site by personnel from the agricultural extension service of Clemson University (F. A. Brooks, pers. comm.). The old barn, located in Hunt Compartment 44, was a remnant from one of the site's earlier owners (i.e., the Risher family). Because of its use during the initial hog trapping program, this structure has been subsequently known as the "Hog Barn." In the late 1960s and early 1970s, SRFS staff conducted infrequent opportunistic control shooting of the SRS wild pig population (P. E. Johns, pers. comm.). Both 


\section{Wild Pigs}

of these efforts were discontinued in the late 1960s after 400-500 wild pigs had been removed from the site. A comparable number were trapped on Cowden Plantation to the northwest of the site during this same time period (Jenkins and Provost 1964, Sweeney 1970).

SRS Fall Deer Hunts - Public hunts on the site began in the fall of 1965 in an effort to reduce the size of the white-tailed deer (Odocoileous virginianus) herd. This action was taken primarily to cut down on the number of deer/vehicle collisions on the site's roads (Urbston 1967). The SRS is divided into 50 hunt compartments. The hunt compartments have been hunted in a variety of ways and schedules over the years. Although the hunters were encouraged to shoot wild pigs when the hunts were first held, no recordation of the harvest of this species was maintained until 1969. However, it is known that 30 wild pigs were killed on these hunts between 1965 and 1968. The harvest of wild pigs on these hunts has increased yearly since that time (Table 1). Between 1965 and 2003, the public harvested 3,010 wild pigs on SRS deer hunts. The number of wild pigs taken during these hunts increased from 1982 until the mid 1990s. More recently, these numbers have declined, with a yearly average of 74 animals taken from 19972003. In response to the terrorist incidents of September 11, 2001, the public hunts were greatly curtailed during the remainder of that year. These hunts were fully resumed the following year. During that period of reduced harvest, the site's wild pigs increased in both number and distribution onsite.

SREL/SCWMR Shooting and Trapping - Beginning in 1969, SREL and SCWMRD staff began to conduct intermittent and limited control shooting of wild pigs on site. Some live-trapping by SREL also occurred during 1968 and 1969. These collections were undertaken in an effort to enable the collection of data on the site's wild pig population and to reduce rooting/depredation damage to wild turkey food plots. In general, these efforts have been minimal, contributing to less than five percent of the total site harvest to date (Table 1).

Subcontractor Wild Hog Control Program - In 1984, upon advice from the senior author, DOE requested that the SRFS develop a live-trapping control program to reduce the wild pigs on the SRS (Smithwick 1984). The SRFS implemented a subcontractor-operated trapping program in 1985. The program involved the use of metal wire root-door traps (Belden and Frankenberger 1977) baited with shelled corn. The animals were killed in the traps and deposited in the site's sanitary landfill. This effort has been very successful and has been conducted through the present (Table 1). In the early 1990s this program began to use trained hunting dogs to catch and remove wild pigs. From 1999-2001 SRS temporarily suspended the use of pig-control subcontractors and U.S. Forest Service personnel operated corral traps. The subcontract program was started again in 2001, and has been continued up through the present. Overall, this program has been very successful, with 8,388 animals being removed from the SRS. Most of this removal has been through the use of trained hunting dogs.

SRS Wild Hog Hunts - In 2001, limited public hunts for wild pigs were initiated to supplement other ongoing control efforts. These hunts, administered by the SRFS, used only teams of hunters with packs of trained hunting dogs to catch and remove wild pigs. During January 2001, hunters removed 121 wild pigs. A second special SRS wild pig hunt, conducted in January of 2003, resulted in harvest of 52 pigs.

Crackerneck Wildlife Management Area (CWMA) - Since the early 1970s, the CWMA has been managed as a $45-\mathrm{km}^{2}$ portion of the SRS that allowed public access for hunting and fishing as well as nonconsumptive recreation (e.g., bird watching and hiking). Hunting for wild pigs has taken place from that time up through the present. Most of this harvest has involved still hunting. In 2001, special hunts for wild pigs using trained hunting dogs during January and February were initiated. A total of 807 wild pigs have been removed from the CWMA between 1984 and 2004.

\section{Future Management Needs}

Wild pigs on the SRS are considered to be an invasive species, and pursuant to Executive Order 13112 (Clinton 1999), DOE is required to provide for "environmentally sound control of invasive species" on lands under the Department's jurisdiction. In general, the control of wild pig at the SRS has been very successful, removing an annual average of 253 and a cumulative total of more than 13,000 wild pigs from the site between 1952 and 2004 (Table 1). However, since the early establishment of the SRS, the site's 
wild pig population has continued to grow in numbers and expand in distribution. A combination of control techniques/programs has been able to keep the population size in check, but the distribution of these animals has increased. As would be expected, the level of the damage over the years has been proportionate to the population size.

Established populations of wild pigs, such as the one on SRS, are usually difficult to control. In general, to be completely effective, control efforts must be intensive and continuous. Further, annual removal of $60-80 \%$ of a wild pig population is necessary to keep numbers stable to decreasing in a given area (Barrett and Stone 1983). The SRS control programs have removed an annual average of 406 wild pigs during the last five years, and cost approximately $\$ 50-100,000$ per year. The current management goal for the SRS wild pigs is to keep their numbers at about 500 animals. Recent experience has shown that a site population of that size results in a manageable level of damage done by these animals.

The wild pigs of the SRS will be a component of this federal facility for the foreseeable future. These animals will require ongoing control/management efforts to keep the site population of this species at levels which result in minimal damage to SRS ecosystems and resources. The resiliency of these animals with their high reproductive potential would indicate that any hiatus from the control activities could result in the site's wild pig population rapidly expanding to numbers which would negatively impact the SRS. The SRS plans to continue using a combination of control techniques to keep the site's wild pig numbers in check. In the future, new control techniques that are identified as being useful will be implemented as appropriate. However, in light of the cost of the site program, the ability to maintain an ongoing control effort with decreasing annual budget is a concern. 


\section{Wild Pigs}

Table 1. Numbers of wild pigs collected or harvested on the SRS between 1952 and 2004 during the fall public hunts and control (e.g., shooting, dogging and trapping) efforts.

\begin{tabular}{|c|c|c|c|c|c|c|c|}
\hline $\begin{array}{l}\text { Calendar } \\
\text { Year }\end{array}$ & $\begin{array}{l}\text { Fall Public } \\
\text { Hunts }\end{array}$ & $\begin{array}{l}\text { Wild } \\
\text { Pig } \\
\text { Hunts }\end{array}$ & $\begin{array}{l}\text { SRFS/SRI } \\
\text { Subcontract }\end{array}$ & SCWMRD & $\begin{array}{c}\text { UGA } \\
\text { and } \\
\text { SREL }\end{array}$ & $\begin{array}{l}\text { SRFS/SRI } \\
\text { Efforts }\end{array}$ & Total \\
\hline $1952-64$ & - & - & - & - & - & $500+^{\mathrm{a}}$ & $500+$ \\
\hline 1965 & $7^{b}$ & - & - & - & - & $50^{\mathrm{a}}$ & 57 \\
\hline 1966 & $8^{\mathrm{b}}$ & - & - & - & - & $50^{\mathrm{a}}$ & 58 \\
\hline 1967 & $7^{b}$ & - & - & - & - & $50^{\mathrm{a}}$ & 57 \\
\hline 1968 & $8^{b}$ & - & - & - & 39 & - & 47 \\
\hline 1969 & 6 & - & - & - & 38 & - & 44 \\
\hline 1070 & 33 & - & - & - & - & 1 & 34 \\
\hline 1071 & 10 & - & - & - & 1 & - & 11 \\
\hline 1972 & 17 & - & - & - & - & 1 & 18 \\
\hline 1973 & 12 & - & - & - & - & - & 12 \\
\hline 1974 & 38 & - & - & $25^{\mathrm{c}}$ & - & - & 63 \\
\hline 1975 & 46 & - & - & - & 1 & - & 47 \\
\hline 1976 & 176 & - & - & - & 47 & - & 223 \\
\hline 1977 & 57 & - & - & - & 40 & - & 97 \\
\hline 1978 & 28 & - & - & - & 40 & - & 68 \\
\hline 1979 & 61 & - & - & - & - & - & 61 \\
\hline 1980 & 32 & - & - & - & - & - & 32 \\
\hline 1981 & 33 & - & - & 3 & - & - & 36 \\
\hline 1982 & 189 & - & - & $75^{\mathrm{c}}$ & 4 & - & 268 \\
\hline 1983 & 133 & - & - & $75^{\mathrm{c}}$ & 58 & - & 266 \\
\hline 1984 & 105 & - & - & $30^{\mathrm{c}}$ & 27 & - & 162 \\
\hline 1985 & 78 & - & 158 & 4 & 12 & - & 252 \\
\hline 1986 & 123 & - & 240 & - & 3 & - & 366 \\
\hline 1987 & 123 & - & 214 & - & - & - & 337 \\
\hline 1988 & 146 & - & 240 & - & - & - & 386 \\
\hline 1989 & 178 & - & 192 & - & - & - & 370 \\
\hline 1990 & 134 & - & 295 & - & - & - & 429 \\
\hline 1991 & 126 & - & 217 & - & 3 & - & 346 \\
\hline 1992 & 168 & - & 500 & - & 32 & - & 700 \\
\hline 1993 & 148 & - & 504 & - & - & - & 652 \\
\hline 1994 & 105 & - & 624 & - & - & - & 729 \\
\hline 1995 & 46 & - & 941 & - & - & - & 987 \\
\hline 1996 & 109 & - & 1013 & - & - & - & 1122 \\
\hline 1997 & 85 & - & 834 & - & - & - & 919 \\
\hline 1998 & 62 & - & 1082 & - & - & - & 1144 \\
\hline 1999 & 45 & - & 502 & - & - & - & 547 \\
\hline 2000 & 38 & - & 61 & - & - & 60 & 159 \\
\hline 2001 & 6 & 121 & 240 & - & - & 42 & 409 \\
\hline 2002 & 174 & - & 259 & - & - & 19 & 452 \\
\hline 2003 & 110 & 52 & 272 & - & - & 7 & 441 \\
\hline 2004 & 147 & - & & - & - & - & \\
\hline Total & 3,010 & 173 & 8,388 & 212 & 345 & $780+$ & $12,908+$ \\
\hline
\end{tabular}

\footnotetext{
a - Removed by live-trapping and shooting; annual estimates based Kight (1962) and Sweeney (1970)

b - 30 wild pigs were harvested between 1965 and 1968 on the fall public deer hunts; exact annual numbers harvested are unknown

c - Approximate numbers harvested
} 


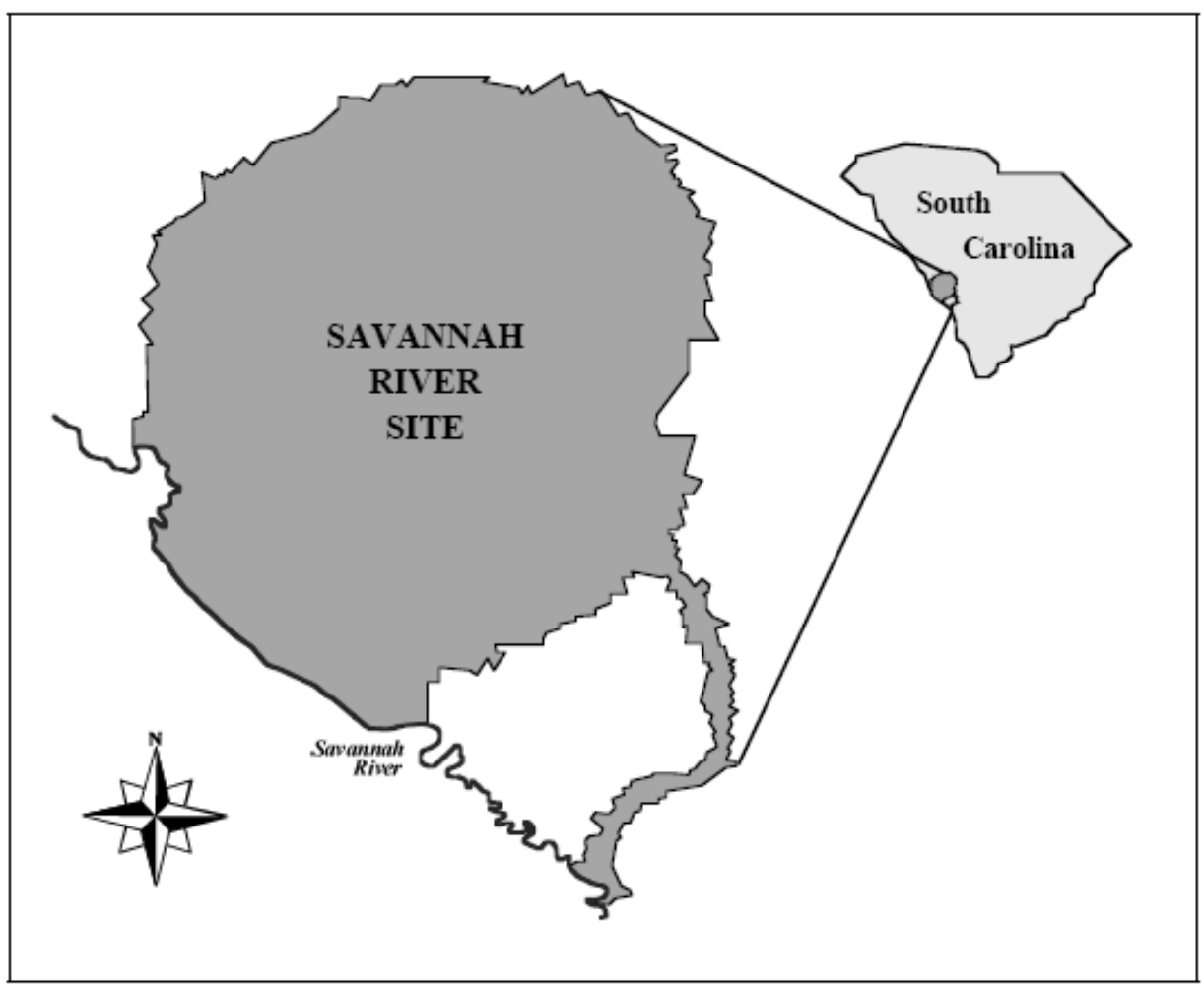

Fig. 1 Location of the Savannah River Site, South Carolina.

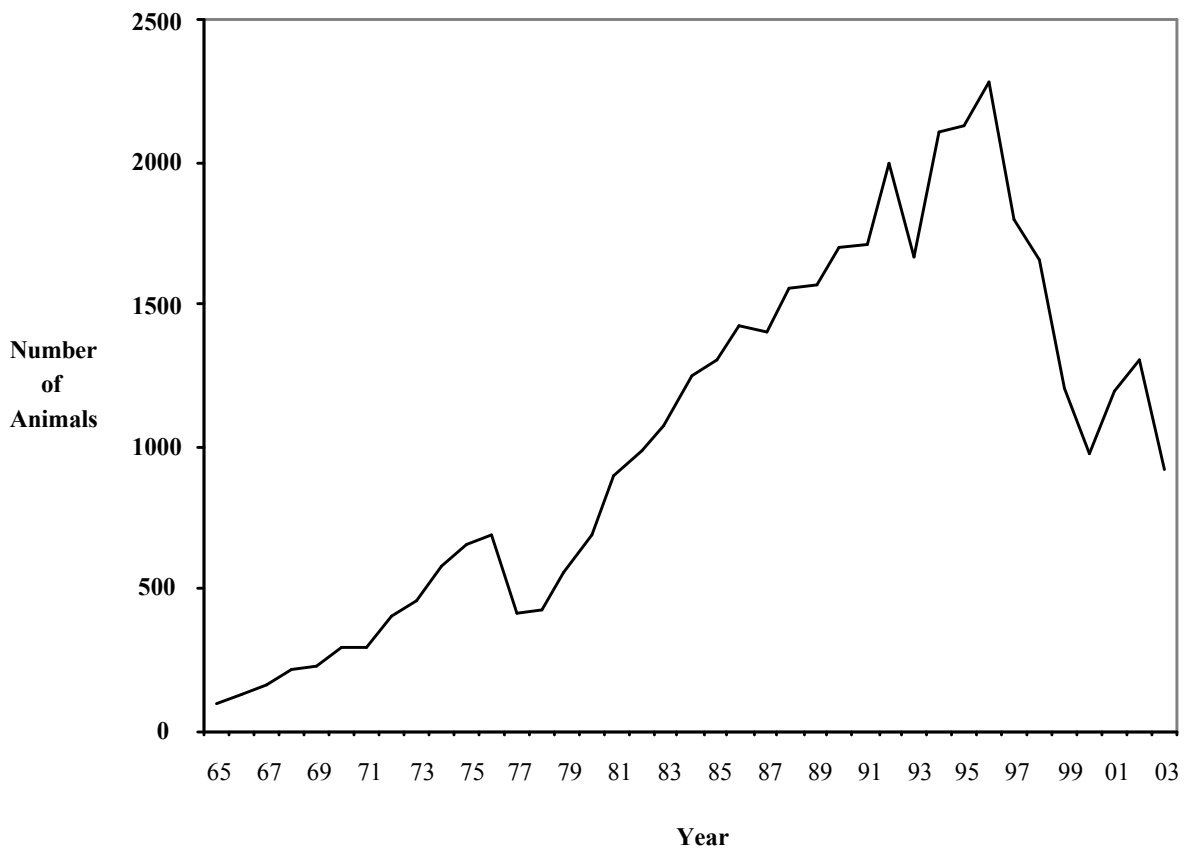

Fig. 2. Annual changes in the estimated population size of the SRS wild pigs. Source: PIGPOP model of the SRS wild pig population. 


\section{Wild Pigs}

\section{Literature Cited}

Barrett, R. H., and C. P. Stone. 1993. Hunting as a control method for wild pigs in Hawaii Volcanoes National Park: A report for resource management. Research Division, Hawaii Volcanoes National Park, National Park Service, U. S. Department of the Interior, Hawaii National Park. Hawaii.

Blake, J. I., J. J. Mayer, and J. C. Kilgo. 2005. Industrial Operations and Current Land Use. Pp. 12-18. In J. C. Kilgo and J. I. Blake (eds.), Ecology and management of a forested landscape: Fifty years on the Savannah River Site. Island Press, Washington, D.C.

Belden, R. C., and W. B. Frankenberger. 1977. A portable root-door hog trap. Proceedings of the Annual Conference of the Southeastern Association of Fish \& Wildlife Agencies, 31:123-125.

Clinton, W. J. 1999. Executive Order 13112: Invasive Species. Federal Register, 64(25):6183-6186.

Crouch, L. C. 1983. Movements of and habitat utilization by feral hogs at the Savannah River Plant, South Carolina. M.S. Thesis, Clemson University, Clemson, South Carolina.

Hughes, T. W. 1985. Home range, habitat utilization, and pig survival of feral swine on the Savannah River Plant. M.S. Thesis, Clemson University, Clemson, South Carolina.

Imm, D. W., and K. W. McLeod. 2005. Plant Communities. Pp. 106-161. In J. C. Kilgo and J. I. Blake, editors. Ecology and management of a forested landscape: fifty years on the Savannah River Site. Island Press, Washington, D.C.

Jenkins, J. H., and E. E. Provost. 1964. The population status of the larger vertebrates on the Atomic Energy Commission Savannah River Plant site. Office of Technical Services, Department of Commerce, Washington, D.C.

Kight, J. 1962. An ecological study of the bobcat, Lynx rufus (Schreber), in west-central South Carolina. M.S. Thesis, University of Georgia, Athens, Georgia.

Kurz, J. C. 1971. A study of feral hog movements and ecology on the Savannah River Plant, South Carolina. M.S. University of Georgia, Athens, Georgia.

Kurz, J. C., and R. L. Marchinton. 1972. Radiotelemetry studies of feral hogs in South Carolina. Journal of Wildlife Management, 36(4):1240-1248.

Mayer, J. J. 1984. Morphological analyses detect the presence of wild boar phenotypes in the SRP wild pig population. Pp. 125-127. In SREL 1984 Annual Report, Savannah River Ecology Laboratory, Aiken, South Carolina.

2005. Wild hog. Pp. 372-377. In J. C. Kilgo and J. I. Blake (eds.), Ecology and management of a forested landscape: Fifty years on the Savannah River Site. Island Press, Washington, D.C.

Mayer, J. J., and I. L. Brisbin, Jr. 1983. Distribution of feral swine undergoes a marked expansion on the SRP. Pp. 13-14. In SREL 1983 Annual Report, Savannah River Ecology Laboratory, Aiken, South Carolina.

1991. Wild pigs in the United States: Their history, comparative morphology, and current status. The University of Georgia Press, Athens, Georgia.

Mayer, J. J., E. A. Nelson, and L. D. Wike. 2000. Selective depredation of planted hardwood seedlings by wild pigs in a wetland restoration area. Ecological Engineering, 15(Supplement 1):S79-S85. 
Reitz, E. J. 1985. Fauna Identified from Various Archaeological Sites on the Savannah River Plant, South Carolina. Department of Anthropology, University of Georgia, Athens, Georgia.

Savereno, A. J., and T. T. Fendley. 1989. Feral hogs on the Savannah River Site: A review of herd history and characteristics with recommendations for management. Savannah River Ecology Laboratory, Aiken, South Carolina.

Smithwick, G. A. 1984. Letter to J. G. Irwin, June 22, re: Feral Hog Control Program. U. S. Department of Energy, Savannah River Operations Office, Aiken, South Carolina.

SRARP (Savannah River Archaeological Research Program). 1989. Archaeological resource management plan of the Savannah River Archaeological Research Program. Savannah River Archaeological Research Program, South Carolina Institute of Archaeology and Anthropology, University of South Carolina, Aiken, South Carolina.

SRFS (Savannah River Forest Station). 1985. Feral hog trapping. Pp. 1-2. In Savannah River Forest Station. January 1985 Highlight Update: Forest Management and Research Progress. Savannah River Forest Station, New Ellenton, South Carolina.

Stribling, H. L. 1978. Radiocesium concentrations in two populations of naturally contaminated feral hogs (Sus scrofa domesticus). M.S. Thesis, Clemson University, Clemson, South Carolina.

Sweeney, J. M. 1970. Preliminary investigation of a feral hog (Sus scrofa) population on the Savannah River Plant, SC. M.S. Thesis, University of Georgia, Athens, Georgia.

Tofte, A. L. 1959. Report on the land management program: Savannah River Operations Office. USDA Forest Service, Savannah River Forest Station, Aiken, South Carolina.

Urbston, D. F. 1967. Herd dynamics of a pioneer-like deer population. Proceedings of the Annual Conference of the Southeastern Association of Game \& Fish Commissioners, 21:42-50. 
Wild Pigs

\section{Wild Pig Management Case Study: \\ Great Smoky Mountains National Park Wild Hog Control Program}

William H. Stiver and E. Kim Delozier

Great Smoky Mountains National Park, 107 Park Headquarters Road, Gatlinburg, TN 37738

\section{Introduction}

The National Park Service (NPS) is a government agency under the United States Department of the Interior. The national park system comprises 384 areas covering more than 34 million ha ( 83 million ac) in 49 States, the District of Columbia, American Samoa, Guam, Puerto Rico, Saipan, and the Virgin Islands. The mission of the NPS is to preserve unimpaired the natural and cultural resources for the enjoyment of future generations.

Non-native species have substantial negative economic and ecological impacts on natural and cultural resources and are one of the biggest threats to the mission of parks. An estimated 1.1 million ha (2.6 million ac) of the 34 million ha ( 83 million ac) managed by the NPS are infested by exotic plants and nonnative animals (Drees 2004). Several NPS policies address non-native animals, including The Organic Act of 1916, Executive Order \#13112 and NPS Management Policies 2001. Policy states that control or eradication of non-native (exotic) species will be undertaken whenever such species threaten protection and interpretation of resources being preserved.

\section{Site Description}

Great Smoky Mountains National Park (GRSM) is a 2,080- $\mathrm{km}^{2}$ area located on the border of western North Carolina and eastern Tennessee. GRSM is the most visited national park in the U.S. with more than 9 million recreational visits annually. Developed areas include 10 campgrounds, 11 picnic areas, 100 backcountry campsites and shelters, 384 miles of road and numerous scenic overlooks. The area surrounding GRSM includes 2 national parkways, 3 national forests, an Indian Reservation and an extensive system of reservoirs.

GRSM is characterized by mountainous terrain with elevations ranging from $270 \mathrm{~m}$ to $2,024 \mathrm{~m}$. Approximately $95 \%$ of GRSM is dominated by forests that comprise a complex of several vegetation types (Stupka 1960). Major forest associations include: spruce-fir, cove hardwood, hemlock, northern hardwoods, closed oak, and open pine. Nearly 1,500 taxa of vascular flora exist in GRSM, including 288 non-native species (White 1982). In addition, over 2,400 non-flowering plants, 330 mosses and liverworts, 230 lichens, and 1,800 fungi have been identified (King and Stupka 1950). At least 70 species of mammals were known to inhabit GRSM, 4 of which are non-native (Linzey 1995). More than 200 species of birds, 80 species of reptiles and amphibians, 50 species of fish, and a large variety of insects and other invertebrates are also found within GRSM (King and Stupka 1950).

\section{Wild Hog Population History}

In 1912, 13 European wild boar were introduced into a private hunting preserve near Hoopers Bald, North Carolina (Stegeman 1938, Jones 1957). Hoopers Bald is located about $24 \mathrm{~km}$ (15 mi) south of GRSM and is now part of the Nanatahala National Forest. The animals were not immediately hunted, and the population was allowed to expand for about 8-10 years (Stegeman 1938). In the early 1920s, an attempt was made to hunt these animals. Only 2 animals were killed and an estimated 60-100 others escaped and 
SRNL-RP-2009-00869

dispersed into adjoining lands and interbred with domestic swine that roamed freely (Stegeman 1938). The term "wild hog" was introduced in the Southern Appalachian because of the mixing of wild and domestic stocks (Bratton 1977). Details of this introduction are described by Jones (1957) and Mayer and Brisbin (1991).

Wild hogs first dispersed into the southwest portion of GRSM in the late 1940s and early 1950s (Jones 1957). Currently, wild hogs inhabit all areas of GRSM; however, their densities are not consistent throughout GRSM because they migrate seasonally in response to the phenology of certain plant species and thermo-regulation (Belden and Pelton 1975). In spring, wild hogs move to ridges at the higher elevations $(>1,220 \mathrm{~m}, 4,000 \mathrm{ft})$ where they feed on the rich herbaceous understory of northern hardwood forests; they remain in these areas throughout the summer (Howe et al. 1981). Wild hogs usually begin returning to lower elevations in mid-August; these movements are correlated with the drop of acorns, which are their primary food during this time (Henry and Conley 1972, Scott and Pelton 1975, Otto 1978). During fall and winter months, wild hogs prefer warm xeric slopes at low elevations (Otto 1978).

The population density of wild hogs in GRSM is unknown. Surveys to estimate wild hog population abundance are difficult to conduct and have not been applied in GRSM. Singer and Ackerman (1981) estimated the GRSM wild hog population to be approximately 1,500 animals. Observations, rooting damage and control program success indicate that the current population estimate of wild hogs in GRSM is only a few hundred animals (E. K. DeLozier National Park Service personnel communication.). Anecdotal information suggests that the population fluctuates drastically with available food resources.

\section{Wild Hog Impacts}

The impacts caused by wild hogs in GRSM result directly from their movements, habitat use, and foraging activities. Of greatest concern are the destructive effects hogs have on natural and cultural resources of GRSM. Rooting by wild hogs profoundly disrupts natural vegetative communities, individual species populations, forest succession patterns, and forest nutrient cycles (Bratton 1974, Bratton 1975, Howe and Bratton 1976, Huff 1977, Howe et al. 1981, Bratton et al. 1982, Singer et al. 1984). Wild hogs affect the fauna in GRSM through predation, habitat alteration, and competition for available food resources (Matschke 1965, Henry and Conley 1972, Ackerman et al. 1978, Singer et al. 1984). Wild hogs are a host for infectious and parasitic diseases that may affect other wildlife, livestock and people (Wood and Barrett 1979, Davidson and Nettles 1997). Serological surveys of wild hogs in GRSM have revealed evidence of porcine parvovirus, leptospirosis, and toxoplasmosis (New et al. 1994, Diderrich et al. 1996). Cultural resources including home sites and cemeteries are also negatively impacted by wild hogs. Details of wild hog impacts in GRSM were described by Tate (1984).

\section{Management}

Because wild hogs have a negative impact on GRSM resources, complete eradication is desirable. However eradication probably is an unattainable goal. The high reproductive potential of this species allows for rapid recovery of population levels which may quickly compensate for any reduction following food shortages or effective control actions. Because of this biological potential of the species, the relative inaccessibility to remote areas of GRSM, and existing populations outside GRSM, the wild hog population may be difficult to eradicate. Current management strategies, therefore, emphasize mitigating the impacts of wild hogs by maintaining population abundance at the most reduced level that can be sustained and supported by long term base funding.

\section{Research and Monitoring}

Research on wild hogs in GRSM has included species biology (Henson 1975, Scott and Pelton 1975, Williamson and Pelton 1975, Williamson and Pelton 1976, Singer and Ackerman 1981, Johnson et al. 1982, New et al. 1994, Diderrich et al. 1996), movements and habitat use (Belden and Pelton 1975, Belden and Pelton 1976, Howe and Bratton 1976, Matschke and Hardister 1966, Otto 1978), resource impacts (Bratton 1974, Bratton 1975, Singer et al. 1984, Lacki and Lancia 1986, Lusk et al. 1993), and management (Matschke and Hardister 1966, Williamson and Pelton 1971, Fox and Pelton 1977, Tate 1984, Wathen 


\section{Wild Pigs}

1987, Peine and Farmer 1990, Keller et al. 2003). A wild hog rooting index to monitor population levels was also developed but proved to be ineffective.

In recent years, there has been evidence of the illegal release of feral hogs in the region. Several hogs trapped or shot in GRSM have exhibited atypical colorations or physical characteristics (e.g., white or spotted coloring, curly tail, short snout) that differ from the traditional black color phase found in GRSM, but are typical of feral hogs from other regions. The illegal transport and release of feral hogs raises concerns regarding disease transmission. These concerns, along with state regulatory demands, prompted us to begin a cooperative effort with the North Carolina Department of Agriculture and Consumer Services (NCDACS) to monitor for diseases of wild hogs. Since 1999, 177 serum samples have been collected from hogs removed from the North Carolina side of the GRSM (16.9\% of wild hogs removed in North Carolina since 1999). All of the samples have tested negative for swine brucellosis, pseudorabies and hog cholera (classical swine fever). Other wild hog monitoring programs include exclosures to monitor long term impacts to vegetation, and hard mast surveys to ascertain acorn production (Wentworth 1989) an important food for wild hogs.

\section{Population Control}

Personnel - Wild hog control began in GRSM in 1959. Early control activities were sporadic and conducted by law enforcement and maintenance employees who also had other duties. In 1977, Resource Management staff was hired and devoted exclusively to wild hog control with about 2 personnel-years of effort per year. From 1986 to 1988 and 1990 to 1992, GRSM received special funds to conduct wild hog control. The increased funding provided additional personnel and more equipment to substantially address the problem throughout GRSM. This more aggressive approach improved the efficiency of the program and the reduction effort (Fig. 1). Since 1991, field staff has remained nearly the same with a full staff consisting of 3 permanent employees, 3 seasonal employees and 4 interns through the Student Conservation Association, Inc. Typically, a full staff expends about 4.8 personnel-years of effort per year. Law enforcement rangers still shoot wild hogs as part of their duties, but have accounted for less than $5 \%$ of the hogs removed during the past 5 years.

Volunteers have been used to assist with wild hog control in GRSM. In 1981, a citizen's volunteer group was established with members of a sportsmen club from Graham County, North Carolina. The citizen's volunteer group provided personnel to livetrap and relocate wild hogs at low elevations in the southwest portion of GRSM. The program was an effort to reconcile differences with local residents of North Carolina regarding the GRSM methods used to control wild hogs. The conflict was associated with shooting wild hogs, which sportsmen considered as a waste of meat. Because GRSM does not have a practical, economical or legal avenue for donating wild hogs to charitable organizations, euthanized hogs are buried or used for research. Historically, trapping by the citizen's volunteer group was a significant part of the wild hog control program in North Carolina. However, as the hog population declined so did the interest by the group and by 1991, the effort was terminated. Today, volunteers assist only by locating areas with recent hog rooting.

Fencing - Fencing in GRSM has been minimal and directed at protecting sensitive habitats otherwise known as special protection areas. In 1985, 3 areas in GRSM were identified and fenced. Two of these areas were wetlands where the habitat is unique and rare species occur (Bratton et al. 1982). The third area is in a northern hardwood forest, high elevation beech gap. These areas range from 4 to 15 ha (10 to $37 \mathrm{ac}$ ) and are protected by $1-\mathrm{m}(39 \mathrm{in})$ high woven wire fencing with a $10.2 \mathrm{~cm}(4 \mathrm{in}) \mathrm{mesh}$.

Trapping - The box-type portable trap has been the most practical and efficient trap for capturing wild hogs in GRSM. The trap frame is $1.3 \mathrm{~cm}(0.5 \mathrm{in})$ inside diameter schedule 40 pipe braced in the corners with flat bar steel. Trap dimensions are $91.4 \mathrm{~cm}$ (36 in) high x $91.4 \mathrm{~cm}$ (36 in) wide x $152 \mathrm{~cm}$ (60 in) long. The back of the trap frame is covered with 9 gauge-5.1 cm (2 in) mesh chain-link fencing and the sides, top, and bottom are covered with 11 gauge- $5.1 \mathrm{~cm}$ (2 in) mesh chain-link fencing. The fencing is attached to the frame with $15.3 \mathrm{~cm}(6$ in) wire ties. The top of the trap has a $22.9 \mathrm{~cm}(9 \mathrm{in}) \times 22.9 \mathrm{~cm}(9 \mathrm{in})$ opening to allow non-target animals to escape. The door frame is $193 \mathrm{~cm}$ (76 in) high and $92.7 \mathrm{~cm}$ (36.5 in) wide 
and made of angel iron and flat bar. The door is made of $96.5 \mathrm{~cm}$ (38 in) by $91.4 \mathrm{~cm}(36 \mathrm{in}), 0.23 \mathrm{~cm}$ (0.090 in) 6061 alloy aluminum sheeting. The cost of materials is approximately $\$ 150$ per trap.

The trap trigger mechanism consists of 2 pieces of $38.1 \mathrm{~cm}$ (15 in) rebar, of which, $7.6 \mathrm{~cm}$ ( 3 in) is bent 90 degrees at one end and a $25.4 \mathrm{~cm}(10 \mathrm{in})$ piece of wood tied with parachute cord. The rebar is driven into the ground about $25.4 \mathrm{~cm}$ (10 in) apart near the back of the trap with the 90 degree angle pointing to the rear of the trap. The stick is placed under the rebar and the cord goes straight up through the top of the trap and over the door frame, to the door. Traps are baited with shelled or fermented corn. We have experimented with other baits and attractants with little success (Wathen 1987). The trap is triggered by the rooting behavior of the hog as it eats the shelled corn.

Historically, GRSM has maintained cooperative agreements with the North Carolina Wildlife Resources Commission (NCWRC) and the Tennessee Wildlife Resources Agency (TWRA) to relocate trapped wild hogs to wildlife management areas (WMAs) outside GRSM that are open to public hunting; these WMAs are located on United States Department of Agriculture Forest Service (USFS) lands. In 2003, the cooperative agreement with TWRA was not renewed because of concerns by the USFS related to wild hog impacts on their lands. Trapped hogs not donated to state wildlife agencies are humanely euthanized (Beaver et al. 2001) and buried or collected for scientific purposes.

Shooting - A combination of trapping and shooting has been the most cost-effective method for controlling wild hogs in GRSM. The type of firearm and hunting method utilized vary by season. From late fall to early spring (November through March), large caliber rifles (30-30, 30-06, 300 whisper) are used to shoot hogs. Shooting with rifles is done mostly during daylight hours and allows individuals to hunt in more remote and rugged areas which generally cannot be trapped or hunted at night. During summer months (April through August) shooting is done mostly with a 12-gauge shotgun equipped with a light and " 00 " buckshot. During summer the shooting range is limited because of thick vegetation and low light conditions. Handguns are not a recommended firearm for free range shooting of wild hogs because of their limited range; however, .357 handguns are used to humanely euthanize trapped wild hogs. Shot wild hogs are buried or used for research purposes. Draft guidelines for use of natural resources firearms have been established in the NPS Departmental Safety Manual.

Other Equipment - There are new technologies associated with hunting big game animals that are useful in controlling wild hogs. We recently purchased night vision scopes, scent lock suits, suppressed firearms, portable tree stands, and digital cameras. Night vision scopes have improved hunting success by increasing the ability to detect wild hogs at night. Scent lock suits improve hunting success by reducing human scent which may scare a wild hog. Suppressed firearms improved hunting success by allowing multiple shots at a group of hogs increasing the number of hogs removed per encounter. Digital remote cameras have also proven useful for determining activity patterns of wild hogs.

\section{Control Statistics}

Since 1959, GRSM personnel have removed 10,392 wild hogs, of which 5,672 (54.6\%) were from the North Carolina side and 4,626 (44.5\%) were from the Tennessee side; location coordinates were not recorded for 85 animals $(0.8 \%)$. The number of wild hogs removed annually has ranged from 2 in 1959 to 1,146 in 1986 (Fig. 1). Differences in the number of wild hogs removed annually are associated with funding and staffing levels, political constraints, and abundance of the wild hog population.

Wild hog control in GRSM is conducted primarily from December to late June (Fig. 2). Factors affecting seasonal wild hog control in GRSM include the availability of natural foods which influences trapping and hunting success, phenology of plants which inhibits visibility and hunting success during summer, staffing requirements for other wildlife management activities, restrictions associated with the length of employment for seasonal employees and limited funding.

GRSM has donated 4,006 wild hogs (38.5\% of all animals removed) to state wildlife agencies (Fig. 3) of which 3,105 went to NCWRC (54.7\% of all animal removed from North Carolina) and 901went to TWRA (19.5\% of all animals removed from Tennessee). More wild hogs have been donated to NCWRC because 


\section{Wild Pigs}

there is better wild hog habitat in North Carolina, more emphasis has been expended on trapping to control wild hogs in North Carolina, historic restrictions on shooting to control wild hogs have existed in North Carolina, and a more flexible cooperative agreement has existed with the NCWRC.

GRSM staff has removed 4,059 wild hogs (39.1\% of all animals removed) by shooting (Fig. 3). The proportion of animals removed annually via shooting has changed in recent years (Fig. 4). From 1959 to 1992, 27.9\% of wild hogs were removed by shooting, however since 1993, 63.2\% have been removed by shooting. The greater proportion of animals removed by shooting in recent years can be attributed to low trapping success because of a lower hog population, more liberal and widespread shooting due to less controversy, better equipment (e.g., high-caliber, suppressed rifles and accessories) which improved hunting or shooting success, and increasingly experienced employees.

\section{Environmental Considerations}

The availability and distribution of natural foods, particularly acorns, affects control efforts. When acorns are abundant, trapping success is generally lower. Sometimes the oak mast is abundant in the less accessible high-elevation areas, which affects logistics associated with trapping and hunting. Wild hog reproduction is also strongly associated with oak mast production (Matschke 1964) and control efforts following an oak mast failure result in a greater proportion of adults removed. Since 1991, oak mast failures in GRSM occurred in 1992, 1997 and 2003, and the proportion of adults removed the years that followed, were $78.0 \%, 78.6 \%$ and $79.3 \%$, respectively, compared with an average of $58.3 \%$ in other years (Fig. 5).

Large carnivores may also impact the GRSM wild hog population. Wild hog remains are frequently found in coyote (Canis latrans) scat throughout GRSM and during months when wild hog control in GRSM is less intense. GRSM staff has witnessed coyotes killing and feeding on young wild hogs and observed indirect evidence (e.g., coyote tracks overlapping wild hog tracks in snow). In 1993, during the attempted recovery of the red wolf (Canis rufus) in GRSM, Fish and Wildlife Service staff documented the kill of a wild hog by red wolves (C. Lucash, Fish and Wildlife Service, pers. comm.). Black bears (Ursus americanus) and bobcats (Lynx rufus) likely also kill wild hogs in GRSM.

\section{Political Considerations}

The GRSM wild hog control program has always been controversial as the wild hog is considered a valuable big game animal to sportsmen in east Tennessee and western North Carolina. In 1977, the controversy escalated following the experimental use of non-NPS contract hunters and dogs. After an unsuccessful attempt to find local hunters, GRSM hired 2 hunters with 6 dogs from Georgia to capture 100 hogs in 14 days. Four days of dog hunting resulted in 1 hog removed. Moreover, the contract ignited extreme hostility by local hunters, particularly in North Carolina. As a result, a moratorium was established on shooting hogs in GRSM until a wild hog management plan was written and approved. In April 1978, the moratorium was lifted but shooting could only occur in Tennessee. Areas in North Carolina could only be trapped. In 1985, a smaller "zone of control" was established in North Carolina where only trapping could be conducted to control wild hogs; in 1987 this zone was reduced to areas below $792 \mathrm{~m}(2,600 \mathrm{ft})$ and in 1990 the zone was eliminated. Since 1977, dogs have never been used again for wild hog control in GRSM.

In 1980, GRSM was accused of using chemical sterilants, poisons, and/or pesticides in the bait used to capture wild hogs. The accusations resulted in representatives from Graham County, North Carolina and the North Carolina Department of Public Health collecting bait samples and sending them to the Environmental Protection Agency, all of which tested negative for the presence of any toxic ingredients. In 1981, controversy resulted from a publication in the Wall Street Journal, which described government hog hunting in GRSM.

More recently, in 1999, a petition was initiated in Blount County, Tennessee and Graham County, North Carolina to stop killing wild hogs in GRSM. Although the petition received some attention, local support 
was minimal. Today, although there are still a few local sportsmen who express concern about the GRSM wild hog control program, it is less controversial than the late 1970s and early 1980s.

\section{Future Management Needs}

An expansion of the scope and sophistication of new technologies that may assist with control techniques for wild hogs is needed to improve the overall effectiveness of the program, particularly when population levels are low. A practical population index technique needs to be established to ascertain effectiveness of management programs and to relate acceptable impact limits to population numbers. More attention should be directed at the illegal movement of feral swine, particularly as it relates to disease issues. GRSM needs to continue to improve relationships with local sportsmen groups and continue to share information with other agencies on control techniques. Finally, GRSM needs to secure stable funding to maintain a staff that can keep the GRSM wild hog population consistently low. 


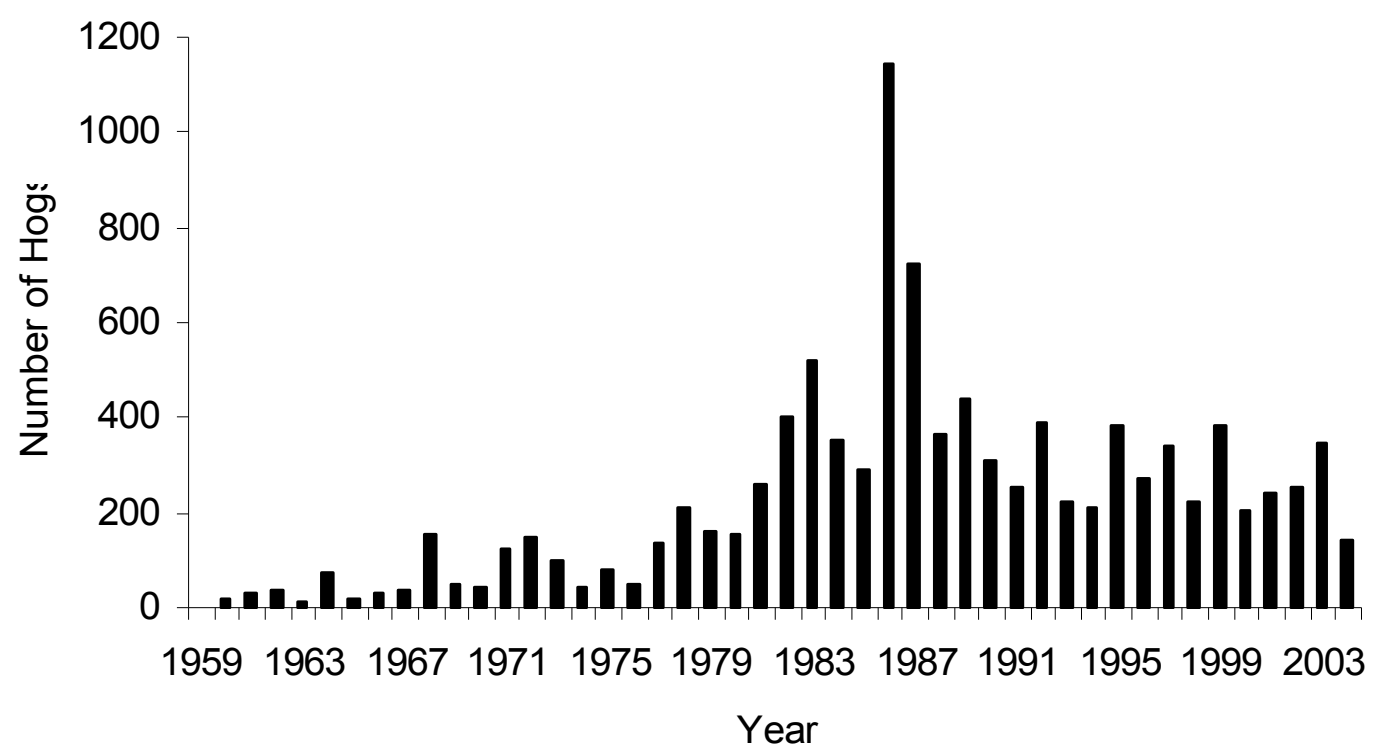

Fig. 1. Number of wild hogs removed by year from Great Smoky Mountains National Park, 1959-2004.

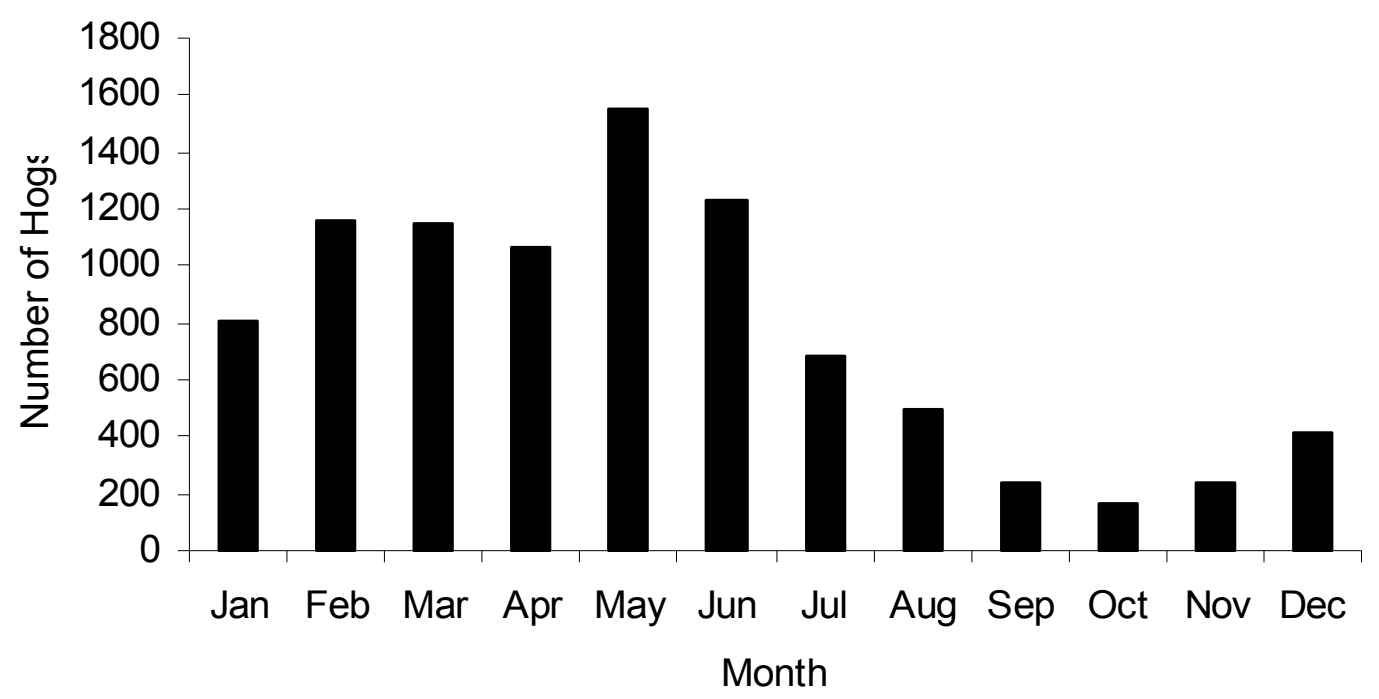

Fig. 2. Number of wild hogs removed by month from Great Smoky Mountains National Park, 1977-2004. 
— Shot $⿴$ Trapped/Euthanized $\square$ Trapped/Donated $\square$ Other

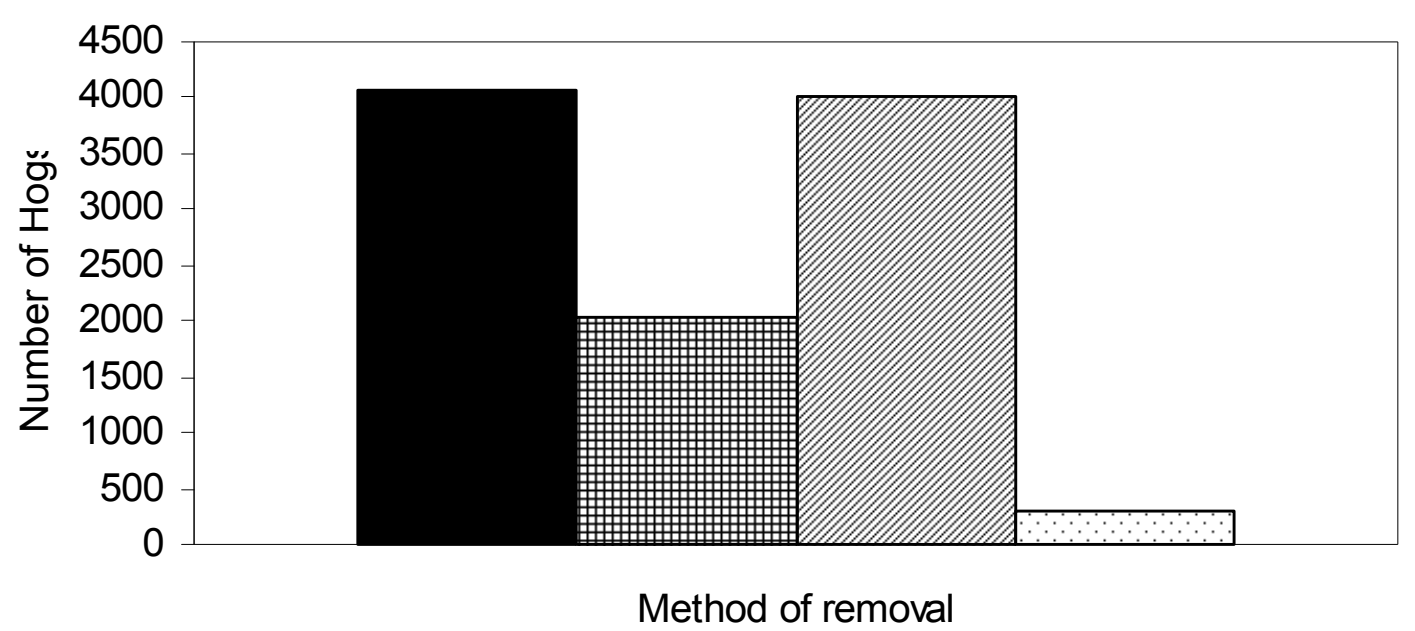

Fig. 3. Number of wild hogs removed by method from Great Smoky Mountains National Park, 1959-2004.

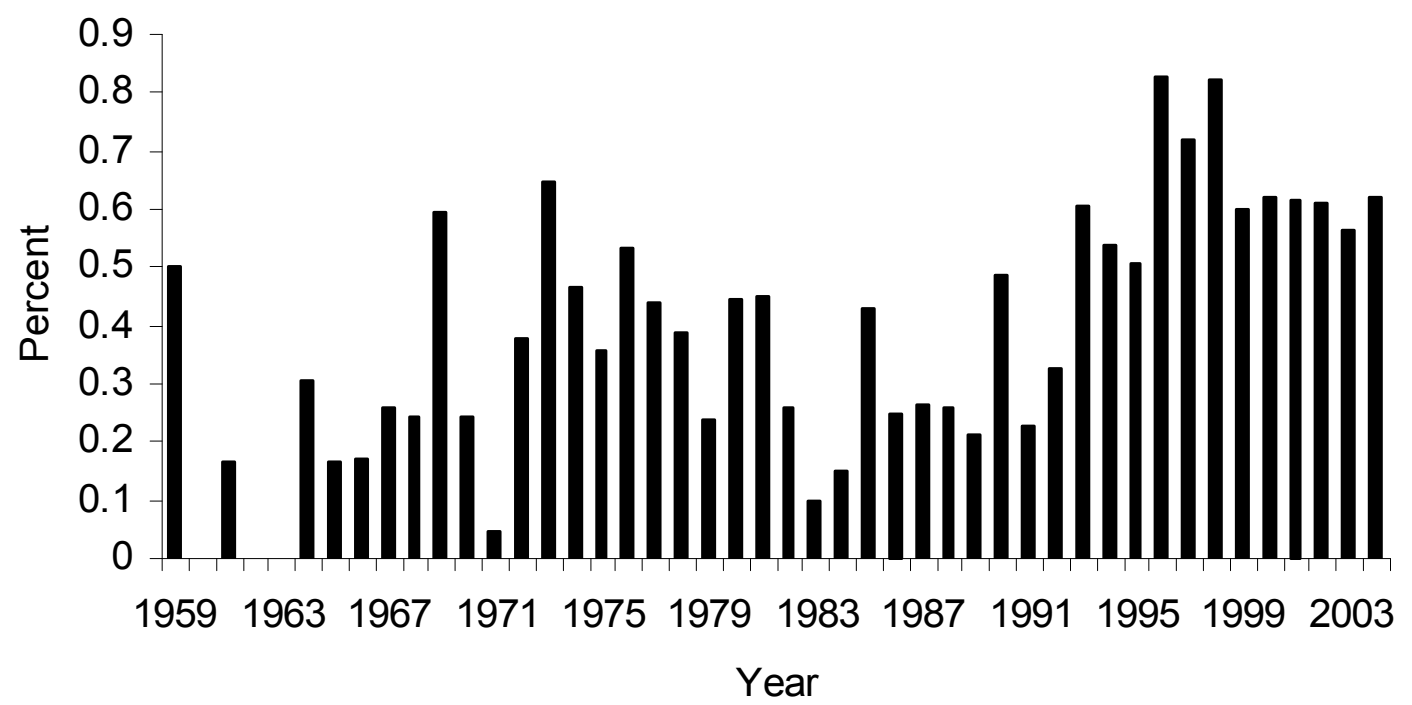

Fig. 4. Percentage of wild hogs removed by shooting from Great Smoky Mountains National Park, 19592004. 
Wild Pigs

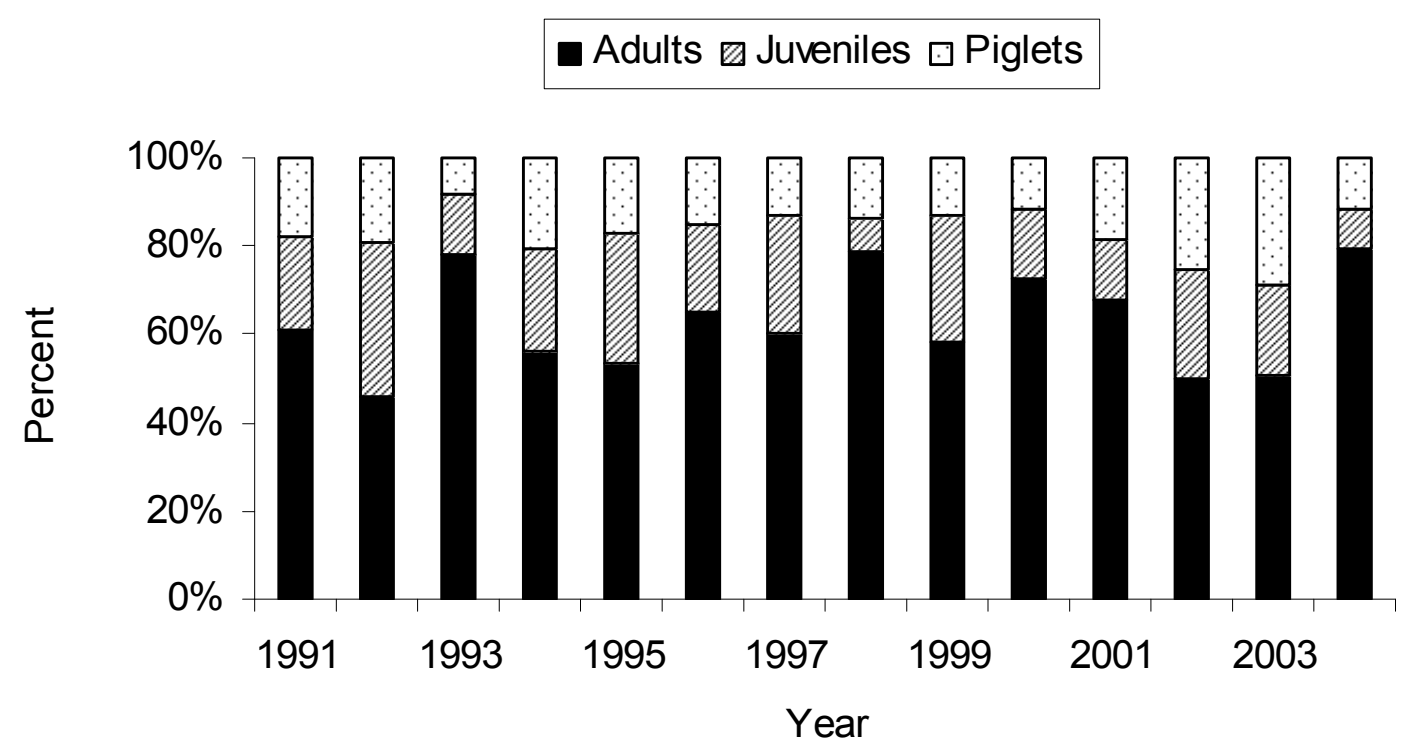

Fig. 5. Percentage of wild hogs removed by age class from Great Smoky Mountains National Park, 19912004. 


\section{Literature Cited}

Ackerman, B. B., M. E. Harmon, and F. J. Singer. 1978. Part II. Seasonal food habits of European wild boar - 1977. Pp. 94-137. In F. J. Singer (ed.), Studies of European wild boar in the Great Smoky Mountains National Park: 1st annual report; a report for the Superintendent. Uplands Field Research Laboratory, Great Smoky Mountains National Park, Gatlinburg, Tennessee.

Beaver, B. V., W. Reed, S. Leary, B. McKiernan, F. Bain, R. Schultz, B. T. Bennett, P. Pascoe, E. Shull, L. C. Cork, R. Francis-Floyd, K. D. Amass, R. Johnson, R. H. Schmidt, W. Underwood, G. W. Thornton and B. Kohn. 2001. Report of the AVMA panel on euthanasia. Journal of the American Veterinary Medical Association, 218:669-696.

Belden, R. C., and M. R. Pelton. 1975. European wild hog rooting in the mountains of East Tennessee. Proceedings of the Annual Conference of the Southeast Association of Fish and Wildlife Agencies, 29:665-671.

Belden, R. C., and M. R. Pelton. 1976. Wallows of the European wild hog in the mountains of east Tennessee. Journal of the Tennessee Academy of Sciences, 51:91-93.

Bratton, S. P. 1974. The effect of European wild boar (Sus scrofa) on the high-elevation vernal flora in Great Smoky Mountains National Park. Bulletin of the Torrey Botanical Club, 101:198-206.

. 1975. The effect of the European wild boar (Sus scrofa) on the Gray Beech Forest in the Great Smoky Mountains. Ecology, 56:1356-1366.

. 1977. Wild hogs in the United States - Origin and nomenclature. Pp. 47-52. In G. W. Wood (ed.), Research and Management of Wild Hog Populations: Proceedings of a Symposium. Belle W. Baruch Forest Service Institute of Clemson University, Georgetown, South Carolina.

Bratton, S. P., M. E. Harmon, and P. S. White. 1982. Patterns of European wild boar rooting in the Western Great Smoky Mountains. Castanea, 47:230-242.

Davidson, W. R., and V. F. Nettles. 1997. Field manual of wildlife diseases in the Southeastern United States. Book Production Resources, Athens, Georgia, USA.

Diderrich, V., J. C. New, G. P. Noblet, and S. Patton. 1996. Serologic survey for Toxoplasma gondii antibodies in free-ranging wild hogs (Sus scrofa) from the Great Smoky Mountains National Park and from sites in South Carolina. The Journal of Eukaryotic Microbiology, 43:122

Drees, L. 2004. A retrospective on NPS invasive species policy and management. Park Science, 22:21-26.

Fox, J. R., and M. R. Pelton. 1977. An evaluation of control techniques for European wild hog in the Great Smoky Mountains National Park. Pp. 53-65. In G. W. Wood (ed.), Research and Management of Wild Hog Populations: Proceedings of a Symposium. Belle W. Baruch Forest Service Institute of Clemson University, Georgetown, South Carolina.

Henry, V. G., and R. H. Conley. 1972. Fall foods of the European wild hogs in the southern Appalachians. Journal of Wildlife Management, 36:854-860.

Henson, T. M. 1975. Age determination and age structure of European wild hogs (Sus scrofa). Master of Science Thesis. The University of Tennessee, Knoxville.

Howe, T. D., and S. P. Bratton. 1976. Winter rooting activity of the European wild boar in the Great Smoky Mountains National Park. Castanea, 41:256-264. 


\section{Wild Pigs}

Howe, T. D., F. J. Singer, and B. B. Ackerman. 1981. Forage relationships of European wild boar invading northern hardwood forests. Journal of Wildlife Management, 45:748-754.

Huff, M. H. 1977. The effect of European wild boar (Sus scrofa) on the woody vegetation of gray beech forest in the Great Smoky Mountains. Management Report No. 18, Uplands Field Research Laboratory, Southeast Region, National Park Service, Great Smoky Mountains National Park, Gatlinburg, Tennessee.

Johnson, K. G., R. W. Duncan and M. R. Pelton. 1982. Reproductive biology of European wild hogs in the Great Smoky Mountains National Park. Proceedings of the Annual Conference of the Southeast Association of Fish and Wildlife Agencies, 36:552-564.

Jones, P. 1957. A historical study of the European wild boar in North Carolina. Master of Arts in Education Thesis, Appalachian State Teacher's College, Boone, North Carolina.

Keller, R. D., R. G. Litchford, J. C. Brinson, A. D. Carroll, J. M. Houck, H. F. Mauney, and M. T. McDonald. 2003. Hog Wild: Using GIS to examine 26 years of wild boar control efforts (1976-2001) in the Great Smoky Mountains National Park. ArcUser, 6:12-13.

King, P. B., and A. Stupka. 1950. The Great Smoky Mountains - their geology and natural history. The Scientific Monthly, 71:31-43.

Lacki, M. J. and R. A. Lancia. 1986. Effects of wild pigs on beech growth in Great Smoky Mountains National Park. Journal of Wildlife Management, 50:655-659.

Linzey, D. W. 1995. Mammals of Great Smoky Mountains National Park. Journal of the Elisha Mitchell Scientific Society, 111:1-81.

Lusk, M. R., M. J. Lacki and R. A. Lancia. 1993. Responses of deer mice, Peromyscus maniculatus (Mammalia: Rodentia), to wild hog rooting in the Great Smoky Mountains National Park. Brimleyana, 19:169-184.

Matschke, G. H. 1964. The influence of oak mast on European wild hogs. Proceedings of the Annual Conference of the Southeast Association of Game and Fish Commissioners, 18:35-39.

1965. Predation of European wild hogs on dummy nests of ground-nesting birds. Proceedings of the Annual Conference of the Southeast Association of Game and Fish Commissioners, 19:154-156.

Matschke, G. H., and J. P. Hardister. 1966. Movements of transplanted European wild boar in North Carolina and Tennessee. Proceedings of the Annual Conference of the Southeast Association of Fish and Wildlife Agencies, 20:70-84.

Mayer, J. J., and I. L. Brisbin, Jr. 1991. Wild pigs in the United States: Their history, comparative morphology, and current status. The University of Georgia Press, Athens, Georgia. USA.

New, J. C., Jr, K. DeLozier, C. E. Barton, P. J. Morris and L. N. D. Potgieter. 1994. A serologic survey of selected viral and bacterial diseases of European wild hogs, Great Smoky Mountains National Park, USA. Journal of Wildlife Diseases, 30:103-106.

Otto, D. K. 1978. Movements, activity patterns, and habitat preferences of European wild boar in Great Smoky Mountains National Park. Master of Science Thesis, Virginia Polytechnic Institute and State University.

Peine, J. D., and J. A. Farmer. 1990. Wild hog management at Great Smoky Mountains National Park. Proceedings of the Vertebrate Pest Conference, 14:221-227. 
Scott, C. D., and M. R. Pelton. 1975. Seasonal food habits of the European wild hog in the Great Smoky Mountains National Park. Proceedings of the Annual Conference of the Southeastern Association of Fish \& Wildlife Agencies, 29:585-593.

Singer, F. J., and B. B. Ackerman. 1981. Food availability, reproduction, and condition of European wild boar in Great Smoky Mountains National Park. United States Department of the Interior, National Park Service, National Park Service-Southeast Region Research/Resources Management Report Number 43.

Singer, F. J., W. T. Swank, and E. E. C. Clebsch. 1984. Effects of wild pig rooting in a deciduous forest. Journal of Wildlife Management, 48:464-473.

Stegeman, L. J. 1938. The European wild boar in the Cherokee National Forest, Tennessee. Journal of Mammalogy, 19:279-290.

Stupka, A. 1960. Great Smoky Mountains National Park natural history handbook. Number 5. United States Government Printing Office, Washington, D.C.

Tate, J. 1984. Techniques for controlling wild hogs in Great Smoky Mountains National Park: Proceedings of a Workshop, November 29-30, 1983. United States Department of Interior, National Park Service, Research/Resources Management Report SER-72.

Wathen, G. 1987. Attractant and bait preferences of wild hogs in Great Smoky Mountains National Park. Pp. 23. In J. D. Wood Jr. (ed.), Abstracts of the Thirteenth Annual Scientific Research Meeting, Great Smoky Mountains National Park, May 21-22, 1987. United States Department of the Interior, National Park Service, Science Publications Office, Atlanta, Georgia.

Wentworth, J. M. 1989. Deer habitat relationships in the Southern Appalachians. Dissertation. University of Georgia, Athens, Georgia, USA.

White, R. H. 1982. The flora of Great Smoky Mountains National Park: An annotated checklist of the vascular plants and a review of previous floristic work. United States Department of the Interior, National Park Service, Southeast Region Resource Management Report Ser-55.

Williamson, M. J. and M. R. Pelton. 1971. New design for a large portable mammal trap. Proceedings of the Annual Conference of the Southeastern Association of Game and Fish Commissioners, 25:315322 .

1975. Some biochemical parameters of serum of European wild hogs. Proceedings of the Annual Conference of the Southeastern Association of Game and Fish Commissioners, 29:672-679.

1976. Some hematological parameters of European wild hogs (Sus scrofa). Journal of the Tennessee Academy of Sciences, 51:25-28.

Wood, G. W., and R. Barrett. 1979. Status of wild pigs in the United States. Wildlife Society Bulletin, 7:237-246. 
Wild Pigs

\title{
Wild Pig Management Case Study: \\ Cumberland Island Feral Hog Management
}

\author{
W. Edward O'Connell and John F. Fry \\ Cumberland Island National Seashore, P.O. Box 806, St. Mary’s GA 31558
}

\section{Introduction}

Cumberland Island National Seashore is a federally owned property administered by the National Park Service. The primary function of the park is to provide opportunities for the public to experience the cultural, biological and recreational features of the barrier island ecosystem. The barrier island, located in the southeast corner of Georgia, is comprised of approximately 22,000 acres of upland, $96 \%$ of which is under federal ownership. The island is 17 miles in length from north to south and varies in width from $1 / 2$ to $2 \frac{1}{2}$ miles. Twenty two plant communities have been described (Hillestad et al. 1975) and 5 of these are upland forest with oaks as a major component. Developed areas are approximately $2 \%$ of the island and include historic park structures, private homes, park maintenance facilities and fields/airstrips. The remaining portion of the island is largely undeveloped and composed of a variety of habitats. The habitat breakdown is as follows: upland oak forests $(40 \%)$, mixed forest $(25 \%)$, pine/shrub $(10 \%)$, swamp $(5 \%)$, lakes/sawgrass $(5 \%)$, beach/dunes $(10 \%)$, and interdune (5\%). It is in part due to this variety of habitats that the hogs are so successful. Hogs can typically move short distances and capitalize on available food sources depending on season and rainfall. Typical feeding patterns include: (1) acorns from fall to early spring, (2) tuber, forb and grass consumption in wetlands during greenup, and (3) fiddler crabs in marshes and rooting through the summer. As an island, Cumberland does not have adjoining land areas except on the northern tip where Little Cumberland Island is separated by Christmas Creek and salt marsh. There are pigs in small numbers on Little Cumberland, but otherwise immigration from adjoining land areas is not a factor.

\section{History of Pig Population}

The precise arrival of pigs to the island is uncertain. Due to a lack of historic information, a definitive date cannot be set. However with the arrival of Spanish and British colonists, it is likely that pigs accompanying them were released on Cumberland (Mayer and Brisbin 1991). Presumably the pigs brought by these colonists were of domestic and European origin. Feral hogs are established throughout the island presently, and display a variety of domestic and wild characteristics. Changes in the population size over time have been poorly documented. Due to the large acreage and difficulty in reaching portions of the island, accurate estimates of population have not been made. Most observations tend to be qualitative and focus on direct sightings of pigs and their rooting areas.

\section{Damage/ Impacts}

At some point during the year, pigs utilize almost all of the habitats on the island. There are very few areas that are not impacted in some way by them. The majority of the impacts center on the rooting behavior of pigs. Disturbance of the soil surface and the uprooting of plants is readily observable. Pigs may alter the plant community composition in both the understory and overstory. Their consistent consumption of oak acorns may change the recruitment rate of oaks. It is their rooting of sea turtle nests on the island that is particularly undesirable. Loggerhead sea turtles (Caretta caretta) utilize the beaches of Cumberland Island for their nesting habitat. Large numbers of these nests located above the high tide line have been depredated by pigs in past years. As a federally threatened species, the protection of these turtles and their eggs is an important goal of the Park Service. Despite screening of the nests, pigs were still able to destroy 
them. With the arrival of a contractor in 2001 who was able to hunt the beaches at night, the pigs demonstrating this behavior have largely been removed.

A second area of concern is impacts in wetlands, due to their importance as unique habitats for many plant and animal species, their role in water and nutrient cycling, and their limited extent. Rooting by pigs in these areas can affect shallowly rooted plants, substrate configuration and bank condition. Hogs may spend considerable time in these areas in order to stay cool during the summer. Wetlands on Cumberland, both forested and not, vary both in extent and duration depending on recent rainfall. The forested wetlands tend to have a less developed groundcover and often are used by pigs in times of mast production. These areas often have a well developed shrub layer and are not generally open enough for hunting. The more open interdune wetlands have a varied forb and grass layer, in which the pigs often search for roots and tubers. With enough rain in the spring, these areas become lush and attract hogs when the acorns have been finished.

The third area in which impacts have been seen is general rooting in the upland forest communities. From late spring through fall, small areas are often observed with the uppermost several inches essentially turned over. While small in extent they often occur frequently throughout the forest and have in the past covered acres in extent when combined. These areas were prominent island wide in the fall of 2002, but after a half year of management in the fall of 2003 showed an estimated 50\% decrease. Rooted areas may remain evident for over a year, but recent activity is readily discernible.

\section{Management}

The National Park Service policy toward the feral hogs is that they are an exotic species that does not belong in the native ecosystem. Their competition with native species for food, disturbance of natural and cultural areas, and impact on nesting sea turtles are all reasons to eradicate them. Our current management goal is eradication of the pig population on Cumberland island if possible, otherwise to limit adverse effects on seas turtle nests, rare plant communities and cultural/recreational resources receiving public visitation (NPS 2002).

Cumberland Island National Seashore was established in 1972 and the history of hog control has been varied. Between 1975 and 1983 1,500 hogs were live trapped and removed from the island. Feral hogs were added as a bonus animal to the public hunts in 1983. In the next 9 years 402 pigs were taken by public hunters. In the spring of 1992 commercial hog trappers removed 300 pigs in two months. With the addition of two hog only public hunts, 1,190 hogs were taken on public hunts between 1992 and 2000. Park Service personnel shot 513 hogs between 1994 and 2001 in an effort to reduce the impacts on sea turtle nests. Through a contract with U.S. Dept. of Agriculture-Wildlife Services, 372 hogs were taken from 2001-2003. For the period beginning in 1975 and ending in 2002, the average number of pigs taken through all means each year was 164 .

The Park Service received funding for a full time technician to work exclusively on pigs in 2003 . The following data incorporates the results of control efforts from March 2003-March 2004. The two primary methods of control that have been utilized are controlled shooting and trapping. Controlled shooting targets pigs in open oaks, marshes and using night vision capability on the beach. As the island is visited by the public, we place a priority on their safety. By having someone on the island working exclusively on the pigs, travel corridors and typical seasonal movements have been documented. With attention to prevailing wind, tide and food availability hunting in specific areas of the island has been successful. For the first year of the current program, 457 pigs were removed with shooting. The distribution and percentages within age classes and sexes were as follows: adult male 123 (27\%), adult female 169 (37\%), juvenile male $87(19 \%)$ and juvenile female 78 (17\%). The trend of slightly higher numbers in the adult female category is what we expected. As adult boars are solitary for the most part, they were taken as encountered. Large groups of pigs were typically composed of several adult females and their offspring. When encountering a drift of pigs, the shooter would typically try to select a "lead" pig, often a mature female. Other pigs in the group, particularly juveniles would often stay in the area following the first shot. The totals of pigs taken with controlled shooting indicate the encounter rate plus the bias towards targeting 


\section{Wild Pigs}

larger females. Pigs have largely been removed from developed areas and along roads and trails. Sightings of pigs and rooting activity have decreased significantly.

Trapping is the other control method utilized on the island. In the same one year period as above, 750 trap nights resulted in the capture of 123 pigs. The distribution of age and sex classes: adult male $33(27 \%)$, adult female $27(22 \%)$, juvenile male $30(24 \%)$, and juvenile female $33(27 \%)$. Traps were of a corral design, with a root trigger and sliding door. They are designed to be large enough for multiple captures, but are also constructed to be broken into four pieces and transported by one person. The general inside dimensions were 5 by 10 feet. The distribution among age classes and sex in captured pigs suggested no bias in the individuals captured. Prebaiting had occurred in order to find out in what areas the pigs were active and to acclimate them to the presence of the traps. The overall capture rate was $16 \%$, but it decreased from $30 \%$ to $2 \%$ through the year as the density of hogs decreased. Large portions of the island are designated wilderness, and it is impractical to move traps far into these areas. Traps were generally placed near travel corridors, in areas with abundant hog sign, and adjacent to the beach. Due to the large size of the island and limitations in placement of traps, generally less than 10 were open at a given time. Typically when acorns are plentiful, the use of traps is not successful.

For the first year of the program, cost per pig removed from the park was near $\$ 100$. This price will increase as the density of pigs decreases and the time spent in locating them grows. Both controlled shooting and trapping have been successful. Trapping success appears to be correlated with pig density. In many cases traps have removed most of the pigs in the areas where the traps could be located. In general, whole corn was the bait employed, but consideration should definitely be given to other baits when available. The presence of large numbers of raccoons (Procyon lotor) often interfered with trapping, largely due to false trigger trips. Once raccoons became familiar with a baited site, they were consistently present. Shooting can be effective in areas with acorns on the ground, marshes at low tide and twilight, and locations with recent hog activity or food sources. With the use of night vision equipment, hunting of the pigs that utilize the beach nocturnally has been successful. This was particularly effective in dealing with pigs impacting nesting sea turtle nests. Portions of the island with dense vegetation were not conducive to hunting. Having someone in the field full time has proven to be valuable. Observations of the movements of pigs along with the locations of food and water sources over time has led to site specific management efforts. Control efforts need to remain flexible to be effective.

Future management activities will largely be the result of funding and personnel availability. While our goal remains eradication, we realize that this may not be possible. The one factor in our favor is island geography. Cumberland is far enough from the mainland to remove the possibility of immigration from neighboring pig populations. Future management will consider all options including the use of dogs. However the presence of extensive dense vegetation, private inholdings on the island, and the lack of accessibility to some of the wilderness designated areas may limit the success of this technique as well. 


\section{Literature Cited}

Hillestad, H. O., J. R. Bozeman, A. S. Johnson, C. W. Berisford, and J. I. Richardson. 1975. The Ecology of Cumberland Island National Seashore, Camden County, Georgia. Georgia Marine Science Center, Technical Report Series 75-5.

Mayer, J. J., and I. L. Brisbin, Jr. 1991. Wild pigs in the United States: Their history, comparative morphology, and current status. The University of Georgia Press, Athens, Georgia.

NPS (U. S. National Park Service). 2002. Environmental assessment of the management alternatives, feral hog population control, Cumberland Island National Seashore, U. S. National Park Service, St. Marys, Georgia. 
Wild Pigs

\section{Wild Pig Management Case Study: Ft. Benning Military Reservation}

Stephen S. Ditchkoff and Michael S. Mitchell

School of Forestry and Wildlife Sciences, Auburn University, AL 36849 (SSD)

Alabama Cooperative Fish and Wildlife Research Unit, 108 M. White Smith Hall, Auburn University, AL 36849 (MSM)

\section{Introduction}

Site Description - This manuscript provides a description of the feral pig (Sus scrofa) population on the United States Army Infantry Training Center located at Ft. Benning, Georgia (Fig. 1). The Ft. Benning Army Infantry Training Center is a United States Department of Defense facility and is 73,655 ha in size: $93 \%(68,745 \mathrm{ha})$ of the contiguous facility is located in 2 counties in Georgia, with 7\% (4,910 ha) located in 1 county in Alabama. The Alabama and Georgia sections of the facility are separated by the Chattahoochee River, which is approximately $100 \mathrm{~m}$ wide at this portion of its course.

Approximately $16 \%(11,734 \mathrm{ha})$ of the military base comprises unmanaged cantonment areas and range/military closures. The cantonment areas (5,260 ha) are developed lands with housing, administrative, storage, and other developments necessary for the operation of a military facility. The remaining unmanaged lands $(6,474 \mathrm{ha})$ are natural/disturbed habitats heavily used for military training. Throughout most of this area, human activity is tightly restricted due to live-fire training and other dangerous or sensitive activities. The managed natural lands of the facility comprise $84 \%(61,921 \mathrm{ha})$ of the total land area. Mixed pine (21,069 ha), hardwood (21,000 ha), longleaf pine (Pinus palustris; 3,856 ha), and loblolly pine (P. taeda; 7,296 ha) are the major floral communities found on the base. Planted pine communities consist of loblolly pine $(3,844 \mathrm{ha})$ and longleaf pine $(4,856 \mathrm{ha})$.

The installation is located within the East Gulf Coastal Plain and is characterized by level ridges tops and gentle slopes. The climate is semi-tropical with an average annual rainfall of $124 \mathrm{~cm}$ (Dilustro et al. 2002). Pine forests dominate ridges and are separated by hardwood bottoms (Doresky et al. 2001). The dominant softwood species on the area are longleaf, loblolly, and slash pine (P. elliottii), and the dominant hardwood species found are post oak (Quercus stellata), laural oak (Q. laurifolia), turkey oak (Q. laevis), water oak (Q. nigra), southern red oak (Q. falcate), white oak (Q. alba), sweetgum (Liquidambar styraciflua), tulip poplar (Liriodendron tulipifera), and blackgum (Nyssa sylvatica). The northwestern portion of the military base is bordered by Columbus, GA, which is a metropolitan area with a human population of approximately 185,000 . The remainder of the facility is surrounded by a mixture of agricultural and forest lands. The major agricultural crops of the area are cotton, peanuts, and soybeans. The forested lands are a mosaic of pine plantations, mixed pine-hardwood uplands, and hardwood bottomlands.

Site Management - Natural lands on Fort Benning are managed by civilian Department of Defense employees of the Environmental Division. Within the Environmental Division are the Conservation and Land Management Branches. The Conservation Branch is responsible for management decisions relating to wildlife, endangered species, etc. The Land Management Branch takes the lead on decisions relating to forests, and is responsible for implementing timber harvest prescriptions, prescribed burning, etc. Management decisions relating to feral swine fall under the jurisdiction of the Conservation Branch. Forests at Ft. Benning are managed primarily for the longleaf pine ecosystem as driven by conservation needs for the red-cockaded woodpecker. Approximately 2,250 ha of forests are harvested (thinned or clearcut) annually, with most of this harvest consisting of thinning. Additionally, approximately 500 ha of longleaf pine are plated each year: only longleaf is planted to meet objective of restoring the longleaf pine 
SRNL-RP-2009-00869

ecosystem. Because of the importance of fire to longleaf pine habitats, 14,000 ha are treated with prescribed fire annually. Approximately 80 ha of wildlife plantings are maintained on the installation.

\section{History of Pig Population}

Introduction of the Population - The original source of feral pigs at Ft. Benning is unknown. It is believed that feral pigs became established on the facility through normal range expansion. The Chattahoochee River and several other large tributaries of the Chattahoochee flow across the base; because feral pigs tend to prefer riparian habitats, these tributaries could have served as travel corridors. Although official records of feral swine are not available prior to the 1970s, anecdotal records indicate that feral swine were present at Ft. Benning at least as early as the 1950s. The predominance of agriculture surrounding Ft. Benning at that time suggests it is possible that feral swine could have been introduced, although this is conjectural. Within an intensively agricultural landscape matrix, Fort Benning may have provided the only available forested habitats and local residents could have introduced pigs onto Ft. Benning to create a huntable population. Alternatively, free-ranging livestock have been a part of agricultural practices in the Southeast since European settlers arrived; pigs almost certainly escaped domestication on many occasions since then and may well have been present well before the 1950s.

Since the 1920s, introducing Eurasian wild boar as a game animal has become common throughout the Southeast. Intentional or unintentional introductions of wild boar have undoubtedly contributed to the feral pig population on Fort Benning. It is not clear to what extent current populations are descendents of escaped or released domestics or introduced Eurasian boars. Most likely, the type of wild pig that inhabits Ft. Benning is descended primarily from domestic stock. Coloration patterns (white spots, etc.) and morphology (curled tails, heavy hams) of many of the hogs on the base suggest considerable domestic influence. Most of the animals that are harvested by hunters annually, however, demonstrate a physical appearance (e.g., slim body line, heavy shoulders, and long snout) similar to the Eurasian wild boar. Although the presence of these body forms do not indicate that pure-strain Eurasian wild boar were ever introduced to Ft. Benning or surrounding lands, they do suggest either a hybridization between domestic breeds and wild boar, or reversion among the feral pigs to ancestral morphologies best adapted to surviving in the wild.

Expansion of the Population - Little data are available regarding expansion of the feral pig population following introduction/colonization. Ft. Benning personnel suggest that feral pigs have increased continually over the past several decades. Ft. Benning personnel further suggest that the frequency of sighting increased dramatically during the early 1990s, suggesting that the pig population was exploding. Originally, feral swine were found almost exclusively in lowland areas and riparian drainages. However, during the late 1990s, they had become much more prevalent in upland areas, suggesting that high population densities and competition for resources were forcing individuals to move into what are normally considered marginal habitats. Due to the difficulty in censusing wild animal populations, particularly feral swine which tend to aggregate in habitats with low visibility, no data are available regarding densities of feral pigs on Ft. Benning. However, data collected from hunter harvest surveys suggest that more feral pigs are harvested annually than white-tailed deer (Odocoileus virginianus).

\section{Damage by Feral Pigs}

Summary of Damage - Damage by feral pigs at Ft. Benning can be classified into 2 categories: disturbance of natural systems and disturbance of human activities and structures. Disturbance of natural systems at Ft. Benning is similar to what can be found in other locales where feral swine are present. Rooting or overturning of soil is probably the most widespread form of damage. As has been described previously (Singer et al. 1984, Dickson et al. 2001), feral swine, in their search for insects and edible roots and tubers, overturn soil extensively while foraging. At Ft. Benning, it is not uncommon to find areas of overturned, bare soil and exposed roots in excess of $1,000 \mathrm{~m}^{2}$ in area. Rooting is most common in riparian habitats and wildlife plantings, but can be found almost anywhere. This form of disturbance is probably least common in upland areas predominated by dry soil types. As a result of their propensity to root and wallow in riparian areas, resulting stream sedimentation can be a major problem. Stream sedimentation 


\section{Wild Pigs}

due to hog activity is not uncommon (Singer et al. 1984) across their range, and while not yet studied on Ft. Benning, visual observations suggest that sedimentation is occurring.

Probably the greatest concern of resource managers at Ft. Benning is the impact that feral swine may have on species of concern. Of specific interest at Ft. Benning are the relict trillium (Trillium reliquium), gopher tortoise (Gopherus polyphemus), and red-cockaded woodpecker (Picoides borealis). Relict trillium is a federally-listed species, and currently there are 7 populations of relict Trillium on Ft. Benning. Rooting by feral pigs has historically caused damage to these populations indirectly through soil disturbance. Although there is little, if any, direct evidence of impacts of feral pigs on the Georgia state-listed gopher tortoise, there have been documented examples of pig predation on herpetofauna and their nests (Coblentz and Baber 1987, Taylor and Hellgren 1997), suggesting that feral pigs may adversely affect gopher tortoises as well. Additionally, feral pigs have the potential to indirectly influence the endangered red-cockaded woodpecker by inhibiting recruitment of longleaf pine seedlings. Lipscomb (1989) found that rooting by feral pigs could reduce density of regenerating longleaf pine seedlings by $98 \%$. The well-developed tap roots of long-leaf pine seedlings are highly preferred forage when available (Hardtner 1935). While hog predation on longleaf pine would not have short-term effects on red-cockaded woodpeckers, the presence of feral pigs could reduce longleaf recruitment and ultimately availability of preferred longleaf habitat in the future.

Feral pig disturbance of human activities and structures at Ft. Benning is widespread, but the magnitude of the disturbance and damage is unknown because much of the damage may be indirect and no means of reporting pig damage is common to all military units using the base. Feral pig rooting can result in extensive damage to equipment and motorized vehicles. Several live-fire ranges are spread across the installation, and often include underground wiring that is a part of executing and monitoring training exercises. When feral swine root in these areas, it is common for underground electrical wires to be damaged. In rare circumstances, equipment can become stuck or be overturned and damaged where pigs have rooted extensively. The effects that feral swine can have on motorized vehicles have been documented, but the impact that feral pigs have on motorized vehicles at Ft. Benning is unknown. Considering that military training exercises often rely upon heavy use of motorized vehicles in uneven terrain, damage caused to vehicles by hog rooting likely is considered to be the result of normal wear-andtear of uneven terrain. Feral swine are also indirectly responsible for injuries to humans at Ft. Benning. On several occasions, paratrooper training exercises have resulted in injuries due to landing on uneven ground caused by hog rooting. Additionally, it is likely that soldiers on foot have sustained injuries from stepping on uneven ground caused by hog rooting.

History of Damage - The extent of damage caused by feral pigs has been positively associated with increases in pig density. As pig density increased during the 1990s, damages increased as well. Although a thorough review of hog damage has yet to be conducted at Ft. Benning, natural resource management personnel at the facility believe that if the feral pig population continues to increase, it is likely that it could become a significant threat to the ecological integrity of the Ft. Benning landscape. Additionally, it is likely that a concurrent increase in damage and disturbance to human activities and structures would increase as well.

\section{Management of the Feral Pig Population}

Management Strategy - Currently, the main management objectives of Ft. Benning regarding feral pigs are to monitor and to control the population. The pigs are valued by hunters as a big game species, and considerable numbers of feral pigs are harvested annually. However, the propensity of pigs to disturb natural resources and human activities, and undermine ecosystem integrity has caused considerable concern among natural resource managers on base. The challenge for managers is thus a difficult one, where they must balance reduction of damage by pigs to a critically important ecosystem against providing their hunting constituency with satisfactory opportunities to harvest pigs. Whereas eradication may be the optimal solution for preserving ecosystem functions, eradication is probably impossible at Ft. Benning because of the extensive acreage of the installation, the large acreage that is not readily accessible, and the potential source pool of feral pigs outside the installation. Further, because feral pigs are highly valued by many hunters at Ft. Benning, serious attempts at eradication would be politically disastrous. At best, 
management efforts can hope to keep the pig population at a size providing a satisfactory annual harvest while minimizing negative effects on the ecosystem and military training.

Management Activities - Ft. Benning currently employs 3 control techniques for feral pigs. The primary form of control is through hunting. Although the Ft. Benning installation in not open to the general public for hunting, active military, retired military, active reservists, and federal employees stationed on Ft. Benning are permitted to hunt. In 2003, Ft. Benning natural resource personnel began trapping feral pigs in localized areas where damage was extensive and hunting pressure was ineffective at controlling damage. Large, live traps are baited with whole corn, and any pigs that are trapped are euthanized. Personnel at Ft. Benning remove approximately 25 wild pigs annually, but these removal efforts are normally confined to areas of high human activity where hunting is not permitted. The final technique that is employed to control impacts of feral pigs is exclusionary fencing. Three of the 7 relict trillium populations that had been damaged by pig activity were surrounded by $1 \mathrm{~m}$ exclusionary fencing secured with t-posts in 1997 . The areas that have been fenced range in size from 0.3 to 2.5 ha. Within the fenced areas, the trillium populations are now prospering due to the low level of disturbance. On rare occasions, pigs have gained entry into these areas, but their impacts have been negligible.

Prior to 2000, no data were collected regarding number of pigs that were harvested by hunters. Since then, harvest cards have been distributed to each hunter annually, and hunters were requested to report the number of pigs harvested. However, approximately $33 \%$ of the cards were not returned each year, and unlike deer, hunters were not required to report pig harvest. Table 1 provides data on the number of hunters returning harvest cards, as well the numbers of pigs and white-tailed deer that were reported. From 2000-2004, almost as many pigs (938.75 \pm 321.08 [SD]) were reported harvested as white-tailed deer (1196.75 \pm 107.36$)$. Considering hunters are not required to report harvest of feral pigs, it is likely that actual harvest of feral pigs substantially exceeded that of deer. The data indicate that on average, hunters harvest a pig for every 78 ha. However, if we do not include unhuntable areas (e.g., cantonment and permanent closures) in the calculation, then hunters harvest a pig for every $65 \mathrm{ha}$, and normally at least part of this "huntable" landbase is closed on a daily basis due to military activities. Ft. Benning personnel suspect that the low numbers of feral pigs harvested during the 2001-2002 hunting season may have been due to the terrorist attacks of 11 September 2001. While the deer harvest did not diminish appreciably, there was a noticeable decrease in hunter effort during that year.

Currently, few data are available regarding costs of the feral pig control programs at Ft. Benning. The hunting program, like at most other locations, is a cost-effective tool for removing large numbers of feral pigs, although its effectiveness in controlling or reducing pig density is unknown. Expenses associated with constructing exclusionary fencing were not documented, but results suggest the exclosures have been very effective. However, economics dictate that in most cases only small areas can be protected with this technique. There are no data available to estimate the costs associated with trapping of feral pigs at Ft. Benning.

\section{Future Management Needs}

Planned Management Strategy - The planned management strategy for the feral pig population is to monitor and control the population. Although this strategy is somewhat general and vague, implementation of a more detailed strategy with precise management objectives is not currently possible. Ft. Benning personnel acknowledge that feral pigs pose a serious threat to the integrity of the natural ecosystem on the facility, and additionally cause large amounts of disturbance to human activity and structures. However, uncertainty about the efficacy of control techniques for feral swine do not allow for a more detailed strategy. Little is known about the pigs inhabiting Fort Benning, to include population size, demographic trends, movements, foraging behaviors, and food habits. Particularly in the absence of demographic information, the success of a lethal control program is hard to predict. Nothing is known about the level of mortality needed in a lethal control program needed to minimize or reverse population growth. Given the immense reproductive capacity of feral pigs, it is entirely possible that increasing mortality would result in a compensatory reproductive response from the population and control would thus be ineffective. Because of these and other questions, Ft. Benning is collaborating with researchers at Auburn University and the 


\section{Wild Pigs}

Alabama Cooperative Fish and Wildlife Research Unit to examine the ecology and management of feral pigs on the facility.

Current and Future Research - Currently, researchers at Auburn University and the Alabama Cooperative Fish and Wildlife Research Unit have begun a 5-year project to examine the ecology of feral hogs at Ft. Benning. The overall goal of the study is to generate data that will allow Ft. Benning personnel to develop a more detailed feral pig management strategy and allow more effective responses to problems associated with feral pigs. The specific objectives of the study are to:

1. Estimate the relevant demographic parameters and sensitivities of feral hog populations (annual survival, fertility, and population growth rates) necessary to examine the effects of management practices on the Fort Benning area.

2. Evaluate the distribution, movements, and habitat use of feral hogs and associated effects on gopher tortoises and sensitive habitats.

3. Evaluate effects of feral hogs on species of special concern through food habits analysis.

4. Evaluate effects of feral hogs on military training.

5. Determine the efficacy of population control measures in reducing the impact of feral hogs on the distribution and abundance of gopher tortoises, sensitive habitats, and military training.

Concurrent with this research, Ft. Benning is changing the way hunter harvest data are collected for feral pigs. More accurate harvest data, combined with detailed research, should provide a baseline from which a more effective management strategy can be implemented. Additionally, the detailed analysis of population

demographics that will be generated from the research should enable development of more effective control techniques for feral pigs that can be tested with the Ft. Benning population.

\section{Acknowledgments}

We appreciate reviews of this manuscript by P. Swiderek and R. Thornton. Assistance with maps was provided by A. Silvano and the Alabama Gap Analysis Project. Support was provided by the Ft. Benning United States Army Infantry Training Center, the School of Forestry and Wildlife Sciences at Auburn University, and the Alabama Cooperative Fish and Wildlife Research Unit. 
SRNL-RP-2009-00869

Table 1. Number of hunters ${ }^{\mathrm{a}}$, and feral pigs and white-tailed deer harvested during 2000-2004 at the U.S. Army Infantry Training Center in Ft. Benning, Georgia.

\begin{tabular}{cccc}
\hline Hunting Season & Hunters & Feral Pigs Harvested & Deer Harvested \\
\hline $2000-2001$ & 1,455 & 981 & 1,223 \\
$2001-2002$ & 1,308 & 499 & 1,197 \\
$2002-2003$ & 1,430 & 1,270 & 1,313 \\
$2003-2004$ & 1,437 & 1,005 & 1,054 \\
\hline
\end{tabular}

${ }^{a}$ Number of hunters represents the number of harvest cards that were returned each year. Approximately $33 \%$ of the harvest cards were not returned annually. 


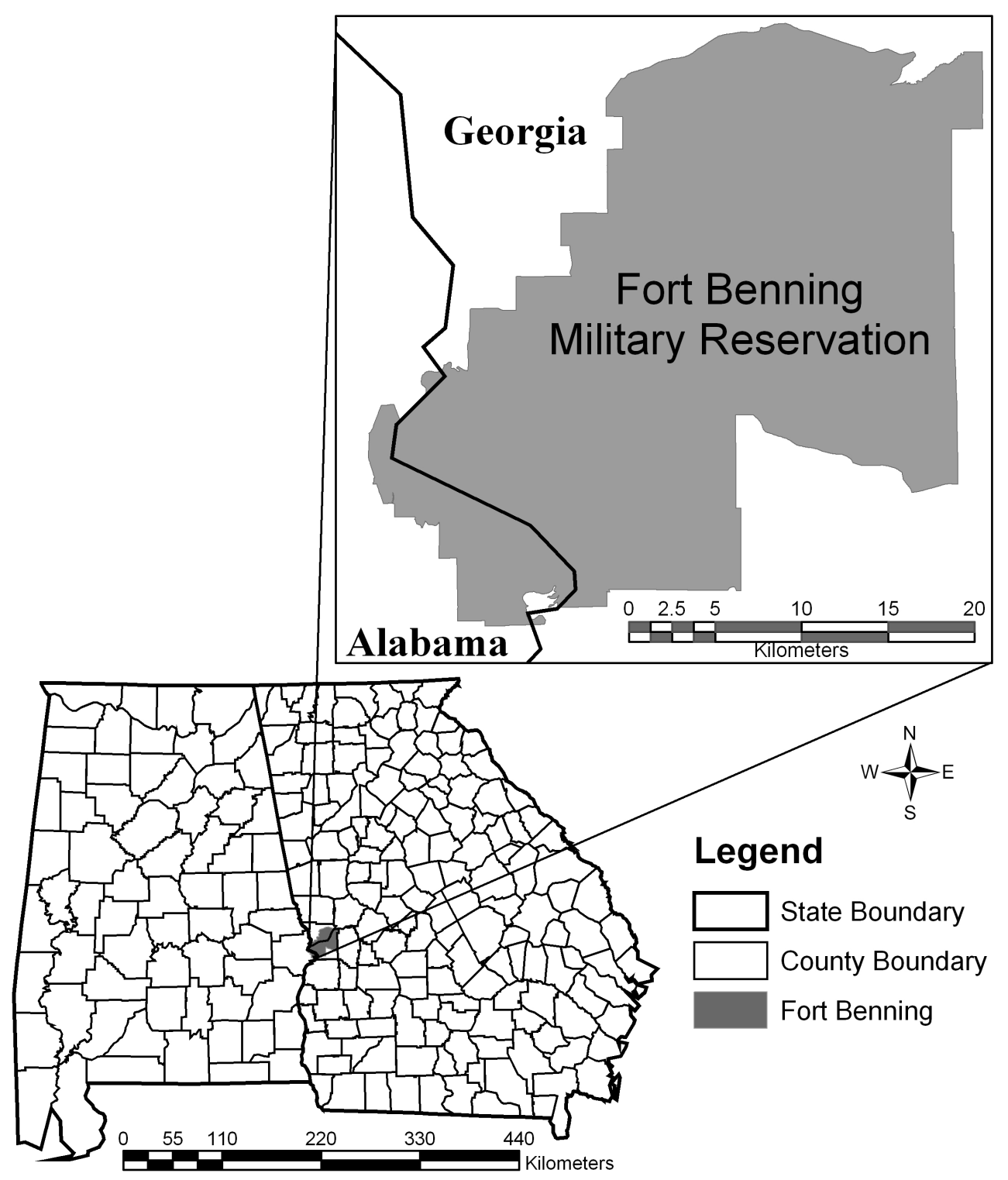

Figure 1. Map depicting the relative location and size of the United States Army Infantry Training Center in Georgia and Alabama, USA. 


\section{Literature Cited}

Coblentz, B. E., and D. W. Baber. 1987. Biology and control of feral pigs on Isla Santiago, Galapagos, Ecuador. Journal of Applied Ecology, 24:403-418.

Dilustro, J. J., B. S. Collins, L. K. Duncan, and R. R. Sharitz. 2002. Soil texture, land use intensity, and vegetation of Fort Benning upland forest sites. Journal of the Torrey Botanical Society, 129:289-297.

Dickson, J. G., J. J. Mayer, and J. D. Dickson. 2001. Wild hogs. Pp. 191-208. In J. G. Dickson (ed.), Wildlife of southern forests: habitat and management. Hancock House Publishers, Blaine, Washington, USA.

Doresky, J., K. Morgan, L. Ragsdale, and H. Townsend. 2001. Effects of military activity on reproductive success of red-cockaded woodpeckers. Journal of Field Ornithology, 72:305-311.

Hardtner, H. E. 1935. A tale of a root - a root of a tale, root hog or die. Journal of Forestry, 33:351-360.

Lipscomb, D. J. 1989. Impacts of feral hogs on longleaf pine regeneration. Southern Journal of Applied Forestry, 13:177-181.

Singer, F. J., W. T. Swank, and E. E. C. Clebsch. 1984. Effects of wild pig rooting in a deciduous forest. Journal of Wildlife Management, 48:464-473.

Taylor, R. B., and E. C. Hellgren. 1997. Diet of feral hogs in the Western South Texas Plains. Southwestern Naturalist, 42:33-39. 
Wild Pigs

\section{Wild Pig Management Case Study: \\ The Pigs of Ossabaw Island: A Case Study of the Application of Long-term Data in Management Plan Development}

I. Lehr Brisbin, Jr., and Michael S. Sturek

Savannah River Ecology Laboratory, P.O. Drawer E, Aiken, SC 29802 (ILB)

Department of Cellular \& Integrative Physiology, Indiana University School of Medicine, 635 Barnhill

Drive, MS 309, Indianapolis, IN 46202-5120 (MSS)

\section{Introduction}

Management programs to control feral pigs and/or make them available for hunter harvest frequently must be instituted without the benefit of long-term databases describing the characteristics of the animals to be managed. When available however, such long-term data can prove invaluable in helping to tailor the resulting management plan and goals to the specific habitat and population to be managed. In some rare instances moreover, such long-term data can also identify unique characteristics of the target population and may in turn raise important issues that need to be considered, beyond simply how best to exterminate or reduce numbers to the maximum extent possible. We describe one such case concerning the pigs of Ossabaw Island, Georgia, which long-term research has now shown to represent an important animal model for studies of obesity and diabetes, two diseases which have now become epidemic in many human populations worldwide (Marx 2002, Holden 2004). We also describe how properly coordinated data collections from animals being removed in control programs can serve the best interests of both research aimed at studying the pigs themselves, as well as conservation interests attempting to reduce pig numbers to the maximum extent possible.

\section{Study Area}

Ossabaw Island is one of the largest of the few remaining Georgia coastal barrier islands that are undeveloped and still largely uninhabited. The island is 16 kilometers in length and 13 kilometers wide and is located to the southeast of the city of Savannah (Chatham County), Georgia. In May, 1978, Ossabaw Island was sold/gifted to the State of Georgia whose Department of Natural Resources (DNR) now manages it as a State Heritage Preserve (Waller and Barrett 2001). The island encompasses 3,641 hectares of high ground and 6,499 hectares of tidal salt marsh. A detailed account of the flora, fauna and major habitat associations has been provided elsewhere (Waller and Barrett 2001, and references therein).

\section{Population History}

Throughout its recorded history Ossabaw Island has been inhabited by free-ranging feral swine which, as in the case of other southeastern coastal barrier islands, were first released by the earliest Spanish explorers of the New World. These releases were made in an effort to stock these islands with readily available sources of fresh meat to provision the Spanish missions and fortresses which were being established in this region in the early-mid 16 ${ }^{\text {th }}$ century (Mayer and Brisbin 1991). Mitochondrial DNA analysis of Ossabaw Island pigs captured in 2002 revealed an Asian DNA sequence in all individuals, not the European DNA sequence of Iberian pigs as previously thought (Lloyd et al. 2006b). This Asian haplotype was similar to that of pigs from the Canary Islands (Clop et al. 2008), which are known to have been the source of many pigs brought to the New World by Spanish explorers (Mayer and Brisbin 1991). Feral swine have continued to occupy Ossabaw Island through the following periods of colonial plantation development and subsequent private 
ownership by sportsmen who valued these animals as quarry for hunting. During their history of occurrence on the island, Ossabaw pigs have remained largely isolated from any significant introductions of mainland feral, domestic or other swine - certainly more-so than in the case of any other Georgia barrier island (Mayer and Brisbin 1991). Although several domestic boars were released on the island in the 1960's 70 's in an effort to "improve" the quality of the resident herd, these individuals were short-lived and although some phenotypic markers of their genetic input still exist in certain portions of the island, allozyme analyses have shown that Ossabaw feral swine, as a population, are genetically distinct from their mainland counterparts (Smith et al. 1980).

A Hampshire boar was introduced to Ossabaw Island and persistence of the belted coat color phenotype attests to its continuing genetic impact. Since the Ossabaw pig has no natural predators, coat color has relatively little impact on survival. However the "VQ" mutation (Arginine $200 \rightarrow$ Glutamine) in the PRKAG3 gene (the $\gamma 3$ isoform of AMP-activated protein kinase), which is associated with high muscle glycogen and low intramuscular fat and is found in high frequency in Hampshires (Andersson 2003), was not found in any of the Ossabaw pigs sampled (Lloyd et al. 2006b). This finding suggests that the unpredictable island food supply selects against the Hampshire "unthrifty" metabolic genotype, i.e., propensity for leanness, not obesity. No adult pigs genotyped were homozygous for the wild-type "VR" allele (Valine 199-Arginine 200); in contrast, the Ossabaws were heterozygous or homozygous for the "IR" mutation (Valine 199 $\rightarrow$ Isoleucine) in the PRKAG3 gene (Lloyd et al. 2006b). The IR allele is associated with low muscle glycogen and increased intramuscular fat, consistent with the obese Ossabaw pig "thrifty genotype" and their ability to survive the "feast and famine" ecology of Ossabaw Island. A piglet obtained by cesarean section was homozygous for the VR allele of the PRKAG3 gene and it is intriguing to know whether it would have survived to adulthood in the island environment (Sturek and Brisbin, unpublished).

A new era in the history of Ossabaw Island feral swine began in the late 1960's when scientists from the University of Georgia and a number of other research institutions began to study the Ossabaw Island pigs and publish the results in the peer-reviewed literature of a number of scientific disciplines. This contrasts strongly with the history of most other populations of feral swine which are usually subjected to control measures without the benefit of a significant body of published literature concerning the biology of the animals themselves. Usually, previously published studies if any, are limited to issues of general ecology, and particularly, possible strategies for management/control of the population (e.g., Bratton 1975, Singer et al. 1984).

At the time that in-depth studies of the general biology of the Ossabaw Island pigs began, the population had been existing for at least a number of decades in a state of periodic cycles of "boom or bust" response to cycles of the island's acorn mast crop abundance. Although no quantitative data were collected during this period, collaborated reports of a number of former island residents confirmed that any sport hunting pressure by the island's previous owners had failed to control population growth to the point of eliminating severe over-abundance, resulting in consequential malnutrition and starvation. Even into the early 1970's, the senior author personally observed fully-grown adult pigs that were so weakened by malnutrition that they would fall to the ground and be unable to rise when pursued by humans or dogs. As will be indicated later however, these periodic episodes of overabundance and exceeding of the island's food resources undoubtedly favored adaptations that would enhance survival during such periods of food shortage and malnutrition. Beginning in the late 1980's, more intensive efforts were made to control pig numbers on the island. Information from the Department of Natural Resources (1992) indicated that from 1989 through mid-1992, pigs were being removed from the island at an average rate of 1,147/year. Pigs removed from the island were used for various purposes including research and/or slaughter, or sale to mainland hunting preserves (R. Parker, pers. comm.). However despite this removal of over a thousand pigs per year, discernible damage to other island resources continued to occur in the form of depredation of sea turtle nests and the rooting of oak hammock and salt marsh vegetation (Department of Natural Resources 1992). 


\section{Wild Pigs}

\section{Previous Studies}

Taken together, three decades of research have documented the following unique traits in the Ossabaw Island pig, which (to our knowledge) have never been reported in any other population of feral swine. These unique traits include:

1. Ossabaw Island pigs have the smallest adult body size of any feral population of swine anywhere in the world, with the possible exception of the pigs of the Andaman Islands in the Bay of Bengal (Brisbin et al. 1977, Mayer and Brisbin 1991). A full-grown sexually mature female Ossabaw Island pig, carrying a full-term litter of fetuses can weigh less than 100 pounds!

2. Ossabaw Island pigs have been shown to contain higher levels of body fat reserves (mass of fat/mass of lean-dry body) than those from any other population of feral swine or, for that matter, than any other species of terrestrial wild mammal (Stribling et al. 1984). Recent studies on pigs removed from Ossabaw Island in 2002 have verified the propensity to obesity that far exceeds other laboratory research and domestic swine (Talbott et al. 2006, Dyson et al. 2006, Witczak et al. 2005).

3. Controlled captive studies at the Pennsylvania State University have shown Ossabaw Island pigs to be able to tolerate high concentrations of salt in their diet, and the water they drink (i.e., high concentrations of seawater) compared to other swine (Zervanos et al. 1983).

4. Ossabaw Island pigs have unique lipid-handling enzyme and hormone systems, which allow them to rapidly and efficiently mobilize body fat reserves (Martin et al. 1973, Martin and Herbein 1976, Wangsness et al. 1977, Buhlinger et al. 1978, Hoffman et al. 1983, Scott et al. 1981a, 1981b). Closely related to this trait is the following:

5. Ossabaw Island swine show the "metabolic syndrome" which is largely driven by their outstanding propensity to obesity. When allowed high levels of caloric intake in captivity obesity, insulin resistance, glucose intolerance, dyslipidemia, and hypertension develop (Sturek et al. 2006). Ossabaw swine are the only miniature pigs to develop type 2 diabetes, as evidenced by elevated fasting blood glucose (Bratz et al. 2008). In essence, the metabolic syndrome expressed on Ossabaw Island seems vital to survival, while in captivity, continued excess food supply available to Ossabaws, like the case with their modern day human counterparts, results in the expression of type 2 diabetes pathology (Chobanion et al. 1982, Dyson et al. 2006).

6. Subsequent to long-term obesity, metabolic syndrome, and progression to type 2 diabetes in Ossabaw swine, a constellation of modern human diseases are now being studied in pigs removed from Ossabaw Island in 2002. As indicated in Table 1, these diseases include nonalcoholic steatohepatitis (Lee et al. 2009), polycystic ovary syndrome (Krisher et al. 2006), and coronary artery atherosclerosis and restenosis (Edwards et al. 2008). Evidence suggests that Ossabaw swine are an ideal animal model for studying the efficacy of bariatric surgery (Flum et al. 2007).

The above traits have resulted in the International Union for the Conservation of Nature and Natural Resources (IUCN), in a 1991 survey of conservation priorities for world-wide wild and feral pig populations, naming the Ossabaw Island pig as one of only two forms of feral pigs in the world, which at that time were actually worthy of conservation consideration (Oliver and Brisbin 1993). Of all of these traits however, the most important for consideration in the development of any management guidelines and goals for this population are those related to the metabolic syndrome controlling lipid metabolism and storage and the potential to develop type 2 diabetes and subsequent long-term health complications. These traits make the Ossabaw Island pig an extremely important animal model for applied biomedical and basic biochemical, physiological and genetic studies of these now epidemic conditions in humans (Grundy et al. 1999, Marx 2002). Above all, the Ossabaw pigs now offer researchers in these fields the opportunity, possibly for the first time, to study these conditions in the field under those conditions which likely provided natural selection for the development and/or maintenance of these traits in the first place. 
As described by Neel (1962), the "thrifty genotype" leading to the condition shown by the Ossabaw pigs, would confer a selective advantage under environmental conditions of dependence on a fluctuating and unpredictable food supply such as the annual acorn mast crop of Ossabaw Island. As mentioned previously, during periods of mast crop failure or depletion in late winter months, Ossabaw pigs are often exposed to conditions of severe malnutrition and starvation. This was especially true when a past lack of population control and harvest led to unsustainable high population densities which were a consequence of the inability of this insular population to disperse to other areas such as would be the case with a mainland population. It is not possible however, to determine whether the metabolic syndrome currently shown by the Ossabaw pigs arose de novo after the pigs were released on the island by early Spanish explorers or whether this trait was already present in the pigs released to this and other coastal barrier islands as a result of prior adaptation to similar selection pressures to which these pigs' ancestors had been exposed in the Old World. Unfortunately, hybridization of the free-ranging pigs of other coastal barrier islands of the southeast with either wild boar hybrids or domestics (Mayer and Brisbin 1991) would compromise attempts to study this question by sampling free-ranging pigs from other barrier islands. Some insight however might be gained by studies seeking to document this trait in unselected free-ranging pigs of the Iberian peninsula and/or the Caribbean region where free-ranging populations of pigs were established by the Spanish and then used to subsequently stock expeditions to locations elsewhere in the new world (Mayer and Brisbin 1991). Stribling et al. (1984) concluded that the uniquely high levels of total body fat which they found in Ossabaw Island pigs were not likely to have been derived from earlier domestic ancestors, since more recently derived mainland feral pigs did not show such elevated fat levels.

There has been debate whether the thrifty genotype hypothesis explains the increasing prevalence of metabolic syndrome and type 2 diabetes in modern human society (Diamond 2003, Baschetti 2006, Gerstein and Waltman 2006). A "selection and adaptation" hypothesis that is almost the reverse of the thrifty genotype hypothesis, posits that Ossabaws and all pigs were always exposed to a "diabetogenic" environment in which food was plentiful and only those pigs that could tolerate the excess calorie environment could survive and reproduce. Even only a modest decrease in reproduction would select for resistance to diabetes over just 12-25 generations. Controlled laboratory studies clearly showed that Ossabaw neonates survived longer after food deprivation than leaner breed domestic Yorkshire pigs (Kasser et al. 1981). This finding suggests that "thriftiness" could be essential for Ossabaw Island pigs to reach reproductive age and, thus there would be a strong selection pressure. Whether genotype is related to survival before reproductive age is a critical piece of evidence to address the thrifty genotype hypothesis.

Closely related to the above is the question of whether any other extant populations of free-ranging feral pigs, particularly those isolated in other insular situations, might not also show the above biochemical and physiological traits which are being claimed as being "unique" to the pigs of Ossabaw Island. To date however, no data of this kind has ever been sought in any other free-ranging pig population, and again, the extensive history of hybridization of most all other feral pig populations (Mayer and Brisbin 1991) would suggest that there is little or no probability of such traits remaining detectable in any other population today, particularly in North America.

\section{Management Plan Development}

Whatever its origin, the metabolic syndrome shown by the Ossabaw pigs has important implications for the development and implementation of any plan for the long-term management and control of these animals as part of their island ecosystem. Preliminary studies suggest that some of the unique traits of these pigs may not be stable over time under conditions of captive propagation on the mainland and may be lost over time as the regime of natural selection favoring its development/maintenance on the island is removed. In response to concerns for the continued maintenance of a stable free-ranging population of pigs on Ossabaw Island for use in research in the areas described above, the Georgia DNR appointed a committee of experts in 1992 to make recommendations pertaining to the management of feral hogs on the island, and specifically to (1) evaluate the impact of the hogs on the native flora and fauna and (2) recommend the desired hog population level to control ecological damage to the island (Department of Natural Resources 1992). Although this committee recognized that an argument could be made for the eradication of pigs on the island because of their negative impacts on island resources, the committee did not make this 
recommendation for four reasons: (1) the history of feral pigs as part of the biota and culture of the southeastern coastal region for a long period of time, i.e., for the past nearly 500 years since introduction by Spanish explorers; (2) the value of these pigs as a resource for recreational hunting; (3) the prudence of maintaining a core population on the island as subjects for studies of their unique characteristics as outlined above; and (4) total eradication would be costly and likely would not succeed because of the likelihood of unauthorized/illegal restocking/releases that would almost certainly follow any successful eradication effort as a result of efforts by a "pro-wild pig" lobby of hunters in this region.

From 1998-2000 the Georgia DNR developed a comprehensive management plan (CMP) for Ossabaw Island in order to provide "clear direction to Department personnel and [their] partners in the management and protection of Ossabaw" (Waller and Barrett 2001). The portion of this plan dealing with the management of pigs on the island was developed within a "Management Subcommittee" whose area of responsibility included the management of all wildlife species and other natural resources on the island. This subcommittee was charged with examining all available scientific information, considering public comments made both in writing and orally at designated public meetings seeking public input on the CMP, and then writing a report that served as a chapter in the final plan. Following a procedure similar to that of the 1992 Hog Advisory Committee (see above), the Management Subcommittee of the CMP also considered and expressed strong sentiment for the option of total pig eradication on the island. Consensus could not be obtained on this option however, and thus the subcommittee's report, as published in the CMP, indicated that the DNR would "continue to remove feral hogs to result in no measurable ecological impact." The CMP further indicated that removal rates may, "at times need to exceed 2500 per year." However the CMP did not indicate how this particular removal level was calculated and no quantitative criteria were provided for determining when a level of "no measurable ecological impact" had been attained. The plan did however indicate that "Hunter harvest, observational data, exclosures, shorebird nesting success, sea turtle nesting success and other ecological data" would all serve as "indices" to monitor any ongoing impacts of the island's pigs.

\section{Conclusion: Coordinating Research and Management}

While the goal of removing pigs to minimize their numbers on Ossabaw Island might at first glance appear to conflict with research interests aimed at studying the biology of these animals in their natural island habitat, this need not necessarily be the case. In fact, both of these interests, despite their seemingly disparate goals, would benefit greatly if a coordinated effort could be made to collect even simple demographic data from the pigs which are removed as part of any control program. While feral pigs in general may be a scourge, only a pest, to most ecologists, these pigs in particular also represent a biomedical treasure (Mayer and Brisbin 1995). Ossabaw Island pigs, by all accounts, recapitulate the complex diseases of obesity, metabolic syndrome, and progression to type 2 diabetes and all the long-term health complications associated with these diseases. Demographic, biochemical, and genetic data could help to evaluate the effectiveness of removal/control efforts by enabling conservation interests to better "know thy enemy," while at the same time providing an invaluable data set of basic biological/demographic information needed by researchers, both ecological and biomedical. Such efforts are consistent with a recent plea to promote the use of farm animals in biomedical research (Roberts et al. 2009). Even the recording of several simple pieces of information (e.g., sex, date and location of collection, and body size/weight) could indicate which seasons, age classes and sexes of pigs would be the most effective to target in future removal efforts in order to most effectively achieve a goal of a given reduction in population size. Furthermore, if removed lethally, invaluable data could be obtained concerning age (using dental criteria summarized by Mayer and Brisbin 1991), reproductive condition and foraging habits (Brisbin and Mayer 2001). Genotyping pigs to gain insights about obesity and survival genes would provide an unprecedented opportunity to address the thrifty genotype hypothesis (Du et al. 2008, Neel 1962). The application of new stable isotope techniques to stomach content samples removed from pigs taken in control removal programs could provide important information on the types of habitats being impacted by the pigs and the dynamics of their trophic role in the island's various food webs (Brisbin et al 2003).

To be sure, the collection of this kind of information places additional time demands on personnel charged with pig removal, and state and federal agencies responsible for undertaking these kinds of removal 
programs often do not have sufficient financial resources to compensate for the additional resources that such sample collections and field data recording would require. This may however, be an example of being "penny-wise and pound foolish" in that the kinds of information provided by the collection of even minimal basic data could, when properly analyzed and incorporated into appropriate demographic models (Tipton 1977), make predictions that could in turn, result in substantial savings of personnel time and other resources. This would result from allowing future control efforts to be tailored to the specific population attributes of the pigs themselves and those island habitats from which they most need to be removed in order to realize management plan goals.

To our knowledge, the kind of close coordination of pig removal operations with basic biological research interests and data collection described above has yet to be successfully realized for any free-ranging pig population in the world. We see no reason however, why Ossabaw Island could not and should not be the first to be successful in this regard for several reasons: (1) the deed of transfer which established the island as a Heritage Trust property of the state requires that the interests of both research and island habitat protection be priorities in any management plan; (2) there are few if any pig populations for which the stakes are so high in terms of the potential for basic research to make a direct contribution to human welfare (through studies of obesity and diabetes, particularly the "thrifty genotype" hypothesis); and (3) there is probably no other free-ranging pig population in the world for which a comparable long-term base of published scientific information suggests such a potential for high-return scientific understanding which could be realized from a minimal investment of resources and proper management plan development.

\section{Acknowledgements}

Numerous colleagues have contributed to the research on Ossabaw pigs over the past several decades. For the most part these individuals are acknowledged as authors of the research papers which we have cited. None of this work however could have been undertaken without the strong support, encouragement and hospitality of Ossabaw Island's former owner, Mrs. Sandy West. We hope that future studies of these pigs can eventually prove to be a part of the vision which she has had for her island as a resource for research and education, and thereby contribute to the enhancement of environmental conservation and understanding. We also thank Roger Parker for sharing his experience gained from working with these pigs for many years, and Clarence Bagshaw D.V.M. for his help in the recent removal of a cohort of Ossabaw pigs to the mainland for further study. Dr. Jack Mayer provided invaluable advice and assistance over the years and also provided a critical reading of an earlier version of this manuscript. This work was supported by National Institutes of Health grant RR013223. Fieldwork and manuscript preparation were also supported in part by the Environmental Remediation Sciences Division of the Office of Biological and Environmental Research of the U.S. Department of Energy, through Financial Assistance Award No. DEFRC09-96SR18546 to the University of Georgia Research Foundation. 


\section{Wild Pigs}

Table 1. Modern diseases and uses of Ossabaw miniature swine for biomedical research.

Disease and/or Use

Comments

References

- Adrenal medullary and cortical hormone regulation

- Alzheimer's disease, neurodegeneration

- Atherosclerosis

- Bariatric surgery

R.V. Considine, Indiana

University School of

Medicine, Indianapolis, IN

- Bladder function and disease

- Cardiac innervation and arrhythmias

- Cardiac ischemia

- Cardiomyopathy

- Cholesterol and lipid metabolism

- Coronary artery pharmacology

- Coronary collateral artery development

- Diabetic eye disease

- Dietary probiotics
D. Lefer, Emory University, Atlanta, GA; L. Lerman, Mayo Clinic, Rochester, MN
F. Sellke, Harvard University, Cambridge, MA

B.G. Kennedy, Indiana University School of Medicine, Gary, IN

G. Solano-Aguilar, U.S.
Lee, W. Indiana University School of Medicine, Indianapolis, IN Department of Agriculture, Beltsville, MD; P. Heegaard, National Veterinary Institute, Technical University of Denmark, Copenhagen, Denmark

Alloosh et al. 2008, Hu et al. 2009

Kaser et al. 2004, Zafar et al. 2004a, Zafar et al. 2004b, Mokelke et al. 2005, Dyson et al. 2006, Edwards et al. 2006, Sheehy et al. 2006, Sturek et al. 2006, Le et al. 2007, Sturek et al. 2007, Bender et al. 2008, Bratz et al. 2008, Edwards et al. 2008, Langohr et al. 2008, Lloyd et al. 2008, Neeb et al. 2008, Kreutz et al. In Press, Wang et al. In Press

Flum et al. 2007

Mattern et al. 2007

Han et al. 2009

Miller et al. 2007, Bender et al. 2008, Borbouse et al. 2008

Dincer et al. 2006

Dyson et al. 2006, Sturek et al. 2007, Bratz et al. 2008, Lee et al. 2009

Bender et al. 2008, Bratz et al. 2008

Sturek et al. 2007 
SRNL-RP-2009-00869

Table 1. Modern diseases and uses of Ossabaw miniature swine for biomedical research. (Continued)

Disease and/or Use
Comments

J.J. Verlaan, University

Medical Center Utrecht,

Utrecht, The Netherlands

- Gastrointestinal tract, electrical stimulation of

- Endothelial progenitor cell biology

- Exercise physiology

- Genetics

- Hypertension

- Kidney function and disease

- Metabolic syndrome

- Neonatology, fetal imprinting

- Non-alcoholic steatohepatitis (NASH), liver disease dyslipidemia, hypertension)

Pig is classical neonatology model; ideal for determining epigenetic effects of metabolic syndrome

D. Crabb, Indiana University School of Medicine, Indianapolis, IN
E. Firestone, W. Starkenbaum, Medtronic, Inc., St. Paul, MN

D.P. Basile, M. Yoder, K.L. March, Indiana University School of Medicine, Indianapolis, IN

Lloyd et al. 2006a, Sturek et al. 2007

Z. Machaty, Purdue University, West Lafayette, IN; S. Fahrenkrug, University of Minnesota, St. Paul, MN

Smith et al. 1980, Andersson 2003, Lloyd et al. 2006b, Sturek et al. 2007, Clop et al. 2008

Dyson et al. 2006, Sheehy et al. 2006, Sturek et al. 2007, Bratz et al. 2008

B. Molitoris, Indiana University School of Medicine, Indianapolis, IN; J. Strickland, FAST Diagnostics, Indianapolis, IN

Alloosh et al. 2008

Dyson et al. 2006, Lloyd et al. 2006b, Sturek et al. 2007, Bender et al. 2008, Bratz et al. 2008, Spurlock and Gabler 2008, Lee et al. 2009
Lee et al. 2009 


\section{Wild Pigs}

Table 1. Modern diseases and uses of Ossabaw miniature swine for biomedical research. (Continued)

Disease and/or Use Comments $\quad$ References

- Obesity and adipokines

- Percutanous catheter interventions

- Polycystic ovary syndrome (PCOS)

- Pancreatic beta cell function and isolation

- $\quad$ Peripheral artery disease (PAD)

- Platelet aggregation and thrombosis

- $\quad$ Skeletal muscle metabolism

- Testicular development

- $\quad$ Type 2 diabetes

- Vascular stents
Boullion et al. 2003, Witczak et al. 2005, Dyson et al. 2006, Flum et al. 2007, Sturek et al. 2007, Bender et al. 2008, Bratz et al. 2008, Spurlock and Gabler 2008, Lee et al. 2009

Kaser et al. 2004, Zafar et al. 2004a, Zafar et al. 2004b, Edwards et al. 2006, Sturek et al. 2006, Sturek et al. 2007, Edwards et al. 2008, Lloyd et al. 2008

Krisher et al. 2006

R. McCarthy, VitaCyte LLC, Indianapolis, IN

Lloyd et al. 2006a, Langohr et al. 2008, Wang et al. In Press

Kreutz et al. In Press

M. Perez-Enciso, Universitat Autonoma, de Barcelona, Bellaterra, SPAIN

J. Ford, U.S. Department of Agriculture, Lincoln, NE

Habegger et al. 2008, Kostrominova et al. 2008

Bender et al. 2008, Bratz et al. 2008

Sturek et al. 2007, Edwards et al. 2008, Lloyd et al. 2008, Kang et al. In Press 


\section{Literature Cited}

Alloosh, M., J. H. Pratt, M. Sturek, and D. P. Basile. 2008. Elevated renin and enhanced adrenal steroidogenesis in the Ossabaw miniature swine model of the metabolic syndrome (abstract). FASEB Journal, 22:736.7.

Andersson, L. 2003. Identification and characterization of AMPKg3 mutations in the pig. Biochemical Society Transactions, 31:232-235.

Baschetti, R. 2006. Diabetes susceptibility. Canadian Medical Association Journal, 174:1597-1598.

Bender, S. B., J. D. Tune, L. Borbouse, X. Long, M. Sturek, and M. H. Laughlin. 2008. Altered mechanism of adenosine-induced coronary arteriolar dilation in early-stage metabolic syndrome. Experimental Biology and Medicine, 234:683-692.

Borbouse, L., G. A. Payne, G. M. Dick, M. Sturek, and J. D. Tune. 2008. Impaired contribution of voltagedependent $\mathrm{K}^{+}$channels to ischemic coronary vasodilation in Ossabaw swine with metabolic syndrome (abstract). FASEB Journal, 22:1152.3.

Boullion, R. D., E. A. Mokelke, B. R. Wamhoff, C. R. Otis, J. Wenzel, J. L. Dixon, and M. Sturek. 2003. Porcine model of diabetic dyslipidemia: Insulin and feed algorithms for mimicking diabetes in humans. Comparative Medicine, 53:42-52.

Bratton, S. P. 1975. The effect of the European wild boar (Sus scrofa) on gray beech forest in the Great Smoky Mountains. Ecology, 56:1356-1366.

Bratz, I. N., G. M. Dick, J. D. Tune, J. M. Edwards, Z. P. Neeb, U. D. Dincer, and M. Sturek. 2008. Impaired capsaicin-induced relaxation of coronary arteries in a porcine model of the metabolic syndrome. American Journal of Physiology: Heart and Circulatory Physiology, 294:H2489-H2496.

Brisbin, I. L., Jr., R. A. Geiger, H. B. Graves, J. E. Pinder III, J. M. Sweeney, and J. R. Sweeney. 1977. Morphological characterizations of two populations of feral swine. Acta Theriologica, 22:75-85.

Brisbin, I. L., Jr., and J. J. Mayer. 2001. Problem pigs in a poke: A good pool of data. Science, 294(November 9):1280-1281.

Brisbin, I. L., Jr., C. S. Romanek, and M. Sturek. 2003. Contaminant and food-web relationships of feral hogs and raccoons on a coastal barrier island: The role of sea turtle nest depredations. A proposal funded by the M.K. Pentecost Trust of the Savannah Presbytery of the Presbyterian Church (USA). Brunswick, Georgia.

Buhlinger, C. A., P. J. Wangsness, R. J. Martin, and J. H. Ziegler. 1978. Body composition, in vitro lipid metabolism and skeletal muscle characteristics of fast-growing, lean and in slow-growing, obese pigs at equal age and weight. Growth, 42:225-236.

Chobanian, A. V., E. R. Arquilla, T. B. Clarkson, H. A. Eder, C. F. Howard, Jr., T. J. Regan, and J. R. Williamson. 1982. Cardiovascular complications. Diabetes, 31:54-64.

Clop, A. M., J. L. Amills, A. Noguera, J. Fernandez, M. M. Capote, L. Ramon, J. Kelly, J. M. H. Kijas, L. Andersson, and A. Sanchez. 2008. Estimating the frequency of Asian cytochrome B haplotypes in standard European and local Spanish pig breeds. Genetics, Selection and Evolution, 36:97-104.

Department of Natural Resources. 1992. Report of the Committee on Ossabaw Island Hogs. Report on File. Georgia Department of Natural Resources, Wildlife Resources Division. Social Circle, Georgia.

Diamond, J. 2003. The double puzzle of diabetes. Nature, 423:599-602. 


\section{Wild Pigs}

Dincer, U. D., Y. Gao, M. Alloosh, M. Sturek, and J. D. Tune. 2006. Cardiac $\beta$-adrenoceptor expression is markedly depressed in the Ossabaw swine model of cardiometabolic risk (abstract). Medicine and Science in Sports and Exercise, 38(Supplement 1):S21.

Du, Z. Q., B. Fan, X. Zhao, R. Amoako, and M. F. Rothschild. 2008. Association analyses between type 2 diabetes genes and obesity traits in pigs. Obesity, 17:323-329.

Dyson, M., M. Alloosh, J. P. Vuchetich, E. A. Mokelke, and M. Sturek. 2006. Components of metabolic syndrome and coronary artery disease in female Ossabaw swine fed excess atherogenic diet. Comparative Medicine, 56:35-45.

Edwards, J. M., J. Vuchetich, E. A. Mokelke, M. Alloosh, K. L. March, D. Hou, and M. Sturek. 2006. The Ossabaw swine model of the metabolic syndrome exhibits greater stenosis after coronary stenting than lean Yucatan swine (abstract). FASEB Journal, 20:A698.

Edwards, J. M., M. Alloosh, X. Long, G. M. Dick, P. G. Lloyd, E. A. Mokelke, and M. Sturek. 2008. Adenosine $A_{1}$ receptors in neointimal hyperplasia and in-stent stenosis in Ossabaw miniature swine. Coronary Artery Disease, 19:27-31.

Flum, D. R., A. Devlin, A. S. Wright, E. Figueredo, E. Alyea, P. W. Hanley, M. K. Lucas, and D. E. Cummings. 2007. Development of a porcine Roux-en-Y gastric bypass survival model for the study of post-surgical physiology. Obesity Surgery, 17:1332-1339.

Gerstein, H. C., and L. Waltman. 2006. Why don't pigs get diabetes? Explanations for variations in diabetes susceptibility in human populations living in a diabetogenic environment. Canadian Medical Association Journal, 174:25-26.

Grundy, S. M., I. J. Benjamin, G. L. Burke, A. Chait, R. H. Eckel, B. V. Howard, W. Mitch, S. C. Smith, Jr., and J. R. Sowers. 1999. Diabetes and cardiovascular disease - A statement for healthcare professionals from the American Heart Association. Circulation, 100:1134-1146.

Habegger, K. M., L. Tackett, L. N. Bell, J. T. Brozinick, P. J. Gallagher, E. Blue, M. Sturek, and J. S. Elmendorf. 2008. Evidence that insulin-resistant/cholesterol-laden plasma membrane results from hyperlipidemia in L6-myotubes (abstract). Diabetes, 57(Supplement 1): A360.

Han, S., B. Joung, E-K. Choi, M. Hwang, M. Maruyama, T. Shinohara, Y. Zhang, S-F. Lin, J. D. Tune, M. Alloosh, M. Sturek, and P-S. Chen. 2009. Cardiac nerve sprouting in Ossabaw miniature pigs with genetic predisposition to metabolic syndrome (abstract). Heart Rhythm, 6(Supplement 2): S370.

Holden, C. (ed.). 2004. Obesity watch. Science, 305:1236.

Hoffman, E. C., P. J. Wangsness, D. R. Hagen, and T. D. Etherton. 1983. Fetuses of lean and obese swine in late gestation: body composition, plasma hormones and muscle development. Journal of Animal Science, 57:609-620.

Hu, G., E. A. Oboukhova, S. Kumar, M. Sturek, and A. G. Obukhov. 2009. Canonical transient receptor potential channels expression is elevated in a porcine model of metabolic syndrome. Molecular Endocrinology, 23:689-699.

Kang, E., K. Vedantham, X. Long, M. Dadara, I. K. Kwon, M. Sturek, and K. Park. In Press. A drug eluting stent for delivery of signal pathway-specific 1, 3-dipropyl-8-cyclopentyl xanthine (DPCPX). Molecular Pharmacology. 
Kaser, S., E.A., Mokelke, M. N. Zafar, M. C. Dyson, and M. Sturek. 2004. Microvascular dysfunction after coronary stenting in a porcine model of the metabolic syndrome (abstract). Diabetes, 53(Supplement 2):A408-A409.

Kasser, T.R., R. J. Martin, J. H. Gahagan, and P. J. Wangsness. 1981. Fasting plasma hormones and metabolites in feral and domestic newborn pigs. Journal of Animal Science, 53:420-426.

Kreutz, R. P., M. Alloosh, Z. P. Neeb, Y. Kreutz, D. A. Flockhart, and M. Sturek. In Press. Metabolic syndrome in Ossabaw miniature swine is associated with increased sensitivity of platelet aggregation to adenosine diphosphate (abstract). Arteriosclerosis Thrombosis and Vascular Biology.

Krisher, R., M. Wulster-Radcliffe, M. Spurlock, and M. Sturek. 2006. The Ossabaw pig as a model of polycystic ovary syndrome (abstract). FASEB Journal, 20:A825.

Kostrominova, T.Y., B. A. Clark, D. del Rosario, M. Alloosh, J. W. Wenzel, and M. Sturek. 2008. Increased fiber size and intramyocellular lipid accumulation in skeletal muscles of Ossabaw miniature swine with metabolic syndrome (abstract). Physiologist, 51:53.

Langohr, I. M., H. HogenEsch, G. W. Stevenson, and M. Sturek. 2008. Vascular-associated lymphoid tissue in swine (Sus scrofa). Comparative Medicine, 58:168-173.

Le, T., I. M. Langohr, M. J. Locker, M. Sturek, and J-X. Cheng. 2007. Label-free molecular imaging of atherosclerotic lesions using multimodal nonlinear optical microscopy. Journal for Biomedical Optics, 12:054007.

Lee, L., M. Alloosh, R. Saxena, W. Van Alstine, B. A. Watkins, J. E. Klaunig, M. Sturek, and N. Chalasani. 2009. Nutritional model of steatohepatitis and metabolic syndrome in the Ossabaw miniature swine. Hepatology, 50:56-67.

Lloyd, P. G, G. M. Dick, M. Alloosh, J.L. Unthank, and M. Sturek. 2006a. Exercise training improves peripheral vascular function following chronic femoral artery occlusion in the Ossabaw swine model of cardiometabolic risk (abstract). Medicine and Science in Sports and Exercise, 38(Supplement 1):S1.

Lloyd, P. G., M. Fang, I. L. Brisbin, Jr., L. Andersson, and M. Sturek. 2006b. AMP kinase gene mutation is consistent with a thrifty phenotype (metabolic syndrome) in a population of feral swine (abstract). FASEB Journal, 20:A299.

Lloyd, P. G., A. F. Sheehy, J. M. Edwards, E. A. Mokelke, and M. Sturek. 2008. Leukemia inhibitory factor is upregulated in coronary arteries of Ossabaw miniature swine after stent placement. Coronary Artery Disease, 19:217-226.

Martin, R. J., J. L. Gobble, T. H. Hartsock, H. B. Graves, and J. H. Ziegler. 1973. Characterization of an obese syndrome in the pig. Proceedings of the Society of Experimental Biology and Medicine, 143:198-203.

Martin, R. J., and J. Herbein. 1976. A comparison of the enzyme and in vivo utilization of various substrates for lipogenesis in pair-fed lean and obese pigs. Proceedings of the Society for Experimental Biology and Medicine, 151:231-235.

Marx, J. 2002. Unraveling the causes of diabetes. Science, 296:686-689.

Mattern, H. M., P. G. Lloyd, M. Sturek, and C. D. Hardin. 2007. Gender and genetic differences in bladder smooth muscle PPAR mRNA in a porcine model of the metabolic syndrome. Molecular and Cellular Biochemistry, 302:43-49.

Mayer, J. J., and I. L. Brisbin, Jr. 1991. Wild pigs in the United States: Their history, comparative morphology, and current status. University of Georgia Press, Athens, Georgia. 


\section{Wild Pigs}

1995. Feral swine and their role in the conservation of global livestock genetic diversity. Pp.

175-179, In R. D. Crawford, E. E. Lister, and J. T. Buckley (eds.). Proceedings of the Third Global Conference on Conservation of Domestic Animal Genetic Resources. Rare Breeds International, Warwickshire, England, U.K.

Miller, M. A, K. M. Perry, P. I. Rogers, K. L. March, M. Sturek, and G. D.Hutchins. 2007. Initial experience with [13N] ammonia cardiac PET in Ossabaw swine model of metabolic syndrome (abstract). Nuclear Medicine, 48(Supplement 2):225P.

Mokelke, E. A., R. Misra, and M. Sturek. 2005. Caspase-3 levels are elevated in myocardium of hypercholesterolemic Ossabaw minipigs (abstract). Diabetes, 54(Supplement 1):A433.

Neeb, Z. P., J. M. Edwards, I. N. Bratz, M. Alloosh, C. Schultz, K. Thompson, T. Cunha, and M. Sturek. 2008. Occlusive, diffuse coronary artery disease in Ossabaw miniature swine with metabolic syndrome (abstract). FASEB Journal, 22:1152.10.

Neel, J. V. 1962. Diabetes mellitus: a "thrifty" genotype rendered detrimental by "progress"? American Journal of Human Genetics, 145:353-362.

Oliver, W. L. R., and I. L. Brisbin, Jr. 1993. Introduced and feral pigs: problems, policy, and priorities. Pp. 179-191. In W.L.R. Oliver (ed.), Pigs, peccaries and hippos: Status survey and conservation action plan. IUCN, The World Conservation Union. Gland, Switzerland.

Roberts, R. M., G. W. Smith, F. W. Bazer, J. Cibelli, G. E. Seidel, Jr., D. E. Bauman, L. P. Reynolds, and J. J. Ireland. 2009. Farm animal research in crisis. Science, 324:468-469.

Scott, R. A., S. G. Cornelius, and H. J. Mersmann. 1981a. Effects of age on lipogenesis and lipolysis in lean and obese swine. Journal of Animal Science, 52:505-511.

1981b. Fatty acid composition of adipose tissue from lean and obese swine. Journal of Animal Science, 53:977-981.

Sheehy, A, E. A. Mokelke, P. G. Lloyd, J. Sturek, and M. Sturek. 2006. Reduced expression of leukemia inhibitory factor correlates with coronary atherosclerosis in the metabolic syndrome (abstract). FASEB Journal, 20:A698.

Singer, F. J., W. T. Swank, and E. E. E. Clebsch. 1984. Effects of wild pig rooting in a deciduous forest. Journal of Wildlife Management, 48:464-473.

Smith, M. W., M. H. Smith, and I. L. Brisbin, Jr. 1980. Genetic variability and domestication in swine. Journal of Mammalogy, 61:39-45.

Spurlock, M.E., and N. K. Gabler. 2008. The development of porcine models of obesity and the metabolic syndrome. Journal of Nutrition, 138:397-402.

Stribling, H. L., I. L. Brisbin, Jr., J. R. Sweeney, and L. A. Stribling. 1984. Body fat reserves and their prediction in two populations of feral swine. Journal of Wildlife Management, 48:635-639.

Sturek, M., E. A. Mokelke, J. Vuchetich, J. M. Edwards, M. Alloosh, and K. L. March. 2006. In-stent neointimal hyperplasia is less fibrous in metabolic syndrome Ossabaw compared to lean Yucatan swine (abstract). FASEB Journal, 20:A1399-A1400.

Sturek, M, M. Alloosh, J. Wenzel, J. P. Byrd, J. M. Edwards, P. G. Lloyd, J. D. Tune, K. L. March, M. A. Miller, E. A. Mokelke, and I. L. Brisbin, Jr. 2007. Ossabaw island miniature swine: Cardiometabolic 
syndrome assessment. Pp. 397-402. In: M. M. Swindle (ed.), Swine in the laboratory: Surgery, anesthesia, imaging, and experimental techniques. CRC Press, Boca Raton, Florida.

Talbott, C, T. See, P. Kaminsky, D. Bixby, M. Sturek, I. L. Brisbin, Jr., and C. Kadzere. 2006. Enhancing pork flavor and fat quality with swine raised in sylvan systems: Potential niche-market application for the Ossabaw hog. Renewable Agriculture and Food Systems, 21:183-191.

Tipton, A. R. 1977. The use of population models in research and management of wild hogs. Pp. 91-101. In G. W. Wood (ed.). Research ad Management of Wild Hog Populations. Belle W. Baruch Forest Science Institute of Clemson University. Georgetown, South Carolina.

Waller, D., and L. C. Barrett. 2001. Ossabaw Island Comprehensive Management Plan. Georgia Department of Natural Resources, Wildlife Resources Division. Social Circle, Georgia.

Wang H-W., I. M. Langohr, M. Sturek, and J-X. Cheng. In Press. Imaging and quantitative analysis of atherosclerotic lesions by CARS-based multimodal nonlinear optical microscopy. Arteriosclerosis, Thrombosis and Vascular Biology.

Wangsness, P. J., R. J. Martin, and J. H. Gahagan. 1977. Insulin and growth hormone in lean and obese pigs (abstract). American Journal of Physiology, 233:E104-E108.

Witczak, C.A., E. A. Mokelke, R. D. Boullion, J. Wenzel, D. H. Keisler, and M. Sturek. 2005. Noninvasive measures of body fat percentage in male Yucatan swine. Comparative Medicine, 55:445-451.

Zafar, M. N., S. Kaser, E. A. Mokelke, M. Alloosh, M. C. Dyson, and M. Sturek. 2004a. Ossabaw swine having the metabolic syndrome exhibit greater neointimal hyperplasia after coronary stent placement than lean Yucatan swine (abstract). FASEB Journal, 18:A565.

Zafar, M. N., E. A. Mokelke, S. Kaser, and M. Sturek. 2004b. C-reactive protein is predictive of in-stent neointimal hyperplasia, but not atheroma at baseline, in swine with the metabolic syndrome (abstract). Arteriosclerosis, Thrombosis and Vascular Biology, 24:103.

Zervanos, S. M., W. D. McCort, and H. B. Graves. 1983. Salt and water balance of feral versus domestic Hampshire hogs. Physiological Zoology, 56:67-77. 
Wild Pigs

\section{Wild Pig Management Case Study: \\ Prevalence of Antibodies to Selected Disease Agents in an Insular Population of Feral Swine}

D. Bart Carter, Kyle K. Henderson, I. Lehr Brisbin, Jr., Clarence Bagshaw, and Michael Sturek

Animal Resource Center, University of Texas Southwestern Medical Center, 5323 Harry Hines Blvd, Dallas Texas 75390-9037 (DBC)

Cardiovascular Institute, Loyola University Medical Center, Maywood, IL 60153 (KKH)

Savannah River Ecology Laboratory, P.O. Drawer E, Aiken, SC 29802 (ILB)

Edgefield Veterinary Clinic, Edgefield, South Carolina 29824 (CB)

Department of Cellular \& Integrative Physiology, Indiana University School of Medicine, 635 Barnhill

Drive, MS 385, Indianapolis, IN $46202-5120$ (MS)

\section{Introduction}

Free-ranging populations of feral swine (Sus scrofa) may serve as reservoirs for various porcine diseases and represent a potential for disease transmission to domestic herds. As a result, a number of surveys have been conducted in a variety of feral populations. We report here the prevalence of serum titers to brucellosis, PRV, VSV-IN and VSV-NJ, Mycoplasmosis, PRRS virus, TGE virus, SIV serotypes H1N1 and H3N2, PPV, and Leptospirosis in a population of feral swine which has been relatively isolated from immigration due to its location on a coastal barrier island (Ossabaw Island, Georgia, USA (31 $46^{\circ} \mathrm{N}$, $\left.81^{\circ} 05^{\prime} \mathrm{W}\right)$.

\section{Materials and Methods}

From 1 March through 22 March 2002, 104 pigs (54 males and 50 females) were trapped on the island and serum samples were collected from all pigs. Pigs were captured alive in box traps baited with shelled corn. Ninety-eight of the pigs were trapped from locations near the northern end of the island; the remaining 6 pigs were trapped from the southern tip of the island. Trapped pigs were manually restrained and 5-10 ml of blood were collected from the external jugular vein or cranial vena cava. All samples were stored at $4{ }^{\circ} \mathrm{C}$ immediately after collection, and shipped overnight to the University of Missouri Veterinary Medical Diagnostic Laboratory (Columbia, MO, USA) for serologic evaluation using their routine diagnostic testing. All commercial test kits were used according to the manufacturer's recommendations and had been previously validated by the diagnostic laboratory.

Serum samples were evaluated for antibodies to Brucella sp. using a USDA approved card test, (Brucella Card Test, Becton-Dickinson Co., Baltimore, MD, USA). Antibodies for PRV were detected by latex agglutination (Autolex ${ }^{\circledR}$ Anti-PRV Screen, Viral Antigens Inc., Memphis, TN, USA). Positive PRV samples were confirmed by serum neutralization ( $\mathrm{SN}$ ) using the following laboratory protocol: for the test, MDBK cells were used in the log stage of growth. Serum samples were heat-inactivated at $56^{\circ} \mathrm{C}$ for 30 minutes and titered in duplicate against the virus starting at a 1:4 dilution. The sera were initially diluted at $1: 2$ but this was considered to be a test dilution of 1:4 after addition of an equal volume of challenge virus. After the addition of the challenge virus, the serum-virus mixture was incubated for 1 hour at $37^{\circ} \mathrm{C}$. The cells were trypsinized and incubated at $37^{\circ} \mathrm{C}$ in a humid, $5 \% \mathrm{CO}_{2}$ incubator for 48 to 72 hours. If neutralization occurred, samples were diluted in a serial two-fold fashion to determine the endpoint titer. Sample wells were observed using an inverted light microscope looking for cytopathic effects (CPE) at 48 to 72 hours. For PRV testing, a TCID 50 was used of $100-300$. 
Antibodies against VSV serotypes New Jersey (VSV-NJ) and Indiana (VSV-IN) were determined by SN using the same technique as described above for PRV, except using the RK-13 cell line and a TCID T0 $_{50}$ $700-1200$. Titers $\geq 1: 8$ for VSV indicated exposure to VSV and are considered to be a positive sample by the Missouri Department of Agriculture. Antibodies for TGE were determined by SN using the same technique as described above for PRV, except using the ST cell line and a TCID $_{50}$ of $100-300$. For detection of antibodies to $M$. hyopneumoniae, a DAKO ${ }^{\circledR}$ blocking ELISA test was performed (DakoCytomation, Carpinteria, CA, USA). The HerdChek PRRS® ELISA (IDEXX Laboratories, Inc. Westbrook, ME, USA) was used to detect the presence of antibodies to PRRS, in the swine serum. A hemagglutination-inhibition test (HAI) was used for antibody determination to PPV and to SIV subtypes $\mathrm{H} 1 \mathrm{~N} 1$ and H3N2. The HAI procedures were performed by first heat inactivating the serum at $56^{\circ} \mathrm{C}$ for 30 minutes. Duplicate serial 2-fold dilutions of sera were created using V bottom microtiter plates. For PPV, the dilutions are made across the microtiter plate with the end result being dilutions ranging from 1:10 to 1:20480. End result dilutions for SIV ranged from 1:10 to 1:1280. A viral suspension of four hemagglutination units (HAU) was prepared from commercially available viral antigens. A two-fold back titration of the virus suspension was then performed on the serum dilutions. Samples were incubated for 30 minutes at room temp and then guinea pig red blood cells (RBC's) were added to each well. Samples were again incubated at room temperature until the cells formed a button in the positive cell control well, normally 1 to 2 hours. A button of cells on the bottom of the wells with serum and virus indicated that the serum prevented the virus from hemagglutinating the RBC's, and that the serum was therefore positive.

A microscopic agglutination test was used to detect the presence of antibodies to L. interrogans serovars: canicola, grippotyphosa, hardjo, icterohaemorrhagiae, pomona, and bratislava. The procedure was performed by diluting the test sera 1:50 and adding the diluted sera to each of 6 wells of a flat-bottomed microtiter plate. Diluted antigen from each serovar being tested was added to one well of each test sera. Samples were incubated at room temperature for two hours and then examined for agglutination under dark field microscopy. Endpoints were recorded as the highest dilution in which at least 50\% of the Leptospira were agglutinated. Titers $\geq 1: 100$ were considered positive for leptospirosis.

All of the 104 animals tested were in good to excellent physical condition. The 78 pigs that tested positive for brucellosis, PRV or VSV were humanely euthanized and necropsied. Eight of the 50 females were either pregnant or nursing a litter at the time of capture. No evidence of gross lesions suggestive of an infectious disease was found in any of the sacrificed animals. All procedures involved with this study were reviewed and approved by the University of Missouri Animal Care and Use Committee. Chi-squared contingency tests were used to test for differences in seroprevalance between the sexes.

\section{Results}

Of the 104 animals captured, 54 were male and 50 were female (Table 1). A 2x3 contingency table analysis indicated no statistically significant differences in the frequencies of positive titers for either $P R V(P=0.45)$, brucellosis $(\mathrm{P}=1.0)$, or VSV $(\mathrm{P}=0.79)$ due to gender. Further, the cumulative seroprevalences of brucellosis, $\mathrm{PRV}$ and VSV-IN and VSV-NJ in males were not different than those of females $(\mathrm{P}=0.80)$.

Among the 104 samples tested, no evidence of antibody was found for Mycoplasma, PRRS, or TGE. No evidence was found of antibodies to L.interrogans serovars: canicola, grippotyphosa, hardjo, icterohaemorrhagiae, and pomona, but 22 animals had low titers (1:100) to L. bratislava. All samples showed serologic evidence of exposure to SIV. The SIV H1N1 serotype had titers ranging from 1:10 to 1:80 with a numerical average for the 104 samples of 1:44 \pm 24 . The H3N2 serotype had titers ranging from 1:20 to $1: 160$ and a numerical average titer of 1:46 \pm 25 . Porcine parvovirus (PPV) HAI revealed 58 positive animals with titers ranging from $1: 160$ up to $>1: 20,480$.

Twenty-six of the 104 animals tested negative to brucellosis, PRV and VSV (IN and NJ serotypes). These 26 pigs were removed from Ossabaw Island and held under quarantine for six months for additional PRV and brucellosis serologic testing. After 60 days of isolation, seven females seroconverted to PRV on both the latex agglutination and SN tests. Serum neutralization titers ranged from 1:8 to 1:128 for these seven animals. These seven pigs were retested to confirm the results and subsequently removed from the group. A program of complete herd testing of the remaining 19 pigs was initiated at two week intervals for three 


\section{Wild Pigs}

months (7 testing periods). During this time, a breeding colony was established and no further pigs tested positive for PRV.

\section{Discussion}

This report of Ossabaw Island pigs being infected with Brucella sp. in 2002 is the first report of the occurrence of this disease in this population and provides evidence for the need to document infectious disease prevalence in all subsequent Ossabaw pig management programs. Brucellosis has been reported in numerous other feral swine populations in the United States, with seroprevalence rates ranging from 0 to 33\% ( Corn et al. 1986, Drew et al. 1992, van der Leek et al. 1993, New et al. 1994). The 6.4\% infection rate reported in this study is consistent with these reports for other feral populations.

The occurrence of Brucella sp. in Ossabaw pigs raises the question of possible mechanisms for the introduction of such disease agents to this largely isolated population. A few domestic boars were deliberately released on Ossabaw Island in the early-mid 1970's (Mayer and Brisbin 1991). However none of these animals survived for more than a few years at the most and had contact with only a limited portion of the island's feral population, remaining for the most part near the area of human settlement at the north end of the island, and we feel that it is unlikely that any of these animals could have served as significant vectors for the introduction of any, particularly sexually-transmissible, diseases to the island' feral population as a whole. However, the authors have personal knowledge of both past and continuing illegal introductions of pigs to Ossabaw Island from mainland feral populations. Many of these mainland populations have shown the Eurasian wild boar hybrid phenotype, and the introduction of such animals from the mainland is now evidenced by occasional observations of this form's juvenile striped phenotype in the present Ossabaw population. However no such striped juvenile phenotypes were ever observed on Ossabaw Island through the mid-late 1970's (Brisbin et al. 1977). Illegal introductions of mainland pigs onto Ossabaw Island have been and continue to be largely made by individuals wanting to improve the size and "trophy quality" of the Ossabaw pigs which are taken by hunters during public hunts managed by the Georgia Department of Natural Resources, and these illegal introductions have almost certainly been in the past, and now still continue to be a factor in the introduction and maintenance of disease agents in the Ossabaw pigs. This further emphasizes the need for continual monitoring and documentation of the prevalence of infectious diseases in this unique and important population.

A previous study conducted from 1981-1986 indicated that the prevalence of PRV seropositive animals on the island ranged between 1 and 25\% in 1984 and 1986 respectively (Pirtle et al. 1989). Our seroprevalence rate of 39\% may seem higher than those of this earlier report. However, small sample numbers and different laboratory testing methods make comparison between such studies difficult. A recent study in an isolated coastal South Carolina population documented an increase in prevalence of PRV antibodies (Gresham et al. 2004). The presence of latent PRV infections in seven of the 50 females removed from Ossabaw Island is not unexpected when dealing with an endemically infected PRV herd. Periods of environmental stress or farrowing are known to result in viral recrudescence in latently infected animals (Davies and Beran 1980). The removal from the island and adjustment to life in a mainland colony of pigs in a research institution could provide just such a source of stress.

VSV has been extensively studied on Ossabaw Island (Fletcher et al. 1985, Stallknecht et al. 1985, Stallknecht 2000), and the island is regarded as the only area in the United States enzootically infected with this disease (Stallknecht et al. 1985). In this study, as dictated by the Missouri Department of Agriculture, a titer value of $\geq 1: 8$ was used to indicate a positive animal for VSV. If a titer value of $\geq 1: 32$ had been used, which is a better indication of recent exposure, then only 10 of the 104 animals (10\%) would have been considered positive for VSV.

For brucellosis, PRV and VSV, males tended to have a higher seroprevalence of disease than females, although these differences were not statistically significant. Higher frequencies of exposure to brucellosis and PRV might be expected in adult males since venereal contact is one of the methods of disease transmission and males could, depending on the (as yet unknown) breeding structure of the Ossabaw population, be subject to increased exposure as the result of breeding multiple females more frequently than 
vice-versa (Romero et al. 2001). In an earlier report however, Ossabaw Island females were shown to have a slightly higher seroprevalence rate for PRV (Pirtle et al. 1989).

PPV is ubiquitous in the commercial swine population (Siegl 1976), and it has been reported in a number of other feral populations (New et al. 1994, Saliki et al. 1998, Gipson et al. 1999). This agent is known to cause fetal deaths, frequently with mummification of the fetus. However no such evidence was found in any of the necropsied animals or in any of the animals that farrowed in captivity. Clinical disease is only seen in seronegative gilts, so widespread infection in this population would prevent the occurrence of embryonic or fetal deaths (Mengeling 1992). Our 56\% seroprevalence rate is comparable to other reports in the literature documenting PPV infections in feral swine (Nettles 1989, New et al. 1994, Saliki et al. 1998, Gipson et al. 1999).

Swine influenza is a common cause of viral respiratory disease in commercial hogs with infected herds having a high morbidity but low mortality; it has also been reported in feral swine (Saliki et al. 1998, Gipson et al. 1999), but at much lower prevalence levels than we report here. Without virus isolation, the most accurate method to diagnose SIV is by testing paired serum samples collected three to four weeks apart. In this study however, we were unable to obtain paired serum samples from these animals. While it would be remarkable, it is possible that a highly contagious respiratory virus such as SIV has spread throughout the island population. However, the possibility of non-specific inhibitors or non-specific agglutinins being present in the serum should also be considered as a possible explanation for the $100 \%$ prevalence of SIV reported in this study.

Several serovars of Leptospira can cause reproductive losses in swine and other species (Ellis 1992). $L$. bratislava is a serovar that was first isolated in the United States in 1985 (Hanson 1985). Our survey revealed $21 \%$ of the tested swine to have antibody evidence of exposure to L. bratislava. Other reports have indicated the seroprevalance of Leptospira to range from 5 to 87 percent depending upon the serovars studied (Clark et al. 1983, Corn et al. 1986, Nettles et al. 1989). Our seroprevalance of $21 \%$ is consistent with these reports. It is not known why L. bratislava was the only serovar detected on Ossabaw Island.

A limitation of the current study was our inability to test paired samples from every animal. This would have allowed us to determine changes in antibody levels over time. Rises in serologic titers would have been indicative of active infection. No attempt was made at virus isolation, and all results reported here were based solely on serologic data. With these limitations, we can only assume that the presence of antibodies to a particular agent is evidence of exposure to that disease agent. The presence of antibodies to PPV, SIV and L. bratislava, thus indicates that this island population has been exposed to these agents. Since L. bratislava was not reported in North America until 1985, it's presence on the island would indicate the first exposure of the island population to L. bratislava at some unknown time between 1985 and 2003. Again, this time frame would be consistent with the initial and continuing illegal introductions of mainland pigs to the island as evidenced by the appearance of the striped juvenile phenotype of the Eurasian wild boar hybrid, as described above.

The documentation of infectious disease prevalence is another example of the need for any Ossabaw pig management program to include properly coordinated data collection from animals being removed in control programs. Data collection over the intervening seven years between our data collection in 2002 and the present would have enabled a more thorough description of disease progression and regression, which would serve the best interests of research aimed at studying both the disease ecology of the pigs themselves as well as interest in their conservation.

Although feral swine are most frequently viewed as pests that damage ecosystems, Ossabaw swine recapitulate the complex diseases of obesity, metabolic syndrome, and progression to type 2 diabetes with all of the long-term health complications associated with these diseases. This arguably defines them as a biomedical treasure (Dyson et al. 2006, Krisher et al. 2006, Flum et al. 2007, Sturek et al. 2007, Bratz et al. 2008, Edwards et al. 2008, Lee et al. 2009). This project was conducted because there was a compelling need to remove pigs from Ossabaw Island and establish a disease-free colony of these pigs in a laboratory setting before any attempts were made to either eradicate or severely deplete the numbers of pigs on the island. Ossabaw Island is managed by the Georgia Department of Natural Resources, Wildlife Resources 


\section{Wild Pigs}

Division and a long-range plan has been implemented to significantly reduce the numbers of these feral swine remaining on the island (Georgia DNR, 2000). A breeding and laboratory research colony of Ossabaw swine established in 2004 in collaboration between Indiana University School of Medicine and Purdue University has shown that animals in such a colony can be maintained entirely free of these infections and can therefore be used widely for biomedical research (Sturek et al. 2007).

\section{Acknowledgements}

This work was conducted while several authors (DBC, KKH, MS) were affiliated with the University of Missouri. The authors thank Mr. Roger Parker and Cathy Hargrove for their invaluable assistance in trapping the pigs used in this study, Mr. Allan Usher for transporting the pigs to the mainland, and Ms. Eleanor West for her hospitality in allowing us to stay in her home on Ossabaw Island. We thank the Missouri Department of Agriculture, the Georgia Department of Agriculture, and the Georgia Department of Natural Resources, Wildlife Resources Division for their support and cooperation in allowing this project to take place. We thank Mouhamad Alloosh, M.D., Robert Boullion, Chris Downs, D.V.M., Dale Lenger, James Vuchetich, and James Wenzel for technical assistance and Audrey Rottinghaus for serology. This work was supported by National Institutes of Health Grants RR013223, HL062552 and the American Diabetes Association. Fieldwork and manuscript preparation were also supported in part by the Environmental Remediation Sciences Division of the Office of Biological and Environmental Research of the U.S. Department of Energy, through Financial Assistance Award No. DE-FRC09-96SR18546 to the University of Georgia Research Foundation. 
Table 1. Percentages of feral swine from Ossabaw Island, Georgia showing positive.serum titers to various porcine disease agents when collected in March, 2002. Values in parentheses represent the total numbers of individuals tested in each cohort.

\begin{tabular}{lrrr}
\multicolumn{1}{c}{ Agent } & $\begin{array}{c}\text { Male } \\
(54)\end{array}$ & $\begin{array}{c}\text { Female } \\
(50)\end{array}$ & $\begin{array}{r}\text { Total } \\
(104)\end{array}$ \\
\hline Pseudorabies virus (PRV) & 44.4 & 34 & 39.4 \\
Brucella sp. (Brucellosis) & 9.3 & 4 & 6.7 \\
Vesicular stomatitis virus Indiana (VSV-IN) & 59.3 & 50 & 54.8 \\
Vesicular stomatitis virus New Jersey (VSV-NJ) & 14.8 & 12 & 13.5 \\
M. hyopneumoniae (Mycoplasma) & 0 & 0 & 0 \\
Porcine Reproductive and Respiratory Syndrome (PRRS) & 0 & 0 & 0 \\
Transmissible gastroenteritis virus (TGE) & 0 & 0 & 0 \\
Swine influenza virus (SIV), serotypes H1N1/H3N2 & 100 & 100 & 100 \\
Porcine parvovirus (PPV) & 46.3 & 66 & 55.8 \\
Leptospirosis Bratislava & 18.5 & 24 & 21 \\
\hline
\end{tabular}




\section{Wild Pigs}

\section{Literature Cited}

Bratz, I. N., G. M. Dick, J. D. Tune, J. M. Edwards, Z. P. Neeb, U. D. Dincer, and M. Sturek. 2008. Impaired capsaicin-induced relaxation of coronary arteries in a porcine model of the metabolic syndrome. American Journal of Physiology: Heart and Circulatory Physiology, 294:H2489-H2496.

Brisbin, I. L., Jr., R. A. Geiger, H. B. Graves, J. E. Pinder, III, J. M. Sweeney, and J. R. Sweeney. 1977. Morphological characterizations of two populations of feral swine. Acta Theriologica, 22:75-85.

Clark, R. K., D. A. Jessup, D. W. Hird, R. Ruppanner, and M. E. Meyer. 1983. Serologic survey of California wild hogs for antibodies against selected zoonotic disease agents. Journal of the American Veterinary Medical Association, 183:1248-1251.

Corn, J. L., P. K. Swiderek, B. O. Blackburn, G. A. Erickson, A. B. Thiermann, and V. F. Nettles. 1986. Survey of selected diseases in wild swine in Texas. Journal of the American Veterinary Medical Association, 189:1029-1032.

Corn, J. L., D. E. Stallknecht, N. M. Mechlin, M. P. Luttrell, and J. R. Fischer. 2004. Persistence of pseudorabies virus in feral swine populations. Journal of Wildlife Diseases, 40:307-310.

Davies, E. B., and G. W. Beran. 1980. Spontaneous shedding of pseudorabies virus from a clinically recovered post parturient sow. Journal of the American Veterinary Medical Association, 176:1345-1347.

Drew, M. L., D. A. Jessup, A. A. Burr, and C. E. Franti. 1992. Serologic survey for brucellosis in feral swine, wild ruminants, and black bear of California, 1977-1989. Journal of Wildlife Diseases, 28:355-363.

Dyson, M., M. Alloosh, J. P. Vuchetich, E. A. Mokelke, and M. Sturek. 2006. Components of metabolic syndrome and coronary artery disease in female Ossabaw swine fed excess atherogenic diet. Comparative Medicine, 56:35-45.

Edwards, J. M., M. Alloosh, X. Long, G. M. Dick, P. G. Lloyd, E. A. Mokelke, and M. Sturek. 2008. Adenosine $A_{1}$ receptors in neointimal hyperplasia and in-stent stenosis in Ossabaw miniature swine. Coronary Artery Disease, 19:27-31.

Ellis, W. A. 1992. Leptospirosis. Pp. 529-537. In A. D. Leman, B. E. Straw, W. L. Mengeling, S. d'Allaire, and D. J. Taylor (eds.). Diseases of Swine Iowa State University Press, Ames, Iowa.

Fletcher, W. O., D. E. Stallknecht, and E. W. Jenney. 1985. Serologic surveillance for vesicular stomatitis virus on Ossabaw Island, Georgia. Journal of Wildlife Diseases, 21:100-104.

Flum, D. R., A. Devlin, A. S. Wright, E. Figueredo, E. Alyea, P. W. Hanley, M. K. Lucas, and D. E. Cummings. 2007. Development of a porcine Roux-en-Y gastric bypass survival model for the study of post-surgical physiology. Obesity Surgery, 17:1332-1339.

Georgia DNR (Georgia Department of Natural Resources). 2000. Ossabaw Island Comprehensive Management Plan. Georgia Department of Natural Resources, Wildlife Resources Division, Social Circle, Georgia.

Gipson, P. S., J. K. Veatch, R. S. Matlack, and D. P. Jones. 1999. Health status of a recently discovered population of feral swine in Kansas. Journal of Wildlife Diseases, 35:624-627.

Gresham, C. S., C. A. Gresham, M. J. Duffy, C. T. Faulkner, and S. Patton. 2004. Increased prevalence of Brucella suis and pseudorabies virus antibodies in adults of an isolated feral swine population in coastal South Carolina. Journal of Wildlife Diseases, 38:653-656 
Hanson, L. E. 1985. Report of the committee on leptospirosis. Proceedings of the Annual Meeting of the United States Animal Health Association, 89:217.

Krisher, R., M. Wulster-Radcliffe, M. Spurlock, and M. Sturek. 2006. The Ossabaw pig as a model of polycystic ovary syndrome (abstract). FASEB Journal, 20:A825.

Lee, L., M. Alloosh, R. Saxena, W. Van Alstine, B. A. Watkins, J. E. Klaunig, M. Sturek, and N. Chalasani. In Press. Nutritional model of steatohepatitis and metabolic syndrome in the Ossabaw miniature swine. Hepatology.

Mayer, J. J., and I. L. Brisbin, Jr. 1991. Wild pigs in the United States: Their history, comparative morphology, and current status. University of Georgia Press, Athens, Georgia.

Mengeling, W. L. 1992. Porcine parvovirus. Pp. 299-309. In A. D. Leman, B. E. Straw, W. L. Mengeling, S. d'Allaire, and D. J. Taylor (eds.). Diseases of swine. Iowa State University Press, Ames, Iowa.

Nettles, V. F. 1989. Disease of wild swine. Pp. 16-18. In N. Black (ed.), Proceedings: Feral pig symposium. April 27-29, Orlando, Florida. Livestock Conservation Institute, Madison, Wisconsin.

New, J. C., Jr., K. Delozier, C. E. Barton, P. J. Morris, and L. N. D. Potgiete. 1994. A serologic survey of selected viral and bacterial diseases of European wild hogs, Great Smoky Mountains National Park, USA. Journal of Wildlife Diseases, 30:103-106.

Pirtle, E. C., J. M. Sacks, V. F. Nettles, and E. A. Rollor. 1989. Prevalence and transmission of pseudorabies virus in an isolated population of feral swine. Journal of Wildlife Diseases, 25:605-607.

Romero, C. H., P. N. Meade, J. E. Shultz, H. Y. Chung, E. P. Gibbs, E. C. Hahn, and G. Lollis. 2001. Venereal transmission of pseudorabies viruses indigenous to feral swine. Journal of Wildlife Diseases, 37:289-296.

Saliki, J. T., S. J. Rodgers, and G. Eskew. 1998. Serosurvey of selected viral and bacterial diseases in wild swine from Oklahoma. Journal of Wildlife Diseases, 34:834-838.

Siegl, G. (ed.). 1976. The Parvoviruses. Springer-Verlag, Vienna, Austria.

Stallknecht, D. E., V. F. Nettles, W. O. Fletcher, and G. A. Erickson. 1985. Enzootic vesicular stomatitis New Jersey type in an insular feral swine population. American Journal of Epidemiology, 122:876-883.

Stallknecht, D. E. 2000. VSV-NJ on Ossabaw Island, Georgia: The truth is out there. Annals of the New York Academy of Science, 916:431-436.

Sturek, M., M. Alloosh, J. Wenzel, J. P. Byrd, J. M. Edwards, P. G. Lloyd, J. D. Tune, K. L. March, M. A. Miller, E. A. Mokelke, and I. L. Brisbin, Jr. 2007. Ossabaw Island miniature swine: Cardiometabolic syndrome assessment. Pp. 397-402. In M. M. Swindle (ed.). Swine in the Laboratory: Surgery, Anesthesia, Imaging, and Experimental Techniques. CRC Press. Boca Raton, Florida.

Van Der Leek, M. L., H. N. Becker, P. Humphrey, C. L. Adams, R. C. Belden, W. B. Frankenberger, and P. L. Nicoletti. 1993. Prevalence of Brucella sp. antibodies in feral swine in Florida. Journal of Wildlife Diseases, 29:410-415.

Zygmont, S. M., V. F. Nettles, E. B. Shotts, W. A. Carmen, and B. O. Blackburn. 1982. Brucellosis in wild swine: A serologic and bacteriologic survey in the southeastern United States and Hawaii. Journal of the American Veterinary Medical Association, 181:1285-1287. 
Wild Pigs

\section{Wild Pig Management Case Study: \\ Influence of Habitat Attributes on Removal of Feral Hogs from Merritt Island National Wildlife Refuge and Kennedy Space Center, Florida}

Arik Rosenfeld, C. Ross Hinkle, and Marc Epstein

Department of Natural Resources and Environmental Management, University of Haifa, Israel (AR)

(Present Address - P.O.Box 133. Moshav Berotim, 42850, Israel)

Dynamac Corporation, Mail Code DYN-1, Kennedy Space Center, FL. 32899 (CRH)

U. S. Fish and Wildlife Service, Merritt Island NWR, PO Box 6504, Titusville, FL 32782 (ME)

\section{Introduction}

Feral hogs (Sus scrofa) are hogs that were released or escaped from domestication (Brooks et al. 1986). These hogs were introduced by humans to locations where they did not disperse naturally which also makes them an invasive species (Miller 1993, Engeman et al. 2001).

Feral hogs are highly adaptable, have a high reproductive rate and in favorable habitats maintain large and dense populations (Katahira et al. 1993, Miller 1993). Dense populations can have a considerable impact on the ecosystem, damaging vegetation by feeding, rooting and changing soil properties and succession rate (Peine and Farmer 1990, Synatzske 1993, Leaper et al. 1999). Although feral hogs are primarily herbivores, they also feed on animals consequently affecting the indigenous fauna and human livestock. This impact can arise from competition on habitat resources, predation and habitat destruction (Hone 1984, Peine and Farmer 1990, Miller 1993, Synatzske 1993). Feral hogs are also vectors and carriers of several types of diseases, which are transmissible to humans and livestock (Hone 1984, Davis, 1993).

Because feral hogs can have an ecosystem wide impact, management programs have been developed throughout their distribution aiming to control their populations. Most feral hogs are removed through the implementation of these management programs. Feral hogs population reduction can be accomplished through hunting, trapping and poisoning (Peine and Farmer 1990, Katahira et al. 1993, Littauer 1993). Feral hogs are also removed from the landscape because of vehicle collisions. Collisions with vehicles have become a major source of wildlife mortality in the U. S. and industrial countries. For example, the number of deer-vehicle collisions in the U. S. was estimated at 1.5 million annually (Conover et al. 1995). Wildlife-vehicle collisions are a source of mortality for many species of wildlife in Florida, including the Florida panther (Puma concolor coryi), armadillo (Dasypus novemcinctus) and others (Inbar and Mayer 1999).

Hogs were first introduced to Florida in 1539 by the Spanish (Engeman et al. 2001). During the $18^{\text {th }}$ century settlers, who came to Merritt Island, brought with them domesticated hogs, which were raised in open range within the forests of Merritt Island. During the early 1960s, NASA acquired the island for the construction of the Kennedy Space Center (KSC). Farmers, who were evacuated from their holdings, left some of their hogs behind. These hogs were the foundation of the extensive feral hog population that has thrived on the island since (J. Tanner, pers. comm.).

This paper analyses the influence of habitat characteristics on: 1) management results (hogs removed), and 2) number of hog-vehicle accidents. This paper analyses data collected at Merritt Island National Wildlife Refuge (MINWR) during the last ten years. The database contains records on road-accidents with hogs on 
KSC roads (data from KSC security), records on road kills collected by Dynamac Corporation personnel while driving along KSC roads, and data collected by MINWR personnel on hogs trapped onsite. On MINWR, there are no public hunts. Hogs are taken off the refuge by authorized trappers (hunters). All hogs must be taken off the refuge alive.

\section{Methods}

Study Area - KSC is located on a barrier island of the eastern coast of Florida. Land surface area is about $330 \mathrm{~km}^{2}$ of which NASA uses only a small fraction for space launch facilities. The rest of the island (56,657 ha.) is a designated wildlife refuge (i.e., MINWR).

Feral hogs management activities onsite include trapping in cage traps, hunting with dogs and shooting from a vehicle. Trapping has been conducted for about 30 years. In 1995, MINWR management decided to change the feral hogs management program. The refuge was divided into three sections, which were auctioned to trappers (Fig. 1). The area of the northern section (Section 1) is $38 \mathrm{~km}^{2}$; the central section (Section 2) $75 \mathrm{~km}^{2}$; and the southern section (Section 3) is $234 \mathrm{~km}^{2}$.

Trapping Records - On MINWR, there are no public hunts. Hogs are taken off the refuge by authorized trappers (hunters) who use both traps and dogs to catch hogs. The trappers work in regular teams with all personnel receiving KSC security and MINWR clearance. Therefore, an effort in terms of number of men working per day is constant. The trappers submit hunting and trapping records every month to MINWR. Trapping records from the years 1998 - 2001 were summed by month. Hunting success (hog trapped $/ \mathrm{km}^{2}$ section area) was compared between sections, years and seasons using ANOVA (SPSS 8). Differences within factors were analyzed using Tukey HSD test. The year was divided into four seasons: winter (December to February); spring (March to May); summer (June to August), and fall (September to November).

The number of hogs trapped in summer during the years 1998-2001 was the lowest throughout the year. Hunting records for the month of July over the years were examined to determine the average number of days (effort) trappers were on refuge grounds to trap feral hogs. This was done to determine whether the low number of hogs trapped in summer, compared to the other seasons, was due to lower effort.

Accident Reports - Data on vehicle accidents with feral hogs on KSC roads is compiled by KSC security. This data set was available for the years 1995-1997 and 2001-2002. Vehicle accidents with feral hogs occurred only on paved roads in KSC. Average monthly accidents rate (i.e., number of vehicle accidents with feral hogs per km paved road length in section) was compared between sections, years and seasons using ANOVA (SPSS 8). Differences within factors were analyzed using Tukey HSD test.

Road Kill Reports - During the years 1992-1995, Dynamac personnel collected data on road-killed animals spotted along KSC paved roads. From this data set, we used the reports on feral hogs. We calculated average monthly road kill rate (RKR) (number of road killed feral hogs spotted per km paved road length in section), which was compared between sections, years and seasons using ANOVA (SPSS 8). Differences within factors were analyzed using Tukey HSD test.

Influence of Food Resources Availability on Feral Hog Removal - We analyzed the influence of different vegetation types on feral hogs removal. Dynamac Corporation produced vegetation coverages of KSC from LANDSAT images and soil types coverages. We prepared a table, which included for each vegetation type, its parts (e.g., roots, fruits etc.) which were edible by feral hogs, and season of availability (P. Schmalzer, pers. comm.) (Table 3). These possible food resources were estimated based on prior knowledge of feral hog biology and not quantified from stomach content or other data sources (J. Tanner pers. comm., Antonelli 1979, Taylor and Hellgren 1997, Arrington et al. 1999).

Influence of Food Resources Availability on Trapping Results - A buffer of 200 meters was built into GIS around MINWR road coverage which included all roads: paved and dirt roads. Two hundred meters was selected as buffer width because this is the furthest a hunter would go to haul hogs captured during dog hunting (J. Tanner, pers. comm.), and because it is assumed a reasonable distance for hogs to travel to a 


\section{Wild Pigs}

trap. Previous studies in MINWR showed that feral hogs have small home range of $1 \mathrm{~km}^{2}$ (Poffenberger 1979). The buffer cover was intersected with the vegetation cover. The area of each vegetation type was calculated for each section, and the total area of food resources was calculated for each season in every section.

Average number of hogs hunted per month in each season in each section was regressed against the total area of food resources available in each season in each section, to examine the influence of available food resources on the hunting outcome. During winter, spring and the beginning of summer the most attractive food source is citrus of different types grown in grooves scattered around the refuge. During fall, the most attractive food source is mast of oak and hickory trees. Because of the seasonal difference in possible food types, we separated the fall data from the other seasons for the regression analysis.

Influence of Food Resources Availability on Number of Accidents - Most of the accidents and road kills observed in MINWR happened along the two main roads: SR 3 and SR 402. We examined the influence of habitat type on the number of accidents and road-kills by analyzing the influence of citrus and mast availability on collisions with feral hogs. First, we measured the length of these two main roads, which was within 1000 meters from citrus grooves and mast producing hammocks (the term mast includes fruit produced by oak, hickory and similar trees). Then we used $\chi^{2}$ test to examine if the number of accidents near citrus grooves was higher then expected by the length of roads. Actual number of accidents was used as observed data, and expected numbers were calculated by multiplying the percent length of road by the total number of accidents.

A similar analysis was conducted to examine the role of mast producing hammocks on the number of accidents on MINWR roads.

\section{Results}

Trapping Records - During the years 1998-2001 an average ( \pm sd) of 2419 \pm 198 feral hogs were trapped or hunted on MINWR each year. Average monthly trapping success (MTS) was $0.6 \pm 0.3 \mathrm{feral}$ hogs $/ \mathrm{km}^{2}$. The factors that significantly affected MTS were: season $\left[\mathrm{E}^{2}=0.268\right]$, section $\left[\mathrm{E}^{2}=0.200\right]$ and the interaction between season and section $\left[\mathrm{E}^{2}=0.185\right]$. The year and other interactions did not significantly influence MTS (Table 1). Simple effect analysis of the interaction between season and section revealed significant differences in MTS between seasons in the three sections (Section 1 [Adj. $\mathrm{R}^{2}=0.205 ; \mathrm{F}=5.044 ; \mathrm{df}=3 ; \mathrm{p}<$ 0.004]; Section 2 [Adj. $\mathrm{R}^{2}=0.102 ; \mathrm{F}=2.78 ; \mathrm{df}=3 ; \mathrm{p}<0.05$ ]; and Section 3 [Adj. $\mathrm{R}^{2}=0.503 ; \mathrm{F}=16.83$; $\mathrm{df}$ $=3 ; \mathrm{p}<0.0001]$ ). In all sections, MTS was highest in winter (Fig. 2). In Section 1, MTS remained high in spring and summer and declined in fall, while in Sections 2 and 3 MTS dropped in spring to about half of that in winter, and remained low to fall.

During the month of July of the years 1998-2001, trappers were trapping an average of $18.5 \pm 3.7$ days a month.

Accidents Reports - During the years 1995-1997 and 2001-2002, seventy-five vehicle accidents with feral hogs were recorded by KSC security. These accidents occurred on $168 \mathrm{~km}$ of paved roads throughout KSC with an average of $0.09 \pm 0.08$ accidents $/ \mathrm{km} /$ year. Average Monthly Accident Rate (MAR) was different between years $[\mathrm{F}=6.136 ; \mathrm{df}=4 ; \mathrm{p}<0.0001]$, and seasons $[\mathrm{F}=2.645 ; \mathrm{df}=3 ; \mathrm{p}<0.05]$, but did not differ between sections (Table 2), nor was any of the interactions significant. The analysis was significant but explained a low percentage of the variance in MAR [Adj. $\mathrm{R}^{2}=0.154 ; \mathrm{F}=1.535 ; \mathrm{df}=56 ; \mathrm{p}<0.029$ ].

Average MAR declined from 1995 to 1997 and increased again in the years 2001 and 2002 (Fig. 3). Tukey's test showed that MAR in 1995 was higher than in the other years but there was no difference in MAR between the following years (Fig. 3). Average MAR was highest in spring and lowest in summer. Winter and fall MAR was of intermediate value (Tukey's HSD) (Fig. 4).

Road Kill Reports (RKR) - During the years 1992-1995, ninety-four feral hogs were spotted dead along KSC roads. These accidents occurred on $168 \mathrm{~km}$ of paved roads throughout KSC with an average of $0.14 \pm$ 0.03 accidents $/ \mathrm{km}$ road length/year. Highest number of road kills found was on Section 3 and the lowest on 
Section 1 (Table 2). Average monthly RKR was $0.02 \pm 0.042$ hogs $/ \mathrm{km}$ road $/ \mathrm{month}$. Average monthly RKR was different between sections $[\mathrm{F}=6.203 ; \mathrm{df}=2 ; \mathrm{p}<0.003]$ but not between years $[\mathrm{F}=0.51 ; \mathrm{df}=3 ; \mathrm{N}$.S.], or seasons $[\mathrm{F}=1.46$; $\mathrm{df}=3$; N.S.]. The analysis was significant but explained a low percentage of the variance in $\mathrm{RKR}$ [Adj. $\mathrm{R}^{2}=0.067 ; \mathrm{F}=2.29 ; \mathrm{df}=8 ; \mathrm{p}<0.025$ ]. Tukey's test showed that RKR in section 1 was higher than in the other two sections. RKR was similar in sections 2 and 3 (Fig. 5).

In 1992-1995, the average RKR number of road-killed hogs found along the roads in MINWR was $0.14 \pm$ 0.03. This road kill rate was higher than the accidents rate reported to KSC security in the years 1996-2001 $(0.06 \pm 0.02)[\mathrm{t}=3.82 ; \mathrm{df}=5 ; \mathrm{p}<0.013]$.

Influence of Food Resources Availability on the Results of Trapping - The 200-meter buffer area around the roads in MINWR includes $179.7 \mathrm{~km}^{2}$ out of the total $330 \mathrm{~km}^{2}$ of the refuge. Possible food resources cover the highest portion of this area in fall and lowest in summer (Table 3). Average monthly number of hogs hunted in each section in every season increased with increase in seasonally available food resources area. This relationship was found for the seasons winter to summer $\left[\right.$ Adj. $\mathrm{R}^{2}=0.91 ; \mathrm{F}=79.22 ; \mathrm{df}$ $=8 ; \mathrm{p}<0.0001]$, and for the fall [Adj. $\mathrm{R}^{2}=0.98 ; \mathrm{F}=118.41 ; \mathrm{df}=2 ; \mathrm{p}<0.058$ ] (Fig. 6). Differences between the slopes of both regression lines were computed using test for equality of slopes (Sokal and Rohlf 1995). The increase in the number of hogs trapped, as the area of food resources increased, in fall (the slope of the regression line) was significantly lower than that of the other seasons $\left[\mathrm{F}_{(3,9)}=6.7 ; \mathrm{p}<0.012\right]$.

Influence of Food Resources Availability on Vehicle-Hog Accidents - Total length of roads SR3 and SR 402 is $87.8 \mathrm{~km}$; along these roads, 58 accidents were reported during the years 1995-1997 and 2001-2002. This number of accidents is higher than expected by the relative length of these two roads from the total length of paved roads in MINWR $\left[\chi^{2}=18.89 ; \mathrm{df}=1 ; \mathrm{p}<0.0001\right]$. Of the 58 accidents, 35 were within 1000 meters of a citrus groove (Table 4$)$. A $\chi^{2}$ test showed that the number of accidents near citrus grooves was higher than expected by the length of roads near the grooves $\left[\chi^{2}=8.87 ; \mathrm{df}=1 ; \mathrm{p}<0.003\right]$. These differences were most significant in Section $3\left[\chi^{2}=18.86 ; \mathrm{df}=2 ; \mathrm{p}<0.001\right]$.

Along SR 3 and SR 402, seventy-one road kills were spotted during the years 1992-1995. This number of road kills is higher then expected by the relative length of these two roads from the total length of paved roads in MINWR $\left[\chi^{2}=20.4 ; \mathrm{df}=1 ; \mathrm{p}<0.0001\right]$. Of the 71 road kills, 39 were within 1000 meters of a citrus groove (Table 4 ). The number of road kills spotted near citrus grooves was higher then expected by length of roads near the grooves $\left[\chi^{2}=4.19 ; \mathrm{df}=1 ; \mathrm{p}<0.04\right]$. These differences were most significant in Sections 2 and $3\left[\chi^{2}=22.41 ; \mathrm{df}=2 ; \mathrm{p}<0.0001\right]$.

Another available food source examined was mast-producing hammocks. Total paved road length in the refuge is $167.8 \mathrm{~km}$. 75 accidents were reported to KSC security along these roads. Seventy-one accidents were within 200 meters of mast producing hammocks (Table 5). This number is higher then expected by length of roads near mast producing hammocks $\left[\chi^{2}=11.73 ; \mathrm{df}=1 ; \mathrm{p}<0.0001\right]$. No significant differences were found between sections $\left[\chi^{2}=2.98 ; \mathrm{df}=2 ;\right.$ N.S. $]$.

During the years 1992 - 1995, ninety-four road kills were spotted along MINWR roads. Of these 85 were within 200 meters from mast producing hammocks (Table 5). This number is higher then expected by length of roads near mast producing hammocks $\left[\chi^{2}=6.65 ; \mathrm{df}=1 ; \mathrm{p}<0.01\right]$. No significant differences were found between sections $\left[\chi^{2}=2.92 ; \mathrm{df}=2 ; \mathrm{N} . \mathrm{S}\right.$. $]$.

\section{Discussion}

The number of hog-vehicle collisions per km per year during the years 1992-1995 was higher than the number of collisions during later years. This suggests that the management program initiated in 1995 had a significant effect on the feral hog population at MINWR. The average collisions rate per km per year dropped by more then $50 \%$ from 0.14 to 0.06 accidents per $\mathrm{km}$ per year. This, probably, implies that the hog population on the refuge was also reduced. In order to ascertain this further, demographic studies of the feral hogs at MINWR must be conducted. 
Hog-vehicle accidents occurred on paved roads all over MINWR, but especially along two of the main roads - SR 3 and SR 402. These two roads are wide roads with high speed limits. The results of the current study concur with those of Gunther et al. (2000), which demonstrated that on roads with high speed limits the number of wildlife-vehicle collisions was higher than on roads with low speed limit.

An exception to this rule is road SR 405 that leads directly from the town of Titusville to KSC. This road has a high speed limit but no accidents or road-kills were recorded on it. The absence of collisions is probably due to the habitat surrounding the road. On both sides of the road are storm water canals, which were built and maintained as drainage ditches. American alligators (Alligator mississippiensis) that prey on feral hogs are abundant in these canals, which probably limit feral hogs movement across these canals.

Another factor that influences the number of collisions is the habitat surrounding the road. In Yellowstone, forest-dwelling large mammals like mule deer (Odocoileus hemionus) were road killed more in forested sections of roads then in non-forested sections (Gunther et al. 2000). The current study showed that the number of feral hogs accidents near citrus grooves and mast producing hammocks was higher then expected by the relative road length. This is probably the result of higher feral hogs activity in those areas. Citrus is an important food source for hogs on MINWR and therefore hogs are attracted to the citrus grooves in the fruiting season (winter to early summer). During fall, mast is the most important food source for the hogs and therefore they are more active near mast producing hammocks. With large numbers of hogs concentrated in relatively small areas the possibility of accidents increases. Similar phenomena were observed with deer-vehicle collisions. In areas with higher deer density, the number of collisions and the probability of collision increased (West et al. 2000)

The purpose of the feral hog management program in MINWR is to control and reduce feral hog populations on the refuge (USFWS 2003). The main tool for reducing feral hog populations on the refuge is hunting (i.e., trapping, dogging, and shooting). Analysis of hunting records showed significant differences between seasons, with highest hunting success in winter. Since there are no public hunts on MINWR, and trappers have to obtain permits and clearance for every person working with them, then it is reasonable to assume that the efforts in terms of number of hunters working each day is similar between seasons.

Analysis of trapping records showed that even in summer, with the low number of hogs trapped each month, trappers spend nearly 20 days a month on the refuge. This means that the seasonal differences in MTS probably do not arise from seasonal differences in effort.

Most births of pigs (whether true wild boars or feral hogs) occur in spring (Brooks et al. 1986, Leaper et al. 1999). Therefore, population abundance should be highest in summer. Nevertheless, MTS was lowest during summer, which probably means that population abundance was not the main determinant of MTS.

Analysis of the vegetation on the refuge and the food sources that these can provide to the feral hogs showed seasonal differences in local food availability. This probably means that hogs migrate across the refuge between seasons to get close to food sources. This movement of hogs across the refuge and the fact that some areas of the refuge are virtually inaccessible to trappers is, in our opinion, the main factor in seasonal differences in MTS.

Hunters and trappers do most of their hunting in areas that are close to the roads of the refuge. This leaves about half the refuge area as a no-hunting zone. Those areas are mostly marsh and swamps, which provide roots and bulbs for the hogs in summer when other food items are scarce. On the other hand, the citrus grooves, which provide food from winter to early summer, are well covered by roads. Thus in seasons when the areas near the roads provide ample food for the hogs the trapping success is high.

The difference in the average number of hogs trapped per month between the fall and other seasons probably arises from differences in the habitat. In winter, the high number of hogs trapped per month is related to the high productivity of the citrus grooves. As the weather warms to summer, productivity of the groves declines, and so does the number of hogs trapped per month. The hogs probably move out to the marsh areas of the refuge, where access is limited. In fall, the mast is ready on the trees and the hogs move to the hammocks and more accessible areas. But the attractiveness of the mast might be lower then that of 
the citrus, and they are spread over larger areas and thus the numbers of trapped hogs per month is lower because they are less concentrated in relatively small areas.

\section{Management Implications}

The present study demonstrates the importance of understanding habitat influence on wildlife management. The analysis of trapping records exemplifies the influence of habitat and accessibility on trapping success. Therefore, in order to increase trapping success the refuge should increase accessibility to different parts of the refuge. However, the increased accessibility should be weighed against the probability of increased damage to the habitat and other natural resources in those areas.

Drivers using MINWR roads should be informed of the higher probabilities of collisions with hogs. Perhaps speeds should be controlled along the main roads near citrus grooves in winter.

\section{Acknowledgements}

We wish to thank the staff at MINWR and Dynamac Corporation for all the help and access to the hunting and collision records and to GIS coverages of MINWR. We wish to thank J. Tanner for his assistance in performing this study and for sharing his extensive local knowledge of feral hogs. The study was funded by a NASA Planetary Biology Internship scholarship and a scholarship from the University of Haifa, Israel. 


\section{Wild Pigs}

Table 1: The effect of season (SSN), year and section (SCTN) on Monthly Trapping Success (MTS) using three-way ANOVA.

\begin{tabular}{cccc}
\hline Source & Df & F & Significance \\
\hline Corrected Model & 47 & 2.484 & .000 \\
Intercept & 1 & 749.034 & .000 \\
SSN & 3 & 11.744 & .000 \\
YEAR & 3 & 2.266 & .086 \\
SCTN & 2 & 12.019 & .000 \\
SSN*YEAR & 9 & .487 & N.S. \\
SSN*SCTN & 6 & 3.632 & .003 \\
YEAR*SCTN & 6 & .810 & N.S. \\
SSN*YEAR*SCTN & 18 & 1.092 & N.S. \\
Error & 96 & & \\
Total & 144 & & \\
Corrected Total & 143 & & \\
& & &
\end{tabular}

Table 2: Number of road related killed hogs in the different sections.

\begin{tabular}{cccc}
\hline Parameter & Section 1 & Section 2 & Section 3 \\
\hline Number of reported accidents ${ }^{1}$ & 8 & 22 & 45 \\
Number of road kills $^{2}$ & 23 & 28 & 48 \\
Total paved road length $(\mathrm{km})$ & 13 & 36 & 119 \\
\hline
\end{tabular}

Table 3: Area covered by possible feral hog food resources in the different sections ${ }^{1}$

\begin{tabular}{|c|c|c|c|c|}
\hline Season & & Section 1 & Section 2 & Section 3 \\
\hline \multirow[t]{2}{*}{ Winter } & Vegetation types & $\begin{array}{l}\text { Citrus, fruit, root, } \\
\text { seeds }\end{array}$ & $\begin{array}{l}\text { Berries, citrus, } \\
\text { fruit, root, seeds }\end{array}$ & $\begin{array}{l}\text { Berries, citrus, } \\
\text { fruit, root, seeds }\end{array}$ \\
\hline & Area $\left(\mathrm{km}^{2}\right)$ & 9.05 & 7.46 & 26.57 \\
\hline Spring & $\begin{array}{l}\text { Vegetation types } \\
\text { Area }\left(\mathrm{km}^{2}\right)\end{array}$ & $\begin{array}{l}\text { Citrus, root } \\
5.93\end{array}$ & $\begin{array}{c}\text { Citrus, maple, root } \\
6.57\end{array}$ & $\begin{array}{c}\text { Citrus, maple, root } \\
13.99\end{array}$ \\
\hline Summer & $\begin{array}{l}\text { Vegetation types } \\
\text { Area }\left(\mathrm{km}^{2}\right)\end{array}$ & $\begin{array}{l}\text { Berries, root } \\
\quad 1.93\end{array}$ & $\begin{array}{c}\text { Berries, elm, root } \\
6.36\end{array}$ & $\begin{array}{c}\text { Berries, elm, root } \\
9.28\end{array}$ \\
\hline \multirow[t]{3}{*}{ Fall } & Vegetation types & $\begin{array}{l}\text { Berries, fruit, mast, } \\
\text { root, seeds }\end{array}$ & $\begin{array}{l}\text { Berries, fruit, mast, } \\
\text { root, seeds }\end{array}$ & $\begin{array}{l}\text { Berries, fruit, mast, } \\
\text { root, seeds }\end{array}$ \\
\hline & Area $\left(\mathrm{km}^{2}\right)$ & 12.55 & 21.7 & 54.29 \\
\hline & Section area $\left(\mathrm{km}^{2}\right)^{2}$ & 23.0 & 40.1 & 116.6 \\
\hline
\end{tabular}

${ }^{1}$ - Areas within 200 meters of roads; ${ }^{2}$ - Total area within 200 meters of roads 
Table 4: Feral hog-vehicle accidents near citrus groves.

\begin{tabular}{ccccccc}
\hline Section & $\begin{array}{c}\text { Total Road } \\
\text { Length }(\mathrm{km})\end{array}$ & $\begin{array}{c}\text { Percent } \\
\text { Road Length } \\
\text { near Groves } \\
\text { within } \\
\text { Section }\end{array}$ & $\begin{array}{c}\text { Observed } \\
\text { Number of } \\
\text { Accidents } \\
\text { near Groves }\end{array}$ & $\begin{array}{c}\text { Expected } \\
\text { Number of } \\
\text { Accidents } \\
\text { near Groves }\end{array}$ & $\begin{array}{c}\text { Observed } \\
\text { Number of } \\
\text { Road kills }\end{array}$ & $\begin{array}{c}\text { Expected } \\
\text { Number of } \\
\text { Road kills }\end{array}$ \\
\hline Section 1 & 12.9 & $75 \%$ & 7 & 6.0 & 10 & 17.3 \\
Section 2 & 26 & $29 \%$ & 11 & 6.4 & 19 & 9.06 \\
Section 3 & 48.8 & $24 \%$ & 17 & 6.8 & 10 & 4.11 \\
\hline
\end{tabular}

' - expected number of accidents or road-kills was calculated by multiplying the percent road length near groves within section by the total number of accidents or road-kills found in the section (Table 2)

Table 5: Feral hog-vehicle accidents near mast producing hammocks

\begin{tabular}{|c|c|c|c|c|c|c|}
\hline Section & $\begin{array}{l}\text { Total Road } \\
\text { Length }(\mathrm{km})\end{array}$ & $\begin{array}{c}\text { Percent } \\
\text { Road Length } \\
\text { near } \\
\text { Hammocks } \\
\text { within } \\
\text { Section }\end{array}$ & $\begin{array}{l}\text { Observed } \\
\text { Number of } \\
\text { Accidents } \\
\text { near } \\
\text { Hammocks }\end{array}$ & $\begin{array}{l}\text { Expected } \\
\text { Number of } \\
\text { Accidents } \\
\text { near } \\
\text { Hammocks }\end{array}$ & $\begin{array}{l}\text { Observed } \\
\text { Number of } \\
\text { Road kills }\end{array}$ & $\begin{array}{l}\text { Expected } \\
\text { Number of } \\
\text { Road kills }\end{array}$ \\
\hline Section 1 & 12.8 & $89 \%$ & 7 & 7 & 20 & 20.5 \\
\hline Section 2 & 35.8 & $75 \%$ & 21 & 16.4 & 31 & 23.1 \\
\hline Section 3 & 119.2 & $78 \%$ & 43 & 35.3 & 34 & 31.3 \\
\hline
\end{tabular}

\footnotetext{
1 - expected number of accidents or road-kills was calculated by multiplying the percent road length near groves within section by the total number of accidents or road-kills found in the section (Table 2).
} 
Wild Pigs

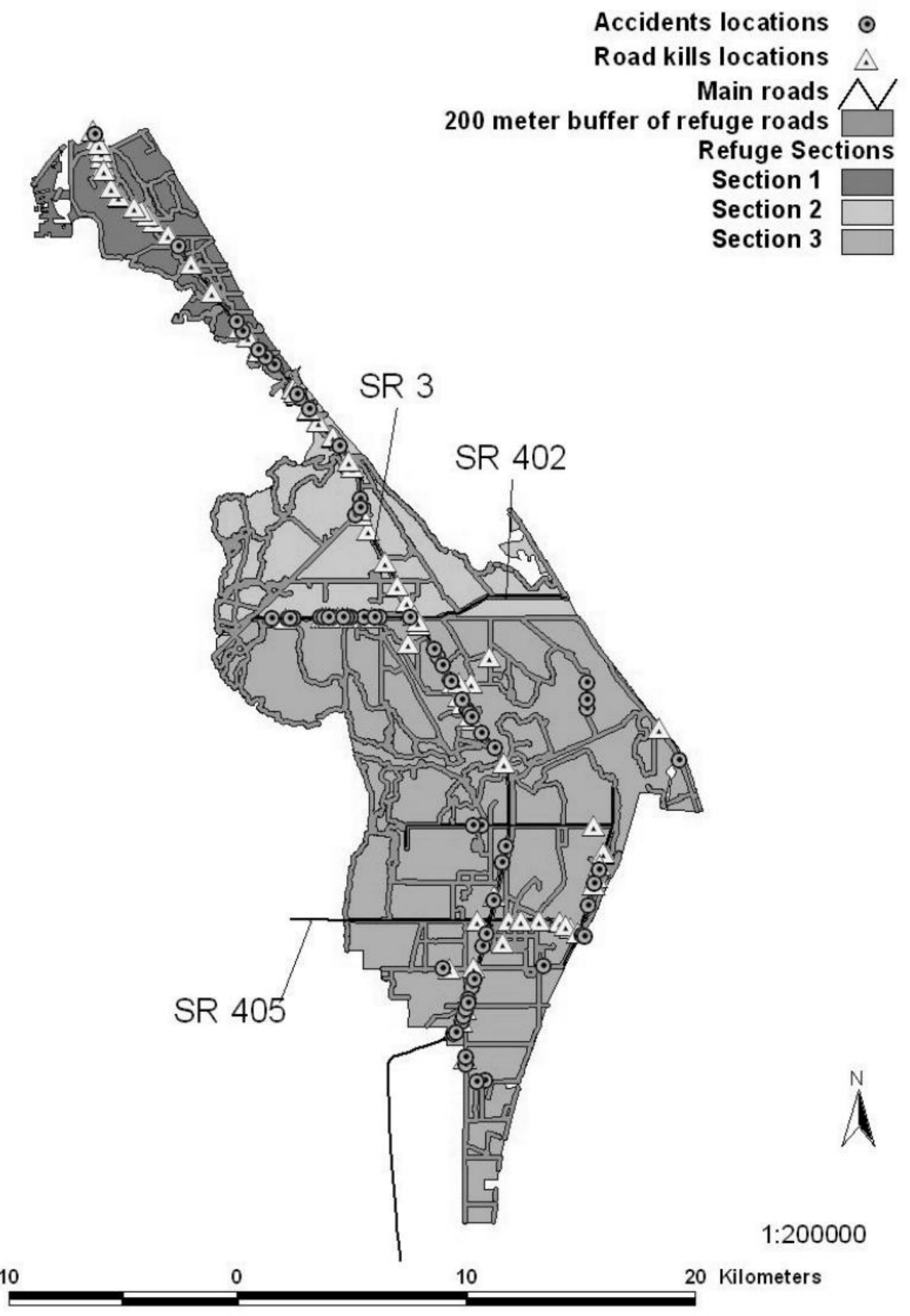

Fig. 1. Feral hog-vehicle collisions locations in the sections of MINWR. 


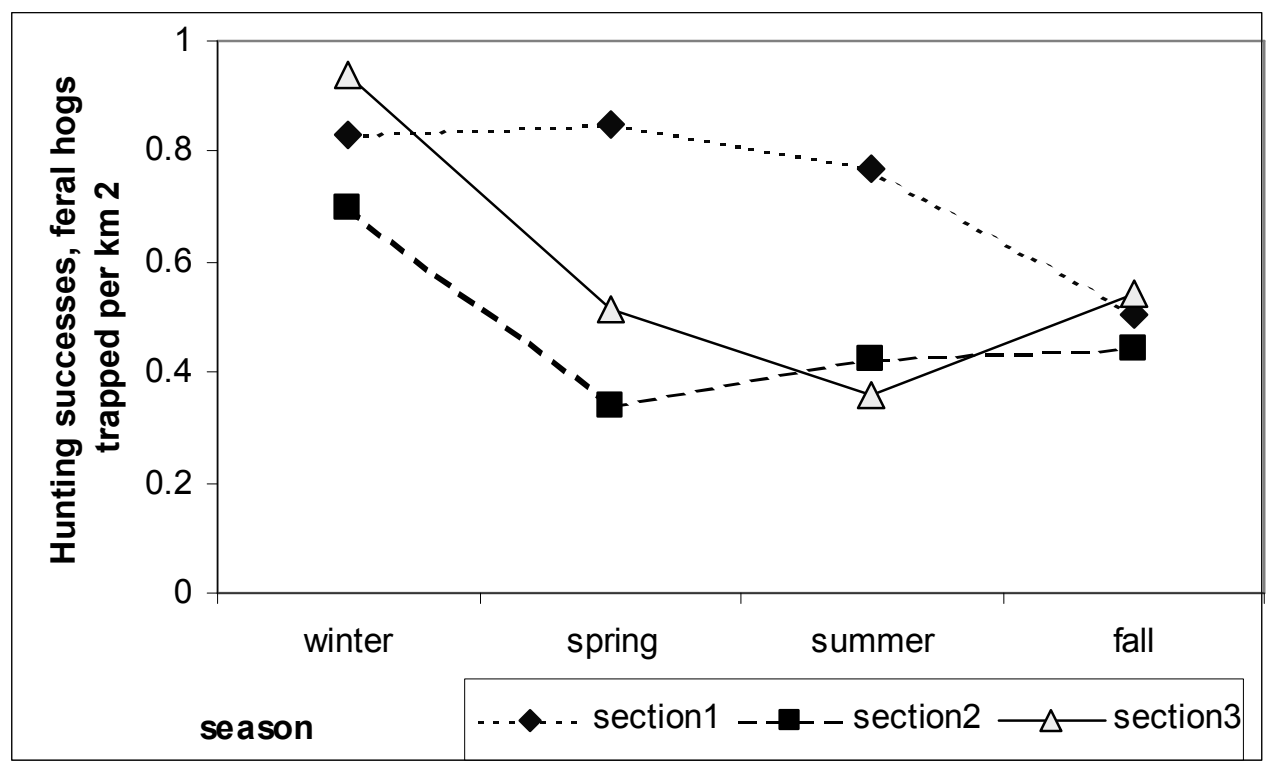

Fig. 2. Trapping successes on the different sections in MINWR (average of monthly records, for the years 1998-2001).

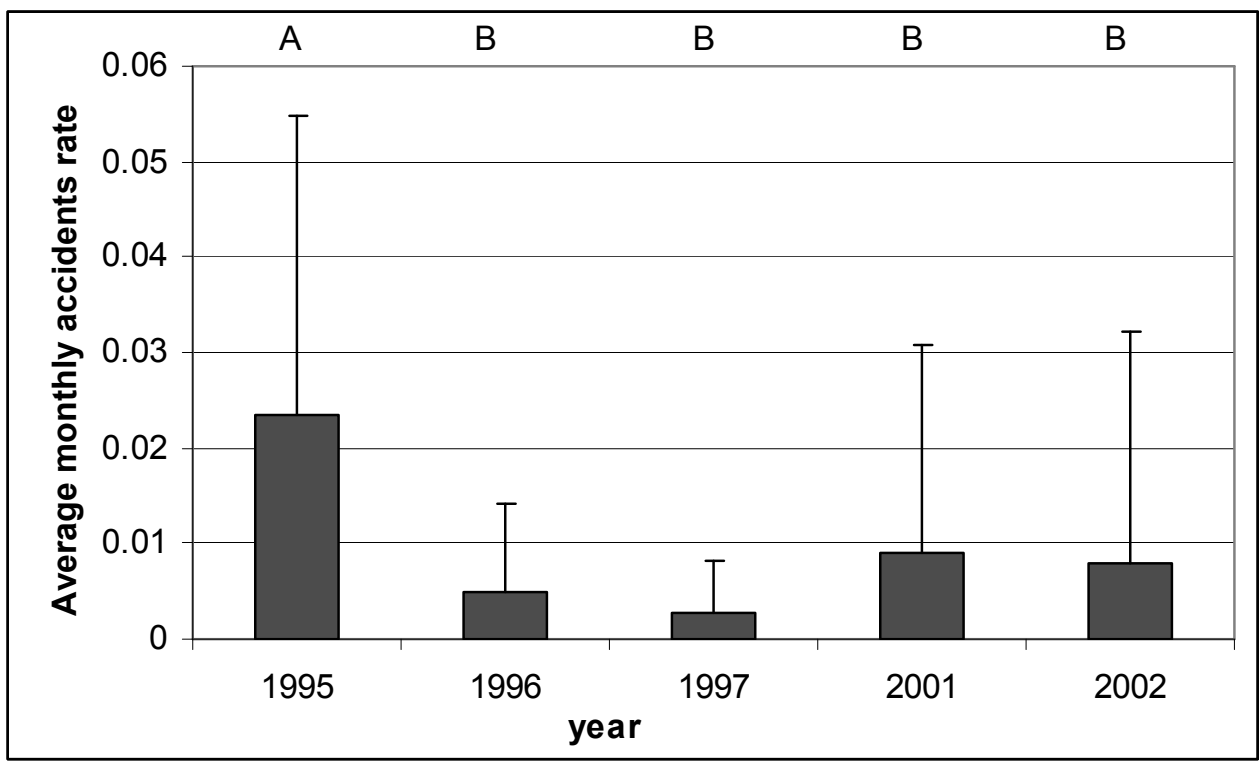

Fig. 3. Monthly Accidents Rate (+sd) (1995-1997, 2001-2002). Monthly Accident Rate is calculated as the number of accidents per km length of road. Different letters denote significant differences in MAR between years as defined by Tukey's test $(\mathrm{p}<0.05)$. 


\section{Wild Pigs}

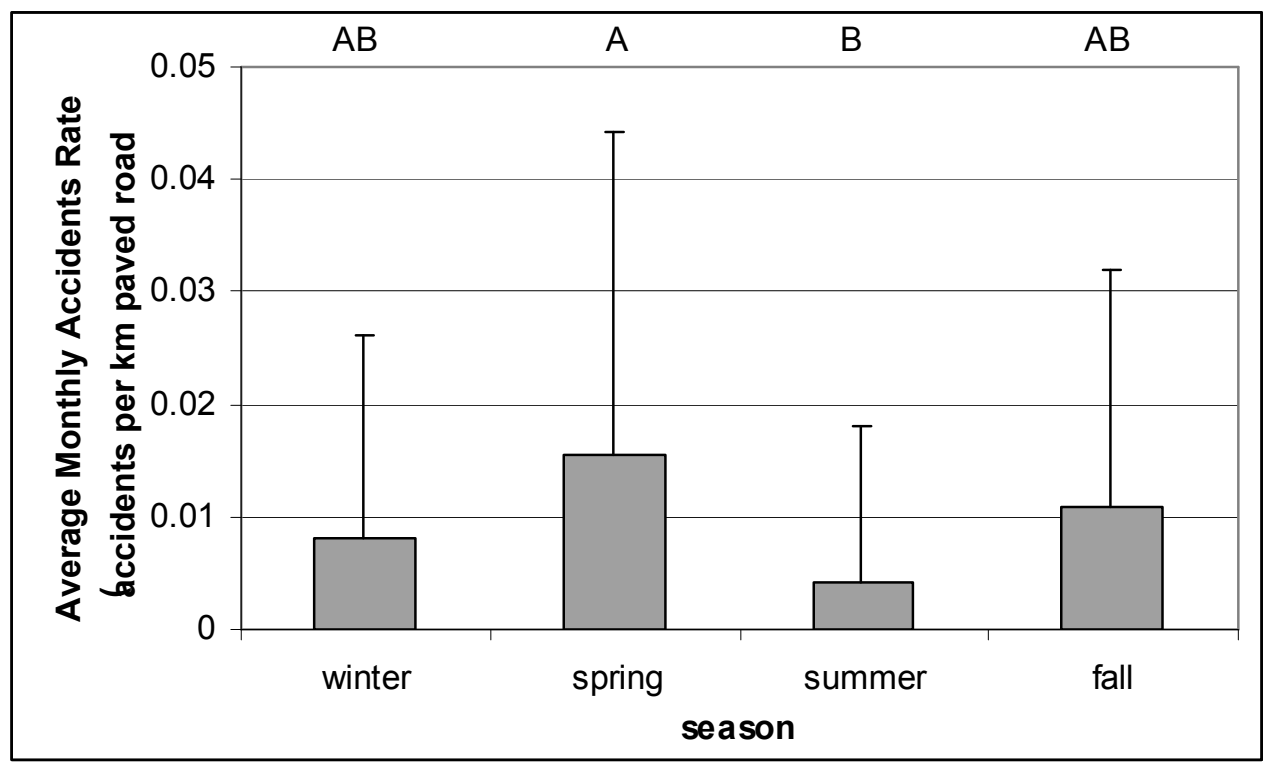

Fig. 4. Average Monthly Accident Rate $(+s d)$ in the different seasons. Data for the years $1995-1997$ and 2001-2002, combined for all sections. Different letters denote significant differences in MAR between seasons as defined by Tukey's test $(\mathrm{p}<0.05)$.

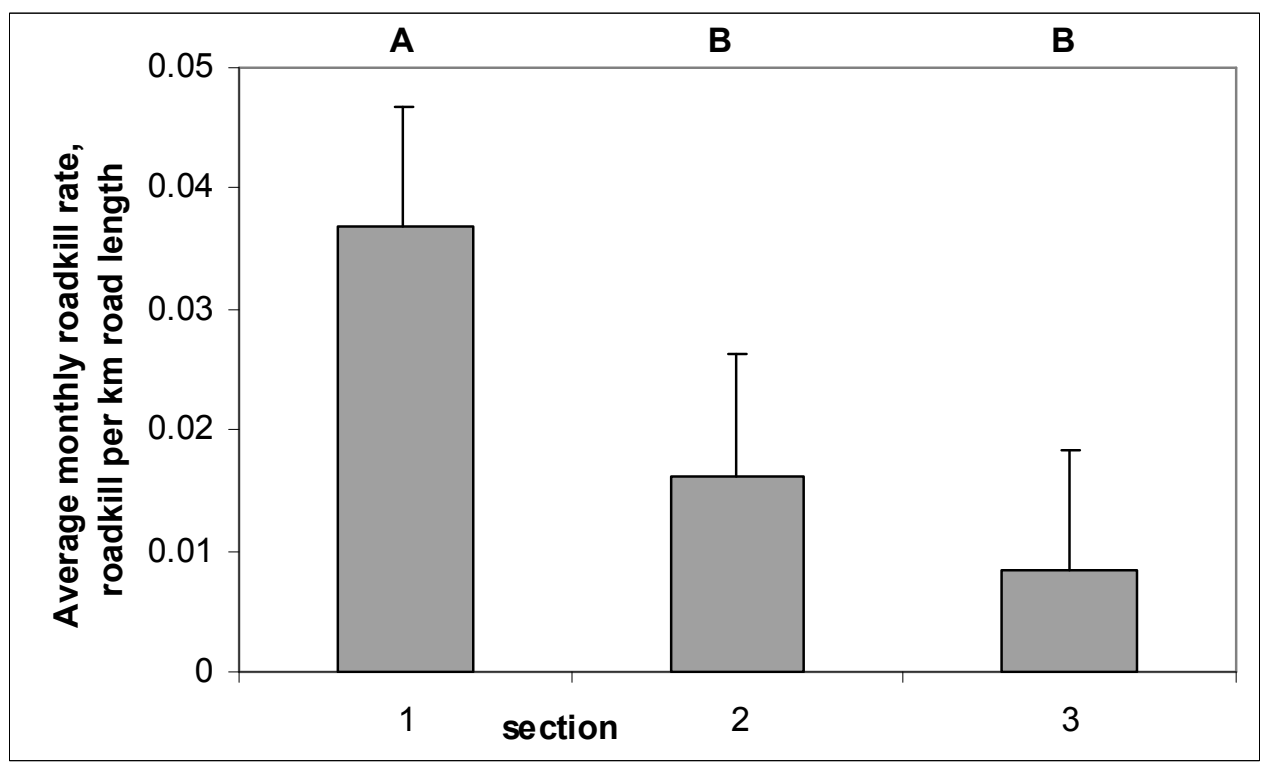

Fig. 5. Differences in average Road Kill Rate $(+s d)$ in the different sections. Road kill data from the years 1992-1995. Different letters denote significant differences in RKR between sections as defined by Tukey's test $(\mathrm{p}<0.05)$. 
SRNL-RP-2009-00869

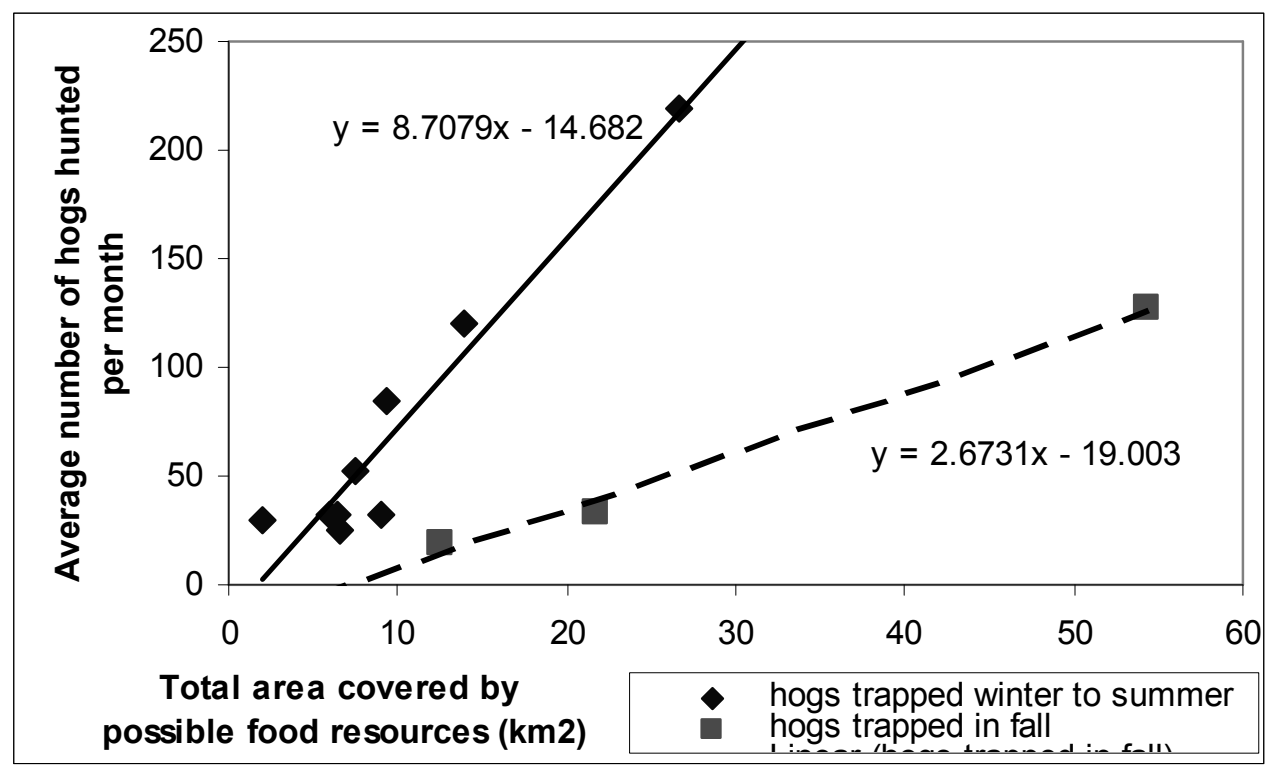

Fig. 6. Influence of seasonal food resources within 200 meters buffer of MINWR roads on the average number of hogs trapped per month. 1- Seasonal average number of hogs trapped per month during the years 1998-2001; 2- Line represents regression analysis for trapping records for the seasons: winter to summer; and 3- Hunting records for the years 1998-2001. 


\section{Wild Pigs}

\section{Literature Cited}

Antonelli, D. S. 1979. Population structure and habitat use of the feral hog (Sus scrofa) on Merritt Island National Wildlife Refuge, Florida. M.S. Thesis, Florida Institute of Technology, Melborne, Florida.

Arrington, D. A., L. A. Toth, and J. W. Koebel, Jr. 1999. Effects of rooting by feral hog Sus scrofa L. on the structure of a floodplain vegetation assemblage. Wetlands, 19:535-544.

Brooks, J. E., E. Ahmad, and I. Hussain. 1986. A partial research bibliography on the biology and control of feral pigs and wild boar. GOP/USAID Vertebrate Pest Control Project. Islamabad, Pakistan.

Conover, M. R., W. C. Pitt, K. K. Kessler, T. J. DuBow, and W. A. Sanborn. 1995. Review of human injuries, illnesses, and economic losses caused by wildlife in the United States. Wildlife Society Bulletin, 23:407-414.

Davis, D. S. 1993. Feral hogs and disease: Implications for humans and livestock. Pp. 84-87. In C. W. Hanselka and J. F. Cadenhead (eds.), Feral swine: A compendium for resource managers. Texas Agricultural Extension Service, Kerrville, Texas.

Engeman, R. M., B. Constantin, M. Nelson, J. Woolard, and J. Bourassa. 2001. Monitoring changes in feral swine abundance and spatial distribution. Environmental Conservation, 28:235-240.

Gunther, K. A., M. J. Biel, and H. Robison. 2000. Influence of vehicle speed and vegetation cover-type on road-killed wildlife in Yellowstone national park. Pp. 42-51. In T. A. Messmer and B. West (eds), Wildlife and highways. Seeking solutions to an ecological and socio-economic dilemma. Proceedings of the 7th Annual Meeting of The Wildlife Society. September 12-16. Nashville, Tennessee.

Hone, J. 1984. Controlling feral pigs, Agfact A9.0.9. Agdex 673. New South Wales Department of Agriculture, Sydney, Australia.

Inbar, M., and R. T. Mayer. 1999. Spatio-temporal trends in armadillo diurnal activity and road-kills in central Florida. Wildlife Society Bulletin, 27:865-872.

Katahira, L. K., P. Finnegan, and C. P. Stone. 1993. Eradicating feral pigs in mountain mesic habitat at Hawaii Volcanoes National Park. Wildlife Society Bulletin, 21:269-274.

Leaper, R., G. Massei, M. L. Gorman, and R. Aspinall. 1999. The feasibility of reintroducing Wild Boar (Sus scrofa) to Scotland. Mammal Review, 29:239-259.

Littauer, G. A. 1993. Control techniques for feral hogs. Pp. 139-148. In C. W. Hanselka and J. F. Cadenhead (eds.), Feral swine: A compendium for resource managers. Texas Agricultural Extension Service, Kerrville, Texas.

Miller, J. E. 1993. A national perspective on feral swine. Pp. 9-16. In C. W. Hanselka and J. F. Cadenhead (eds.), Feral swine: A compendium for resource managers. Texas Agricultural Extension Service, Kerrville, Texas.

Peine, J. D., and J. A. Farmer. 1990. Wild hog management program at Great Smoky Mountains National Park. Proceedings of the Vertebrate Pest Conference, 14:221-227.

Poffenberger, D. L. 1979. An investigation of movements of feral swine (Sus scrofa) in east central Florida. M.S. Thesis, Florida Institute of Technology, Melborne, Florida.

Sokal, R. R. and F. J. Rohlf. 1995. Biometrics: the principles and practice of statistics in biological research. Third edition. Freeman and Company. New York. 
Synatzske, D. R. 1993. The ecological impacts of feral swine. Pp. 59-66. In C. W. Hanselka and J. F. Cadenhead (eds.), Feral swine: A compendium for resource managers. Texas Agricultural Extension Service, Kerrville, Texas.

Taylor, R. B., and E. C. Hellgren. 1997. Diet of feral hogs in the western South Texas plains. Southwestern Naturalist, 42:33-39.

U.S. Fish \& Wildlife Service, 2003. Merritt Island National Wildlife Refuge Comprehensive Conservation Plan. http://merrittisland.fws.gov/ccp/index.html

West, B. C., J. A. Parkhurst, P. F. Scanlon, and W. M. Knox. 2000. Vehicle/deer collisions in Virginia: Implications for management. Pp. 22-23. In T. A. Messmer and B. West (eds), Wildlife and highways. Seeking solutions to an ecological and socio-economic dilemma. Proceedings of the 7th Annual Meeting of The Wildlife Society. September 12 - 16. Nashville, Tennessee. 


\section{Annotated Bibliography of the Wild Pig (Sus scrofa)}

Includes:

- 4,868 references on wild pigs

- Each reference classified into one or more of 21 categories

- References ranging in date from 1801 to 2006

- CD format searchable and copyable 


\section{Savannah River National Laboratory Savannah River Nuclear Solutions LLC Savannah River Site Aiken, SC 29808}

